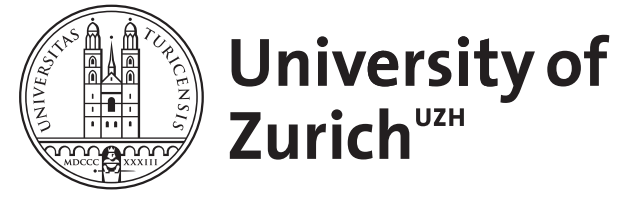

\title{
Mesopotamia: The Old Assyrian Period
}

\author{
Veenhof, Klaas R. ; Eidem, Jesper
}

\begin{abstract}
The first part by Klaas Veenhof "The Old Assyrian Period" is a critical overview of our knowledge of and at the same time an introduction to the study of the Old Assyrian Period (first two centuries of the 2nd mill. B.C.), as we know it from discoveries in ancient Assur and in particular from the cuneiform archives of the Old Assyrian traders living in an commercial colony (called karum) in the lower town of ancient Kanesh (modern Kültepe) in Central Anatolia. The first chapters establish what "Old Assyrian" is and analyze the chronology and the available sources (material and written). There follows a critical sketch of the publications of and research on the Old Assyrian sources, subdivided in a dozen thematic studies. After a sketch of Old Assyrian history, follows an overview of "the Old Anatolian scene", which deals with the cities, local rulers and the about 40 Old Assyrian commercial settlements in Northern Mesopotamia and Anatolia. A special chapter analyzes the important Old Assyrian commercial treaties. The contribution ends with a detailed presentation of the Anatolian titles and officials and the religious festivals and agricultural seasons that figure as terms of payments in Anatolian debt-notes. The second part by Jesper Eidem "Apum: A Kingdom on the Old Assyrian Route" summarises recent evidence for the history of northern Syria during the period contemporary with the late phase of the Old Assyrian trade. To the detailed study of the sources an Appendix of important texts is added. The book is fully indexed (subjects, texts, geographical names, kings and rulers, gods and temples, persons, Assyrian words) and contains a extensive bibliography.
\end{abstract}

Posted at the Zurich Open Repository and Archive, University of Zurich

ZORA URL: https://doi.org/10.5167/uzh-151184

Monograph

Published Version

Originally published at:

Veenhof, Klaas R.; Eidem, Jesper (2008). Mesopotamia: The Old Assyrian Period. Fribourg, Switzerland / Göttingen, Germany: Academic Press / Vandenhoeck Ruprecht. 
Veenhof / Eidem The Old Assyrian Period 


\section{ORBIS BIBLICUS ET ORIENTALIS}

Published on behalf of the BIBLE+ORIENT Foundation

in co-operation with

the Department of Biblical Studies, University of Fribourg (Switzerland), the Egyptological Institute, University of Basel, the Institute of Archaeology, Near Eastern section, University of Berne, the Department of Religious Studies, University of Zurich, and the Swiss Society for Ancient Near Eastern Studies

by

Susanne Bickel, Othmar Keel and Christoph Uehlinger

About the Authors:

Klaas R. Veenhof

Ph.D. degree 1972 with diss. on "Aspects of Old Assyrian Trade and its Terminology". Research assistant chair of Assyriology at Leiden 19651968, Lecturer ancient Semitic languages, University of Nijmegen 1968174; Professor of Assyriology and History of the Ancient Near East, Free University Amsterdam, 1974-1981; Professor of Assyriology Leiden Univ. 1981 until 2000 (retirement date).

Specializations: Old Assyrian, Old Babylonian and History of the ANE. Since 1980 consultant of the CAD for Old Assyrian. Honorary member American Oriental Society.

\section{Jesper Eidem}

Jesper Eidem received his Ph.D. in Assyriology from the University of Copenhagen, where he now teaches. His main field of research is the history of northern Mesopotamia. He is currently engaged in epigraphic and archaeological work in Syria. 


\section{Orbis Biblicus et Orientalis $\quad 160 / 5$}

\section{Klaas R. Veenhof Jesper Eidem}

\section{Mesopotamia}

The Old Assyrian Period

Annäherungen 5

herausgegeben von Markus Wäfler

Academic Press Fribourg

Vandenhoeck \& Ruprecht Göttingen 


\section{Bibliografische Information Der Deutschen Bibliothek}

Die Deutsche Bibliothek verzeichnet diese Publikation in der Deutschen Nationalbibliografie; detaillierte bibliografische Daten sind im Internet über http://dnb.d-nb.de abrufbar.

Veröffentlicht mit Unterstützung der Schweizerischen Akademie der Geistes- und Sozialwissenschaften.

Gesamtkatalog auf Internet:

Academic Press Fribourg: www.paulusedition.ch

Vandenhoeck \& Ruprecht, Göttingen: www.v-r.de

Camera-ready text submitted by the author.

(C) 2008 by Academic Press Fribourg

Vandenhoeck \& Ruprecht Göttingen

Herstellung: Paulusdruckerei Freiburg Schweiz

ISBN: 978-3-7278-1623-9 (Academic Press Fribourg)

ISBN: 978-3-525-53452-6 (Vandenhoeck \& Ruprecht)

ISSN: 1015-1850 (Orb. biblicus orient.) 


\section{INHALTSVERZEICHNIS}

INHALTSVERZEICHNIS

VORWORT

TEIL 1

KLAAS R. VeENHOF

The Old Assyrian Period

Preface

I. INTRODUCTION

1. 'Od Assyrian'

1.1. THE OID Assyrian Period

1.2. From Old Assyrian to Midde Assyrian

1.3. Śamsi-Adad's CONQUest of Assur

1.4. 'Later Old Assyrian'

2. CHRONOLOGY

2.1. The Od Assyrian Period in General

2.2. The Period before ERISUM I

2.3. The Period of kárum Kanesh level II

2.4. The Period of kärum Kanesh level iB

3. SOURCes for the OD Assyrian Perlod

3.1. SOURCES FROM ASSUR

3.1.1. Written sources from Assur

3.1.2. Remains of material culture in Assur

3.2. SOURCES FROM KÄRUM KANESH

3.2.1.1. Texts from the kärum and texts from the cily-mound

3.2.1.2. Official and private texts

3.2.1.3. Privale archives

3.2.1.4. Archives from kärum Konesh level Ib 
3.2.1.5. Main text types

3.2.1.6. Sealed and inscribed bullae 55

3.2.2. Remains of material culture in kärum Kanesh 55

3.3. Other SOURCES

II. RESEARCH ON THE OLD ASSYRIAN PERIOD

1. EaRly ReSEarCH AND teXt PUbilcations 62

1.1. RESEARCH UNTIL 1963

1.2. WORK ON 'OLD TEXT' 65

1.2.1. Publications of 'old lexts' 65

1.2.2. Reconstruction and edition of archives 66

1.3. WORK ON TEXTS EXCAVATEO SINCE 1948

1.3.1. The first volumes published 68

1.3.2. Problems of archival reconstruction and edition 69

1.3.3. Prospects for the tulure 72

1.4. Thematic text EDITONS 73

2. THEMATIC STUDIES 76

2.1. INSTTUTIONS 76

2.2. Caravans and trade routes

2.3. GOODS TRAOED 82

2.3.1. Tin $\quad 82$

2.3.2. Textiles 83

2.3.3. Lapis lazuli 84

2.3.4. Iron 84

2.3.5. Antimony, copper and bronze $\quad 85$

2.3.6. Wool 187

2.3.7. Grain $\quad 87$

2.3.8. Gold 88

2.3.9. Level lb

2.3.10. Quantification 90

2.4. FINANCING, COMPANIES AND PARTNERSHIPS 90

2.5. LAW AND THE ADMINISTRATION OF JUSTICE

2.6. HistORY AND POUITCS 96

2.7. REIGION 102

2.8. SOCIEN 105

2.8.1. Houses 105

2.8.2. Children 100

2.8.3. Women 107

2.8.4. Slaves 110

2.9. LaNGUAGE AND WRTING III

2.10. SEALS ANO SEAIINGS 114 
1. Before Kärum Kanesh level II

I.I. UNTIL THE UR III PERIOD

1.2. From the Ur III Perloo until Ilušuma

1.3. ILUS̃UMA AND ERISUM I

2. THE PERIOD OF KÄRUM KANESH

2.1. THE MAN PHASE, KÄruM Kanesh LEVEL II

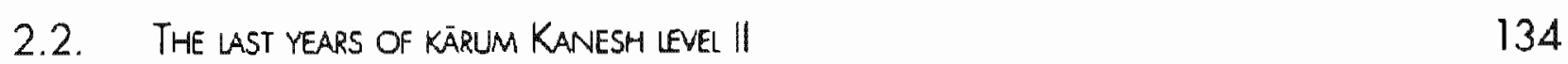

2.3. The later Olo Assyrian Perioo

2.4. The ENo of Kärum KaNeSH IEVEL lo

1. The political and eCONOMIC landscape

2. Cities, rulers and AsSyrian settlements

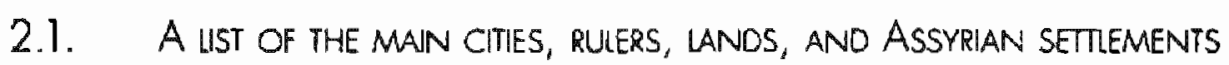

2.2. COMMENTS ON THE TABLE

23. ASSYRIAN COMMERCIAL SETIEMENTS

2.4. The Anatollan cites and their rulers

2.5. 'NOTARIZATION' aND DATING IN IEVEL 18 tEXTS

2.5.1. List of altested 'notarizations'

2.5.2. Dating of rulers and events

2.6. Cites, "LANDS" AND territories

3. THE POSITION OF KÄRUM KANESH

V. COMMERCIAL TREATIES

1. earler Data on treaties

2. The new treaties With Kanesh and HahHum

2.1. THE TREATY WITH KaNESH

2.2. The tREATY WITH HAHHUM

3. Comparison AND INTERPRETATION

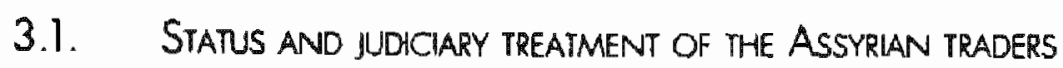

3.2. Free trade and the protection of caravans

3.3. HOMIIDE, BLOOD MONEY AND COMPETTION 
Annäherungen 5

3.4. Taxation AND purchase gy the anatolian aUthortTes 211

3.4.1. Texiles 211

$\begin{array}{ll}\text { 3.4.2. Metals and lapis lazuli } & 212\end{array}$

$\begin{array}{ll}\text { 3.5. The oblgations of the AsSYRlans } & 214\end{array}$

$\begin{array}{ll}\text { 3.0. DEVELOPMENTS AND DIFFERENCES } & 215\end{array}$

VI. ANATOLIAN TITLES, OFFICIALS AND PAYMENT TERMS

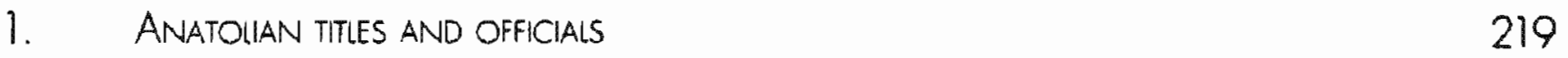

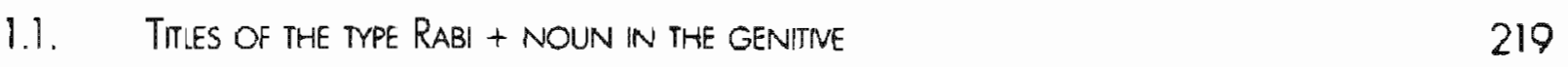

1.2. VARIOUS TIMES AND OFFICLAIS 225

1.2.1. allohtinnum, "steward, manoger" 225

1.2.2. kašsum, "official" 226

1.2.3. robi sikka/itim 227

1.2.4. kumnm, "pries" 230

1.2.5. Other titles and functions 231

2. TERMS OF PAYMENT IN ANATOLIAN DEBT-NOTES $\quad 234$

2.1. FESTNALS 235

2.2. AGRICUITURAL SEASONS 238

2.3. INTERPRETATION 241

VII. ABBREVIATIONS AND BIBLIOGRAPHY 247

$\begin{array}{ll}\text { 1. ABBREVIATIONS } & 247\end{array}$

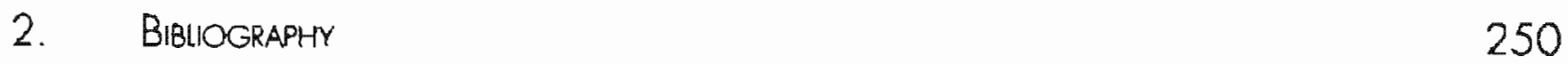

MAP 


\section{TEIl 2}

JESPER EIDEM

ApIm: A KIngdom ON the Old Assyrian ROUTE

Preface

1. General Introduction

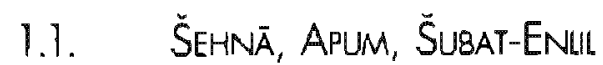

1.2. The ArChives from LeIIAN Operation 3

1.3. COMPOSITION OF THE EVIDENCE

1.4. HISTORICAL SUMMARY

2. Geo-Poutical Overview

2.1. The International Horizon

2.2. THE JEZIRA KINGDOMS

2.3. The KIngdom of APUm and its Vassals

3. Of War and Peace

3.1. Apum against Andarig and Razamá

3.2. TREATIES

3.3. NEW TROUBLES

4. GLIMPSES OF SOCIETY

4.1. Gods and Festrals

4.2. Trade AND ECONOMY

4.3. PEOPIF

5. Eplogue: The End of an ERA

Appendix 1. Selection of Information In L.87 Dated Tabiets 
Annöherungen 5

TEl 3

INDICES

1. SUBJECTS

2. TEXTS

2.1. Categores, types, provenance

2.2. ATter teXt edtTONS AND COLlECTONS

2.3. After eXCAVATON NUMBers (KT/ ETC.)

3. Geographical names

3.1. Geographical names, ancient

3.2. Geographical names, modern

4. KINGS AND RULERS

373

5. Gods and temples

o. Persons

7. ASSYRIAN WORDS 


\section{VORWORT}

Auch jede Reform fordert ihre Opfer. Vor allem unler den Kleinen. Die durch "Bologna" erzwungene Umstruklurierung des Lehrangebots liess keinen Spielraum mehr für jene Vorlesungsreihe, aus der sich die "Annäherungen" speisten; der vorliegende Band ist das vorzeitige Ende der ursprünglich auf zehn Bände veranschlogten Reihe.

Ausstehend seit 1996 ist noch: A. Archi, M. Krebernik, Ebla, Annäherung 2, OBO 160.2 .

Mein Dank gehörł den beiden Autoren des vorliegenden Bandes, welche die Verzögerung des Drucks mil bewundernswertem Versländnis begleitet - gehörl den Herren Domenico Perroni und Thomas Hofmeier, welche den Band für den Druck vorbereiter haben. 

TEII 1

KLAAS R. VeEnHOF

\section{The Old Assyrian Period}

In memory of Tahsin Özgüc, the excavator of Kültepe-Kanesh 1910-2005 

Old Assyrian studies, thanks to the efforts of a small number of scholars in Europe and in Turkey, have witnessed a considerable development during the last decades. Progress has been made in the publication and edition of the textual sources and in the analysis and interpretation of the data they contain, in particular those bearing on the Old Assyrians institutions and trade and the network of commercial settlements in Anatolia. The following pages for a variety of reasons do not offer a comprehensive overview of all the results obtained. It would not be in line with the title "Annäherungen" of this series and the ongoing publication of new sources, excavated since 1948 in kärum Kanesh, makes it too early for a complete and final picture of the Old Assyrian period. In addition, many important publications have appeared during the last decade, which present valuable descriptions and interpretations of a great number of issues, such as archives, eponymic dating and chronology, law and the administration of justice, financing and credit, the copper trade, Assyrian institutions (the City Hall in Assur and the kārum office in Kanesh), commercial and administrative procedures, Anatolian society, texts from Alisar and Boğazköy, women and children, and elements of the material culture. I mention and use them by at times summarizing their data and conclusions, but those really interested in Old Assyrian should read them, also because the complicated and at times rather technical nature of several commercial and administrative features makes summaries rather unsatisfactory. Finally, two important themes are the subject of forthcoming dissertations, one on the historical and economic geography, by Gojko Barjamovic, and one on the juidicial procedures and administration of justice by Thomas Hertel (both in Copenhagen, under the guidance of Larsen). This makes it unwise to present here short, preliminary and therefore unsatisfactory surveys of these topics. The bibliography in this volume and the more complete one published by Cécile Michel in 2003 will help those interested to find their way in the relevant literature, and they can also profit from the introductions and indexes of Michel's Correspondance des marchands de Kanish published in 2001 in the LAPO series.

What I am offering here starts with a description of what 'Old Assyrian' means and comprises and with a sketch of Old Assyrian chronology. It is followed by a description and classification of the available sources, both those for the material culture (in Assur and Kanesh) and the written sources, especially those found in the Assyrian commercial settlements in Anatolia and dating to the periods of kärum Kanesh level II and Ib. Nexl comes a survey of past and present research on the Old Assyrian Period, the first part of which deals with the publication of texts and the reconstruction and edition of archives, which includes a discussion of its possibilities and problems on the basis of the first publications of the texts officially excavated in kārum Kanesh. Its second part, "thematic studies", offers an overview of the results achieved and problems encountered in eleven different areas, ranging from institutions and caravans to language and personal names. After a short history of the Old Assyrian Period' (chapter III) I move on the 'the Anatolian scene', a long chapler which presents and discusses the data on the main cities, their rulers and 'lands' and on the Assyrian commercial settlements, including the position of kärum Kanish in this system. The recent 
publication of two new commercial treaties from the period of level lb, by my colleague Cahil Günbath, offered the occasion to present a more general treatment of such texts and an analysis of their stipulations and their development. The last chapter (VI) furns to the Anatolian society, some aspects of which were recently studied by J.G. Dercksen. It offers tabulaled surveys of and comments on the (titles of the) main officials and of the scattered data on festivals and the agricultural seasons as mentioned in Anatolian debt-notes. They can serve as a dota-base for a more comprehensive study of the ancient Anotolian sociely, which is needed and will become possible when also some of the archives of Anatolian business men discovered in kärum Kanesh have been published.

I have tried to supply, especially in the numerous foomoles, the necessary bibliographical information and references to the texts on which conclusions are based, whether they are quoted and discussed or simply referred to. Some readers may consider this wealth of data too much, but it will help those who want to pursue special issues, and it is also due to the siluation as to the publication of the sources, described in chapter 1.3.2. We have to work with a limited number of reliable and systematic text editions alongside a great quantity and variety of articles in all kinds of journals and special volumes, which publish and at times also analyze single or small groups of usually new texts. Many of them contain very interesting new information, which frequently is the reason why they were singled out for separate publication. To help the reader references to important letters frequently are accompanied by their number in Michel $2001 \mathrm{~b}$ (CMK), where the whole text is available in translation. Since the reading and interpretation of damaged texts and especially of letters still poses philological problems, occasionally philological or linguistic remarks were added in foolnotes) to account for my readings or interpretations. The tronsliterations follow the normal rules, but note that 1 . render the name of the city of Assur always in this way and not by Aššur, which is resenved for the name of the god lalso as part of theophoric personal names).

I have used with much profil and deep gratilude many still unpublished texts that are being studied and prepared for publication by several of my colleagues in the field, notably Ifan Albayrak, Sabahattin Bayram, Saleh Ceçen, Veysel Donbaz, Cahir Günbattı, Karl Hecker, Yasushi Kawasaki, Mogens Trolle Larsen, Cécile Michel, and Leila Umur, apart from the excavated texts which Professor Tahsin Özgüc has assigned to me for publication. I have refrained from presenting complete texts or lorger excerpts and in nearly all cases I quote only one or a few words or lines from them or simply refer to them in footnotes, to show on which textual evidence my observations are based. I believe that this use of them is acceptable and may be on incentive to publish the complete texts, many of which are important sources of our knowledge. I thank all those who have supplied me with information, texts, collations, and observations, notably the members of the "Old Assyrian Text Project", which proves a welcome forum for discussion and exchange of information. Marten Stol, as customary, was helpful with references and original observations; Jan Gerrit Dercksen proved always ready to supply data and I used both his collection of personal names and his recent publications with great profit. Finally / thank my wife, who had to accept that Old Assyrian, several years after my retirement, still claimed more of my time and allention than she had hoped for, but never failed to support me in every way. 


\section{Prefoce}

It is my hope that this volume will make the fascinating, but for many still somewhat alien world of the Old Assyrian traders and their unique archives more accessible to assyriologists, hislorians (of ancient Anatolia and Assur) and students of economic history. The few people (several of them already retired; working in this lield, where there is still so much to be done, would be happy to welcome the cooperation of young scholars, perhaps stimulated by this book, just like its writer's interest in Old Assyrian studies was sparked, more than forly years ago, by Paul Garelli's admirable Les Assyriens en Cappadoce.

I dedicate this volume to the memory of professor Tahsin Ozgüc, the excovator of KüliepeKanesh, to whom I am much indebted for entrusting me some of the archives found in kärum Kanesh for publication, who died shortly after the manuscript of this book was completed. The original manuscript was completed in June 2005. Delay in its publication has allowed me to make additions and to take into account what has been published until the summer of 2006 .

Heemstede, August 2006. 



\section{INTRODUCTION}

\section{1. 'OID AsSYRIAN'}

'Old' in 'Old Assyrian' is a chronological label, which applies to the earliest phase of the culture of ancient Assur that is historically sufficiently recoverable to be called Assyrian. 'Assyrian' here does not refer to Assyria as a rerritorial slate, which only took shape after the period we are dealing with, but to the city of Assur, the core of a small city-state. 'Old Assyrian' therefore characterizes its culture during the first centuries of the second millennium BC, when it exhibited a sel of distinctive features in the areas of political institutions, economic structures, law, religion, language, and art, which set it off sufficiently from the preceding Ur Ill empire, contemporary Babylonia and the following Middle Assyrian period.

Assur of course was much older, going back to the middle of the third millennium BC, when its Ištar temple arose on the sandstone of the mountain ridge on which the city was built.' But in spite of the traditions embodied in the beginning of the Assyrian King Lisl (AKL), ${ }^{2}$ its mention of Ušpia (no. 16), remembered as early builder of the temple of Ašsur, ${ }^{3}$ and a few early inscriptions, ${ }^{4}$ little is known of this 'Early Assyrian Period'. It was, moreover, a period during which the city for long periods was dominated by the powerful Old Akkadian and Ur III states. ${ }^{5}$ Assur only becomes liable for historical analysis after $\mathrm{ca}$. $2000 \mathrm{BC}$, when enough written sources are available.

These sources, as will be elaborated below, derive only to a very limited extent from discoveries made in Assur itself, where the strata of the Old Assyrian period were only reached in some areas of the upper city, and practically no archival texts were

1 See for this temple now Bär 2003.

2 The first group of rulers listed in the AKL, "who lived in tents", apart from nos. 16 and $17(2)$, have no historical relation with Assur and are "a disjointed list of Amorite tribal-geographical names ... representing the Amoritic nomadic origin of Śamši-Adad's family" (Yomada 1994, 16).

In an inscription of Shalmaneser 1, RIMA 1, 185, line 113. Van Driel 1969, If., considers the possibility that his mention as early builder (and perhaps also his inclusion in AKL - K.R.V.j derives from oral tradition.

4 Those of litit, Azuzu and Zariqum (RIMA 1 A.0.1001-1003). litil, whose title is written PA (for waklum?) and who records a successful campaign against Gasur (later Nuzi), moy have been an independent ruler of the city, perhaps in the period between the Old Akkadian and the Ur IIl empires. Azuzu, who dedicated a spearhead for the life of king Maništusu, is withoul litle, but may have been a local governor, like Zariqum, who was governor of Assur under kings Sulgi and Amar-Suen or Ur iil. None of the three is mentioned in AKL, the last two perhaps becouse they were no independent rulers. 1 refer to the analysis by Larsen 1976, part 1, ch. 1, 'The Origins', which is still basically valid. 
discovered. Moreover, later construction has obliterated much of the architecture of the so-called Old Palace and the early phases of temple of Aššur, ${ }^{\circ}$ and only few royal inscriptions came to light. ${ }^{7}$ Nearly all the written evidence, and also a wealth of impressions of Old Assyrian cylinder seals, was discovered in the Old Assyrian trading colony (called kärum) at the city of Konesh in Central Anatolia, which flourished during what are called kärum Kanesh levels II and Ib. Level II contains abundant evidence of Assyrian presence and activity, documented in close to one hundred houses, most of which contained the archives of their inhabitants, which have thus for yielded in all ca. 23.000 cuneiform tablets. Ca. Mhirty-five years after the destruction and desertion of level II (ca. 1835 BC according to the Middle Chronology) the colony revived in level $\mathrm{lb}$, but with a reduced Assyrian presence and activity land hence only a lew hundred texts), while many houses now belong to non-Assyrian, presumably native Anatolian traders.

However rich this documentation, especially from level II, part of which (in particular letters) also originated from Assur itself, it focuses on the trade and its administrative and legal implications. Many aspects of life in ancient Assur, the temples, the palace, the ruler, the people and economy apar from the trade, etc., remain in the shadow and are not easily reconstructed. This explains why we end up with a somewhat biased picture of Old Assyian history, culture and sociely, which leaves large gaps in our knowledge.

\subsection{The Old Assyrian Period}

The Old Assyrian period starts when the state of Ur III, around $2025 \mathrm{BC}$ /middle chronologyl, a few years after the accession of lbbi-Suen, lost its administrative grip on what has been called its periphery or "the defense zone", to which the city of Assur belonged. ${ }^{8}$ Soon Assur, which had been ruled by a royally appointed governor, designated both as $\mid u$ and è n s i Ašsurki, "the man / governor of Assur", 9 became an independent city-state under its own rulers. These rulers, members of the so-called "Puzur-Aššr dynasty" (named after Puzur-Aššur l, king 30 of AKL), were now considered to be "governors" (e n s $i=$ issick-

- See for a short presentation of the archaeological dala, Marzahn - Salie 2003, 111-28.

7 Ediled in R/MA 1, 14-18, 22-51, 60-63, and 77-78. The pages not listed contain inscriptions found elsewhere, in Kanesh, Ninive, and Mori. The inscription recording building activity by "Isme-Dogan, son of Ṡamši-Adad", on which his mention by Enlil-nāșir I (RMM4), 95, 7) was bosed, has not been found, and the question is which Isme-Dagon is meont, I (king 40) or II (king 58). The existence of namesokes, sons and once a father of a Samsi-Adad, is confusing, also for the ancients, as shown by the presumably mistaken "Distanzangabe" of Tiglath-Pileser I (RIMA 2, 29, VIII:2f.), see Eder 2004, 208. See for the early royal inscriptions of Assur diso Galler 1997.

8 See Sollaberger 1999, 161 with note 136.

- See Maeda 1992, 149f., on Zariq(um). 
kuml appointed by the god Aššr, who was the true king of the city, as expressed on the seal of Silulu and in an inscription of Erišum. ${ }^{10}$ Gradually, over the next century, the spelling A šsurki in the ruler's title, which, following Ur lll usage, referred to his realm, was replaced by dAššur, to express that he was primarily an appointee of the god Aššur, after whom the city was named." Assur's new independence must have increased the prestige and power of the temple of the city-god, who had asked Salim-ahum to build it (RIMA 1, 14), and with which the ruler appears to have been closely associated ${ }^{12}$, while the palace does not appear in the written documentation. It also lead to a dominant administrative role for the "City $\{$ Assembly; ălum), with its "City Hall" (bet ălim\} controlled by the eponymic limum.

The Old Assyrian period is also characterized by the emergence of the Old Assyrian dialect, specific types of written records, a native Assyrian calendar, a brisk international trade, a body of legal customs and rulings, a different style of cylinder seals, and various other cultural features. I use the term 'emergence', because some of these features may not have been completely new or may have developed gradually after the city had become independent. Existing native features may have been obscured by the dominant Sumerian administrative practices of the Ur III state or have remained invisible for us due to the lack of written documentation from Assur before ca. $2000 \mathrm{BC} . .^{13}$ The Old Assyrian dialect, which developed out of Old Akkadian, may have received its distinctive traits during the last centuries of the third millennium $B C$, but its specific writing conventions (both its syllabary and its orthography) apparently took at least a century to fully develop the peculiarities which we consider typically 'Old Assyrian'. 14 The iconography and style of the so-called 'Old Assyrian seals' according to specialists show links with the Ur III glyptic, perhaps due to "the impetus given to local manufacture at the time of Assur's

See R/MA 1, 13 and 21 lines 35f. Lorsen 1976, 114, compares the inscriptions on royal seals from Eshnunna and calls attention to the fact that in Assur the relation between city-god and the ruler is again conceived along the lines of the early city-states of southern Mesopotamia. Galter 1997, 55f., points out that in the statement that a ruler of Assur built a remple or made a dedication "for the well-being of himself and of his cily" (ano balōtisu u balōt älisu), the cily now appears prominently.

11 See Golter 1996

12 See now also Galter 2004. Rulers in their letters regularly promise that they will intercede with Ašs̆ur on behalf of their correspondents (mahar Ašsur karäbum with personal dative suffix, see Larsen 1976, 119f.).

13 We have no information on the origin of so-called 'Old Assyrian Calendar', with months apparently named after cultic and seasonal features (Lewy 1939; R/A 5, 1976-1980, 301, §ु 3.4; M.E. Cohen, The Cultic Calendars of the Ancient Near Eost, Bethesda, 1993, 237-46;, first attested around $1900 \mathrm{BC}$ and still in use during the Middle Assyrian period. It may have been an Old Assyrian creation, but also hove had earlier roots.

14 See for the peculiarities of the syllabary, larsen 1976, 144 with note 109; Veenhof 1982, 365, with nole 14; and Veenhof 2003, 12. 
dominance by the Ur III empire". ${ }^{15}$ Judging from the available epigraphic and archaeological evidence the flourishing trade on Anatolia, logether with the institution of the annually appointed limum, only took shape during the second half of the 20th century BC, probably when Erišum I was ruler of Assur.

Whatever the origin and development of these features, their sum made ancient Assur sufficiently different from contemporary Babylonia to justify the use of 'Old Assyrian' as a cultural label, derived from Ašsur, the local god, originally probably the defied local mountain range, ${ }^{16}$ and the name of his city. This would have been impossible without the participation of Assur's citizens, especially the prominent families which, as soon as we can trace their history, play an important role in the City Assembly and through the office of the eponymous limum. Assur's distinctive characler, under a native dynasty, was maintained when in the south (including Eshnunna), after the collapse of the Ur III empire, Amorite elements came to play a prominent role, also in the political power structure. Lewy's attempts to discover a variety of ethnic and religious Amorite features in Assur are not convincing and the number of clearly Amorite personal names is extremely small.

Lewy 1961, in a study entitled 'Amurritica', considered the veneration of the god Amurrum, at times designated as "the god of my father", as proof of 'Amorite' influence. But this is not warranted, because Amurrum had already been well accepted into the Mesopotamian pantheon, and there is no Assyrian qualified as "Amorite" (DUMU MAR.TU) in his seal inscription, 17 since we have to read DUMU MAR.TU-[ba-ni], "son of Amurru-bōni", as shown by his completely preserved seal impression on $k t n / k 1821$ (courtesy V. Donbaz). Lewy also believed that the god An(n)a was "an Old West Semitic god" and "a deity of immigrants from the "Western Land" (Lewy 1961, 37 and 41), but this cannot be maintained. The texts acquaint us with a local Anatolian god of that name (spelled $A-n a, A-n a-a$, and $A n-n a$, occasionally also with the divine determinative), who had a priest (TC 3, 181:18, kt 89/k $376: 4$ ) and a temple in Kanesh ( $k+87 / \mathrm{k} 39: 25$ ), by whom the oath was sworn in KK 1 , 32 and Prag $1651,{ }^{18}$ and whose festival figures as a due date for the payment of debts by local Anatolians. 19 The "priest of Anna", who occurs in TC 3, 181:8, beors the name A-zU and to all appearances was an Anatolian indebted to an Assyrian trader.

15 Teissier 1994, 52t., $\S 7.3$. Seals of people of status, in particular, show introduction scenes derived from the Ur III tradition, but there was olso "a progressive interaction with Anatolian, SyroCoppadocian and Old Babylonian groups". She doubts the Syrion origin of the Old Assyrian linear style.

16 See for the nalure of Aššur, Hirsch 1972, 0-16, Larsen 1970, 291. (on mount Abeh), Lombert 1983, and Veenhof 1993, 052 with pl. 124.

17 On the envelope of $A A A \mid$ no. 10, as stoted in Lewy 1961, 39.

18 In the oath in ICK I, 32:10ff, by Aššur, Anna and the ruler, one mighi take Anna was on Assyrian god, but in Prag I 051:12 ff. (a divorce in Konesh), the oath is by Ašsur, Anna, the ruler, and the rabi sikkatim, where Aššur and the ruler are Assyrion and Anna and the rabi sikkatim Anatolian. These occurrences suggest thal Anna was the city-god of Kanesh.

See below, chapter VI.2.1, no. 1 . 
This does not mean that the Assyrian community did not comprise non-Assyrians. We meet them, recognizable by their names or the nisbe added to it, and even among the (early) eponyms Assur there are a man from Nërabtum and a hapirum (with a good Akkadian name; KEL nos. 44 and 49 \}, but they remain exceptions. ${ }^{20}$ On the whole, as reflected by the large corpus of personal names, the city apparently remained ethnically fairly uniform. It may help to explain the outburst of Puzur-Sin, a later (17th century BC?) ruler of Assur, who voices ${ }^{21}$ his repugnance against what had been built by a predecessor, offspring of Šamši-Adad I, "of foreign stock(?), no flesh of the city of Assur", though we cannot isolate it from his indignation about the fact that for this project "sacred places" (ešrătum) of the city had been demolished.

\subsection{From Old Assyrian to Middie Assyrian}

Marking the Old Assyrian period off against the following Middle Assyrian period is not easy. This is due to the lack of Assyrian historical data for the 'dark ages' between the end of the eighteenth and the end of the fifteenth century BC, when Assur had been able to free itself from political domination by or influence of the Mitanni state, which had culminated in the conquest of Assur by king Sauštatar. ${ }^{22}$ The conquest of Babylon by the Hittite king Mursilis I (in $1595 \mathrm{BC}$ ), which spelled the end of the so-called Hammurabi dynasty, probably did not have a serious impaci on Assur and therefore cannot serve as time limit. Domination by Mitanni must have left traces, but they are not easily detected or distinguished from native developments, ${ }^{23}$ and there was also cultural and administrative continuity with the Old Assyrian period. ${ }^{24}$

Historians usually let the Middle Assyrian Period start in the second half of the fifteenth century $B C$, when documentation - both archival texts and some royal inscriptions, beginning with those of king 59, Šamši-Adad III - resumes. But for lack of data it is not easy to say what was then new or different, apart from the fact that the city was enlarged by adding the southern "new town" (älum eššum), whose walls were constructed by Puzur-Aššur III. ${ }^{25}$ The

20 There are a few persons with Hurrion names and people like Pilah-Adad, designated as "the man from Tadmur" (see Dercksen 1996, 163f.).

2) In his inscription RIMA 1, 77F.

22 See G. Wilhelm, Grundzüge der Geschichte und Kultur der Hurriter(Darmstadt 1982) 37, and C. Kühne, Imperial Mittani: An Attempt at Historical Reconstruction, in: D.I. Owen and G. Wilhelm (eds.), Nuzi at Seventy-five, SCCHN 10 (Berhesda, 1999), 203-222, esp. $215 \mathrm{ff}$.

23 According to von Soden 1963, 134, "darf es als sicher gelten, dass der Charakter der führenden Schicht in Assur am Ende dieser Zeit (i.e. that of the Hurrian domination - K.R.V.) ein andere geworden war als noch zur Zeit Šamši-Adad's I.", by which he means much more military, ruthless and imperialistic, possibly also due to the incorporation of many people of Hurrian descent.

24 See for continuity and change in respect to role of the "City Hall" of Assur, Dercksen 2004a, 10ff.

25 See RMA 1, 100, 5f. The mention of the "new cily" in RIMA 1, 80:7 is nol certain. 
city also became the capital of a territorial state, whose rulers now called themselves "king of the land of Assur (mât A Ašsur)", and would soon join the "club of the greal powers" of the Amarna Age, in the $14^{\text {th }}$ century $B C$.

Looking for the transition between 'Old' and 'Middle Assyrian', we would like to be guided by the Assyrion historical tradition, embodied in AKL. But this tradition becomes confused towards the end of the 18th century $B C$, with different versions of the list, none of which seems to know (or acknowledge) the above mentioned king Puzur-Sin, son of Ašsur-bēlšamē, and his hated predecessor Asinum, "oftspring of Šamši-Adad". 20 It is possible that with king 48, Bēlu-bāni, the first ruler of what has been called "the dynasty of the Adasides" (Esarhaddon was the first to refer to Adasi as his ancestor), a new historical phase was inaugurated, but we have no idea what might have changed apart from the ruling dynasty. However long the interval between Išme-Dagan (and his son Mut-Asqur) and Bēlu-bāni may have been - Eder, on the basis of the Assyrian "Distanzangaben" assumes it to have been ca. 125 years, ${ }^{27}$ - if would mean a caesura somewhere in the second half of 17 th century BC. But lack of inscriptional evidence before king 59 (Šamši-Adad Iil) does not allow us to take Bëlu-banni's accession as the beginning of the so-called Middle Assyrian Period, which anyhow is a modern concept, only applicable from the second half of the fifteenth century BC onwards. ${ }^{28}$ We can only conclude that for the historian the Old Assyrian period de facto ends somewhere during the last quarter of the 18th century BC, when a "dark period" starts.

\section{3. ŠAMSï-Adad's CONQUEST of Assur}

The change from capital of a cily-state to one of a territorial state, which probably marks the Middle Assyrian period, was not a completely new one. Something similar already had taken place in 1808/7 BC, when Šamsi-Adad I conquered Assur. The city now became part of what has been called the "Kingdom of Upper Mesopotamia" and dependent on a powerful ruler, by origin "king of Ekallätum". ${ }^{29}$ He added "governor of divine Aššrur" (išssiak

See RIMA 1, 77f, and for the confusing traditions, Eder 2004, esp. 209-12.

Eder 2004, 205ff. He believes that the 40 (sic, see his nole 44) years of reign assigned to lismeDagan by AKL refer to the length of his rule after Samsi-Adad's death, which I still consider doubtul.

See Veenhof 1982, 363, with note 4, for attempts to apply the label "early Middle Assyrian".

See Ziegler 2002, esp. 212-220; the text where Dadusa designates Śamsi-Adad (Sa-am-seed dW as "king of Ekalläum" is now available in BaMitr. 34 (2003) 146, col. X:9-10. Ziegler 2002, 212, considers the passibility that Ekalläum was a new name, given to his residence as a seat of royol power, avoiding Assur, the "divine cily" (usually simply colled "the cily", alum), where the gad Aššur was king ond the nuler his "governor". This could only be true if Ekallatum was not the original seat of his dynasly, an issue which is still disputed (see Charpin 2004, 148 for the various proposols). One earty letter (Charpin 2004, 134) indicales that his realm was called "the land of the Tigris" and AKI states that Ekalläturn was conquered three years before Assur, probably a recapture, olter Samši-Adad had given it up due to the pressure of Narōm-Sin of Eshnunna, which made him seek asylum in Babylonia (see Veenhof 2003, 61). 
'Aššr) and "beloved of Aššr" (narām 'A Ǎšur) to his tilles and observed his royal duties by building (restoring) the remple of the city-god ${ }^{30}$ and caring for its cult. ${ }^{31}$ The prestige of the city and of being its ruler also must have made him (or his successor) insert his name and genealogy in the ciry's king list. But, though calling Assur "my city", 32 he did not make it his capital and he was not a native Assyrian ("not of the flesh of the City of Assur"), as the later Assyrian king Puzur-Sîn reminds us. He made his influence felt, a. o. by having his son and successor appointed as limu-eponym, which none of Assur's earlier rulers has done. ${ }^{33} \mathrm{His}$ reign also sees an increase of influence from the south, noticeable in his use of the Babylonian dialect, ${ }^{34}$ also in his building inscription for the ancient temple of the god Aššr, whom he presents as the Assyrian Enlil by calling it Enlit's temple.

Under Šamši-Adad's successor, Išme-Dagan, the city continued to play an important role in the trade in Northern Mesopotamia and beyond. ${ }^{35}$ His dynastic capital Ekallatum was not far from Assur and several letters show that he occasionally stayed in the city, cared for its cults, ${ }^{36}$ and later Assyrian royal inscriptions tell us that he was also active as a builder. ${ }^{37}$ This concern was politically sensible, since he used Assur's troops in his military operations, ${ }^{38}$ but it may have been stimulated by the fact that his wife, called Lamassi-Aššur, was from Assur, perhaps even a member of the family of rulers ousted by S̆amši-Adad I. ${ }^{39}$ Assur also shared his political misfortunes, when he had to flee his country and capital three times, in 1771 (when Eshnunna occupied Assur), 40 in 1765 and in 1763 BC..$^{41}$

In 1761 BC Hammurabi of Babylon, according the name of his 33rd year, subjugated "various cities of the land of Subartum and Ekallätum", a success which was consolidated by additional campaigns in his 36 th and 39 th years. It must have included Assur, to judge from a statement in the prologue to his laws (col. IV:53-58), where he expresses his con-

Calling himself bāni bēt Ašsur. See for his titles and inscriptions mentioning work at Assur, RIMA I, A.0.39, nos. 1, 9, 10 (see now the edition in Tunca 1989), and 11, and p. 228, col. III. His work at the ziqqurrats of the Anu-Adad temple is mentioned by Šamši-Adad III, see RIMA 1, 81, 1001.

31 See the letter A 2703 edited in Ziegler 2002, $214 \mathrm{ff}$.

RIMA 1, 49f, lines 35, 56, and 78 .

See Veenhof 1982, 385.

See for the innovations introduced by him also Galter 1997, 55.

See Ziegler 1996 and Charpin-Durand 1997, 376f.

See Charpin-Durand 1997, 372f.

See RIMA 1, 95, lines Off. It is frequenly assumed that when Tiglath-pileser I, in RIMA 2,28, lines 6Off., states that the Anu-Adad temple had been built 701 years before his time by Šamši-Adad, son of Išme-Dagan, this is a mistake for lšme-Dogan son of Šamši-Adad I, though RIMA takes the builder to be Šmši-Adad III.

See e.g. ARMT 26, 411:32, together with troops of Babylon and Ekallätum, under the command of his son Mul-Asqur.

See for her letters P. Marello, MARI7 (1993) 271-279.

See Ziegler 2002, 238f., with note 114.

See Charpin-Durand 1997, 372 note 43, and Charpin-Ziegler 2003, 198 and 235f., also on the role of Assur's "Overseer of the merchants" during the absence of lšme-Dagan. 
cern for the city and its people, ${ }^{42}$ but we lack any concrete information of what happened. Eder believes that lšme-Dogan, whom he assigns a forty years reign (1776-1738 BC). after a short interregnum during the final years of Hammurabi, again entered his capital and even developed "eine rege Bautötigkeit" in Assur, ${ }^{43}$ but we lack all evidence for this reconstruction.

After that, during the reign of Samsu-iluna of Babylon $\{1750-1712 \mathrm{BC}\}$, the information on the city becomes scarce, although AKL lists a continuous series of rulers. ${ }^{44}$ But we have evidence for the continued role of Assur as a trading ciry, both from documents found at Sippar, dating to the early years of Samsu-iluna, and from the treaty concluded around 1740 BC between Till-Abnû, the ruler of Apum (capital Šehno = Tell leilan) and Assur. ${ }^{45}$ That Apum's ruler had to swear an oath to "the city of (the god) Ašsur, the citizens of Assur traveling up or down, and the kārum that is in your city" shows that the institutional fabric (without mention of a king or ruler!) was basically still the same as a century earlier and that trade remained very important. But this is close to the time when all documentation, apart from the confused traditions of AKL, stops, also that supplied by the texts discovered in kärum Kanesh level lb.

\section{4. 'Later Old Assyrian'}

It is clear that the conquest of Assur by Šamši-Adad I in ca. $1807 / 8$ BC is the most important event during the ca. three centuries of the Old Assyrian period we can follow. But there was also another break, for the evidence brought to light in karrum Kanesh shows that the flourishing trading colony of level ll came to a violent end in ca. $1837 \mathrm{BC}$. This not only means that we lack written sources for the next decades, but it must also have had a serious impact on Assur itself. ${ }^{46}$ The colony was rebuilt in the so-called phase karum lb, after an interval of perhaps ca. 35 years and this resumption of the commercial activities therefore must have taken place during the reign of Šamsit-Adad I.

We have only co. 340 cuneiform tablets from this phose of the karum, but the intormalion they provide can be supplemented by the textual evidence for Assyrian presence at Hattuša, Amkuwa (Alişar Höyük) and Acemhöyük lequated by some with ancient Burushad-

42 The words "who guides the population $\{a m m i\}$ properly and who restores its benevolent protective spirit to the city of Assur", whatever they meant in concrete, ottest to his respect for this ancient city.

43 Eder 2004, 2081., who ignores the impacl of Hammurabi's conquesl of Ekollätum in 1701 BC.

44 The main recension of AKL, 'King list 9', after Išme-Dagon lists an usurpotor and six kings who ruled for short or unknown periods (bäb ruppisu). A tragment of a different recension (Grayson 1981, 115, 'King List 10'), mentions as successors of Isme-Dagan his son Mut-Asqur (known from sources from Mari) and a Rimu[š], both of which do nol figure in 'King list 9'. AKL also does not include Puzur-Sin, who is known from his inscription RIMA I, 777.

45 See for the evidence trom Sippar, Veenhof 1991, and for the trealy with Apum, Eidem 1991.

46 Even if the destruction of karum Kanesh should turn out to be o regional event and a number of other colonies conlinued to function. 
dum). ${ }^{47}$ Among them are a few very important rexts, such as the new eponym list mentioned above, a letter written shortly after the accession of Isme-Dagan by the authorities in Assur to kärum Kanesh, and two treaties concluded between the Assyrians and Kanesh and Hahhum. ${ }^{48}$ Together with the texts from this period discovered at Mari, Tultul, Qatțarā, Šehna, and Ššarrā, they allow us to recover something of Assur's history during the tumultuous 18th century $B C$. The new eponym lists indicates that the period of korrum level lb continued until at least $1725 \mathrm{BC}$, and probably a few years longer, because the last eponym it mentions does not necessarily coincide with the end of the Assyrian presence in Kanesh.

Considering the developments inaugurated by Šamši-Adad's conquest, the gap in the documentation from kärum Kanesh, and the restart around 1800 BC, it is useful to keep this period apart and label it as "Later Old Assyrian". This label was already used in the edirion of legal documents of that period, ${ }^{49}$ and proposed by $E$. Porada for the contemporary Old Assyrian seals, 50 the iconography and style of which indeed evokes comparison with Babylonian seals from the reign of Samsu-iluna. ${ }^{51}$ In Assur itself the label might also be applied to the 17th and perhaps the 16th century BC, depending on when we believe the Middle Assyrian period has started.

47 See now Dercksen 2001 a.

48 See Michel 2005 and Donbaz 2005, and below V.2. Note also the interesting lext published in Dercksen-Donbaz 2001.

49 By Gelb-Sollberger 1957, and Veenhof 1982.

50 Porada 1980, 385

51 N. Özgüc 1968, 59ff. 


\section{ChronOLOGY}

\subsection{The Old Assyrian Period in general}

The chronology of the Old Assyrian periad for a long time has been uncertain. The numbers of the regnal years of several early rulers of Assur are missing or damaged in the copies of AKL we know and we lacked a list of limu-eponyms, whose terms of office were used to date records. Without such a list we could only start from the total number of eponyms actually attested and try to reconstruct their order on the basis of archival texts, and it remained difficult to estimate the length of the period covered by karum Kanesh level it and the size of the gap between levels II and lb, the existence of which was demonstrated by stratigraphy.

Much has changed by the publication, in 2003, of the 'Kültepe Eponym List' $(K E L), 52$ which acquaints us with a sequence of 129 limu-eponyms. The few gaps in it could be restored thanks to the "Mari Eponym Chronicle" (MEC), ${ }^{53}$ the beginning of which overlaps with the end of KEL. Fortunately KEL also links the accession of a new ruler in Assur (called "the waklum, our lord") with particular eponyms, which allows a restoration of several figures in AKL. Moreover, the overlap with MEC reveals that the gap between karrum Kanesh levels II and Ib starts with MEC sequence B no. 5, which is eponym 137 after the accession of Erišum 1. ${ }^{54}$ Since none of the next twenty eponyms listed in MEC is known from Kanesh, the gap must have covered a few decades, but we cannot yet establish when exactly kárum level lb storted.

These new insights can be refined when a new eponymy list, discovered in 2001, will have been published by $C$. Günbalti. Storting with eponymy 110 it overlaps with the end of KEL and continues with an additional ca. 120 year eponyms. This brings us down to ca. $1725-1720 \mathrm{BC}$ and shows that the "Later Old Assyrian period" of kärum Kanesh level lo must have lasted at least 80 years. 55

The discovery of KEL and its correlation with MEC shows that the figure of 40 years given in AKL for Erišum I is correcl, and it also proves that the so-called "Distanzangaben" in later Assyrian building inscriptions, which give or imply a temporal distance of 199 years between the accession of Erišum I and the death of Šamši-Adad I, are correct. This makes it possible

54 The new eponym list, as C. Günbattı kindly told me, reveals that the gap between the end of KEL and the beginning of sequence $B$ of MEC conlains not four (as I had suggested) but only three year eponyms, those numbered D, $A$ and $C$ (in that sequence, hence to be counted as nos. 130-132) in Veenhof 2003, 56. This means that the end of kanum level II came during eponymy no. 137, in 1837 BC, just three years betore the accession (in Ekallāum?) of Samši-Adad I.

55 The list is badly written and presents problems, also because the eponyms during which, according to AKL, Šmši-Adad I conquered Ekallätum and Assur do nol seem to figure in it. 
ta link the Old Assyrian chronology with that of Babylonia, via the date of Šamši-Adad's death, which occurred in $1776 \mathrm{BC}$, the 18th year of Hammurabi of Babylon, the 4th year of lbal-pi-El II of Eshnunna. 50 This means that the rule of Erišum I started in 1974 BC, which is also the year when the institution of the annually appointed limu-eponym was introduced, since all five manuscripts of this list start in that year. The lack of earlier eponyms explains why AKL is unable to give the regnal years of Erišum's predecessors, kings nos. 27-32, among which his three ancestors. It writes after king 32: "In all six kings [known from] bricks, whose eponyms have not been marked/found". ${ }^{57}$

The eponym list KEL A breaks off after year 27 of Narām-Suen, but the temporal distance between Erišum I and Šamši-Adad I, who dethroned Erišum II, shows that their combined reigns must have lasted 64 years. Because the figure for Narām-Suen ends in 4, the best solution is to assign him 44 or 54 years of reign an d his son, who lost his throne to ŠamšiAdad, a shorter one, of 20 or 10 years. The destruction of kārum Kanesh level II must have occurred during Narām-Suen's 35th year, in 1837 BC.

\begin{tabular}{|c|c|c|c|c|c|}
\hline$n r$. & name & son of & regnal years & \multicolumn{2}{|c|}{ date (middle chron.) } \\
\hline 27 & Sulili & Aminum & $?$ & \multicolumn{2}{|l|}{$?$} \\
\hline 28 & Kikkiya & ? & ? & \multicolumn{2}{|l|}{ ? } \\
\hline 29 & Akia & ? & ? & \multicolumn{2}{|l|}{$?$} \\
\hline 30 & Puzur-Aššur I & $?$ & $?$ & \multicolumn{2}{|l|}{$?$} \\
\hline 31 & Šalim-ahum & Puzur-Ašs̆ur 1 & ? & \multicolumn{2}{|l|}{$?$} \\
\hline 32 & llušuma & Šalim-ahum & $?$ & \multicolumn{2}{|l|}{$?$} \\
\hline \multicolumn{6}{|c|}{ In all six kings [known from] bricks, whose limum's hove not been marked/found } \\
\hline 33 & Erišum 1 & |lušuma & 40 & $1974-1935$ & $B C$ \\
\hline 34 & Ikūnum & Erišum 1 & 14 & $1934-1921$ & $B C$ \\
\hline 35 & Šarru-kin & lkūnum & 40 & $1920-1881$ & $B C$ \\
\hline 36 & Puzur-Aššur II & Šarru-kīn & 8 & $1880-1873$ & $B C$ \\
\hline 37 & Narām-Suen & Puzur-Ašs̆ur II & 54 or 44 & $1872-1829 / 19$ & $\mathrm{BC}$ \\
\hline 38 & Erišum II & Narām-Suen & 20 or 10 & $1828 / 18-1809$ & $B C$ \\
\hline 39 & Šamši-Adad I & lla-kabkabuhu & 33 & $1808-1776$ & $\mathrm{BC}$ \\
\hline 40 & Išme-Dagan & Šamšī-Adad I & 40 & 1775-1761(?) & $B C$ \\
\hline
\end{tabular}

The chronology of kings nos. 27-40, with the doto from KEL A/MEC integroted into those of AKL. [See for a slight adoptatiion, whereby Jkūnum, no. 34, reigned 15 years, my observations in NABU 2007].

56 In month XII of the Assyrian eponymy year, commemorated in the name of Ibal-pi-EL II's 5th year, see Charpin-Ziegler 2003, 136ff. and 163.

57

Veenhof 2003, 21. 
The number of 40 regnal years of lšme-Dagan in AKL cannot be checked, since we have no historical data on him after the end of the Mari archives, in Zimrilim's 13th year (1762 BC). Eder accepts them and is able to fit them into his revised chronology, ${ }^{58}$ but others consider the figure of 40 too high and assume that the years he ruled from Ekallatum, while his father was still alive, have been included. We do not know exactly when this rule started, ${ }^{50}$ but if he lost his throne in $1761 \mathrm{BC}$, when Hammurabi conquered Ekallätum, ${ }^{60}$ he would have reigned independently for ca. 15 years and his rule at Ekalläum should have started shortly after 1800 BC. ${ }^{11}$

The last column gives the dates according to the "middle chronology", which is followed in this volume, not because it can be proved to be the correct one, but in order to allow correlation with $O B O 160 / 4$. An absolute chronology still cannot be offered and there are now more competing solutions than ever. An ultra short one has been advocated by Gasche, who dates Šamši-Adad's death 101679 BC., 62 also on the assumption that Assyria before Tiglath-Pileser I used lunar years without intercalation. In this system Erišum I would have started his reign in $1874 \mathrm{BC} .{ }^{63}$ Another solution was presented by Michel and Rocher 2000 , who used both the mention in MEC of a solar eclipse during the year after the birth of Samši-Adad, in the year KEL 126, and dendrochronological data from contemporary Anatolio oblained at Acemhöyük. After the latter had been refined, the final proposal is that Šamši-Adad I was born in 1836 and died in $1760 \mathrm{BC}$, which means a reduction of the middle chronology by ca. 16 years. ${ }^{\circ 4}$ An ultra long chronology, based on the reliability of the so-called "Distanzangaben" in Assyrian building inscriptions, has now been advocated by Eder, who arrives at 1846 BC as the year of Šamši-Adad's death and at an accession of Erišum I in 2044 BC. ${ }^{65}$

Eder 2004, 207. With a 40 years' reign after his father's death, Isme-Dagan would have reached an age of ca. 75 years and have been born when Šamši-Adad I was ca. 30 years old.

59 Charpin 2004, 158 with note 725

60 Eder 2004, 208 note 46 mentions the possibility that he occurs in OBTR 253:5, from this some year, which records a.0. "issues to foreign rulers and military commanders or their messengers".

ol Arguments against a forty years' reign are his illness, reponted in texts from Mari (see MAR/7, 1993, 273, lines 21ff.; there were even rumors aboul his death, ARM 20, 493-495), and the fact thoto variant version of AKL (Grayson 1981, King Lis1 10) lists his son Mut-Asqur as his successor. Mut-Asqur already in $1765 \mathrm{BC}$ was considered old enough to replace his father on the throne of Ekallotum (ARM $371: 43^{\prime} \mathrm{f}$.) and to lead an amy (ARM 20, 411:37ff), and there were plans to let him mariy with a doughier of the king of the Turukkü in $1763 \mathrm{BC}$ (Charpin-Ziegler 2003, 218 and 236). Taking the 40 years of AKL at face value he would hove had to wait another 30 years before succeeding his father.

02 Gasche 1998 with Gasche 2003; ct. also D.A. Worburton, Shamshi-Adad and the eclipses, in: Studies Lorsen, 583-98

03 I have presented arguments against this "lunar reduclion" in Veenhot 2000, 141ff; see also Veenhot 2003, 58f.

64 Michel-Rocher 2000 and 2002b. The dendrochonological argument is that the building at Acemhöyük, in which bullae with the seal of Samsi-Adad I hove been found, was constructed in the period between 1778 and 1767 BC.

65 Eder 2004. An important aspect of his reconstruction (205H.) is that the "Distanzangabe" by Esarhaddon (after correcting the figure of 434 into 494 years) yields $1759 \mathrm{BC}$ as the accession 
It is difficult to choose between these proposals, all of which, moreover, have to work with assumptions and hypotheses and as such are liable to criticism. ${ }^{60}$ Fortunately, it is not too important for the following analysis whether the whole Old Assyrian Period moves up or down fifty or hundred years, as long as important synchronisms ${ }^{67}$ - with Babylonia and Mari via Šamši-Adad I; indirectly with Samsu-iluna, via Assur's treaty with Apum/Šehna - remain intact and also the temporal distance between the end of kärum Kanesh level lb and the emergence of the Old Hittite Empire (under Hattusilis l) remains more or less the same. ${ }^{68}$ The real problems, if we accept Eder's solution, would only start after lšme-Dagan, whose reign, however, due to a lack of written documentation after ca. $1762 \mathrm{BC}$, for the time being is the latest phase of the OA period which we can study.

\subsection{THE PERIOD Before ERIŚUM I}

If the reign of Erišum I started in ca. $1974 \mathrm{BC}$, there are only ca. fifty years after the end of Ur III into which we hove to fit the rulers preceding him. They are in the first place his direct predecessors, nos. 30-32 of AKL, the last two known from original inscriptions, ${ }^{69}$ in which Puzur-Ašsur l, presumably the founder of a new dynasty, is mentioned as their ancestor. These three rulers, father, son and grandson, are enough to fill these fifty years and it is very uncerlain whether we have to fit in here also nos. 27-29, about whom almost nothing is known, neither their genealogy, nor the length of their reigns, nor their chronological position. Only Kikkiya is mentioned in a later inscription as builder of the city-wall, ${ }^{70}$ but Akiya and Sulili are completely unknown outside AKL and rexts which use or reflect it, unless one

year of Samši-Adad I. This is 119 years laler than 1878 BC, the year which results from the data supplied by Shalmaneser I, which KEL and MEC hove proved to be correct. This discrepancy is solved by assuming that the scribe of Esarhaddon used the late, cononical version of the Assyrian King List, which was drafted after Tiglath-pileser I and in which the successors of Išme-Dagan I until king 48 (Bēlu-bāni) would have been omilted.

so I onty mention here, in connection with Eder's proposal, that the deviating, perhaps older version of AKL (Grayson 1981, 115, List 10 = KAV 14), which would still have contained lsmme-Dagan's successors, who are needed to fill the gap of 125 years, only has two lines with four (possibly six) names available for them, before moving to king 54 of the cononical version, which is clearly too little. Eder (208) mies to "fill" Išme-Dagan's disputed forty years of independent reign by mentioning "eine rege Bautatigkeil" in Assur, which is more than the sources document, and he ignores the consequences of Hammurabi's conquest of Ekallatum in the latter's 32nd year, which would have normally meant the end of Išme-Dagan's reign, if not life (if we compare the fate of Zimrilim).

o7 A presumed synchronism between llusuma and Sumu-abum (of Babylon), read in the "Chronicle of Early Kings", line 37 (which has Su-a-bu and does not mention Babylon), was already refuted by Larsen 1976, 69f. KEL now makes it clear that Sumu-abum of Babylon ruled about a century ather llušuma. Assured by the link between the end of the Hammurabi dynasty and the reign of Mursilis I. Eder 2004, 228 puts the dates at ca. 1775 and ca. $1700 \mathrm{BC}$.

By Ä̌sur-rêtr-niššsu, in RMA 1, 101, line 5, where he is mentioned as builder before lkünum, king no. 34. 
identifies Sulili with an e $n s i$ of Assur called Șilulu, who is only known from a later seal impression (see below III, 1.2). If so, he can only be inserted before Puzur-Aššur I, possibly as the first ruler of an independent Assur, with only a short rule, if he had begun his coreer as the last governor of Assur under the Ur Ill empire. But there is no proof for this solution.

\subsection{The period of Kärum Kanesh LeVEe II}

Thanks to the new eponym list we know that level II lasted until ca. 1837 BC, the 35th yeor of Narōm-Suen. And a piece of an envelope with an impression of Erišum's seal, presumably from a letter sent by him, found in the kärum in 1983, suggests that the Assyrian presence at Kanesh started during his reign. ${ }^{71}$ That the annual eponymous limums, so important for the administration and finances of the city, first appear during his reign supports this conclusion, but the exact beginning of this phase is still unknown, because the oldest dared texts from the kārum are later than his reign. ${ }^{72}$ As will be explained in chapter III.1.3, it is possible that the trade had already started under Erišum's energetic predecessor llušuma, but if so probably first as a venture trade by visiting caravans, which used temporary lodgings /bet ubrim), before Assyrian settlement in Kanesh took place.

Whatever the exact date of its beginning, it is now clear that level Il of kärum Kanesh lasted well over a century, which implies developments over time, which we must tiy to map with the help of KEL. In level II we moy distinguish a "best documented phase", the years with the biggest number of dated records from the main archives, which starts about halfway the reign of Sarru-kin (ca. $1900 \mathrm{BC}$ ) and continues for ca. Forty to forty-five years. From the last twenty years of kärum level II there are much less dated records, which cannol simply be due to the chances of discovery.

\subsection{The period of kärum KanesHi leVEe lB}

The existence of this period, at first doubted, is now clear, both from the stratigraphy in karrum Kanesh, the eponymic datings of texts found there, and the occurrence of a number of Anatolian kings, and it is also documented by the textual discoveries made at Amkuwa

71 See Veenhof 2003, 41. Knyszat 2004a, 5, doubts the conclusive force of this discoveny, because a dead ruler's (son and) successor could still use this father's seal, a thesis elaborated in Kryszot 2004b. But the fact that Puzur-Aššr II, soon after his accession, still uses his father's seol does not prove that this also hoppened with Erišum's seal.

The oldest eponym thus for attested was no. 47 (see Veenhof 2003, 30, 47a), but larsen now informs me that the memorandum 94/k 1263 rev. 19 mentions the eponymy KEl 41 , which brings us to the first year of lkünum. It is only natural that earty texts were discarded after some generations, since old commercial records were no longer needed as written proof of transoclions which had been completed long ago, which is different with title deeds and contracts as prool of stans or rights. 
and Hattuša ${ }^{73}$ It must have started after an interval of ca. 35 years, but as long as the new, late eponym list has not been published, we cannot date its beginning, which must fall in the gap after eponym 27 of sequence $B$ of MEC. This means that the revival of kārum Kanesh falls within the reign of Samši-Adad I, and one might be inclined to connect it with his domination of Northern Mesopotamia, accomplished after the defeat of his rival Yahdun-Lim of Mari, in ca. 1794 BC. However, as the destruction of level II of kārum Kanesh was due to internal Anatolian conflicts, we may assume that its revival in level lb was also primarily conditioned by developments there. We also know from Mari texts that commercial caravans and traders could travel even in times of war, on the basis advance notices and trealy agreements, which served to secure their passing. ${ }^{74}$ The treary between the ruler of Apum (Tell Leilan) and the city of Assur, from ca. $1740 \mathrm{BC}$, proves that the caravan trade did continue in periods of political instability.

Whatever the possibility of a link between the emergence of kōrum level lb and the political career of Śamši-Adad I, it is likely that he would have greeted and exploited the revival of the trade as a contribution to the economy of his realm. The discovery in the ruins of Acemhöyük of bullae with impressions of his seal, originally attached to packets, shows that he was also personally involved (see below chapier IV.2.3). Texts from the level Ib period, whose number is anyhow rather small, also indicate that there were at times problems of communication, because the names of some year eponyms only became known in the colonies more than a year after they had been elected. ${ }^{75}$ Because we cannot yet date these eponyms, it is impossible to connect these communication problems with political events in Northern Mesopotamia and, again, also developments in Anatolia could be the cause.

The information on the total number of eponyms of the new list (which starts with eponym 110 of KEL) makes it clear that this period may have lasted until the middle of the reign of Samsu-iluna of Babylon, or ca. 1720 BC. We do not know what caused the now definitive end of the Assyrian commercial penetration of Anatolia, but the destruction of level $\mathrm{lb}$ of kārum Kanesh and of level IVa of the lower cily of Boğazköy certainly were the result of the political competition and rivaly between the various Anatolian kingdoms, as they are known from the letter of Anum-hirbi of Mamma ${ }^{70}$ and, somewhat later, from the so-called "Anitta text". 77 It seems unlikely that Samsu-iluno's raid on Šehna (Apum) in 1728 BC, 78 even though this lown had a kărum with Assyrian traders and was a traditional road station for caravons on the way to Anatolia, was the cause of the breakdown of the system. The new eponym list suggests that trade and contacts between the colonies and Assur continued

Analyzed in Dercksen 20010. Both cities apparently already harbored Assyrian settlements during the level II period, see ibidem 40 note 5 and 50 note 59 (and below N.2.1-2), but the main archeological and textual discoveries were made in the levels contemporary with karum Kanesh level lb.

74 Charpin-Durand 1997, 377ff.

75 The dating than takes the form of limum ša qöt qãtim PN, "eponymy of PN, who look it over from the one who took it over from PN" (KBo 9, 4:8ff.).

76 See Balkan 1957.

77 See for this text Neu 1974 and a summory of its contents in Klengel 1999, $27 f$.

78 Recorded in the name of his $23^{\text {th }}$ year. 
for some time after that year. There may have been other players too on the North-Mesopotamian scene, such as the ruler of Yamhad (Aleppo), who tried to strengthen his grip on northern Mesopotamia, as texts from Tell leilan indicate. When kârum Kanesh level lb came to an end, Assur itself, in our perception, had already entered a "dark period", marked by a lack of written sources, which, considering the data in AKL, was due to political confusion. But we do not know to what extent the end of the Anatolian trade, which certainly must have had a negative effect, was also responsible for it. 


\section{SOUrces for the Old Assyrian Period}

We have written sources and remains of the material culture from various archeological sites and most of the former are contemporary, but some later and belong to the historical tradition. The following survey classifies them according to their provenience and presents them more or less in chronological order.

\subsection{SOURCES FROM ASSUR}

\subsubsection{Written sources from Assur}

We only have a small number of written sources from Assur. They include a few royal inscriptions of kings nos. 31-34 and 39 of AKL, written on stone vessels, a statue, a mace head, a door socket, stone slabs, bricks, clay plaques and pors. ${ }^{79}$ We may add the important inscription of Erišum I, discovered in two somewhat younger school copies in a house in kārum Konesh level II. Its original, ${ }^{80}$ an inscribed sikkatum, must have been displayed in Assur, perhaps in the muslalu-gate, whose construction and role in the administration of justice receive much altention. ${ }^{81}$ These inscriptions mention various building activities in the city and on the temples of Aššr, lštar and Adad, and measures of llušuma and Erišum I, which probably were taken to promote the role of Assur as a trading centre (see below chapter III.1.3). Šamši-Adad I in an inscription, written in the Babylonian dialect (RIMA 1, 48ff.), boasts of the prosperity of the city, of receiving tribute from far away regions (the kings of Tukrish and of the Upper land), and of reaching the Lebanon and the Mediterranean Sea. Finally there is the remarkable building inscription of Puzur-Sîn, son of Aššur-bël-šadu'ēe (RMA 1, 77, no. 1001), a ruler probably from ca. 1700 BC, ignored by the king list, perhaps because of his criticism of Samši-Adad I.

In addition, thanks to later copies or references in later royal inscriptions, we know of the work of rulers whose original building inscriptions have not been preserved. They

79 Edited in RIMA 1, 14-18, 22-51, 60-63, and 77-78; see for them also Golter 1996, 1997 and 1998. The pages of RIMA 1 not listed contain inscriptions found elsewhere, in Kanesh, Niniveh and Mari.

80 Unless one believes that the lablet found in Konesh is a combination of two different inscriptions.

81 RIMA 1, 19-21. Dercksen 2003 proposes the following restoration of lines $31 \mathrm{ff}$. (which only occur in ms. B): "In the month Normak-Ašsur ...... in order to render verdicts for my cily, righteousness was indeed established in my city .... " $[[\ldots, i-n] a$ na-ar-ma-<ak>-A-sür $[x \times x] /[a-n a d i-n] a-a t$ $a-\int[i-a$ di-a-nim] etc. $)$ 
tell us about building activities of Kikkiya and lšme-Dagan 1, ${ }^{82}$ of lkūnum's work on the temple of Ereškigal (in Assur),,$^{83}$ and of that of Šamši-Adad I on the ziqqurrats of the AnuAdad temple. ${ }^{84}$ In addition we have an inscription of Aššr-imittĩ, who dedicaled a stone chest (pirnumi, which his farher lkūnum had vowed to As̄sur ${ }^{85}$ (RIMA 1, 46, no. 2001), a private dedication made "when Sargon was governor of Ašsur", and a unique inscription, published by Gelb, 86 written on an Old Assyrian votive vessel, which was erected "on the market of Urāmê". ${ }^{87}$

We also have impressions of inscribed cylinder seals of some rulers of the "Puzur-Aššr dynasty" and of Šamši-Adad I. While one of the seals of Erišum I was found in Assur, impressed on a clay vessel $\{R I M A 1,39$, no. 17\}), a second one of his and those of Šarru-kin and Narām-Suen were found on envelopes of letters discovered in kārum Kanesh level II. ${ }^{88}$ Those of Šamši-Adad I were on bullae excavated in Acemhöyük in Anotolia. ${ }^{89}$ In addition we have an impression of the seal inscribed "Of divine Aššrur, of the City Hall" (šad Ašsur | $\check{s a} \dot{E} a^{\prime} / \mathrm{l}^{\mathrm{k}} \mathrm{i}$, impressed on the tablets with the so-called vassal treaties of Esarhaddon. 90 it may be compared with that bearing the inscription "Of divine Assur, of the tax, of the City

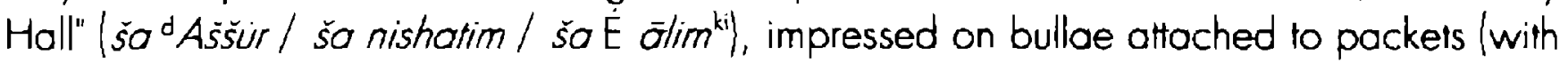
goods or tablets) sent from Assur by the nibum, ${ }^{91}$ addressed to kärum Konesh and from there apparently sent on (without having been opened?) to Acemhöyük.

Kikkiya, no. 28 of AKL, by Aššur-rêm-nišēšu (see RIMA 1, 101, 5), and Išme-Dagon I by Enlil-nāșir I (see RIMA 1, 95, 7), assuming that he and not Isme-Dagan II (king 58) is meant. The existence of namesakes, sons and once a father of a Samsii-Adad, is confusing. also for the ancients, as shown by the presumably mistaken "Distanzangabe" of Tiglath-Pileser I (RIMA 2, 29, VIII:2f.), see Eder 2004, 208. An inscription of Samši-Adad I, RIMA 1, 55 no.3, mentions that lkūnum (king no. 34) buils the lemple of Ereškigal.

83 According to Galter 1998, 4ff., on the rev. of RIMA 1, 81, 1001 (read in line 21 [/4]-re-er). The obv. contains an inscription of Šamsi-Adad I on his work on the same temple, which mentions Ikūnum as his predecessor.

84 Mentioned by Šamsī-Adad III in RIMA I, 81, 1001

85 In Veenhof 2003, 42f. I considered the possibility that the early death of Ikunnum prevented him from fulfilling his vow, a duty now performed by his son.

80 Gelb 1974; cf. $A O A \Pi 7355$, for the implications of the mention of a market (mahinum).

87 The meaning of this last word is unknown, Gelb takes it as a nisbe, writes Urämië and translates "of the Uramians". A place-name Uräm is unknown, and one might compare the name of the town Ubãsê ( RIMA 1, 141, line 30), but it could also be a designation of a class of people, like ubāre. The discovery of the sherd suggests that the market, whatever it name means, was located in Assur.

88 See Veenhof, 2003, 41-46 and Kryszat $2004 b$ on the letters whose envelopes contain the impressions of the seals of the rulers.

See Tunca 1989 and the inscriplion on Ac-1-1098, menfioned by Tunca 1993 note 1, where the king's name is spelled Samsi- ${ }^{\mathrm{d}}$ Addu.

See Dercksen 20040, 901.

91 See Veenhot, 1993, 651, with pl. 124; the caving on the seal renders a seven tiered mountain, standing on four teet, with o bull's head protruding, which probably is a rendering of the god Asšur. See for the nibum now Dercksen 2004a, 621 . 
Finally we have the historical data in the eponym lists, in particular of KEL A, which mentions the accession years of several kings of the so-called Puzur-Aššur dynasty, a document of which I have tried to show that it was written in the city of Assur. ${ }^{92}$ Such a list and perhaps also an early "eponym chronicle" (after the pattern of MEC), must have been at the basis of AKL and its various editions, whatever their origin and their later redaction.

The number of other epigraphic finds in Assur from our period is extremely small. Since the strata of the Old Assyrian lower city were not reached by the excavators, we have no archives and only a small number of Old Assyrian lablets was found in various places, ${ }^{93}$ several of which were published by Donbaz. ${ }^{94}$ One group of 14 tablets emerged logether with a large MA archive (Ass. 13058) in the destruction layer of a Middle Assyrian "administralive building". 95 A tew later $O A$ texts turned up in Pedersén's archive $M 9$ (with Ass 14446 numbers), which may indicate that they had been preserved for centuries by the family of the archive holder. One of them, as shown by Donbaz, ${ }^{96}$ prosopographically links up with two contracts in other collections and all three record the sale of houses and house plots in Assur, dated after still unknown "Late Old Assyrian" year eponyms. ${ }^{97}$ I myself published a late OA tablet in private possession, dated to the eponymy year of lšme-Dagan, son of Šamši-Adad, which records a manumission and adoption. ${ }^{98}$ Finally, there is a small group of rather damaged administrative, partly sealed rablets, which turned up in the ruins of the so-called "Schotterhofbau", below the foundation trenches of the so-called Old Palace. 99

Mention must also be made of a a few epigraphic discoveries of this period outside Assur, but relating to our period. In the first place that of an inscribed spear-head found in the Istar temple at Niniveh, apparently a volive gift, recently studied by Reade 2005, 358ff.

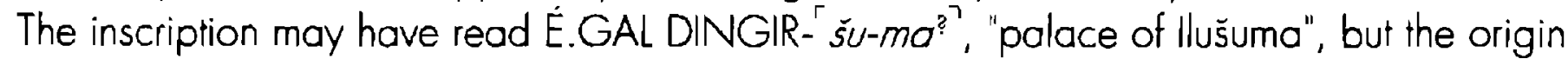
of the object (found together with the famous copper head of an Old Akkadian king) is

92 Veenhof 2003, 16-19.

93 See for their bibliography, Michel 2003c, 121f., 2.1.2.

94 Donbaz 1974, 1979 and 1985.

95 Archive $M 7$ of Pedersén 1985, 75F. Severol of the texts were published, mainly from photos, by Donbaz 1985. Ten of them are lentil-shaped and hence perhaps school tablets, four of which deal with the rale of conversion of gold and copper into silver. The rate silver : copper is $74: 1$, that of pure (zakium) gold : silver is $51 / 2: 1$, which is much less than the current $O A$ rate (which approximates $8: 11$ and more in line with the rates of the $O B$ period, which may indicate that the tablets are 'Late(r) Old Assyrion'.

96 Donbaz NABU 2001/55 and 56. The three rexts are Pedersen 1985, 99 (124), provisionally published by Donbaz 1985, 9 nole 6; $M A H ~ 15962$ (Gelb-Sollberger 1957), and a tablet in a privale collection at lzmir (Donboz, NABU 2001/56).

97 Those of Adad-bāni, Urad-Šerua, and Qiš-Amurru. The latter two tablets must have been stolen from the Assur excovations.

Veenhof 1982; it is dated in the eponymy of lšme-Dagan son of Šamši-Adad. The tablet since has been donated to the Allard Pierson Museum, Amsterdam. of the 'Schotterhofbau' in Miglus 1989, 107, consists of Old Akkadian tablets. 
not clear. Reade considers the possibility that it had been displayed in front of the shrine of the Phase 5-6 temple and had subsequently been buried there or had been deposited (later) in the foundation level of the Phase 7 temple. We also do not know whether it had been originally dedicated to Ištar of Nineveh by llušuma (whose connection with that city is unknown; it was to all appearances independent of Assur during the Old Assyrian period) or had arrived there as booty, perhaps even from Assur. In the second place there are a few Old Assyrian texts discovered in Nuzi, which in our period must have been called Gasur, ${ }^{100}$ five of which were published in 1935 and discussed in lewy 1938, while a sixth one, a letter, was edited in Owen 1995.

\subsubsection{Remains of material culture in Assur}

Architectural remains of the Old Assyrian period were found in the upper town, the area with the temples and the palace. Of the temple of Istar, according to the new analysis by $B a{ }^{2},{ }^{101}$ phases $E$ and $D$ are relevant for our period. Temple $E$, a new construction after a caesura, would date to the Ur III (when it must have been built) and (early) Old Assyrian periods, while $D$, a completely new and enlarged temple, must also have been erecied during the Old Assyrian period and lasted until Middle Assyrian times. Then Tukulti-Ninurta I replaced it by a completely new building and in doing so, according to his inscription RIMA 1, 254:19ff., he must have found a building inscription of llušu(m) ma, dating to 720 years earlier. But the exact dates of the end of $E$ and the building of $D$, and therefore the question to which ruler $D$ has to be assigned and to which phase the inscriptions of llušuma ${ }^{102}$ and the dedicalory inscription, dated "when Šarru-kin was ruler of Assur", ${ }^{103}$ belong, remains unclear. ${ }^{104}$ However, a new analysis of the stratigraphy of temple $E$ has made it likely that with the end of its first phase (E I) we are already in the beginning of the twentieth century BC. For the leveled fill underneath the first floor of remple $E 2$ yielded the impression of a seal whose inscription mentions the ruler Isi-Dagan of Mari, who must have reigned around or shortly after 2000 BC. 105

The history of the Aššur temple is also complicated, but it seems clear that there was already a sanctuary in Early Dynastic times, in view of the discovery of the votive statue

100 Two persons with good Akkadian names, who occur in texts from kärum Kanis level ll, ore identified as Gasurum, "man from Gasur", see Nashef 1991, 40 5.v. Gasur.

101 Bär 2003, see especially 37ff. and 65ff., and see now also Bär 2005.

102 The so-called "Riegelstein", RIMA 1, A.O. 32,1, found in secondary position in the temple buill by Tukulti-Ninurta, and the inscribed bricks, RIMA | A.O.32.2, some of which were found in the ruins of the Ištar temple.

103 RIMA 1, A. 0.35 .2001$.

104 Bär 2003, 65, states that $E$ was "ousgeräumt und gezielt abgetrogen" and that its building material was reused for $D$, which of course creates problems, in particular for using llušuma's inscribed bricks, which were found in various places.

105 See Bär 2005, with on p. 22 o new drawing of the seal inscription. See for Iși-Dagan, who belongs to the line of sakkanakku-rulers of Mari, J.-M. Durand, MAR/ 4 (1985) $155 f$. 
Assur 16710 (SK 14). The poor remains of the Ur III period are overlaid by those of the Old Assyrian period, recognizable from the many inscribed bricks of king Erisum I'some of which were found in secondary usej. He probably embellished and enlarged a temple built by a predecessor, presumably Šalim-ahum who states that the god requested the temple from him. ${ }^{100}$ Erišum I himself, after describing his work on the temple, in RIMA 1, 20:16 mentions that its name was ${ }^{107}$ "House, Wild Bull" (betum rimum). Its remains, insufficient for reconstructing a good ground-plan, are overlaid by the temple built by Šamši-Adad 1 , which in turn is only preserved in its basic ground-plan, with leaves uncertainly about doorways and passages and hence about the functions of the various rooms. According to the latest interpretation of this temple by Miglus, ${ }^{108}$ Šamši-Adad I, whose inscription speaks of "the temple of Enlil", formerly erected by Erišum l,109 constructed two sanctuaries under one roof. One for Enlil, in the south-western part of the building, after the pattern of a Babylonian "Breitraumtempel", and one for Aššr, in the north-eastern part, which he designates as a "knickachsialer Breitraumtempel", a kind of "Hofhaus mit gefangenem Hauptsaal", also found in palaces. Respecting the tradition (embodied in the name of the temple mentioned by Erišum) he named it "House, Wild Bull of the Lands". The fact that this name is given both in Sumerian and in Akkadian 110 may well reflect Šamši-Adad's ideological attempt to combine the cults of Enlil and Ašsur, but his efforts could not prevent that in due lime the building was again simply called the Aššr temple.

The so-called Old Palace also has a complicated history. The earliest recoverable remains, to the west of the ziqqurrat, belong to the "Schotterhofbau", and consist of a paved courtyard adjoined by what could be the remains of a corridor and rooms. It may have been the oldest palatial building, but it function is not clear and specialists do not agree on its date, ${ }^{111}$ but the discovery in this area of a small group of OA tablets ${ }^{112}$ at least suggests an $O A$ date. We should not forget that $O A$ texts (royal inscriptions and archival records) never mention a palace," 13 while the "City Hall" was extremely important, which made Dercksen consider the possibility that the "Schotterhofbau" may

100 See van Driel 1969, 8. Enlargement is suggested by his statement "from the Sheep Gale to the People's Gate I left (reserved?) terrain (qaqqurü) to Aššur my lord" (R/MA 1, 20, 8ff), with the variant "I removed houses" (RIMA 1, 23, 35ff).

107 Not "I called its name", as Yahdun-Lim did with the temple of Šamaš in Mari.

108 Miglus 2001, where fig. 17 on p. 331 offers his reconstruction of the arrangement and function of the rooms of the Ašsur temple.

109 RIMA I, 49, 18ff., and 227, 1, 3', but Erišum himself only speaks of the temple of Aššur.

110 RIMA 1, 49, 52ff., E AM.KUR.KUR.RA E Ri-im-ma-ta-a-tim É dEN.Lil belia ... šumšu abbi.

111 Miglus 1989 and 2004 suggests the Old Assyrian period, on the basis of the discovery of some clay tablets and of bricks of Erišum 1 in the debris separating this complex from the 'Old Palace'. Pedde 2003 apparently assumes an earlier date, since he assigns the 'Urplan' to the 19 th century $B C$.

Ass. 19062a-k, described in Pedersen 1989, who calls it 'O 2'.

H3 There is only a reference to a man called Asqüdum, who is a wardum of the palace (KTS 1, 55b:3F.). 
have housed the Old Assyrian "City Hall".144 The next phase is the so-called "Urplan des Alien Palastes", which consists of foundation trenches, partly in the rock, partly in older layers, which dispay the ground-plan of a building of 98 by $112 \mathrm{~m}$., which Pedde is inclined to date to the 19th century BC. ${ }^{115}$ This polace was never completed and somewhat later one stanted with a building which Pedde, on the basis of the size of the bricks in the foundation trenches, assigns to the time of Šamši-Adad I. Work on it, however, also was never finished and there are traces of later destruction. ${ }^{116}$ Whatever its exact date, the remains offer little more than a groundplan, so that the functions of the rooms are not clear. Heinrich's comparison of the northeastern part, courts IX and X surrounded by series of small rooms, with a Near Eastern suq and therefore possibly a design for the 'City Hall' (bet ólim)."17 has not convinced Dercksen. An important Old Assyrian architectural feature was the so-called "Step Gate" (mušalum), where the seven divine judges resided and justice was rendered, built (or restored) by Erišum I, which had a long life. ${ }^{118} \mathrm{~A}$ text from kärum Kanesh suggests that it was situated "behind the temple of Aššr" "119 and Adad-nārāri I (RIMA I, 140,35ff.) speaks of "the Step-Gale of the Temple of Ašsur, which is opposite the Gate of the Oath of the God of the Land and the Gate of the Judges", but it has not been identified. Other leatures menrioned in early royal inscriptions are several city gates - the A'ušum Gate, the Werrum Gate, the Sheep Gate, the People's Gate, the llulayya Gate - but without the topographical information necessary to identify them. Also some graves dating to the Old Assyrian Period were found, notably grave 20, whose contents (including several OA seals) were last analyzed by Calmeyer. ${ }^{120}$

All in all the archaeological data only provide a rather limited and vague picture of the city during the first centuries of the 2nd millennium BC, which makes it also difficult to estimate the number of its inhabitants. The excavations of Assur unfortunately have not reached the OA levels in the lower cily, where the prominent administrators and traders, which we know from the iexts from kärum Kanesh, must have lived in their expensive and presumably sumptuous houses, with the ancestral tombs underneath them. ${ }^{121}$ Their material remains and

114 Dercksen 2004, 7-13. Later, when the Old Paloce took its place, the 'City Hall' could have been incorporated in the palace or have been moved to the areo east of the lstor temple, where in the Middle Assyrian period a large administrative building arose.

115 Miglus 1989 and R/A 10 (2004), 247, \& 8.1.4f., assumes that it was the work of Samsi-Adad 1

116 Perhaps to be connecled with the actions of Puzur-Sin, as described in his inscription RIMA 1, 777.

117 Heinrich, Die Polöste im Alien Mesopotamien, Berlin 1984, 72.

118 See for its mention in Erisum's inscriptions, RIMA 1, 20f., lines 5f., 26f., 39F., 54, for later occurrences van Driel 1969, 29ff, and CADM/II, 277.

119 See Veenhof 1995, 1721, note 12. El 244:0, k 94/k 350:12, and 480:8H. (courtesy larsen) also mention legal procedures and decisions (simtam siämum, anvim, awaram radänum) which took place "behind the lemple of Ašsur" ( wanki bett Asssur).

120 Calmeyer 1977. Another 'Old Assyrian' grave was Ass 13122 no. 27, mentioned by Dercksen 2004a, 20.

121 See for data on houses Michel 1997b and for a measure of the authorities to repair the forced sale of tamily houses, Veenhof 1999b. 
archives, if preserved, could teach us much about ancient Assur, but there is little chance that those of the City Hall, the polace and the temple of Ašs̆ur have survived.

\subsection{SOURCES FROM KÃRUM KANESH}

The most important source for our knowledge of the OA Period is the cily of Kanesh, in Central Anatolia, especially the lower city, called kārum, "commercial quarter", where the Assyrian traders lived and where two archaeological strata, levels II and Ib, excavated since 1948, yielded both material remains and written documents. ${ }^{122}$ Much more modest and damaged remains of Assyrian presence were also discovered in the Assyrian settlements at Amkuwa and Hattuša. The rich molerial remains brought to light at Kanesh basically reflect the local Anatolian material culture, with a number of iterns apparently imported from Northern Syria, 123 and therefore will be treated here (in 3.2.2) only in as far they shed light of the material culture of the Assyrians. The lexts, all written in the Old Assyrian dialect, document many aspects from $O A$ life and history and will play a prominent role in what follows.

\subsubsection{Written sources}

\subsubsection{Texts from the körum and texts from the city-mound}

The great majority of the lexts discovered in kärum Kanesh stems from the archives found in the houses of the rraders settled there during the level 11 period, which must have lasted from ca. 1950 to $1837 \mathrm{BC}^{124}$ Their total, comprising the tablets found by local diggers lestimated al ca. 4000 ), those excavated or acquired in 1925 by B. Hrozny lestimated at ca. 1000) and those excavaled by the Turkish archaeologists since 19.48 (ca. 18.000), now amounts to $\mathrm{ca} .23 .000$. Of these ca. 350 rexts belong to the younger level tb, mostly deriving from small archives, but in 2001 a group of 145 lexts from this younger level was discovered. In addition we have ca. 135 (partly rather damaged) texts from the excavations of the Assyrian settlements at Amkuwa and Hattusi(a), nearly all of which also belong to the period of level $\mathrm{lb} \mathrm{l}^{125}$ The texts found in the last two colonies are important because they offer a different perspective and, notwithstanding their limitations, help to map the changes in the Assyrian trade during this later period (see also below chapter III. 2.3).

122 See for a general and well illustrated ovenview Özgüc 2003.

123 See Özgüc 1986 on the cultural relations between Anatolia and Northern Syria and the presence of Syrian antistic traditions, which live on during the period of kōrum Kanesh.

124 See for an overview Veenhof 2003a, and for a listing of the main collections and excavated archives, Michel 2003c, ch. 1.

125 See the comprehensive analysis in Dercksen 2001 a. 
Ca. forty cuneiform texts were discovered in the ruins of levels 8 and 7 on the city-mound, 120 which are contemporary with levels $\|$ and $I b$ of the karum. A few derive from the so-called "palace of Waršama", among them the famous letter of king Anum-hirbi of Mammo and two important lists of personnel. ${ }^{127}$ Some turned up in other monumental buildings, one of which, called "Official Storage Building" by the excavator, also yielded the famous spearhead of Anitta, which bears the inscription E.GAL A-ni-ta ru-bo-im, "palace of king Anita". ${ }^{28}$ One of the temples (no.1) yielded three tablets, one of which $(\mathrm{kt} h / \mathrm{l} 330)$ is the record of an Anatolian slave sale, which seems to belong to time of kärum level $11 .{ }^{129}$ Some texts were discovered in situ in a house belonging to the level II period and a lew are strays or from mixed fill. While some record transactions among Anatolians ( $k t \mathrm{n} / 12100$, adoption; $k t y / t 4$, a barley loan ${ }^{130}$, several are Assyrian archival records, including a business letter, debt-notes for silver and barley, and even a verdict of kärum Kanesh. ${ }^{131}$ Even when some tablets may have been displaced by the desiruction and later rebuilding, ${ }^{132}$ these purely Assyrian records must originally have been kept in houses there, which implies that some Assyrians lived on the cily-mound.

120 See for the results of the excovations on the city-mound, Özgüc 1986, and for a list of the textual discoveries, Ozgüc 1986, 21, 1999, 103 ("Fragments of tablets and envelopes"), Donbaz 1998c, and Michel 2003c, 1.3.2.

127 See Balkan 1957. Bilgic 1964, and Günball 1987a. The first lisl enumerates forty persons with various professions and from various towns, some of which are said to follow ("to be behind") a superior. All logether they are said to be "the personnel (astopirum) of Turupani, the Chief of the Stainay".

128 See Donbaz 1998c and now Özgüc 1999, 126f., with pl.107.1, who finds no support for an interprelation as volive gift. The inscription identifies the object as "palace property", words not normally inscribed on weapons, but in the Mesopotamian Irodition not uncommon to mark objects as booty, captured (and at times subsequently dedicated) by a king

129 Balkan 1957, 4f., with noie 8, republished in Kienast 1984, 114f., no. 8. See for its provenience, Ozgüc 1993a, 170 and 173. Explaining its presence in a temple from o concern for security lo safe deposit for a litle deed) is difficult, since the buyer, logan(i), is not a priest, and if this custom existed one should have found many more tablets there. The second toblel from the temple $/ \mathrm{kt} h / \mathrm{h}$ $331 \mathrm{H}$ is a letter addressed to the Assyrian Iddin-Abum. Note that the tablel with seal impressions shown in Ozgüc 1993a, pl. 17.4-5, is not one of the loblets found in this lemple, but $\mathrm{kt} n / \mathrm{k} 31$ / $\mathrm{ct}$. T. Ozgüc 1968, pl. XVI and Donbaz 1989a, 93).

130 Published as AKT 1, 79 (without intormation on its provenience); read in line 12: i-du-nu IGI. Another text from the mound is AKT 1, 81, an Assyrion note of tive lines deoling with textiles.

131 See Veenhof 1989, 515, note 4, and Donbaz 1998c, 415H. Note also kt z/t 18 (Özgüc 1999 , pl. 87,2), part of the envelope of an Assyrian service controcl, and $k t 74 / 1,4$, a debl-note with an Assyrian creditor and debtor, both of which are identical to the parties in the debi-note Chantre $16=E L 17$, which has a duplicale in Garelli 1965, 22 no.10. EL 157 is a debt-note with the same creditor, llis-tikal, also a very otd text, originally published by Sayce in 1887. Are such texts also from the city-mound, where Chantre made investigations?

132 A damaged Assyrion memorandum $(\mathrm{kl} \mathrm{g} / \mathrm{t} 44)$ even tumed up in the debris underneath the late palace. 


\subsubsection{Official and private texts}

All texts from kārum Kanesh level Il were found in private archives and the important "kärum house", which had its own archives, has not been located. ${ }^{133}$ The texts therefore document in the first place the commercial interests and private affairs of the traders and their families, which makes them an extremely rich source for social and economic history. But the role of Assur's Ciry Assembly and Ciry Hall in furthering and regulating the trade, the participation in it of the rulers and some temples (which invested funds called ikribü) and the fact that many legal conflicts among traders ultimately had to be settled in Assur, explain why privare documents contain a lot of information on public life in Assur. They report on decisions of the Ciry Assembly (a/um). ${ }^{134}$ on actions of the limu-eponyms (who headed the "City Hall"), on the administration of justice, and on various other events in Assur, such as disturbances in the arrival of import goods and fluctuation in the rates of exchange. Moreover, kärum Kanesh as an organization, with a general assembly (puhrum), a smaller 'executive board' (the "big men", rabiütum), a secretary (fupšarrum), official messengers (šiprum ša kārim) and rotating officers responsible for specific tasks (called limum and hamuštum) was the administrative centre of the colonial network. It took care of the administration of justice, of diplomatic contacts with the local Anatolian rulers, of implementing decisions of the City and transmitting them to the other colonies, and of collecting certain taxes, which would ultimately accrue to the City. ${ }^{135}$ As such it served as a kind of extension of the City of Assur, which kept in touch with it by official letters and "Envoys of the Ciry". These activities, which are also reflected in private records, must have generaled many documents, which may still lie buried in the archives of the "kärum-house". Fortunately, a good sampling of them for various reasons is also present in private archives. The officials of the kārum were traders who combined their rolating administrative duties with their private business and apparently also kept official documents in their archives, as was the case with Kuliya, a messenger of the kārum, whose little archive was excavated in 1992.136 Important texts, such as official letters to a kärum and letters of the ruler in which verdicts of the City were transmitted to the colonies, at times were sent from Assur in more than one copy, apparently one meant for the karrum authorities and the other for the person involved (e.g. in a lawsuit). This happened also with texts written by kärum Kanesh, such as circular letters and official summonses. ${ }^{137}$ Also texts that report on contacts between Assyrians (privale traders or representatives of the kāruml and Anatolian rulers, for establishing diplomatic relations

134 A nice example in Veenhof 1999b, and see for more evidence Veenhof 2003d, 89ff.

135 Including that of collecting the silver needed for work on the wall of Assur, charged to the colonies, as we know from the famous letter TC 1, 1, written to kärum Kanesh by a body (called nibum). which opparently represented its interests in Assur. This letter must have ended up in a private archive; see now Dercksen 2004a, 62ff., with a photo of this rablet.

137. Examples in CMK chaprers 1 and 2, and in Veenhof 2003a, 81f. 
or solving problems, are found in private archives. This happened because their owners served or represented the $k a \bar{r} u m$ in such cases ${ }^{138}$ or because these confrontations led to lawsuits in which Assyrians testified or submitted depositions, of which they at times obtained a copy. ${ }^{139}$ Privale archives also contain many records that reflect administrative activities of the kārum, especially accounting in connection with the "dätu-contributions" and deposits made by traders to take part in what has been called "communal Irade", and the administration of justice. The latter is reflected a large variety of judicial records, which apparently became the property of the winner of the lawsuit, ${ }^{140}$ some of which may have been duplicates of originals kept by the karum.

The archives contained a few other non-private documents of great impontance. They are the so-called "Statutes of the Kârum", fragments of three large tablets which detail the procedures to be followed when the kärum assembly meets, ${ }^{141}$ the draft of a treaty with a small ruler in southern Anatolia, 142 five eponym lists (among which KEL A, with a colophon and presumably written in Assur, stands out), ${ }^{143}$ and two copies of an inscription of Erišum l, discovered

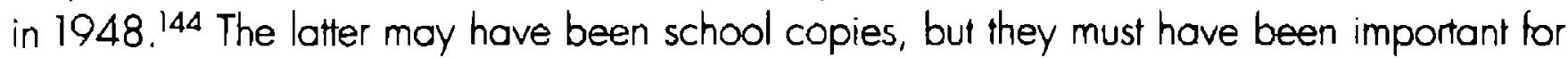
the traders and the kōrum, because they contain regulations concerning the administration of justice in Assur, notably the possibility of bona fide plaintiffs to acquire an "attorney" (räbisum. from the cily and the ruler, who would help them to win their case. Scribal education is documented in some damaged exercise texts, 145 notably a "paradigmatic letter" on a very large, multi-column tablet, and a badly written kind of "practical vocabulary", listing Uunits of weight and continuing with melals and stones. Scribol or scholarly interest also explains the presence of a well preserved legendary tale about Sargon of Akkod, ${ }^{446}$ one of the oldest known, whose existence can be linked with the admiration of two OA rulers for the Old Akkadian kings, whose names they borrowed. ${ }^{147}$ In recent years a few more "official" texts

138 This must be the case with the letters in which Analolian rulers ask for (the renewol of) the comerciol realies, which con be read in CMK95ff.

139 A good example is the sworn deposition about what was said during a confrontation between Assyrians and an Anatolian ruler in the case an Assyrian arrested for espionage, of which we have two copies. One is from the orchive of Usur-ša-lskar $(k t n / k$ 504). who signed the deposition, and one from the archive of Alöhum, son of Iddin-Suen ( $k$ ' 93/k 145), whose son was the man arrested. See for these texts Michel-Garelli 1980 and Günbati 2001.

$140 \mathrm{Or}$, in case of depositions, of the parly who hod supplied the witnesses or their written testimany.

141 Presentalion and analysis in Larsen 1976, 2834 .

$142 \mathrm{KI} \mathrm{n} / \mathrm{k} 794=$ CMK 87, see now Günbalt। 2004, 250 note 8.

143 Edition and analysis in Veenhof 2003

144 See Landsberger-Balkan 1950, later edited in RIMA I, 20 .

145 Most of which were edited in Hecker 1993, see Michel 2003c, ch. 3.3. A recent addition is Donbaz 2004, 185, kl OOk 12, half of a tablet listing theophorous personal names composed with the name of the gods Aššur, Adad and Samaš. A tew private archives contained incantations, rather for protection against evil than as exercise texts, see Michel 2003c, ch. 2.2 and 2005.

i46 Published in Günbaltı 1988, cf. also Van de Mieroop 2000 and especially Dercksen 2006.

147 The deliberale choice of their names is also clear from the foct that they wrote them with the divine determinative, see Veenhol 2003, 44 and 40. 
were found, a late eponym list, which seems to go down to ca. $1720 \mathrm{BC}$, a political letter written to Hurmeli, the king of Harsamna, and two treaties from the level lb period concluded between kărum Kanesh and the rulers of Kanesh and Hahhum. ${ }^{148}$

\subsubsection{Privale archives}

The first Old Assyrian tablets from Konesh were discovered shortly before 1880 by the inhabitants of the local village. When these so-called "Cappadocian tablets" 49 proved to interest collectors and to yield money, the villagers kept supplying them to dealers and travelers over the next sixty years. In all probably ca. 4000 such texts were sold and large numbers were obtained by the museums of Berlin, London, Paris, ${ }^{150}$ and (as part of the collection of J.B. Nies\} by the Yale Babylonian Collection. Smaller groups ended up in Geneva, Giessen, Heidelberg, Jena, Leiden, Liverpool, Moscow, New York, Oxford, Philadelphia, and St. Pelersburgh. Many are scattered over small, partly private collections and many no doubt have been lost. ${ }^{151}$ Turkish museums in Adana, Ankara, Istanbul, and Kayseri in all also have ca. 500 "old" texts, acquired by purchase, donalion or confiscation.

Their provenience, not from the ancient city mound (Kültepe, "Ash mound'), but from the lower lown, called kārum Kanesh, now covered by fields and orchards, was discovered in 1925 by $B$. Hrozny, whose one year excovation must have yielded perhaps 500 tablets. ${ }^{152}$ Finally, in 1948, official excovarions were started on behalf of the Turkish Historical Sociery (Türk Tarih Kurumu), under the direction of Professor Tahsin Özgüc of Ankara University, in later years carried out by his successor Kutlu Emre. They continue until today and in all hove brought to light ca. 18.000 tablets, tablet envelopes and bullae, which are presenved in the Anatolian Civilizations Museum at Ankara. Finally, there are the texts found during regular excavations at Alișar Höyük (ancient Amkuwa) and during various campaigns at Boğazköy (ancient Hattuša), nearly all of which belong to the period contemporary with kărum Kanesh level lb. ${ }^{153}$ A number of inscribed and/or sealed bullae from the same period

See Günbatt 2004, and for the treaties below V.2.

149 Because the information on their provenience soon pointed to the central Anatolian area formerly called Cappadocia.

150 Including the 16 tablets found and acquired by E. Chantre during his exploration of Külhepe in 1893-94.

151 The private collections of Frida Hahn ( 40 texts, published by Lewy in 1930) and of Erlenmeyer (published in ATHE) were eventually auctioned and scattered. B. Landsberger had a collection of transliteralions of more than forty texts (usually quoted as $C+$ number), belonging to private collectors, which they had shown to him when he worked in Ankara.

152 Exact numbers cannot be given, because he also acquired tablets from the villagers and good records of his work and acquisitions are missing; the grand lolal may have been ca. one thousand. Part of the excavated texts entered the collections of the Archaeological Museums in Istanbul, others, together with his acquisitions, became the property of the University of Prague. See for more details Michel 2003c, 53-59.

153 See Michel 2003c, 124ff. and Dercksen 200la. Both collections are now in the museum at Ankara. 
was discovered at Acemhöyük, in the ruins of a palatial building in an ancient city whose identity (Burušhaddum?) is still not certain.

How many archives have been found in kärum Kanesh is not clear. Reconstruction of the scattered archives from the tablets acquired from dealers is only possible to some extent for important traders with large archives, mainly on the basis of letters and legal documents. ${ }^{154}$ The texts excavated since $1948^{155}$ are numbered per year ( $k t a / k$ until $k t z / k$ for 1948 1972, continued by $k t 73 / k$, elc.) and, nolwithstanding the information provided in the excavalions reports, ${ }^{150}$ it is not alwoys fully clear how many different houses, with different archives, were excavated in one year. Occasionally texts trom one archive bear numbers from two years, when its excavation could not be completed in one season. ${ }^{157}$

There is a great variation in the size of archives found, which may comprise a few dozen to more than a thousand texts, occasionally even two thousand. The latter figures may be assumed for the archives of Püšu-kèn and Imdilum, found before 1948, and for those of Alāhum, Usurur-ša-Aššur and Šalim-Aššur, found in 1950, 1962 and 1994. Other large archives are those of Adad-șululi (1948), Ahšalim (1958). Pilah-Ištar (1988), Elamma (1991/2) and Alähum and Aššur-taklāku (1993). For level II a number of ca. 80 to 100 different archives seems to be a reasonable guess. Some of the archives of this level belong to native Anatolian traders, such as Peruwa ( $k$ ) $d / k$; see for some texts of a man of that name, Albayrak 2006), Šuppiahšu and Šarapunuwa, but they have not yet been published.

\subsubsection{Archives from kārum Konesh level lb}

Level lb of kōrum Kanesh (ca. 1800 to $1720 \mathrm{BC}$ ) has yielded a relatively small number of tablets, in all thus far ca. 340. Many of the houses now belong to Anatolian inhabitants, some of which, probably those involved in commercial operations and in contact with the Assyrian traders, yielded some cuneiform rexts. The number of Assyrians living in the kannum must have been much smaller and their houses contained only small lots of texts; only a few (from the years 1949, 1954, 1959, 1902), with more than twenty texts, might be called archives. ${ }^{158}$ But a house excavated in 2001 yieided co. 140 texts, among them the new.

154 E.g. in the recent edition of the letters and other records from the archive of Asssur-nādā, son of Ašsur-idi, by larsen 2002.

155 For detailed information I refer to the excovation reports and to the many articles by Tahsin Özgüc, listed in Michel 2003c, 195ff, and to his recent volume Külepe. Kanis Nesa, published in 2003 by the Middle Eastern Culture Centre in Japan. Özgüc-Tunca 2001 also provides many welcome data.

150 Özgüc 1950a, 1953a, 1959, 1986a, 2003, and Özgüc-Tunco 2001.

157 The archive of the trader Elamma, which I have been invited to publish, was excavated in 1991 and the beginning of 1992. The texts excavaled in 1989, sludied by Y. Kawasaki, belong to three different archives.

158 See for a list of tablets found until 1996, N. Ozgüc 1968, 24. The archaeological context of these tablets is discussed in Ozgüc 1986, 18-21, and tour houses that yielded bigger lats are described in Özgüc 2004. He does not discuss the level lb tablets of the $\mathrm{kt} n / \mathrm{k}$ group (of 1962), the seal impressions of which were published and discussed in N. Ozzüc 1968 pls. XIll-XXY. Several of these texts were quoled by Balkan and some were published in Donbaz 1989a and 2004a, 180f. (k/ n/k 27). 
late eponym list and the letter to king Hurmeli of Harsamna, mentioned above, ${ }^{159}$ but there is no description yet of this important archive. 100 The biggest group, $k t n / k$ with ca. seventy rexts, consists mainly of the small archives of two Assyrian traders, an older one of EddinAššur, son of Aššur-mălik, probably from the beginning of the level lb period, and a later one (perhaps from around $1770 \mathrm{BC}$ ), of Eddin-Aššr son of Ahiyāya. ${ }^{101}$

Özgüc 1986, 19, describes the archaeological contexts of these tablets as follows: "The rablets of level lb were discovered ... lying on dirt floors near the walls, in scattered fashion, but in the seasons 1948/b, 1959/k, 1967/s, 1969/u, 1973 and 1978 the tablet finds evidently were dispersed hoards. In addition to tablets found on floors, tablets and broken envelopes also came to light in burnt debris which filled the rooms." He also mentions that "87 tablets were found in mixed fill overlying level lb, as strays. Among these are quite a few that belong to level II." This makes it understandable that in a number of cases the attribution of a tablet to level $\mathrm{II}$ or $\mathrm{lb}$ is not clear or debatable. According to Balkan about half of the ca. menty tablets found during the excavations of level $\mathrm{lb}$ in $1949(\mathrm{kt} b / \mathrm{k})$ and $1954\left(\mathrm{kt} / \mathrm{k}\right.$ ) actually belong to level $111^{162}$ and he was also able to identity a number of "old texts" as deriving from level lb. 163 If archaeological data are unclear or (for the old texts) missing, a variety of criteria can be used to date them. Convincing are the presence of late year eponyms, the so-called "notarization" of a transaction by named local rulers (only during level lb) 164 , and the presence of seal impressions on a tablet (in level It only on envelopes). More subtle ones are based on writing (the shape of certain signs ${ }^{165}$ and the slyle of writing), language (both grammar and lexicon), 160 and the appearance in judicial records of specific administrative bodies, such as the "datu-payers" and "the travelers on the road to the City". ${ }^{167}$ Some of these criteria have to be applied with care, because tablets from the first period of level lb can be very similar to those of the end of level II and some of the changes noted only took shape later. ${ }^{168}$

159 See Günbatt 2004. The two treaties he publishes there were found in a plan-square adjacent to that of the 2001 house.

100 From this archive thus far only kt 01/k 325 (Albayrak 2004) has been published, an arrangement among the heirs of the Assyrian Sallim-Aššur (dated to a thus far unknown year eponymy of level (b), meant to secure the rights of his unmarried daughter who is a priestess.

161 See Veenhof 1998a, 441.

162 Balkan 1955, 65 note 8.

163 Balkan 1957, 45ff.; see also Balkan 1965b, 155 on ICK 2, 139 and 301.

164 'Notarization' is expressed by stating at the end of a legal record that the transaction was performed under the supervision/with the authorization (iqqäte) of the named local ruler and the rabi simmillim, see below chapter IV.2.5.

165 See the observations made in Veenhof 1982c, $366 f$.

100 See Balkan, 1955, 65ff, notes 8 and 9 , and 1957, $18 \mathrm{ff}$.

167 See Balkan 1965b, $154 f$.

168 Photos of level lb tabets are found in Özgüc 1986, pls. 44ff. The writing is much less slanting than in level II tablets and the outward appearance of rablets and their ductus of the $\mathrm{kt} r / \mathrm{k}$ group ( $\mathrm{pl}$. $46,2 ; 473,49,1 ; 50,1)$ is rather similar to that of Old Babylonian ones. 
A complicating factor is that quite a number of the level lb tablets belong to Anatolians, which makes us hesitate between attributing certain "late" features to the quality of the scribe or to chronological developments. There con be little doubt that Assyrian scribes were employed to produce the nicely written and grammatically accurate texts, some of which, e.g. those about establishing brotherhood and joint households, use a rather specific terminology. But it is difficult to prove it, since scribes are never mentioned among the witnesses of contracts whose conclusion they attended or whose text they wrote down. The text of the well-written tablet with the letter of Anum-hirbi, king of Mamma $(\mathrm{kt} \mathrm{g} / \mathrm{t} 35)$, according to Balkan ${ }^{169} \mathrm{con}$ tains no "barbarisms and solecisms", while "the orthography ... is consistent and culfivated", which suggests a scribe "well rrained in Assyrian". But the "colloquial diction" and "some oberrations in the use of Assyrian words" make him hesitate, "unless we suppose that the king of Mamma himself dictated the letter so quickly that the scribe was not able to change a word". This last suggestion, which implies that the king spoke good Assyrian, does not convince. I would rather explain what Balkan calls "carelessness" and "aberrations" (erasures, use of wrong signs, etc. $\left.\right|^{170}$ as indications that the writer was an Assyrian trader, who knew very well how to handle the stylus, but who may have been less experienced in writing such a diplomatic letter and, not being a professional writer, may have made a few scribal mistakes (without somebody to correct him) and may have used "colloquial diction".

We have no information on Mamma under Anum-hirbi or on the role of scribes during the level Ib period, but a piece of information found a memorandum from the archive of Kuliya ( $\mathrm{kr}$ 92/k 196; late phase of level II) is worth quoting here. It mentions a "Hannanārum, son of Elali, who had taken up the function of scribe in Mamma". "17! We know nothing of the man in question, nor whether he worked free-lance, in the service of the Assyrian community or for the local palace. But I would propose to see in him an Assyrian trader who had mastered the art of writing (perhaps by education in Assur, as a son of the trader Püsu-kèn had), ${ }^{172}$ and had settled in Mamma to practice this craft alongside his commercial activities (he still had a kassārum in his service), which apparently could well be combined in OA sociely. ${ }^{173}$

In rore cases also prosopography can be helpful to assign texts to level lb, when Assyrians occurring in them prove to belong to a later generation of a family attested during the level

169 See Balkon 1957, 18ff, on the language and figs $1-6$ for the ductus.

170 Erosures and occasional omission of a sign occur in many letters; the use of TA for / do' is not uncommon in OA. See for variation between - $a$-and - $u$ - GKT $\S 9_{\mathrm{a}}$; "colloquial" u for introducing the apodosis is nol unique.

17140 kassär H. mer'a E. sa ${ }^{41}$ hup-sa-ru-tam i-na Ma-ma-a is-bu-hi.

172 In CCT 4, be:4ff. Sueja writes to his father: "We have now indeed learned the scribal crat. Send me an epaddum-lextile for my master" (tupsarnitam wadde lamdäni epaddam ana ummeania sübilam). The use of the plural suggests that this son of a well-known troder was not the only one to receive this training. From texts found in level II of käum Kanesh we now know co. twenly different persons designated as DUB.SAR, among them also scribes of a kärum.

173 A good example is the scribe Adada, whose commercial activities are clear from AKT 3, 28 and who, according to AKT 3, 27:20, had accumulated debts of more thon one talent of silver. Commercial debts owed by him are also mentioned in CCT 2,25:11f and $\mathrm{kl} 91 / \mathrm{k} 141: 39$ and 47,8 and 3 minas of silver!. 
Il period. The custom of "papponomy" (calling a son after his grandfather) can be helpful, but the limited number of Assyrian level lb texts makes proof difficult and we must always reckon with namesakes. Hecker asked whether Buzāzu, son of Aššur-mutappil, witness in the level $\mathrm{lb}$ text $\mathrm{kt} n / \mathrm{k} 22$, might not belong to the Püsu-kēn family, since father and son have the same names as two sons of Püšu-kēn, and Kryszat considered it very probable. ${ }^{174}$ We cannot date the eponymy of this record (of which we anyhow know only a few lines), but Buzãzu appears here at least sixty to seventy years after the latest dated attestation of Aššur-mutappil, son of Püšu-kēn (in eponymy year 108). If we believe in the continuity of "family names", which is not unlikely, he might be a grandson of Püšu-kēn's son Buzāzu. Publication of more level lb texts from Assyrian archives may allow safer conclusions and probably reveal more cases of trading families with long histories.

Also from the level lb period, with only very few exceptions, ${ }^{175}$ are the remains of archives found as small hoards and scattered tablets in Amkuwa (Alisar Höyük), the seat of an Assyrian wabartum, ${ }^{170}$ and Hattus (Boğazköy). ${ }^{177}$ The in all ca. 135 rablets have recently received a comprehensive trearment by Dercksen, ${ }^{178}$ who analyzed the archival lots belonging to NabiEnlil and Iddin-Kūbum of Amkuwa and of Dāya, son of II-bāni, who lived in Hattušs. While Amkuwa most probably still harbored an Assyrian wabarum during level lb (see OIP 27, 17:1f.; 18:26f., and below chapter IV.2.1 no. 11, as it did during level 11, ${ }^{179}$ the form of Assyrian presence at Hattuš, which had a kărum during level II, is not yet clear for the level lb period. The texts from Amkuwa and Hattuš, as analyzed by Dercksen 200la, are important because they offer a different perspective and give us some idea of the changes in Assyrian sociely and trade during this later period. The discovery of two trealies from this period, with the rulers of Kanesh and Hahhum, now provides important new insights (see below chapter V.2).

174 Hecker 1998b, 306, and Kryszat 2004a, 45. Hecker demonstrates both the potential and the pitfalls of this approach. He uses it to draw conclusions on the length of the (in his opinion short) interval between levels II and $\mathrm{lb}$, but now that the emponym lists indicates an interval of ca. thirtyfive years, the evidence has to be reconsidered.

175 From Amkuwa we have in OIP 27, 8 a prospographically completely isolated debt-nole of level II, dated to eponymy 115, perhaps preserved for generations as proof of an unpaid debt. OIP 27, 3100 , a damaged judicial record, preserved with its envelope, on the basis of the stratigraphy of its find-spot may be older than level 16 . KBo 36, 113, found in waste from earlier excavations, for prosopographical reasons must be assigned to level it (see Dercksen 200la, 50). It is uncertain whether the text "Nesr. Bog. 2", which circulates in iransliteration (= CMK 58), is really from from Hattus. One would have to restore the address of this letter, written by the wabartum of

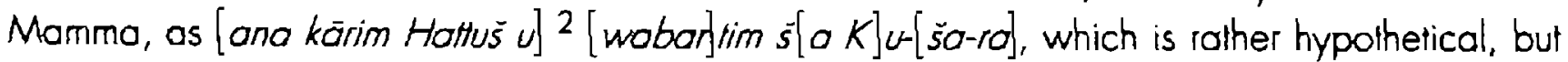
the occurrence of the well-known scribe Aššur-banni proves that it belongs to the level II period.

176 Published by I.j. Gelb as OIP 27, 1-53 (nos 54-62 are texts from level II, acquired by the Oriental Institutel.

177 Published in KBo 9, 28 and 36. See for both cities, below chapter IV.2.2.

178 Dercksen 2001a, with on p. 66 a list of the texts discussed and presented in translation and transliteration.

179 Recorded in kt a/k 1070:3. 
Several texts from level Ib, which stem for Anatolian archives and whose knowledge we owe in particular to $\mathrm{V}$. Donbaz, ${ }^{180}$ offer welcome information on the ancient Anatolian sociely, especially its family life, law and commercial activities. Among them are a number of contracts for the formation of a joint household by (natural and adopted; sons, who live and work in and "for a single household", with and under the outhority of their father and mother, and others which record a separation from such a household. ${ }^{181}$ Other contracts stipulate service duties (called arhalum and unušsum) of Anatolians, at times attached to the possession of a "house of the king" and reveal something of the syslem of land holding coupled with service obligations and of royal land-grants to important servants of the crown. ${ }^{182}$ See for the few level lo texts discovered on the city-mound chapter 1.3.2.1.1.183

\subsubsection{Main text types}

All these private archives consist in principle of three categories of texts, letters, legal documents and a variety of memorandums, notes and lists, and each of these groups, with variation per archive, usually makes up one third to one fourth of the totol holdings. ${ }^{184}$

\section{Letters}

Most are business letters of all kinds, many sent from Assur to report on the arrival and equipment of caravans, but also letters sent inside Anatolia, to communicate with people \{relatives, partners, agents, personnel) trovelling around or living in other colonies. In several cases letters received by Assyrians somewhere in Anatolia, when they were outside Kanesh for business, were in due time taken back home and became part of the archive in Kanesh. In addition there are letters (including those from and to women) dealing with family issues and more official letters (mentioned above) that ended up in private archives. The archives in various measure also contain copies of letters sent out and letters sent to Kanesh by traders (like Imdilum) who had in due time returned to Assur and corresponded with their sons who now managed the affairs in Kanesh. letters were sent wrapped in clay envelopes, which mentioned the writer (who also impressed his seal on the envelope) and the addressee (s). Many broken envelopes have been found, but also letters still in their envelopes, presumably either duplicates or never opened because the addressee had left. In some cases a "supplement" (șibar tuppimi was added to a letter in the form of a small, thin, round or oval piece of clay inscribed on the convex side only, placed on the tablet and encased in the same envelope.

180 Donbaz 1989a, 1990a, 1993a, 1999, and 200 lb.

181 See Veenhof 1978c, 145 and Dercksen 2004b, 143f. (who identified the damaged KTK 33 as an additional "joint household contract").

182 Analyzed in Dercksen 2004b, who presents all relevant sources in transliteration and translation in an appendix.

183 See now also Donbaz 1998c.

184 See the analysis in Veenhof 2003a, with further bibliographical information. 


\section{Contracts}

The second category, that of legal documents, consists of two types of texts, contracts and judicial records, both attested in a large variely of types. The contracts are the biggest group and comprise hundreds of debt-notes, some of which record irue loans, but mostly financial liabilities resulting from credit sale or commission, both formulated from the point of view of the creditor, who is said "to have a claim on" $(i s s ̦ e \bar{e} . .$. išu $\rangle$ the debtor. ${ }^{185}$ These dated contracts only mention the amount of silver (in some cases also gold, copper or grain) the debtor owes (usually as payment for an amount of merchandise he has received on credit, but which is not mentioned) and the due date, plus the default interest if he fails to meet it. Such claims, especially those on Anatolian debtors, could be secured by pledges and sureties, either when the contract was concluded or when the debtor defaulted, and in the latter case ensuing legal actions, including forfeiture and execution, again generaled other types of contracts. Since debt-notes mention the date of the contract and the due date for payment or when default interest becomes due, these texts are the main source of eponymy datings (by both year- and week-eponyms). Their survival usually indicates unpaid debts, but some may have been preserved for administrative purposes, atter their sealed envelopes had been broken, which meant the loss of their legal validity. Their counterpart are quittances ("tablet of satisfaction", tuppum ša sabääe), issued when upon payment the debt-note ("his tablet") could not be returned to the debtor. ${ }^{180}$ Other important categories of contracts are those for hiring caravan personnel for the transport of trade goods (called be'ülatu-contracts, after the amount of silver they received as an interest-free loan),,$^{187}$ contracts for the purchase of houses and slaves (which serve as tille deeds), 188 and of investments in the trade, usually by making silver available to a trader in order to obtain a share in a joint-stock company (naruqqum). ${ }^{189}$ In addition there is a variety of contracts in the area of family law, recording adoption, marriage, divorce and inheritance /usually last wills, called šmtuml, several of which also concern Anatolian inhabitants of the kārum, from whom we also have a kind of brotherhood adoptions and deeds which record the separation from a household (iš̆ bëlim parāsim). 190

185 The standard formulation used in Babylonia, which stales that the debtor "has received" (ŠU BA.AN. $\mathrm{TI} /$ ilge) something from the creditor is rare in $\mathrm{OA}$ (which never uses the Sumerian formulation).

186 Some texts state that in such cases the original debt-note and the quiltance could be exchanged agoinst each other to be conceled ["to die", mu'ätum, "to be smashed", mahāșum\}, or that the original debt-nole, if if turns up, is invalid (sar).

187 See for these contracts Kienasl 1989, supplemented and in part correcled by Veenhof 1994b. The oldest dated contract we have, fom eponymy year 47 , edited as $E l 97$, with its envelope CCT $6,23 c$, is such a service contract.

188 Trealed in Kienost 1984.

189 See now Larsen 1999

190 See Veenhof 1998c, 145-160, and Dercksen 2004o, 143ff. 


\section{Judicial records}

Judicial records document all phases of the administration of justice, from private summons and voluntary arbitration to final verdicts by the highest judicial body, the City Assembly. Particularly numerous are depositions and testimonies rendered by witnesses and parties (called sibütum, "testimony", or fuppum ša šibē, "tablet of witnesses"), records of oaths sworn (fuppum so mamit PN, "tablet with PN's oath"), and of interrogations (one category of these could be called napaltum, "answer"). Most are the result of legal controntations and they usually start by mentioning that one parly had "seized" (sabätum) the other or both parties, by mutual agreement (ina migrótisunu) the persons who were to act as arbiters. ${ }^{191}$ In addition we have agreements (mitgurtum), various protocols of lawsuits handled by the colonial authorities, and a number verdicts (dinum) passed by wabartums, kärums, the Ciny Assembly, and occasionally by an ad hoc body, such as El 283, passed by "The group of five" (hamuštum).192 A special calegory are the "powertul lablets" (ruppum dannum), sent from Assur, which contained procedural instructions and provisional decisions by the Cily in tavor of one parly.

All these records, apart from copies (mehrum) made for the benefit of parties and (occasionally) witnesses, originally consisted of a tablet wrapped in a clay envelope, which carried the seals of witnesses, parties and/or judges, normally listed in the text on the envelope as "seal of PN, son of $\mathrm{PN}_{2}{ }^{2}, 193$ and the essence of the text on the tablet. Such rablets were called tuppum harmum, "valid deed", 194 and they were carefully preserved in the archives, at times in special containers, identified as such by inscribed labels. The records of this type provide us with probably close to two thousand different seal impressions, both of cylinder seals owned by the Assyrians and of stamp seals used by many Anatolians. They are important not only for studying their technique, style and iconography, 195 but also for reconstructing the sealing procedures, ${ }^{190}$ and for knowing "who is who". This can be established with the help of the text on the envelope or the relatively rare Lonly ca. ten tot fifteen

191 There are also a few cases where the parties "seize each other" (nosbutum).

192 Cf. El 244, where "the group of five" (hamišrum) acted as such in Assur.

193 These identifications are presented as a list and not as captions written next to the individual seal impressions. This may leave some doubts on the identification of the seal owner, since the order of the seal impressions may vary from that in the list; see Veenhof 1987c. On the tablet inside the envelope the wimesses ore listed at the end, introduced by $|G|=$ mohor, "in the presence of". Some texts say that a witness, whose seal has been impressed, "lies on the tablet" (ina tuppim naf).

194 The verb horamum originally means "to cover, encase", but acquires the legal meaning of "to validate" by a seal impression. Texts regularly speok of sibe haramum, "to encase wimesses", which means to have them make a deposition under $\infty$ ath and impress their seals on the encased record of it.

195 Especially by N. Özgüc in her many publications, notably in N. Özgüc 1965, 1908, 2006 and in Ozgüc-Tunco 2001.

190 Studied by Teissier 1994, which contains an overview of the different types of records which were sealed and the drawings of 077 seal impressions. See Michel 2003c, ch. 4.4, for publications of and literature on the seals and their inscriptions. 
percent of the seals) inscriptions on the seal itself. 197 When a controctual liability had been met or a contract was cancelled the "valid deed" could be broken or "die".

\section{Lists, memos, drafts, and notes}

The third calegory of documents is a mixed one and includes all tablets that are neither letters nor legal documents, such as memorondums, notes, list, drafts, copies, etc. Their recent edition by Ulshöfer calls them "private records", 198 because they have no legal force, but this is somewhar misleading, since nearly all records found in the karrum are privale ones. Many small tablets with less than ten lines of text are notes of current transactions, which in due time would be digested in formal records. Lists register people, frequently with a number of textiles or an amount of silver (received or due), expenses made (especially during caravan trips), goods and merchandise 'grain, wool, textiles, copper, tin, silver, wool') owed, to be received, stored or issued. Special types, found in various archives, are long lists of substantial numbers of breads (in groups of 50,60 and 100), jugs of beer (kirrum), and types of sheep (lakannum and silqum). 199 The numbers frequently seem to be too big for one family or firm and one wonders whether they reflect a system of collective or shared provisioning, but there are no descriptive texts to explain their purposes. One lext registers ca. hundred donkeys, distinguished into two kinds, called kibsum and upqum, apparently together one big caravan. ${ }^{200}$ We also have notes about settlements of accounts, colculations, people, personnel, and witnesses, and there also many drafis, especially of testimonies to be presented as written depositions. ${ }^{201}$

\section{Transport records and memorandums}

Two important types of lexts of this third calegory deserve special mention. The first are records which list amounts of silver and gold (consisting of heavy packets, neepesum, and smaller bundles, riksum), each with mention of the persons for whom they are meant, which were entrusted to named persons for shipment to Assur. These lists include small amounts of silver or gold, designated as sëbulfum, meant for women, occasionally as a gitt, but more frequently as payment for textiles they had made and sent to Kanesh for sale in Anatolia. ${ }^{202}$

197 See for the ways in which seal owners can be identified, Veenhof-Klengel Brandt 1991, 54ff.

198 "Privaturkunden", in the edition of ca. 600 of such texts in Ulshöfer 1995; see the remarks in Veenhof 1997d, 303

199 See for example Ulshöfer 1995 nos. 309, 314, 324, 334 (lists in all 3080 breads plus some sheep, oxen, beer and wine), 339, 340,364, and 370 .

200 TC 3, 192 = Ulshöler 1995, 371, analyzed in Dercksen 2004a, 279-283.

201 They owe their existence to the lact thal in legal proceedings a number of people, who had acted together (they called each other tappā' um, "colleague") as witnesses or arbiters during a privale summons, when the case developed into a formal lowsuit, had to render one single kestimony (they were called sibui etamdütum, "wimesses in agreement"), which could require consullation and drafts. See Veenhof 2003a, 95F.

202 See for šébulum and its background, $A O A \Pi T 14$ Off, and for examples of such lists Ulshofer 1995 , nos. $46 \mathrm{ff}$. 
The second type consists of big memorandums (called rahsistum), in which a trader at a particular moment registered all his outstanding claims by excerpting his debt-notes in order to obtain an overview of his assets. Occasionally this was also done because this informafion had to be sent overland, either to Assur or to a partner elsewhere in Anatolia, who had to collect a number of them. 203 . Some contain up to one hundred lines of lext and register dozens of apparently yet unfinished transactions. The biggest one known to me $\mathrm{e}^{204}$ registers sixty-two different credit sales and other claims from a period of eighteen years, with a total value of more than three talents of silver.

Both categories are important in giving an overview of a trader's activities, the volume of his trade, its yield, his agents and business partners. But they also present problems, because they frequently are "anonymous", since the creditor who drew up the memorandum did not always mention himself, and in porticular because the "transport records" are alwoys written in the first person. ${ }^{205}$ They can only be exploited if their writers can be identified, which can be a problem if they are not from regular excavations. This problem can be solved for the memorandums with the help of the names of the debtors and (if mentioned) the witnesses, for the others from the names of recipients of silver and gold. In the latter cases the names of the women are very helpful, since they usually belonged to the writer's family and received the just mentioned small packets of silver and gold. Some such records also mention special persons, e.g. the ruler of Assur, for whom the writer had carried out a commission. 206

The "Iransport records" (which are no real contracts, because they are not witnessed) are never dated, so that we cannot use them to calculate the size of the trade in a particular period (assuming we had complete sets of such texts). Larsen used the memorandums to reconstruct the sequence of the year eponyms, ${ }^{207}$ and Krsyzat 2004a for his investigations on the chronology of the archives. If we wish to use the memorandums to draw a picture of a trader's business at a particular moment, we must also know how many of the claims listed as outstanding were eventually poid. A large memorandum in the archive of Elomma suggests that most such debis were indeed paid, because only one of the original debt-notes digested in it was still present in the archive when it came to an end; the others apparently had been returned to the debtors upon payment. Such memorandums therefore supply valuable information on earlier phoses of the trade, for which original contracts frequently are not longer available. ${ }^{208}$

203 If is occasionally mentioned that this was done because one did not like to send the valuable original records overland.

$204 \mathrm{Kt} \mathrm{c/k} \mathrm{839,} \mathrm{edited} \mathrm{in} \mathrm{Donbaz} 1985$ and analyzed in Veenhof 1985.

205 The lists of silver etc. shipped to Assur therefore are no transport contracts, but personal memorandums. They are not daled and do not mention the witnesses in whose presence the money was entrusted. One wonders how the transfer of these large amounts of money actually look place and how the property rights of their owners were secured.

200 Note as examples of how a sender can be identified the cases of CCT $0,27 \mathrm{~b}$ and $46 \mathrm{~b}$ (Ulshöter 1995, nos. 176 and 177). discussed in Veenhof 1998c, 585.

207 Larsen 1976, 375f.

208 See Veenhof 2003o, §5, for the meaning of the presence or absence in an orchive of such debi-noles. 


\subsubsection{Sealed and inscribed bullae}

A special category of inscriptions, finally, are those on so-called bullae, clay labels and sealings of different formats (disk shaped, triangular, hemispheroid, etc.), attached to a variety of jars, boxes, packets and other conlainers, in order to identify and/or safeguard their contents. Some where attached by means of strings, others were pressed on the surlace of a basket or a piece of cloth, many were mushroom shaped stoppers which closed the mouth of a jar. They were sealed and frequently carry a short inscription that identifies the contents of a container or a tablet. Occasionally the inscription is longer, especially when the contents of a tablet are summarized, together with the names of those who had sealed it. ${ }^{209}$ In all more than four hundred bullae, discovered until 1997, were published in Özgüc-Tunca 2001, with photos and drawings of the seal impressions, the seal inscriptions, and the texts written on ca. 150 bullae. They offer insight into the system of shipment or storage of goods and of safekeeping and classifying groups of tablets in an archive and by their sealings show which persons were involved in these actions. Many bear the inscription naspertum, "missive", and identify tablets containing an important statement or authorization with legal force, kept in a sealed package, which had been sent or entrusted to the archive owner and had to be carefully preserved. ${ }^{210}$ The exploitation of the information contained in the seal impressions and inscriptions on the bullae is still hampered by the fact that most of the archives in which they were found have not yet been published, so that they could not be presented in their archival context. While the general introducfion of Özgüc-Tunca 2001 offers important information on their use, several of them bear sequential numbers, which suggests that they were registered as groups of similar objects and not together with the (groups of) rablets to which many of them cerlainly must have belonged. Studying them together with the archival texts may yield interesting results, also for the identification of the seal impressions. ${ }^{211}$

\subsubsection{Remains of material culture in kārum Kanesh}

The excavations of karrum Kanesh have yielded a wealth of evidence on the material culture, among which of course the finds made in the houses of the Assyrian traders have our main interest. How many Assyrian traders lived in kărum Kanesh is unknown, but a few hundred seems a reasonable guess. In his recent survey of the city and its excavations, the excavator states that, while the lower city as a whole may have had a diameter of at least two kilometers (stretching both east and west of the city-mound), the area where the Assyrians were setled was only a small part of it, measuring ca. 250 by $350 \mathrm{~m}$, situated

209 The biggest are the disk shaped $\mathrm{kt} n / \mathrm{k} 1708$, with fifteen, and $\mathrm{kt} 86 / \mathrm{k} 158$, with fourteen lines of script (see Ozgüc -Tunca 2001, plates 62 and 90). The second bulla describes the contents of the encosed tablet kt $86 / \mathrm{k} 171$ ( $a$ deposition under oath) and must have been attached to this separately stored/packed legal record.

210 Note the description of corefully packed, shipped or stored records, mentioned in Veenhof 2003a, 101.

211 See e.g. Michel 2000b, 8 and see below 11, 1,3.2. on the bullae of the $k \mathrm{v} / \mathrm{k}$ archive. 
to the northeast of the city-mound. ${ }^{212}$ "The native Anatolians lived in separate and much more extensive quarters of the Lower City", apart from some native traders who were connected with the Assyrians through marriage and business relations and lived in their quarter. Whether this quarter, to which the Assyrian designalion kärum Kanesh must have applied in a stricl sense, was somehow marked off from the rest, is not clear, anyhow not by a wall, since the remains of a "karrum wall ", discovered in some places, are those of the wall of the lower cily as a whole, not of the "Assyrian quarter". 213

In the "Assyrian quarter" only private houses have been found, not the important "karum house", with housed its archives, administrators and a secretary, had room for storage and deposit, and was also the place where the plenary kărum met. Close by, if not a part of the same complex, was the temple of the god Ašsur, with its "sacred precinct" (hamrum), the place of his stotve, where the oaths were sworn before his dagger (parrum) and his sugariō"um ("knife"?). The "kärum house" may have been on the city-mound, which would have allowed the local palace better to check it, or have been situated under the present-day village, immediately north of the city-mound. ${ }^{214}$ Dercksen has convincingly argued that "the gate of the karum", mentioned in a few rexts, means the entrance to the complex called "körum house", 215 not the entrance to the karum itself as a separate living quarter.

For a volume which deals with ancient Assur and its citizens the question is how to evaluate all the discoveries in the area of material culture, a good overview of which is offered in T. Özgüc 1986, chapters 3-5. It is clear that the houses of the traders and their contents, not surprisingly, reflect the local material culture, because there was only little that the Assyrians could have brought along (or have sent later) from Assur over a distance of a thousand kilometers. One thinks of clothes, belts, ${ }^{210}$ and personal possessions, such as ornaments, seals, weapons (a dagger?), cultic figurines, amulets and the like. Only part of these, mainly objects of metal and stone, had a chance of surviving the millennia, and only a few seals have been found. The inhabitants apporently had been able to leove the city before the destruction (there were no unburied skeletons), raking along their seals and other valuable possessions, perhaps alongside a selection of valuoble tablets. Most of their graves, under the Hoors of the houses, which may have contained also some Assyrian items

\section{2 Özgüc 2003, 24f.}

213 See the data collecled by Dercksen 2004a, $99 \%$.

214 Suggestion made by larsen, based on the fact that there are a large number of important 'kárum texts' (including the Statule Texts) among the first tablets discovered. The first discoveries could have been made there, when one dug into the subsoil, e.g. for laying loundations

215 Dercksen 2004a, 101f., also on the distinction between bäbum, "gate", and obullum, "cily gate" (the latter is once attested in the title "the gatekeeper of the Addahšu Gate"). The tifle rabi abullatim. "chief of the city gates" (in $\mathrm{kt} \mathrm{g} / \mathrm{/} 42: 8$ ) belongs to an Anatolian man and refers to the gates of the city.

216 In the letter POAT 18B:Off. the ruler of Assur promises Püsu-kēn, who is doing him a favour, "a belt for his waist" (sakkukam ana gablika), and in VS 26, 7:34 the same kind of belt, inlaid with babbardillu-stone, is sent from Assur. 
as grave-goods, had been robbed in antiquily, but fortunately the robbers have overlooked some burial gifts. ${ }^{217}$ While most of the copper vessels ${ }^{218}$ were of Anatolian make and there is evidence for imports from Syria, there were also abjects that were of Assyrian or Mesopotamian origin. They comprise bronze weapons, spools and belt buckles, and a sampling of pins (especially toggle pins for costume fastening), ${ }^{219}$ diadems, rings, beads, and pendants, made of gold, silver, electron, and precious stones, some with lapis lazuli attachments or inlays. This is confirmed by the discovery in tombs 20 and 25 in Assur of a rich variely of lapis lazuli beads in various shapes, alongside necklaces and bracelets containing beads of gold, lapis lazuli, carnelian, agate, and other semi precious stones. ${ }^{220}$ Assyrian origin is also assumed for two gaming boards, discovered in the house of an Assyrian trader in level $\mathrm{lb}^{22 \mathrm{l}}$ but it is not certain that this applies also to the various flat lead figurines of goddesses and divine couples (occasionally also with their children) and the moulds in which they were made, found in houses in both levels of karum Kanesh. ${ }^{222}$ They already turn up before the Old Assyrian Period in a very wide area, and Canby points to a certain resemblance with sculpture in Northern Syria. She assumes that their presence and distribution depends on those who possessed or travelled with their moulds, and since the latter were found in the kārum, Assyrian traders may well hove been among them. ${ }^{223}$ Weights were important in a sociely of traders, the texts mention them frequently and the excavations have produced them in great numbers; they are usually made of hematite, occasionally also of other types of stones or of lead. ${ }^{224}$ Texts distinguish between the weights used by the Assyrions, also called "our weights", 225 and the "local weight" (aban mätim),

217 See the overview in Özgüc 2003, 242-262, with literature.

218 See Dercksen 1996, 76f., for tablets listing a great variety of copper and bronze objects.

219 Such loggle pins, in Akkadian called tuditum, made of goid, silver and iron, also occur in rexts. Nole a "lapis lazuli head of a toggle pin", in kt n/k 695:4f. and kt 93/k 548:5f., "loggle pins with their heads made of [...] stone", in OIP 27,41:12f., and " $x$ shekels of lapis lozuli, 3 1/3 shekels of babbardillu-stone, heads of toggle-pins", in BIN 6, 179:21'ff. See also Michel 200la, 353ff. "Les usages du lapis-lazuli". Assyrians imported lapis lazuli (called husārum) into Anatolia and also traded in carnelian (sāmium). In CCT 4, 24a:I.e 3'F., a lady in Assur complains that she collected all such toggle-pins and handed them over to the City Hall to cover a debt in silver.

220 See Calmeyer 1976, Harper e.a. 1995, 48ff., and Michel 2001a, 354.

221 Özgüc 1986, 81f.

222 Those of level II are called "rather schematic", those of level lb "take on more realistic features".

223 See recently Canby 2003, and for those found in kärum Kanesh, Emre 1971 and 1993, and now Özüc 2003, 268-281. Balkan 1992, 18ff. considered some of these figurines proof of the concept of a divine trinity in Anatolia.

224 See the documentation in Özgüc 1986, 79-81.

225 In the expression ina abnatini. "(established) by meons of our weights". There are references to the 1 mina weight of the kārum office (EL 228:9f., TC 3, 171:13; kt $\mid / \mathrm{k} 605$ :7ff.) and to those belonging to privale traders (even one belonging to the lady Lamassatum, see below, II.2.8.3\}, and note aban ramkārim in kt 94/k 1136:30. They are usually mentioned to indicate which weighing stones had been used to establish the weight of an amount or of silver borrowed and texts may stipulate whose weighing stones have to be used when a loan is paid back. 
occasionally also identified as the weight of a particular town, used in particular in connection with copper. ${ }^{226}$ The difference between the two standards was determined by their relation to (a fraction or a multiple of) the underlying one mina weight, the Assyrion or the local Anatolian, of which the former (of ca. 495 grams) was ca. 10 percent heavier than the latter (of ca. 450 grams). Dala on Assyrian weighis and their manipulation were first studied by Veenhof, 227 and the issue was taken up in detail in Dercksen 1996, 80 Off. $\mathrm{He}$ concluded that the majority of the weighing stones excavated in the kärum reflect the Assyrian standard, with weights ranging from $1 / 12$ shekel to 2 minas. ${ }^{228}$ Moreover, several duck-shaped weights by their shape betray their Mesopotamion origin. 229

in general one could soy that without the cuneiform tablets with their seal impressions, it would have been rather difficult to identify the inhabitants of the kärum as Assyrians. The prolonged stay in Anatolia of many traders, several of which only returned to Assur in old age, may have left some marks on Assyrian material culture and the transport lists show that accasionally, atongside silver and gold, also a few Anatolian items were sent from Anatolia. But such influence is difficult to prove and trace, becouse no houses of this period have been excovoled in Assur.

The main contribution to Assyrian material culture is the rich harvest of seal impressions on tabtet envelopes and bullae, which have been thoroughly investigated for their iconography, style and rechnique, whereby Old Assyrian, Old Babylonia, Syrian, and Anatolian types and a certain mix of them, apparently also due to local production, have been distinguished. ${ }^{230}$ The seals themselves were only rarely found, because their owners must have token them along when they fled the karum and the impontance attached to them is clear from their mention in last wills and legal tights. ${ }^{231}$

\subsection{Other sourCes}

There are almost no other sources which shed light on the Old Assyrion Period before the time of Šamši-Adad I. There is very little written evidence for contacts and synchronisms with contempo-

226 Note aban Bunushaddim in Sadberk 16:4f., and aban Tuhpia in $\mathrm{kt} 93 / \mathrm{k} 278: 2 \mathrm{f}$. (courtesy Michell. Rarely one also meets "the weight of the palace", e.g. in kt 94/k 1023:111.

227 1972, 54-68. "Weights in Old Assyrian Texts".

228 The two heaviest weights, of respectively 4250 and 5250 grams, might reflect 10 minas, but the deviation from both norms is very big; BIN 6, 205:10 mentions an Assyrian 10 mina weight, esartum mana um. See for details the list in Dercksen 1996, Appendix 5.

229 Ögüc 1986, 81.

230 Notably in N. Özgüc 1965, 1908 and 2006, Özgüc -Tunca 2001, Teissier 1994, and in the other literature listed in Michel 2003c, 187-194.

231 See for seals found in the kārum, Ozgüc 2003, 293-303. The value of a personal seal is clear from last wills which stipulare who will inheril it; see also Hecker 2004a, 291, on a legal fight about a tather's seal. See for textual references to seals, especially those made of lapis tazuli, Larsen 1977. 93 notes 14 and 66 , and Michel 200la, 354f. CCT 5, 9b:26 mentions the tanster of a seol on a Irader's deathbed, and BIN 6, 7:14 a lapis lazuli seal sent to a troder from Assur by his wife. 
rary Babylonia, though we know that Babylonians (called "Akkadians") visited Assur and might try to undertake trips to Anatolia, which a local ruler near the Euphrates had to prevent, according to the draft of a trealy. ${ }^{232}$ Commercial contacts with Northern Syria are documented by some texts from kārum Kanesh that mention that traders from Ebla ${ }^{233}$ came to Kanesh to trade. Such contacts are also documented by the discovery, in kärum Kanesh, of the unique letter $k t$ $\mathrm{k} / \mathrm{k} 4$, edited and studied by Hecker, ${ }^{234}$ which reflects Syrian scribal traditions. It was sent by a certain Ehli-addu from somewhere in Syria (he mentions the cities Tunip, in the land Huzzi, and Haššm) to Unapše, in Kanesh, and claims that the latter since no less than twenty-five years owes him a sum of silver, as people in Haššum can testify. It seems likely that Unapše (who has a Hurrian name, as several others mentioned in the letter as witnesses of the transaction underlying the claim) was a Syrian trader who had moved to or temporarily stayed in Kanesh. ${ }^{235}$ The only important written source is the so-called "Mari Eponym Chronicle' (MEC), which starts in the year of the accession of Narām-Suen of Assur, so that its first part overlaps the end of kärum Kanesh level II. ${ }^{236}$ But the damaged historical information added to the names of the eponyms does not mention Assur and concerns only the dynasty and realm of Šamši-Adad's family. Most historical events mentioned in this part refer to confrontations between Aminum and Eshnunna, especially with the powerful Ipiq-Adad II, who would have become king in 1861 $\mathrm{BC},{ }^{237}$ while for their part the texts from Assur and kärum Kanesh, surprisingly, never mention Eshnunna or Ekallātum.

Information in MEC on the years dealing with Šamši-Adad's early career (his accession, as king of Ekallatum took place in $1834 \mathrm{BC}$ ) is very limited. These years are also not covered by the archives of Mari and this is also the period when karum Konesh lay deserted after having been destroyed in ca. 1837 BC. We have more sources after ca. 1800 BC, from the palace archives of Mari, which cover the period until 1762 BC. Some information on the years before ca. 1792 BC, when Šamši-Adad I conquered Mari, can be derived

232 Günbatt 2004, 250 note 8, lines llff. He has to promise that he will extradite them to the Assyrians who will kill them. See below chapter V.1.C.C.

233 See ATHE 32:17 (traders from Ebla acquire a lot of copper in the palace of an unnamed Anatolian cily, for which they pay in silver), BIN 6, $193 \mathrm{rev}$. 6' ("4 minas of silver of [owed by?] the man of Ebla"!; TPAK 109:4 (silver which S. paid to a man of Ebla on behalf of Suejia); kt 91/k 338 (debt in silver of an Eblaite "who acquired wool"), and kt 94/k 421:28.

234 Hecker 1990a, cf. $1996 \mathrm{~b}$.

235 The letter shows no link with other texts of the archive and this is also true of the letter $k t 91 / k 539$, addressed to (the same) Unapše by a certain Abduata, which mentions that the former had setlled accounts in Mamma. The letter is remarkable for its last lines, already quoted in Veenhof 2003, 17, where Unapše is asked to give a tablet (in which he has recorded a third man's reaction on a proposal to sell textiles) "to a scribe who understands Subarean, to read it". Such texts make us curious for kt $90 / k$ 360 , qualified as "texle alypique (Syrie du Nord)" in TPAK p. 59, but not published in that volume.

236 Birot 1985, with Veenhof 2003, ch. 7. In Birot's edition one eponym (Enna-Suin from M 7481:12) was omitted atter 11 , so that the dates from there on are always one year later.

237 To which city lpiq-Adad's conquest of a ziqqurrat, in $1857 \mathrm{BC}$, refers is unclear as long we do not know where Aminum reigned (perhaps in Ekalliătum?). 
From documents from the reign of Mari's king Yahdun-Lim, Šamši-Adad's main rival in the struggle for the dominatrion of the Jazira, and from a number of texts that refer to earlier history. They do not mention Assur and only provide some background information, but it is useful to learn which of the important towns in Northern Mesopotamia between Tigris and Euphrates, mentioned in texts from Mari and of Samši-Adad I also occur as caravan stations in texts from kärum Kanesh. 238

When the Mari archives become more eloquent we receive some information on Assur as it functioned within the empire of Samši-Adad and during the reign of his son išme-Dagan, and on its commercial activities and caravans, even in periods of political tension and war, when trade continued. ${ }^{239}$ These data were recently analyzed in Charpin-Durand $1997^{240}$ and their conclusions will be used in the next chapter. Two interesting lexts, relevant for the trade of Assur and on Kanesh, were recently published by Ziegler and by Durand. ${ }^{241}$ In the first, probably written from Karkemish, the writer promises his lord (Zimrilim) all kinds of desirable luxury items (as/alü), which he hopes to receive from Kanesh, Harsamna and Hattusa. In the second a certain Habdu-mālik, a prominent trader in Assur, ${ }^{242}$ proposes Iddin-Numus̃do, the "overseer of the merchants" in Mari, because "he in Mari and I myself in Assur and Kanesh, we are men of fame" (awil sumil, to come to an agreement on commercial cooperation by meeting each other's wishes for fine merchandise. The letter is accompanied by an itemized gift and an order for specific types of textiles, whose value in silver the man in Mari should state in writing when sending them. Habdu-mälik is even willing to seal the agreement by a marriage between his son and Iddin-Numusida's daughter. ${ }^{243}$ The letter nicely illustrates the desire for foreign luxury items and the role of commercial cooperation by mutual exchange on the basis of a personal relationship.

A scattering of other data on Assur is found in a variety of texts from in Northern Mesopotamia, in cities such as Qottarā (Tell Rimah), Šehnâ/Šubat-Enlil (Tell Leilan), Chagar Bazar, and Tuttul (Tell Bi'a), which had been integrated into Samši-Adad's empire ${ }^{244}$ and/or had

238 From east to west: Qatțarā, Razamā, Apum, Pahudar (presumably identical to OA Puhidar), Eluhthut. Talhōyum (OA Talhat), Nehria, Zalpa, and Ursu. But Kahat. Nagar, Emar, and Karkemish do not occur in OA texts. Tuttul has recently turned up in kitâm so Tu-hi-ul, $\mathrm{kt} 93 / \mathrm{k}$ 196:6 (countesy Michell)

239 See for the commerce of Mari, Michel 1990 and the literature listed in Charpin 2004, 471f.

240 Their analysis is supplemented by Ziegler 2002, with the important correclion thal the occurrences of alum, "the city", after all do refer to the city of Assur.

241 Ziegler 1990 and Durand 2001.

242 Perhaps a wakil tamkäré, a function which first appears during the Later Old Assyrian Period, see below, chapter III, 2. 3.

243 A sequel to this letter shows that the man of Mari has not yet accepted this proposal. That the Assyrian colls himself "your son" is rather an indication of the urgency of his request than on admission of real difference in status.

244 This explains why they used Assyrian eponymy datings, occasionally (e.g. in Qattara) even after the empire of Samsii-Adod I no longer existed. 
contacls with the city on the Tigris, also after this empire had collapsed. ${ }^{245}$ These sources have recently been listed in Charpin and Ziegler 2003, 20ff. and Charpin 2004, 448ff, and they will also receive attention in Eidem's contribution to this volume. I will only refer to them in the next chapter if they contain important information on Assur.

Assur of course also occurs in texts from Babylonia proper, apart from the reference to it in the prologue (IV:53-58) of Hammurabi's collection of laws (see chapter 1.1.3). Most references, ogain, document commercial relations with Assur, especially during the early years of Samsu-iluna's reign, when Babylonian traders visited the town on the Tigris and Assyrians traders went to and even lived in Sippar for that purpose. The relevant texts show "that there were regular conlacts belween Aššur and Sippar; men, women, silver and goods travel in borh directions, a.o. as gilts (rämanum) and "packets" (riksum)". 240 Some records found in Sippar contain excerpts of bonds that mention the Assyrian "weight of the City Hall" and even use Assyrian eponymy datings, which shows that the records had been drawn up in Assur with Assyrian clients or partners. It is interesting to note that these records show that the "overseers of the merchants" in Sippar were important customers of a trader active in Sippar, who was most probably of Assyrian origin. ${ }^{247}$ On the whole, however, the information is limited and only reveals that Assur still was an important trading city, a fact which is confirmed by its treaty with the ruler of Šehna/Apum from ca. 1740 BC, edited by Eidem 1991, and by the evidence from houses in level lb of kārum Kanesh.

245 Nole 0.0. the letters OBTR 12O-122, written to lltani, the queen of Qattarō, by her sister Lamassani, a priestess in Assur, who invokes Aššu's blessing the reading DINGIR Kaniš $\mathrm{ki}$ in 122:4 is not acceptable), speaks of regular carovans between Assur and Qalfară, and sent her sister "2 quartsi!) of acorns (hazelnuts?) of Kanesh" (122:15f.).

246 Veenhof 1991b (the quote is from p. 301). See also the letters $A 6 B$ 12,54-60, of the Babylonian troder Awil-ili, who does business in Assur.

247 See Veenhof 1991b, 300ff. 


\section{RESEARCH ON THE OLD ASSYRIAN PERIOD}

\section{EARlY RESEARCH ANO TEXT PUBUICATIONS}

\subsection{RESEARCH UNTIL 1963}

The early history of the research has been well described in Garelli's les Assyriens en Cappodoce (Garelli 1963) and in what follows I will only point out the main trends. After the problems of the origin of the tablets, their wriling and language had been solved, progress was only possible thanks to the publication of cuneiform copies of the hundreds of $O A$ texts acquired by a few great museums (London, Paris, Istonbul, the Yale Babylonion collection) and by some smaller collections. On the basis of these texts a small number of scholars laid the groundwork of Old Assyrian research. Landsberger, who already in 1925 published a pioneering synthesis, ${ }^{248}$ Gelb, who edited the texts tound at Alisar Höyük, 249 and in particular Julius Lewy, who edited several smaller collections and before 1940 published a dozen orticles on OA history, language and institutions. His main ond lasting accomplishment wos El(1930-35), the systematic edition of all 340 legal documents ("Rechtsurkunden") known by that time, provided with a rich commentary, which after seventy years retains it value. Co-author was the legal historian $G$. Eisser, who was the first to present a provisional "Uikundenlehre". 250 Unfortunately the "juristische Erläuterungen" on the texts, which the preface of $E l$ describes as "eine zusammentassende, rechtsvergleichende Darstellung des in den Urkunden enthalienen allassyrischen Rechts" and to which the authors repeatedly refer, were never completed and published.

After the second world war the Turkish excavations of Kanesh, started in 1948, with a first report already available in 1950, ${ }^{251}$ provided a new impetus, soon followed by the first volume of texts excavated by Hrozny, ICK I of 1952, publications which also stimulated the study of the seal impressions. ${ }^{252} \mathrm{~A}$ lith volume of texts in the British Museum (CCT 5) appeared in 1955, followed by Kienast's edition of texts in Heidelberg and Basel (ATHE, 1960). Bilgic 1951 and Lewy 1952 studied the geography, Landsberger 1954 dealt with the chronology, while the study of the language, the OA dialect that had created many

248 Landsberger 1925.

249 Gelb 1935.

250 Eisser 1939.

251 The first excavation report, Özgüc 1950, and the edition of the inscription of Erisum I, in Landsberger-Balkan 1950.

252 ICK I and the second excovation report, Özgüc 1953, contained many illustrations of seal impressions. Both publications could profit from earlier work on the seals, notably by $\mathrm{H}$. Franktor and E. Porado. The first comprehensive studies were N. Ozzüc 1965 (on Anatolian seals) and 1968 (on seals trom level lb). An overview was also presented by Tosun 1905. 
problems, made progress thanks to contributions by Landsberger, Lewy, Oppenheim, and Bilgic. ${ }^{253}$ It matured in its treatment in von Soden's Grundriss der akkadischen Grammatik of 1956, in the CAD, which started in the same year and could use transliterations of OA rexts supplied by Julius Lewy, and later in Hecker's Grammatik der Kültepe-Texte (1968). ${ }^{254}$ A first general overview of the OA trading colonies was presented in Goetze 1957, while Hirsch in 1961 studied the religion, including all the theophorous personal names. ${ }^{255}$

The new material also stimulated the analysis of the political context and institutional structure of Old Assyrian trade, on which there still was no consensus. Elaborating on views already expressed before the war, Julius Lewy in various articles defended the thesis of an Assyrian domination of central Anatolia and assumed the existence of a political structure called "Halys Assyria", ${ }^{250}$ issues on which Landsberger disagreed with him. ${ }^{257}$ lewy also rejected the proposal in Balkan 1955, $41 \mathrm{ff}$., based on the new discoveries at Kanesh, to distinguish kãrum Kanesh level II, the main period of Assyrian colonial presence, from a younger level Ib. The latter would have started after a substantial gap and have been contemporary with the Assyrian commercial settlements discovered in Alisar Hüyük and Hattuša (Boğazköy). ${ }^{258}$ The discussion on these issues absorbed a lot of attention and time, which unfortunately slowed down the edition of the rexts and a reconstruction of the nature and the patterns of the trade itself. It was the great merit of P. Garelli's Les Assyriens en Cappaoce (1963) to have shown that in Old Assyrian trade did not follow the flag and that no "Halys Assyrio" existed, although the political statute of the colonies in relation to both Assur and the local Anatolian kingdoms still needed further definition. He hesitated on the chronological issue, but it was soon resolved by the data which Balkan extracted from the newly excavated texts, to which also the discovery of the fomous letter of Anum-hirbi of Mamma, addressed to king Waršama of Kanesh (Balkan 1957) and found in the palace of Kanesh contemporary to level $\mathrm{lb}$, contributed. But details of the chronology - the length of the periods of kărum level II and $\mathrm{lb}$, the dates of their beginnings and ends, the dating of archives and careers of prominent traders - in the absence of an eponym list for many decades remained unclear and research on these matters consumed a lot of time. ${ }^{259}$

253 Bilgic 1954 studied the native Anatolian appelatives found in the texts.

254 See also the thorough review by Hirsch, OrNS 41 (1972) 390-42).

255 Reprint with subsiantial additions in 1972; see also Garelli 1962.

250 Already in 1923 and 1925, and especially in Lewy 1956 and 1958.

257 Their disagreement on the meaning of Hattum, mär Hattim and Hattus in OA lexts was fought out in subsequent volumes of the Festschrift for B. Hrozny (ArOr 18/I-II, 1950).

258 lewy 1957, reacting on Bolkon 1955. Lewy also believed in the presence of an important Amorite element in Old Assyrian culture, a view that is difficult to substantiote (see chapter I.1.1). Many of his views on these matters are also found in $\mathrm{H}$. Lewy 1971, two chapters contributed to the Cambridge Ancient History, published separately already in $1965 \%$.

259 See Lorsen 1970. 375ff., Matouš 1978, and Veenhof 1985 and 1998. A copy of the eponym list had already been excavated in 1962, but was not identified. Part of another eponym list, ICK 2, 345, had been found in 1925 by Hrozny, but could not be recognized, because it only contains the beginning of the list, with eponyms not attested in the later archival texts. 
In order to answer the questions of political structure and chronology, Garelli 1963 undertook a comprehensive analysis of many aspects of the Old Assyrian material, and dealt also with the geography and itineraries, the composition of Anatolian population, the nature and roles of karrum and local palaces, and the trade (notably the credit system) and the merchandise. Orlin's Assyrian Colonies in Cappadocia of 1970 also intended to solve the issue of the political status of the Assyrian colonies in Anatolia, but for all its merits, its approach was less broad and the command of the sources less solid. Moreover, its basic manuscript, completed in 1963, somewhat reworked in 1965, was only published in 1970, which meant that there could be no serious discussion with nor progress beyond Garelli's results. ${ }^{260}$ Neither Garelli nor Orlin, moreover, could use the second volume of rexts from Hrozny's excavations, ICK 2, published in 1962.261

Garelli 1963 proved to be a kind of watershed and stimulated further research, which unfortunately still could not use the thousands of texts excavated since 1948. Balkan, the epigraphist of the Turkish excavation, probably read many of them found during the first ten years of the excavation, used their data for his studies on the chronology and in several articles, ${ }^{202}$ but a systematic edition of the archives was not realized. Research therefore still had to be based mainly on the texts excavated by Hrozny and those in Istanbul and western museums, published earlier in cuneiform copies, which I will henceforth coll "old texts". But many of the latter, deriving from the same archives as those published, were also still inaccessible and there was a general lack of systematic editions and prosopographic tools as a basis for further research. To make progress more was needed than the information culled from many scattered records, in particular the reconstruction of the archives and the operations of the individual trading firms that were the backbone of the trade and its commercial success.

Mainly based on "old text" and on Garelli 1963, Hirsch 1973 wrote a survey the Old Assyrian trading sociely for RIA 4, under the lemma "Handelskolonien". In RIA 5, under the lemmo "Kaniš, kărum", new surveys were published in three parts, "A. Philologisch" (Veenhof 1980), 263 "B. Archäologisch", by W. Orthmann, and "C. Glyptik", by E. Porada. In addition several articles in Studies Landsberger and Shdies Matous provided new data and insights.

260 See the evaluation in Larsen 1974 and the review by Matous in BiOr 29 (1972) 198ff.

201 It counts 348 rexts, but many are (tragmentory) envelopes belonging to texts published in ICK 1 , see the review Balkan 1965b, the remarks in the introduction to Prog 1 , and the observations by Kryszal 2001, $268 f f$.

262 Balkan 1955, 1957, 1905, 1967, 1974, and 1992.

203 Who could use Lorsen 1976. 


\subsection{WORK ON 'OLD TEXTS'}

\subsubsection{Publications of 'old texts'}

After 1963 the identification and publication of groups of "old' rexts", which belonged to the by now well known archives of important traders, but had been scaltered by antique dealers and were preserved in a great number of public and private collections, made good progress. The most important publications were Garelli 1964-1960 (texts in France and Switzerland), KUG (rexts in Giessen, 1966), KTK (collections in the USSR, 1968;, and CCT 6 (London 1975). They were followed in later years by KTS 2 (1989) and Sadberk (1999, both in istanbul), CTMMA 1 (1988, in New York), Michel 1987 (in the Louvre), and VS 26 (1992, texts in Berlin). We can now add Prag I (1998), which includes many texts belonging to 'old' archives, excavated and acquired by Hrozny in 1925.264 A few smaller groups of "old texts" were included in editions with mainly officially excavated texts: nine from Chicago as OIP 27, 54-62, eleven from the Istanbul Museum as KTS 2, 1-11, ${ }^{265}$ and eighteen from the Ankara Museum as AKT 1, 1-18. In addition, over the years many small groups ${ }^{260}$ and even single new lexts, ${ }^{267} \mathrm{kepl}$ in a great variely of small museums and private collections were identified and published

The few groups of "old rexts" still to be published are a few dozen in the Yale Babylonian Collection, a dozen in the Adana Museum, small groups in the Los Angeles County Museum and in the Museum in Bruxelles, ${ }^{268}$ and the ca. twenty-five texts acquired by the Schoyen Collection (Norway). Bigger groups are the ca. 160 texts in the Kayseri Museum ${ }^{269}$ and the ca. 110 texts and fragments in the De Liagre Böhl Collection in Leiden. ${ }^{270} \mathrm{~A}$ group of ca. 40 unpublished 'old texts', originally in private collections Jamong them the Kalley Collection) are available in partly provisional transliterations, usually quoted as $\mathrm{C}+$ number, made by $\mathrm{B}$. Landsberger, but the whereabouts of most are at present unknown, which is

204 Part of these texts seem to have been found in the remains of houses already dug up by the local inhabitants, others were apparently acquired locally, see Prag I, p. XVI-XXII, with the detailed observations in Dercksen 2002.

205 Surprisingly also published as AKT 1, 19-29.

260 Duly listed in Michel 2003c, 4-52 and 154f. Nole in particular Dalley 1979 (Edinburgh Museum), Donbaz 1991a, Donbaz-Horansanl1 1976, Donbaz-Veenhof 1985, Garelli 1957, Larsen 1978. Mayer-Wilhelm 1975, Larsen-Moller 1991, Michel-Foster 1989, Moren 1980, Sturm 2000, and Wilcke 1982.

207 Biggs 1996, Donbaz 1984, 1990b, Farber 1990, Garelli 1982, Garelli-Homès-Fredericq 1987، Veenhof 1980, 1984b, and 1989.

268 Both have been copied by Veenhof.

269 Transliterations of most of them are known, made by Landsberger, Gelb, Hecker, and Veenhof. A few were edited by Hecker and nine were included in Michel 199ld. See for details Michel 2003c, $41 \mathrm{f}$.

270 Many of them are fragmentary, some are included in lchisar 1982 and Michel 1991d. See for details Michel 2003c, ch. 1.1. 
also the case with some smaller German private collections, from which lewy published and quoted some texts. ${ }^{271}$

\subsubsection{Reconstruction and edition of archives}

The realization that all 'old' texts belonged to a group of perhaps fifteen different archives belonging to family firms, made it desirable to reconstruct and edit these, to allow the study of the firms, which could serve as building stones for a more general analysis. The easiest approach was to edit letters written by and/or received by the same person, and contracts and judicial records in which he was a party (creditor, involved in a lawsuit, buyer, giving goods in consignment for transport, hiring personnel, etc.). An early attempt was that by Van der Meer 1932, who edited 75 letters of Püšu-kēn, but after that it look almost fifty years before another attempt was made. In the mean time there were a few attempts at reconstructing parts of or small archives or "dossiers". Very instructive is Matous 1969, an edition and analysis of a dozen records dealing with the legal fight about the intheritance of the prominent trader Puzur-Aššur. ${ }^{272} \mathrm{~A}$ reconstruction of a small archive of an Anatolian businessman was attempted in Veenhol 1978.

An obvious candidale for the reconstruction of a large archive was that of Imdilum, partly dug up and sold by local diggers, partly excavated by Hrozny in 1925, even though not all the information on his discoveries (find spots and excavation numbers of the tablets) had survived the second world-war. ${ }^{273}$ in the same year larsen 1982a published a thorough analysis of this archive and lchisar 1982 classified and edited all ca. 200 texts from it, with an introduction and prosopographic indexes. Both publications demonstrated the potential of such an undertaking, but also the difficulty of identifying additional archival lexts, especially those called "Privaturkunden" by Ulshöfer 1995, while also letters and legal documents still presented many problems. Letters written by Imdilum normally would not be part of his archive, but we know (because he himself stated so) ${ }^{274}$ that he made archival copies of some of them, and the archive also contained letters written by him after his return to Assur and addressed to his son who stoyed in Kanesh. As for the judicial records, espe-

271 The collections of Neukirch (one text transliteraled in EL 1, p. 231, note d). Winkenbach (no. 7 quoted in El II, p. 180), Rosenberg (wo texts published as EI 36 and 278). Schmidt (two texts published os El 246 and 303), and Tübingen (wo texts published as El 263 and 325a). The envelope of 'Schmidt I' = El 3038 has now turned up in a private German collection (information S. Moul). Two of the tablets transliterated by landsberger, numbered $C 26$ and $C 34$ (from the Kolley Collection) in the mean time have been acquired by the Bible Lands Museum in Jerusalem (intormation J. Goodnick Westenholz).

272 More texts can now be added to this file, the comments on Prag I 633 (which is a duplicate of BIN 0,188 .

273 See Lorsen 1982, 213.18, and the observations in Dercksen 2002 on the find spots of the tablets. Hrozny published a preliminary report on his work in Syria 8 (1927) 1.12, and see also his observation in the 'Avant-propos' of ICK 1.

274 In CCT 2, 6:14f. Imdilum writes: "I keep copies of all the letters which I have been sending you". 
cially depositions drawn up in connection with legal fights, it is not always clear which of the two parties would have owned a text and in some cases two copies may have been made. Finally, we know that traders for a variely of reasons could give records in deposit with a partner or friend (ana nabšem ezābum), while valid records of debt-claims could also be transferred or handed over as pledges and therefore be found in somebody else's archive. ${ }^{275}$ Editions around 1980, moreover, were still somewhat premalure, because of unsolved lexical problems (especially the technical, commercial jargon), while the existence of substantial numbers of unpublished 'old' texts made them by definition incomplete. ${ }^{276}$ In the absence of complete lists of names and prosopographical studies it also proved difficult and at least very time consuming to establish the relationship between and identity of the main persons (family members, business partners, personnel), which was made more difficult by the big number of namesakes. ${ }^{277}$

Since reconstructing a real archive proved problematic, Michel 1991d used another approach, as is clear from its title, Innäya dans les tablettes paléo-assyriennes. Assembling all texts that concern Innaya (and there proved to be two important traders of that name), she offered a picture of both men, their families and business, and in a separate volume (after collation! edited in all 285 relevant texts. Among the texts there are, of course, many which never belonged to their archives - such as letters of other traders which mention an Innayya and a variely of contracts and judicial records in which they figure only as witness 278 - but some of these do contain valuable information on them. This is perhaps a more realistic approach for archives scattered by dealers, but here too the problem remained of linking "Privaturkunden" with both men, and the existence of two namesakes required a large amount of prosopographical analysis and discussion.

The decision how to edit "old" texts is inevitably also conditioned by practical considerations, because it will never be possible to reconstruct a scattered archive. Imdilum's one, edited by lchisar, could serve as an example, but is a special case, because the surviving data on the excavation of his house allowed him to assign to it texts which would

\section{See Veenhot 2001, 132f.}

276 The number of ca. 200 Imdilum texts, used by lchisar 1982, can now be increased by ca. sixty percent, especially thanks io VS 26 and Prag I. Another problem was that Ichisar was unable to collate the originals of most of the texts he edited.

277 Imdilum fortunately had no namesake, but the two different Innāya's gave Michel 1991d a lat of problems. See for the piffalls of archival reconstruction also the recent survey in Kryszat 2004a, $7-12$, followed by an analysis of the daling of six archives, including that of Imdilum.

278 To what extent witnesses received copies of records they had 'signed' is not known. Michel is inclined to assume it for more cases than the present writer, who prefers to restrict it to important records, such as depositions, and considers it unlikely that witnesses of debt-notes received copies of the contract. That parties in view of a lawsuit wished "to make solid" (dannunum) their witnesses - i.e. to make sure they would oppear and render a reliable restimony - in my opinion implies that they had no written depositions ovailable and that one realized the problem of testimonies from memory in complicated matters, which is nicely illustrated by POAT9. 
not normally be identifiable as such. ${ }^{279}$ The approach on which those cooperating in the new "Old Assyrian Text Project" have agreed is visible in the project's first volume, M.T. Larsen's The Ašsur-näda Archive (OAA 1, 2002), which brings the edition of 176 texts, 135 of which are letters and 40 a variety of other records, which could be shown to have belonged to or could be linked with the archive, which is appropriately called "the Aššr-nādā dossier". The long introduction offers general observations on the problems and possibilities of archival reconstruction, an overview of the texts, and a reconstruction of the family, firm and business of Aššrur-nādā who had settled in Kanesh, and of his father Aššr-idi, who lived in Assur. Additional volumes of this type are planned for the next years and it is hoped that they will be able to profit from the results of prospographical research undertaken by J.G. Dercksen, at first probably in the form of a complete list of names and lext references, which is vital in view of the extraordinary large number of different persons and namesakes which occur in the texts. The availability of the eponym list now makes it possible to establish during which period a trader or firm was active and when some of its important members served in official capacities, as year eponym (limum) in Assur or as week eponym (hamuštum) in Kanesh. ${ }^{280}$

\subsection{WORK ON TEXTS EXCAVATED SINCE 1948}

\subsubsection{The first volumes published}

The excavations of Kanesh, started in 1948, have thus far yielded ca. 18.000 cuneiform tablets, the overwhelming majority from archives found in level ll of the karum, ca. 340 from houses of level $\mathrm{lb}$, and ca. 40 from the city-mound. As mentioned above (chapter 1.3.2.1) the exact number of archives is not yet clear and some assignments to particular traders must be preliminary, until the texts have been published and a complete ground-plan, which identifies the houses of the individual trading families becomes available. It was only in 1990 that the systematic edition of these lexts started and the results, however welcome in providing important new textual sources, from an archival point of view are less satisfactory. ${ }^{281}$ The three volumes of the new AKT series, published between 1990 and $1995,{ }^{282}$ contain

279 Curiously, a number of texts found in the archive were not edited by Ichisar, but only quoted and discussed in the introduction, because Imdilum did not figure in them. This concerns a.o. a small group of records which belonged to one of his tronsporters (who also corried out some business of his own w who did not own a house and apporently had deposited his records somewhere in Imdilum's archival room.

${ }^{280}$ A complete list of the week eponyms is now ovailable in Kryszal 2004a, 164-197, and he has also prepared an alphabetical list with all dated references to persons.

281 See also Michel 1998c, on the newly published orchives.

282 Vols. I and 2 as Ankara Külepe Tabletteri, by the Türk Tarih Kurumu in Ankara, in 1990 and 1995; vol. 3 as Ankaraner Kültepe-Texte, as Beihelt of the FAOS series, in Stutigart, in 1995. 
in all 256 texts, but 33 of them are "old" lexts from Ankara and Istanbul (AKT 1, 1-33). Most of the remaining texts stem from three archives, excovated in $1948(\mathrm{kt} a / \mathrm{k}$, AKT $\mathrm{l}$, 34-78), 2831962 ( $\mathrm{kt} \mathrm{n} / \mathrm{k}$, AKT 2, 60 texts), and 1970 ( $\mathrm{kr} \mathrm{v} / \mathrm{k}$, AKT 3, 1-114). The texts published in AKT 1 and 2 belong to very big archives; the first, of Adad-sululi, comprised ca. 800 rexts, ${ }^{284}$ the second, of Usur-ša-lštar, ca. 2000 texts, ${ }^{285}$ so that we know only small parts of each of them. Moreover, the three volumes do not offer a general description of the archives and of the circumstances of their discovery. ${ }^{280}$ AKT 3 contains 114 lexts of the archive excavated in 1970, ${ }^{287}$ which belonged to Ennum-Ǎšur and Dān-Aššur, sons of Salim-ahum, ${ }^{288}$ which in all must have contained ca. 170 tablets and envelopes. Four tablets published elsewhere were not included and in particular 46 tablets in sealed envelopes are lacking. ${ }^{289}$

The fourth volume, TPAK, published by $C$. Michel and P. Garelli in 1997, is much more satistactory. It contains in all ca. 230 texts, apparently the archives of two different traders, excavated in 1990 in grid squares LVIII-LIX/132-134, and the circumstances of their discovery are described in the "Avant-propos" by the excavator. This volume contains a good introduction and for the first time allows an anclysis of the contents of a complete excavated archive, but it still presents a variery of problems, which I mention in the next paragraph in order to show how difficult the lask of the epigraphist is and how much he depends on the cooperation with the excavator. ${ }^{290}$

\subsubsection{Problems of archival reconstruction and edition}

The first problem is that not all fexts excovated as part of a particular archive were or could be published in an edition. In the previous paragraph I already mentioned that AKT 3

283 AKT 1, 79-82 are tablets belonging to a small group found in 1971, of which 79 and 81 are from the city mound and 80 and 82 from the kârum.

284 See for this archive Michel 2003c, 60-67 and the ovenview in Dercksen 1996, 93F., with Kryszot $2004 a, 23-25$.

285 See Michel 2003c, 83-91 and Dercksen 1996, 140-49. S. Bayram, S. Cecen and C. Günbattı have done much work on this large, important archive and published selected texts from it, and it is to be hoped that the bulk of the rexts will be published in the near future.

280 Adad-sululi's house is situated in grid squares F-G/9-10, see Ögüc 1950, 142f., supplemented by 1953, 111f. (the second groundplan from the left in the top row in Özgüc 2003, 26). The house of Ușur-ša-lštar is in grid squares C-D/11-12, as described in Özgüc 1986, 5f., with 116 fig. 10.

287 Grid M/10, see Özgüc 1986, 88, with 116 fig. 15, and pl. 24,1-2. AKT 3, 1 and $2 / \mathrm{kr} \mathrm{v} / \mathrm{k} 2 \mathrm{~b}$ and 8 , the first two texts excavated in that yearl, as their year eponyms show, belong to the level ib period.

288 Šalim-ahum was Püšu-kēn's main business partner and it is therefore not surprsing that the archive contains a few letters addressed to Püsu-kēn and Dän-Aššur together, AKT 3, 72-74; 75 is a copy of a letter sent by the latter two to Šalim-ahum, 70 a letter of Püšu-kên alone.

289 See the survey in Michel 2003c, 93F. Kt v/k 152 was published in Donbaz-Veenhof 1985, 147; $\mathrm{k} k \mathrm{v} / \mathrm{k} 147 \mathrm{a} / \mathrm{b}$ in Donbaz 2003; $\mathrm{kt} \mathrm{v} / \mathrm{k} 186$ is the envelope of $\mathrm{kt} v / \mathrm{k} 47=\mathrm{AKT} 3,15$.

290 See for what follows also the review by Dercksen 1998. 
lacks a few dozen tablets that belonged to the archive as excavated. The problems with TPAK are of a different kind. The texts it publishes in great majority are those of the wwo main archives, those of Šumi-abiya and Aššur-mutappil, excavated in 1990 (kt 90/k), but fourteen of them belong to an archive excavated in 1989, ${ }^{291}$ apparently that of lkuppi-Aššur (or lkuppia), son of llia, studied by $Y$. Kawasaki, which comprises the tablets $\mathrm{kt} 89 / \mathrm{k} 191$ $274 .{ }^{292} \mathrm{~A}$ few texts in TPAK are from the later period of level $\mathrm{lb},{ }^{293}$ and both groups should have been kept separate in the edition. It is also regrettable that not all texts found in 1990 could be included, ${ }^{294}$ and this also concerns $\mathrm{kt} 90 / \mathrm{k} 111,112,206-207,209-210$, called "objets archeologiques divers" in the descriptive catalogue. They prove to be sealed and (in four cases) inscribed bullae, originally attached to packets and tablet containers of the archive, which were published a few years later in Özgüc-Tunca 2001. 295 This meant that the epigraphists could not use them together with the archival texts to which they must have belonged. The edition of the bullae contains another surprise, because on p. 220, under the heading "Bullae from Sumiabiya's Archive", we read that it contained seventeen bullae, also those with excavation numbers $\mathrm{kt} 91 / \mathrm{k} 112-122$, which were found in the next year, apparently because the excavation of the 1990 house could not be completed in 1990 . Professor Özgüc, who kindly provided me with a description of the discovery of the 1991 archives, mentions that $k \uparrow 91 / k$ 100-113 "have been found in a scaltered pattern" and in the "Avant-propos" of TPAK he already observed that the removal, in 1991, of level lb houses built on top of the ruins of the level II house excavated in 1990 allowed him to reach tablets which were not accessible then, and this may well apply to the group $k t 91 / k$ 123-246. ${ }^{290}$ It is a pity that the editors of this archive were not aware of this complication, which made their volume incomplete.

A second problem is the relation belween the two main persons in the archive, Aššurmutappil and Sumi-abiya, who apparently worked together, but whose relationship, described in TPAK, is not very clear, also because some letters which might have cleared it up (nos. 18 and 19, addressed to both men together) remained inaccessible in unopened

291 The excavator states that they were scoltered and found when the area excovated in 1989 was cleaned.

292 Note that the last group of tablets found in 1990, $\mathrm{kt} 90 / \mathrm{k} 429$ ff, according to TPAK p. 15 , belongs to a different archive, apparently again that of lkuppi-Aššur (or Ikuppia) as is clear from letters addressed to him, the bulk of which was excavaled in 1989.

293 Anyhow nos. 110 and 121 , with o late year eponym and the month-name Suen.

294 We lack kt 90/k 358+359 and especially 360, called "rexte arypique (Syrie du Nord)* Kt 90/k 178, a tablet with two incantations, was published in Michel $2004 a$.

295 Descriptions on p. 220ff., drowings of the seals on pl. 28ff., copies of the inscriptions on p. 289 .

290 This is confirmed by the fact that $k 191 / k$ iO7 is the tablet which belongs to the envelope $k 190 / k$ 212 and that the bulla $\mathrm{kt} 91 / \mathrm{k} 122$ bears the inscription "Tablel of Urdum, son of Arata, of the price of his slave-girl", while the letter $k+91 / k$ 157, written by Sumi-abiyo, in line 5 deals with "the slavegirl of Urdum". KI 91/k 105 is a letter written by Iddin-Aššur to Urdum, Šumi-abiya and Kunnunu, which probably belongs with the bulla kt 91/k 119, with the inscription "Seal of Kunnunu, son of Abranānum, [missi]ve of iddin-Aššuur, son of Babālum". 
envelopes. Judging from the texts the house may have belonged to Šumi-abiya and we find also debt-notes in which his father and brother figure as creditors, while he himself occurs in one record (no. 84), dated to eponymy year 118. Ašsur-mutappil, on the other hand, whose dated activities fall ren to fiffeen years later, ${ }^{297}$ is not represented by debt-notes and of the good twenty letters addressed to him there are five in unopened envelopes, which suggests that he had left and that (part of, his archive had been deposited in Sumi-abiya's house. ${ }^{298}$ These observations, derived from the texts, should be related to those made by the excavator, who mentions (TPAK, Avant-propos) that 75 tablets were found in situ, on the floor, in a corner of the archive room of the house, while the remaining 184 were found scattered among debris which filled the ruined rooms and probably had fallen down from an upper storey which had collapsed. This valuable observation apparently reached the editors of the volume too late to use it for classifying the texts and this also meant that they could not address the questions raised by the find-spots of some of the tablets, which is also of interest for the archaeologists. While most letters addressed to Aššur-mutappil were found in the debris, three (nos. 17 - very similar to $1-21$ and 10a) were discovered on the floor, ${ }^{299}$ but the envelope of letter 10a turned up in the debris. It is not clear what this means, because it is difficult to visualize what happened when the roof collapsed and becouse we do not know how the tablets were stored on the upper floor (in contoiners, on shelves along the wall or simply in heaps?). Some of the first tablets to fall down may have ended up on the floor of the room, while the others became scattered in the debris. If so, the division indicates that the lot of Ašsur-mutappil may have been stored on the upper floor, but apparently also the bulk of the debt-notes of Sumi-abiya. Lots of both therefore may have been kept separate not by storing them on two different floors, but by keeping them in separated containers and it is clear that exact information on the find spots of the bullae of this archive would have been most welcome.

A last problem is that none of the volumes mentioned contains photo's or drawings of the seal impressions on the envelopes, while AKT 3 does not even include the sealed and inscribed envelopes, with or without tablels inside. The underlying decisions imply that the text editions are incomplete, because important documents could not be deciphered and names of the persons sealing (as parties or witrnesses), lisled with their patronymics in the text written on the envelope, are separated from their seal impressions. This makes it also impossible to identify impressions of seals preserved on the many broken envelopes included in TPAK. And because many seal impressions, especially those belonging to witnesses, turn up in other archives too, their omission creates a more general problem for archival studies. In this way the potential of excavated archives cannot be exploited and we hope that this will be different in future volumes.

297 He still occurs in kt i/k 124, dated to eponymy year 133.

298 Or he may have acquired this house; see also TPAK p. 34.

299 While most dated debt-notes, including nos. 78-80 and 82 of Puzur-lštar, the father of Sumiabiya, were found in the debris, no. 81, dated to the same year as the others (restore line 5 ' as [imum] $B u-[z u-t a-a]]$, was found on the floor. 


\subsubsection{Prospects for the future}

Several archives have been assigned for publication by the direclor of the excavations to a number of scholars and should be published in the coming years. Balkan published and used mainly lexts excavated between 1948 and 1960. Stimulated by the retired E. Bilgic, assyriologists of Ankara University, such I. Albayrak, S. Bayram, S. Ceçen, C. Günbattı and H. Sever, apart from what they published in AKT 1-3, have worked on selected texts from many different archives. ${ }^{300} \mathrm{I}$. Albayrak has completed a publication of ca. seventy texts from the $\mathrm{kl} \mathrm{o} / \mathrm{k}$ orchive. $V$. Donbaz, in Istanbul, published many texts, especially those belonging to karum level $\mathrm{lb}$. The members of the "Tablet section" of the Anatolian Civilizations Museum, A. Uzunalimoğlu (now A. Karaduman\}, S. Gül, and I. Esen, published small groups of texts, mostly from the early years of the excavation, ${ }^{301}$ while A Karaduman prepares an edition of the $\mathrm{kl} h / \mathrm{k}$ texts, on which she wrote her dissertation. The rexts of Peruwa's archive, excavated in 1954, were copied and studied by $L$. Umur, but she seems to have left the field. Turkish assyrliologists in general hove preferred to publish selected texts and small groups, ${ }^{302}$ which belong to the same archive ${ }^{303}$ or period, ${ }^{304}$ are similar, ${ }^{305}$ document a particular legal feature ${ }^{300}$ or commercial practice, ${ }^{307}$ or present a special interest in dealing with politics, ${ }^{308}$ social phenomena, ${ }^{309}$ the

300 Bayram, Cecen and Günbattı have deciphered hundreds of texts from the large $\mathrm{kt} n / \mathrm{k}$ archive, Albayrak works on the $k t o / k$ group and soon will publish port of this archive; see further the information presented in Michel 2003c, 60ff.

301 A. Karaduman-Uzunalimoğlu published texts from the $\mathrm{kl} / \mathrm{k}$ group in AMMY1990-1992, as did S. Gül and I. Esen (both in AMMY 1990). Karaduman is preparing her dissentation on texts from the $\mathrm{kt} h / \mathrm{k}$ archive for publication, and I. Esen also worked on texts from the $\mathrm{kt} e / \mathrm{k}$ group (Esen $1994,2000$ and 2001$\}.$

302 Examples are found in Michel 2003c, 154ff, under the names of Albayrak, Balkan (1986). Boyram, Bilgic (1904 and 1990), Cecen, Donbaz, Esen, Gül, Günbott1, Sever, and Uzunalimozlu.

303 Donbaz 1998o edits and analyses eight texts which ore the (remains of the?) archive of the Anatolian Irader Aśe'ed.

304 A particular file, Donbaz 1988a (on the trader Aše'ed); texts from the cily mound, Bilgic 1964, Donbaz 1998c; texts from kärum level lb, Donbaz 1989a, 1990a, 1993a, 200lb, and 2004b, d. Özgüc 2004.

305 Waklum letters, Cecen 1990a, Sever 1990a; kärum letters, Albayrak 2003, Günbatt 1995, 1998c, Cecen 19970.

300 House sales, Günbait 1989, Bayram-Veenhof 1992; slave sales, Boyram-Cecen 1996, Sever 1998a; marriage, Sever 1992o and 1992b. Boyram-Cecen 1995, also Michel-Garelli 1996b, and Veenhof 1998b; last wills, Alboyrok 2000 and 2004, also Wilcke 1976; water ordeol. Gunbalt 2001; idinnum, Cecen 1997c. In this connection I also mention the orticles Gökcek 2003 and 2004, on jars and pots, and on animal husbandry and trade.

307 Boyram 1998b (smuggling). Cecen 1997a (rade in amühm), Günbalt 2002 (awium and döAm).

${ }^{308}$ Such as the two teaties, published in Günbatt 2004, also Bilgic 1998, Günbalt 1995 and 1997 (political relations), Ceçen 1998b (blood money), Donbaz 2001 (parum sa Aśsur, oaths).

309 Sever-Ceçen 1993, Ceçen 1995 (muränū, epidemics). 
Anatolian scene, ${ }^{310}$ or from a lexical point of view. ${ }^{311}$ Particularly welcome were Günbatti's publications of the "Tale of Sargon" and the treaties with Kanesh and Hahhum (Günbatt। 1998a and 2004).

Several European scholars have been invited to take part in the publication program. K. Hecker works on the texts excavated in 1959 ( $k t k / k, 212$ tablets), 1961 (kt m/k, 183 tablets), ${ }^{312}$ and 1987 (kt $87 / \mathrm{k}$, ca. 542 tablets). M.T. Larsen studies the largest archive of kt $94 / k$, with ca. 1300 tablets, in which Šalim-Aššur and his brother lddin-abum, sons of Issurik, are the main figures. C. Michel, after publishing TPAK and having read many texts excavated in 1975, is now working on the large archive kt $93 / \mathrm{k}$ (ca. 880 texts), which belongs to Aššrurtakläku, son of Alāhum, and his family. K.R. Veenhof, having studied the mixed group (ca. 120 texts) excavated in 1986, is now preparing for publication the archives of Elamma, ca. 350 texts, excavated in 1991 and the beginning of 1992 / kt $91 / \mathrm{k} 295-563$ and $\mathrm{kt} 92 / \mathrm{k} 94-187),{ }^{313}$ and the small and late archive of Kuliya, son of Aläbum, found early in 1992 (kr 92/k 188-263), the manuscript of which is in the press. ${ }^{314}$ This archive also contained the eponym list KEL A ( $k+92 / k$ 193), published separately in Veenhof 2003. Their occupation with these archives also resulted in articles in which selected, important rexts were published and studied. 315

\subsection{THEMATIC TEXT EDITIONS}

Even without systematic archival studies, it had soon become clear that Old Assyrian overland trade could only flourish thanks to a good communication system based on written texts. Moreover, the highly developed trade, in which large amounts of valuable goods and money circulated and credit and accounts played an important role, required not only oral witnesses, but also a variety of legal documents to record contracts, debts, quittances, and settlements with evidentiary force and therefore kept in envelopes sealed by parties and witnesses. Study and edition of typologically similar texts from different archives therefore was logical and rewarding. EL, with 340 classified records, was a first result of that approach, based on a distinction according to formal, usually legal cri-

310 Bayrom 1990 (festivals as due dates in Analolian debi-nores).

311 Alboyrak 2001 (mâü), Balkan 1965b (isurtum), 1967 (commercial idiom), 1969 (wagons and ploughs), 1980 (ushium), Bayram 2001 (naditum ša naruä ${ }^{i} \mathrm{~m}$ ), Dercksen-Donbaz 2000 (habbötum), Donbaz 1989 (terms for bread), 2001 la (patrum), 2004 ("lexts with rare terminology", which contains six lexts excovaled in 2000).

312 See Hecker 2004a and 2004b.

313 According to the excavalor kt 92/k 94-187 "document the presence of a new Assyrian merchant", probably Enna-Suen, to whom a number letters are addressed, but in this group there also a few addressed to Elamma, which complicates the picture.

314 See Veenhol 2008 and for the chronological distribution of the texts, Kryszat 2004a, 15-18.

315 See Garelli-Michel 1994 and 1995. Hecker 2004a and 2004b, Michel 1997c and 2000b, Michel-Garelli 1996a and 1996b, and Veenhof 1998b, 2003b, 2006b, and 2007a/b. 
teria, ${ }^{310}$ which provided much insight into the legal procedures. A partial sequel was Rosen 1977, who edited and analyzed ca. 100 debt-notes published after the appearance of $E l$. A different concept is that of the large volume Ulshöfer 1995 (see above chapter 1.3.2.1.4), which contains transliterations and translations of more than six hundred so-called "private records" - notes, lists, memorandums, drafts, copies, accounts, etc. - divided into thirteen different groups. It has an introduction and the last part (p. 464-83) deals with a number of related records, but the volume is basically a classified text edition, with little commentary. While very helpful as a collection and careful edition of all such records, the originals of many of which were collated, their purely formal classification, without establishing links with particular traders or archives, makes them less easy to use, also becouse indexes of personal names and subjects are missing. ${ }^{317}$

Three other volumes to be mentioned here have in common that they use a specific and relatively limiled text corpus as a basis for a thematic investigation, to reconstruct and explain particular features or procedures. The first, which has the focus of the legal historian, is Kienast 1984, on the Kaufvertragsrecht, where an edition of 40 deeds of sole of houses and slaves ${ }^{318}$ serves as the basis for analyzing the law of sale, its substance, form and terminology, but with less interest for their social and economic background. The second is Larsen 1967, Old Assyrian Caravan Procedures, which edits in all 50 texts, which are divided into three categories, called "transport contracts", "notifying messages", and "caravan accounts", and are used as a basis for a very illuminating reconstruction of the caravan system. Finally there is Nashef 1987, Rekonstruktion der Reiserouten, who mainly uses a group of records that list expenses during the various stages of the caravan trip for reconstructing the itineraries of the traders and their caravans (see below chapter II.2.2).

Of a different nature are two contributions by $C$. Michel. The first, Correspondance des marchands de Kanesh $(C M K)$, presents a broad selection of 400 letters in an an-

316 The contracts whereby goods were entrusted to caravaneers for transport to Analolio in El were classified as "Verwahrung" ("deposit", nos. 110-137) and distinguished from "Transportventrage" (nos. 138-144). Both use the key verb paqaidum, "to entrust", but while the first group odds no further specifications (olthough the purpose is obvious), the second adds verbs like wabalum. "to bring", or radä "um, "to lead" (a verb which implies pransport by donkey. a tronsporter could be called a radi luquitim), and "to the ciry, for purchases" (nos. 139-140).

317 The classificalion is nol without problems (see my review in JESHO 40 [1997] 301ff.), also because such private records have o less fixed structure and wording than legal records. Moreover, within each category the texts ore presented in an order based on the olphabetically arranged titles of their first publication and nol by grouping them together on the basis of structurat identity.

318 See also Hecker 1980b and 19980, on a specific feature in slave sales. Kienast 1984 contains almost no records on the sale of merchandise, since this was done casth or on credit, which only resulted in numerous debi-notes or quithances. In some excurses the volume presents a tew dozen lexts (complete or in part) that deal with the sole of houses and with slaves and slave-girls. The number of records is now much bigger, see the survey, with references, in Veenhof 2003c, 461 with note 147 . 
notated French translation, divided into seven categories, ${ }^{319}$ with good introductions and indexes, which offers an excellent overview of the variety and informative value of letters. It is a kind of companion to El, with contains only legal records. The second, Michel 2000a, is an annolated translation of twenty-four selected judicial records ("litiges commerciaux"), which gives a sample of this type of records as illustration of the judicial procedures. It is a kind of supplement to $E L$, especially its part IV (nos. 311-340), which deals with "sachliche zusammenhängende Urkunden" and is accompanied by a very detailed commentary. It is supplemented by Veenhof 1991, which classifies and describes the various types of records dealing with private summons and judicial arbitration. Instead of the systematic "juristische Erläuterungen", promised and even referred to in El, bul never published, one may now consult the survey of all aspects and "provinces" of Old Assyrian law in Veenhof 2003d, which also provides many bibliographical data. Finally I mention two contributions by Dercksen. The first, Dercksen 200la, offers a systematic analysis and interpretation of the remains of archives found at Amkuwa and Hattuša, with translations and transliterations of many texts; the second, Dercksen 2004a, deals with aspects of the Anatolian society, with the relevant sources in transliteration and translation in an Appendix. His comprehensive study of the copper trade (Dercksen 1996) in a similar way included the edition of a sample of twenty texts.

319 Letters of Assyrian and Anatolian authorities, letters on caravans, on fraud and smuggling, on commercial societies, of family firms, and of women. 
More numerous are thematic investigations, listed in Michel 2003, chapter 4.3, "Historical and philological studies", of which what follows presents an overview, arranged by subject and focusing on the more important items, to show the lines of research and to document progress and problems.

\subsection{InSTITUTIONS}

After Garelli 1963 and Orlin 1970, AOA 7 dealt with a number of institutional features of karrum Kanesh, such as collective trading operations organized by the "Office of the Colony" (bèt kärim), its system of taxation and the contributions paid to the kārum by important traders called "dätu-payers", and the existence and role of the market. ${ }^{320}$ The most important study of the institutions was Larsen 1976, The Old Assyrian Ciny State and its Colonies, which, after o long historical introduction, offers a comprehensive analysis and interpretation. He treats the political structure of Assur, its king, city assembly and year eponymy (part two), and the government of the colonies, its system and administration (based on a thorough analysis of the so-called "Statute Texts"), the limums of the kārum, and the week-eponymy (hamusitum; part three). ${ }^{321}$ On the basis of more textual sources Dercksen 2004a, Old Assyrian Institutions, presents a new, more detailed investigation of a number of institutional features of Assur and kärum Konesh. ${ }^{322}$ His first part focuses on the City Hall (bët älim), its possible location, commercial role, debt policy, officials (nibum, laputtó um, müsium, birum and the secretary; and its function in the city-state. This part also deals with the question, already raised in Larsen 1976 (part. 2) of the influence and representation of the Anatolian traders in the City, recently also discussed by Veenhof 2003d, who olso analyzed the evidence "in the form of legal decisions) for a "trade policy" on the part of karum Kanesh and the City of Assur. The second part of Dercksen's book (99-244) deals with the "Office of the Colony" (bet kärim). Supplementing and correcting $A O A T$ and elaborating on the observations in Dercksen 1996, chapter 5.3-6, he deals with its finances, taxation lespecially the saddu'utu-tax), and the important leature of the so-called "datu-contributions" 10 and deposits (sitapkum) with the karrum, which entails the analysis of the meaning of various technical terms and sophisticated procedures. Special attention is paid to the system of the "declared value" of the goods shipped and traded (awitum), which

in chaplers 7, 10-13, and 17

321 Siudied primarily as a dating device in Balkon 1965a.

322 Lorsen's interpretation of the rote of the nuler is now generally occepted. See for whot is known about individual rulers Veenhof 2003, ch. 6. for legislation in Assur Veenhof 1995a, and tor a special measure raken by the City to help indebted traders who had to sell their famity houses, Veenhof 19996. 
proves to be important for fiscal reasons and for apportioning costs and expenses of a caravan among its participants. ${ }^{323} \mathrm{He}$ also investigates the structure of the caravans and especially the important concept of the ellutum, a caravan based on a form of partnership, "most of which seem to have existed on an ad hoc basis and functioned for only a single journey. "324 It played an important role in the "communal trade", which is reflected in the periodic settlement of accounts (nikkassü) in kärum Kanesh. Dercksen describes it as "a form of partnership that could be used for the joint shipment of merchandise and for specific trading opportunities", 325 and as such they appear in the context of the office of the colony. "The accounting of the import caravans took place in that office" and concerned the claims "that arose from the purchase of textiles by the palace". By organizing "communal fund raising" (sitapkum) the colony supplied caravans which carried out special trading ventures in wool with the necessary capital.

Dercksen did not discuss the "week-eponyms" (hamuštum), which had been studied by Larsen 1976, 354-365, who could use data supplied by Balkan 1965a. Veenhof 1996a was able to show that a hamuštum as a dating device equaled one week of seven days, and Kryszat 2004a, chapler 4, who presents an alphabetical list of all week-eponyms, discovered that the older system of (mentioning) double week eponyms in the dating formula, during the eponymy years 97-98 changed into one of single eponyms, but its implications are not clear. He assumes that its name, "one-fifth", wants to identify the hamuštum as two members of a ten-men college (esartum), but for lack of informalive texts this remains unclear, as are the rasks of these rotating officials, though they may have been involved in the financial administration of the kärum.

As the list in Kryszat 2004a, 164ff. shows, nearly all the hundreds of persons attested as hamuštum are Assyrians, but there are some whose names are not and Balkan 1965a, 169 listed seven of them. Larsen 1976, 358, convincingly explained this feature by pointing out that people with linguistically different names could be "of good Assyrian descent", 226 and by assuming that those who were not "belonged to the group of local people who had established close ties with the Assyrian community". Since the hamusitum eponymy was a "colonial" institution we should indeed be much less concerned about ethnicily or even Assyrian citizenship than about being a member of the Assyrian trading community in Kanesh. New data confirm his interpretation, for Tuhniš (with an Anatolian name) now appears in KKS $7 \mathrm{~b}: 4 \mathrm{f}$. as son of lií-dän and an unpublished letter speaks of "Tuhniš, my in-law", 327 which indicates acceptance in the Assyrian community by intermarriage. This may apply to other hamuštums with non-Assyrian names too, such as Abluhul ( $k t 99 / k$

323 See Günbattı 2002 for some new texts on awitum and dōtum.

324 Where he corrects and goes beyond Michel 1992b.

325 In particular for the wool trode, as already pointed out in $A O A \Pi 134 \mathrm{~F}$. and now elaborated in Dercksen 2004a, ch. 10.

320 Patronymics show that of those listed by Balkan anyhow Agua, Aguza and Banaga are of Assyrion descent.

$327 \mathrm{Kt} \mathrm{87/k} \mathrm{37:9ff.,} \mathrm{silver} \mathrm{given} \mathrm{ano} \mathrm{Tuhnis} \mathrm{s̆a} \mathrm{bèt} \mathrm{êmia} \mathrm{(tablet} \mathrm{read} \mathrm{during} \mathrm{a} \mathrm{visit} \mathrm{to} \mathrm{Kültepe} \mathrm{in} \mathrm{1987).}$ 
13:7ff.), ${ }^{328}$ Zuplo)palali (kt 87/k 260:8), or Awarnahuš (also written A'urnahuš; kt 86/k 223:5), the last one the father of two sons with the good Assyrian names, Sü-Suen and Iddin-Suen (kt a/k 906:36).

What exactly the just mentioned "ten-men boards" (ešartum) were, attested for the towns of Buruddum, Hahhum, Kuššra, Nehria, and Šimala, 329 is not clear, in particular not since all five towns also had a kärum or wabartum (see below chapter IV. 2.1, nos. 4, $8,15,18$, and 23). That of Hahhum (see CMK 97-99), together with Elali and "IddinKübum and his caravan", negotiates with the local ruler about the contents of the oath (a commercial treaty) on the basis of letters written by kärum Kanesh, and it could have been a special committee (consisting of members of the local karum? purpose. That of Buruddum has a conflict with that of Simala (CMK 60) and asks the trader Püšs-kēn to intervene with kărum Kanesh on ils behalf. That of Kuššara receives a letter from kärum Kanesh, which reproaches it for a deal with the local ruler on the credit sale of textiles, which violates the interests of other traders. The ten-men board of Nehrio receives a letter from the Püšu-kēn, in which he reports on the sale of and proceeds from a donkey load of textiles, apparently belonging to this group of ten !line 28, "the rest of your silver"). Larsen 330 considers them "commercial units", composed of traders who had their base in the lown mentioned, "on the dividing line between public and private", who were active in the trade - which is confirmed by the new references - but locally also performed administrative tasks within the colonial system. Their role in Hahhum suggests that they may have acted as the "standing committee" of the local Assyrian commercial settlement, but the evidence is too limited. ${ }^{331}$

Equally difficult is the role of the already mentioned "datu-payers" and "the travelers on the road to the Ciry" (älikü sa harrān älim), who appear in a judicial capaciry in official letters and depositions not only during level $\mathrm{lb}$, but also during level II. ${ }^{332}$ Both were important men, the former the financial backbone of the colonial sociery (see above), but who the "travelers" were is less clear. Larsen's idea $(1976,276)$ that they might be the successors of the "Envoys of the Ciry" of level II, is refuted by the level lb text $k t 98 / k$ 125:12',333 where both still occur logether. Their designation "travelers" probably identifies them as the members (or leaders) of the caravans, that is the entrepreneurs who maintained the commercial contacts with Assur. In kt 87/k 552:26-29 (courtesy Hecker) they occur together with the "dätu-payers and the residents (wašbütum) of Tuhpia" as a court of low that summons witnesses and in Prag | 478:1-3 we meet the "secrelary (scribe)" of this

328 Coupled with Wašiburum-bāni, a man whose father was Šu-Dagan.

329 Buruddum and Šmala: CCT 3, 30a:1-4 (CMK 60j; Hahhum: CCT 4, 30a:4 with CCT 6, 15b:81 (CMK 98-99); Kuššra: ki 93/k 67:2 (courtesy Michel); Nehria: AnOr6, 15:2 (CMK O1).

330 Larsen 1976, 269H., see also Orlin 1972, 68, note 124, and Kryszal 20040, 161.

331 There are, as far as 1 am aware, no new attestations after those mentioned in nore 329.

332 Garelli-Homes-Fredericq 1987, 113, questioned the level lb dote of Prag | 478 on prosopographical grounds and becouse of it links with Prog 1445 and ICK I, 2.

333 Donbaz 2001b, 106. Note also kt 94/k 802, a level II letter addressed to the Envoys of the Ciry and the aliku. 
same body, who assigns a guarantor to a plaintiff. The occurrence of "the residents of Tuhpia" is remarkable, because the town during the level II period harboured an Assyrian settlement with the status of a wabartum and (subsequently?) a kārum (see chapter IV.2.12 no.30). To explain the composition and activities of these bodies I assume that when the Assyrian presence in some towns in Anatolia, in particular situations or times, had become weak (as to numbers and status), "dattu-payers" and "the travelers on the road to the City" were asked to assist the local traders in the settlements they visited with the administration of justice by functioning as an (ad hoc) judicial body or court of law. ${ }^{334}$ In a similar way the "dātu-payers" also figure together with the beruttum of Šaladuwar as recipients of five letters written by kārum Wahšušana, which to all appearances date to the level II period and deal with the local collection of the saddu'utu-tax. ${ }^{335}$ While this town during the level lb period had an Assyrian wabarium (see below chapter IV.2.1-2 no.20), no kārum or wabartum is attested during level II and it therefore seems likely that the beruttum and datu-payers formed a gremium thal served the local Assyrian commercial interests, supervised by the neighbouring kárum Wahšušana. In three level lb texts the "travelers on the road to the City" in a comparable way function in a judiciary capacity together with a wabartum, twice with that of Suppilulia, once with that of Amkuwa. In all cases they summon persons to render testimony in a lawsuit. ${ }^{336}$. These references provide important evidence for forms of local Assyrian representation for discharging judiciary and commercial tasks, especially in smaller towns, but we need more evidence to understand their composition (who were the beruftum?) and tasks and to map the differences between the periods of levels $\mathrm{II}$ and $\mathrm{Ib}$.

\subsection{Caravans and trade routes}

Larsen 1976 and Dercksen 2004a contain valuable observalions on the overland irade (notably Dercksen's analysis of ellutum), but there are also publications with deal more specifically with it. The caravan system as such, together with the issues of prices, taxation and sale, had been convincingly reconstructed in Larsen 1967, supplemented for some aspects by $A O A \Pi$, whose chapters 1-3 dealt with the packing of the merchandise and the equipment and loads of the donkeys. In ch. 14-16 it treated "smuggling" (pazzurum, pazzuntum) and the use of the so-called "sukinnu-route", items now also dealt with in CMK ch. 4,1,

$334 \mathrm{Kt} n / \mathrm{k} 5$ (logether with wabantum Mamma), $\mathrm{kt} n / k 32$ (together with kārum Wašhania), Prag 478 (with "the residents of Tuhpia", taking a juridical decision in a case of surely). In KBo 28, 181, according to Dercksen 200la, 60, note 118, they would figure as addressees in conjunction with kärum [Hattuš] of a letter sent by kärum [Kanesh]. See also Balkan 1965b, 155a, on an unpublished letter addressed by the dōtu-payers and kärum Timilkia to kärum Šamuha.

335 The letters were recently discussed in Müller-Marzahn 2000, in their comments on no. 1.

336 Read in OIP 27, 18:26ff. probably a-ki[ku ü w] a-b[a-ar-tum]/ sa $A m^{\prime}-k u$-wa. See for kt 78/k 125:10ff., Donbaz 2001b. 
with translations of the relevant letters. ${ }^{337}$ Caravan trade in general was discussed in Larsen $1982 \mathrm{~b}$, while the issues of transporters and donkeys were again taken up by Michel $1992 \mathrm{~b}$ (notably the concept of seepum) and in Appendix 3 of Dercksen 2004a, which is devoted to "the pack-donkey". Prices and their background were analyzed in Veenhof 1988, and building on his observations in $A O A \Pi$ chapter 19, he again dealt with the related issue of the market (the existence of a special locale and 'market features', such as prices conditioned by supply, demand and costs of transport), in Veenhof 2003d, 5, on which also Dercksen 2004a, 3 iff. made observations.

In this connection also the itineraries followed by the caravans were studied, resulting, after several more detailed contributions by Julius Lewy, in "Les voies de communication", chapter 2 of part 1 of Garelli 1963. Some aspects were also discussed in AOATT, 237-244, in connection with specified lists of travel expenses and the "road tax" (dörum), paid in Northern Mesopotamia. Its approach tried to establish the approximate location of road-stations on the basis of the tariff used to fix the amount of tin paid by caravans for trovel expenses between them. It was applied and further developed in Nashef's attempt to reconstruct the itineraries (Nashef 1987). Thanks to more textual evidence, presented in the Old Assyrian volume of the Répertoire géographique des rextes cunéiformes (Nashef 1991) and the identification of a few road stations (Qațarā = Tell Rimah, Apum = Tell Leilān), our knowledge has increased. But both for Northen Mesopotamia (though data from Mari are helpful) and for Anatolia many problems and uncertainties remain. For Northern Mesopotamia one may now consult Forlanini 2004 and especially 2006, where he brings evidence for two different routes for coravans after they have reached Qatharā. A longer and more northern one would have followed the upper course of the Tigris, by way of Mardaman, to turn west in the area of the confluence of the eastern branch of the Khabur with the Tigris, near Haburatum. From there it would reach the crossing of the Euphrates in the general area of Samsat (where we must locale Hahhum), via Eluhhut (in the area of Mardin) and Burundum, which Forlanini calls "the Kašiari route". The shorter, more direct road would have passed north of the Gebel Sinjār, to head in northwestern direction lowards the area of Samsat via Apum, Nahur and Luhã. An alternalive for the last part of this road was to use a more (southi,western crossing of the Euphrates and to travel on via Uršu and Mamma (in the area between Maras and Göksun?), a route suggested in the letter TC 1, 18 (Larsen 2002 no. 18), if one wished to avoid Hahhum. But in this reconstruction too the location of many towns visited by the Assyrian caravans en route in Northern Mesopotamia (Abrum, Almum, Ašihum, Nehria, Talhat, etc.) still remains hypotherical or unclear. Many questions also exist concerning the itineraries in Anatolia, because so few ancient cities and lowns with Assyrian commerciol

337 Including the informative new letter CCT 0, 220 = CMK 17. A dozen additional references from texts excovated since 1948 in Bayram 1998b and see also k1 83/k 284 (Günbatt 1995) on the issue whether maders ariving via the "sukinnu-roule" have to pay the taxes due to the kanm. This question is answered positively in the letter of körum Kanesh addressed to several other kärums, kj 92/k 203 /no. 2 in Veenthof 2007b): "Whoever has brought in loaded donkeys via the sukinnuroute... even when he is a resident of körum Konesh, make him poy 3 shekels of siver per mina" (the normal rale of saddu uk-tax). 
settlements have been identified (even the identification of Acemhöyük is disputed). Thanks to additional references in new OA rexts (which require a new edition of Nashef 1991), archaeological surveys, the use of new Hittite data from the lexts of Masat-Höyük (Tapigga) and the "Bronze Tablet", some progress has been booked. ${ }^{338}$ But the location of important cities like 8urušhaddum, Durhumit, Kuššara, Ulama and Wahšušana is still disputed. The nature of the "sukinnu-route" also needs clarification, especially the question whether this term (Michel translales by "chemin délourné") was a typological or a topographical designation. The fact that one could import (šerubum) merchandise "from Hahhum to Burušhaddum via the sukinnu-route" ( $\mathrm{kt} \mathrm{m} / \mathrm{k} 75: 3 \mathrm{ff}$; cf. $\mathrm{kt}$ 93/k 488:31ff., "PN has just entered Burushaddun via the sukinnu-roule") shows its wide range and makes the proposal of $\mathrm{H}$. Lewy 1963, that it was a special road connecting Timilkia with Durhumit, less likely. The fact that, as mentioned in note 337, traders using it hoped to avoid paying taxes owed to kărum Kanesh, suggests that it may have connected Hahhum and Timilkia with the areas to the north and north-west withoul passing Kanesh, which could indicate the use of a more eastern route (via Kuššara and Tegarama?). It is to be hoped that the publication of the dissertation on the historical geography of this region in the Old Assyrian period, defended by $G$. Barjamovic in Copenhagen, in March 2006, will bring more clarity in these and other geographical questions, though it will be difficult to solve our problems without strategic excavations and a few unambiguous identifications of ancient towns. His dissertation for me is a reason to refrain from proposing provisional and hypothetical interpretations and locations, though a number of essential data and issues connot be ignored, as will be clear from chapler IV. ${ }^{339}$ A recent map, which reflects most of the current views, prepared by Cécile Michel and Martin Sauvage, can be found as frontispiece of Larsen 2002 (OAA 1).

Evidence from Mari shows that Assyrian caravans during the first half of the 18th century $B C$ still roveled through Northern Mesopotamia on their way to Anatolia, 340 and their passage continued to be secured by treaties, as the one with the cily of Hahhum lon or near the right bank of the Euphrates, probably at or near the site of Samsat) and that between Assur en the ruler of Apum (Tell Leilan) ${ }^{341}$ show. From Mari we also have evidence for an attempt to assure commercial cooperation between a prominent trader, active in Assur and Kanesh, and the "overseer of the traders" in

338 Bayram 1998a (geographical names), Beitzel 1992 (caravan roads), Dercksen 1996, ch. 4 (geography of the copper trade), 200ia (on Hattus and Amkuwa), Forlanini 1985, 2001, 2004, and 2006 (general, with the use of Hittite data, North Mesopotamian and Anatolian areas, analysis of particular texts), Garelli 1989 (Burušhaddum), 1998b (Hahhum), Hecker 1998a (Euphrates), Kawasaki 1996b (Šalahšuwa), Michel 1991a (Durhumil), Miller 2001 (on Zalpa, Haššum and Mamma), and Veenhof $2006 b$ (Tapagaš/Tapigga).

339 See also the attempt in Veenhof $2006 \mathrm{~b}$, in the comments on some new records with interesting geographical dato.

340 Note the letter A 285:6'ff., edited in Charpin-Durand 1997, 385F,, where it is mentioned that the king of Karanâ allowed a large caravan (its size must have been mentioned in the missing beginning of the letter) to poss through his country, 50 donkeys of which traveled on to Kanesh. The letter ARMT 26432 mentions a caravan of three hundred Assyrians who traveled from Assur to Karanâ.

341 See Günbatt 2004 (and below V.2.2) and Eidem 1991 (and below chapter V.1, 8). 
Mari. ${ }^{342}$ Laler in the 18 th century there were also problems of security and passage, due to the threal posed by habböh (employed as mercenaries in these times), of a kind not known from texts from kärum Kanesh level II, as told in the emotional letter (Dercksen-Donbaz 2000), addressed to "the gods and the City".

\subsection{GOODS TRADED}

The goods traded, their identification, provenience, prices, sale, and taxation were systematically treated in Garelli 1963, port 3 chopter 2.

\subsubsection{Tin}

As regards tin, after Garelli 1963 its occasionally still disputed identification with AN.NA $=$ annukum ${ }^{343}$ became an accepted fact. Larsen 1967 and $A O A T$ chapter 1-3 deali with the packing and shipment of tin to Anatolia, its taxation and sale, while Veenhof 1988 investigated its prices on purchase in Assur and on sale in Anatolia, and their background, also in relation to the data from Mari. ${ }^{344}$ The assumption that it was produced and shipped as ingots, which had the shape of slabs or plaques, suggested by data from Mari, is now confirmed by new texts such as AKT 3,49:24, which mentions a slab (/e-a-am) of a little over 9 pounds. ${ }^{345}$ ARMT 23,555, reveals that tin arrived in this shape from Susa and mentions 3 slabs weighing $32 \mathrm{l} / 4$ minos, or ca. $103 / 4$ pounds apiece, which together have almost exactly the same weight as the standard OA packet of ca. $321 / 2$ pounds, two of which made a "standard weight" (suglumi of 65 pounds, which was transported in one half-pack (muttatum) of a donkey. This agrees with kt 94/k 1679, which lists 5 slabs that together weigh 1 talent and one of $35 / 6$ pounds, in all nearly exactly the quantity contained in one suglum.

As for the origin of the tin, an earlier suggestion by J. Laessøe, based on a lefter found at Shemshare, that tin reached Assur via Southern Kurdistan, possibly from mines in the higher ranges of the Zagros Mountains, east of Tabriz (cf. Larsen 1967, 4), has been refuted in Eidem-Laessge 2001, 29. It is very likely that the tin originated from northeastern Afghaniston or Uzbekistan, where casserite was lound, and reached Assur (together with the lapis-lazuli traded by the Assyrians) vio Suso (cl. Dercksen 2005, 19). We now have references (AKT 3,73 and 74) which show that it arrived with caravans "of the Lower Country" (sa mat sapiltim), probably the name for the area south of Eshnunna and reaching into the plain of Dêr (Badreh). ${ }^{340}$ But the mechonics of these imports and their sale in Assur \{usually at prices of 14 to 15 shekels of tin for 1 shekel of silver, with occasional fluctuations of up to 10

342 Durand 2001.

343 See for the problem already landsberger 1965 and Muhly 1973, ch. 5.

344 See Joonnès 1991 .

$345 \mathrm{~K} 194 / \mathrm{k} 1352: 3 f$. mentions a lood of 2 slabs and 2 bundles (riksum), together weighing 35 pounds.

340 See Dercksen 2004a, 28ff. 
percent), in which the City Hall seems to have played a role alongside the warehouses of individual firms, are still not clear; see most recently Dercksen 2004a, $17 \mathrm{~F}$.

\subsubsection{Textiles}

The trade in textiles was analyzed by $A O A T$, part 2, which dealt with provenance, types, shapes, materials, qualities, sizes and prices of the various textile products. It also discussed the right of the local Anatolian rulers to take five percent of them as nishatu-tax and their right to pre-empt another ten percent (called "tithe", išräum, or "those bought", sa simmim) and the resulting calculations and balancing payments, because for both purposes only complete and half rextiles were handed over. Recently, Dercksen 2004a, 173ff. has shown that the kärumoffice was involved in the pre-emption, because the local palace could pay for the textiles bought through the colonial office. He also pointed out that the number of textiles pre-empted could vary from the norm of ten percent, because the office of the colony in some cases "assessed the situation, apparently involving a calculation of the percentage of textiles required to result in the quantity the Assyrian merchants were bound by trealy to deliver to the palace. The office then charged this percentage to the merchants involved. This procedure points to a close cooperation between the palace and the Assyrian institution". Unfortunately, we do not have the text of a treaty of the level li period to give more insight into this device; in those from the younger level lb period the system is apparently different, though pre-emption still occurs (see below chapter V.3.4.1). Veenhof 1988, 250ff. dealt with the purchase and sale prices of the textiles and the profit that could be realized on them in comparison with that earned on the tin and the investments required (taxes, transport, etc.).

The quantitative relation between the expensive "Akkadian textiles", imported from the south, and the institutional or domestic lextile production in Assur, also raised by Dercksen 2004a, 14-17, is still nol clear, but the importance of the textile trade for Assur is underlined by evidence for clearly protectionist measures of the City Assembly, contained in the letters VS 26, 9 and AKT 3, 73:Off., studied in Veenhof 2003d, 89ff. The first forbids trade in specific types of Anatolian textiles and the second probably obliges traders to buy more textiles, by limiting the quantity of tin that could be bought with the silver arriving from Assur. Data from Mari offer clues about how Assur acquired the wool necessary for its production not only from (presumed) local herds, but also from the Sukhu nomads, whose herds grazed along the Middle Euphrates and in the area of the Wadi Tarthar. ${ }^{347}$ The evidence for Assyrian trade in local Anatolian textiles, in particular in those called $p a /$ ira/ ikannum (see $A O A M T 124$ ) has increased and their quantities make the verdict of the City, quoted there, even more understandable. ${ }^{348}$ It is interesting

347 See Charpin-Durand 1997,377 and 387 no. 4.

348 Note the mention of 209 pirikannu in $\mathrm{kt} 89 / \mathrm{k} 421: 4$, but also the expectoration in CCT 6 , 14:49f., What profit do pirikannu yield that I should made them? May the gods Aššu and Šamaš trample (read in line 51, after collation $/ i-d i-s u$ ) that profit to dung! 30 donkeys (loaded with them) are worth onty thity pounds of silver and how many donkey-drivers and how much harness are needed, and what kind of journeys do they have to make?" The value mentioned means a price of ca. 2 shekels of silver apiece or a little more. See for these textiles also nole 908 . 
to read in the recently published treaty from the younger level lb period concluded between the Assyrians and the ruler of Kanesh, ${ }^{349}$ that the latter is entitled to levy as tax (nishatum) ten percent of the parakannu-textiles traded, which implies that Assyrian trade in these products was an accepted fact. The tariff of this tax is more than the five percent on imported textiles levied during level II and shows their increased importance in the internal Anatolian trade, in which the Assyrians still played an important role.

\subsubsection{Lapis lazuli}

Lapis lazuli, called husārum in Old Assyrian, recently studied by Michel and Dercksen, 350 was oblained in Assur from the "City Hall", where it must have arrived with the same caravans that brought the tin to Assur. The evidence for a supply monopoly of the City Hall, already suggested by Larsen 1976, 198ff., has now become clear. VS 26, 12:7ff. reveals that the kärum office in Kanesh levied a tithe (išrătum) on lapis lazuli, which would ultimately accrue to the City Hall in Assur. Its price in Assur was roughly half that of silver, but in Anatolia, where it must have been in demand with the elite (it is mentioned in the new treaty with Kanesh, see below chapter V.3.4.2) it was two to three times more expensive than silver. It was traded in small pieces (kt 93/k 169 mentions 24 stones or beads with a total weight of less than one pound) and in lumps of a few pounds, the biggest one weighing twelve pounds. ${ }^{351}$ The stone was used for making seals (see below chapter II. 2.10 with note 509), for decorating various objects (such as the heads of toggle-pins, see note 219), for making cups (TC 2,22:16), and for inlays. ${ }^{352}$

\subsubsection{Iron}

Meteroric iron (amütum or asium) was very expensive, up to sixly times the price of silver and even more, no doubt depending its quality and purity. $\mathrm{Kt} n / \mathrm{k} 67: 10 \mathrm{Hf}$. (Donbaz 200la) distinguished between pure iron $\check{s a}$ ha-ar-ša and iron $\check{s} a k i-\check{s i}-a$, and while we do not know what these terms mean, the figures on the tithe levied on both kinds of iron, to be paid in silver, indicate that the latter was about ten to fifteen percent cheaper than the former. VS 26, 61 mentions that karum Kanesh bought two pieces of iron at rates of respectively 95 and 40 shekels of silver for one shekel of iron. In view of its high volue and perhaps the risks of its trade, we meet several cases where traders cooperate or make a partnership to handle it, as in $\mathrm{kt} \mathrm{m} / \mathrm{k} 93$, where wo traders shipped an amount of 45 shekels of amütum from Šaladuwar, which fetched a price of more than one talent of copper for one shekel of iron. The best known case concerns a partnership of four men, with

349 Günbatı 2004, 252, lines 69f.

350 Michel 2001a, and Dercksen 2004a, 18-23; see for relevant letters also CMK 194-198.

$351 \mathrm{Kr} 94 / \mathrm{k} 757$ mentions a quantily of $165 / 6$ pounds, qualified as temple property (ikribu) of Assur.

352 In the throne of Ašsur, see RIMA 1, 20, lines 7f. An unpublished letter, quoted in tandsbergerBalkan 1950, 234, speaks of "extremely fine lapis lazuli which will fetch a good price over there for inlay" (romlüm). 
a capital of 20 minas of silver made available by an investor for buying iron in Hattum, which became the subject of a legal controntation which generated several records /see Landsberger 1950a, 331-336).

Iron was much in demand in Anatolia, especially with the elite connected with the palaces. In Assur it was supplied by the City Hall, but it was also obtainable in Anatolia. It was summarily dealt with in Veenhof 2003d, 99-102, in connection with the question of a monopoly and contraband, ${ }^{353}$ and Dercksen 2004a, $112 \mathrm{ff}$. investigated the taxation by the kărum of the iron trade, documented in some very interesting new letters. ${ }^{354}$ They indicale a change in the system of its taxation demanded by a decision of the Ciry Assembly of Assur and communicated to the various Assyrian commercial settlements in strongly worded letters delivered by messengers of the kärum. Copies of them were found in the archive of Kuliya and I refer to my comments on texts nos. 1-6 in the chapter "Kuliya as messenger of kārum Kanesh" of my farthcoming edition of his archive (Veenhof 2007b). The tithe on all iron traded henceforth ("from this day on") had to be "taken" by kārum Kanesh. This probably did not mean that Assur (written ${ }^{d} A \check{s} s \check{s} u$, which could mean the god/temple or the city) relinquished its right to part of the proceeds or profit (nemulum), but that this was no longer levied in Assur, but sent there after having been collected by kärum Kanesh, which made all Assyrian settlements responsible for levying it from any trader and caravan, whatever his status or itinerary. ${ }^{355}$ The measure may perhaps be explained from the fact that there was now more trade in iron found and worked in Anatolia, which could be better monitored by karum Kanesh than by the City, which was originally the main source of iron imported into Anatolia and therefore entitled to a share in its proceeds. The high price implied that the amounts of iron mentioned in the texts were modest, usually ranging from a few to about twenty shekels, ${ }^{350}$ and its importance for the trade is documented by the fact that it also occurs in the new treaty with Kanesh, see below chapler V.3.4.2.

\subsubsection{Antimony, copper and bronze}

The main goods not imported from Assur, but traded by Assyrians inside Anatolia, and therefore occurring mainly in transactions with Anatolian customers, were grain, wool, antimony and copper. Antimony (/u/äum) occurs more often than the single reference in CADL, 243 suggests, and at times in quantities of several talents, but the pattern of its trade lacquisition

353 See for some important letters on its irade, Cecen 1997a.

354 Cecen 1997a and Donbaz 200la $(\mathrm{kt} n / \mathrm{k} 66$ and 67).

355 See in particular the letter kt 92/k 221:Off. (Ceçen 1997a, 227). "From this doy onwards, whoever buys iron, Aššur is not entitled to its profit, it is körum Kanesh which will collect the tithe on it".

$350 \mathrm{Kt} 94 / \mathrm{k}$ 826:32ff. (courtesy Larsen) mentions rings of iron together weighing $183 / 4$ shekels, which seem to hove ferched 22 1/2 minas of silver. K1 93/k 637 (courtesy Michel) registers 31 $1 / 6$ shekels of pure iron (amütum zakütum) sold to the palace, which yielded $463 / 4$ minas of silver, which means a rate of exchange of $90: 1$. 
and sale) is not yet clear. ${ }^{357}$ The idea that the export of copper to Assur was one of the goals of the $O A$ trade, regularly lound in the older literalure, but not confirmed by the caravan texts, has proved to be wrong, though occasionally small amounts of copper were taken along to Assur. ${ }^{358}$ The purely commercial reasons for not exporting it (price and cost of tronsport) were pointed out by me. ${ }^{359}$ Anatolian copper and all aspects of the copper trade - sources, metallurgical treatments, qualities, quantities, weights used, transport (olso by wagons), trading procedures, the role of the kārums, settling of accounts, and attested objects of copper - received a thorough treatment in Dercksen 1996 (see also below chapter IV.I, with notes $696 \mathrm{ff}$.). But there is still discussion about the location of the mines and of Durhumit, which Derkcsen 1996, 154 describes as "pivotal in the copper trade and its market was the link between the neighbouring copper producing areas and merchants wishing to procure the metal". 360 In trading copper the Assyrians, using their transport facilities and commercial network, exploited the differences in resources of the various Anatolian areas and practiced indirect exchange. They sold part of what they imported (fin and rextiles) for copper where it was locally and presumably cheaply available, to ship it elsewhere to sell it for silver and gold, which was the main goal of their trade. While the main clients of the copper trade were the local palaces and rulers, we also meet many Anatolian individuals, some probably connecied with the palace administration, others presumably native copper traders, called pāsirum, or blacksmiths. A good example of the number and variety of the clients is provided by CCT 6, 34a, which, though damaged, still lists twenty-five Anatolians who owe an Assyrian in all 2370 minas of copper, with individual amounts ranging between 140 (once 240) and 10 minas. Most of them are just listed by name, but we also meet the queen, the bel $m \bar{\sigma}[t i] m$ and the ruler of Nen[aššc] (lines 3-5), a priest of [...], and on the reverse another ruler, a chief of the threshing floor, and a lord of the town (be/alim, lines 4, 7 and 15).

While the import of tin and the availability of copper imply an important Anatolian bronze production, the texts tell us nothing about it, apparently because the Assyrians were not involved in it and, surprisingly, also did not trade in it, but bronze objects of course occur as belonging to households in Kanesh and Assur. ${ }^{361}$

$357 \mathrm{KI} \mathrm{h} / \mathrm{k} \mathrm{38:8} \mathrm{(Sever} \mathrm{1998c)} \mathrm{mentions} \mathrm{the} \mathrm{plan} \mathrm{to} \mathrm{import} \mathrm{from} \mathrm{Hattum} \mathrm{ten} \mathrm{talents} \mathrm{of} \mathrm{anlimony} \mathrm{into}$ Luhusaddia to sell it there, AKT $3,52: 2$ records $21 / 4$ talents alongside 41 talents of copper, $k t$ $\mathrm{k} / \mathrm{k} 79: 1 f$ more than nine talents, and according to $\mathrm{kt} \mathrm{m} / \mathrm{k} 1: 34 \mathrm{f}$. the assets lett behind by a dead irader comprised also 2 talents and 10 pounds of antimony. Writings like $k$-ló-am and $/ u-t o-a-a m$ show that the uncontracted form is lula ium and not lulium, as CADL suggests.

358 Note in LB 1202:28ff. Imdilum's request to seven men "to take along each 30 pounds of refined copper for (making) bronze", a letter which (contrary to Dercksen 1996, 119) was probably written from Assur, as a comparison with KTS $19 \mathrm{~b}$ suggests.

359 See Veenhof, 1988, 258, and Veenhof 2003d, 71 with note 11

360 See for this important city, Michel 199lo and Dercksen 1996, 14 and 254, map $B$.

361 See the list in Dercksen 1990, Appendix 3 (textual evidence) and 4 (objects found). In LB 1220 (unpubl.), a list of goods left to/in the care of a woman, alongside large amounts of silver and copper also four tolents of bronze appear, and a trader's storeroom, according to kt 94/k 1247:5 contained also bronze. Note that an Anatolian official with the title rabi siporrim, "chief of bronze", claimed by lewy 1958, 95, and Garelli 1903, does not exist, see below note 915 . 
Several aspects of the trade in wool (including its prices, quantities and provenience) inside Anatolia were first treated by $A O A \Pi$ chapter 7,362 We read about the preference for "soff, long and very fine wool from Mamma" (TC 3, 65:18ff.) and a debt-nole of the wife of Elamma, who lived in Kanesh, records her claim on an Assyrian of 30 pounds of soft wool, to be used for the woof. ${ }^{303}$ This could be o commercial operation, but also be an indication of rextile production by some Assyrian women in Anatolia, which matches the discovery of spinning whorls and loom weights in some houses in the karrum. ${ }^{364}$ The role of wool in "the communal trade through enterprises" (ellutum) was further analyzed in Dercksen $2004 a$, chapter 10 . Some texts mention considerable quantities ${ }^{305}$ and especially the archive found in 1994, to be published by Larsen, contains interesting evidence, which calls for a new analysis of the wool rade. It was frequently linked with that in copper and both were eventually converted into silver and gold for export to Assur. We do not have much evidence for the production or acquisition of wool in Assur, but it is implied by the existence of a home industry by the wives and daughters of the traders, described in AOA 7.2). Occasional remarks like "wool is expensive in the Ciry", 300 or that a particular type of wool was not obtainable, ${ }^{367}$ indicate that it was bought there. Data from Mari indicate that wool could be acquired from the Sukhu nomads, whose herds pastured in the steppe southwest of Assur. ${ }^{368}$ Occasionally small quantities of wool were also sent from Anatolia to Assur, perhaps when the prices in Assur were unfavourable and/or the donkeys returning to Assur had some spare capacity. ${ }^{369}$

\subsubsection{Grain}

Grain, especially barley and wheat, 370 were traded by Assyrians and Anatolians and are attested in many debt-notes, probably both for consumptive credit and for commercial purposes. In most of them Anatolians figure as debtors and the due dates, accordingly, are

362 See also Dercksen 1996, 125f., because wool was at times exchanged for copper.

$363 \mathrm{~K}$ 91/k 388:5f., the purpose is indicaled by an infinitive in the terminative, sakākis.

364 See the literature mentioned in Dercksen 2001a, 64 note 141.

365 BIN 4, $181 \mathrm{ff}$. mention in all near 67 talents (or ca. 2200 kilo's) of wool from Luhusaddia, and a similar amount occurs in kt $87 / \mathrm{k} 464: 17$ (courtesy Hecker).

360 AOATT 112f., no. 4.

367 Dercksen 2004a, 16, with the proposol to interpref surbuitum wool nol as "fourfold wool" (AOAT 190f. and $C A D \check{S} / 111342 \mathrm{~b}$ ), bul as wool from Surbu (a town north of Dēr).

368 Charpin-Durand 1997, 377.

369 See $A O A T T 112$ no. 2, where two transporters are to bring each five pounds of wool to Püsu-kēn's wife. In no. 4 lamassi asks to send the silver due to her packed (hidden?) inside a bale of wool (ina gerab saplim suknam).

370 See for the names $\left\{\right.$ se' $^{\prime} u m=$ ŠE and aršătum = GIG $\}$ and the system of measures used, H. Lewy 1956 and Hoffner 1972, ch.2. In Anatolia there was an official called rabi se 'e/i, see chapter VI.1.1. 
frequently the phases of the agricultural year, ranging from ploughing and seeding to the time of the havest or when the grain is on the threshing floor, and even the time of picking the gropes. ${ }^{371}$ But the commerce in grain, at times in considerable quantities, its origin and destination, still needs a comprehensive analysis. In Assur the families of the traders usually bought their barley when the right season was there in order to lay in o stock (sapōkum) for the rest of the year. Some lists of assets in a trader's household register considerable quantities (measured by the simdum of ca. 30 liters). ${ }^{372}$ It is possible that in a situation of traders who did not grow their own crops, but had to buy barley, its supply, storage and sale or distribution was also a concern of the "City Hall". This could explain the existence of an official designated as "limum of the barley" ( so $^{\mathrm{se}}$ ' $\mathrm{im}$ ), but the context of the only occurrence of this title does not reveal his tasks ${ }^{373}$ and we need more evidence to understand what was going on in Assur.

\subsubsection{Gold}

Gold (hurāsum, logographically KU GI and KU.KI) occurs regularly in our texts and various shapes, types and qualities (normal, good and extra good) are attested as circulating in Anatolia, such as good quality pasallu-gold and the cheaper kupursinnu-gold, and gold qualified as HU.SA, sa abnisu ("in nuggets"?), sa damē ("blood gold"), ša ma 'iš ("water gold"), sa sadui su ("mountain gold, ore"?), and sa ti'amtim ("sea gold"); see provisionally Garelli 1963, 268 and Balkan 1965b, 151, but a detailed investigation is needed. Gold regularly arrived in Assur as part of the proceeds of the trade in Anatolia and we usually see that alongside large amounts of silver smaller amounts of gold were shipped bock. A good example is the "notifying message" VS 20, 71, in which a trader in Kanesh informs his respresentatives in Assur that he has sent off 17 minas of silver and 2 minas of gold for making purchases there, amounts also mentioned in the relevant transport contract TC 1 , 70. But before making the purchases the gold was invariably converted (in reality or in the accounts) into gold and the just mentioned transport contract already equates the 2 minas of gold with 10 minas of silver (on the basis of the standard equivalency of 8 to 1 ). The related "caravan account" TC 3, 43, finally (edited in Larsen 1967 as "type 3:2"), which

371 See below chapter VI.2.2 on the poyment terms determined by the seasons, and Matous 1965, $180 f$. on the additional gifts (sheep, barley, bread, occasionally onions) to be made by the debtor when he poys back.

372 According to $\mathrm{kt} 91 / \mathrm{k} 347$ the assets of Elamma's father included 5000 (measures of barley, and Elamma's naruqqu-contract, $\mathrm{kt}$ 91/k 482:27, mentions among his own assets (soltum) 1500 measures of barley.

373 See Dercksen 2004a, 60f. [A new reference occurs in k1 93/k 71:20ff. (courlesy Michel), where - limum sa se im sa emüqim occurs in connection with a debt originating from a line imposed by the Ciry]. Dercksen also quotes a text (note 200) which states that a deblor "will measure out in the city good quality barley according to the exchange rale of the birum-functionaries" (mohir bi-ri) and identifies the latter with the birum sa misittim, "the birum of the storehouse", a functionary "attached to the storehouse of the City Hall". 
reports on the purchases carried out in Assur, reveals that the gold consisted of amounts in two different qualities, normal gold, at a rate of $81 / 4$ to 1 , and cheaper kupuršinnu-gold at $62 / 3$ to 1 . It was converted into 15 minas and $421 / 2$ shekels of silver, the total amount of silver was spent on equipping a new caravan and we never read that merchandise was purchased for gold. We do not know what happened to the gold, but it seems possible that is was delivered to the City Hall, where purchases were made or its value in silver was made available to the traders. A fact is that gold is several times designated as "gold for/of the journey to the City" (hurāṣum sa harrôn ălim) and apparently had a special importance for Assur. This is clear from a verdict of the City, discussed in Veenhof 1995a, 1733ff., 374 which tried to limit its circulation among non-Assyrians and forbade its sale to Akkadians, Subaraeans and Amorites on penalty of death. Veenhof 2003d, 95f. explained this as a prolectionist measure, on the assumption that it may have been used for commercial purposes by the City Hall, possibly to pay for the tin imported by Elamite caravans, since Elamites (or people from Susa) do not figure among those who are denied access to it. This may be supported by evidence from Mari, because during the few years that this city managed to import tin directly from Susa, gold was frequently paid to buy it (see Joannès 1991). But there may have been other reasons too, also considering the fact that invesiments in the capital of a joint-stock company (naruqqum), though made in silver, normally were rated in gold. Dercksen 2004a, 86, tries to explain this from the city's interest in trade and I quote his proposal, also to show how sophisticaled the system may have been. "It is conceivable that the naruqqu-partnerships were formed under the auspices of the City, which somehow (perhaps by receiving part of the funds collected during the formation of the partnership) credited the merchant for gold which entitled him to "drowing rights" and to obtain credit and merchandise in that way. The City would then guarantee the capital of the naruqqucontract in gold for an amount which was in effect double that of the market value because of the preferential exchange rate of 4 to l" (instead of normal ca. 8 to 1 - K.R.V.). We sorely lack the archives of the Cily Hall, which might substantiate this interesting suggestion, but an explicit statement in a letter could also reveal the truth.

\subsubsection{Level lb}

For the trade during the period of kärum level Ib, when there were a number of changes, also in the assortment of goods, I refer to Dercksen 2001, 63ff, $\S 5$. We must be somewhat cautious with conclusions, since our knowledge is limited by the small number of written sources, and we may expect new information, as the discovery of two new commercial treaties in 2000 shows. But it is clear that the Assyrian presence and activity was less dense than before, that the commercial network was smaller, and Dercksen assumes a shift of focus from Kanesh to Mamma and the area called Hattum, while there is no evidence for commercial relations with cities such as Durhumit (in the north) and Burushaddum (in the west), which during the level II period harboured im- 
portant Assyrian trading colonies. Tin was still imported, but the quantities were much smaller and from this period we lack the typical "caravan reports", with their detailed information on quantities, prices and transport, so prominent during the level II period. Moreover, a new adjective, rapšum, denoting a poor quality of tin, appears. The assortment of textiles also changed and while kutannum, kusitum and other textiles attested in texts from level II were still imported (and therefore are mentiond in the new treaties with Kanesh and Hahhum, see V.3.4.1), textiles and garments called kušsatum and nahlaptum become more popular, while saqqum and subart saptim make their appearance, logether with zappum, "bristle", used for the manufacture of brushes. ${ }^{375}$

\subsubsection{Quantification}

Quantifications, necessary for economic history, are not easy to give. Most texts concern loads belonging to individual traders or firms and the "caravan letters" which list purchases and shipments are not dated, so that it is difficult to know how much was shipped in one particular year. A first (and thus far only) attempt in AOAT 69-76, "Table of Caravan Texts", based on 188 texts, yielded a total number of ca. 17.500 (or ca. 650 donkeyloads of woollen textiles and ca. 13.500 kilograms (or ca. 200 donkey-loads) of tin. The evidence now available, including letters that describe very large caravans, ${ }^{370}$ probably allows at least to triple these figures and those for the whole period, with presumably several hundred donkeys each year, must have been much bigger. Occasionally we encounter enormous quantities of copper and wool, several memorandums list debt-claims adding up to many ralents of silver, ${ }^{377}$ and some of the lists mentioning the total "declared value" (awitum), in tin, of merchandise belonging to traders cooperating in an ellutum, ${ }^{378}$ register huge amounts. The biggest thusfar counts 410 talents of tin and 18 talents of silver, which fits the mention of a trading caravan of 300 donkeys in ARMT 26/2, 432. There is need for more statistics and the better understanding of the chronology may help us to assign our sources to particular periods, so that we may also discover developments over the time.

\subsection{FINANCING, COMPANIES AND PARTNERSHIPS}

Garelli 1963, part 3, chapter I, "Le crédit", dealt with the role of the figures called ramkärum and ummianum and the financing of the trade, and on p. 379-390 he offered a most welcome "liste des créances". He still assigned a special role to persons called romkärum, who were considered to be a kind of licensed "intermédiaires agrees", who would have had the

375 See for details, Dercksen 200la, 63ff.

$370 \mathrm{~K}+94 / \mathrm{k}$ 1680:11H. (courtesy Larsen) mentions one carrying 684 woolen rextiles and 20 talents of tin, shipped on 34 donkeys.

377 See now e.g. Hecker $2004 b$.

378 See Dercksen 2004a, 159ff. 
duty of facilitating transactions by supplying credit and also by carrying out sales for others, but this idea has since been given up. ${ }^{379}$ Still, tamkarum, basically the trader who travels with his merchandise, remains a somewhat opaque term, with a variely of meanings in particular situations. ${ }^{380}$ In the Old Assyrian context it can be as well the trader who manages a capital and directs his firm, as the traveling agent, who acquires merchandise on credit to sell it elsewhere. As "capitalist" a ramkārum may also, in particular in Assur, function os moneylender or as a kind of banker, who gives out commercial loans. ${ }^{381}$ As such the term also acquires the meaning "creditor", especially in debt-notes where the creditor (in order not to reveal his identity or to make transfer of claims easier) is not mentioned by name, but is designated as tamkãrum, "the creditor". ${ }^{382}$ Ummiannum is the term for "principal", "investor", and may apply to anyone who supplies capital to a trader, not only those who invest in a joint-stock company (naruqqum), as we can observe when they come into action when a trader dies and they want to collect their claims. Many lexts speak of mer' $\bar{u}$ ummiannim, "sons of an ummiannum", which may denote both the son of such a man and a trader who belongs to the category of ummianu. They are preferred for responsible tasks, especially for shipping valuable merchandise or for selling goods given in consignment, presumably because of their status and their financial reliability. ${ }^{383}$

An important contribution was Larsen 1977a, supplemented by Larsen 1999, on commercial partnerships (roppa'ütum), ${ }^{384}$ and in particular on the "joint-stock company" (naruqqum), whereby a number of investors (ummiānü) by means of a special contract supply a trader for a fair number of years with a large capital. The few examples we have mention capitals of ca. 30 pounds of gold, made available for periods of ten and twelve years for the generol purpose of "conducting trade" (makārum). The investments are made in silver, but are booked in gold, on the basis of a conversion rate of $4: 1$ (while the normal one in Assur was ca. 8:1). The investors, some of which figure anonymousty (as tamkärum, "the creditor") will receive a share in the profits (nemulum), unless they withdraw their capital prematurely. What they will receive is usually called "thirds" (sa/sätum), which they may acquire both in the form of dividends (šipkätum) and at the final settlement of accounts, partly guaranteed (hundred percent, because

379 See now Garelli 1998a, which revises the ideas put forward in Garelli 1977.

380 Since the Assyrians in Anatolia were traders par excellence, tomkärum, from the Anatolian perspective could be used for "Assyrian" las variant of mer'a Ǎšrut in contrast with nu'ä'um, "native", used for "Anatolian". Kt n/k 1414:7f. stipulates that a divorced wife can go either to a nu'ä'um or a lomkärum of her choice. Similarly records may speak of debis due either by nu'a'ü or by lamkāru, and $\mathrm{kt} k / \mathrm{k} 46: 9 \mathrm{~F}$. (courtesy Hecker) distinguishes between tamkärü and mer'ü Kanis.

381 See Veenhof, 19990, 60-69.

382 See Veenhof 1997b, 351ff. The texts in such cases speak of "marking (the debt-note) by the designation tamkāum" 'sumi tamkarrim waddu'um). A next step is to add that "the bearer of the tablet is the creditor" (wöbil tuppim sut tomkörum), for which we twice find "the holder of the rablet" (TPAK 120a:6, muka il tuppim, kt 91/k 195:27f., mu-ki-ils tuppim).

383 See for them Dercksen 1999, 86f.

384 See already Landsberger 1950a, 331ff. and now also Dercksen 2004a, ch. 9,1 on the ellutum as a form of pannership. 
shares rated in gold will be paid back in silver on the basis of the normal conversion rate of 8:1) and partly depending on the success of the business. 385 The issue of credit was treated more in detail by Veenhof 1997b, 35 If., "Anonymous creditors and bearer's cheques", and this was followed up by Dercksen 1999 and Veenhol 1999a, in the volume Trade and Finance in AncientMesoporamia. The former analyzed forms of credit designaled as bülähm, saltum la trader's own assets\}, maškattum, qiptum, tadmiqum and ebutum (long term investment loans). and furthered the understanding of partnerships (tappo'üum) and the joint-stock companies (narugqum). Veenhof focused on the role of silver ${ }^{380}$ and of commercial credit granted by Iraders to clients and especially to traveling agents (called tamkörum) who received merchandise in consignment and were used by the Assyrians to sell their merchandise over a wide area ${ }^{387}$ In addition he investigated the role of the (perhaps professional) moneylenders, who granted commercial loans to traders, and the various ways in which such credit was secured, a subject treated more in detail in Veenhof 2001. Dercksen 1997 studied the way in which temples invested in the trade, by making merchandise or funds, designated as ikribu, "votive gifts", available to traders as long term profitable investments. Dercksen 2004a, chapter 2 . collecied evidence for the role of the City Hall in granting loans and selling textiles, lapis lazuli and possibly also tin for export to Anatolia on credit.

All these financial operations, many also carried out by book transfer or by depositing goods, required careful accounting. Apart from the numerous private legal actions to dun debtors and agents who failed to meet their due dates, we have evidence for privale settlements of accounts (nikkassi sasa $\bar{u}^{3}$ ) in kärum Kanesh, which could take place in the presence of witnesses or perhaps arbiters and some of which were carried out to solve conflicts. ${ }^{388}$ But there were also periodic (presumably annual) general settlements of accounts organized by the körum office (nikkassü sa kärim), analyzed in Dercksen 2004a, chapter 11. They were particularly important for the class of main traders, the "big" (rabiüum) members of the karum, also designated as sagail datim, "those who pay the datufee". They contributed to the finances of the kärum and for that reasons enjoyed the privilege of not having to pary fees and taxes due to kärum Kanesh en route in Anatolia, but of settling them periodically in Kanesh. This also earned them the designation awitu sa nikkassi, "men of an account", and as such they also occur in the "Statutes of the kārum". ${ }^{389}$

385 See now also Larsen 1999, Hecker 1999 (collation of the main nonqqu-contract) and Dercksen 2004a, ch. 5.4, quoted in the previous paragraph. The nanqqu-contract of Elammo, $\mathrm{kt} 91 / \mathrm{k} \mathrm{482}$, from year 77, writes in lines 23ff., "After ten years he will render on account" (nikkasse iddan) and at the end adds that his own assets "solmum, which presumably served as a kind of securityl consist of 1500 measures of barley, wo slaves and the share in his father's inheritance, (called zitum tu kursinnähm).

380 Eloborating on $A O A T T \mathrm{ch}$. 17, where he opposed the view on OA trade pul forward by Polanyi 1957 and 1968, on the institutional setting of the trade and odvacated the role of a price-torming markel governed by supply and demond.

387 See also Veenhof 1997b, 351 ff., on "anonymous creditors and bearer's cheques".

388 Simple settlements of accounts in El $107-109$ and 173, settlements before witnesses, recorded in depositions submitted during a lawsuit in El 200-201, 209-270, and CCT 5, 15a.

389 See for a first interpretation AOATT 274ff. and now Dercksen 2004a, ch. 7,1. 
Several studies paid attention to the role of women, both those who had stayed behind in Assur and those living in the colonies in Anatolia, who supponted their husbands, but were also liable for the consequences of bad business. When debts had to be paid, especially in Assur, private or public creditors (the limum as head of the Cily Hall) could dun the fomilies and especially the wives of debtors and create serious problems by forcing them to hand over valuable pledges (jewels and objects of bronze), and even their houses in Assur could be sealed and sold. 390

Debts of Anatolians, both to Assyrians and to fellow Anatolians, make a special category. The basic features of credit granted to Anatolians are well presented in Garelli 1963, 257ff., and though we now have much more sources and know more details, the basic picture still stands. It is characterized by higher interest (than the 30 percent current among Assyrians) and by stipulating or actually obtaining more and better securities (pledges, guarantors, joint liability - especially of married couples, - and a kind of general mortgage on the possessions of the debtor) in order to enhance the possibilities of enforcing poyment or obtaining compensation. The latter have been reated more in detail by Veenhof 2001 , esp. $\S 4$, who also noted new devices to protect creditors, such as the right to borrow the amount due from a debtor from a moneylender at the expense of the defaulting debtor ( $\xi$ $2, c)$. The methods of the Assyrian traders and creditors in this respect were not much different from the ways in which Anatolian creditors tried to protect their financial interests and secure their claims, ${ }^{391}$ occasionally even by an occumulation of securities, which at times may reflect a limited underslanding of the legal rules, but may also have been stipulated to leave the creditor the choice of how to indemnify himself if his debtor defaulted. Contracts with Anatolian debtors (not infrequently multiple debtors, among which many married couples) and in particuar loans between Anatolians are important because they acquaint us with a variery of due dates, the phases the agricultural years and festivals of the gods (see below chapter VI.2) and in addition contain interesting stipulations on additional gifts (sheep, breads, onions, see Matous 1965, 180f.) to be delivered by debtors.

\subsection{LAW AND THE ADMINISTRATION OF JUSTICE}

The commercial activities, especially the system of credit and investment (with the concomitant need of securities), forms of cooperation with business partners, employment of personnel, but also the acquisition of slaves and houses, and the need to regulate and record important events in the life of the family (adoption, marriage, divorce, inheritancel generated a great variety of contracts. El contains a large selection of such texts, which can now be substantially increased, but this volume has not had a sequel. The increased importance attached to archival studies does not favour separate editions of legal documents and the growing number of

391 AOATT ch. 6.2, Hecker 1978b, Garelli 1979, Michel 1998a and 2003c.

See the contracts listed in Garelli 1963,384f., the records analyzed in Matous 1965, the files of Enišaru (Veenhof 1976). Aše'ed (Donbaz 1988a), and Madawada (Alboyrak 1998), and KKS nos. $7.8,11$, and 31 . 
texts rather stimulates a focus on particular types of records and specific areas of low and legal procedures. The latter approach resulted in editions and studies of specific types of contracts, such as Rosen 1977, on the loan contracts published atter $E L$, and Kienast 1984 on deeds of sale. There also appeared a variety of thematic studies, at times in the form of a commentary added to the publication of new sources. An example of an archival approach in legal matters is Matous 1969, the analysis of a large dossier dealing with a fight about the inheritance of a prominent trader. Full data and bibliographical references on the developments can be found in Veenhof 2003c, and here I only mention studies on be 'ülätum the interest tree loan by means of which caravan personnel was hired). ${ }^{392}$ securities, ${ }^{393}$ the sale of houses and slaves, ${ }^{394}$ marriage, ${ }^{395}$ inheritance, ${ }^{390}$ and also those on the validity and duration of contracts. ${ }^{397}$ A special study of the rules of inheritance /starting from the survey in Veenhof $2003 \mathrm{c}$, $\S 6, c)$ is a desideratum, since all OA inheritances were divided on the basis of lestaments or last wills (simium), which must have allowed the testator to interfere with the traditional rules in order to care well for the female members of his family (the widow and unmarried daughters who were priestesses) and to take also commercial interests into account.

Some of the stipulations and formulations encountered in OA contracts prove to be forerunners of what is known for later periods, both from Assyria proper (Middle Assyrian documents) and from the northern periphery (Nuzi, Emar, Ugarit). An example is a recently published testament in which the Assyrian widow not only receives a full share in the silver, but her property rights are defined by stating that "she is mother and father over the silver". ${ }^{398} \mathrm{OA}$ also produced the first house sale contract that explicitly states that the original title deed of a house was handed over by the seller to the new owner. ${ }^{399}$ Other original legal solutions may be due to the creativity of the Assyrians, who had to cope with new social and commercial issues. A recently published contractual agreement fixes the position of an unmarried sister, a priestess, after the death of her father, by stipulating that "she will live, be fed and be anointed" in the house of her sister and the latter's Anatolion husband, "just like (or: as if) she was their mother". ${ }^{400}$ Creorivity is also attested in developing contractual rules to protect and indemnify creditors

392 Kienast 1989, with corrections and additions in Veenhof $1994 \mathrm{~b}$.

393 Kienas\$ 1976, and more in general Veenhof 2001

394 Hecker 1980b and 1998a, Günbaltı 1989, Farber 1990, Bayram-Veenhol 1992, Bayram 1990, Donbaz 2001d, and Veenhof 2003b.

395 Matouš 1973, Balkan 1980 (betrothal), Bayram-Cecen 1995, Rems 1996, Michel 2006, MichelGarelli 1996b, and Veenhof 1998b.

390 Wilcke 1970, Alboyrak 2000 and 2004

397 Michel 1995 and Veenhot 20030, $112 f$.

398 See Michel 2000b, 3ff.

$399 \mathrm{Kr} 91 / \mathrm{k}$ 522:15f., see Veenhol 2003b, no.1. "The deed of purchose of this house, seoled by

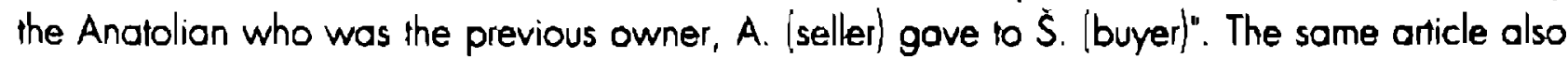
publishes a contract, kt 91/k 410:7ff., which mentions a symbolic action accomponying the sale of a slave, "he (the seller) cut off the hämum in our presence".

$400 \mathrm{Kr}$ 2001/k 325a, published in Alboyrak 2004; the words used are kimo ummisunu ... usbat aklat $u$ pašs̆at išisisunuma, the contract is from the level ib period. 
against defaulting debtors, such as the authorization to borrow the amount of the debt from a moneylender at the expense of the debtor, ${ }^{401}$ and the possibility for a guarantor who had been forced to pay for a debtor, to charge the latter compound interest.

Such contractual relationships together with the ensuing legal conflicts or commercial problems, especially in cases of default of payment, bankruptcy, fraud, disagreements, and the death of a trader, ${ }^{402}$ could lead to conflicts, which produced a large variety of judicial records. They reflect the attempts to recover the facts, to solve conflicts, and to make justice prevail, especially by enforcing payments due. El contained a large body of all kinds of relevant texts, and Michel 2000a presents a smaller sample in translation. The documents range from records of private summons, which may lead to "seltlements of account" inikkassi sasä́um), "payment contracts" (tarkistum), ${ }^{403}$ arbitration, and verdicts by the kārum or the City Assembly. Their increased numbers and variely have lead to new attempts to reconstruct the judicial norms and procedures (e.g. in Veenhof 1991a and the outline in Veenhof 2003ci, and T. Hertel, in Copenhagen, is now preparing a dissertation on this subject, starting from a very large file (of ca. 70 texts) on a complex legal fight, preserved in the archive excavated in 1994. During the last decennium progress has been made both by the commenlaries accompanying editions of new texts and by more thematic studies. They can deal with specific cases, ${ }^{404}$ types of texts, such as testimonies and depositions by witnesses submitted to a kārum, ${ }^{405}$ protocols of interrogations and of oaths sworn, 406 provisional and final verdicts, and the procedures followed. Also studied are the bodies that administer justice (wabartum, karrum, City Assembly, 407 and "the elders", sibütum), 408 and the role of those involved, ranging from the parties in a conflict to witnesses /factual and court witnesses ${ }^{409}$ and arbiters (dajiānū $\}$. In addition persons designated as "those who solve the conflict" (pāsir awätim), "those who settle the conflict" (gämir awätim), and the "attorney" (räbisum) assigned to a plaintiff in Assur by a decision of the city and the ruler and mentioned in the inscription of Erišum $1 .{ }^{410}$ Specific issues studied are a ruling on the compensation of losses of a communal caravan, legal instruments to secure care

401 See Veenhof 1999a, 66ff.

402 See on some cases Michel 1992c, 1994, and 1998e, and more in general Veenhof 1995a, $1726 \mathrm{HI}$.

403 See Veenhof 1999o, 81f.

404 Malous 1969 (legal fight after a trader's death), comparable to the elaborate analysis of a number of interrelated records in the last port of $E L$.

405 Veenhof 1991

406 Garelli 1982 and Michel 1997c (on oalhs), Bayram 2001, and Donbaz 200la (on "the dagger of Ašsur").

407 Larsen 1976, 153f. and 175f.

408 Lorsen 1976, 162ff.

409 See for the distinction Veenhof 1991, 457ff.

410 See Larsen 1976, 184-89. Veenhof 1994b, and RIMA 1, 21:55, which speaks of "an attorney of the palace" (Grayson "a palace deputy"). 
in old age, and a decision (described as an act of clemency of the god Ašsur) ${ }^{411}$ on the redemption of houses in Assur sold lor debis. ${ }^{412}$

Ancient Anatolian law, as documented in the many native controcts, but alwoys in Old Assyrian linguistic garb and therefore liable 10 Assyrian intluence, still needs a comprehensive separate analysis, especially now that more native records from the level ib period become available. Some records document features that probably are of Assyrian or Mesopotamion inspiration, such as royal measures for the concellation ("washing off", masä'um) of debts, 413 stipulations on defaulting deblors and securities, ${ }^{414}$ and penallies for breach of contract and elements in marriage law. This may also be true of the remarkbale Anatolian contract $k t 84 / k$ 169 (Bayram-Veenhof 1992, 92 no.1) on the acquisition of a field as antichretic pledge for longtime exploitation by the creditors, formulated as a purchase in order to focilitate its eventual conveyance. As a kind of forerunner of similar Middle Assyrian contracts it suggests Mesopotamian inspiration, but we cannot exclude native Anatolian elements. There is, in fact, sufficient evidence for Anatolia's own legal customs, such as a particular type of brotherhood adoption and contracts about separalion from a household, 415 and rules about a system of sevice obligations attached to the possession of a house. ${ }^{.10}$ The relatively small number of documents available means that our knowledge of Anatolian law is still limited and that new discoveries may bring surprises, such as a recent deed of sale of fields and an orchard, which contains a provision on the shared used of the irrigation water. ${ }^{417}$

\subsection{HISTORY AND POIITCS}

The small number of royal inscriptions, now easily accessible in RIMA 1 , does not tell us much about Assur's early history, but altention has focused on those of llušuma and Erišum I, with their references to royal measures that point at a deliberate economic policy. ${ }^{418}$ The archival texts from the colonies are so much concerned with the rade that they contain almost no information on the wider political or economic setting of the city of Assur, apart from a rare reference to problems with the import of "Akkadion lextiles": Akkadians do not come to Assur because their country is in

411 Ašsur ennān àlišu illeqe. See for "clemency" (ennanätum) in Old Assyrian now also Dercksen 2004a, 251ff.

412 Respectively Veenhof 1995a, 1730f. (with Dercksen 2004a, 171f.), Veenhof 1998c, and 1999b.

413 See Balkan 1976.

414 Veenhof 1978 and 2001, 142ff. Nore the interesting case of the conditional sale by debtors of a field which the buyers can cultivate for five years, during which period the owners can get it bock at the original price, a forerunner of similar Middle Assyrian "restricted conveyances" (BayramVeenhof $1992,92 \mathrm{ff}$, no. 1$\}$.

415 Veenhof 1998c, 145H. and Dercksen 2004b, 143f.

410 See Dercksen 2004b, 140ff., an arhalum, unušsum and tuzinnum.

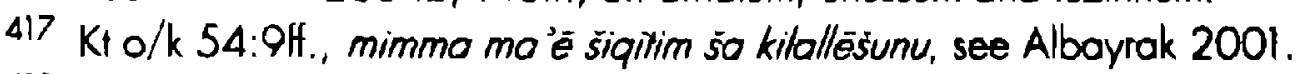

418 See larsen 1976, part 1, ch. 2, and below, chapter It.1.3. The inseription of Erišum discovered in kórum Kanesh, RIMA 1, 20f., is not helpful for political history, but importont for understonding the administration of justice in ancient Assur. 
"upheaval", but we connot identify or date the event. ${ }^{419}$ Occasional problems with the supply of tin, which was imported from the south, ultimately from Susa, were hardly due to political events, since the texts simply state that "the caravans from the Lower Country (mät sapiltim) are delayed", but are expected to arrive. ${ }^{420}$ Texts from kārum Kanesh never mention any Mesopotamian cily or king, so that synchronisms are lacking; even Assur's important southern neighbour Eshnunna does not occur in the texts. ${ }^{421}$ We also learn nothing about the political status of the various towns in Northern Mesopotamia, belween Tigris and Euphrates, which functioned as road stations for the Assyrian caravans, apart from references to anonymous local dignitaries (called massu'um and kašsum, ${ }^{422}$ who receive gilts and occasionally to a palace or ruler. ${ }^{423}$

We have a remarkable verdict of the City Assembly, which forbids Assyrians to sell or banter gold to "an Akkadian, Amorite and Subaraean", 424 which means traders from Babylonia, from the Hurrianized areas north of Assur, on both sides of the Tigris (including Niniveh) ${ }^{425}$, and from the area of the western bend of the Euphrates and the Balikh, called Amurrum (written MAR. TU, dMAR.TU, or Amurnum), in which 0.0. the town of Nehrio was localed and where Amorites (Amurrium) lived. ${ }^{420}$ How far to the west, from the Assyrian point of view, "Amurrum" reached

419 In VS 26, 17:6-8, the writer of the letters considers the possibility that they will arrive before the winter. This event may hove caused a rise in the price of these expensive products, as reponted in TC 1, 11:9f. (see AOAT98).

420 AKT 3, 73 and 74; see Dercksen 2004a, 28 f

421 See for Eshnunna, Dercksen 2004a. 294., who points to the fact that Eshnunna was in decline until the reign of piq-Adad II (ca. 1860 BC). Eponym no. 44, from ca. 1930 BC, is Šu-Anum, said to be from Nērablum.

422 See Nashef 1987, 22ff. and for kašsum below chapter VI.1.2.2. TC 3, 163:26ff. mentions an expense for a libation for the dagger of Ašsur in Apum, which implies that the god had a cella or shrine there, probably in the local Assyrian kärum, attested in AKT 2, 19:13.

${ }^{423}$ Garelli 1965, 40 no. 17.

$424 \mathrm{~K}+79 / \mathrm{k} \mathrm{10l}$, see Veerhof 1995a, 1732f. and Dercksen 2004a, 81f. Lines 19ff. read: hurōṣam ana A-ki-di-im A-mu-ri-im u Su-bi-ri-im mamman la iddan. I assume that the singular of the nisbe refers to persons from these areas in general, in particular traders, and not specifically to a ruler or king.

425 See for the Hurrianized region, called Subarum, Dercksen 1996, 163. Nineveh is mentioned only once in $\mathrm{kJ} n / \mathrm{k} 931$ (AWMY 1992, 6lf., no. 10), which books expenses in tin (which means for a caravan ronsport) for a trip from Ni-nu-a io Burallum and for a compensatory payment (because more tin was spent en route than the leader of the caravan had received in advancel for a trip from Assur to Ninua.

420 Amurrum as a region or area (nol listed in Nashef 1991) occurs in two letters of Šalim-ahum, who writes DMAR.TU and uses it with the prepositions ina libbiand ana libbi, which also occur with mätum. CCT 2, 3:5, "I sold the merchandise in Amurrum (illibbi Amurrim) and collected my silver", and TC 3, 20:9, "Buy tin (in Assur) and let P. leave with D. for (allibbi) Amurrum" (see lewy 1961, 62f.). Also in kt $\mathrm{n} / \mathrm{k}$ 522:4 (a letter sent išn libbiMAR.TUim), CCT 2, 5a: 194. (copper for a value of 5 minas of tin given for <covering expenses to be made in> Amurtum, ana A-mu-ri-im), same phrase in $\mathrm{kt} n / \mathrm{k}$ 524:22 (copper for a value of $x$ tin given for <payments to be made in> Amurrum, ana MAR.TU; both $\mathrm{kt} n / \mathrm{k}$ texts courtesy Günbatil). See perhaps also AKT 3, 75:15, among expenses of a caravan journey, "6 minas of fin which you paid ano Amurrim". There are also some references to "Amorites" of this orea, e.g. "wo Amorites of Nehria" (CCT 2, 49a:14). The qualification a-mu-ru-um used of silver does not mean "Amorite silver", but "inspected, tested" (ammunum) silver of good quality, see Sturm $1995 \mathrm{a}$. 
is not clear, but it is possible that traders from Ebla, who occur several times in the texts, were also considered Amorites. ${ }^{427}$ Assur had commercial contacts with "Akkad", the area south of Assur, from which "Akkadian textiles" were imported, which must have included Eshnunna, in line with the statement of llušuma that his measures affected the Akkadians all the way from the Persian Gulf until Dēr and Assur (see below chapter III.1.3). But import of textiles and presumably copper from the south apparently did not prevent considering "Akkodians" as rivals in the trade. This is implied by the just mentioned prohibition of selling gold to them and contirmed by a surprising stipulation in the draft of a trealy ${ }^{428}$ with a ruler in southern Anatolia, probably somewhere in the area of the great western bend of the Euphrates, near Hahhum. He has to promise that he will extradite Akkadians, presumably Babylonian traders who travelled north via the Euphrates and came to his country, to be killed by the Assyrians (see below chapter V.3.3). But alongside such protectionism also good relations were necessary with cities and lands whose cooperation was essential for the trade and the safety of the caravans. We do not know which traders, apant from the already mentioned "Akkadians" visited Assur to sell their goods and make purchases. But the just mentioned verdict on the restricted circulation of gold does not mention people (itraders) from Elam or Susa, from where the tin was imported in Assur, directly or indirectly. If indeed caravans from Susa visited Assur, the fact that they are not mentioned in the decree could imply that they were welcome and that part of the gold Assur acquired may have been used to pay them. ${ }^{429}$

We have a variely of information on the relations between the Assyrians and the rulers of the various city-states in Anatolia, in whose territories the Assyrians had settled and traded on the basis of treaties (called "oaths", mamitum). From level II we only hove the just mentioned report on a treaty, but there are now also two (damaged) treaties from the time of kōrum Kanesh level $\mathrm{lb}$, concluded with the rulers of Kanesh and Hahhum (below chapter V.2). Both are nearly exclusively concerned with bilateral issues, but the second. in a damaged passage (I [II] 26 'ff.) considers the possibility that hostilities have broken out between rulers of Hahhum and Timilkia (in the plain of Elbistan, north of Hahhum) or Batna (presumably south of Hahhum, near Süruc, the location of classical Bannae), both cities with an Assyrian kärum. This of course would create difficulties for Assyrian caravans on the way to Kanesh. Damage of the tablet deprives us of information on what this rule meant in concrete, but it is possible that the treaty stipulated that such hostilities could not be a reason for blocking the caravan traffic. The mention of such hostilities .just like that of the penetration of Akkadian traders into the territory of the ruler who concluded the earlier treary) probably reflects experiences or at least the awareness that such things could happen and the wish to minimize their effect on Assyrion business.

Information on the political situation in Anatolia is rare and often laconic, since it is only given to inform traders or to warn them against problems and dangers. The most

427 See for Eblaites in our sources, Dercksen 1996, 164, and above note 233.

$428 \mathrm{Kf} \mathrm{n} / \mathrm{k} 794$, see now Cecen-Hecker 1995, Günbatt 2004, 250 nole 8, and below chapler V.I.C.

429 Tin was usually imported in Mari via intermediaries (Eshnunno and/or Sippar), but when for a few years Mari managed to establish direct commercial contacts with Susa and the Elamites, gitts and payments sent to Elam were predominantly in gold. See Joannès 1991. 
interesting source is the very broken letter KTK 10, presented in Larsen 1972 under the title "A Revolt against Hatluša", where an Assyrian reports on a serious conflict which involves several kings:

"... the ruler of Amkuwa here ... and the rulers of Sinahutum, Amkuwa, and Kapitra made common cause and rebelled against the ruler of Hattus (Hattušāim). To the ruler of Kanesh...".

There is no need to assign this letter to level $\mathrm{lb}$, since the nisbe Hatusaaium is now well attested during the level II period and does not presuppose the later form of the city name Hathuša (instead of current OA Hattuš). Moreover, it is unlikely that nakārum here means "to rebel against", and if we translate "to start hostilities" 430 the text would speak of a coalition of three cities against Hattus, but not a rebellion of three vassal states against their overlord, the ruler of Hattus. Unfortunately, the exact date and context of this event is unknown.

Two Anatolian debt-notes mention kings by name to fix the date when a debt was contracled. In ICK 1, 178:2ff. it happened "when Larbarša became king" (inümi Labarsa rubā'ütam işbutul, but we do not even know of which city, ${ }^{431}$ and in $\mathrm{ki} n / k$ 76:12f. it was "when Asu, the king of Luhusaddia had died". ${ }^{432}$ KTS $50 \mathrm{c}$ records a gift presented "when the queen of Wahšušana entered (her city)", which must have been a special occasion, perhaps when she arrived as bride of the local king. ${ }^{433}$ This is one of the many cases where an Anatolian ruler during the level II period is only identified by a nisbe, without giving his name and often even without stating of which city he was king, because this was known to the correspondents. This is the case in AKT 1, 78:12ff., where a ruler (city not mentioned) advises an Assyrian trader not to travel to Wahšušana "until the (his?) rabi sikkitim has made the ruler of Burušhaddum, Ušunālum and the ruler of Wahšušano swear the oath". Another fascinating lext, a deposition, contains a report on a discussion with a local ruler and his queen on the fate of an Assyrian trader who is accused of having

430 Larsen mentions that the construction of the verb with personal accusative object is not normally used for "to rebel against", where a preposition (itti/isht) is common, but note that OAkk royal inscriptions (Naram-Sinn's tale on the "great revolt") and an OB royal inscription inspired by his example, use nakōrum with accusative object ("against me"). The new trealy with the ruler of Hahhum, which considers the possibility of hostilities or war with Timilkia and Batna, uses nokärum isti, which cannot mean "to rebel against", since Hahhum was not a vassal stale, but an independent kingdom.

431 See Balkan 1957, 54. The record is broken and only contains the name of the debtor, withoul patronym. He has to pay "when he relurns from Hattum", the designation of the area within the bend of the Kızilırmak, which suggests that Labarša ruled elsewhere. Note also the grain loan kt $\mathrm{k} / \mathrm{k} 33$ (courtesy Hecker), to be given back "by means of the measuring jar of Labarša" (ikkarpitim so Labarsa), where Labarša is neither creditor, nor deblor, nor witness, hence perhaps the official standard of the ruler.

432 See for the text Donbaz 1988a, 5if. (level lb period).

433 Inümi nubātum Wahšusanāitu terrubanni, see for the text Ulshöfer 1995, 126. The text cannot be dated, since the limum mentioned is not the year eponym, but a representative of the karum. 
acted as messenger for the ruler's enemy, the king of Towinia. ${ }^{434}$ The letter BIN 6,23 /CMK $69)$ reports on the conflagration of a palace, which so much occupies the minds of the court that it is impossible to ask the local rabi sikkitim to pay his debts, "the man has spent all his silver on/for his land". CCT 4,30a (CMK 98) tells us that at a certain moment the throne of the king of Hahhum was not secure, because he had committed bloodshed, which is the reason why there is no agreement yet on the oath (treaty) to be sworn. ${ }^{435}$

Other scattered pieces of information mention political rensions and hostilities between various cities. Kt n/k 1429:14 speaks of hostilities of (in) Kanesh" (nukurätum ša Kanis") ${ }^{330}$ and several texts refer to "upheoval" or "revolt" (sahö um, sihitum) in a city or a "land", in CCT 4, 42a:18f. in Hahhum, in LB 1209:14 in the land (of) Kunanamit, in KTH 1:4f. in Burushaddum and Wahšušana, in $\mathrm{kt} \mathrm{m} / \mathrm{k}$ 13:25 in Burušhaddum alone, and in BIN 4, 34:8f., CCT

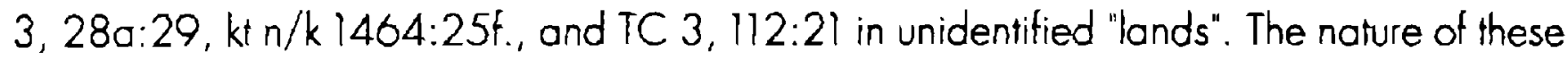
events remains unclear, apart from the fact that they interfere with the trade, but one text seems to link "upheaval" with the death of a king and military danger.

"Here the king has fallen during/in the sikkätum and there is upheaval within the ciny and we fear for our lives. There are enemies over a distance of one and a half hour and nobody dares to go out into the couninyside. One even tries to make us set out logether with him for doing battle! In the meantime absolutely no contracts must be drawn up, lest we get indebred to our principals for no less than one tolent of silver. When the country becomes peaceful again and the ruler will conciude an agreement with him, tablets can again be sent somewhere. ${ }^{437}$

434 The report is preserved in two duplicates $k 1 \mathrm{n} / \mathrm{k} 504$ and $k 193 / \mathrm{k}$ 145, see Günbalt 2001, also on the question which ruler might be meant. See also ki $87 / k 249$ (Hecker 19900, 1481).), the emotional letter of an Assyrian who complains that he, olthough the ruler (city not mentioned) initially had spoken "very good words", having been defamed as being only "a slave of the ruler" (of Assur?), had been put in jail ten months ago. He asks for intervention of the karum (Konesh?) to prevent that silver of the city of Assur gets lost and he himself dies without reason (note the order of the two arguments). We would like to know which ruler was involved.

435 The king in this case probably was the one of Hahhum, because the local "Ten-men board" [esartum| was among the writers of this letter, who repealedly went up to the palace in order to settle the matter of the oath.

436 Mentioned as the time when a financial liability started, presumably somewhere in the vears 81 84 , see Veenhof 2003, 61. The possibility of nukurtum with neighbouring cities or states, which might disturb the Irade, is also mentioned in the text of a level II treaty (kt n/k 794:25), and with the use of the verb nakanum in the level lb treaty with the ruler of Hahhum (see Günbatt 2004, 250 note 8 and 258, 111:26'ff, and below V.3.2).

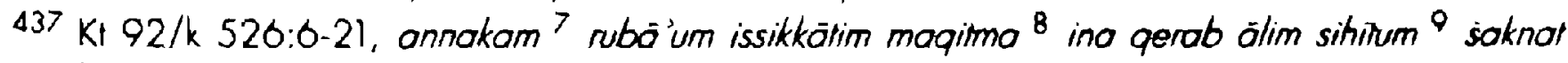
(Cecen 202, 67l.). Sikkatum is an outdoor event of ceremonial and/or military nature, in which people toke part en masse, and which may be harmful for the trade (see Veenhof 1989, 521f.). Read in line 11 béra u züzo, and in 14 qädis̀uma ušrenessunniăfima, bul il is nol clear to whom "logether with him" refers and who is meant in line 22 by "with him", unless magônm in line 7 does nol mean "to fall (in battle)", but "to fall upon", "to arrive suddenly". We cannot date this event, also becouse the orchive to which the text belongs is still unpublished. 
Since in such Assyrian texts of level II not a single Anatolian king or queen is ever mentioned by name, historical conclusions are extremely difficult to draw and it is even impossible to say something about the royal line of Kanesh itself.

More names of Anatolian rulers are known from the level lb period, rarely from their own archival texts (such as the Anum-hirbi letter) and mainly from the so-called 'notarizations' at the end of Anatolian legal records. They state that the transaction was passed under supervision and probably with permission of the king mentioned by name (e.g. iqqâte Inar rubä'im), frequently followed by the mention of "chief of the stainway" (rabi simmilfim; see below IV.2.5). But these Anatolian documents are never dated, so that we do not know how long these rulers reigned. Their sequence has to be deduced from prosopographic and other dato, with the help of the fact that twice the ruler's rabi simmilfim apparently was the crown-prince who in due time succeeded him (Inar - Waršama, Pithana - Anitta). But this was not always the case, not with Halgiašu, the "chief of the stainway" of Waršama (who occurs six times) and also not with Peruwa-Kammalia, the one of Anitta (attested in $\mathrm{kt} 89 / \mathrm{k} 371$ ). Was the dynastic sequence in these cases interrupted by death, 438 conquest or revolt?

Most references in which Anatolian rulers figure have to do with the trade and concern normal procedures relating to sale, fixing prices, trade in iron, and taxation, but several also deal with smuggling, confiscation, losses, theff, fines, imprisonment, and ransom. There are even a few cases where Assyrians are killed and "blood money" had to be paid as compensation. ${ }^{439}$ The normal commercial relations with "the palace", when merchandise was cleared by paying taxes, are not normally detailed in letters, which only mention prices, amounts and figures. Problems and conflicts, on the other hand, just like political events that interfere with the trade, ${ }^{440}$ may result in lelters that report on them and ask for help of colleagues or of the Assyrian colonial authorities. The handling of such conflicts shows that there were certain rules governing the relation between the palaces and the Assyrians and it was scon concluded that they had been stipulated in a kind of treaties (simply called "oath", mamitum). Their substance could also be reconstructed from recuring features in caravan texts, regarding taxes, the right of pre-emption, and protection of caravans, to which one could add residence rights and extraterritorial rights (see below V.1.A). ${ }^{44 l}$ Those on compensation for the loss of merchandise and on the payment of blood money are best attested, because they could lead to discussions and negotiations with the rulers, both by the victimized traders and by representatives of the kärum, reported in letters (see below V.3.2 and 3).

438 Note the mention of "an epidemic of (in) Burušhaddum" (muiänü ša Burušhaddim) in kt n/k 1339:10f. (Cecen 1995, no.1).

439 See below, V.3.3, also Günbalt 1995, 1997, and Cecen 1998b, with references to settlements about blood money (damü) between Assyrians, which in some cases may concern money paid by Anatolians. In kt b/k 258 an Assyrian owes the kärum an interest bearing debt of 80 shekels of silver, described as "expenses of (made for) the blood money of Zaniwata, he (the kārum?) paid it in the name/because of Ennum-Aššur". Was Z. victim or culprit, was the whole sum spent to obtain the blood money or did it comprise expenses and blood money, and was the sum advanced for E. or paid because he was the victim?

440 Texts moy speak of sukurtum, "suspension (of traffic)", see CADS s.v.

44) See the picture drawn in Larsen 1976, 243-46, and below chapter V.1.A. 
In the absence of treaty texts (which only became available in 1994) information on the relation between the Assyrians and the Anatolian rulers was derived from a relatively small number texts, especially from the correspondence between Assyrian colonial authorities and Anatolian rulers, from private Assyrian letters which report on contacts and conflicts with the latter, and from a few depositions in which persons involved in such contacts report on what was said and done. Garelli 1963 carefully analyzed those known by then and used them to refute Lewy's thesis of a political domination of Anatolia by Assur, but since the letters report on ad hoc situations and there obviously were differences in status between the different Anatolian rulers, not all questions could be solved. Larsen 1976, 244f., already pointed out that we should be careful in extrapolating from the available texts in which the local rulers may address kärum Kanesh as "our fathers", usually make the diplomatic ouvertures to conclude or renew a treaty and swear the oaths. A recently published deposition ${ }^{442}$ may serve as a corrective, though it does not deal with trade, but with the accusation that an Assyrian trader passed on information of a ruler's enemy. Since Garelli's analysis not many new letters have become known, ${ }^{443}$ and the picture still is not very sharp. But it is clear that this remarkable relationship, in which the Assyrians had no recourse to military power, was based on mutual economic interests and strict observance of what had been agreed, though this could not prevent individual persons on both sides from occosionally infringing on details of the agreements.

Evidence on Anatolia during the period of kärum level $\mathrm{lb}$, notwithstanding the smaller number of texts, is at times more detailed, in particular thanks to ca. thirty records of the sale of houses and slaves, of redemption, divorce, and the establishment and dissolution of a kind of brotherhood community, which involve Anatolians persons and were "notarized" by the local ruler, usually logether with "the head of the stairway". ${ }^{444}$ They acquaint us with the names of several rulers, Anitta, Inar, Pithana, Warša/uma, and Zuzu, ${ }^{445}$ and, in the absence of numbers or names of years, present the challenge ${ }^{446}$ of dating them or at least of putting those of Kanesh in an acceptable chronological sequence, which thus far is only clear for the sequences Inar - Waršuma and Pithana - Anitto.

\subsection{REIIGION}

All data on Old Assyrian religion were collected and analyzed in Hirsch 1972, a treatment which can now be updated thanks to new lexts, though the picture drawn remains basically

442 See now Günbattı 2001 and above note 434

443 New were CMK nos. 35, 37, 44, 55, 56, 59, 91, 93, 94a, 95, 100, 101, and 105.

444 See below IV.2.5. 'Nolarizalion' was expressed by staling that the transaction took place "through the hands of " (iqqātê) the ruler, see Bolkan 1957, 45 and Garelli 1963, olf.

445 References in Donbaz $1990 \mathrm{~b}$ and $1996 \mathrm{~b}$ and in N. Ozgüc 1996a, who publishes the seals on these texts and tries to assign them relalive dales. Add kl n/k l: 12'f, a slave sale, [iqgäte] Pittona.

440 Taken up by Forlanini 1995 and N.Özgüc 1996a, cf. also Miller 2001, 82ff., in connection with the evidence on Anum-hirbi of Mamma. 
the same. As already mentioned in paragraph 2.5 we now know more of the oath, e.g. that men had to swear it by the dagger of Assur ${ }^{447}$ and women by what probably is the tambourine (huppum) of lstar, ${ }^{448}$ divine emblems which must have been present in a sacred place, perhaps a cella, called hamrum, which was also designated as "the gate of the god", attested both for Assur and for the karums. ${ }^{449}$ To stress that they speak the truth troders frequently invoke gods to act as witnesses and to punish them "'to watch", nata/um; "to rake notice of", ida' 'um, or "to reject them", nada'um if they lie. In such invocations we usually meet Asššur, in the company of other gods, Amurrum, llabrat, Ištar the Star, Ištar-ZA-AT, and even Nisaba. ${ }^{450}$ Some of these gods can be qualified by an apposition as "your god" or "the god of our father $(s)$ ", i.e. the family god or personal god of the speaker, but we also meet "your/our god(s)" used independently, and in addition "the god of friendship" and "the god of brotherliness". ${ }^{45)}$ The invocations of "the god of the farher $(s)$ ", and occasionally also of "the spirits (etammü) of the ancestors", were discussed by Van de Toorn in the context of his study on family religion. ${ }^{452} \mathrm{~A}$ recently published arbitral arrangement mentions among the irems left behind by a father "golden (figurines of) his gods". 453

Most Assyrian colonies apparently had a shrine or sacred area where Aššr was venerated and where (a statue of him with) his weapon was present, but it is usually only mentioned in connection with the swearing of the oath. An exception is the letter addressed by the colony of Uršu (west of the Euhprates, presumably in the area of Gaziantep) to kārum Kanesh, in which it reported that thieves had entered Ašsur's temple (bêtum) there and had stolen his sacred paraphernalia, among which the sun disc on his breast and his dagger". 454 We

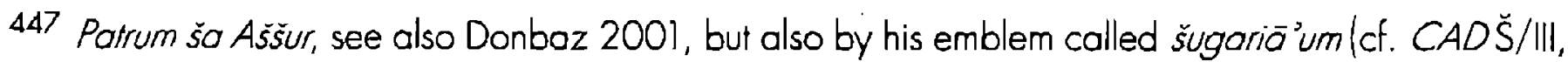
$197, b)$, which also occurs in the dual and is occasionally rendered by the logogram gišKAK-en.

448 See Michel 1997c; also kt 86/k 155:3f., 13f. lštar must be the goddess invoked in kt a/k 244 with the words: "Listen goddess, lady of the oath". Anatolians could also be sent to the water ordeol by their king or judges, see Günbattı 2001.

449 See Matous $1974 \mathrm{~b}$.

$450 \mathrm{Kt}$ 87/k 460:16ff., Ašsur and Nisaba, ki 93/k 198:25ff. (courtesy Michel), "Aššur and llabrar, our $\operatorname{god}(\mathrm{s})(i-l i-n i)$ and the spirit of our father", "Aššur, Amurrum and the god of Kanesh" $(\mathrm{kt} \mathrm{m} / \mathrm{k} 7: 18 \mathrm{~F}$., courtesy Hecker). See for Amurrum now G. Kryszar, RA 100 (2006) 53-56.

451 See Hirsch 1972, 35-37, and some additional references in Donbaz-Veenhof 1985, 137. "The god of friendship" also in kt a/k 339:30 and Prag 1784:9, "the two gods of brotherliness (i-lá a-hu-fim)" in Prag 1 447:11, in all cases in combination with the god Aššur. Aššuritum occurs also, if we read in BIN 6, 99:8f. (with Hirsch 1972, Nachträge 13a, ad S. 22) d A-sur

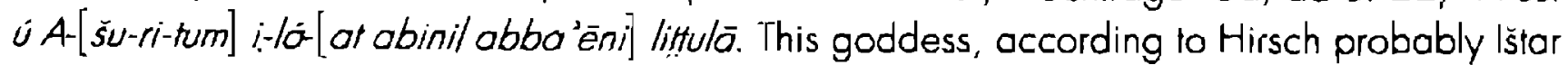
of Assur, is not identical with lstar kakkabum or lšhara (cf. TC 3, 106:5F, votive gifts to lšlar and lšharal.

452 K. van der Toorn, Family Religion in Babylonia, Syria and/srael, Leiden-New York, 1996, 62ff. and 72ff. Note on p. 72 note 33 his proposal to take pirikkum ša Ašsur, by which occosionally oaths were sworn, not as a lion (symboll) or a lighming bolt (biriqqum), but as as word for "shrine".

453 See below in 2.4.2.8; the text has ili sa hurösim sa abiša.

454 SUP 7. discussed in Larsen $1976262 f$. A still unpublished text mentions "a chair in front of Aššur" and a "beaker in front of Šarru-mâtēn". 
would expect such shrines to have been served by Assyrian priests, but there is thus far no evidence for a cult and the presence of a priestly functionary in the karum.

Little is known of "organized religion" in Assur, where many gods were veneroted, 455 but the god Aššur clearly was the dominant deity, with whom the ruler had a special relationship, as also appears from the promise in royal letters to pray (karäbum) to Ašsur for the addressees. ${ }^{456}$ Traders are encouraged to come to Assur to visit their family and to pay homage to the god Aššr (the texts speak of "to see his eye",. Numerous (eldest?) doughters of prominent traders became priestesses (NIN.DINGIR = ugbabium) presumably of Ašsur, but the texts tell us nothing of their cultic duties, and they can perhaps be compored with the naditus in Babylonia, who did not belong to the cultic personnel, but were a kind of votaries living near the temple. Dercksen in his "The silver of the gods" 457 analyzed how the temples received votive offerings and (using them?) participated in the trade by making funds (called ikribü) available as long-term investments to traders. He assumes that such a trader's "covert obligation to present valuable offerings to the god as a token of gratitude confirmed his status as a respectable member of the community. ${ }^{458}$ This system implies that the temples were rich, but in the absence of temple archives we lack data, we do not even have a contract by which a temple made capital available to a trader, either as a commercial loan or in the framework of a commercial partnership. ${ }^{459}$ There is some evidence that packets with silver and gold could be stored in temples (especially in that of Ašsur), but they were marked with the names of their owners, who apparently reserved the right to take them out again. ${ }^{460}$ The archival texts reveal that a few priests (called kumrum) played a role in the trade, such as Mannuba, priest of Ašsur, who received amounts of silver apparently earned in Anatolia. ${ }^{461}$ But this may only mean that he, like other wealthy citizens of Assur, indeed like the rulers themselves, took part in the commerce by entrusting merchandise bought in Assur to traders, who would sell it for him in Anatolia. In CCT 6, 20b rev.:11'ff. Ištar-pilah, priest of Aššur, owes 35 shekels of silver to Püšu-kēn. More interesting is that according to TC 3, 129:9' ff. a trader in Assur several times made purchases "in the house of the priest (kumrum) of Suen", and that eponym no. 91, Eläli, was a sangüm, a title which in contemporary Babylonia denotes the administrative head of a temple. ${ }^{462}$ The former

455 Ikribü are mentioned of the gods Adad, Aššur, Bêlum, llabrat, lšhara, Ninkorrak, Sinn, Šamaš, Šarra-mätēn, and Tošmētum, see Dercksen 1998. Kryszat 2003 publishes a very damaged letter by a woman addresses "to my mistress Tašmeetum".

450 The ruler was Asšsur's "sleward" (išsiakkum), but he was not yet designated as the god's SANGA, as was later the case. Which god or temple the sangum Eläli, year eponym 91, served is unknown.

457 Dercksen 1998, with on $95 \mathrm{ff}$. a list of all gods (temples) attested.

458 Votive gilts, not only in the shape of ornaments (notably sun disks and moons), but also little figurines or staluettes (mazzözum), see Dercksen 1998, 84f.

459 As we know them from Babylonia, cf. the analysis in Veenhot 2004a.

460 See Dercksen 1998, 86ff., and Hirsch 1972, 49f. on silver and gold belonging or owed to the god Adad, which is an important issue in the correspondence of Sobasia.

461 One pound of silver in TC 3, 203:6 and 15 shekels, payment for a textile, in CCT 6, 27b:4.

462 Nole that eponym no. 24, Iddin-Aššur, was "the son of the priest". 
reference suggests that this priest in Assur belonged to the owners of "houses", where traders could purchase their merchandise, ${ }^{463}$ and a limum-eponym, as head of the Cily Hall, must have been involved in financial administration and the trade. Unfortunately, we do not know whether both acted for, in the nome of, or with funds of the temple (that of the moongod Suen anyhow was not very prominent), or simply as rich citizens.

\subsection{SOCIETY}

The texts acquaint us with a variely of social features, some of which have already been mentioned above under "institutions" and "law". Most noteworthy are data on the family houses, women, children and slaves. See for people who hired themselves out as personnel (suhärum), especially to travel with the caravans as regular transporter or "harnessor" (kasșārum) or as "packer" or donkey driver (sāridumi, Veenhof 1994b.

\subsubsection{Houses}

Houses were important and successful traders usually had two of them, one in Assur and one in a karum, as we know from occasional references and especially from testaments, in which the properly is divided. ${ }^{464}$ Houses in Assur could be extremely expensive (the highest price mentioned is sixteen pounds of silver for one with a surface of ca. $\left.100 \mathrm{~m}^{2}\right)$ and they apparently were a mark of prestige la woman complains that her family, contrary to others, had not yet built a new house) and were perhaps also considered a good investment. A number of letters mention the sale and purchase of houses, in several cases by people in financial problems who had to satisfy their debtors. Valuable houses could be pledged and we know that unpaid debts to the City Hall or to private creditors could lead to the houses being sealed or "seized" and to appropriation of their contents (especially bronze objects) as security or payment. ${ }^{465}$ The loss of one's paternal house, probably with the tombs of the ancestors, was difficult to accept and from one letter ${ }^{\Delta b 0}$ we learn that at a certain time, in Assur, an official measure had been taken to facilitale its redemption: "Aššu has now had mercy with his city. A man whose house has been sold has to pay \{only\} half of the price of his house to (be allowed to) move into it (again). For the remainder (of its price $=$ his debt) terms in three instalments have been set". Unfortunately, the excavations in Assur have not yel revealed what such a prestigious house looked like, but we have two deeds of sale of houses in Assur of the Later Old Assyrian Period. ${ }^{467}$

463 He must have been a well-known man, since his title was sufficient to identify him, and he may have been the father of "Dadāya, son of the priest of Suen", who occurs several times, especially as transponter.

$\triangle 64$ See for houses and real estare, Michel $1997 \mathrm{~b}$.

${ }^{405}$ See Veenhof 1999b, part l, and Dercksen 2004a, 73f.

406 Analyzed in Veenhof 1999b.

467 Gelb-Soltberger 1957 and Donbaz, NABU 2001/56, where ir measures only ca. $18 \mathrm{~m}^{2}$. 


\subsubsection{Children}

Children (šerrum, collective șutrum ${ }^{408}$ were important, because they could take over their father's "firm", care for their parents in old age, and ultimalely bury them and provide what the dead needed. But they might also be pledged or even sold when their father could not pay his debts. ${ }^{469}$ Two marriage contracts (ICK I, 3 and Prag 1 490) contain stipulations on the possibility to take a second(ary) wife or use a slave-girl, if the main wife does not bear children within two or three years. Several letters tell us about children raised in Assur, occasionally by their grandparents, ${ }^{470}$ while their father \{or parents\} was in Anatolio. ${ }^{47}$ Püsuu-kēn's son, according to CCT 4, be, together with other boys was educated as scribe. Girls were married off by their parents, at times apparently on the basis of earlier promises, when they were of age ${ }^{472}$ and could then travel to Anarolia. There are also several cases where such a promise or betrothal, presumably due to the problems and strains in a society of traders - many of whom left Assur, travelled much and lived abroad - was not kept and a verdict was passed to dissolve the agreement. It might entail the poyment of a penally by the party who breached the contract and allowed the parenl of a girl to marry her now off to whomever he wished. ${ }^{473}$ There are also a relatively (compared with the number of marriage contracts preserved) big number of divorces, which may be explained by the long seporation between husband and wite and by the fact that Assyrian traders who had married Anatolian wives in a kärum, when they were to return to Assur could divorce them if a fair financial arrangement was made. Contracts of divorce may contain stipulations on who will get the children and on what conditions. ${ }^{474}$ The importance of childbirth is underlined by the fact that of the few Old Assyrian incantations found, two are against Lamoštum, the female demon who aimed at pregnant women and babies, and one is to facilitate birth. ${ }^{475}$

$\triangle 68$ See on all aspects Michel 1997d.

409 That El 8:19f. stipulates the right of an Anatolian father to sell his adopted son if he gets poor, could be a reflex of an Assyrian rule.

470 Aššur-idi raised his son's children in Assur, presumably ofter the death of their mother. He was concerned about their well-being, complains about their behovior and how they lett him to join their father, and slates how much he spent to feed them, see OAA1, 9:50ff., 14: 12ff., and 22:24ff. A parner of Assurnādō in Assur in OAA1, 94:4ff. also claims payment of expenses he made for his children.

47) That several texts mention tarbitum, "the cost of upbringing", moy also be connected with the situation of young children, raised by others, but the term is also used for the compensation for a divorced wife (or her family), who raised a child which its tather eventually rook along, so in ICK 1, 32:20ff.

472 See Balkan 1984 and Cecen 1995,56 no. 4: 5ff. The phrase "when they are placed in the lap of the god Assur" is taken by some to designate their dedication to the deity, in order to become his priestesses, while others consider it a rite to mark the reaching of puberty, as a condition for being married off; see CADS 388, c, l' and Michel 1997d, 103.

473 See Veenhol 2003d, 451 and Cecen 1995, 56f. nos. 4 and 6.

474 In El 6 the wite keeps her daughrer and the husband con obtain his son after a payment, in El 270 the husband keeps the three children after he has poid his wite the divorce money (ēzibnum).

475 See Michel $1997 \mathrm{c}$ and $2004 a$. 


\subsubsection{Women}

More evidence exists on women, both in legal documents dealing with marriage, divorce and inheritance, and in the many letters written by or 10 women. ${ }^{470}$ They concern still unmarried daughters, daughters who did not marry because they became ugbabiu-priestesses in Assur, women in Assur married to traders who for long periods lived in Anatolia, women living with their (frequently troveling) husbands in Anatolia, and those who had become widows there, some of which remarried, also with Anatolian husbands. Women in Assur, whose husbands had settled in Anatolia, were their valuable partners in taking care of the household, producing lextiles he could sell in Anatolia, and guarding his interests in contacts with the family and with authorities, especially those of the City Hall, who could pressure them for their husband's unpaid debis. But wives living in Anatolia also played an important role, especially when their husband travelled around and they had to guard the house with it contents, especially merchandise and commercial records. While women who lived alone in Assur are well known from the letters they wrote to their husbands, some of those in Anatolia are documented in records that reflect their own, small business transactions. A good example is Lamassatum, the wife of the trader Elamma (whose archive was excavaled in 1991/92), according to a description of what she left behind (kt 91/k 421, nearly ren minas of silver, partly in debt-claims of her husband, textiles, ten slaves) a wellto-do woman. She appears as a creditor for modest amounts of silver, copper and wool, and in one of them ( $k t 91 / k$ 146:21f.) the debtor had to pay back using her own weighing stone. She also assured herself of the services of a man whom she gave a be 'ulatu-loan, bought a slave-girl and sold a slave, and she several times sent amounts of silver to her daughter Ummi-lshhara, who was a ugbabru-priestess in Assur. Some of the relevant records are dated to the period when her husband was still alive, others reflect her activities when she was a widow (who survived her husband a few years), when she was also involved in legal matters related to her husband's inheritance and in problems of some relatives living in Anatolia. Such women apparently had private property and funds at their disposal, which could derive from what they had inherited, from their dowry and marriage gift (iddinü), and from income they had generated by producing textiles or doing some business I granting small loans and credit). It does not surprise that they could also make a testament (simtum), by means of which they bequeathed their property to their sons and daughters. While we know that of lamassatum only by references to and quotations from it, that of her close relative Ištar-lamassi ( $k t 91 / k$ 453), was found in the archive of Elmma. ${ }^{477}$

The case of this Istar-lamassi (which I analyzed in Veenhof 2007a) sheds some light on what an Assyrian woman in Anatolia might experience. After the death of her Assyrion husband, whom she bore two sons and a daughter, she was for ten years married to a second, Anatolian husband. After her death problems arose in connection with the implementation of her

470 See CMK ch. 7, with more than hundred letters of women in an annotated translation. See for a new, dramatic letter, Veenhof 2007b.

477 See Veenhof $2003 c, \$ 6.2$ 
testament, which generated a file of ten records, which provide us with some rare pieces of information. Since both of lštar-lamassi's sons died at the same time, her second husband paid for their burial and funerary rites; the texts mention their "bewailing" (bikitum\} and what is called "the removal her chair" (kussiam tabbu 'um) and there were expenses for a meal. He had to be refunded from what the sons would have inherited, apparently because her funeral would have been their filial duty. The settling of the accounts required written specifications of what had been paid and was supervisied by lštar-lamassi's close relatives, notably the above mentioned Lamssalum and her son, and the oulcome was reported in writing to lštar-lamassi's only surviving heir, her doughter who lived in Assur as ugbabtu-priestess.

The most notable feature relating to women was that Assyrian traders who worked or lived abroad could have two wives, one in Assur and one in "the colonies", only one of which could have the formal status of "married wife" [ašsutum\}, while the other, who could be an Assyrian or Anatolian girl and was married on the basis of a formal contract, was called amtum, "maid". This type of bigamy has recently be analyzed in detail in Michel 2006. The status of amtum probably had implication for the hereditary rights of the children and perhaps also for the conditions for a divorce, if the Assyrian trader eventually wished to return to Assur. Such legal complications of course generated a variely of stipulations laid down in marriage contracts. ${ }^{478}$

In general the wives of the frequently absent traders acquired more responsibilities than was the rule in ancient Mesopotamia, which may explain that they could divorce on equal lerms with their husbands. The latter in their last wills provided for them by giving them a share in the inheritance, which usually comprised money (occasionally in the form of debt-claims) and a house, and at times the sons were obliged to give them a life-long annual allowance. In a recently published testament a trader, in order to make it very clear that his wife will have full disposal of what she inherits, stipulales that she "is father and mother of her share in the silver", a clause which is a precursor of (and was perhaps the inspiration for) similar ones used several centuries later in Nuzi and Emor. ${ }^{479}$ Thanks to these provisions and of what was mentioned above in connection with lamssatum, OA women had their own possessions (money, slaves, jewels, etc.) and this allowed some of them to live independently in the house their husband had left to them, but there are also cases where the (eldesti son, who inherits the family house, has to take care of his widowed mother and her burial. ${ }^{480}$ Fathers usually took care in their testaments to provide well for their widows and especially for unmarried daughters, who had become priestess (ugbabium) and had to be able to live independently. In a recently published record of an arbitral hereditary arrangement, the daughter of an Assyrian, who was a priestess, is granted the right to live with and be provided for in Kanesh by her sister and the latter's Anatolian husband $H_{\text {. }}$, who had inherited the paternal house, "just like (as if she were) his mother and wife". If her rights are violated she will receive from H. "the golden (figurines of the) gods of her tather", her jewelery, one servant, a slave-girl, a donkey,

478 See the literature on "marrioge", mentioned obove in $\$ 2.5$, and Veenhof $2003 \mathrm{c}, \S 5.1$.

479 See for the lestament, Albayrak 2000, with the comments in Michel $2000 \mathrm{~b}$.

480 See for these lost aspects, Veenhof 1997a, 137-145. 
and all her belongings, and leave for her brothers. ${ }^{481}$ But wives of traders could also suffer from the consequences of their husbands' commercial failures, ${ }^{482}$ when they had to help them by "scraping together" (/aqätum) all possessions they had in order pay his debts or to pledge or sell them, or worse, when the house itself was sealed or pledged for their husbands' debts. Pledging wives was rare, but they could be "seized", taken as distress by a creditor, a danger that one might try to prevent by stipulations in the marriage contract. ${ }^{483}$ There is a verdict of kărum Wahšušana that stipulates that an Assyrian's wife, "retained" (presumably as pledge for his debis) somewhere in Anatolia, has to be provided for by him by means of a monthly allowance of copper that would allow her to buy food, oil and fire-wood. No wonder that we hove several letters in which women, in Assur or Anatolia, in deep sorrow or with indignation, complain about their plight and the fact that they live in "an empty house" ${ }^{484}$

In view of the important role of women in the Old Assyrian society it is surprising that we have very few seal impressions by women, and seals inscribed with the name of their female owner are almost non-existent. There is a seal with the inscription "Rubātum, daughter of Amur-ili" ( $N$. Özgüc 2006, 105, CS 357 on $\mathrm{kt} \mathrm{n} / \mathrm{k} 1700$ ), but it is not used by her, but by a certain Usānum, who must have acquired it somehow. The lack of seal impressions is in part explained by the fact that women do not occur as witnesses, who had to seal commercial contracts and judicial records. Women would have to seal contracts and judicial records if they were personally involved as party, as proof of their agreement with a transaction or their acceptance of a liability, but such records are not numerous and their sealed envelopes are frequently missing. We meet several Assyrian women as creditors, who give out small loans or extend credit, but creditors never seal, and Assyrian women as debtors are extremely rare. That women did own seals is clear from the case of the above mentioned Istar-lamassi, who in her testament ( $k+91 / k$ 453) assigns her seal to her daughter in Assur, who may have needed it as ugbabiu-prietess, that is an unmarried, economically independent womon. But other women also owned seals and we have and know some from the few preserved envelopes of letters they wrote, which always carry the seal of the sender/writer, e.g. that of lštar-bašti, impressed on the envelope ICK 1, 28A (see KKS p. 185, seal 130). There are a few records that in listing the seal impressions they carry (KIS̆IB PN) mention also a woman's seal, but this does not guaranty that her seal was indeed impressed on the envelope. The envelope of KKS 15, according to which an Assyrian couple owes a silver debt, lists five seal impressions,

481 Albayrak 2004. The clauses are in Assyrian: kima ummisu ša H. ${ }^{17}$ y a ăsifisu ušbat ${ }^{18}$ aklat u

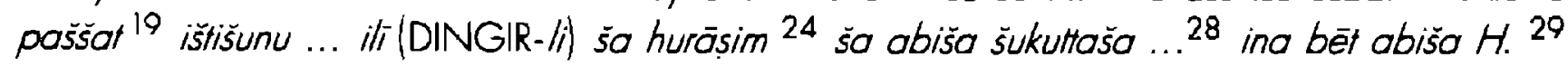
iddašsimma așsër ahhēša 30 tușsi. This is a document from the younger level lb and it reflects the now closer association between Assyrians and Anatolians, but this does not mean that the provisions meant to protect the daughter, who was a priestess, were only a later creation.

482 See in general Michel $2003 \mathrm{ca}$, "Les femmes et les deftes".

483 See e.g. the contracts Veenhof 1998b, nos. Ib and 1c. El no. 2 forbids the husband to sell or pledge (urrubum) his wife, presumably a secondary wife or concubine.

484 See CMK Ch. 7 and also Michel 1998d, on "les malheurs de Kunnaniya". See for very emotional letters about the estrangement between a man in Assur and his wife in Kanesh, Veenhof 2006a, and Larsen 2001 on the emotions expressed in such letters. 
including KIŠiB Istar-lamassi, but the envelope carries only four different impressions, three of the witnesses and the remaining one must be that of the husband. By impressing his seal his wife was made liable as co-debtor and this was expressed by stating that her seal was present, though she had not actually sealed. This suggests that in more cases the sealing of a record by the husbond also bound his wite if she was mentioned as co-debtor and this also happened when Anatolian couples figure as debtors (see Veenhof 2001, 148ff., IV.I, on joint liability). A different case is that of $E l 11$, a witnessed record in which the children of Püsu-kēn, in the wake of the division of their father's inheritance, renounce mutual claims. The record, listing the seal impressions, also mentions (line 9), "the seal of Ahaha, doughter of Püsu-kèn". While we cannot check its presence, because the record is a copy of an envelope, it is unlikely that her seal was actually impressed, since she lived in Assur as ugbabru-priestess. And this is proved by the foct that the record also mentions (line 5) the seal of iddin-abum, son of Aššr -mālik and at the end states that he represented Ahaha (kima A. izziz) in the procedure. The words "the seal of PN" apparently may suffice to fix an absent person's liability.

\subsubsection{Slaves}

Old Assyrian people owned slaves, both in Anatolia and in Assur. ${ }^{485}$ In Anatolia they could acquire them by purchase or by foreclosure of persons pledged by defaulting debtors, because loans granted to Anatolians were frequently secured by pledging the debtor's wite and children. ${ }^{480}$ But Assyrian children too, pledged and ultimately sold for their father's debts, could become slaves in Assur, where we even have a reference (kı 93/k 76:32, courtesy Michell) to a man designated as "slave of the City Hall". How many slaves there were and how they may have been employed, when not serving in a family household, is unknown, but the traders were rich and slaves relatively cheap, in particular in Anatolia. They appear in several testaments as "slaves and slave-girls" and as the collective subrum, ${ }^{487}$ and there are quite a number of slave-sales and references to them in letters. ${ }^{488}$ Note that even Lamassatum, the widow of the trader Elamma, owned five slaves and five slave-girls (kt $91 / \mathrm{k} 421: 23 \mathrm{ff}$.$) , and that in the division worked out in$

485 We lack a systematic investigation of Old Assyrian slavery. See for slave sales Kienast 1984, with Exkurs 2 and 3 on accurrences outside sale contracts, and for new contracts Sever 1998a and Boyram-Cecen 1996, and for on overview Veenhof 2003c, § 4.2, with § 7.1.4 on redemption. In Exkurs 2, Kienast in 100 many cases assumes a meaning "servant, subject", though this meaning might oblain in the unique occurrence of a "wardum of the polace", in KTS 55b:2f, since in the Mesopotamian view a citizen was a wardum of his king.

480 In El 188 on Anatolian family, handed over " "given", to an Assyrian creditor by the local ruler, is redeemed by their guarantor, an Anatalian official.

487 In Garelli 1966, 134 lines 12, 20, 41; Prag 1 705:3; VS 26, 132:II'ff., "the rest of the subrum. two slave-girls, a boy and a girl, I leff to P."; and CCT 3, 27b:4ff., "I had six suhouru brought to you ... rake action, sell my subrum ...".

488 See also the short note TC 3,183, which mentions wool, textiles and sheep. "The price of four slave-girls and nine youngsters" (sutium). 
El 287 one son will obtain one slave-girl as his concubine(?) and three other sons each one of the slave-girls with whom they have had sexual contacts (lamadum), logether with their offspring \{lillidum\}. ${ }^{489}$ Slaves can be claimed or seized as security for a debt, ${ }^{490}$ and when slaves alone are pledged (erubbatum), we may assume that they served as possessory, antichretic pledges, who "were held by the silver (owed)" (isti kaspim ukiallü) and had to work off the interest on the debt. ${ }^{491}$ We have to assume that slaves, in particular in Assur, also worked as servants, who could be used to ship goods ${ }^{492}$ and even be hired out to work as caravan personnel, in which case their owner received the traditional interest-free loan (be'ulätum) that counted as wages. ${ }^{493} \mathrm{~A}$ special investigation on slavery in the $O A$ sources would be very welcome.

\subsection{LANGUAGE AND WRTING}

Knowledge of the somewhat archaic Old Assyrian dialect, its grammar and lexicon, and especially of the idiom and the commercial jargon have presented problems and make many assyriologists still feel ill at ease with Old Assyrian. ${ }^{494}$ This is in part due to the use of a limited syllabary and a series of orthographic rules that exhibit a measure of variation, which makes it at times difficult to reconstruct the underlying phonetic realities. This is at times compounded by the fact that not all writers were professional scribes, so that individual idiosyncrasies occur. Old Assyrian grammar is well presented in K. Hecker's Grammatik der Kültepe-Texte ${ }^{495}$ of 1968 (GKT), although his consistent use of syllabic transliterations instead of bound transcriptions and the lack of verbal paradigms present problems. After so many years and which so many new sources additions and correclions are of course possible. ${ }^{496}$

489 See for slaves as part of a person's assets also Kienast 1984, 96 no. $2 \mathrm{e}$.

490 The verbs used are qătam sakōnum ina and kattu'um; note TC 3, 60:18ff., "Since he has no slave-girl or slave in Kanesh ... take his slave-girl and slave (over there) as security (karö'um) and so collect the silver". In Assur the eponym as head of the Ciry Hall could do this with a debtor's slaves, see Kienast 1984, 98f. nos. 2s-2v.

491 See Veenhof 2001, 132ff.

492 See the examples in Kienast 1984, 91 nos. $2 \mathrm{~h}$ and $2 \mathrm{i}$.

493 See Kienast 1984, 93 no. $3 \mathrm{~g}$.

494 See Reiner 2001, "Who is afraid of Old Assyrian?".

495 The tille is correct in so far as the grammar is based on the texts found at Kültepe. Since numerous texts from which data are used originale from Assur and there is no reason to assume a difference between the language spoken in Assur and in kärum Kanesh, the fitle could simply have been "Old Assyrian Grammar". In that case, however, the data from the older royal inscriptions should have been treated separately because of their peculiarities (see above nole 14).

496 See AOAT 492f., Index, 3. Grammatical Features; Hirsch 1972 (review of GKT), 2001 (use of ventive); Hecker 2000 ( $i$ in construct state), 200 la (dental explosives, use of DA and TA): Matouš 1972 (OA dialect); Michel 1992 and 1998 (fractions and numbers); Reiner 2001 (general); Veenhof 1986 c (auxiliary verbs). 
Old Assyrian writing uses a relatively modest number of cuneiform signs and a limited number of logograms, which makes its decipherment easy, but the limitations of the syllabary and the not always strictly applied orthographic conventions, require a well considered choice between possible alternative phonetic values and readings, on the basis of grammatical and lexicographical facts, for reconstructing the phonetic and morphological facts. E.g., TU is not used and DU can render $/ d u /, / \mathrm{tu} /$, and $/ \mathrm{h} /$, the distinction between le/ and /i/ is poor, doubled consonants and in most cases also long vowels are not indicated, the rules for marking syllable boundaries (broken spellings) and "aleph-signs" are not very strict, while the Assyrian "vowel harmony" (which affects short $a$ in open syllables) also complicates the picture. Convincing solutions and interpretations depend on a systematic approach, which also pays careful attention to syntactic features, as is shown by several recent studies of Kouwenberg. ${ }^{497}$

OA writing also exhibits certain developments over time and larsen 1976, 114 with note 109 (dealing with the early royal inscriptions), already showed that some of the typical Old Assyrian writing conventions (notably in the choice of syllabograms) are the result of a development, which seems to have been completed only during the reign of Erišum I. Veenhof 2003, 12f., in analyzing the spelling variants in the manuscripts of the Kültepe eponym list (KEL) could show that the oldest part of the list (covering the tirst ca. 60 eponyms), as preserved in KEL $A$, was based on a manuscript in an orthography which was "conservative" in its preference for certain syllabograms and logograms, e.g. in using $A B_{1}, L A_{1}, M_{1}$ (extremely rare inslead of ME), $A$-šur, ${ }^{\mathrm{d} E N}$.ZU and PUZUR ${ }_{4}$. In addition, it now becomes possible to distinguish paleographically early texts, such as the oldest dated (to eponymy year 47) contract CCT I 10a (El no. 97), with its envelope CCT 6, 23c (see now Kryszat 2001, 263\%, and Veenhof 2003, 39, no. 47al.

The OA lexicon is well covered in AHW and especially in CAD, which could use transliterations of the "old" texts made by Julius lewy and for its first volumes the expertise of Landsberger. Several specialists in Old Assyrian (Kienast, Hirsch, Larsen, Veenhof) later contributed transliterations, wrote entries or acted as consultants of the CAD. But here too corrections and additions are possible from new sources and new interpretations, for which one may consult the lexical indexes added to most new text editions and to several monographs. ${ }^{498}$ Together they reveal that Old Assyrian comprises quite a number of words not attested in other periods of the Akkadian language. Some reflect the peculiarities of the Old Assyrian dialect, others are the names of a variety of products, including rextiles and lood-stuffs, conditioned by the Anatolian setting of the transactions, others again belong to

497 Kouwenberg 2003 (glottalized consonants), 2004a (first weak verbs), 2004b (N-stem), also Edzard 2001 (syllable closing aleph). Kouwwenberg's study of the stative (OrNS 69 [2000] 21-71) and his disserlation, Gemination in the Akkadion Verb (Assen 1997), also pay much altention to Old Assyrion, as do his recent studies on "Ventive, Dative and Allatives in Old Babylonion" (ZA92 [2002] 200-240), and "Reflections on the Gt-stem in Akkodian" (ZA 95 [2005] 77-103).

498 See especially those added to Michel CMK, Dercksen 1996 (copper made), and 20040 (institutions). 
the commercial jargon. The latter comprises both a fair amount of idiom and many technical terms in the sphere of administration, law, trade and finance, in which the Assyrian speakers and scribes demonstrated a measure of linguistic creativity by introducing new words or using derivatives from ar times well-known verbal or nominal rools in specialized, new meanings. The development must have been due to the fact that they had to describe in detail (perhaps the first to do so) their commercial transactions and financial operations, both in the letters exchanged between Assur and Anatolia and in their administrative and judicial records. The study of the texts inevitably also resulted in a variety of articles and notes with lexical observations, dealing with idiom, technical terminology (mentioned above under II.2.4 and 5), and material culture, and new texts keep acquainting us with interesting new lexical data. Only the more important ones found in the recent literalure are mentioned here, ${ }^{499}$ but nearly all are digested in "Register Assyriologie. 2. Wörter", which appears regularly in $A F O$.

To gain a better insight into the lexical aspects of Old Assyrian, Kogan (2007), in a pioneering article, carried out a lexical comparison between Old Babyonian and Old Assyrian, in which he distinguished lexemes attested exclusively or pre-dominantly in Assyrian, common Akkadian lexemes with special prominence in Assyrian, common Akkadian lexemes with specific meanings in Assyrian, and derived stems unattested or having a different meaning in Babylonian, and in addition treats a number of "minor lexical features" and "fixed expressions". He considers it important that "some terms of the Old Assyrian lexicon, while apparently of commercial nature, survived into Middle and Neo-Assyrian periods", since this "testifies to their being deeply rooted in the Assyrian dialectal vocabulary".

Linguistic analysis of the Old Assyrian personal names also contributes to the understanding of the language and the lexicon. Most personal names exhibit a mixed logographic-syllabic writing, which is generally understandable, but the orthography and the limited syllabic repertoire may cause problems. ${ }^{500}$ Various spellings reflect the actual pronunciation, which is linguistically interesting and may provide clues for rules of contraction, vowel elision and stress. ${ }^{501}$

499 Balkan 1957,9-30 (on the language of the Anum-hirbi letter), 1967 (idiom), 1969 (wagons and ploughs), 1986 (ushi'um), Bayram 1990 (seasonal due dates), Dercksen 1998 (ikribü), 1999 (terms for lypes of loans and credit), 2004b (arhälum, unuššum, tuzinnum, ubadinnum). Donbaz 1989 (terms for bread), Donbaz-Veenhof 1985 (nabritum, nam 'udum, sulusāäum, ubädinnum), Hecker 1978 (family relationship), Hoffner 1996 (kumrum, epattum), Larsen 1967 (slander), 1977o (naruqqum, šipkātum, šelu'utum), Lion-Michel 2001 (erbi râmtim, shrimpsi, Michel 1992b (šepum, ellutum). 1997a (drink and food), 1997c (huppum), 200la (husārum, lapis lazuli), 2003b (perdum, mule), Sturm 1995a (kaspum ammurum), Veenhof 1987a (ba/ătum, muätum), 1989 (perdum, sinahilum, sikkātum), 1995a (naruāum, kuānum, awōtum), 1995c (ișunum), 1997a, 150 (iddinü), 1997b (tamkārum, wäbil fuppim), 1999b (ufuptum, isittum), 2003b (mahirum, hāmum).

500 Does iDi render idi, "my arm, supporn", iddi, "he deposited", ide, "he knows", or iddin, "he gave"?

501 Note spellings like A-Di-lá-at for Adad-ellat, also written dM-lLLAT; Śä-mah for Salim-ahum Inole the remarks in Balkan 1974, 37 ad IA, where also the forms Šalimmuh and Šalmuh, used by an Anatolian with this Assyrian name, are mentioned); S̆Ė-BA-lim for Šēp-alim; TA-BE-A-šur for Tăb-pi-Ǎšsur, etc. 


\subsection{SEALS AND SEALINGS}

Reconstruction of the commercial activities is impossible without knowing "who is who", which requires collections of names and of the numerous seal impressions. Since most seals have no inscription, they have to be identified from their occurrence on inscribed envelopes. While this is simple with letter envelopes, where the seal is that of its writer, those on legal documents present more problems. ${ }^{502}$ The accompanying text that lists them ("Seal of A, son of B", etc.) is not a real biscript ("Siegelvermerk") as on Old Babylonian legal documents and the order of the seal impressions does not always match that of the text. ${ }^{503}$ By comparison and elimination many owners/users can be identified, ${ }^{504}$ and several articles try to do this for particular seals. ${ }^{505}$ Already in 1927 the standard for text publications was set by A.T. Clay with BIN 4, which includes indexes of names and photographs of seal impressions. In his wake text editions with drawings or photos of seals gradually became the norm, ${ }^{506}$ and in CCT 6 (of 1975) D. Collon made up for this omission in earlier volumes of the British Museum series. Some recent editions (e.g. Kienast ATHE) present the seal impressions by means of photographs, but good drawings (as in CTMMA 1, KKS and VS 26) in general are more helpful. Many seal impressions on excavated envelopes are shown in the excavation report of 1953 and in monographs and articles by Nimet Özgüc, ${ }^{507}$ but it is unfortunate that the first editions of officially excavated texts (AKT 1-3 and TPAK) do not contain them. The publication of all sealed (and inscribed) bullae in Özgüc-Tunca 2001, with information on their archival provenience, is a valuable addition, but for a prosopographic purpose the seal impressions have to be studied in combination with the lexts from the same archives, which will allow more identifications. ${ }^{508} \mathrm{~N}$. Özgüc 1965a, 1968, 2006 are valuable publications and descriptions of large numbers of seals, bur most of the inscribed envelopes on which they figure unfortunately are still unopened and unpublished, so that the owners/users of many seals remain unknown and in many cases we cannot date the seal impressions more accurately or connect the quality and iconography of a seal with the status and role played by the person who owned it. Still,

502 Apart from the fact that the user of a seal is not always its owner, and occasionally the inscription on an inherited seal was not (immediately) adapted, see Teissier 1994, ch. 0 . The laputto um official Hupitum on the envelope of a letter written by him, used the inscribed seal of another laputtöum (his predecessor?). Ṡu-Anum, son of Amur-jit, as shown on Özgüc 2003, 292, ill. 341, cf. Dercksen 2004a, 67f. Note also the use of the seal of the issiakkum Siludu by o later namesake, Silulu, son of Uku, mentioned below in chapter III.1.2.

503 See the observations in Veenhof 1987c, and for some examples Teissier 1994, 12.

504 See for the method used VS 20,54F.

505 Garelli 1993. Hirsch 1971, Larsen 1977b (seal use), Larsen-Moller 1991. Matous 1974a, 1977. 1982a, Sturm 1999a. Waetzold 1990. See also N. Ozgüc 1996a, and 1996b (on the seal of Adad-ellat), and Veenhof 1993, 050 with pl. 128 (seal of the City Hall in Assur).

500 Texts with seal impressions in Prague were even published in o separale volume, KKS.

507 See Özgüc 1953a \{report on the excovotions of 1949) pl. LIX-LXV and Özgüc 2003, 282-311. N. Ozgüc 1965a, 1908 and 2006, and her many articles listed in Michel 2003c,191f.

508 Larsen in OAA I, XXIXY. shows the seals of four main persons of the Aššur-nádá archive. 
N. Özgüc 2006, which publishes and analyzes more than 600 seal impressions, mainly from archives excavaled in 1951 ( $k t d / k ; 43$ rexts of the Anatolian Peruwa), and 1962 (kt $n / k$, mainly between numbers 1700 and 2093; the archive of Ușur-ša-lštar) is a step forward thanks to the efforts of $A$. Karaduman, who read the seal inscriptions and also identified a few dozen of their owners/users from the rexts written on the envelopes. For the time being, alongside Özgüc-Tunca 2001, Teissier 1994, with drawings of 677 seals, lisls of their occurrences on texts, and indexes of names, is the best tool for the epigraphist.

Texts from kōrum Kanesh are not only a rich source of seal impressions, they also contain a lot of data on seals and their use. They inform us on the stones they were made of, 509 how they were inherited and transferred, and how they were used. Išlar-lamassi in her testament (kt 91/ 453:11f.) assigned her lapis-lazuli seal to her daughter, a priestess in Assur, and in a conflict between two brothers aboul the inheritance of their father, the latter's lapis-lazuli seal, given to one of them in order to deliver it to his sister in Assur, plays an important role (Hecker 2004, 291f.). Seals were valuable and a seal in wrong hands was dangerous, as is clear from the existence from the Old Babylonian period of a few records in which the loss of somebody's seal is publicly announced. Transfer of a seal was a formal act and CCT 5 , 9a:26f. contains the testimony on how a man on his deathbed "loosened his seal from his girdle and gave it to me" in the presence of two witnesses. 510 CTMMA 1, 84:50ff. mentions that a man's strong-room contained "one seal of $I$., son of A, which, while he was still alive, four principals put under seal and entrusled to me". 511

Seals were impressed for a variely of purposes and the general aspects of sealing were first discussed in Larsen 1977. During the level II period all seal impressions are on the clay envelopes in which the tablets were encased; sealing of tablets begins during the level $\mathrm{lb}$ period. Those on envelopes of letters identify their writers and those on the envelopes of legal documents were applied by parties, witnesses and others who assumed an obligation or confirmed the correctness of statements made, verdicts pronounced, or facts established. Encasing such a document in a sealed envelope turned it into what was called truppum harmum, ${ }^{512}$ a valid, sealed record with evidentiany value, see Larsen 1977. The corresponding verb haramum, "to encase in an envelope, to turn into a valid record", is very frequent and used in abbreviated formulations, such as šibe harāmum, "to draw up valid deposition of the testimony of witnesses", short for tuppam ša s̈̈be harämum.

509 See e.g. Michel 200ia, 354ff. on seals of lapis lazuli. Most seals were made of haematite, cf. $\mathrm{kl} \mathrm{c/k} \mathrm{441:3,kunukkam} \mathrm{sa} \mathrm{saduānim.}$

510 kunukkusu $H{ }^{27}$ ina qabliš iplurma ${ }^{28}$ iddinam.

511 On the assumption mat kunukkum indeed means a cylinder seal and not a sealed record, as is occasionally the case in OA, of. KTS 2, 45:4f., PN kunuk rubä'im ilqe akkum, "PN obtained for you a document sealed by the ruler".

512 Similar to $O B$ ermum (CADE 302, s.v., 1,a), but also written hirmum, CT 48, 15:12, ruppum sehšum hirmum.

513 In OA one could say that witnesses who had impressed their seals on a record "are lying on the tablet" (ina tuppim nä/ü), cf. TPAK 109 rev. 3'(!), or that they "had sealed for testimony" (ašsibütim konkü., see TPAK 120:4. 
Sealings, usually in the form of clay bullae in various shapes, 514 on which the seal was impressed and which offered room for a few lines of text, seved many purposes. They could be applied to safeguard and identify items (textiles, ${ }^{515}$ packets with merchandise, silver and gold, or tablets) that had to be stored ${ }^{516}$ or shipped, but aiso to seal houses, strongrooms (named maknukum, "sealed room") and containers in which voluables where kept. $A O A \Pi 3 \mathrm{OH}$. and $4 \mathrm{lff}$. analyzed the sealing of packets of tin and bogs with textiles, and Teissier 1994, as the title of her book indicates, also studied the sealing practices and seal ownership (chapters 3, 4 and 6). 517 Dercksen 2004a, 90ff. examined the meaning of the frequently mentioned "seals of the Cily" |kunukkü sa alim|, applied to merchandise shipped. He concluded that this expression does not mean the application of an official sea| ${ }^{518}$ by the city authorities as proof of clearance for export (by payment of the export tax, wasitum). Apparently the packets or containers with merchandise had been sealed on departure from Assur by their owners or those entrusting them for transport, so that they could not be opened en roule ${ }^{519}$ and their contents were safeguarded against fraud.

A seal impression alone was not alwoys sufficient, probably because most seals were without inscription and identifying their owners was at times difficult, as we con experience when studying the numerous, rather similar $O A$ seals, but of course, relatives and partners knew each other's seals. In the deposition ICK I, 153 people tell: "We entered (the house) and identified the seals (on a bag with textiles) and they are indeed Imdilum's seals!" On the clay of bullae the name of the owner (or user) could be "indicated, marked" (sumam waddu um) alongside the seal impression. Several texts deal with the problem of identifying the owner of a seal impressed on a legal document which furned up in the archive of a dead trader and whose validity was contested. In El 293 a son identifies the seal of his father on a debt-note and because its presence in the creditor's archive normally implies that the debt had not yet been poid, he has to provide witnesses to the contran. $520 \mathrm{~A}$ verdict of the City $(k t n / k 147$, courtesy $S$. Bayram) authorizes a man to lead the wife and son of a dead trader to the gate of the god in order to identify the latter's seal on a text, and in kt 89/k 279:9-12 (courtesy Y. Kawasaki) a man who denies a debt is told by his

514 See for the variety in shapes, usuolly conditoned by their purpose (label attached by means of strings, slopper of a jar, sealing pressed on a basket, etc.). Ozgüc-Tunca 2001, $134 f f$.

SIS Seals were applied to the hem (sissiktum) of textiles, to identily their owner, see AOAT $43 \mathrm{~F}$.

516 Also in a temple, as in TC 3, 68:19ff. (see AOAT 43), where o mon is ordered to bring a packet (riksum) with gold into the temple of Ašsur. "Ask the priest for the leather bag which contains the pockets with my seals, then inspect my seals and break them and place the packer with gold in the ..., apply sealings and mark the front (panum) of the sealing with my name".

517 Subjects discussed are second hand seals, borrowing and entrusting, ownership, nalionality and stotus, and women and seals. Nole also Kryszat 2004b on the use of the seals of the rulers of Assur.

518 Such as the seal inscribed with the words "Seal of Asssur, of the nishatu-lax, of the City Hall", shown on his $\mathrm{p} .91$

519 See for texts warning against opening packets of tin (sugtum) by breaking their seals, $A O A \Pi 30$ H.

$520 \mathrm{He}$ (or somebody represenling him) might have paid cash, or against a quiltance, without yet having exchonged the latter for the debi-note, to cancel both. 
creditor: "I hold you because of your tablet for identifying your seal (impression)". 521 In the case of a disputed debi-nole, sealed by wro witnesses, it is agreed that if one of them "has identified" (waddu'um) his seal impressions by saying: "They are mine", the debtor will pay (kt a/k 264:off.).

Breaking somebody's seals was a formal act, which required a permit, e.g. in cases where special committees are authorized to break the seals on a dead trader's strong-room in order to take out certain tablets or goods they are entitled 10.522 Broken sealings are tangible evidence of such an action and the writers of ICK I, 149 tell a man, whose seals on a packet with silver they have broken (sarämum). "We sent you your sealings which we broke". 523 In the official letter TPAK 44a (CMK 27a) $)^{524}$ kōrum Kanesh asks kōrum Durhumit to produce a number of records which are "in kärum Durhumit (in containers) sealed by the seal of the kārum", to break (sarāmum) those seals and take cognizance of the tablets and send the relevant records, "placing the seals which you are breaking inside", under your seals to kärum Kanesh.

\subsection{ProsopograpHY AND PERSONAL NAMES}

To understand the trade, the constitution of the family firms, the patterns of partnership, investment, commission, and credit, it is essential to know who is who. This requires a full collection of the thousands of occurrences of personal names, with their parronymics, in particular in dated texts, preferably together with their identified or identifiable seal impressions. But many persons in letters are not identified by patronymic, and while some Iraders, fortunately, have rare or even unique names (Imdïlum, Püšu-kēn, Elamma), most have many namesakes, which is particularly nasty in the "old texts", whose archival provenience is not known. In such cases identification requires the analysis of the commercial or family context in which a trader operales, which means drawing up lists of his correspondents, debtors, partners, investors, transporters, and the people who belong to his family or who confront him in lawsuits. Usually, however, problems remain, and in his recent edition of the dossier of Aššur-nādō and his father, Aššur-idi, Lorsen writes: "The reconstruction of the family of Aššr-idi is seriously hampered by the unfortunate fact that all the central persons

ana tuppim ano kunukkika uddu'êm ukälka.

522 E.g. in CCT 5, 3a: 27 ff., where people had opened Elamma's sealed strongroom, saying: "We act under the orders and responsibility of the principals". The report continues with "When they had opened the strong-room they brought five persons, outsiders, into the house and had them apply their seals (on the door) and they applied their own seals logether with them".

523 In all such cases the texts simply write kunukkum. OA knows the special term for "sealing", sipossum, but it is very rore; it is used in TC 1, 30:10 for sealings placed on the doors and windows of a house. In TPAK 7:4f. we meet the expression pitroar fuppim, "the broken pieces of the (opened) tablet".

524 A pholo of the obverse of the envelope in Dercksen 2004a, 244, and photos of the eight different seal impressions of those who act for the karum in Özgüe-Tunca 200I, pls. I-K. 
in this group had extremely common names. For the name Aššr-idi we have 23 different patronymics attested; 22 are known for Aššur-nādā; 26 different patronymics are attesled for Ǎšsur-takläku, whereas we have "only" twelve for lli-ālum" (the last three are sons of Aššur-idī). 525 Michel 1991d met similar problems with people nomed Innōya, and with traders called Puzur-Aššur or Aššr -mālik (with more than sixly namesakes) they are even worse. At limes the problems are aggravated by the use of abbreviated names (Ikuppia for lkuppi-lšsar, lkua for Ikünum or Ikün-pi-DN, etc.) and occasionally even nicknames. ${ }^{526}$ Not surprisingly, the Assyrians themselves at times wanted to make clear which person was meant, for which they used several devices. ${ }^{527}$ Some persons are identified by their profession, ${ }^{528}$ others apporently hod such common names and probably namesakes within the family or firm that, with omission of their personal name, they were designated as "son of PN" or as "our PN" (PN niā um). ${ }^{520^{\circ}}$ Others again were identified by mentioning the town from where they originated or where they lived, the latter no doubt when the commercial network had expanded and members of firms had settled more or less permanently in various colonies. ${ }^{530}$ Similar strategies were also used in the eponym list, where we have eponyms designated as hapirum (no. 40), sa kakkē, "the man of the weapons", sai.NUN, "the man who trades in ghee" (no. 25), and even tamkarum (no. 128). ${ }^{531}$ Dated occurrences are heipful to map a person's career and to know who were his contemporaries.

Kryszat also tries to derive clues from the writing, paleography and sign use, since there are differences related to time, perhaps also due to the scribal tradition within a family or archive. ${ }^{532}$ With a growing number of digital photos of original tablets becoming avail-

525 Larsen 2002, XIX.

526 Dercksen 1990,96, suggests that Šu-Anum, the father of Adad-șululi, was olso called Kuskusum. See for examples of nicknames, Veenhof 2003, 26f., PN sakkukum, "the deal one", sollomum. "the black one", and rimum, "the twin".

527 See Veenhof 2003, 25f.

528 People designaled as priest (kumnm) of a particular god, e.g. "Mannubo, priest of Assur" (this happened regularly in Anatolion records, especially during the level lb period, see VI.I.2.4): as "lieutenant" (laputhō um), interpreter (rorgumannum, Ašsur-mölik in AKT 3, 30:19f., Ištar-pilah, 1a-ar-gu-me-a-nim in kt 92/k 194:40), as "scribe" (Aupsarrum, passim). malahum, "boatman", nappōhum, "blacksmith", säbium, "brewer" etc. Also panticiples used as professional designations, such as (see CADM/II for references) mupozzirum, "smuggler", musōoridum, musioqaitum lalso TPAK 116:7), and musirebbilum [also VS 26, 10:21]. In addition we have designations of the Mpe sa tabtim, "salt dealer" ( $\mathrm{kt} 86 / \mathrm{k}$ 153A:4). Women too were occasionally identitied in this way, note PN sabium, "tavern keeper" (KBo 9, 10:4\}, and PN sabsütum, "midwife" (TC 3, 219:9).

529 Never confused with nuä um, "native", "Anatolian", pace $V$. Donbaz NABU1995/113.

530 This was regularly done by writing PN sa GN, but in some cases nisbes were used, e.g. PN Hawilium, "from Hawilla)" (Nashef 1991, 58, twice of Aššur-täb, also lli-bāni in AKT 3. 01:27), Todmurium (Nashef 1991, 11, note also kt 86/k 168:5, "Pilah-Adad, son of the man from Tadmur"); Ašsururtāb Simaläijum, TTC 9:16; Alähum Ušsōium, CCT 0, 46b:24f.; etc.

531 See Veenhot 2003, 25f.

532 See Kryszat 2004a, 19f., 30 and 32. Veenhof 2003, 11f. also noted scribal differences between the various monuscripts of the eponym list and assumed an older source for the first $c$. sixly 
able, paleographic słudies can become a means of distinguishing older and younger texts, and also different hands, both of professional scribes and of traders who had learned how to write. Distinctive criteria are the style of the writing / slanting or more upright, more or less cursive), features such as the use of the word dividing wedge or the "Personenkeil", and the preferences for certain signs (in cases where there are options). Krsyzat 2004b applied such criteria in an attempt to determine which ruler of Assur had written a letter in which he only figures as (anonymous) waklum. In his analysis of the spelling in the main manuscript of the eponym list (KEL A), Veenhof 2003, 12t., could show that the source for the oldest part of the list used a more conservative orthography (see above chapter 2.9).

Early text publications, such as CCT 1-4 (1921-1927), did not yet contain indexes of names, but A.T. Clay's BIN 4 (1927) set the example and indexes slowly became the norm, although TCL 14 and 19-21 (1928-1937), by F. Thureau-Dangin and J. Lewy, did not yet include them. The first systematic collection of personal names was Stephens 1928, and much later Hirsch 1961 listed and discussed all theophorous names, 533 while Gwaliney 1977 presented a names index on El. The enormous increase of texts now calls for a comprehensive list, which is being prepared by J.G. Dercksen and may also serve as a basis for more detailed prosopographic studies of the main traders and their families. The eponym list can now help to find out which years a trader's career spanned, when he served as year-or week-eponym ${ }^{534}$, when he first appeared in the sources, when he took over /when his father died or returned to Assur), and when he himself vanished from the sources. ${ }^{535}$ This has been done for a number of important traders in Kryszat 2004a, chapter 2,530 and he also compiled o (still unpublished) list of all occurrences of persons in dated texts.

Prosopographic studies have been undertaken for quite some time, ${ }^{537}$ and some also offer genealogies. Good examples are lchisar 1982 and Larsen 1982a, on the archive of Imdilum, Michel 1991d on the Innāya texts, and more recently Michel 1997 on Sumi-abiya and Aššur-mutappil, Larsen 2002 on the family of Ašsur-idi, and Kryszat 2004a on various traders and their families, in particular on Püšu-kēn (pp. 40-50, with genealogy). Dercksen 1996, chapter 4, studied some important merchants engaged in the copper trade, 538 and Dercksen 200la the main persons of the texts from Amkuwa and Hattus (Nabi-Enlil, IddinKübum and Dāya). Kryszat 2004a also collected data on the better-known year eponyms,

eponyms, identifiable by its preference for certain syllabograms and by more logographic spellings in the names of persons and gods.

533 See now also Eidem 2004.

534 But there are many datings by week-epoynm with do not mention the year-eponym.

535 Several texts mention that a irader "unfortunalely" ( / l libbi ilim) has died. Deaths are also reflected in last wills and in agreements on and legal fights about inherllance matters.

530 In some cases we know the year of their death, if problems with the division of an inheritance had generated dated records or records which mention when the death had occurred (e.g. kl m/k 69:45, cf. Hecker 2004; kt 91/k 420:18f., refers to the death of Elamma).

537 El and the various articles by Julius Lewy contain many prosopographic data.

538 Adad-șululi, Alähum, Imdilum, Puzur-Aššsur, and Ușur-ša-lštar, some of them were also studied in Kryszat 2004a. 
several of which were also active in the trade and therefore occur in archival texts. ${ }^{530}$ in addition a number of articles investigates particular persons or families, at times in considerable detail. 540 .

Of most families of traders three generations are attested in the sources, occasionally four, in which case the first generation usually only appears in patronymics. The evidence of course depends on the size and completeness of reconstructed or excavaled archives and, as noted above, the early period (before eponymies 75-80) and the last two decades of level II are usually poorly attested. As an example I mention the case of Püsuu-kēn, son of Sueija ${ }^{541}$ who is attested in texts dated between years 78 and 98 , followed by his son Buzāzu, attested between years 100 and 111 , while the latter's son Püšu-kēn, called after his grandfather, occurs a few times in undated, but apparently lare lexts, ${ }^{5 \Delta 2}$ which is also the case with his second son, Aššur-iddin.

A special issue are the hundreds of names of Anatolians, which occur in texts of the Assyrians and in those of their own archives. Many remain just names, but several have regular commercial contacts with Assyrian traders, at times within the framework of a marriage between two tamilies, or act as dealers and money-lenders within the Anatolian community. Of some we know the profession or function, especially of the numerous persons with a title of the type rabi + noun and of those qualified as priest of a particular god, which are especially numerous in the Anatolian texts of the younger level Ib / see below VI.1.). Linguistic analysis of their names ${ }^{543}$ also allows to determine their ethnicity and provides a picture of the composition of the early population of Anatolia. The first to do so systematically ${ }^{544}$ was Garelli 1963, part 1, chapter 3, "Les populations en présence", who dealt with Hittiles and Luwians (and how to distinguish them), the (Proto-)Hattic population, and the Hurrians. He also treated the hypocoristic names, which usually dely ethnic classification and discussed (p. 161-168) the merging of different ethnic groups, in particular the marriages between Assyrians and Anatolians and the names of their offspring. He was followed by Loroche 1966, Les Noms des Hittites, which includes names

539 See also Larsen 1976, part 3, chaplers 4 and 5, and Dercksen 2004a, $56 f f$.

540 Kryszat 2001 (Iddin-|štar). Matous 1969 (Puzur-Aššur). Michel 1994 (Hurasānum), 1998d (Kunaniya), Sturm 2000 (Būșija, Idnaya), 2001 (Puzur-Anna, the blacksmith).

541 See Kryszat 2004a, 40-50, with genealogy on p. 44. Suejia (to be distinguished from Püsukën's eldesl son, named after his grandfather) himsell is not active and only occurs as patronymic. We cannot identify him with Su-Suen, son of Buzazu, who occurs as transporter in CCT 2,40:9, a letter sent from Assur to our Püšu-kēn. While Sueja might be abbreviated hom Su-Suen, it is difficull to assume that the tather of an imporant trader worked as transporter. Lines 28ff., "when he arrives (in Kanesh) he must give you (back) $121 / 2$ shekels of silver, his service loan, and then he can go where he wishes", moreover, would mean that Suejia was is in the service of his son or the latter's parmer, which is impossible.

542 Also in $k t 92 / k$ 194:2, from the archive of Kuliya, where he is stoying in Kuburnat.

543 Which has to take into account the features of OA orthography and spelling variations, see GKT SS $8 c, 9 b, 12,15 b, 17 b, 19 h, 25$, and $27 \mathrm{e}$.

544 He had some precursors, notably A. Goetze, in various studies listed in Michel 2003c, 104. 
from the texts from Kanesh, 545 which was supplemented by laroche 1981. Since then the number of non-Assyrian names, provisionally distinguished into Neshite (or Proto-Hittite), Luwian, Hurrian ${ }^{546}$ and (Proto-j) Hattic, has considerably increased. ${ }^{547}$ Both OA studies and Anatolian linguistics would profit from a new, comprehensive collection and analysis of all such names, which can build on work already done, in particular by Balkan in various articles. ${ }^{548}$

545 See the review by L. Matous, ArOr 37 (1967) 619-21.

546 See for Hurrians and Hurrian names, aport from Garelli 1963, 155ff, also Dercksen 1996, 163, and Wilhelm 1996. See for the Hurrian lerm sinahilum, "second in command", Veenhof 1989, 524, and for unuššm, "service obligation", Dercksen 2004b, 140 (he assumes that ubödinnum is of Luwion and nzinnum perhaps of Hittite origin). Early recognized Hittite loanwords are ishiul, "contract" (?), and ispatal(i), "lodging".

547 And will increase even more if the archives of Anatolian traders found in the kärum are finally published.

548 Balkan 1973, 1974, 1979, and 1992, see also Donbaz 1996b. 


\section{A SHORT HISTORY OF THE OLD ASSYRIAN PERIOD}

\section{Before kärum Kanesh teVel II}

\subsection{Until the UR III Period}

Our knowledge of the early history of Assur, before $2000 \mathrm{BC}$, is limited. In I.1 I already mentioned the fact that the city, ruled by a governor, belonged to the Ur III empire, but there is little material evidence for the early phases, which are mostly only documented in the temple of Ištar. Domination by the Old Akkadian empire, probably already under Maništusu, who built at the lštar temple in Ninive, ${ }^{549}$ is clear from o few inscriptions, which mention Maništusu, as lord of Azuzu 'RIMA 1, 8', and Rimuš, and from a small group of Old Akkadian texts found in a destruction layer under the Old Palace. ${ }^{550}$ This links up with NarāmSin's northward push and his subjugation of the rulers of Subartu and "the Upper lands", which is documented at Niniveh, Nagar (Tell Brak), by his relief at Pir Hüseyn (north-east of Diyarbakı), and by inscriptions which commemorate that he reached Talhat, Hahhum, the sources of Euphrates and Tigris, ${ }^{551}$ and his Cilician campagin. While these facts, as presented most recently by Goodnick Westentholz 1998, point at the existence of relations between Old Akkadian Mesopotamia and Anatolia, it is not easy to define them, but they may have been of a commercial nature. Levels 11-13 of the city-mound of Kanesh, from the end of the Early Bronze Period, indeed contain evidence for contacts with Mespotamia in the form of imported objects. ${ }^{552}$

Contemporary written evidence for Old Akkadian contacts with Anatolia does not exist and we can only draw on two later compositions. An OB text from Sippar, which belongs to the tales around the "great rebellion" against Naräm-Sin and in which Gutium is the main antagonist, simply lists the kings of Hahhum and Kanest among his enemies. ${ }^{553}$ More

549 As recorded by Šamši-Adad I, see RIMA I, 53 11:21f.

550 See Neumann 1997,134ff., also on the mention of Assur in Old Akkodian texts from Gasur and in a fragment of an "archaic kudum".

$55)$ See for the inscription now C. Wilcke, ZA 87 (1997) 24, J, VIII:31-39.

552 See Goodnick Westenholz 1998, 13 and 19F. Özgüc 2003, 29, states that Konesh by that time "had developed economic and cultural connections with Mesopotamia and Northern Syria, evidenced by the imported cylinder seals, pottery and metal objects", but it seems to be more a matter of designs and ypes than of identified Akkadian objects importerd into Anatolia.

553 Goodnick Westentholz 1997, text 17:1 6'-7'; the names of both kings are broken, they end in -anda and -ha-an. 
informative is the tale called "King of Battle" (sar tamhari), 554 on Sargon's campaign to Anatolia and his victory over the king of Burušhanda, later known as an important trading city and the seat of an Old Assyrian colony. Could this tale contain a historical "core", the source of the surprising mention of Burušhanda and perhaps also of Ka[nish] and of the fact that the king is persuaded to take action by the representative ( $\check{s u k a l / u m}$ ) of the traders, whose interests apparently have been harmed by what the king of Burušhanda did? 555 But much remains unclear and after the conquest of "the fabled Burushanda" and in the meeting with its ruler trade is not an issue. The mention of a mighty mountain with lapis-lazuli and gold and of a series of impressive trees (lines 28f.) is to stress how difficult the road to the city is and not to describe its (commercial) riches. And in the end (rev. 24'ff.) only the attractive fruits of a variety of trees are mentioned, 550 which nevertheless are said not to be worth a journey to the city. The text might reflect memories of early trading contracts and perhaps even use data mentioned in a (now lost) original Sargonic inscription, ${ }^{557}$ supplemented by later knowledge. ${ }^{558}$ But without additional evidence we cannol use it for a historical reconstruction. While the existence of an early community of Mesopotamian traders working and staying in Anatolia, after the pattern of the Old Assyrian colonies, seems anachronislic, trade conlacts by caravan are possible. That Hittite historiographic tradition has knowledge of the great kings of Akkad and that battles of them are somehow linked with their own military history, is better explained from later borrowing, either from the North-Mesopotamian Hurrian traditions or from ancient Assur, where these same kings were admired already in the 20th century BC., when Assur's ruler Šarru-kin I borrowed the great Sargon's name, complete with its divine determinative. ${ }^{559}$

554 See now Goodnick Westenholz 1997, 102ff., lexl 9. There olso exists on originally Middle-Hithite version, see now $E$. Rieken, in: $/ C H I V, 576 f$.

555 Text 985 f., "The cily of Ka[nesh ......] I desire war, they have subjugaled [ ]", but Kanesh is restored and the city does not figure in what follows. Goodnick-Westenholz takes "they have subjugated" as the casus belli, but if so, it remains unclear what had happened; perhaps the subjugation of Konesh by Burušhanda, which would have harmed Mesopotamian traders? Later on the traders seem to say that they went there under Sargon's protection, but now face violence (line 18).

556 Nole the mention of "pistachios of Burušhattum" in a letter from Mari, in Durand 2001, 130, lines $16 f$.

557 If so, we cannot exclude that an exploit of Naram-Sin was transferred to Sargon. The possibility of literary, legendary elaborations of data in original inscriptions has been confirmed by the discovery of Naram-Sin's original inscription aboul "the great revoll", see C. Wilcke, $Z A 87$ (1997) 11-32

558 Possibly supplied by OA traders lamiliar with Anatolia, which links up with $O A$ interest in the exploits of the great Sargonic kings, which has become clear by the discovery of a tale of Sargon (published in Günbattı 1998a, see now also Van de Mieroop 2000 and especially Dercksen 2006), written down before 1900 BC, which actually makes it the oldest tale of that kind preserved.

559 His grandson Naram-Suen did the same, see Veenhof 2003,44ff. 


\subsection{FrOM the UR III PERIOD UNTIL IIUŠUMA}

If the reign of Erišum I, under whom the trade on Kanesh and the system of eponymous limums became established lacts, started in ca. 1974 BC, there are only ca. Fifty years available after the end of $U r$ III to accommodate the rulers who precede him. They are in the first place his direct ancestors, nos. 30-32 of AKL, the first rulers of the "Puzur-Aššur dynasty", and in addition perhaps also no. 27, but nos. 28-29 are a problem. Akiya, 28, is completely unknown, and Kikkiya, no. 29, is only mentioned by Aššur-rēm-nišēesu as an early builder (before lkünum, no. 34) of the city-wall, ${ }^{500}$ which suggests that the Middle Assyrian king had found a building inscription (an inscribed brick?) of him. We could doubt this by assuming that Tušpiya and Kikkiya were taken from the King list and presented as earliest builders of respectively the temple of Ašsur and of the city-wall, but we cannot prove it. If Kikkiya really has fortified Assur, it could have been an activity linked with the newly gained independence. ${ }^{501}$

In AKL he is preceded by the mysterious Su-li-li(variant Su-le-e), whose "father" Aminum recurs as no. 26, as son of lla-kabkabū, and therefore as elder brother of Šamši-Adad I. He apparently served to link the line of Šamši-Adad's ancestors (kings nos. 26-17, listed in reverse order) with the rulers who preceded him on the throne of Assur. ${ }^{502}$ Since this link is clearly secondary, Sulili remains an isolated figure, but his position in the list, as first ruler after the group of "ancestors" and before the beginning of the "Puzur-Ašsur dynasty", could identify him as the earliest independent ruler of Assur, perhaps even as Ur ill's last local governor, who in due time had become independent. He is mentioned in a text of Tukulti-Ninurta I, 503 which states "From the beginning to the appearance (?) 564 of the dynasty of Sulili, up to the dynasty of [ ]". The concept of his "dynasty" (bala) must be based on the fact that, after the group of six kings that he heads, the King list inserts the summarizing remark "In all six kings [known from] bricks, whose limums have not been found/marked" (see chapter 1.2.1). But this remark only explains the lack of information on the length of their reigns and it is extremely likely that a new dynasty in fact started with king no. 30, Puzur-Aššr, the earliest ancestor mentioned by both Salimahum and llušuma. The only possibility of identifying Sulili would be to equate him, as has been amply discussed, ${ }^{505}$ with a ruler only known from his seat inscription found on

560 See above, note 2.

501 See already Larsen 1970, 39.

502 That the identity and chronological position of Aminum have become problematic due to MEC has been noted in Veenhol 2003, 02 note 112.

503 Edited in Lamber 1985, the quote is from lines $5 f$.

564 Lambert takes Sumerian a . d a . m i n, "fight, quarrel", on the basis of the Akkadian equivalent resitu as "the going out", which in concrete probably means "the appearance", since in AKL Sulili heads the group of six rulers without known regnal years, which follows the group of rulers called "ancestors". If Sulili really marks the emergence of Assur as an independent city, "struggle" should not surprise.

505 By Balkan 1950, 54ff.; Lewy 1950, 72ff.; Garelli 1963, 33ff. 
tablet envelopes from kārum Kanesh level il: $A$-šürki / LUGAL / Și-lu-/u / ENSİ $A$-šüri DUMU Da-ki-ki / NIMGIR URU A-sijrki, 500 on the assumption of a serious scribal mistake in the King list. ${ }^{507}$ This seal is only known from its later use on envelopes found in kārum Kanesh level II, by a namesake, Șilulu, the son of Uku, 568 who was year-eponym 98 of the year 1876 BC, by which time he must have been an adult and experienced citizen. This creates a problem for Lewy's claim (based on the principle of papponomy) that he would have obtained the seal as this ruler's grandson, because the temporal distance is too big. We simply do not know the relation between the eponym and the ruler whose sea he used. If we equate king no. 27 with the Silulu of the seal, he can only have ruled before the Puzur-Aššur dynasty. Some support for this dating could be derived from the seal inscription, which begins with the "credo" that Ašsur is the king of the city and Șilulu its governor, which, as pointed out by Balkan, closely resembles the text on the seals of early rulers of Eshnunna after the Ur Ill period. ${ }^{569}$ The fact that Sulili is not related to the following "Puzur-Ašsur dynasty" may be compared with the situation in Eshnunna, where the first independent ruler after the demise of Ur III is also an isolated figure, with a different title ("mighry king"), after whom a new dynasty starts.

The earliest ruler known from an inscription is Šalim-ahum, who records that he built (at) the Ašsur temple "at the god's request", mentioning a number of chapels and rooms situated around the main inner court, among which one called "the palace $\langle\dot{E} . G A L)$ of ... Dagan", presumably identical to what was later called bet Dagan, an important chapel shared by Dagan with Enlil and other gods. ${ }^{570}$ This building activity would fit well into the early years of political independence, when the temple of the eponymous city god mattered much.

506 See Balkan 1955, 54ff. and 1957, 60f., with R/MA 1, 12. See for a drawing Teissier 1994, 221 no. 237.

567 This is not easy, not only because the vowel pattern is different, but also because in the seal inscription his name begins with the sign SII (extremely rare in OA), which should not have caused confusion, as an $O A$ spelling with initial $Z I$ could have (cf. a comparable case with the ambiguous DU, mentioned in Veenhof, 2003, 21).

508 See Larsen 1976, 146 note 120, with literature; he does not rule out the possibility that Șilulu belonged to the family of the rulers.

509 The earliest independent ruler, Šu-ilia, called himself "king of the land Warûm", but his successors (RIME 4, 489ff.) called themselves e $\mathrm{n} s \mathrm{i}$ of the ciry, whose "mighry king" was the god Tišpak. With Ipiq-Adad I (522) the inscriptions becomes different, starting with $\mathrm{RN}_{1}$ naräm DN ENSI GN DUMU RN 2 . See also Whiting, AFO 34 (1987) 24 and C. Reichel, in: Siudies Kienast, 355373 , who is inclined to link the change in title with political misfortune after Šu-ilia, "when political power had suffered a terrible and lasting blow' (359).

570 See Larsen 1976, 56f., and Van Driel 1969, $32 f$. 


\subsection{ILUŠUMA ANO ERIŠUM I}

The next wo kings, nos. 31 and 32 , are also known from original inscriptions, 571 which present full genealogies, starting with Puzur-Aššur I (no. 31), apparently the founder of the dynasty, whose name (extremely common in ancient Assur) was also used by two later rulers, nos. 36 and 61 . llušuma did work on the Istar temple, on the wall and on the residential area of his city ${ }^{572}$ and he also provided it with water from springs in mount Abih, the Jebel Mahlul, a northern spur of the Gebel Hamrin, on which the city was built. llušumo is best known for what he describes next, at the end of inscription 2:

"I established the addurārum of the Akkadians and their children. I washed their copper. I established their addurārum from the front of the lagoon and Ur and Nip-

pur, Awal and Kismar, Der of the god Istaran, until the City (of Assur)".

Larsen, ${ }^{573}$ atter a solid analysis of these intriguing lines, considers it a description of a measure that "attempted 10 attract traders from the south to the market of Assur by giving them certain privileges". The problem is to know what "establishing addurārum" and "woshing a person's copper" in concrele mean. The latter measure is al times interpreted as a cancellation of debts in copper, since the verb masā 'um, "to wash awoy", can be used for it, 574 but it is difficult to envisage it, since Assur to all appeorances was supplied with copper from the south (presumably from Oman, via the Persian Gulf) and "washing copper" cannot mean "lo abolish taxes on copper". Dercksen 1986 suggested that the king "boasts himself of hoving been able to melt and refine copper that was brought to his city by the Akkadians, as proof of power or of prosperity". But in 2003 he suggested that the words could indicate that Babylonia during this period was supplied with copper via Assur, presumably with copper from the mines at Ergani Maden, when imports via the Persian Gulf had been interrupted. "To wash their copper" then would mean "to supply them with refined copper", and imply that copper was refined at Assur before being shipped to the south. Both interpretations have their problems and for lack of evidence from Assur the choice is difficult, but I prefer the first one because it better suits the basic meaning of "to wash".

Addurārum primarily means the restoring of the original situation, which can mean granting "freedom", if its beneficiaries had been subjected to forced labor or slavery. The latter is meant in the recently published treaty between kärum Kanesh and the king of Kanesh (chapter V. 2.1), which speaks of establishing the "addurärum of slave-girls [and slaves]". s7s This could be accomplished by a royal cancellation of debts and its consequences, but

57 RIMA I, A.O. 31 and 32

572 The words of lines 23-29 probably hove to be translated as "I designed a new wall crosswise [?] and in this woy ladded ("ossigned") house plots to my cily". His work on the lstar temple, considering the new reconstruction by Bär 2005, must have been on temple $E$.

573 Larsen 1970, 63-78.

574 Local rulers of Anatolia in the Old Assyrian period use the expression hubullom maso um (see Balkan 1970), which was probably borrowed from Assyria.

575 See Günbattl 2004, 253, lines 82t., where in line 83 on expects a verb, possibly ta-sa-ku-nu-ni. 
also by eliminating on oppressor. This is the case in the oldest occurrence of the term in an inscription of Narām-Sinn of Akkad, who did so by defeating "the oppressor" of Kish, obviously Lugalzagesi of Uruk. ${ }^{570}$ But it is extremely unlikely that llušuma had the military power to do so land from whose oppression?) with the "Akkadians", that is people living south of Assur in an area ranging from Eshnunna all the way down to Ur and the Persian Gulf. ${ }^{577}$ And he might perhaps cancel the debts of "foreigners", but only if they had become indebted to Assyrians and lived as debt-slaves in Assur, which is extremely unlikely. ${ }^{578}$ This leaves us with derived meanings of andurärum, such as exemption from taxes and freedom of traffic and circulation of goods, advocated by Lewy, ${ }^{579}$ for which there are old examples. ${ }^{580}$ This makes it a measure with an economic, commercial goal, which fits the development of Assur as a trading city. It also makes it understandable that it applies to "the Akkadians and their sons", since an abolition of raxes and tolls has a lasting effect, while a cancellation of debts, in $\mathrm{OB}$ royal decrees designated as "restoring equity" (misaram sakanuml, always was an ad hoc measure, which was only retroaclive.

This interpretation is supported by the geographical range of the measure, which suggests an itinerary which links southern Babylonia (Ur and the area of the lagoons) with Assur, via Nippur, with a crossing of the Tigris somewhere near Maškanshapir, from where the roule continues to the north-east, to Dēr (Badreh) and via Kismar across the Diyala to Awal, ${ }^{581}$ and then along the foothills of the Zagros and east of the Tigris to Assur. This may have been the route taken by "Akkadian" caravans that visited Assur to do business there. ${ }^{582}$

576 See C Wilcke, ZA 87 (1997) 25 J, X:12f. who restores and reads: in [KASKAL] mu[salli] sunu

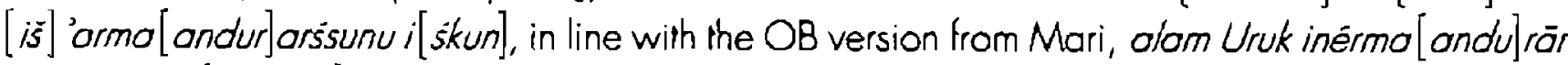

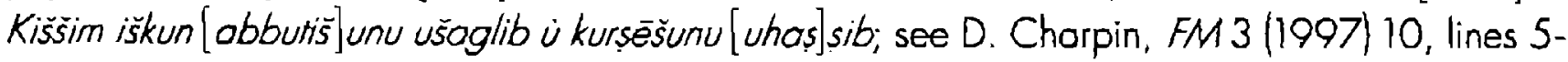
8 , with on $\mathrm{p}$. 12t. the comments on the andurārum, which he interprets as the liberation of people of Kish, made prisoners and kept as slaves by Uruk.

577 "Akkadians" olso occurs in the legal decision of the City Assembly, which forbids Assyrians to sell gold to "Akkadians", and in the draft of a trealy with a minor South Anatolian ruler, who promises not to let "Akkadian" traders visit his country, see Günboltt 2004, 250 note 8, lines 11-15.

578 The fact that we now have an occurrence of addurārum wašsurum, "to release 'debts by means of) an $a$." (a synonym of hubullam masä'um\}, performed by an Anatolian ruler, does not prove that this is the meaning in llušuma's lext.

579 J. Lewy, Erelz Israel 5 (1958) $23^{*}$.

580 Kraus 1970, 30 nore 94, on lexts from Girsu in Gudea's time, where its Sumerian precursor a ma.ar.gi ${ }_{4} g$ ar. ra is used of goods such os silver, copper, bronze, lextiles and grain.

581 Texts from the Hamrin area have shown that Awal is Tell Suleimeh, just west of the middle course of the Diyala. See for this ciry also JCS 28 (1976) 178f. (an Ur lll e n si of Awal, who is also military governor of Maškan-šarrum) and $A b B 3,60$ :가., the letter of an $O B$ trader ("I am in Awal and my goal is Assur"). Kismar, better know from Ur lil texts and al times associated with Maškanšarrum (see also $O B T / 305: 1$ and 50), has not yet been identified, but probably must be located to the south-east of Mē-Turan and Eshnunna.

582 See the letter VS 26, 17:4-14 (= CMK 110), which reports that the Akkadians have not come to Assur, because their country is in revolt, but may rurn up before the winter. 
While tangible evidence of Assur's commercial penetration of Anatolia, as will be shown below, only becomes available with Erišum I, llušuma's inscription makes it rather likely that the cily's trade already flourished under him and thanks to his policy. New evidence could be available in the impression of a seal of (a servant of) Iși-Dogan, a ruler ('sakkanakkum) of Mari, found together with other sealings under the floor of temple E 2 of Istar and dating to around $2000 \mathrm{BC}$ or a little later. Such sealings, originally applied to a variety of containers, usually are evidence of the arrival of goods from elsewhere (in this case from Mari), probably (unfortunately all details escape us) in the context of diplomatic gift exchange or trade. ${ }^{583}$

The term addurârum also occurs in the report by Erišum I on what he accomplished when he built the temple of Aššr:

"When I applied myself to the work, my cily obeyed me and I realized the ad-

durārum of silver, gold, copper, tin, barley, wool, until even brand and chaff".

We may compare this claim with those of contemporary Babylonian rulers, who mention the favorable rates of exchange and generous rations for workers at the time they built a temple, as proof of economic prosperity during their reign, ${ }^{584}$ but there are differences. Erišum does not describe a prevailing situation, but a measure he took, preceded the statement that "the city obeyed him". This stresses the king's authority, but perhaps also the willing cooperation of Assur's citizens, which was then Inote the connecting - ma) rewarded by the measures described. And while the other royal "tariffs" mention the prices of basic foodstuffs and necessities of life - barley, dates, oil, lard, wool, and copper - given out as rations or sold on the domestic market (so ṠamšiAdad I). Erišum also mentions silver, gold and tin, which happen to be vital in Old Assyrian overland trade. The final words are a kind of merismus, "ffrom silver and gold ...) down to bran and even chaff", 585 and stress that the measure applied to every item used or traded. This only makes sense if addurärum here, again, means free circulation and unrestricted barter and trade in the items mentioned.

This interpretation implies that the measure was taken to further the prosperity of Assur, in particular by stimulating a free exchange of goods. The mention of tin is intriguing

583 See Bär 2005. He states that the piece of clay with the name of Mari's ruler must have been part of a sealing used to close a door or a box, and even speculates that, if the former were the case, the Išlar temple might have contained a sealed room where goods arriving from Mari were stored.

584 See for these so-called "tariffs", D.C. Snell, Ledgers and Prices. Early Mesapotamian Merchant Accounls, YNER 8 (New Haven 1982), 204ff., and now also the toriff of rations and market prices of Sin-iddinom from Mashkanshapir, in E. Stone-P. Zimansky, The Anaromy of a Mesopotamian Ciny. Survey and Soundings at Mashkan-Shapir (Winono Lake 2004) 142, 11:5f.

585 Well known from Old Babylonion records on the division of on inheritance. The words adie.TA in line 23 of Erišum's text are nol clear and RIMA's interpretation as "hire, wages", tumed into "os payment of" is not acceptable, because it does not fit pö um, "chaff" (not straw), which is worthless, and becouse there is no evidence for a icompulsory?". payment of or tax on bran and chaff. They probably mean something like "oll the woy down to". 
and could be taken to imply that Assur in this way could produce its own vital bronze. But the combination with gold and silver, which do not occur in other "tariffs", point to the overland trade on Anatolia, which thrived on the export of tin and the import of silver and gold. Taken thus the measure would have stimulated Assur's role in the international trade as a kind of central place for assembling merchandise for export to the north.

This implies that this trade was already practiced in Erišum's time and this is now confirmed by the discovery of pieces of an envelope (presumably of a royal letter; $k t 83 / k$ 246), with an impression of his seal, in karum Kanesh in 1983. ${ }^{586}$ This discovery not only proves that caravan trade was practiced, which may already have been the case under llušuma, but also that Assyrians had settled in kārum Kanesh, since the impressions were found in the house of an Assyrian trader. ${ }^{587}$ This is welcome evidence, since the oldest dated records found in the kărum are later than Erišum's reign. That trade developed in his times is also supported by the fact that the institution of the annually appointed limum, who became the head of the "City Hall", which was so important for the commerce, starled in the first year of his reign. ${ }^{588}$ It is also supported by two copies of an inscription of Erišum I, found in the kãrum in 1948, now available in RIMA I, 20f. Its first part, on the Erišum's building activities, is followed (lines $26 \mathrm{ff}$.) by a report on the measures he took to improve the administration of justice, which should result in righteous verdicts. In lines $39 \mathrm{ff}$. two items receive full attention, the concern to prevent false testimony (šibüt sarratim) and help for a plaintiff in the form of a royal permission to use an "attorney" (räbisum). The importance of both is clear from the many judicial records found in the archives of the karrum. They show that due to the legal and commercial complications of the trade, with people and evidence in Assur and Anatolia, in many legal fights the matter of establishing facts and providing proof was vital. By testimony of witnesses under oath ${ }^{589}$ dispuled lacts, for which no records existed, and whose validity was contested, could be "confirmed, proved", a rule which occurs in an official letter of the karum, in a verdict of the City, and even in a "law" written on a stela. 590 The "attorney", which the plaintiff himself had to hire and pay, was authorized to

580 See Veenhof 2003, 41, for a photo Özgüc 2003, 18 no.4, and for a description, Özgüç-Tunca, 2001, 137/"belongs to the earlier group of isin-Larsa seals", but the seals referred to in the footnote ore all later than Erišum I!).

587 Only a few texts from the 165 found in 1983, in the house in grid e/12, are thus far known, see Michel, 2004a, 160 and only one of the bullae from this archive has a (damaged) inscription. See Veenhof 2003, 41 note 63, for the possibility that it was inhabited by a kärum official.

588 See Veenhol 2003, 41f.

589 The inscription lakes great pain to describe the terrible fate of the periurer.

590 Veenhof 1995a, 1725 and 1729. The verb is kuänum, iniransitive (OA occurrences not listed in CADK s.v.); see now also kt 94/k 1133:14f., on a claim, ina tuppēsu y šiběšu ikuanma ... kaspam ilaqge. 
search for and verify facts by summons, interrogation and inspection of documents. ${ }^{591}$ The link between royal inscription and judicial practice may explain the presence of two copies of this text in a house in the kărum ${ }^{592}$ and supports the view that Erišum's judicial measures were an answer to legal problems in connection with the overland trade which the ruler wished to address.

591 See for his role larsen 1970, 284f,, and Veenhol, 1994b, 182ff. (he hod to be hired by the plaintiff and his duties and wages were recorded in a controct).

592 There is no proof that this house contained a school, as claimed initially. but the existence of two not identical copies (lines 31-35a only in ex. 1; see for a proposed reading Dercksen 2003, 95) indicates scribol activity (the orthography is later than that of Erisum's other inscriptions on stone) and shows the importance attached to the text. 


\subsection{The main phase, kärum Kanesh level II}

How the trade developed still needs much more research, but it is already clear that its growth in size and sophistication are linked. The range of action of the traders increased and must have resulted in more colonies and trading stations, also in more marginal areas, and to exploit these possibilities more capital, more traders and more personnel must have been needed. Increase of capital presumably led to the formation of "joint-stock companies", which worked with a large capital (called naruqqum), invested by shareholders. ${ }^{593}$ A wider range and increased quantities of merchandise led to the use of traveling agents (called tamkarum), who took lots of merchandise lat times with the donkeys on which they were loaded) in commission on credit to sell them in the country-side and this is reflecled in the hundreds of debt-notes which record their financial liabilities, with due dates. Since the early phase of the trade, before eponymy-year 75, is badly documented, ${ }^{594}$ it is difficult to map these developments, but it is noteworthy that the three known, dated contracts by which a joint-slock company was founded are dated to eponymies 64,67 and 77 , hence already fairly early in the reign of Šarru-kin.

Need for more capital and more credit to tamkärums required new rypes of financial arrangement, including more securities and it is my conviction that this gave rise to new ways of financing and new security devices. The first, both for short-term and long-term investments and with differences as to sharing risks and profits, have been well analyzed in Dercksen 1999, ${ }^{595}$ the latter in Veenhof 1999. A measure of security was also provided by the heavy default interest of thitty percent, which seems to have been based on a ruling of kărum Kanesh, which introduced a standard rate. ${ }^{596}$ Special security devices were the stipulation that the creditor himself could borrow the amount owed from a money-lender at

593 We have only a few contracts recording the foundation of such a naruqqum, since they were usuolly kept in Assur, where the investors lived.

594 At least by dated contracts, mainly debt-notes. This is not surprising, because when a debt was paid the contract was given back and destroyed. Since the increase of the number of debt-notes was a consequence of the use of tamkaru-agents, the lack of early ones might also indicate that this happened less in early years. Moreover, traders will have occasionally cleaned their archives by discarding old records no longer valid or necessary.

595 It is possible that the usually small, so-called fadmigtum loan or commission (also known from OB texts, where they may occur alongside investments in parnerships), whereby merchandise was entrusted in good faith to a trader to sell it "as well as possible" (dammuqum), without guaranteed comission or profit, is also a later development.

590 Kima awar kärim (Kaniš), passim. Note also interest on a silver debt kima awat kárim Timilkiya, in kı 87/k 256:6f. (courtesy K. Hecker), and interest on a debt in copper kima owat kärim Durhumit, in $\mathrm{kt} 91 / \mathrm{k} 390: 8 \mathrm{f}$., but we do not know whether these rare rotes were different. 
the expense of his defaulting debtor (who will be charged double interest), the creation of a "payment contract" (tarkistum), which stipulates a hundred or two-hundred percent penally for pressing an unfounded or refusing a valid debt-claim, and the introduction of apparently transferable debt-notes due to an anonymous creditor (called ramkärum), who could also be identified as "the bearer of the tablet" ( wäbil tuppim sut tamkärum). ${ }^{597}$ The development of the role of guarantors (ša qatatim), the securities they needed (right of regress on the debtor, protection by a pledge), 598 and rules for charging simple or compound interest should also be mentioned here. Finally we also have a category of 'protected' loans, with close supervision of the debtor, which should allow him to make a journey to Assur and make profitable purchases which, after their sale in Anatolia, would "secure his economic survival" (ša balätisu) and might prevent bankruptcy. ${ }^{590}$

Increased caravan traffic must also have had consequences, if only for the breeding and training the expensive "black donkeys" for which there was a constant need. 600 They were acquired in a special station or corral (gigam/um) outside Assur, which also had to be supplied with harness, saddle rugs and bags for packing and carrying their loads. More caravans also meant a need for more personnel, transporters (kasșärum) and donkey drivers |"packers", sāridum), who had to be hired. Unfortunately, is it difficult to use the contracts by which they were engaged as a chronological indicalor for the volume of the trade, because they are normally undated. Moreover, the contract was basically the record of the receipt of an interest-free loan (called be 'ulatum) in exchange for an obligation to work, which was duly given back (and in most cases presumably destroyed) when the contract was terminated. It is purely by chance that the oldest dated record is such a be iulatum contract, CCT 5, 10a (EL 97) perhaps preserved, in its envelope CCT $6,23 \mathrm{c}$, because the loan was never paid back. It is instructive to note that the terminology used in this contract deviates from the later, standardized stipulations and that its orthography and paleography exhibit older features, ${ }^{601}$ because this illustrates that these features can be used as chronological indicalors. The two seals impressed on the envelope of this contract, nos. 16 and 52 in CCT 6, are early Old Assyrian, in the tradition of the Ur III repentoire, with a combat scene and a supplication scene. This makes them, apart from the seal of Erisum himself, 002 the earliest dated seal impressions, which is useful for typological and stylistic comparisons and for the relative dating of other seals.

597 See for these devices, Veenhof 1999, 811 ., and for the Old Assyrian "bearer's cheque", Veenhat $1997 \mathrm{~b}, 351 \mathrm{ff}$.

598 See Veenhof, 2001, $108 \mathrm{ff}$.

599 See for these transactions, Veenhof 19870.

600 Because most donkeys, with their hartness, were ultimately sold in Anatolia, since only a few were needed for shipping silver, gold and persons back to Assur. See for all aspects of the "packdonkey" in OA now Dercksen 2004a, Appendix 3.

601 Frequent use of $T I$, many "Winkelhaken" in signs like $L I, U S$ and $Z I$, and full" forms of $L_{A}$ and UG.

002 See Veenhał 2003, 41, for a photo Özgüc 2003, 18, no. 4, and for a description Özgüc-Tunca 2001,137 , where it is stated that "it belongs in style to the earlier group of Isin-larsa seais". But note that the seals mentioned there in toomote 05 are all later than Erišum l, who died in ca. 1935 BC. 
After the first half of the reign of Šarru-kin there is a substantial increase in dated documents ${ }^{003}$ and this marks the beginning of the "best-documented" phase of karrum Kanesh level II. It is the period covered by the archives of the main traders, such as those of Alāhum, Adad-șuluiī, Aššur-taklāku son of Alāhum \{kt 93/k, C. Michell, Elamma son of Iddin-Suen (kl 91/k and 92/k, K.R. Veenhof), Enlil-bāni, Šalim-Aššur son of Issūrik (kt 94/k, M.T. Larsen\}, Ușur-ša-Ǐstar $\{k t n / k$, Bayram, Cecen, Günbattil\}, and the archives published in AKT 3 and TPAK 1. The picture of Old Assyrian trade in full swing, with all its institutional, legal and social characteristics, is based on the texts of these archives, which in general cover the period between eponymy years 75 and 120 .

It is not easy to discover changes in this period, but there was one in the system of the hamustum or week-eponym who functioned lone single text speaks of him as "holding", ka "ulum, the office) in kârum Kanesh. ${ }^{604}$ This system meant that a great many traders, for short periods, usually in the course of a number of years, were designaled to serve as week-eponym in the administration of the karrum. ${ }^{605}$ It must have been introduced (but we do not know exactly when ${ }^{\infty 00}$ ) to meet the administrative needs of the expanding organization of kărum Kanesh and may have played a role in the settling of accounts. At first these eponyms always appear in pairs, but in year 98 a change to single week eponyms has taken place, ${ }^{607}$ while for the last years of this period, after eponymy 120,008 no week eponyms are attested. We do not know what this change from single to double eponyms meant.

The political history of this period, apart from what the sources tell us about diplomatic and commercial relations with the Anatolian cities and palaces, remains unknown. The evidence we have on the activities of the ruler of Assur, the City Assembly and the City Hall is restricted to their involvment in the economy and rulings and decisions that were of direct importance for the trade. Above (Il.2.3) I mentioned measures that aimed at protecting the Assyrian trade (and possibly production) of textiles and restricting the circulation of gold by

603 Eponymy 78 occurs ten times and after 79 most are attested twenty or more times, while for $65-77$ we have only between two and seven alteslations each.

004 See Larsen 1976, 354ff. That a hamuštum as a calendaric unit of time equaled one week was shown in Veenhof 19960. The maximum number of different hamuštums attested during one and the same month (month $(X$ of eponymy 89 ) is now four.

sos Exact data are dangerous, because many of the theoretically ca. wo thousand week-eponymies of the 'best attested period' are still unknown, many occur without mention of month and year eponym, and there are many namesakes. Selecting only well-known traders with (fairly) unique names, we can state that men like Buzutāya, Elarnma, Imdilum, Pūšu-kēn and Puzur-šadu'e each functioned ca. five to seven times over periods of up to ten years. See for frequency also Larsen 1976, 358f., but his numbers now have to be raised.

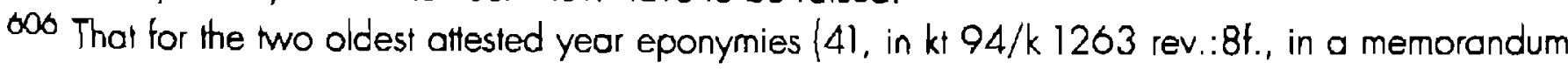
with excerpts of debt-notes - courtesy larsen, and 47, in CCT 1, 10a, a service contract, which usualty is not dated) no week eponyms are mentioned does not mean that they did not exist. The third oldest text, ICK 1, 143:17ff., from year 59, has a (double) week eponymy.

607 See Kryszat 2004a, 160. That some single week eponyms already turn up during the years KEL 96 and 97 may indicate a gradual transition or perhaps a gradual scribal simplication.

608 See Kryszat 2004a, 98 with note 360 (altested for the first month of that year). 
a categoric interdiction to give it ,'no doubl by way of commercial exchange) to Akkadians, Subareans and Amorites. We also hove a very interesting, but completely isolated letter, TC 1, 5, written by a body called nibum to kärum Kanesh, on the payment of a (modest) sum of ten pounds of silver, imposed by the City Assembly as the kärum's contribution to the expenses (gamrum) made for the city wall or fortifications (written BAD.KI) of Assur. We cannot date it, nor do not know what exactly the nibum was, so that its possible political implications escape us. ${ }^{.09}$

The rulers of Assur after Erišum I, who succeded each other as members of one family and dynasty, during a period of ca. one hundred years, notwithstanding some information on their family 10 and the existence of some of their letters addressed 10 karum Kanesh, basically remain shadowy figures. We do not have a single inscription of them and even Šarrukin, with a clearly programmatic name (was it given by his father or as throne name?) and a long reign, during which the trade on Anatolia flourished, is basically just a name, and the same is true of his long reigning grandson Narām-Suen, also called after an illustrious Old Akkadian emperor. ${ }^{11}$

\subsection{The last years of kärum Kanesh level II}

The disappearance of week-eponyms in year 120, seventeen years before the end of kárum level II, deserves more attention. It points to a change in the administrative procedures that was lasting, since they do not recur during the later level $l b$, and may be linked with the remarkable fact that most of the well-known, large archives stop in that same period, usually even a few years earlier. The latest record of the archive of "Püsukēn and Sons" is from year 111, and of that of Enlil-bāni from year 114, and the latest text in the archive of "Imdilum and Son" is dated to year 109 (in OIP 27, 56). 012 The oldest dated records of Elamma, son of Iddin-Suen ' $k t 1991 / 1992 / k$ ), to mention an officially excavated and hence complete archive, are from years 06 and 73, after which he remains active during the next twenly years, 131 to occur for the last time in year 94 , but we do not know when he died. His widow and sons represent him in a legal case of year 105 and there is an agreement from the tenth month of year 106 about the division of his inheritance among his children. This may have been in consequence of the death of his wife, lamassatum, last altested in a record from the second month of year 106, whose last will is referred to in some (undated) texts. Apparently his sons, who already figure in records ten years earlier, carry the business on and the latest dated record in which

000 See the latest treatment of this letter in Dercksen 2004a, 02f.

$\$ 10$ Nate also the occurrence of Salim-Ašsur, son of LUGAL-GI.NA, in kl 87/k 552:40f., most probably a royal prince.

oll The data known on them are presented in Veenhof 2003, ch. 6 .

012 Years alter Imdilum himself, altested since year 78, had refurned to Assur.

013 His naruqqu-contract is from year 77 and he served several times as week-eponym between the years 82 and 91 . 
they appear is from year 115.014 In the archive of Salim-Ašsur, son of Issūrik, excavated in 1994, according to information kindly provided by Larsen, the latest record in which his son is attested is from year 108. The lexts excavated in $1970\{\mathrm{kl} v / \mathrm{k}\rangle$, which belong to Salim-ahum and his two sons, ${ }^{015}$ comprise a few records from early years (68-73), but the majority is from the well documented period, the latest are a debt-note of Ennum-Aššr $\{k t$ $v / k$ 171) from year 112, a letter (no. 81) about a debt from year 117, and a debt-note ( $k$ t $v / k$ 146) from year 119.016

This does not mean that there are no records from last fiffeen to twenty years of level 11. A good example is the archive of Kuliya, excavated in 1992, most texts of which were written between the years 123 and 135, but it is an exception. ${ }^{017}$ A few still unpublished archives might change the picture somewhat, but the generally small number of references for lale eponyms is striking. We have only fiffy eponymic dates from the last seventeen years (twelve of which are in Kuliya's archive), hence on average only three per year, which is quite different from the years 90 to 110 , for each of which we usually have between twentyfive and forty references. Nevertheless these archives, as is clear for those of Elamma and "Šalim-ahum and Sons", were found in situ in their houses, where they still must have been stored when the kärum was destroyed and deserted some twenty years later. There is no textual evidence that their houses had subsequently been acquired or inhabited by others, who then should have left the archives of the previous owners in place. The little archive or rather dossier of Kuliya, with a good seventy lexts, according to the excavator was found stored away in a niche, in an otherwise empty house in grid LV-LVI//26-127.

How can we explain this situation? Their owners may have anticipated the coming disaster, which seems likely because no unburied skeletons were found and the strongrooms contained no valuables apart from tablets. They would have left the karum, taking along their still valid, hence latest records, especially dated debt-notes, while leaving many other records behind. 018 It is also possible, but less likely, that some time after the destruction they came back to salvage such records, again primarily the debt-notes. Another scenario is that after year 110 to 115 more and more traders started to leave karum Konesh, to settle more permanently in other colonies, because the focus of their commercial activities and interests was shifting lowards the cilies in the west or north - Burušhaddum, Wahšušana, Durhumit - which were the centres of the trade in silver, gold and copper. This would have

014 In a record of year 113 one of the sons is summoned to produce a tablet of his father in connection with a disputed debt-claim.

615 I use the texts published in AKT 3 and the records in envelopes, kt v/k 146ff., whose knowledge I owe to the kindness of $V$. Donbaz.

016 In this last text the creditor is Honunu, to whom also a letter of the archive is addressed. A single very late debi-note, from year 134, kl v/k 159, does not seem to belong to the archive; the debtor is an Anatolian married to a daughter of the main person of the archive of $k t 94 / k 570 f f$., Śalim-Ašsur.

017 We have two earlier eponymies, one of year 90 , in a long memorandum, and one of year 105 , which deals with a debt-claim of Kuliya's mother. See note 314.

018 This distinction is not without problems, because it is difficult to delermine the date of undated letters, judicial records, and lists. 
meant that kärum Kanesh with its houses remained intact, but functioned ever more as the administrative center of the colonial network. This would fis the noture and dating of Kuliya's archive, since he acted as a messenger of the kărum and therefore must have been more tied to the "colonial capital" than others. Official letters of kärum Kanesh addressed to various Assyrian settlements, found in his archive, 619 show that he traveled to Assyrian settlements in Hanaknak, Haltuš, Kuburnat, Ninašša, Šinahutum, Tamnia, Tišmurna, Tuhpia and Durhumit, and this suggests that the trading network was still functioning. The main cities (and colonial settlements) to the (south-least - Timilkia, Hurama, Luhusaddia, Kuššara, Tegarama - and to the (north-) west - Burushaddum, Wahšušana, Wašhania - are indeed not mentioned in these letters. But is this really proof of disintegration, of a situation in which the latter cities would have been "out of reach of the central colony in Kanesh at the time", as Dercksen suggests? 2020 Kuliya's commission apparently wos to make a circular trip in the area north of Kanesh, within the great bend of the Kizlirmak, and other messengers may well have been sent out to inform the cities in the areas more to the west and east. One of his lethers in fact does mention Wahsiušano and the letters $\mathrm{kt} n / \mathrm{k} 67,021$ sent from Wahšušana to Kanesh, and kt $83 / \mathrm{k} 284,{ }^{\circ 22}$ sent by kärum Wahšušana to Kanesh, deal with the same issue of the collection of the tax on iron and from traders arriving via the sukinnu-route. ${ }^{623}$ However this may be, it would be understondable that a situation with fewer active traders in karum Kanesh led to the abolition of the system of week-eponyms, either because the administration did no longer need it or because there were too few competent traders available to do the job.

It is not easy to prove this hypothesis. While we have references to various traders who live or stay (the verb wašäbum is used in both meanings) in other colonies, or even have a house there, it is difficult to date these references and to discover a pattern, which may only be possible by thorough archival and prosopographic analysis. In the mean time the development suggested seems to offer the most "natural" explanation both for the end of the system of week-eponyms and for the lack of records dated to the last fiffeen to twenty years.

The destruction of level II of kärum Kanesh must have been the result of a military conflict inside Anatolia, but we cannot identily the actor(s), nor do we know wherher it affected only Kanesh. The possibility that its destruction was due to its conquest by king Uhna of Zalpuwa t the northern Zalpa, possibly lkiztepe, northwest of Bafra!, mentioned as an event of the past in the "Anitta Text" (obv. 39ff.), cannot be proved. ${ }^{624}$ While a destruction of the whole of the colonial network, stretching from the Pontus to the Taurus and from the Tuz

019 Cecen 1997a and cl. Dercksen 2004a, 114H.

020 Dercksen 2004a, 110.

o21 Donbaz 200la.

022 Günbattı 1995, 111 .

023 Note also the interesting suggestion by Dercksen 2004a, 144, that in the Assyrian system Kanesh and Burushhaddum may have been "two separate tax districts".

624 Possibility suggested by Klengel 1998, 20. Uhna's campaign connot be dated and it is not certain that it resulted in the destruction of Kanesh. 
Gölü (or even the plain of Konya) to Malatya, is very unlikely, a larger area than Kanesh is feasible, but evidence is hard to bring. We know that there was a kärum Hattuš during the level II period, ${ }^{\circ 25}$ but all dated texts found there, with one exception, belong to level $\mid \mathrm{b} .026$ The same is irue of Amkuwa, which during the period of karum Kanesh level II was the seat of an Assyrian wabartum, ${ }^{627}$ but yielded only one isolated record (OIP 27 no. 8) from this period, dated to year 115. These two Assyrian settlements consequently should have noticed the effects of the destruction of Kanesh, but they remain silent. Moreover, there are clear traces of a major destruction and conflagration at Boğazköy, which spelled the end of level IV, which is conlemporary with kärum Kanesh level Ib, not with level II. We can only state that neither Amkuwa nor Hattus have yielded a single text dated to one of the good twenly years (whose eponymies are known from the Mari Eponym Chronicle) following the destruction of karum Kanesh level II. But this is negative evidence, weakened by the small number of texts available.

In an undated letter ( $k \uparrow 92 / k$ 248) two men, Alpili and Aššur-lamassi, writing from Tawinia, located southwest of Hattuš on the road that leads across the Kizilrmak to Wahšusana, ${ }^{628}$ tell Kuliya:

"We are well, we are staying in Tawinia. We are catching rumors that the residents (wašbütum) of Wahsusuana have left. Within two days, when we will hear the facts, we will let you know by letter where we will iurn". 629

Dercksen 2004a, 116, suggests that the departure of Assyrian Iraders could be due to political turmoil, which is not impossible. And since Kuliya's archive is lote, one might even assume that the political upheaval is foreboding the destruction of Kanesh. While it is true that also the native population occasionally left the cities en masse, for a public, perhaps military event called sikkätum, ${ }^{030}$ it is rather likely to toke "residents" ( wašbütum) as referring to the Assyrians. The verb in our lexts is used to denote that traders are temporarily staying somewhere, during a caravan journey or for doing business, as the writers of our letter use it, but also to denore that traders had settled in a town, in a kārum or wabartum, which may have given them a certain status. An official letter of kärum Kanesh on the lewying of the sadd' 'utu-tax owed to it ( $k 192 / k$ 203:32, Veenhof 2007b no. 2) prescribes that every Assyrian who carries out business (sutebbulum) in a particular town has to pay it, "even when he is a resident of the kărum" (/u wäsib kārim), which could reter to the local kārum

025 Apart from the unpublished and untracable text, mentioned as evidence in Nashef 1991, 58, we now have clear evidence from $\mathrm{kt} n / \mathrm{k}$ 1952:19f. and $\mathrm{kt} 92 / \mathrm{k} 203: 3$.

626 See Dercksen 200la, 59 an KBo 36, 113.

627 See Nashef 1991, 9, and now also kt a/k 1070 (letter of kärum Kaniš to it) and k/k 101:14f. (verdicl).

628 Se for Tawinia as the seat of an Assyrian kārum, below chapter IV.2 no. 26, and for its location on the road to Wahšušana, ATHE 63, $18 f f$.

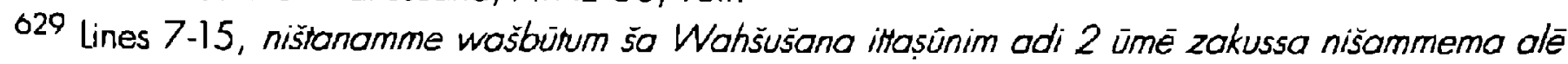
nipannú nišopparakkum.

030 See for sikkäum, Veenhof 1989. During the time a sikkātum lasted no trade was possible and Assyrian activity could even be somewhat dangerous. 
or to that of Kanesh. The term is found in a few other lexts, twice in the combination "the dätu-payers, the residents of Tuhpia, and those traveling to the City" I wäsbütum sa GN u alikü harrän ălim), ${ }^{\circ 31}$ similarly in a text from Hattuš, which speaks of "those who reside in Har $z i$ ik $-[x \times]$, those traveling to the Ciry, and kärum Hattus"," 032 and finally in a text 033 that mentions "the residents of the town of Hamalah[...]".

In all these cases the "residents" are involved in legal matters, they figure as a group of traders who happen to be present in a particular town where they function as members of an ad hoc body or court. Apparently one makes use of the presence and expertise of temporary residents and visitors, perhaps because the town in question did not harbor a real Assyrian colony but only a limited number of Assyrion traders, ${ }^{634}$ who could not or no longer function as court. I assume that wašbütum ${ }^{635}$ here designates those who happen to stay and work in a particular lown on a temporary base. It reflects the reality that many Assyrian traders, permanently based in a particular kárum or wabartum, where they owned a house, travel around and in the course of their trips are regularly staying for some time in a town used as a basis for regional commercial activities. In our letter a distinction between permanent and temporary residents is impossible and of little use. The writers of the letter, agents or transporters traveling with merchandise, simply state the the Assyrian traders of Wahsiušana have recently (perfect tense) left the city, so that no trading activities are possible there and they have to find another destination. ${ }^{636}$ As a general statement it is remarkable and suggests a specific event, but we don't know what and when, and this makes it risky to consider it a major crisis somehow linked with the destruction of Kanesh.

Another serious event in Wahšušana is mentioned in the letter kt 87/k 40,037 important enough to become the subject of a letter sent by the ruler of Assur to the plenary karrum Kanesh. We read:

"We hear that native Anatolians and traders (mäkirū) are carnying (zabälum) valid records belonging to merchants (tamkārē) out of Wahsususana and that 'small men

631 Prag | 478:1-3; kt 87/k 552:26f. (courtesy Hecker), cf. note 334.

632 KBo 9, 28 rev. 2'ff., see Dercksen 200la, 60 note 11, who also mentions the heading of the very damaged letter $\mathrm{KBo} 28,181$, but his restoration is uncertain and especially the co-occurrence of karrum [Hattuś] and the [üśbutim sa] Hattu[ $\dot{s}]$ is very doublful.

$633 \mathrm{Kt} 94 / \mathrm{k} 354$, courtsey Larsen.

034 Tuhpia did hove an Assyrion wabartum, which could act as a court, see KTK 107, 13. See for these ad hoc judiciary bodies or courts, abve chapter II. 2.1.

${ }^{635}$ A verbal adjective, which may occur alongside the participle wösibüum, cf. wašbü GN, ARM $8,11: 9$, alongside wāsibüt alim, see CAD A/ll, 429,b. The expression is unusual becouse "the inhabitants of GN" normally is wasbüt or wäsibür GN, without sa. In another context, according to Dercksen 2004a, 126f, wasbum is the designation of a trader who is "present" in the colonies and availoble for accounting, contrary to who is lassisu um, "absent", o troder (returned to and) living in Assur, but this meaning does nol fil here.

"30 pana "um, "to turn to", always with personal dative for the person(s) one turns to in order to achieve something.

037 Hecker 2003, 187t. 
(șahhurūtum) are buying them all the time in the countryside. Please, as soon as you hear this letter, produce ... (end of the obv., edge and beginning of rev. missing) ... let them buy any lablet belonging to a merchant, which the natives and traders have brought out of Wahsušana, collect [these] tablets and let the owner of these tablets pay you the same amount of siver you have paid/for them/ and let them take their tablets (back). And who has bought a tablet, but conceals (katāmum) it and does not bring it before the kärum, or [because] he has [no witness available], does not pay silver, and whose statement [reaches] the City, identify his ... and then let the Ciny [decide his case]."

This text describes a serious crisis in Wahšušana, where the archives of the local Assyrian merchants (tamkārü) have been plundered and their "valid contracts" are being carried out of the city in large quantities (the verb is used of heavy loads) by native Anatolians and local (Anatolian) traders. ${ }^{038}$ The highest authorities in Assur now give instructions on what kārum Kanesh should do to get these records back, which apparently are being offered for sale by the thieves and are being bought by junior Assyrian traders. ${ }^{639}$ This letter cannot be dated, since it does not contain a single personal name, but it could, theoretically, be connected with the previous one, on the assumption that the departure or perhaps flight of the Assyrian residents of (kârum) Wahšusana would have enabled the thieves to do their work. It could then be considered an additional piece of evidence for serious troubles which lead to the end of kârum Kanesh, also because it is difficult to imagine that such a disaster could have happened in normal times, when the treaty with Wahšušana and its ruler was in force. But we cannot prove this nor exclude the possibility of a purely local crisis, comparable to the "hostilities" in Kanesh (mentioned in kt $\mathrm{n} / \mathrm{k}$ 1429:14). This letter, at any rate, describes not a sudden catastrophe, but a long process, which must have taken many months, because reports on the events at Wahšušana must have first reached kărum Kanesh, then Assur, where the City decided on a strategy to counler them, whereupon its decision was sent back by letter to Kanesh.

We have to conclude that thus far the archival texts do not offer us a clue for what happened at the end of the period of level II. We still have three texts dated to the one but last year, 136,040 and the documentation simply ends with a text dated to the second month

638 The noun mäkinum, from the verb makärum, "10 trode, barter", is rare. I assume that it refers to local traders, who do not belong to the Assyrian community (somewhat comparable to päsirum, used for local retailers). Another occurrence in BIN 4, 2:5, but BIN 4, 73:8, also listed in CADM/I 129a, makirši<nas renders mahiršina, "(there is no) market for them".

039 See also Dercksen 2004a, 238, with nole 633. I do not share his opinion that what the "junior traders" did was a "serious crime". They may have acted to reduce the damage by buying the records from the Anatolions and the letter from Assur probably wants to regulate this process, by ruling how they should be refunded by the karum and how the owners could get their records back.

O40 KTB 14:1-17 mention four payments 10 its unknown wriler of in all 8 minos and 27 shekels of silver, in months $N, V, V I$, and $1 X$ of year 136. The first poyment, made for Atata by his brother, is part of the debl of Arata (who must be dead) which his brother, wife and son, according to TC 3, 250, had promised to pay one year earlier. 
of eponymy year 137, which records that Laqipum had given Puzur-lštar sixteen shekels of silver in the presence of two witnesses. There is no hint of an approaching disaster, but the fact the Kuliya's texts (among which almost no contracts!) were carefully stored in a small niche, under a reed-mat, indicates that felt the need to leave, but may have hoped to come back later.

\subsection{The Later Oid Assyrian Period}

As mentioned above (chapter 1, 1.3), the rebuilding of kärum Kanesh and the resumption of the trade during kârum level lb must have taken place during the reign of Samši-Adad 1. We cannot date its beginning exactly, ${ }^{\circ 41}$ but we must ask what influence the rule of this dominant king might have had on the trade. We can take for granted the king's interest in this prosperous trade, which must have benefited his realm and he may have stimulated it. We know that he was involved in it, perhaps in particular on a diplomatic level, by gift exchange and perhaps in order to secure the position of the traders in Anatolia, since bullae with his seal impressions (probably attached to packets with merchandise or letters) were found at Acemhöyük, together with sealed bullae of Assyrion traders and of the "City Hall of Assur". 642 We may assume that, when the commercial activities of the Assyrians were resumed at the beginning of level $\mathrm{lb}$, the statute of the Assyrian traders in Kanesh had again to be secured and (to some extent) be redefined by new commercial treaties. And it is tempting to consider the two new level lb treaties with Kanesh and Hahhum a reflection of these events, which must have fallen in the first half of Šamši-Adad's reign, perhaps not without his interference. This could apply to the trealy with Hahhum, which cannol be dated, 643 but the trealy with Kanesh is of later date, because it mentions "the great king of Kanesh" (see below chapler V.2.1).

Resumption of the Anatolian trade during Šamši-Adad's reign of course raises the question of his and his successor's influence on it. An official first attested during this period in Northern Mesopotamia is the "Overseer of the merchants" (UGUIA DAM.GAR). On the

041 Commercial contacts with Anatolia no doubt will have become easier after his conquest of SubatEnlil (Apum, Tell leilan), which was a road station for Assyrian caravans on the way to Anatolia, and after his defeat of Yahdun-Lim of Mari, in co. 1794 BC, which meant that no rival was left to interfere with the commercial traffic through the area of the Habur and the Balikh.

042 See Tunca 1989 and 1993, note 1, and Veenhof 1993, 050ff. It is remarkable that the bulloe with this seal impression carry an inscription that implies that the packets, apparently without having been opened, were shipped on from Kanesh to Acemhöyük. Whatever the reason for this, it proves that the lines of communication were operative.

643 Ductus, paleography and orthography allow this, because they are similar to that of tablets of level II, but different from those of the later phase of level Ib, as illustrated in Özgüc 1986, plates 44ff. Hahhum, moreover, though not mentioned in the texts from Mari, was on or near the Euphrales, probably at the site of classical Samolhrace (modern Samsat), therefore close to the northern border of Šamši-Adad's reaim. 
basis of $A b B$ 8, 15, where we meet a man designated as "the Overseer of the merchants of Šamši-Adad", who calls the latter "my lord", I had suggested that he might have been appointed by the king, in order to check the city's trade and traders, but this was rightly questioned by Charpin and Durand, because there is no evidence for a royal appointment. ${ }^{\circ \Delta 4}$ We also do not know whether he was an official in Assur, though a man in that city would have been well suited for a diplomatic mission to the south (to Mashkanshapir?), in order to establish contact with Rim-Sîn of larsa. Still, this title is new in this area and his designation implies more than an ad hoc service to the king. A second occurrence of this tille, "Overseer of the traders of Assur", occurs in ARMT 26,342, from the reign of lšmeDagan. Both references may reveal an administrative innovation, which could have been introduced by Šamši-Adad I, who must have become familiar with this institution during his stay in in Babylonia. But it is also possible that the trading community of Assur itself, faced with a new, non-Assyrian king, who had already interfered with the institution of the limum, had decided to appoint one of their own as their representative and leader, especially in the contact with the palace. ${ }^{645}$ According to ARMT 26, 342, during a farmine this official rried to secure the supply of barley for Assur by sending a gift to the ruler of Karano. ${ }^{646}$ Charpin and Zieglero47 assume that he came to play a more political role in a crisis situation, a power vacuum, after lšme-Dagan had fled his country. Whether or not this function was an innovation, stimulated by the king, it clearly was a new feature, but we do not know whether it survived this period. This official at any rate does not figure in the preserved text of the rrealy between the ruler of Apum and the City of Assur, concluded some twenty years later (see below), which only speaks of the city of Assur, travelling Assyrian traders and the karum, he is absent in the texts of the new treaties with Kanesh and Hahhum, and also does not figure in Middle Assyrian documents.

We can to some extent follow the fale of Assur under lsme-Dagan until ca. $1760 \mathrm{BC}$, thanks to the archives of Mari, which also provide evidence that the city continued to play an important role in the trade in Northern Mesopotamia and beyond. ${ }^{448}$ Involvement in Anatolian matters is now also documented by a still unpublished letter, written to king Hurmeli of Harsamna by the Envoys of the City of Assur, in response to a request for military assistance. 649 lšme-Dagan's dynastic capital Ekallätum was not far to the north of Assur

\section{Veenhof 1982, 385 and Charpin-Durand 1997, 3731.}

645 This aspecl of the function, mediating between the traders (or kārum) and the palace, is also attested in Larsa and Sippar. Note also the designation qaqgad kārim, "head of the kārum", in $A 6 B 1,36: 19$.

640 Charpin-Durand 1997, 373, assume that this also happened because Karanä was an imporlant rood station on the caravan route to Anatolia.

647 Charpin-Ziegler 2003, 236. The text continues by reporting that "all of Assur is trying to exercise control in Karana" (ustallat, line 19), presumably in order to secure the access to barley.

648 See Ziegler 1996 and Charpin-Durand 1997, 37 bf.

${ }^{049} \mathrm{Kr} \mathrm{Ol} / \mathrm{k} 217$, see C. Günbatt 2004, 249, Albayrak 2004, and Michel 2005a. The king of Harsamna had asked for Assyrian military assistance in a conflict with Zalpa, shorlly after the death of Samši-Adad I and the accession of Išme-Dagan. 
and several letters show that he occasionally stayed in Assur and also used its troops in his military operations. ${ }^{650} \mathrm{He}$ cared for Assur and its cults, ${ }^{651}$ and from later Assyrian royal inscriptions we learn that he was active as a builder there. ${ }^{052}$ Concern was not only politically sensible, but may have been stimulated by the fact that his wife, called lamassi-Aššur, was from Assur, perhaps even a girl from the family of rulers ousted by Šamši-Adad 1.053 Assur also shared his political misfortunes, when he had to flee his country and capital three times, in 1771 (when Eshnunna occupied Assur), 054 in 1765, and in 1763 BC. 055 Išme-Dagan was succeeded as nominal ruler of the city by Hammurabi of Babylon, in ca. 1761 BC, when, according the name of his 33rd year, he subjugated "various cities of the land of Subartum and Ekallätum" (the residence of Išme-Dagan), a success which was consolidaled by additional campaigns in his 36th and 39th years. It must have included Assur, to judge from a statement in the prologue to his laws (col. IV:53-58), where he expresses his concern for the city and its people. ${ }^{650}$ After that, during the reign of Samsu-iluna of Babylon (1750-1712 BC), the information on the city becomes scarce, although AKL lists a continuous series of rulers. ${ }^{\circ 57}$ We have evidence for the continued role of Assur as a trading city, both from documents found at Sippar, dating to the early years of Samsu-iluna, and from the trealy concluded around 1740-1735 BC between Till-Abnû, the ruler of Apum (capital Šehna = Tell Leilan) and Assur. ${ }^{058}$ That Apum's ruler had to swear an oath to "the City of (the god) Ašsur, the citizens of Assur travelling up or down, and to the kārum that is in your city", shows that Assur's institutional fabric (without mention of a king or ruler!') was basically still the same as a century earlier and that trade remained very important.

050 See e.g. ARMT 26,411:32, together with troops of Babylon and Ekallatum, under the command of his son Mut-Asqur.

651 See Charpin-Durand 1997, 372f.

052 See RIMA 1, 95, lines Off. It is frequenly assumed that when Tiglath-pileser 1, in RIMA 2, 28, lines 60ff., states that the Anu-Adad temple had been built 701 years before his time by Šmši-Adad son of Išme-Dagan, this is a mistake for lšme-Dagan son of Samši-Adad (I), though RIMA takes the builder to be Śamši-Adad III.

653 See for her letters P. Marello, MARI7 (1993) 271-279.

054 See Ziegler 2002, 238f. with note 114.

055 See Charpin-Durand 1997, 372 note 43, and Charpin-Ziegler 2003, 198 and 235t., also on the role of Assur's "Overseer of the merchants" during the absence of Išme-Dagan.

056 The words "who guides the population (ammi) properly ond who restores its benevolent protective spirit to the city of Assur", whatever they meant in concrete, attest to his respect for this ancient cily.

057 The main recension of AKL, King List 9, after ls̀me-Dagan lists an usurpator and six kings who ruled for short or unknown periods (bäb ruppisu). A fragment of a different recension (Grayson 1981, 115, King list 10), mentions as successors of Išme-Dagan his son Mut-Asqur (known from sources from Maril and o Rimulš], both of which do not figure in King List 9. AKL also does not include Puzur-Sin, known from his inscriptian RIMA 1, 77f.

658 See for the evidence from Sippar, Veenhol 1991, and for the trealy with Apum, Eidem 1991 and below V.I.B. 


\subsection{The end of KÄrum Kanesh level lb}

Not long afferwards written sources from karum Kanesh stop, which effectively marks the end of level $\mathrm{lb}$. In my reconstruction of the chronology I mentioned that one of the presumably latest year eponyms attested in a text from kärum Kanesh was that of Nimar-Kube, who also occurs (as Nim/wer-Kubil on texts from Tell Leilan. There he is associated with the city's last ruler, Yakun-Ašar, who lost his throne in $1728 \mathrm{BC}$ in consequence of an attack by Samsu-iluna of Babylon, commemorated in the name of the latter's 23 rd year. ${ }^{659}$ This conclusion is now supported by a new eponym list discovered at Kanesh in 2001 (kt 01/k 287), to be published by C. Günbattı, which offers the names of ca. 120 eponyms after the last one listed in KEL A, which means that it must go down to o least ca. $1725 \mathrm{BC}$. And this is not necessarily the end of this period, since this list need not date from one of the very last years of kārum Kanesh level lb, which may very well have continued until 1720 BC.

The destruction of kärum Kanesh level ib must have been the result of a military action, and there is sufficient evidence for political tensions in this period. The so-called Anum-hirbi letter mentions a protracted war between king Inar of Kanesh and the city of Harsamna. ${ }^{600}$ And this same city, under a king Hurmeli, had a military conflict with Zalpa according to a still unpublished letter (see note 649). There are also stories about military confrontations during this period in the so-called "Anitta Text" and in fragments of legends dealing with Anitta and Anum-hirbi (Anum-herwa), both found at Boğazköy. ${ }^{601}$ Miller 2001 has recently shown that Anum-hirbi, king of Mamma (north-west of Maras), in due time, as indicated by sources from Mari, extended his rule over Zalpa (in Mari Zalp/war, possibly Tilmen Hüyük, west of the Euphrates) and later also over Haššum (perhaps near Gaziantep), which made him a major political player in the South-Anatolian area, perhaps the very king of Zalpa ${ }^{662}$ who threalened Hurmeli of Harsamna ${ }^{003}$ according to the new lether.

How do these rulers and their military actions fit into this period? As shown by Miller, Anum-hirbi's career, the length of which of course is unknown, falls in the first half of the 18 th century $B C$ and the evidence from Mari suggests that it may have ended some years after $1770 \mathrm{BC}$, which fits a conflict with the ruler of Harsamna in ca. $1775 \mathrm{BC}$. Since Anum-hirbi mentions the good relations between his land ${ }^{604}$ and Waršama's father and

\footnotetext{
659 See Veenhof 2003, 67.

660 Balkan 1957, 7, lines 29ff.

661 See Miller, 2001, 97f.
}

062 The request of Assyrian assistance makes it unlikely to think of the northern Zalpo/Zalpuwa, situated near Batra.

003 We do not know the location of Harsamna, which occurs only once in an OA text / from the citymound ( $\mathrm{kt} \mathrm{g} / \mathrm{i} 35: 30$, alam Harsamna), but the town must hove become prominent in the course of the level Ib period. In texts from Mari, from the time of Zimrilim, it is mentioned as a source of luxury goods (astalü) and as a ciry from which horses could be oblained (Ziegler 1996). The sequence "from Koniš, Harsamna and Hattuša" in the first letter and the fact that in both cases the commercial contacts started from Karkemiš, suggest a location in Central Anatolio.

004 Note that he writes "my country" and not "my father", but I am not sure what this might imply. 
predecessor Inar, ${ }^{005}$ who ruled at least ten years, ${ }^{600}$ the latter must be dated fairly early in the 18 th century $B C$, not long atter the beginning of the period of level lb. And since Inar must have been preceded by king Hurmeli, as shown by $\mathrm{kt} n / k 32, \infty 7$ it is impossible to insert the sequence Pithana - Anitta at the beginning of the level lb period, so that they must be placed at the end of it. The "Anitta Text" tells us that Pithana, king of Kuššar, conquered Kanesh/Neša, took its king captive, but spared the city. After his death a revolt in Neša would hove been put down by his son and successor Anitta, who subsequently made the city his residence. Wars against the northern Zalpa and Hattuša (which was utterly destroyed) are described and it is finally related how he was recognized as "great king", even by the people and ruler of the powerful state of Burushaddum. If we believe the main facts of this story, ${ }^{608}$ the conquest of Kanis by Pithana need not have had a profound effect on the trade and indeed, no hints or references to his conquest have thus far been found in the admittedly not very numerous level $\mathrm{lb}$ texts. Pithana it attested as ruler of Kanesh in the "notarization" of three documents, the divorce TC 3, 214, the slave sole $\mathrm{kt} n / \mathrm{k} 11$, and perhaps in the adoption contract $\mathrm{kt} 89 / \mathrm{k} 379.069 \mathrm{He}$ is succeeded by his son Anitta, who already figures as his rabi simmittim in TC 3,214 , and occurs as rubä um in $\mathrm{kt} 89 / \mathrm{k} 37$ (a record of the redemption of a slave). He also occurs in texts from Amkuwa (OIP 27 nos. 1 and $49 \mid$, both as rubä'um and as rubä um rabium, which suggests that both city-states

005 Mentioned once as king of Kanesh in the so-called notarization of $k t n / k 32: 49$ / with Šamnuman as his rabi simmilfiml, see below chapler IV.2.5.1.

000 That long he warred with Harsamna according to Anum-hirbi's letter.

067 This unique legal lexl (see now Dercksen 2004b, 166f), as shown by Forlanini 1995, most probobly records the dissolution of a partnership between on Assyrian trader and wo Anatolians, nolarized by king Inar of Kanesh and his rabi simmilfim (lines 27ff.) The involvement of (iqaate) king Hurmeli and his rabi simmilfim (lines 18ff.) must concern the start of the partnership, betore the reign of Inar, mentioned as background of the present settlement. The words "both in Mamma and in Konesh" (lines 20f.) do not mean that the two kings mentioned were kings of these two cities, but indicates the range of action of the partnership (the Anatolian party may hove worked in Mamma). In general I agree with the interpretation in Dercksen 200la, 03, but I doubt whether the traders operated "by order of the Kaneshite king". Taking Hurmeli as king of Kanesh is supported by the fact that his rabi simmiltim Harpatiwa occurs, without mention of the king, in the notorization of $k t r / k 19$ /a divorce) and $k t 99 / k 139$ (a debl-note), and also in OIP 27 . 53 :13f., trom Amkuwo (here also Kikarson!, priesl of Higisa, who olso figures as wimess in kt $n / k$ 32), which might indicate that Kanesh and Ankuwo al that time were under the same rule. Forlanini suggests that these occurrences of Harpatiwa alone, without being called ruba' um, may indicate that he operated in the period between Hurmeli and Inar, perhaps thanks to a coup d'etat.

068 See the summary in Klengel 1998, 27ff.

009 See for the notarization of legal documents by the rulers, below chapter IV $2.5 .1 . \ln \mathrm{kt} \mathrm{n} / \mathrm{k} 11: 11$ 'ff. I read "He will pay 5 minas of silver ${ }^{12}$ i i-d [u-ku-su i-qa-ke] ${ }^{13}$ 'Pi-ir-ha-no (without ruba' 'im). The reoding [igqōé Pithan]a in kt 89/k 379:24 (Donbaz 1993a, 137) is more doubtful, also because the following rubo' um is not in the genitive. 
were now united under his rule. ${ }^{670}$ This makes it difficult to connect the destruction of kärum Kanesh level Ib with Anitta's suppression of a revolt in that cily, as told in his text. But his destruction of Hattusa could be connected with the conflagration which spelled the end of level IV in Boğazköy (IVd on Büyükkale and IVa in the lower lown, where the Assyrian trading community lived\}, which then would have taken place before the end of kārum Kanesh level $l b{ }^{671}$ This leaves the question open how and when level lb of karum Kanesh came to an end. One might try to connect it with the end of Anitta's reign,, 072 but there is a complication in the appearance of Zuzu, "great king of Alahzina", attested in two records found at Kanesh. ${ }^{673}$ His title does nol identify him as king of Kanesh and one might assume that these records were drawn up elsewhere and somehow ended up in Kanesh. But Forlanini has pointed out that there is a clear relation with Kanesh, 674 because two men who appear in $\mathrm{kl} \mathrm{j} / \mathrm{k} 625$ (one of them Kammaliya, the priest of the storm-god) also turn up in $\mathrm{kt} 89 / \mathrm{k}$ 371 , which is "nolarized" by Anitta. We can solve this problem by assuming that Anitta was succeeded by the "great king" Zuzu, who might have conquered Kanesh, while (at first?) retaining his original title. This would also explain why Anitta's rabi simmiltim Peruwa did not succeed him on the throne. ${ }^{675}$

Lacking many pieces of this historical puzzle, we can only say that this last proposal at present seems to be the solution which takes all available evidence into account. But it would also mean that Zuzu's conquest(?) of Kanesh did not mean the end of level lb, since legal documents were still produced after he had become the ruler of Kanesh, which leaves the question who was responsible for the destruction of kärum Kanesh level lb open. But it supplies us at least with a rather impressive list of rulers of Kanesh: Hurmeli, Harpatiwa(?), Inar, Waršama, Pithana, Anitta, and Zuzu, certainly enough to fill the ca. eighty years of the level lb period. 676

670 This would be even clearer if we may identily Anitta's rabi simmiltim in Amkuwa, Peruwa, from OIP 27, 49:25, with his rabi simmiltim in kt 89/k 371:27f., from Kanesh, called Peruwa-Kammalia. See for rulers of Amkuwa during the level II period, Larsen 1972, on KTK 10, and also $\mathrm{kt} n / \mathrm{k}$ 1374:8ff, and the nisbe Amkuwaium in kt $\mathrm{n} / \mathrm{k} 482: 17$ and 490:8 (courtesy C. Günbattl).

o7 This is not impossible considering the eponymies found in dated lexts from Boğazköy /see for those in the archive of Dāya, Dercksen 2001a, 40, and for the others, Veenhof 1985, 204f.). EnnamAšsur is attested at Mari, Tuttōya at Tell Rimah, only the positions of Dadia, Edinum, en Zazabum are nol centain. Dercksen 2001a, 50 note 60, considers the first two late, but this could still be well before the end of level $\mathrm{l} b$, which after all lasted at leost eighry years.

672 Anitta's rabi simmiltim. Peruwa, is not attested as rubäum, as his succesor.

$073 \mathrm{Kt} / \mathrm{k} 625$ and $\mathrm{kt} 89 / \mathrm{k} 369$ (see Donbaz 1989a, 84 and 1993a, 143), where his tille is written both as rubä'um GAL and LUGAL GAL. See below IV.5.1 on nos. 23-27.

674 Forlanini 1995, 29.

675 The last line of the new trealy between the Assyrians and Kanesh from the level Ib period (Günbatt, 2004, 253:89) mentions that the ruler of Kanesh was a "greal king", therefore, for all we know, either Anitto or Zuzu, but unfortunalely his name is broken off. It is anyhow likely that this trealy was concluded becouse a new king had acceded to the throne of Kanesh, so that 'the oath' had to be renewed.

670 Since native Analolian records that mention the local kings are not dated, we can only speculate about the lengths of the reigns of these rulers. Only prosopography, which occasionally may provide a link with Assyrian records of this period, may provide some clues. 
It has been suggested that the end of the Anatolian trade may have been due not only to political turmoil in Anatolia, but also to developments in Mesopotamia. Samsu-iluna's raid - in 1728 BC on Šehna (Apum), a town with a kōrum and a traditional road station on the way to Anatolia, resulted in destruction (and the end of the written documentation there) and this may hove harmed the Assyrian trade. But its impact cannot be established and the new eponym list indicates that the trade on Anatolia and contacts with the colonies there continued at least for another ten years. Other political players may have come in the way of the Assyrians, such as the rulers of Yamhad (Aleppo), who tried to strengthen their grip on northern Mesopotamia, as we know from the texts discovered at Tell Leilan. Some lexts also reveal that in these times military security, essential for caravan traffic, could become a problem, as the appearance of people or troops, designated as habbötum, "robbers", shows. ${ }^{677}$ But we do not know details and the possible effects of these developments are difficult to assess. They can, moreover, not be isolated from the more general picture of Assyrian trade during the level ib period, in which the Assyrians anyhow were much less prominent and important, as the small number of written documents (ca. 350, and part of these concern Anotolian people) already indicales. Dercksen, on the basis of his analysis of the lexts from Amkuwa and Hattuš, concludes that "the extent of the area covered by the Assyrian trading network of level lb seems to have decreased and this must have offected the trade in a negative way. Except for the remaining wealthy traders ${ }^{678}$ a general impoverishment is discernable, expressing itself not only in the volume of the merchandise, but also in the number of cases where Assyrians had been detained by a native creditor for insolvency". When kārum Kanesh level lb came to an end Assur itself, as indicated by AKL, was already in a "dark period", marked by political confusion. The decline and end of the profitable Anatolian trade must have had a very negative effect on what was a typicol trading centre and it may well have contributed to its crisis, but we lack textual data to prove it.

077 See Dercksen-Donbaz 2001 on $\mathrm{kt} 98 / \mathrm{k} 11$, which mentions problems on the roads and a rebellion of habbätum (used as auxiliary torces in these times and ottested as such in texts from Tell Leilan) who now control the mountains.

${ }^{678}$ Such as Eddin-Ašsur, the Assyrian member of the partrership described in $\mathrm{kr} n / \mathrm{k} 32$ /see above note 667). which was to trade in silver, gold, iron cups, tin, textiles, slaves and lapis lazuli, both in Kanesh and Mommo. 


\section{THE ANATOLIAN SCENE}

\section{THE POLITICAL AND ECONOMIC IANDSCAPE}

Trade on and in Analolia and the crealion of network of trading stations there must be understood within the framework of its economic and political landscape.

Our knowledge of the economy is restricted, because most records reflect the commercial interests of the Assyrians, as sellers of imported lin, textiles, lapis lazuli, and iron, as traders in Anatolian wool, copper and iron, and as buyers and exporters of silver and gold. In doing so they also document commercial contacts with their Anatolian customers, buyers, sellers and debtors and provide some information on the native economy. But these transactions concern a rather specific sector of it, mainly that of the elite of Anatolian businessmen, officials and the palaces. And they usually show less concern for these customers than for issues of transport, cost and yield, unless problems encountered are the occasion for providing a little more background information. Frequently this information is rather general - political unrest, trouble, travel suspensions, and disturbance of the market. ${ }^{679}$ But there are also purely Anatolian records which provide more insights, especially those which belonged to or dealt with Anatolian merchants and money-lenders, which document loans and debts, frequently of grain but also of silver and copper, some consumptive laons, others reflecting local rrade and credit. Some mention the securities agreed upon (pledging of family members, houses and occasionally fields) and the consequences of default, which could lead to forfeiture or formal sale of fields, 680 houses and people. Some records shed more light on Anatolian sociely and economy, especially those from a few Anatolian archives that document family law, but unfortunately, only selected documents have been published. ${ }^{681}$

The nature of the goods traded by the Assyrians did not ask for regular contacts with the rural population and their subsistence economy, which was based on agriculture and herd-

${ }^{679}$ See 11.2 .6 for revolis (sahä'um, sihitum), hostilities or war (nukurätum), the events called sikkärum and sukurtum (see CAD S s.v.); note also kt 94/k 1002:5 (mötum dalhat). See for disturbance of the market, Veenhof 2003d, $105 \mathrm{ff}$. (with earlier literalure). There are also cases where due to conflicks a palace detains traders and does not let them depart freely (wašsurum), and there is an awareness that trade is impossible when the country is busy with the harvest (esädum or ebürum. TC 3, 3:22f.; BIN 4, 39:7ff.).

${ }^{680}$ A conditional sale in kt 84/k 169, analyzed in Bayram-Veenhof 1993, 92ff; a (forced) sale in kt $\circ / \mathrm{k} 52$ (four fields and an orchard, with shared use of the available irrigation water, see Albayrak 2001), fields pledged in $\mathrm{kt} k / \mathrm{k} 31$ (courtsey Hecker) and $\mathrm{kt} f / k 84$ (silver borrowed in exchange for holding tields, ana eqlätim kura'ulim).

687 Interesting lexts ore found in the groups $k \mathrm{~d} / \mathrm{k}$, some of which were published in Balkan 1974 and 1979, and in $\mathrm{k} \mathrm{f} / \mathrm{k}$, the archive of Peruwa. See for native archives also Veenhof 1978, Donbaz 1988a $\langle k \mathrm{~m} / \mathrm{k}$ ), and Alboyrak 1998,2001 (texts from kj o/k), and 2006 'lexts of Peruwa, son of Šuppibra). 
ing. Trade in wool, acquired in particular and at times in enormous quantities in the area south-east of Kanesh, ${ }^{682}$ implied contacts with the country-side, but the large amounts of wool and the communal or collective nature of transactions imply that the Assyrians dealt primarily with the local elite, entrepreneurs and institutions, among which also the palaces. ${ }^{683}$ Anatolian agriculture was important both on a subsistence level and for the local trade and this is reflected in the regular occurrence of phases of the agricultural year as due-dates in Anatolian debt-notes, which range from the time of ploughing and seeding (eräsum) to the picking of the grapes (qitip kerannim). The festivals of the gods, which also served as dates for payments, probably were also mainly of an agricultural nature isee VI.2.1). There are also several Anatolian officials with titles of the type "head of .../upper ..." (rabi + noun in the genitive), several of which refer to agriculture and husbandry and mention barley, vegetables(?), oil, the threshing floor, ${ }^{084}$ gardeners, herdsmen, and oxen (see below VI.I). Still, our knowledge of the countryside, of the villages, farmers and tenants who produced the stople crops, is rudimentary. Dercksen $2004 \mathrm{~b}$ has now analyzed textual evidence on villages and estates belonging to the urban elite and the palace, among which those given out by the king to his officers. ${ }^{685}$

The Assyrians apparently bought what they eat and drank,, 80 together with the olive oil, the firewood and other products they needed, from the local population, probobly through the intermediary of local traders. For that reason they must have considered the acquisition and exploitation of fields a bad investment of time, money and labor in the very season they could travel and trade, ${ }^{\circ 87}$ but they may have occosionally acquired them when an Anatolian debtor, whose fields had been pledged, defaulted, ${ }^{\circ 88}$ and there are rare references to the purchase of a garden. 689 Illustrative of their attitude is perhaps $\mathrm{kt} a / \mathrm{k} 583$, where

682 See for this trade now Dercksen 2004a, 183ff. Amounts of hundred and more kilos are not rare, and the biggest amount seems to be in $\mathrm{kt} 94 / \mathrm{k} 1482,65$ talents or more than wo and o half tons.

083 Dercksen 2004a, 189f. mentions the involvement of an importont figure, called Usinalum, who supplied large amounts of wool, as documented in texts from the $\mathrm{kt} 94 / \mathrm{k}$ archive, which is studied by Larsen.

๑84 We even have a "chief of the workers of the chief of the threshing floor" (rabi sabim sa rabi adrim), witness of a Iransaction involving the Iransfer of pledged fields $(\mathrm{k} k \mathrm{k} / \mathrm{k} 31)$.

685 He discussed in particular tuzinnum, a type of land belonging to a house with a service obligation (monaged by the so-called "lords of the hzinnum", "the persons responsible for making the tenants perform an obligation connected with the fields") and ubädinnum, a land-grant made by the king and consisting of houses and land, probably with its tenants.

680 See for a documented overview Michel 1997a, "a table avec les marchands poleo-assyriens".

087 There is no proof for a possible prohibition of acquiring fields by Assyrians, suggested by Kienast 1984, 5 ("stoatsrechtliche Hintergründe?").

688 It may have been different with gardens, perhaps odjoining houses. In k194/k 125:5H. (courtesy Michell, in an agreement on an inheritance, an Assyrion promises his brother that he will not claim the other's "house, garden and furniture in Towinia", since the latter paid their tather's debis.

689 KTS 34al8ff., letter of Elali, "I bought a garden, send me the silver for the tin which you collected" ("garden" is spelled ki-ra-am, but ki-ri-am in line 25). 
an Anatolian palace, ${ }^{690}$ which is long overdue in paying the enormous amount of twelve tons of copper, offers to put at the disposal of the Assyrian creditor "fields and orchards for a value of 20 minas of silver or even more". But he states that he will not accept them and will leave.

The movement of goods, both those imported from Assur and those of Anatolian origin and exported to Assur or traded inside Anatolia, was conditioned by economic factors of transport, supply and demand, and information on the latter two was available thanks to the commercial network and efficient communication. The Assyrians needed markets where they could sell and buy at good rates of exchange, either directly or by indirect exchange, in order to acquire the silver and gold which were their goal. The large area covered and the geography of Anatolia, with its mountain ranges and rivers, made transport facilities for heavy and bulky goods such as tin, copper, textiles and wool, essential. The caravans used roads, passes, river crossings (neebartum), bridges (kiturrum), road stations and lodgings or karavanserais (bë ubrim) for donkey caravans and porters, and in certain areas even wagons for transport of copper. ${ }^{091}$ But political factors were equally important, because trade in a foreign land, where it could not follow the flag, required arrangements for the protection of people and goods, both during caravan trips and in the places where the Assyrians settled, in combination with sufficient freedom of movement to exploit the commercial possibilities. Political disturbances inside Anatolia always created problems and dangers and they are mentioned in letters, because the relevant information (regularly introduced by the words "I hear by rumor", astanamme) is passed on for the benefit of caravans, which may choose a different destination or decide to keep their merchandise for the lime being in stock.

The use of the words "Anatolia" and "land" simplifies matters, because neither from the economic nor from the political point of view was Anatolia one land. It was, not surprisingly considering its geography, politically fragmented into a fair number of states, many presumably city-states, but some also small territorial states with a dominant capital. They were ruled by kings (called rubä'um), occasionally by queens (rubatum), who headed a palace organization that employed workers and craftsmen, and also counted a number of important officials, notably the rabi simmiltim, "the chief of the stairway" (at times the crown-prince\}, the rabi sikkitim, presumably a man with military tasks, but also involved in the trade, and the rabi huršatim, the one in charge of the stores (see below VI.1.1). Political arrangements in the form of treaties (the texts speak of "oaths", mamitum) therefore had to be made with many rulers and since such oaths by nature only bound those who swore them, they had to be renewed when there was a change of rule. Our knowledge of such treaties, for many years derived from recurring patterns in the contacts between the Assyrians and the local palaces and from letters that report on problems arisen, has now considerably increased. After first the report on and quotation of a treaty with a minor town, presum-

690 The text (line 8) speaks of ekallum u te erätusu, "the palace and its officials" (with te ertum for bel re 'ertim), the passage quoted (17-21) reads: eqlätim u kiriätim sa 20 mana kaspim v eliš ekallum is [akka]nam ezzibsinama arabbiama atallakam.

691 See Dercksen 1996, 04ff. 
ably in Southern Anatolia, had been published, ${ }^{992}$ we now have the text of two treaties, concluded with Hahhum and Kanesh, from the level lb period, which will receive special attention in chapter V. 2.

The economic landscape was far from uniform and we have to distinguish the areas important for the supply of and trade in silver, copper and wool. The sale of imported textiles does not show a particular geographical pattern; they apparently were always in demand and probably could be sold wherever there was an elite who could afford these expensive products. The palaces regularly acquired textiles by collecting the five percent import tax (nishatum) on them and by using their right to pre-empt another ten percent (called "tithe", ï̌rätim, or sa simim, "those to be bought"). ${ }^{093}$ With many caravans a year the total figure could become substantial and we see that palaces regularly do not buy the full ten-percent they were entitled to. Palaces and their officials bought textiles on other occasions too and, to give an example, kt 94/k 1128 registers how in all "95 lextiles have been deposited in the palace", presumably in the framework of a collective transaction. In a remarkable letter, kt 89/k 207 (courtesy Kawasaki), two Assyrians write: "Here we mode inquiries concerning the situation in Wahšušana and (we learned that) the gentleman needs many textiles for his couniry, so that the people are constantly worried about entering (the city)." local ruler may have needed textiles not only for commercial purposes, but also to meet his obligations and keep his servants and officers content, because textiles, as already the archives of Ebla show and the texts from Mari document, were a traditional and preferred royal gitf. They were also used in this way by Assyrian traders who wished to maintain good relations with rulers and officials, 095 and the writer of the letter TC 1, 39/CMK no. 92) tells us in lines 20-2:

"/entered Tuhpia and somewhat later, in accordance with your instruction, I brought (našă'um) the ruler a thin rextile and a garment as present and, separately, I also produced ten textiles and iron. He returned the iron and the textiles, but accepted the present (erbum) with the words, "I do not toke (the rest)". For the present which I brought him, they brought down (from the palace) [...] minas of copper ...".

Puzzled by the question how Anatolia could absorb thousands of expensive woolen rextiles, it has also been suggested that part them were exported again, to east and west, but evidence is still lacking.

Several mines must have produced silver and it was current all over Anotolia for making payments and extending loans. But the Assyrian sources show that it was in particular available in the areas south and south-west of Kanesh, especially in Burushoddum (which has been

$092 \mathrm{KI} \mathrm{n} / \mathrm{k} 794$, see below chapler $V .1$, under $C$.

093 See for this system larsen 1967, 156ff. and AOAT785f.

094 lines 가. awilum ana mātisu subäré mädütim hasah.

695 The term used is nis 'um, "that what is brought", cf. El 150:6, two textiles "presented ano ni-is-e-im (sic) when the queen of Wahsušana entered (the town)", and many rexts register that lextiles "were brought" for such purposes. Note BIN 0, 23:20, where a trader writes, "By the five lextiles I am bringing him he (the afore mentioned rabi sikkitim, who owes him silver) will become ashamed, so that I can recover my silver" (ibäsmo kaspi asallah). 
designated as the main silver market), and it presumably originated from the Bolkardag mining area in the Central Taurus, south of Niğde. Assyrian trade in wool and copper may in part have been due to the fact that in other areas of Anatolia less (cheop) silver was available, so that indirect exchange of the goods imported, using the caravan donkeys the Assyrians had at their disposal, became a way of ultimately acquiring silver and gold elsewhere. Tin was imported from Assur because it was needed in Anatolia for the production of bronze and one would expect it to be shipped to and sold in the copper mining areas. Those which were relevant for $O A$ trade are concentrated in the north, most probably in the areas of Cankirı, to the east of Takat and around Trabzon, ${ }^{696}$ but there is still uncertainty about their relative importance, because the location of the main copper market, Durhumit, is disputed. 697 Dercksen 1996, 43ff, collected data which indicate where copper was mined, refined or traded and presented a list of qualifications in the form of a nisbe used of copper or of $5 a+$ place-name. The former, which presumably refer to the origin and quality of the copper, refer to Haburata, Ištanuwa, Kunanamir, Tapašatta, Taritar and Tišmurna, which, as far as there are indications for their location, mostly point to northern Anatolia. The latter, e.g. sa Burušhattim, š Wašhania and $\check{s \sigma}$ Nenašsa, which refer to cities outside the copper mining areas, presumably mean copper produced lacally by refining. 698

The geographical pattern of the tin trade, as far as we can trace it, 699 was not simply one of massive rransports to the named copper mining areas. Tin was shipped to Durhumit and other northern cities, but also regularly transported elsewhere, often by agents who had received it in consignment, to be sold even for copper. It is also remarkable that Assyrians did not trade in bronze, as one might have expected if they were the regular suppliers of lin to the copper mines and the latter produced bronze. Copper was in wide circulation, also as a form of "money", and most of the textual evidence deals with Assyrians ${ }^{700}$ who acquired it (also in exchange for wool), at times in enormous quantities, ${ }^{701}$ tried to convert

690 See Dercksen 1996, 255, map B. There were also copper mines around Ergani, near Elazığ, but there is no evidence of Assyrian trade with the mining area there, nor of transport and sale of lin there, nor of export of copper from Ergani to Assur, which seerns to have oblained its copper from the south.

697 The traditional location, defended by Dercksen, is southeast of Ankara, on or near the Kızilirmak, but there is also a suggestion to locate it much more to the northeast, near Tokat.

698 In CCT 2, 13:6 there is mention of "10.000 (minas of copper of Burušhaddum, which the palace gave him", but we do not know how it had acquired this huge amount.

699 We loose track of much of the tin after its arrival in Anatolia. Part of it was bought by the palaces, but we have no information on how they used it. Much was entrusted to traveling agents who signed debt-notes that obliged them to pay in due time its price in silver, but we do not know where they went. Sales to Anatolians only yielded written evidence if they were credil-sales.

700 But Anatolian retailers (pāširum) were also active, see AOA 1996, 120 and 127.

701 See the list in Dercksen 1996, 209ff, where we meet several lots of more than 10 talents (360 $\mathrm{kg} .$. and even quantities of fifty ralents or more $\{73$ in BIN 4, 199:10; 98 in Prag 1 471:37.; and 105 in $\mathrm{kt} \mathrm{u} / \mathrm{k} 4: 13$ ). The weight of large quantities was also given in simple numbers, which mean the number of minas, "pounds", and we have cases of four and ren thousands pounds (CCT 2 , 13:5f., nearly 5 rons), and $k t 94 / k 917$ even mentions amounts of 16.000 and 30.000 pounds. 
poor into refined copper, ${ }^{702}$ and shipped it to various cities to sell it for silver, ${ }^{703}$ by way of transactions in which frequently also the local palace was involved. This suggests the existence of a local bronze production in many places and Dercksen 1996, 151, assumes that there was not so much an industrial production of ready bronze for trade, but rather a local production by the coppersmiths who manufactured bronze objects, partly on demand. Workshops, tools and moulds, discovered in kärum Kanesh, fit this pattern. ${ }^{704}$ It must have happened also for or even under the control of the local palaces, which needed bronze tools and weapons, to judge from the Anatolian title "chief of the blacksmiths" (rabi nappāhe p05 $^{705}$ and the fact that palaces frequently appear as holding large stocks of this metal. Trade in copper, which was not exported to Assur, for the Assyrians meant buying in areas where it was readily and probably cheaply available, so sell it eventually elsewhere, at times after having refined it, for silver and gold, which was shipped back to Assur. If successful, it could mean added profit, though at the cost of more traveling and multiple transactions, which required energy and were only possible thanks to the extended network of trading settlements. It seems clear that some traders were much more active in the trade in wool and cooper than others, probably also depending in which areas their operations were concentrated. It would be interesting to find out whether the trade in copper land wool) developed in connection with the expansion of the Assyrian trading network, which penetrated into areas were less silver was available, but enabled them to keep goods in store or ship them elsewhere, where (according to information received from colleagues) the possibilities for sale were better. It is anyhow likely that the transport capacily the Assyrians had at their disposal in the form of caravan donkeys, after their original loads of tin and textiles had been sold, was an important factor in the trade in copper and wool. And the occasional renting of wagons shows how they tried to cope with the problems of transporting heavy loads of copper. ${ }^{700}$

702 This operation was called ana dammuqim to"urum, "to convert into good copper" and / weriom dammuqam) ka "unum, "to secure" by means of conversion, see Dercksen 1996, $53 \mathrm{ff}$.

703 In ATHE 32 Amur-lstar reports that a local palace (the name of the town is not mentioned) had sold a lot of copper to traders from Ebla, who paid for it with good silver. When, in ten days, the palace will be withoul copper, he will sell the copper he has in store latter hoving sold his tin for copper) for silver (he writes "I will buy silver").

704 See for moulds Dercksen 1996, 233, and for workshops and rools Özgüc 2003, 109ff, and $242 \mathrm{H}$.

705 See below VI.1.1. Kt 94/k 208:28ff. registers a poyment to a smith who forged iron in the palace". See for the coppersmith Dercksen 1996, 71f., who points out that alongside Anatiolans also a few Assyrian smiths were present in Kanesh (Puzur-Anna, see Sturm 2001, 477ff; Ennanum, $\mathrm{kt} 94 / \mathrm{k} 292: 2$ and $\mathrm{kl} \mathrm{m} / \mathrm{k} 110: 7$; and Salim-bejli in $\mathrm{kt} 94 / \mathrm{k} 438: 16 t$. .

700 See Dercksen 1990, 64ff. Note TC 2, 18: 7ff., which intorms us that absence of demand for copper in Burushaddum lead to the decision no to hire wagons and to use, in due time, donkeys for its transport. The use of wagons must have been restricted to rather flat areas, such as the valley of the Kizulirmak, and this may have implications for the location of Durhumit, where wagons could be used (KTS 3b:가.). 


\section{Cities, RUIERS AND AsSYRIAN SETLEMENTS}

\subsection{A IIST OF THE MAIN CITIES, RULERS, LANDS, AND ASSYRIAN SETTLEMENTS}

As a basis for the following observations I present an alphabetical table of the main cities, nearly all of which - not (yet?) attested for Luhusaddia and uncerlain for Ninaššô - had an Assyrian kārum or wabartum, with information whether their ruler, palace or land is attested. The numbers 1 and 2 are for references dated to or contemporary with kärum Kanesh leve lb or II; the last column offers some rare or new references. The publication data of the texts whose excavation numbers (omitting "kt") I mention can easily be found with the help of the lists in Michel 2003c, biff. Additional references and other observations are presented below, per number. Data in Nashef 1991 are not repeated unless they are rare or require comments. Many references in the texts to "the ruler" and to "the palace" cannot be linked with a particular city and new texts will certainly bring additional data.

Separately I list references which link particular products, especially wool, textiles and copper, with an Anatolian city by means of $\breve{s a}$, which in many cases denotes a product (produced in or fashioned according to the local technique or style) of a particular town, comparable to Assyrian ša Akkidi'ëe, "Akkadian", š Š Subirim, "Subarean", and even ša ālim, "Assyrian" (see AOATI 181ff.). But ša GN may also mean "stored, available in GN", 707 With metals the reference may be not to the mining area, but to the town where they are refined, alloyed or offered for sale. ${ }^{708}$

copper

oil

allānu, "acorns"

butnātum, "pistachios" wool

rextiles

epattum
Burushhaddum, Durhumit, Haburata, Ištanuwa, Kunanamit, Nenašs̆a, the "land S/Šawit", Tapašatta, Taritar, Tišmurna, Tuhpia, and Wašhania. ${ }^{709}$ Hahhum, CCT 4, 180:26; Kanesh, KTS 2, 31:19.

Hanaknak, kt 94/k 1625: If.

Burušhaddum, Siudies Veenhol, 130, 16 (nisbe, Mari). Hahhum, Hurama, Luhusaddia, Mamma, Timilkia? 710 Hahhum, KUG 13:20; Garelli 1964, 59, no. 4:5 (nisbe). Talhal, see AOAM $128 \mathrm{~F}$

707 "Textiles of Hurama", in KTS 2, 29:14, are textiles first shipped there, see lines 5ff.; note ATHE 63:16ff., "when textiles of (coming from) Zalpa or (sic, u) Huroma arrive".

708 See references for gold and silver "of Burušhaddum", and "good quality liti-silver of Kanesh", in Nashef 1991 s.v. Cities probably always had some kind of textile industry and many may have used local wool, but the areas to the southeast of Kanesh are clearly the main wool producing regions, where the Assyrians bought wool.

709 See Dercksen 1996, 43ff. The references for Tapašatio are kl n/k 1952:191. and kt 91/k 390:6).

70 See $A O A T T 131$ f. and for Timilkia, TC 1, 81:44 ("10 shekels of silver (for) 30 minas of wooll of Timilkia"). 
kitûm

menuniānū

nibrōrū

pirikannù

saptinnū

lisäbū
Tuttul, kt 93/k 196:6 (courtesy Michel).

Mammā, kl 94/k 1465:23.

Zalpo, kt 94/k 734:2k.

Haqa, kt 93/k 60:1f; Hahhum, kt n/k 518:94f.; Kanesh, kt 94/k 734:0. cf. AOATT24; Mammā, TC 1, 43:3f; Zalpa, kt 93/k 59:1f. (courtesy Michell.

Talhat, kt 94/k 1672:20, see AOAT 128f.; bought in Hahhum, KTS 36c:9ff.

Hahhum, kf 94/k 1672:19 (CCT 5, 120:8f. shows that a fisabum belonged to the calegory of saptinnut: Na/ehria $k \uparrow 94 / k 724: 2 f$.

Cities, with their rulers, palaces, "lands", and Assyrian commercial settlements

\begin{tabular}{|c|c|c|c|c|c|c|c|c|}
\hline & \multirow{2}{*}{$\begin{array}{l}\text { cily } \\
\text { Amkuwa }\end{array}$} & \multicolumn{2}{|c|}{ nabaim nisbe } & \multicolumn{2}{|c|}{ palace land } & \multirow[t]{2}{*}{ kārum } & \multirow{2}{*}{$\frac{\text { wab. }}{1,2^{\mathrm{b}}}$} & \multirow{2}{*}{$\begin{array}{l}\text { new and rare references } \\
{ }^{\circ} \text { OIP } 27.1: 1 f . ;^{b} \text { a/k 1070:3 }\end{array}$} \\
\hline 1. & & $1^{a}, 2$ & 2 & - & - & & & \\
\hline 2. & Apum & - & - & - & - & $1,2^{a}$ & - & o AKT $2,19: 13 ; n / k$ 1406:1 \\
\hline 3. & Batna & - & $1^{\circ}$ & - & - & - & $2^{b}$ & ${ }^{\circ} 00 / \mathrm{k} 10, \| 11: 27^{\prime} ;{ }^{b}$ KTH $3: 24$ \\
\hline 4. & Buruddum & - & - & $2^{a}$ & - & $2^{b}$ & - & a 92/k 5:6f.; b 91/k 171:39 \\
\hline 5. & Burušhaddum & & 2 & - & $2^{\circ}$ & $2^{b}$ & $2-$ & a Cole 4:15; b KTH 3:23f. \\
\hline 6. & Durhumit & $2^{a^{2}}$ & - & 2 & - & $1^{b}, 2$ & - & ${ }^{\circ} n / k 1408: 5 ;{ }^{b} / / k 183: 6$ \\
\hline 7. & Eluhhut & - & - & $i^{b}, 2$ & - & $1^{b}, 2$ & - & ${ }^{\circ} \mathrm{b} / \mathrm{k}$ o12:18: ${ }^{b} \mathrm{kt}$ OOK 10 \\
\hline 9. & Hanaknak & - & - & - & - & - & 2 & $k / k 70: 16 . ; k / k$ 91:29 \\
\hline 10. & Hattuš & 2 & 2 & - & & $2^{\circ}$ & - & ${ }^{\circ} \mathrm{n} / \mathrm{k}$ 1952:194.; 92/k 203:5 \\
\hline 11. & Hurama & $2^{\circ}$ & - & $2^{a}$ & - & - & $1^{p b}, 2$ & $\circ \mathrm{m} / \mathrm{k} 134: 4,18 ; b 82 / 451$ \\
\hline 12. & Kanesh & $1^{a}, 2^{b}$ & 2 & 2 & 2 & 1,2 & - & ${ }^{\circ} \mathrm{g} / \mathrm{t} 35: 3 ;{ }^{b}$ KTP $4: 13$ \\
\hline 13. & Karohna & - & - & - & - & - & 2 & Garelli 1966, 119 no. 47 \\
\hline 14. & Kuburnat & $2^{\circ}$ & 2 & - & - & 1 & $2^{b}$ & ${ }^{\circ} \mathrm{m} / \mathrm{k} 148: 75:{ }^{\mathrm{b}} \mathrm{o} / \mathrm{k} 403: 17 \mathrm{f}$ \\
\hline 15. & Kuššara & - & 2 & - & - & - & $2^{\circ}$ & $\circ 91 / \mathrm{k} 145: 22$ \\
\hline 16. & Luhusaddia & $1^{a}, 2^{6}$ & 2 & 2 & 2 & - & - & ${ }^{\circ} n / k 76: 13 ;{ }^{b} k / k$ 51:가 \\
\hline 17. & Mamma & 1,2 & $1,2^{\circ}$ & - & - & - & $1,2^{b}$ & ${ }^{\circ} \mathrm{b} / \mathrm{k} 170: 15 ;{ }^{b} \mathrm{c} / \mathrm{k} 841: 23$ \\
\hline 18. & No/ehria & - & $2^{?}$ & 2 & - & 2 & - & El $210: 2 ; 80 / k 49: 25$ \\
\hline 19. & Nenašša & 2 & 2 & $2^{\circ}$ & - & $2^{b^{2}}$ & - & - TC $3,165: 14 ;$ b $92 / k 203: 0$ \\
\hline 20. & Šaladi/uwar & $r-$ & - & - & - & $2^{\circ}$ & $2^{b}$ & ${ }^{\circ} \mathrm{kt}+/ \mathrm{k}$ 1:9; ${ }^{b}$ KTH 16A:22 \\
\hline 21. & Šalahšuwo & $1^{?}$ & $2^{\circ}$ & 1 & - & $2^{b}$ & - & o KTK 64:16: b $91 / k$ 148:35 \\
\hline 22. & Šamuha & - & - & 2 & - & $2^{?}$ & $1,2^{\circ}$ & - TPAK 182:2'; VS 26, 195:3f. \\
\hline 23. & Šimala & - & - & - & - & 2 & & ${ }^{\circ} \mathrm{a} / \mathrm{k}$ 503:If. \\
\hline 24. & Šinahutum & 2 & - & - & - & - & $2^{\circ}$ & 。 $89 / k$ 387b:5; k/k 63:7 \\
\hline 25 . & Šuppilulia & - & - & - & & $1^{0}$ & $2^{b}$ & - $94 / k 480: 17 ;$ b $\circ 3084: 30$ \\
\hline 26. & Tawinia & $1^{20}, 2^{6}$ & 2 & - & - & $1^{20} 0,2$ & - & $a f / k 183: 4,7 ; b_{n} / k 388: 7$ \\
\hline 27. & Tegarama & - & - & 2 & - & $2^{a}$ & $j^{2 b}$ & ${ }^{\circ} \mathrm{k} / \mathrm{k} 57: 18 \mathrm{i}^{\mathrm{b}} \mathrm{r} / \mathrm{k} 1: 1 ?$ \\
\hline 28. & Timilkia & 2 & 1,2 & - & - & 2 & $1^{2}, 2^{\circ}$ & ${ }^{\circ} n / k 1818: 3 ; 94 / k$ 502:3 \\
\hline 29. & Tišmurno & - & - & $2^{a}$ & - & $2^{b}$ & & ${ }^{\circ} \mathrm{n} / \mathrm{k} 482: 7 ;{ }^{b}$ o/k 1429:23 \\
\hline
\end{tabular}




\begin{tabular}{|c|c|c|c|c|c|c|c|}
\hline 30. Tuhpia & 2 & - & - & - & $2^{a}$ & $2^{b}$ & a 92/k 203:6; b KTK 107:13 \\
\hline 31. Ulama & - & 2 & - & - & - & $2^{a}$ & $a_{m} / k 137: 26 ; 94 / k 340: 18$ \\
\hline 32. Upē & - & - & - & - & - & 2 & AKT $3,55-57$ \\
\hline 33. Uršu & - & - & - & - & 2 & - & CCT 1, 6b:12; SUP 7 \\
\hline 34. Ušša & - & - & - & - & - & 2 & $v / k 164: 5$ \\
\hline 35. Wahšušsona & & 2 & 2 & $2^{\circ}$ & $1 ? 2$ & - & a KTP 10:23 \\
\hline 36. Wašhania & $2^{\circ}$ & $2^{\circ}$ & 2 & - & $1^{b}$ & 2 & ${ }^{\circ}$ KTP $14: 5 ;{ }_{n} / k 27 b: 29$ \\
\hline 37. Zalpa (South) & & - & 2 & - & 2 & - & Chantre 11:4; BIN $0,167: 9$ \\
\hline 38. Zalpo (North) & & - & $2^{?}$ & $2^{\circ}$ & - & $2^{\circ}$ & a $91 / k 149: 22$ \\
\hline 39. Zimishuna & - & - & - & - & - & 2 & AKT 2 p. $38 ; 91 / k$ 212:19f. \\
\hline
\end{tabular}

\subsection{COMMENTS ON THE TABLE}

1. See for data on Amkuwa, Dercksen 200la, 4ilf. Note kı n/k 1374:10f. (Cecen, 1990b), šprum s̆a Amkuwāa u s̆a rubā'im ituramma umma Amkuwāiuma, related is kł $n / k$ 482:17 (nisbe). See for the possible attestation of a queen and a rabi simmittim of Amkuwa in OIP 27, 5:13, the comments on 21, Śalahšuwa.

2. Frequently identified with Tell Leilan, but since in the $18^{\text {th }}$ century $B C$, the cily under the names Subat-Enlil and Šehna, counted as "capital of the land of Apum", Apum may have been the earlier, still unidentified capital of the land, to be located in the same general area. In the $18^{\text {th }}$ century BC Tell Leilan harboured an Assyrian karum according to a treaty concluded between the city of Assur and the king of Apum (Eidem 1991), dated to ca. 1740 B.C. The city was an important road-station for Assyrian caravans, see Nashef 1987, nos. 24:6, 25:25 and 31:12, and see for further information Nashef 1991 s.v., to which we can now add kt g/k 220:6 (Günbatt 2002, 81, in the sequence Assur, Apum, Haqa), while in Prag 1 804:9 (in the sequence Qattara - Apia - the steppe [kassa $\bar{a}^{\circ} u m$ ] - the river (the Euphrates) - Timilkia) the city appears as Apia. Note BIN 4, 124:12ff., a gift for a libation (kirrum) to the dagger of Ašsur in Apum.

3. Town in Northern Mesopotamia, situated between the Euphrates and the Balikh, southwest of Urfa, near Sürüc, see AOAT 243 and 293f. Its name lived on in Roman Bainae [see A. Poidebard, La trace de Rome dans le désent de Syrie (BAH t. 18, Paris 1934], map and p. 148). A ruler of Batna in mentioned in the treary with Hahhum $(\mathrm{ki} 00 / \mathrm{k} 10,1[\mathrm{lll}]: 27)$ as a possible enemy of Hahhum. KTH 3 shows that the town also had a barullum-official. Payment of nishatutax in Batna and Zalpo is mentioned in BIN 6, 245:2' -5 '. The town also occurs in $\mathrm{kt}$ 91/k 451:2 (loss of textiles in B.), $\mathrm{kt}$ 91/k 465:22, and $k t 94 / \mathrm{k} 219: 34$. 4. Kt $92 / \mathrm{k} \mathrm{5:4} \mathrm{ff}$. report on a trader who traveled to Buruddum and wrote from there: "The palace treats me with contempt" (massuhum). The reference in kt 91/k 171:39 to a kärum Bu-ru-dum is at the end of a testimony about a confrontation between Aššr-massu'i and Püsu-kēn about the payment of the price for a house in Kanesh, and one wonders why the witnesses of this confrontation were summoned by kärum Buruddum and whether this might not be a mistake for Burušhaddum. But the kărum is also attested in $k t n / k$ 1730:4f. The occurrence of a "ten-men board" (esartum) of Buruddum in CCT 3, 36a:1 shows that there 
was an Assyrian presence there and we have good evidence for the rown as an important road-station for caravans leaving for Anatolia 711 , where people could meet and handle legal affairs. The town, also known from the Mari texts, is usually located in the area of Mardin, not far from Eluhtut and this is now confirmed by the inscription on the victory stela of king Daduša of Eshnunna (BaMitt. 34 [2003] 146) col. X:12ff., where he cloims a victory in the north ("above" elis), in the land Subartum, from the land of Burunda and the land of Eluhtu until the mountain Diluba and the mountain Lullum.

5. A rubāum rabium (written GAl) presumably in TC 27:7 (no comments in RA 80, 1986, 128), and a rubä'um in AKT 3, 79:13; no nisbe attested. See for this important city also Garelli 1989 and for its remarkable absence from texts from level lb, Dercksen 200la, 61.

6. The presumably single reference to the ruler is in $k \mathrm{n} / \mathrm{k}$ 1408:5 (courtesy Cecen, reference Dercksen), where the karrum of the town writes to a trader: "If you carry with you letters addressed to either the ruler or to us //u ana rubä im lu <a>-ni-a-th), send them ahead"; the palace occurs in $\mathrm{kt} 94 / \mathrm{k} 1124: 8$, where the palace takes the nishatutax of textiles brought to the city. The rarily of both and the absence of even a single reference to "the land of Durhumit", considering the importance of the town, is remarkable. The seal of the kărum in CTMMA 97:2. See for this city Michel 199la. Note interest kima awat kärim D., kt 91/k 390:9, and "the market/rate of exchange of D." in $\mathrm{kt} \mathrm{n} / \mathrm{k} 661:$ 7ff. and 91/k 181:16, both in relation with the trade in copper. See for the important role of this city in the copper trode Dercksen 1996, 12ff., 129, 138, 154f. Envelopes with the text "Seal of kärum Durhumit" are listed in Hecker, 2003, 193f. For the identification of the city it is important to note that $\mathrm{kt}$ 91/k 437:22f. mentions a small payment for "the crossing" (nëbartum) of a river near this city (Veenhof 2006b, 779) and that several texts show that wagons could be used for the transport of copper from it (Dercksen 1996, 64f.).

7. Only one reference for the kärum. Nashef 1987, 60 note 45 and 1991, 38f., identifies the lown with Luhãya, attested as a caravan stop in the Khabur Triangle in BIN 4, 191:2 and 14 (payments to a sibum, "eldermon", in and for an escort sa luhäya), and in TC 2. 57:17ff. (expenses made because "people from Luhäya had stolen a donkey in Abrum"). But lexts from Mari also know both an Eluhhut and a Luhāya, the latter presumably identical to Ulāyum, to be located not far from Talhāyum (see Durand 1998, 270 note a, and Forlanini 2004, 407, notes IIf.). Eluhhut, also attested in $\mathrm{kt} m / \mathrm{k} 3: 34$, has been located by Mari specialists in the northern part of the Khabur Triangle, in the area of Mardin, east of Burundum (and cf. Charpin-Ziegler 2003, 116, note 339, following Durand 2000, 454). which agrees with the victory stele of Dadusa of Eshnunna (see above on no. 4), which

711 Buruddum (nearly twenty attestions, also in $k$, $94 / k 414: 7$ and 14 occurs as a road-station (Nashef 1991, 281., equales it with Baroddum, discussed in lewy 1956, 22, with nole 95) in a passage in an unpublished text (Noshel 1987, 37, 19), which records wages for caravon personnel from Buruddum to Hahhum and from Hahhum to Timilkia, which suggests a location within the Euphrates bend. Evidence for Buruddum as a town where caravans leaving for Anatolia are assembled is provided by Prag 1 550:5, ATHE 46:5 la caravan leaving the town, read: $|i s|-h$ B.). CCT $0,220: 18$, and KTS 2, 43:49. On the other hand, its association with Simala (CCT 3, 300 and ICK I, 84:21) might suggest a more nothern locotion. 
describes his victories in the north, all the way "from the land of Burunda and the land of Eluhtu". While some consider an even more northern location, near the Upper Tigris, in the area of Tigunanum, H. Waetzoldt (Studies Oelsner, 532) opts for a more westen location, in the area of Viranșehir. The other OA references, including Michel 1987 no. 01:5, "from Eluhhut [until ...]", are not informative.

8. In CCT 4,30a:13 the ruler of this city is designated as IUGAL, the equivalent of rubo $\bar{a}^{3}$ um, which thus far occurs only in the unpublished lext $\mathrm{kl} b / \mathrm{k}$ 612:18, mentioned in Balkan 1957, 28. The rubä'um who owns a donkey load of kutannu-textiles in KKS 2:5f., contrary to what Garelli 1998a, 453, suggests, is not the ruler of Hahhum, but the one of Assur, who had given this merchandise in consignment to a trader. The nisbe is only used of a trader (Puzur-Suen Hahhium, kt 94/k 153:19F.) and for a type of wool and textiles, also during the level lb period (but apparently not in KBo 9, 28 rev.2', see Dercksen 2001, 60, note 118), see $A O A \pi$ 129. Information on the level lb period, with mention of various officials, is contained in the treaty with this city, kt 00/k 10, see below V.2.2. The kärum of level II is well attested; one of its verdicts, with "the seal of kärum Hahhum", is kt 94/k 1047. A "ten-men board" of this city occurs in CCT 4, 30a:4, and a mät Hahhim is attested in Mari, ARMT 26/2, 547:2. See For this city Garelli 1998b.

9. The wabartum also in $\mathrm{kt} a / \mathrm{k} 1258 \mathrm{~b}: 34 \mathrm{f}$. (Balkan 1992, 31). $\mathrm{Kr} \mathrm{k} / \mathrm{k} 70$ is an envelope with the text "Seal of the wabartum of Hanaknak" and tive different seal impressions (Hecker 2003,192 note 33). Disturbing is kt 89/k 230:5ff. (courtesy Kawasaki), where it is stated that "as soon as $\mathrm{A}$. and $\breve{S}$. had entered Hanaknak, one seized them in the bët körim". Did one (by mistake?) call the administrative seat of a wabartum also bët karim (the term * bett wabartim is never used)? Kt 94/ 1128: If. lists transactions with textiles "when the ruler went to Hanaknak", but it is not clear which ruler it was and what the rrip meant 'a "state visit" or was the ruler also lord of Hanaknak?). See for the city and its location, Veenhof 2006b, comments on text 1 .

10. The ruler occurs in $k t 92 / k$ 194:43f., where the [gift?] of a textile is said to have occurred "when the ruler of Hattušs (rubä'um Haftusāium) [went?] to Wašhania and Bani-ha-ar-si-im $\times[\ldots]$ "; the nisbe alone in KTK 10:8' and $k+n / k$ 211: 6f., "He said: Entrust him to the man of Hattus ( $\mathrm{Ha}-\mathrm{t} u$-sa-im) and he will take the road the man of Hattus will tell him, so that he will be safe. ${ }^{9}$ He offered him the road to Suppilulia and said to him: The man of Suppilulia should conduct you to Karahna". Line 25 mentions the queen (rubätum) of Hattus. Note that the nisbe is derived from Hattus (the only form of the name attested in $O A$ texts) and not from the form Haltuša, which first occurs in lexts from Mari. The two new references for kărum Hattuš during the level II period make up for the untraceable and for a long period only reference mentioned in Nashef 1991, 58. The city also occurs in kt $89 / \mathrm{k}$ $387 \mathrm{~b}: 14 \mathrm{f}$. (a letter of the wabartum of Šinahutum), "The men (from Mamma) who stayed in Hattuš have left (going; beyond Hattuš" (ina ebar Hattus). " Māt Hattuš does not occur, but the frequent and much discussed Hattum may have substituted for it. According to Dercksen 200la, 57ff., Hattum de faclo equalled the area "within the Kizlırmak basin", but Hattum is not (yet?) altested in texts from kärum Kanesh level lb. Note also kt 94/k 1610:19ff., where the alternalive for selling textiles in Kanesh seems to be to send them to Hattum and see for shipment of merchandise "to Hattum" also kt 94/k 726:18. Note also kt 94/k $1629 \mathrm{rev}$ If., 
"sundry wares (sahertum) of Hattum", k+ 92/k 205:91., illibbi mattim sa Hattim, "in the hinterland of Hattum", kt b/k 54a, where two Anatolians are designaled as sa Hattim (Balkan 1973, 44), and kt 94/k 760:22F., payment to a guide/escort of Hattim. ${ }^{712}$

11. A ruler of Hurama wrote the letter $k+n / k 1024$ (courtesy Cecen), which deals with donkeys, to on Assyrian trader. In kt m/k 134 kärum Hurama wrote a letter to kärum Kanesh to ask its advice on the contents of an oath (sworn freaty). which the ruler of Hurama (whose palace is mentioned in line 18) had offered/proposed (tadonnum) them and in which he staled his claim to a share in the textiles and the right "to search the bags" (naruqgatim naddudum), to check their numbers or perhaps to select the best pieces. I am not sure whether $\mathrm{kt} 82 / \mathrm{t} 51$, which mentions a kärum, is really contemporany with level ib of kärum Kanesh. Additional references for the kärum of level $\|$ are $k t$ $\mathrm{n} / \mathrm{k}$ 1815:5 (deposition), kt 86/k 196:30, kt 91/k 370:27 (saher rabi, "plenary"), and kı 94/k 324:6.

12. Note ATHE 62:33-36, "the queen (rubatum) has written concerning the smuggling to Luhusaddia, Hurama, Šalahšuwa and to her land (ana matrisa)". See for rulers during the level lb period, below $\S 5$, and see for a reference to a "greal [king] of Kanesh" ([LGAI] GAL Kanisium in the treaty, below V.2.1. In TC 1, 18:42 a caravan leaves Mamma to arrive ana mät Kanis. Kt 87/k 275:11-17 (a slave sale, Hecker, 1998, no. 5) states: "Take her (a slave-girl) either to Hattum or to "the land", but do not sell her in Kanesh and the land Kanesh". P. answered: "I will bring her ocross the Euphrates". The nisbe frequently refers to people (traders, messengers, escorts) From Kanesh, but in ATHE 66:9f. to the king: "When my tablet about the man of Wahsušana and the man of Kanesh, that they have pronounced

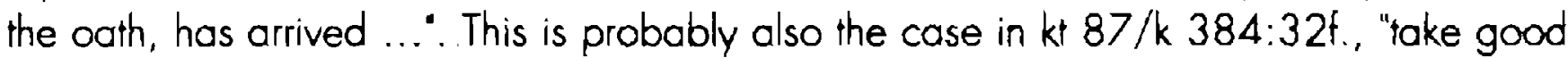
care of yourself until the Kaneshite returns".

The nisbe also occurs in the combination al Kanisi' $e$," "the town of the Kaneshites", in kt 92/ $k$ 103:14f. and 108:6, where it refers not to Kanesh, but to a settlement south of Timilkia, hence presumably in the area where the Euphrates was crossed. Both texts $(\mathrm{kt} 92 / \mathrm{k} 108$ only covers the trip from "he lown of the Kaneshites" to Kanesh) list travel expenses in a geographical sequence, in Qattarâ, Hamisānum, Burallum, Birtu'um, ăl Kanišìēe, Timilkia, Hur(a)ma, Luhusaddia and Kanesh. Since POAT 21:19 and ATHE 63:24713 show that Kanisi' $u$ is used for traders of Kanesh, the "town of the Kaneshises" could be a (temporary?) commercial settlement on the caravan road founded and used by traders from Kanesh. No data on kärum of Kanesh have to be mentioned here; envelopes with the text "seal of kärum Kanesh" are lisied in Hecker 2003, 191f.

13. Note kt n/k 388: 9ff. (Günbatt 1997, no. 2), where the king of Tamnia says: "For your sake I have taken an oath to Karahna .... on the second day one will bring me the oath of Karahna".

712 Remarkable are KTS 1, 80:4f., "in the city of the Hattions" (ino olim sa $[H] a-f i-$ ). and $k 194 / k$ 1226:18, "with 2 kutanutextiles I clothed the Hattians" (Ha-tie ulabbis, ct. TC 3, 101:6, one rextile a-kärim labbusim). Note that LB 1201:18, contrary to the claim of Lewy 1950, 372, has (textiles) ina di-fim nod'ü.

713 The palace in Wahšušan told Assyrians: "When the Kaneshites leave, you too must deport". 
14. A rubä um Kuburnatäium in $\mathrm{kr} \mathrm{m} / \mathrm{k}$ 148:75 (Hecker 2004b, 66), receives a gift, and in $\mathrm{kt} 93 / \mathrm{k}$ 171:3 (courtesy Michel) the Kuburnataium took textiles. The wabartum also in $\mathrm{kt} \mathrm{a} / \mathrm{k}$ 465a:8, kt 91/k 176:21f., kt 92/k 194:3-6, and kt 92/k 200:4 (letter of kärum Kanesh to the wabartums of Kuburnat, Hanaknak and Tišmurnal. The kärum of level lb occurs in kt 98/k 125: 10'-12', logether with the "travelers on the road to the City" (Donbaz 2001b, 110). K1 94/k 636 and 644 (courtesy Larsen) are two letters addressed to this wabartum by a kärum whose name is missing. The proximity of Karahna is clear from $k t 94 / \mathrm{k} 441: 16 f$., sale of textiles either in Kuburnat, or in Hanaknak, or in Durhumit, and from kt k/k 87:6f, a trader on his way to Kuburnat is instructed to go to Hanaknak. Note also kt 92/k 194:21: sadd 'utu-tax levied from Busia of Kuburnat in Tuhpia, and lewy 1950, $438 \mathrm{ff}$.

15. The nisbe occurs in kt 87/547:5, "in the land Zalpa Ku-5a-[ro-1]-um maqitniäti." The address of Nesr. Boğ. 2, a letter of the wabartum of Mamma, to be dated to level II, may be restored as: [ana ... u wa-bar-tim ša Ku-ša-ro, the alternalive, [be-ru]-tim, is unlikely, since the body called beruttum is only attested for Šaladuwar. But another possibility is to read [esar] fim, "ten-men board", which has now turned up in kt 93/k 67:2 (countesy Michel), in the address of a letter written by kārum Kanesh ana 10-tim să Kušs̆ara.

16. $\mathrm{Kt} \mathrm{m} / \mathrm{k}$ 144:10 writes rubäim Lu-hu-za-fo-im and a nisbe referring to the ruler also occurs in CCT 2, 48: 36. The palace is mentioned in CCT 4, 19c:18f., where Assyrians, because of the seizure of their textiles, "went up to the palace", where the queen answered their protests. Land and palace together occur in Kays. 1830:7, "Two Assyrians have been killed in the land of L., we went up to the palace, saying: In you land [two] Assyrians have been killed" (see Hecker 1996a, no. 2). The city was important for the trade (especially in wool, see AOATT 131f.; note also kt 87/k 551:7f., "Did you not see that there is much silver in Luhusaddia?"), but there is no evidence yet for an Assyrian kārum or wabarium. If that is not by accident, it could be the reason why it was the wabartum of Kušsara, which according to Kayseri 1830:6f. (Hecker 1996a, no.2) went up to the local palace and the ruler when "wo Assyrians had been killed in the land of Luhusaddia" (line 11, "in your land").

17. See for a rubäum, Balkan 1957,32, kı 86/k 102:5f., a letter by the wabartum of Mamma to kärum Kanesh, with the information that "the rubā'u Mamaiu is out of town" (wassi, singular!), and $\mathrm{kt} \mathrm{g} / \mathrm{k} \mathrm{51:20f..} \mathrm{Mamma} \mathrm{is} \mathrm{usually} \mathrm{looked} \mathrm{for} \mathrm{in} \mathrm{the} \mathrm{region} \mathrm{of} \mathrm{Maras,}$ perhaps a little north of it; Miller 2001, 68ff. settles for "a location between Maras and Göksun". A text from Tell Leilan (Vincente no. 153) mentions a trader Innāya who arrived from Mammā (Ma-am-ma-aki).

18. The nisbe in VS 20, 138:3 (ni-hi-ri-a-e-em) may well mean the ruler, the palace is attested in KUG 36:5'. Garelli 1965, 42 no. 17: 16ff. records a small gift by a caravan to the kašsum of Nehria (see below chapter VI.1.2.2 on this title) and a payment to the local kārum; a bag with the seal of this kārum is mentioned in kt 93/k 194:9f. In Kayseri 5064 prisoners are to be transported to and sold in Nehria, in AKT 1, 77:7f. a man married in Kanesh is forbidden to marry a qadištum in Kanesh or in Nehria. Note the occurrence of a "Ten-men board" (ešartum) of Nehria in AnOr 6, 15:2. The town is usually located in the area of Uita, on the Upper Balikh.

19. Nearly all occurrences of this city and its ruler (several times referred to by a nisbe only) are discussed in Sturm 2000,499ff. Note also kt a/k 488b, where the allahhinnum of 
Nenašs̆a bought two kurânu-textiles "for the wardrobe of the ruler" (ša lubus rubä im\}, and CCT 6, 34a:3-5, where its queen, bet mät $[\mathrm{im}]^{2}$ and king may occur. It is possible that the queen of ATHE 66:19 is the one of Nenašsâ, the goal of the trip according to line 6 . From $\mathrm{kt} 94 / \mathrm{k} 345: 5$ ' (ina Nenašsa ana nārim) we learn that the cily was on the rood to the Kizilısmak, which is confirmed by $k+94 / k$ 1534:20'f, which lists a payment "for the use of/to the man of the bridge" (ana sa titurrim) there. There is no mention of an Assyrian settlement, but the oddress of the official letter kt 92/k 203:4-6. "To kärum Durhumit, Hattus., Tamnia, Tuhpia until (adi) Nenaššâ", might imply that the city had a karrum. The account TC 3, 165:13-19 lists as expenses in this city tax paid to the palace and small gifts to local dignitaries such as the bel alim, the kašum, the namrum(?), the bë/ ha-Di-tim, and the räbisum, some of which are also mentioned in $\mathrm{kt} 94 / \mathrm{k} \mathrm{1534:20'ff.}$

20. No ruler, palace or "land", are attesled during level II, but a payment to the local kärum appears in $k t 1 / k 1: 9 / / 25: 3$ (Sever 1996). The wabartum occurs also in $k t k / k 122$ rev.:1 (summoned witnesses), kt 83/k 117:6, a letter from kärum Wahšušano, which reports abour "letters sent by the wabartum (sic) of Ulama and Saladuwar", in kt 92/k 195:16, and in kt 94/k 1197:8 (mentions its silver). The existence, during level II of both a kärum and a wabartum, could reflect a development in the status of the Assyrian settlement. Three letters of kärum Wahššsana (TC 1, 32, TuM la, and KTK 2) are addressed to the sōgil dätim u beruttim ša Saladuwar, while two others in the same address omit ša Saladuwar, see MüllerMarzahn 2000, 289f. The letters $\mathrm{kt} t / \mathrm{k} l$ and 25 contain useful information on the stops and expenses of a man leading a mule \{perdum\} via Šaladiwar to Wahšušana, which entailed the crossing of a river, probably over a bridge $i t / k 25: 10$ ). ARM 26 no. $542: 22$ (a letter sent to Mari from Karkemish\} mentions "a golden ring sa Sa-la-du-wa-ark".

21. The palace in OIP 27, 5:9, according to Dercksen 200la, 43, note 22. Since this letter is addressed to Nabi-Enlil, who lives in Amkuwa, the request to approach the queen and the rabi similltim must also refer to Amkuwa, unless the writer, Ennam-Ǎšur, is writing from far away and asks Nabi-Enlil to go to Šalahšuwa from Amkuwa. The city was not too far from Huramo (see Nashef 1991, 99) and note that while EL 252 records a controntation in Luhusaddia, which led to a lawsuit in Hurama, the same confrontation, according to ICK 1, 62:3, took place in Hurama Sa-là $>-a h-\check{s u}-a$, a unique combination of two place-names. Note for level I1, ATHE 62:34, quoted in the comments on no. 12, and a siprum Salahšuwoium in kt k/k/126:0. See for this city $Y$. Kawasaki, NABU 1990/98, who calls attention to its mineral resources (gold, silver, lead, su um-stone) on the basis of $\mathrm{kt} 89 / \mathrm{k} 222$ and 267.

22. The wabartum is beyond doubt for level $\mathrm{lb}$, in view of year eponymy of $k t b / k 21$, and for level II, where it is atso attested in kt 94/k 886:5 and VS 26, 195:3f. (there is no reason to assign this last text to level lb). The existence of a kărum during level lb, claimed by Balkan 1965b, 155, on the basis of the type of address (umma saaqil datri u kärum Timilkia ana kãrum Samuhd of an unnumbered unpubl. letter, needs more proof.

23. None of the nisbes attested refers to the ruler; the single attestation of the korrum shows the limits of our knowledge. CCT 3, 300, 4 mentions the "Ten-men board" (esantum) of the lown. Nole for the location, in addition to VS 26, 148, also the sequence Hamisonnum - Šmala - Zalpo in kt $\mathrm{g} / \mathrm{k} 199$. 
24. $\mathrm{Kt} 89 / \mathrm{k} 387$ is a letter which the wabartum, together with two Assyrians, addressed to kārum Kanesh. It also occurs in $\mathrm{kt} 92 / \mathrm{k} 194: 18$, where iron under the seals of kärum Durhumit is entrusted for transport in Šnahutum "before the wabartum". $K \uparrow 94 / k 340$ mentions the transport of wool from Šinahutum to Durhumit. See for the general location of the town in Hattum, Dercksen 2001a, 58 .

25. The kārum of level lb also in Mayer-Wilhelm 1975, no. 2:23, again in conjunction with "the travelers (on the road) to the City" (älikü sa harrän alim), a text connected with O. 3684, since both concern a summons against Sîn-bēli, son of Bulut-bēli (sic!). A level Ib date is proved by the mention of the eponymy of Kurkudannum in line 19 of the first text. The town was not far from Hattuš; note also the sequence Haltuš - Suppilulia - Karahna in $\mathrm{kt} \mathrm{n} / \mathrm{k} 211$.

26. The ruler of this city (spelled Tamnia and Tawinia) occurs together with his son in $\mathrm{kt} n / \mathrm{k}$ 388 (see above on 13) and in kl 94/k 937 (a meeting with the rubä um Tamniäium about the payment of blood money,. Günbatı 2001, 158f., reacting on Michel-Garelli 1990a, $282 \mathrm{ff}$. and discussing the location of the city and the evidence on its ruler, suggests that $k t$ $\mathrm{f} / \mathrm{k} 183$ (Balkan 1955, 73 note), a letter addressed to kärum Kanesh, which mentions the "messengers of kärum Durhumit", assigned by Balkan to level lb on the basis of its find spot, is also from level II, which would leave us without evidence for level Ib. There is indeed nothing in the text that militates against a level II date and the group of texts to which it belongs is of mixed nature; eponymy datings assign $\mathrm{kt} f / k 177$ and 184 to level $\mathrm{II}$, but $\mathrm{kt}$ $f / k 178$ and 181 are from level lb (eponymy of Enâ, see Balkan 1955, 100 no.2). A kārum during level II is documented in POAT 9:11, kt k/k 89:21, and $k t n / k$ 473:21. The Assyrian "lli-bāni of Tawinia" occurs in KTS 1, 3b:4 and ki m/ $130: 321 \mathrm{f}$.

27. The palace occurs in CCT $5,30 a: 15$, lextiles went up to the palace in T.), the karrum also in $\mathrm{kt} \mathrm{i} / \mathrm{k}$ 120:22f., kt 92/k 207:4 (letter from kārum Kanesh), and kt 92/k 197:21. That $\mathrm{kt} r / \mathrm{k} 1\left(\right.$ AKT2, p. 38, no. 2), a letter by Aniš-kibal, the barullum of Tiburzia, ${ }^{714}$ is a level lb text and would be addressed to $y_{1}$-bar!-tim sa Tegarama, is very doubfful, because of the curious spelling with $u_{1}$, though there are some level $\mathrm{lb}$ texts $(\mathrm{kt} r / \mathrm{k} 15$ and 19 , see Donbaz 1989a, 78ff.) among those discovered in 1965. The suggestion of Bayram 1998a, 54 note 75 , to read $10^{\prime}$-tim = esartim, "ten-men board", is atroctive. See for Tegarama as dwelling place of Assyrians, TPAK 50:9 ("the house of S. in T."), BIN 6, 136:12 !lddinKübum, the man of Tegarama), and TPAK 11:9. The writer of TPAK 198 testifies that he brought a letter of kärum Kanesh to Tegarama.

28. A rubäum Timilkiāum in TuM 1, 24e:2. The nisbe occurs in the level lb treaty with Hahhum $(\mathrm{kt} 00 \mathrm{k} 10, \mathrm{I}[\mathrm{III}]: 26)$, which refers to him as a potential enemy of Hahhum; the nisbe in TC 3, 162:9 (level II) could mean the ruler or an Assyrian living in the city (cf. kr m/ $\mathrm{k} 16: 5$, PN sa Timilkid. The land occurs in kt 75/k 81:4f., "You shall not do business in Timilkia and in its land". The "seal of kārum Timilkia", followed by six seal impressions, is mentioned on the envelope of $\mathrm{kl} \mathrm{m} / \mathrm{k} 66: 1$ (level II), see Hecker 2003, 192f. The answer to the question

74 See for the name also TC $3,191: 33$ and for the man perhaps $k$ 1 91/k 108 rev. 2, a gift of two textiles ana Ti-bu-ur-zi-a-i-e-im. 
in Nashef 1991, 120, "alle zu lb?", is clearly negative. The claim of Balkan 1965b, 155, of a karrum during the level lb period is based on its occurrence in the address of a letter to the kărum of Šamuha, but the text is unpublished and no number is given (see above on 22).

29. The palace also in CCT $6,12 a: 10$, and the wabatum in $k+92 / k 200: 5$. The nisbe is used several times of copper. Note the spelling Tišuwurna in TPAK 170:8.

30. The rub $\bar{\sigma}^{3}$ um of Tuhpia received a present (erbum) in TC 1, 39:4-8, and he wrote the letter kt 85/k 27, see Günbaltı 1997, no.l, who also mentions kt j/k 80:6, nubä'im Tu-uhpi-a-i-im. Both a kärum (once, in kt 92/k 203:6) and a wabartum (KTK 107:13) are attested during the level II period and we have two references to the "residents" (wasbüum) of Tuhpia,

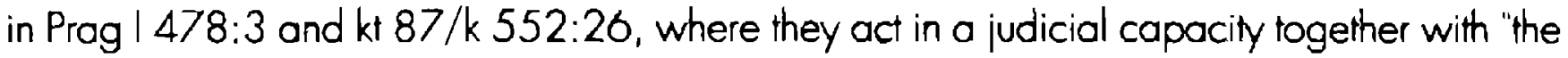
datu-payers and those who travel on the road to the City" (älikü sa harrãn alim), a constellation which is considered typical for the level Ib period (see above II. 2.1). In the letter ki 92/k 224 , addressed to "every single kärum and wabartum until Tuhpia", the town is the northern limit of the area Kuliya has to cover with this circulatory letter. $\mathrm{K}+92 / \mathrm{k}$ 196:2 mentions the allahhinnum of Tuhpia and there are also references to copper from this city (Dercksen 1996 , 45). The "weight of Tuhpia", used for copper, occurs in kt 93/k 278.

31. A ruler is mentioned in $\mathrm{kt} 93 / \mathrm{k}$ 179:3f. (courtesy Michel) in the phrase "the country is in furmoil since the ruler of $U$. is absent / there is no ruler in U." (ruba' um kima ina Ulama lašsut. The nisbe in the fragment TC 1, 118:5' probably refers to the ruler, in view of the preceding lines, $[\ldots$ a/i]-na Ulama $[. .$.$] -al ú sikkatum [... U ]$-la-ma-i-im. The "seal of the wabartum of Ulama", followed by four seal impressions, is mentioned on CCT 5, 180 l=El 282 , see Hecker 2003, 194). The wabartum occurs also in $\mathrm{kt} \mathrm{n} / \mathrm{k} 1801$ (deposition) and in the interesting lext kt 83/k 117 (Günbatt 1998c = CMK 44), a letter to kärum Kanesh by its messengers and kărum Wahsussana, who mention the arrival of 'trablets of the wabar-fum of Ullama and Šaladuwar", which report on problems in (reaching) Burušhaddum. Nashef's assumption that ICK 2, 293, which mentions travel expenses "until Ulama", is from level lb lacks proof.

32. The wabartum is only known from the three records AKT 3, 55-57, where it acts in a judiciary capacity; in 56 the issue is "pure copper of the land of Sowit". Upê occurs also in AKT 3, 48:4, where a trader's house in Upê is held as pledge.

33. See for the letter SUP 7, on the violation of Ašsur's shrine in kãrum Uršu, Larsen 1976. 261. The kärum also occurs in the emotional statement in CCT $6,14: 30$. (collated), that karum Kanis Za-altpa Hu-ha-ma Ur'-su u <Ma>-a-ma-a know the facts. Note kt 87/k 179 (Hecker 1998, no. 5), a slave bought in Ur[sü], handed over in Zalpa and then brought to Konesh.

34. The allahthinnum sa $U_{-5 a}$ occurs in $\mathrm{kt} 87 / \mathrm{k} 447: 24$, and identified by the nisbe in CCT 5 , 28b:6, a large silver debt owed by the allahthinnum Ušsaium, relared to CCT 0,46b:24f.; BIN 4,45:8 mentions the rabi sikkifim U-sa-i-um. The allahhinnum sa U-di-sa in CCT 5, 35c:3, as suggested in Ulshöfer 1995, no. 321, might be a scribal error $\langle\dot{U}<<d i\rangle>-\dot{s} d$, since no place-name $\mathrm{Ud} /$ tiša is known. An Assyrian living there was Alähum Usisoium, in CCT 0, 46b:24f. See for the cily Ušš, which appears as älum Ušsa in $\mathrm{kt} n / \mathrm{k} 63: 8,12$, also R. lebnun, in $\mathrm{KHN}, 328 \mathrm{ff}$.

35. See for rubā um Wahšušanāium also kt $92 / \mathrm{k} 234$ (he paid $3.000<$ minas $>$ of copper to Enna-Suen), AKT 1, 78:15 (without ruba' um), and perhaps, if awilum refers to the ruler, 
kt $89 / k 207$. "We made inquiries about the case of Wahšušana, the awilum needs many textiles for his country". A rubätum in KTS 1, 50c:2, a rabi sikkitim of this city in kt $87 / \mathrm{k}$ 387:26f. (see on this text below VI.1.2.3). The existence of a karrum during the level lb period is not certain, because $\mathrm{kt} r / \mathrm{k} 16$, contrary to Nashef 1991, 135, for prosopographical reasons is from level II. The view of Balkan 1965b, 154f., that ICK 2, 139:32 is from level $\mathrm{lb}$, because this deposition ends with the formulation "for this affair be-el ni-x $[\mathrm{x}(\mathrm{x}\rangle)]$ and kărum Wahšušana gave us", with a private person as subject, ${ }^{715}$ needs more proof. Envelopes with the text "Seal of karrum Wahšušana", with seal impressions, are listed in Hecker 2003, 194f. The existence of a wabartum in this city in the level II period is not correct, since in KTK 5:5 we have to read [ $] \bar{s}$ s $[\lambda] \dot{u}$ Wahsusana (collation jankowska). This makes a kărum also during the $\mathrm{lb}$ period possible, but its occurrence in $\mathrm{kt} \mathrm{00/k} \mathrm{14:1} \mathrm{(level} \mathrm{lb}$, dated to the year eponymy of Hahhial, in "karum Utr- $<\breve{s u}>-\check{s} \sigma-n a$ and the travelers on the road to the City", is problematic because of the emendation, although a spelling with Uth-instead of Waht is no problem, in view of the spelling U-ih-su-sa-na in kt 94/k 1374:3 'and cf. Ušhania for Wašhania, already in rexts from level II). Kr 92/ 248:8ff. mention that "the (traders?) residing in (wašbütum) Wahšušona have left". The gates of the city are mentioned in $\mathrm{kt} \mathrm{j} / \mathrm{k}$ 659:9ff., which advises, since the babb abullim is watched, that entrance into the city should rake place by "onother gate" (abullum sanitum).

36. The letter KTP 14 (CMK 40) mentions that a new ruler has acceded to the throne and wants to swear the oath. $\mathrm{Kt} 89 / \mathrm{k}$ 228:4f. mention the obligation to deliver $100 \mathrm{good}$ textiles to the rubäum. The palace is mentioned in kt 94/k 1534:9'f.: "In Washania the palace took $51 / 2$ shekels of tin as nishatutax" |followed by a small payment to the local kaššum, a man called ša ha-Di-šs and a local rābisum). A wabartum in this city during the level II period is also mentioned in $k t k / k$ 78:19, kt 94/k 442:34, and HS 2932: 9f. (Sturm 2000, 492). Kt 00/k 73f. (Donbaz 2004a, 184) mentions Zua, the scribe of the wabartum of Wašhania.

37.38. There seem to be three cities with very similar names (see Miller 2001, 70-77), wo of which, a northern and a southern one, both spelled Zalpa, occur dozens of times in the OA rexts. The northern one, spelled Zalpuwa and Zalpa in Hittite sources, probably can be identified with Ikiztepe, a town a little northwest of Bafra. The southern one could be Zalpa (Mari: Zalpah) on the Balikh or North-Syrian Zalb/war, located west of the Euphrates and perhaps to be identified with Tilmen Höyük (Miller 2001, 74-77). Nashef, Forlanini and Miller prefer the latter, because the former is rather far to the south for $O A$ caravons, which usually crossed the Euphrates much more to the north, in the area of Samsat. But it is not easy to integrate the North-Syrian Zalpa, ca. $100 \mathrm{kms}$ west of the Euphrates, into the Assyrian caravan system, and therefore Forlanini 2004 (426 and map) wants to locate it southwest of Malatya, in the area of Doğanșehır. This fits better, because this southern Zalpa was a regular stop for caravans on the way to Kanesh (Nashef 1987, 69). Although its position in the itineraries varies, there are several occurrences which show that the town is in the general area where one leaves Northern Mesopotamia and enters Southern Ana- 
tolia. In AOAП292f, note 423, I have presented arguments for identifying the kärum with this southern Zolpa, which is confirmed by the enumeration of a series of kärums in CCT 6 , 14:30f.: Kanesh, Zalpa, Hurama, Uršu and Mamma (see above on no. 33). The southern Zalpo, whatever its exact location, must also be meant in $\mathrm{Kt} 87 / \mathrm{k} 179$ (courtesy Hecker), where a slave-girl, bought in Uršu, is sold in Zalpa and brought to Kanesh. This implies that the wabartum was in the northern Zalpa, and kto/k 24 is an envelope sealed by its representatives (text KIŠIB a'-ba-ar-tim so Zalpa, see Hecker 2003, 195). This Zalpo then is also the recipient of $k t k / k 98$, a letter of karrum Kanesh to the "travelers (to the City?) and the wabartum of Z.", and in EL 267 it handled a legal case about a payment of a debt to the palace (in Zalpa?). In many cases a choice between northen and southern Zalpa is difficult and this also applies to the mention of a rubo 'um and the nisbe, in particular in the important letter TC 3, 85 (= CMK 90, discussed in Gorelli 1963, 344ff.) about negotiations with the ruler about compensation for losses. Mät Zalpa occurs in k/k 98:27f. Isale of a slave-girl ina mät Z.), possibly the northern Zalpa, since the lext mentions the arrival of boys

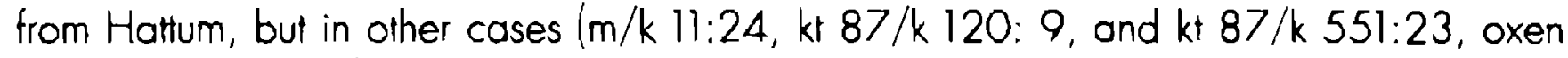
driven to mät Zalpa) the choice is difficult. in the interesting letter $k ! 87 / k 547: 25$ (courtesy Hecker), which may reflect a military conflict, and where we read about "booty (made) in the land Zalpa" (ina šallitim i-mät Zalpa) and where the man (ruler?) of Kušsora appears (whose palace is probably meant in lines $21 \mathrm{lf}$.), the southern city could be meant. The few references to Zalpo in texts from level Ib (OIP 27,5 and $6, \mathrm{kt} \mathrm{n} / \mathrm{k} 10: 5$ ) presumably mean the northern Zalpa (see Dercksen 200la, 59). "Zaipa on the bank of the river" (ina sapat norrim ina Zalpa, ICK 2, 156:3), might refer both to the northern or the southern city.

39. The wabanum is also attested in a/k 1412: 18 and $\mathrm{kt} n / \mathrm{k} 1007: 25$, and the lown as such occurs also in TPAK 4:13, kt t/k 11:13, kt 91/k 356:34, kt 94/k 310:5, and 378:8.

\subsection{ASSYRIAN COMMERCIAL SETIEMENTS}

While the data on Assyrian caravan journeys are helpful, transactions by traders and traveling agents who looked for the best places to do business, could profit from information on the markets, and practiced indirect exchange, make it difficult to discover clear patterns. This makes the data on Assyrian commercial settlements, either in a kärum or colony or in a wabartum or trading station, now attested for nearly forty different cities and towns, important. No texts explain the choice of these towns, nor the reasons for the difference in status between the two and how or why a change in status was effectuated, but there must have been commercial reasons for seltling down permanently with a group of traders in a particular town. Such towns may have been strategically located road-stations, important market towns or central places, centres of production (of wool, copper or silver), or political capitals, and in several cases a combination of these factors is likely. Importance as roadstation depended on the local geography - mountains passes, river crossings, 716 road

716 Texts refer to expenses for nebartum, "crossing", and to payments for bridges (sa timurim). 
junctions, etc. - and while such fealures can to some extent be established on the basis of written sources, good maps, and archaeological surveys, the fact that thus far only the location of Kanesh, Amkuwa and Hattus have been established with certainty is a problem. A city's economic importance can be deduced from textual evidence on the nature, size and frequency of transactions carried out there and on its function as market for specific goods, such as Durhumit for copper, ${ }^{717}$ Burušhaddum for silver, ${ }^{718}$ and Luhusaddia apparently for wool. ${ }^{719}$ A city's political importance, as capital of a state, also played a role and not only because such cities usually were strategically located concentrations of economic power. The trade was based on treaties with local rulers, which stipulated that imported goods had to be cleared and taxes paid in the local palace, while the ruler guaranleed protection to caravans traveling in his land, and this made political centres an obvious choice for commercial settlement. This choice was also in the interest of the local palaces, since it allowed them to better monitor the activities of the Assyrians and to collect the toxes due, while at the same time buying and selling merchandise as cuslomers of the Assyrians. Assyrian commercial activity in a town must have attracted other merchants and stimulated economic activities, also because the traders needed personnel and basic provisions for their daily needs.

We now probably know most kärums and wabartums, which together made the Assyrian commercial system during the best-attested period of level Il, but we do not know how it came into being. It seems likely that Kanesh was the first cily where the Assyrians settled down, perhaps linking up with the city's older reputation as trading centre and moving from a phase of venture trade, when caravans visiting such a central place had to return again after a short stay, to one of more permanent settlement in the target area. This would explain the position of kärum Kanesh as administrative centre of the trading network and also the (early?) existence of several Assyrian settlements on the way to Kanesh, in particular in Northern Mesopotomia and in the area where the Euphrates was crossed, such as Eluhhut, Nehria, Hahhum, Uršu, and Zalpa. Additional settlements must have been founded as the trade grew and a greater area was covered, probably to include the copper mining areas in the north and (if not already earlier) areas more to the southwest, where there was much silver. And in this gradual expansion Assyrian and local Anatolion interests may well have gone hand in hand, considering the benefits the trade yielded to the local rulers and the eagerness shown by some rulers, such as the new king of Wašhania in his letter KTP 14 / CMK 40 l, to swear the oath to the Assyrian authorities. Some might actually have inviled the Assyrian traders to settle down in their town, though we have no evidence to prove this.

71 See for Durhumit, Michel 1991a, and for its role in the copper trade, Dercksen 1996, 154f. Poor copper obtained elsewhere could be converted there into fine or refined copper, which was easier to sell, but at some moment this was forbidden by a ruling of the kärum (CCT 4, 27a:26f., see Dercksen 1996, 54). Note also a stipulation about the poyment of copper "according to the rate of exchange (mahirum) of Durhumit", and "interest according to the ruling of Durhumit" in $\mathrm{kt} 91 / \mathrm{k} 390: 9$.

78 See for this cily Garelli 1989.

79 See $A O A M T 3$ if., also kl 87/k 464:17ff., "in Luhusaddia l acquired 57 talents of wool for 9 minas of silver". 
It is unfortunalely extremely difficult to map this development. Most references to kōrums and wabartums are in private and official letters ${ }^{720}$ and especially in judicial texts, such as verdicts and depositions, which record that a named karrum or wabartum had made people render testimony in a lawsuit, ${ }^{221}$ but both types of documents ore undared. We also have to be careful in drawing too firm conclusions from the system of settlements, because our data probably are not yet complete, especially for the period of level lb. That some settlements ore only rarely attested (see the table in $\xi 2$ ), even leaves room for a few new ones. New texts revealed the existence of a few rather unexpected Assyrian seltlements, such as kārum Eluhhut and wabantum sa Upê. Suppilulio, somewhere between Amkuwo and Hattušs, whose kărum during the time of level lb was known, now turns out to have had a wabartum already during level II ( $k$ 94/k 486:17). The survey of differences between the situation during level II and level lb, given by Larsen 1976, 236ff., now requires some adaptation and there is proof of both more continuity and more change, since we know that Timilkia had a kärum during levels $\|$ and $i b .{ }^{722}$ Change of status is now attested for the Assyrian settlements at Kuburnat, Suppilulia and Wašhania, all three from wabartum during level ll to kărum during level lb. The example of Šamuha, now attested as wabartum during level II (TPAK 182:2'f.) and with both a karum and a wabartum during level $\mathrm{lb}$, indicales that a change of status within one period was also possible. For Tuhpia, on the other hand, both a wabartum and a kārum are attested for level II and one is tempted to assume that the growing importance of the town for Assyrian trade is responsible for a change in status. Something similar may have been the case with Saladuwar, whose wabartum during the level II period is well documented, but we now have two related texts that register a payment to the kärum in that town (see above $\S 2.2$ on no. 20). During level lb Assyrian settlements are not attested in twenty-three of the cities listed in the table, which suggests changes in the system, but with the limited number of (published) level lb texts from Kanesh now available, non-attestation can be dangerous argumentum e silentio.

Dercksen 200la, 6lf., has pointed out that Burušhaddum land perhaps also Wahšuša$n a)^{723}$ does not occur in the level lb texts we have (from Haltušs, Amkuwa and Kanesh) and had suggested loss of importance as a trading centre or inaccesability as a possible explanation. ${ }^{724} \mathrm{He}$ points out that this would make its trequently proposed identification with

720 See for the latter the translations of most of them in CMK, ch. 1

721 See for this rype of records Veenhol 1991. The standard phrose is "For this affoir korum/ wabartum GN gave us and before the dagger of Asssur we gave our testimony".

722 Its absence during level II, noted by Larsen 1970, 239, shows the limitations of our sources. We now have six references and the question posed in Nashef 1991, 120, "(alle zu Ib?)" can be answered negalively. $\mathrm{K} ; 87 / \mathrm{k} 257: 7$ (courtesy Hecker) is an atypical occurrence, stipulating "interest according to ruling of kärum Timilkia" in the text of a debt-note which is dated to eponymy

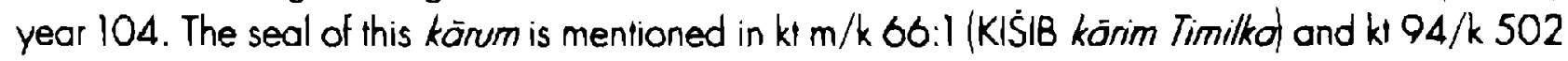
(courtesy Larsen); is a letter of kōrum Kaniš to this kärum.

723 This uncertainty depends on the dating of ICK 2, 139, see the comments on no. 35 of the toble.

724 He notes that Śaladuwar, a neighbouring town of Wahšušana, does occur once, in KBo 9, 0:10, as the destination of tin sent from Haltus. But Ulama, which had a wabartum during the level II 
Acemhöyük a problem, since this site yielded bulloe which are contemporary with the level Ib period and indicate commercial activity and contacts with Assur and Kanesh, ${ }^{725}$ while also the "Anitto Text" proves its importance during the later part of the level lb period. If Burušhaddum is indeed no longer part of the trading nelwork, it might favour identification of this city with Konyo Karahöyük, which in turn would imply Assyrian presence during the level Il period much further to the south-west of Kanesh and an important reduction of the range of action during the level lb period. Loss of Burushaddum, and perhaps also Wahšušana, as Assyrian trading centres might explain why Wašhania, on the road from Kanesh to the west, during that period developed into a karum. Uncertainty about the location and identification of Burušhaddum, unfortunately, only allows hypothetical conclusions.

On the basis of his analysis of all known level lb texts Dercksen (200la, 65f.) concluded "that the focus of Assyrian trade appears to have shifted after level II to the emerging power Mamma near Elbistan and to the area within the bend of the Kizilirmak, formerly called Haltum. This probably happened due to political developments in the course of which some cities in the west lost the position they held during Level II." The rise in status (whatever that may have meant in practice) of the Assyrian settlements at Kuburnat, Suppilulia and Wašhania would fit such a development, but more textual data from the Level lb period are needed to substantiate this explanation.

\subsection{The ANATOLIAN CITIES AND thelr rulers}

Our knowledge of the Anatolian cities, towns, "lands", and their rulers is also restricted, because the information on them in Assyrian sources is often laconic and ad hoc. The lexts acquaint us with o few hundred different place-names, but many towns or villages ${ }^{726}$ are just names for us. Several are only known because the Assyrian booked expenses incurred there during one of their trips, ${ }^{727}$ others are mentioned, especially in native Anatolian records, as places where people lived or came from. A number are only indirectly known,

period and is situaled on the or a road from Wahšušana to Burušhaddum (see the letter CMK 44) is also not attested. There is no reason to lake ICK 2, 293, with Nashef 1991, 128, as being from level $\mathrm{lb}$, but which kärum is meant in line 6 of this text (poyment of 10 shekels of silver to it) is unclear.

725 It yielded bullae sealed by S̆amši-Adad I, sealed bulloe altached to packets sent from Assur (by a group called nibum, see for them Dercksen 2004a, 62f.) to kärum Kanesh and apparenlly sent on to Acemhöyük without being opened, and a sealed bulla inscribed "Seal of Šumi-Aššur, son of Ǎšur-tāb, to my representative", clear proof of the presence of Assyrians traders there; see Veenhof 1993.

726 Some have names of the type $\bar{a} /+$ personal name or noun, e.g. al Kupi/san $(\mathrm{kt} 91 / \mathrm{k} 437: 17 \mathrm{f}),. \bar{a} /$ butnätim, "Pistochio-town" ikt 91/k 437:1], al issurätim, "Birds-lown" (kt 92/k 237:3), etc.

727 Expenses in Bagarime (1 628:13), payment of 2 shekels of silver in Dumelia (kt 91/k 345:19), silver paid for a cloak in Duwānia (kt $\mathrm{u} / \mathrm{k} 5: 6$, collated), payment for lodging in Hanigga and a gift to a local allahhinnum in Tahadizino (kr 91/k 437:6 and 21), ek. 
because they occur as nisbe, used to identify a particular product or person. ${ }^{728}$ In several cases the political status of a town remains unclear for lack of information on a possible ruler or palace, probably because it was not important or had no diplomatic contacts (or conflicts) with the Assyrians, which usually was the reason for mentioning it in letters. On the other hand, several towns do figure in the sources, occasionally even with their ruler, while no Assyrian commercial presence is recorded and even their location and importance remain unknown. Examples are the rubä'um Sirmia 'um, (identical to?') that of Sirmu'in, and the rubä um sa Sithwa. ${ }^{729}$

References to a king, invariably called $r u b \bar{a}^{3} u m^{730}$ with the term the Assyrians used to designate the ruler of Assur, ore clear when the city over which he ruled is added (ruba ${ }^{3}$ um sa $G N^{\prime}$, as happens in the address of letters by Anatolian rulers to Assyrian authorities or traders (cf. CMK93 and 97). ${ }^{731}$ But this specification is often omitted, especially in letters, when it was clear to the correspondents which ruler wos meant, but not to us (e.g. in the letters translated as CMK 94-96). There are also many cases where a ruler or queen is only designated by a nisbe, which reminds us of the use of awil $+G N$ in texts from Mari. Many nisbes obviously refer to rulers, but since they are also used to identify privote persons who live in or are from a particular town, uncertainties remain. Some extremely interesting letters and records of confrontations with local rulers unfortunately only speak of "the ruler" $\left\langle r u b a^{2} u m\right\}$, without mentioning his city, which makes us guess. ${ }^{732}$ The general rule is that Assyrian texts almost never mention an Anatolian ruler by names, ${ }^{733}$ just like they frequently speak of "natives" (Anatolians, nu'a' 'um), without recording their name. Rare exceptions occur when specific events are mentioned as the date when a debt was contracted. In ICK 1 , 178:2ff. this happened "when Larbarsa became king" (inümi labarsa ruba' üram isburu), but

728 E.g. topašathäium, "from Tapašatta", and taritaräium, "from Taritar", used of copper, situnium, used of sheep, s/zus/zeium, used of a garment (lubuisam ZU-Z1-e-o-am, AKT 2, 24:10), dibasnaium used of iron $(k \mathrm{k} u / k$ 3:56, collated), palurusináium, used of a man $\{\mathrm{KTH} 3: 22)$, kilarrium (also altested as nisbe for a population group in the Sargon tale, $\mathrm{kt} j / \mathrm{k} 97: 57)$ used of slaves, etc.

729 See for references Nashef 1991 s.v.

730 See for the use of this term, Balkan 1957, 25f. Sarrum is known, but in Anum-hirbi's letter it is used for pelty rulers, who are vassals of a great king. The use of LUGAL for "king" is exceptionally altested for the ruler of Hahhum in CCT 4, 30a:13 (where his magnates are called rubä $u$ ), but the some ruler is called ruba um in $\mathrm{kt} b / \mathrm{k}$ b12:18. This indicates that the logogram IUGAL could be used for rubā'um, as with Zuzu, "great king of Alahzino", whose title is written IUGAL GAL in kt 89/k 369:1, but rubäum GAL in kt 89/k 370:35.

731 Also in $\mathrm{kt} \mathrm{n} / \mathrm{k}$ 1024, a lehter of the ruler of Hurama to an Assyrian trader.

732 Examples ore $k+87 / k 249$ (Hecker 1990, 148f.) and the duplicates $k t n / k 504$ and $k+93 / k 145$, where a king and queen accuse an Assyrian of having served as messenger for their enemy, the ruler of Tawinia (see Günbatt 2001, also on the question which ruler might be meant).

${ }^{733}$ The same problem arises with references to rulers of Assur, only designated as rubä um, see e.g. Ulshöter no. 176:15'-17', silver sent to Assur to the ruba 'um and tin sa abisu sa ruba 'im, where the identification is not always immediarely clear. See now also Kryszat 2004a, on the similar problem of identifying the Assyrian ruler designated as waklum. 
we do not know of which city, 734 and in $\mathrm{kt} n / \mathrm{k} 76: 12 f$. "when Asu, the king of Luhusaddia, had died". 735 Something similar is the case in kt $\mathrm{n} / \mathrm{k}$ 1371: 14ff. (courtesy Cecen), which reports that trovelers were stopped when the message about the death of the anonymous ruler of (the otherwise unknown lown of) Kaštama became known. Other interesting references to rulers who remain anonymous are in CMK 91 and KTS 50c. ${ }^{736} \mathrm{~A}$ few references to unnamed rulers are in the context of annual or seasonal rituals or festivals, mentioned as due dates in Anatolian debt-notes, whose meaning escapes us. ${ }^{737}$

\section{5. 'Notarization' and dating IN leVel lB texts}

\subsubsection{List of attested 'notarizations'}

More names of Anatolian rulers are known from the level lb period, mainly from the socalled 'notarizations' which appear at the end of Anatolian legal records, and document that the transaction was passed under supervision and perhaps with permission (iqqäre) of the king or the rabi simmiltim mentioned by name. Note in particular the formulation in VAT 4536:15f. (no. 22), "they bought the house iqaâte- Kammalia". The ruler (rubãum) is usually followed by the mention of the "chief of the stainwy" (rabi simmilfim), a title which probably links him with a "stairway leading up to the ciry wall" or perhaps to the main gate $^{738}$, but which is relatively rare outside the notarization (see below chapter VI.1.1). His power is documented by $\mathrm{kt} / \mathrm{b} / 95$, where he is offered a few lextiles to ensure that prisoners may stay alive, and in kt $89 / \mathrm{k} 353$ (courlesy Kawasaki) the rabi simmifim Kura sells a whole family, with their possessions, to an Assyrian, presumably because he himself as

734 See Balkan 1957, 54. The text is broken and only contains the name of the debtor, without patronymicic. He has to pay "when he returns from Hatum", the designation of the area within the bend of the Kizilirmak, which suggests that Labarsa ruled elsewhere. Note also the grain loan kt $\mathrm{k} / \mathrm{k} 33$ (courtesy Hecker), 10 be given back "by means of the measuring jar of Labarša" (ikkarpitim sa labarsal, where Labarša is neither creditor, nor debtor, nor witness, hence perhaps the ruler alier whom the standard measure was named?

735 See for this text Donbaz 1988a, 5lf. (level Ib period). An anonymous queen of Luhusaddia is mentioned in CCT 4, 19c (CMK 103). Would she hove continued to rule after the death of her husband?

736 Records a gift presented "when the queen of Wahsusana entered (her city)", which must have been a special accosion, perhaps when she arrived as bride of the local king.

737 in $k t n / k$ 1716b:9, "payment in one year, when the king comes out of the remple of (the god) Nipas". In kt n/k 306:5ff., "when the ruler enters the Gašsum" "to which kt j/k 9:11 adds: "in the temple of Anna"; see for Gašsum, Dercksen 200la, 45 nore 35). See below chapler VI.2.1.

738 CADS 274,d, which quotes C 5:14-24, where an anonymous trader states that he produced/brought up (šel/u um) for his addressee an amount of silver, which "you accepted (mahhurum) on/in the stairwoy and put into a coffer, which is now deposited under your seals where you instructed me". 
their owner, or the family which is under his power, have to pay their debts. ${ }^{739}$ We have the following notarizations: 740

\begin{tabular}{|c|c|c|c|c|}
\hline nr. text & Iransaction & rubāum & rabi simmiltim & withour titte \\
\hline 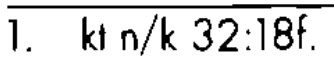 & settlement & Hurmeli (Mamma) & Harpatiwa & - \\
\hline 2. kt $99 / k 139$ & debt & - & - & Harpatiwa \\
\hline 3. OIP 27,53 & redemption & - & - & Harpatiwa \\
\hline 4. $k t r / k 19$ & division & - & - & Harpatiwa \\
\hline 5. $\mathrm{kt} \mathrm{n} / \mathrm{k} 32: 49 f$. & settlement & Inar (Kanesh) & Śamnuman & - \\
\hline 6. TC 1, 62 & joint household & {$[\text { lnar }]^{?}$} & {$[?]$} & Šamnuman \\
\hline 7. $\mathrm{kt} \mathrm{k/k} 10$ & house sole & Inar & - & - \\
\hline 8. $T C 1,122$ & divorce & Waršuma & Halgiašu & - \\
\hline 9. KTP 43 & slave sale & Waršuma & Halgiašu & - \\
\hline 10. kł n/k 31 & house sale & Waršuma & Halgiašu & - \\
\hline 11. $\mathrm{ktr} / \mathrm{k} 15$ & separation & Waršuma & Halgiašu & - \\
\hline 12. kt $89 /$ k 383 & separation & Waršuma & Halgiašu & - \\
\hline 13. kt $99 / \mathrm{k} 138 \mathrm{~A}$ & brotherhood & Warašmo & Halgiašu & - \\
\hline 14. kt k/k 14 & loan or debt & - & Halgiašu & - \\
\hline 15. kt 89/k 379 & adoption & Pithana & - & - \\
\hline 16. kt n/k 11 & slave sale & - & - & Pithana \\
\hline 17. TC 3,214 & divorce & Pithana & Anitta & - \\
\hline 18. kt k/k 9 & debt & Pithana & Anitto & - \\
\hline 19. OIP 27, 1 & {$[?]$} & Anitto & - & - \\
\hline 20. kt 89/k 371 & redemption & Anitta & Peruwa-Kommalia & - \\
\hline 21. OIP 27, 49 & seporation & Anitla r. robium & Peruwa & - \\
\hline 22. VAT 4536 & house sale & - & Kammalia & - \\
\hline 23. KKS 57 & joint household & Zuzu & |ṡtar-ibra & - \\
\hline $24 . k+k / k ~ l$ & divorce & Zuzu & |štar-ibra & - \\
\hline 25. kj 89/k 370 & joint household & Zuzu & |šlar-ibra & - \\
\hline 20. kt j/k 025 & divorce & Zuzu r. robium & Iśtar-ibra & - \\
\hline 27. kt 89/k 369 & joint household & [Zuzu] r. robium & Istor-ibra & - \\
\hline $28 . \mathrm{kl} \mathrm{n} / \mathrm{k} 39$ & sale of woman & {$[\ldots]$} & {$[\ldots]$} & - \\
\hline $29 . k+89 / k 305$ & separation & {$[\ldots]$} & {$[\ldots]$} & - \\
\hline
\end{tabular}

739 A list of personnel from the city-mound, $\mathrm{kt} \mathrm{g} / \mathrm{/} 36$, mentions 40 people, "personnel (ašlapirum) of Turupani, rabi simmiltim" (Bilgic 1904, 148), assembled for a specific purpose [et. Dercksen 2004b, 139 note 5). See further CADS 275f., with references which indicale his power and his involvement in the trade. El 273 is a verdict by the kärum, which pronounces a boycolt of the r. s., because he does not poy his debts, see larsen 1976, 327. In KTK 20:24 we hove to read robi sikkifim.

740 Most of the rexts used in the toble can be found in Balkan 1957, 45f., Donbaz 1990a, 1989a, 1993a, and 2004b; see for 21 Müller-Marzohn 2000, no. 4, and for the seols on some of these lexts, N. Özǘc 19960. See also above, note 069 for some readings. 
1. $\mathrm{Kt} n / \mathrm{k} 32$ (see above nole 667) deals with a partnership between an Assyrian and two Anatolian brothers, "notarized" in the past by Hurmeli, but now land after one of the brothers has died) terminated under the supervision of king lnar. That the partners would trade in Kanesh and Mamma (line 21) does not make Hurmeli king of Mamma and he must have been the (a) predecessor of Inar as king of Kanesh (see on 5-7).

2-4. The man who notarizes must be the same as the rabi simmilfim of 1, cf. 5-6; see for 4, Dercksen 2004b, 168.

5. The Anum-hirbi letter (line 29f.) tells us that Inar was the father of Waršama, but the latter was not Inar's rabi simmilfim; Śamnuman 'if he was crown prince) may have died early. Perhaps the system was flexible, allowing also the ruler $\{7,15\}$ or the rabi simmiltim alone $(2-4 ?, 14,22)$ to notarize.

6. The name of the king is broken off before ruba $\bar{a}^{2} i m$ at the beginning of 1.24, and Samnuman's title (rabi simmiltim?) may be missing.

8-13. A well attested pair, with some variation in the spelling of the king's name (Waršama in Anum-hirbi's letter, Wa-ar-ás-ma in 13). See for $8=E 13$ and $9=E 1$ 189. Balkan 1957, 45f., for a photo of 9, ibidem, figs. 15-21, and for 8 and 11-13 Dercksen 2004b, $167 f$. and 172f. That Halgiašu did not succeed Waršuma as ruler might be due to Pithana's conquest of Kanesh. Halgiašu is probably mentioned in $k t / k 115$, in the remark "when we setlled accounts before Halgiašu", since he is neither party nor witness and may have acted a supervisor. He might even be the same man as "Halgiašu, chief of the market" (rabi mahirim), first witness of a slave sale (kt 93/k 215b:22).

14. Together with 22 the only certain case where only the rabi simmiltim notarizes.

15-18. These documents show that Pithana ruled over Kanesh. Why in 15 he notarized alone and in 16 (collated) without mention of his title is unclear; the absence of Anitta as rabi simmillim could have a chronological reason (too young?). See for 17, Dercksen 2004b, 173. 19-21. These texts show that Anitta ruled over Kanesh (20), and Amkuwa (19, 21) and the conquest of Amkuwa may explain his prestigious title ruba um rabium, thus far only known for the ruler of Burušhaddum (TTC 27:7, cf. Lewy 1956, 53) and Zuzu (see ad 22-26). The situation as to his rabi simmittim's is unclear. The double name in 20 is curious. but note the occurrence of similar 'double names', Kammalia-Peruwa in $\mathrm{kt} d / \mathrm{k} 6 \mathrm{a}: 4$ ', and Kammalia-Tarawa in WAG 48-1464:3 (see lewy 1937); it is not attractive to differentiate the rabi simmiltim under Anitta in 20 from that of 21. Since Kammalia was the name of a lown (Nashef 1991, 64f.), Kammilia may have been added to identify him, since Peruwa was an extremely common name, with many namesakes. Anitta, Zuzu or perhaps even a third ruler may have been the "grear king", who during the period of level lb concluded a treaty with the Assyrians, the one studied in chapter V.2.1.

22. Edited as Müller-Marzahn 2000, 299f., no. 4.

23-27. Zuzu's title of "great king" (in 25 rubā'um GAL, in 26 [LUG]AL GAL) may be due to his conquest of Kanesh, since in 27 he is called "great king of Alahzina" (location of this city unknown). Note that 24 writes ruba ${ }^{3} i m$ Zuzu instead of normal Zuzu rubä im. See for 25 Dercksen 2004b, 170 and for Zuzu's seal on kt 89/k 369, T. Özgüc 2003, $308 \mathrm{f}$. 
28-29. Two records whose damaged or missing ends might have contained the notarizalion, as Donbaz assumes for 28; see for 29, Dercksen 2004b, 169.

The reason why certain contracts were 'notarized' is never stated and is unclear, because some other native Anatolian texts that record debts, divorces, sales and separations lack it. More contracts may have been notarized than we can observe, since the tablet of 14 mentions the notarization, but its envelope not. Notarization was probably conditioned by the status of the persons or the property involved (servants/property of the crown?), whose transfer or change of status was monitored or had to be approved by the ruler, who in this way may have also been made responsible for maintaining the legal situation created by the contract. One might compare the fact that at Ugarit many controcts recording the transfer of immovable property were passed "before (ana pani) the king"; his authorization must have been required because the houses and fields involved my have been originally property of the crown or their owners liable to service duties.

\subsubsection{Dating of rulers and events}

Unfortunately, the notarized records are never dated by year eponymies, so that we do not know how long these rulers reigned and even their sequence is a matter of deduction, but some observations can be made (see also chapler III.2.4 for a historical reconstruction). Pithana's rabi simmiltim was Anitta, apparently the crown-prince, who in due time succeeded him and such a succession is implied by KTK 7 too. ${ }^{74 i}$ But this was not always so, not with Halgiašu, Waršuma's "chief of the stairway" (who occurs six times), and not with Peruwa-Kammalia, the one of Anitta ${ }^{742}$ Dynastic succession in these cases may have been disturbed by death, ${ }^{743}$ conquest or revolt.

Some texts from level II do mention such events. Kt n/k 1429:14 mentions hostilities of (in) Kanesh" (nukurörum ša Kaniš) $)^{74}$ and several texts refer to "upheaval" or "revolt" (sahä um.

741 Read after collation " [.........] we brought (as giff) to the [rabi sim] miltim. The wabartum said: In the time of his father, when the kârum made $[$ him $]$ swear the cath .... one textile for the lord of the town, one textile for ... we brought. Pleose, our fathers ond lords, send us two textiles and we will act exactly as you instruct us" $\left([\ldots] \text { ni-si-i-ma }{ }^{3} \text { [a-na GAL si-m }\right]_{1-i} l_{5}-t i m^{4}$ ni-si-i um-ma wa-bor-

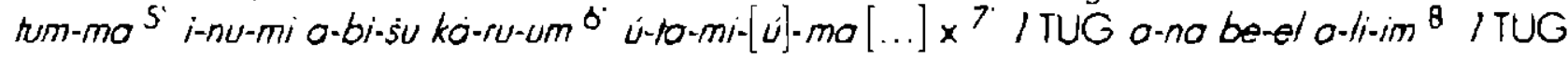
$a-n a \times n i-s i-i$, etc.

742 The rabi simmiltim Turupani, apparently of Kanesh, mentioned in kt $\mathrm{g} / \mathrm{k} \mathrm{30:30} \mathrm{(Bilgic} \mathrm{1904,} \mathrm{148).}$ is neither ollested in a notarization nor (later) as king.

743 Note the mention of "an epidemic (mutönü) of (in) Burushaddum" in kt n/ $\mathrm{k}$ 1339:10f. (Cecen 1995, no. 1).

744 Mentioned as the time when a financial liability had started, presumably somewhere in the years $81-84$ (see Veenhof 2003,61 ). The possibility of nukurtum with neighboring cities or slates, which might disturb the trade, is also mentioned in the level 11 treaty $k+n / k 794: 25$, and, by means of the verb nakōrum, in the level ib treaty with the ruler of Hahhum (see for both reterences Günbolti 2004, 250 note 8 and 258, Ill:26'ff., and below chapter V.I.C and V.2.2 under d). 
sihitum) in a ciry or a "land", in CCT 4, 42a:18f. in Hahhum, in LB 1209:14 in the land (of) Kunanamit, in KTH 1:4f. in Burušhaddum and Wahšušana, in $\mathrm{kt} \mathrm{m} / \mathrm{k}$ 13:25 (courtesy Hecker) in Burushaddum alone, ${ }^{745}$ and in BIN 4, 34:8f, CCT 3, 280:29, kt n/k 1464:25f., and TC $3,112: 21$ in unidentified "lands". An intriguing piece of information is contained in KTP 10 (CMK 57), a letter of the wabartum of Šala<du>war to kārum Wahšušana, where somebody (presumably a ruler of a city, perhaps the one of Burušhaddum) had said in a letter (rev., lines 9-13) "Invade? the country of Wahsušana. If not, I am your enemy!"746 The ruler (of Kanesh?), according to the deposition published in Günbattı 2001, designates the ruler of Tawinia as "my enemy" (bë/ nukurtia, line 16). The nature of these events, however, remains unclear, apart from the fact that they interfere with the trade. But one such text $(k t$ 92/k 526:6ff.) seems to link "upheaval" with the death of a king and military danger:

"Here the king has fallen during/in the sikkatum and there is upheaval within the ciny and we fear for our lives. There are enemies over a distance of one and a half hour and nobody dares to go out into the countryside. One even tries to make us set out logether with him for doing battle! In the meantime absolutely no contracts must be drawn up, lest we get indebled to our principals for no less than one talent of siver! When the couniry becomes peaceful again and the ruler will conclude an agreement with him, tablets can again be sent somewhere."

Since we can hardly expect to discover a Kaneshite, let alone an Anatolian Kinglist, we have to use occasional hints and prosopography for dating such events, but this is very difficult for level II texts, since neither Assyrian nor Anatolian records mention names of rulers. At times we cannot even decide whether a ruler of a particular cily mentioned in several different texts is the same person. We are also not certain whether a queen who occurs alone, makes starements and rakes action, did so after the king, her husband had died or whether she was a princess who, for lack of a son, had succeeded her father. ${ }^{748}$ For level $\mathrm{lb}$, with the notarization, some progress must be possible if more level lb texts, which mention the titles and professions of many Anatolians, have been published.

745 Lines 21-26, "Don'l you know that in Kanesh not even 10 pounds of silver can be earned? There is a revolt in Burušhaddum, no single individual (wedumma' can enter the city".

746 10'ff, ana māt Wahsusana muqtā summa la tamqutā ištikunu nakrāk, taking maqātum ana as it is used in Anum-hirbi's letter, lines 20 and 32. Larsen 1976, 268, gives it a more neutral meaning, "to arrive in the land", as in allibbi matim magātum, said of a caravan in AnOrb, 18:27.

$747 \mathrm{Kt} 92 / \mathrm{k}$ 526:6-21, annokam ${ }^{7}$ rubäum issikkätim maqitma ${ }^{8}$ ina qerab alim sihitum ${ }^{9}$ saknat (Cecen 2002, 67f.). Sikkätum is an outdoor event of ceremonial and/or military nature in which people take part en masse, see Veenhof 1989, 521f. and below VI.1.2.3. Read in line 11 bēro $\checkmark$ züza, and in 14 qōdišuma uštenessunniatima, but it is not clear to whom "logether with him" refers and who is meant in line 22 by "with him", unless maqätum in line 7 does not mean "to fall (in battle)", but "to fall upon", "to arrive suddenly". We cannol date this event, also because the archive to which the text belongs is still unpublished.

748 See for the queens, CMK p. 163ff. Note the queen of Konesh who rakes action in ATHE 62, and the one of Luhusaddia who negotiates with Assyrians in her palace in CMK 103. There are several texts in which king and queen both appear (e.g.in CMK 101), also acting logether in a confrontations with the Assyrians (kt n/k 504, see Günbatt। 2001). 


\subsection{Cities, "LANDS" and terRITORIES}

Apart from the location of the main cities and towns, and the presence of an Assyrion trading settlement, also the extent of their territories is important and here references to the "land" (mâtum) of a city or ruler, noted in the table (2.1.), are relevant. Mähum has various meanings and may also denote the country-side in opposition to a town, at fimes perhaps meaning "hinterland", where the traders could go to acquire or sell goods, ${ }^{749}$ and it can also mean "the (rural) population", who is occupied by the harvest. ${ }^{750}$ in several cases "land" probably does not mean a political entity or territorial state, but is used as a geographical designation of an area near or around a city, explainable from the lack of separate names for regions or larger areas, which could only be identified by the name of its main city. When important cilies are involved one may hesitate about its meaning, e.g. when TC 1, 18:42 states that a caravan leaves Mamma to arrive in "the land of Kanesh", kt $87 / \mathrm{k} 120$ mentions payment upon return from "the land of Zalpa", ki $k / k 94$ coniains a clause about the sale of a slave-girt(?) "in the land of Zalpa", and kt m/k 11:23f. speaks of purchases (simum) of the land Zalpa. Again different is the use of mätum in the designation māt Sawit, referring to a mountain ridge, the origin of copper. ${ }^{751}$ Cases where the expression "land of GN" is probably used as an apolitical, geographical designation are mät Tahruwa (kt 93/k 236:8, wool shipped to it), mât Sarla (kt a/k 165:18), mat Elmelme (Prag 1 537:19, the destination of a shipment of salt), and $m a \bar{t}$ Harabis ( $\mathrm{kt}$ 94/k 1472:10f, the goal of a journey). But we hove to be careful as the example of Śhwa shows, a town altested only once, but one with a palace and a ruler (see Nashef 1991, 105 s.v.) and therefore also with its own territory.

The much discussed name. Hattum, "Hattum (land)", whose origin is unknown, is different, because it does not refer to a cily of that name, which the OA period was called Hattuš, and no "mät Hattuš is attesled; but we have an occurrence of mäum sa Hattim, which in the same text alternates with simple Hattum. ${ }^{752}$ Hattum must refer to a (large) area, ${ }^{753}$ probably the one of the basin of the Kızlirmak, with cities such as Amkuwa, Hattuš, Sinahutum, Suppilulia, Tawinia, and Tuhpia. ${ }^{754}$ it probably survives in the later Hittite use of the term

749 In the combination ino libbi mätim, in CCT 2, 48: 77. the region where Assyrians tried to buy local iron, in lines 24ff. contrasted with ina naqribim, "in the vicinity" of the town, comparable to mätm qerbinum, "the inland", where according to AKT 3, 45:10f. iron could be bought. See Dercksen 2001a, 58, where he considers the possibility that is was the "inland" of the areo called Holum in OA sources.

$750 \mathrm{Cf}$. the use matum in the sense of "the population/army of my country" in Anum-hirbi's letter, 31f., māti ana märika imquram, "my land invaded your land".

751 See also Nashef 1991, 86.

752 According to k: 92/k 205:9 good purchoses can be mode illibbi mätim so Hattim, but lines 131 . speak of "silver which can be earned ina Hattim".

753 The OA Sargon tale (Günbattı 1998a, ct. Dercksen 2006), when enumerating the king's adversaries in lines SOff., speaks of a rubā'um of Tukriš, of Amurri 'ē, "Amorites", Kilari 'é, "Kilarites", but in line ol uses sa Hattim, "those of Hattum", for its people.

754 See Dercksen 200la, 58. He considers the possibility that the existence of the (perhaps older) designation (mä) Hathm had made "mat Hattus as a designation of the (originally probably somewhat smaller?\} ierritory of the cily-stale of Hattuš superfluous. 
"Land of Hatti", which seems to include the basin of the Yesilirmak. As such it could have been distinguished from "The land", that is the land south of the river, extending east and west of Kanesh, perhaps more or less equal to "the land of Kanesh", which apparently did not comprise the city-states more to the south-east, Timilkia, Hurama, Kuššara, Luhusaddia, and Salahšua. 755 "The land" is probably used in this way in a letter that tells that "two persons of the land" (sina sa mätim) will come to administer the oath to the ruler of Washania, who must have been official representatives of karum Kanesh. A similar meaning may be intended in ICK 1, 3, where a man is forbidden to take a secondary wife "in the land", but is allowed to do so "in the city" (Assur), where "in the land" could equal "in the land of Kanesh". 750 We may compare TPAK 161:9ff., where a man who marries a girl in Kanesh, is not allowed to marry a second wife in Kanesh, Burušhaddum, Durhumit, or Wahšušana, that is in the whole area where Assyrian traders worked. ${ }^{757}$

In this way "land" may also refer to the territory ruled by a specific king, whose inhabitants had to pay him taxes and render him services, which he had to defend and in which he allowed the Assyrian traders to settle and conduct their business. While in several cases we do not know whether $m \bar{a} t+$ city name indeed has this meaning, ${ }^{758}$ it is clear in ATHE $62,33 f .{ }^{759}$ where the queen of Kanesh, after discovering a case of smuggling, "wrote to Luhusaddia, Hurama, Šalahšua and to her (own) land" to keep a close watch. ${ }^{760}$ It means the territory of Kanesh, bordered in the southeast by three city-states, each with its own ruler. ${ }^{70 l}$ This some meaning must obtain when Assyrians turn to the ruler of Luhusaddia with the words "In your land Assyrians have been killed" (Kays. 1830:9, see Hecker 1996a, no.2), since the place of the crime makes the ruler accountable. Another example is $k t 75 / k$ 81:4f. (courtesy Michel), where people are forbidden to practice commerce (šulebbulum) "in Timilkia and in its land" (märisu). Clear examples are in the two recently published treaties, where the ruler endorses stipulations that concern "your land" and "your city" (Kanesh treaty, 32ff., 58; Hahhum treaty, II [IV]: 31'f. and IV [I] 23f.). The second treaty is even more defailed in speaking of losses "on the river, in your mountains and in your land" (III [II] I4ff.)

755 There are references to "the land Timilkia" and "the land Luhusaddia" (see chapter IV.2.1-2 under nos. 15 and 28), which suggest that they were independent states.

750 it has been suggested to take "the land" here as a general designation of Anatolia, but the contrast between Assur and Anatolia is normally expressed by alum versus eqlum. Cf. POAT 16:34ff., in a rule formulated by Assur, ša eqlim ina eqlimma sa ălim ina alimma illagqe. "what (is owed) in Anatolia can only be collecled in Anatolio, what (is owed) in the City only in the City", and similarly ICK I, 12:11f, "tablets, either ša alim or 50 eqlim".

757 Cf. kt 94/k 149 (Michel-Gorelli 1996b), where he is forbidden to marry a second wife "in Kanesh", and AKT 1, 77, where he is not allowed to do that in Kanesh or in Nehria.

758 E.g. mät Kunanamit, which is in revolt, LB 1209B:13t.

759 Involves Püšu-kēn and is addressed to Puzur-Ǎšsur, who is altested as his partner in the years belween ca. 89 and 100, see Kryszat 2004a, 48.

760 Note also that the Assyrian addressee of this letter is warned not to bring his iron across, but to leave it behind in a reliable house in Timilkia.

761 for the rulers of these cilies the table in chapter 2.2 .1 . 
and "in your city Hahhum, in your mountains and in your land" (II [IV] 16'f.). The same is the case in the treaty between Assur and Sehno. 702

The expression "land of city A" has to be distinguished from "päticity A", which uses the word pātum (or pattum), "edge, border, border area", well-known from $O 8.703$ The concept of a "land" as a territorial state implies that is has borders, but the word "border" occurs at best only once in OA in the new treaty with the city of Hahhum (see below chopter V.2.2), in broken context (IV [I]:7), if fuhümum is indeed a byform of rahümum, once attested in NAss. There are half a dozen OA references for the use of patum/ pattum, and in kt $n / k$ 388:5 (Günbatt। 1997) an Assyrian trader meets a king, who returns from the countryside, i-pa-ti-su with a present. Most occurrences ore in accounts of expenses made en route, where they occur alongside more frequent ones made in a named town. $\mathrm{K}+91 / \mathrm{k} 364: 5$ lists expenses for bread "in Tawinia" followed by a small payment made ina pāti so Tismurna, kt 91/k 437 expenses in seven different towns and one ina päti sa Hanaknak, for lodging (bët ubril), presumably in the countryside, which is also the case in BIN 4, 124:1ff., a payment for lodging ina päti š Razamā. ${ }^{704}$

The existence of different "lands" and the notion of separale areas or even boundaries is also present in some texts dealing with marriage and slave sale. ${ }^{765}$ When TPAK 161 (quoted above' mentions the possibility of second marriage in the Kanesh, Burushaddum, Durhumit, or Wahšušana, it enumerates the four most important cities with Assyrian colonies, but in fact probably means in the land of Kanesh and in those west or north of it, i. e. the whole of the Anatolian area settled by the Assyrian. We may compare the marriage contract Prag I 490, where the stipulation that the husband may take his Assyrian wite along on his journeys to Burušhaddum or Hattum, probably means "on his journeys to the west and north of Kanesh". This is similar to Michel 1991d, 246:50f, where the enumeration of all a man's assets includes "whatever he has, either in Hattum or in Burushaddum", and to some extent also to kt 87/k 275, where the sellers of a slave-girl tell the owner "You con take her along to Hattum or to the land", where the latter must mean the territory of Kanesh. By these formulations the area southeast of Kanesh (with the cities Timilkia, Hurama, Luhusaddia, and Salahšua) is not covered, because it was neither in "the land (of Kanesh)", nor

702 See Eidem 1991, II:11f., IV 8ff. Anum-hirbi in his letter (line 27f.) also speaks of "my land", which was burned.

703 Note in particular Lows of Hammurabi $\S 23$, which speaks of the city and mayor in whose ersetum and pätum a robbery is committed, perhaps "in whose territory and within whose borders".

764 OIP 27, 13:6' mentions a boy to be taken along ana paiti sa Konis (Dercksen's emendation to $<n>-b a-f i$ is unlikely), cf. perhops kt 92/k 3:24 (in a list of travel expenses). 6 shekels of silver

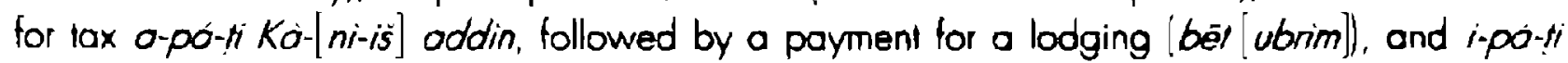
Wahisisana in BIN 4, 45:277. OA does not normally use ersetum os "territor", but note kt 87/k 559:81. (courtesy Hecker), anōku solmum ana erșetim urad.

705 See in particular Hecker 1998a, "Über den Euphrat ...". 
part of Hattum, as is clear from the dossier dealing with the attempis to purchase iron in Hattum or ina libbi mattim. ${ }^{700}$ And it is rather doubtful whether cities more to the east, such as Tegarama and Kušsara, were considered to be in Haltum.

While the just mentioned areas east and southeast of Kanesh, whatever their names, were clearly part of Anatolia, the status of the regions and cities still further south is not clear. Mammo, Zalpa and Uršu, all three to the west or northwest of the Euphrates, in the strategic area where southern Anatolia and Northern Syria meet, were independent city-states. They were important for the trade and Assyrians traders had settled down there, but they do not appear under a common denominator, and it is only later that they seem to have came under one sceptre, that of Anum-hirbi, 767 The area within the great bend of the Euhprates was viewed differently, as "Trans-Euphratia", distinguished from what we now call Anatolia. When in $k+87 / k 275$ (already mentioned before) the sellers of a slave-girl tell her buyer: "You can take her along to Hattum or to "the land", but you shall not sell her in Kanesh or in the land Kanesh", he answers (line 17): "I will bring her across the Euphrates"768 (in order to sell her?). The same restriction occurs in $k t$ 92/k 120 , where a slave may not be sold to an Assyrian or Kaneshite, and in $\mathrm{kl} 87 / \mathrm{k} 99$ an Assyrian buyer in Kanesh can take a slave-girl along where he wishes, but is not allowed to sell her 'presumably in Kanesh or vicinity) to cover the debts of her father and mother; if he wishes "he can sell her to people of Talhat" (Talhati' $\tilde{e}$ ). These stipulations are clearly meant to prevent the re-sale of local slaves in the area from which they originated. ${ }^{769}$ This wish also occurs in three related records, kt 92/k 120,139 and 181, whose writer wants to get rid of a slave-girl that has behaved badly. He rells his addressees not to sell her to on Assyrian or to a man of Kanesh, but to somebody from Talhat, so that she cannot turn up in the land of Kanesh. ${ }^{770}$ And in TC 3, 252, the sellers of a girl have one month 10 redeem her, thereafter she can be sold to people from Talhat or wherever the buyer wishes. Sale to Talhat for people in Anatolia apparently meant sale abroad, with no possibility of return or redemption, ${ }^{771}$ and indeed, Talhat (Talhāyum) is located across

706 See lemy 1950, $423 \mathrm{ff}$.

767 See Miller 2001.

708 Hecker 1998a, 160, Puratiom ušebbarši.

709 The reason for it is not known, perhaps to avoid complications with those (family members or legal bodies, such as tuzinnum and ubädinnum; see Dercksen 2004b) who could try to fight the sale or had the right to redeem such slaves within their own city or land. In other cases no such restrictions obtained and slaves could be sold wherever their owner wished (Hecker 1998a, nos.1-3; even on the market, kt 91/k 123:11f.), but accasionally only if the slave had committed a misdeed (see Veenhof 2003b, 696ff.).

$770 \mathrm{kt} 92 / \mathrm{k} 120: 13 \mathrm{ff}$. adds "And where you sell her you must say: Do not bring the woman back to the land Kanesh"; 139:28f. "Get rid of her and let her not be seen in the land Kanesh"; 180:20ff. "Get rid of the slave-girl, sell her to a man of Talhat, do not sell her to an Assyrian". The last provision is added because an Assyrian buyer, by definition a rrader, could rake her back to Kanesh.

77 See Veenhof 1978, 310f., where this stipulation is compared with UET 5, 97:19ff., where o rebellious adoptive son moy be sold to Elam, Sutum or Jahmutum, to become a chattel slave. 
the Euphrates, presumably south of Viranșehir. ${ }^{772}$ The same notion may apply to Nehria, presumably located in the area of Urfa, on the Upper Balikh, when the marriage contract AKT 1, 77:7f. stipulates that the groom shall not take a second wife, neither in Konesh !"at home") nor in Nehria ("abroad").

The Anum-hirbi letter shows that in the level lb period the rulers of Mamma and Kanesh considered themselves real "kings", each with a number of vassals, called "servants" and in a derogatory way "dogs", and also designaled as sarränu, "petty rulers". They call themselves ruba'u', "rulers", ca. "real kings", and Anum-hirbi expresses the fear that a rebellious vassal of him may profit from his defeat and become "a third rubä um (on a par) with us". If is remarkable that, though overlords of a number of vassals, Anum-hirbi and Warsama do not call themselves "great king" and we note that a predecessor of the rebellious vassal, the ruler of Tēšima, during the period of level II was called rubä um by his Assyrian creditor. ${ }^{773}$ His city-state in due time may have suffered loss of power and have been defeated and conquered by Anum-hirbi, but we have no idea of the real power of such petty rulers; the one mentioned by Anum-hirbi, although formally a vassal, was able to undertake an armed raid into the latter's territory and to conspire with other petty kings. During the level II period only the ruler of Burušhaddum is most probably designated as "great king" (TC 27, 7), 774 but it is possible that the rulers of the main cities, such as Kanesh and Durhumit, also had vassals who had to recognize them as their overlord and were obliged to support them in military matters ("his enemy is my enemy, his friend is my friend", etc.). But the Assyrians had to respect these vassols as rulers of their own towns and moy even have concluded treaties with them; the anonymous ruler of $k+n / k 794$ moy have been one of them. In the trealy with him it was agreed that he would receive a tiny amount of tin or silver for each donkey passing his town, in return for which he would guarantee the safety of the caravans, compensale losses, and extradite those who killed Assyrians and potential Babylonian rivat traders. ${ }^{775}$ The ruler of Til-Tumman, who wrote to kärum Kanesh, and the one of Sirmu'in (or Širmiä), who received a letter from it (CMK91 and 97), both towns without an Assyrian wabartum, may also have been such rulers, who wanted good relations with the Assyrians, ${ }^{770}$ and vice versa.

The status of the other rulers and towns that seem to rank below the main ones is difficult to assess, so that we cannot use it to explain why the formal Assyrian commercial presence in one town had the status of a karrum and that in another town that of a wabartum.

772 In the time of the Mari letters it was the capital of Yapturum, see Chorpin-Ziegler 2003,46 and 55, with Durand 1997, 304.

773 Assuming that this town is the same as the one ruled by the man called Taisimaium by Anum-hirbi, see Nashef 1991, 112.

774 The sign GAL is somewhat damaged, but not other reading seems obvious and Michel 1986 does nol correct the copy.

775. See for the text Günbottl 2004, 250 note 8.

770 The second receives a gift and the kärum seems to be content with his written proposals or promises, assures him that they are concerned with his honour and reputation (takbittum rather than ragbilum) and asks him to comply with what the messenger of the kärum tells him. 
Important cities and towns in commercial target areas, which were production centres and staple towns, may have harbored karums, but perhaps also towns along the main caravan roads and market centres, which could be equally important for the Assyrians. The distance belween the various cities, with Assyrian settlement spread out over the whole of Anatolia, also may have been a factor, perhaps related to the pace of the caravans and the dislance they could cover per day. The economic interests of the Anatolian towns themselves and the facilities they could offer the Assyrians must also have played a role and influenced the decision of the latter. The difference we note in the status of the Assyrian presence in some towns between the periods of level II and $\mathrm{lb}$ (mapped in the table of $\S 2.1$ ) may be due to the factors just mentioned, such as loss or increase of political and economic power and shifts in the focus of the trade. 


\section{THE POSITION OF KÁRUM KANESH}

As has been repeatedly pointed out, the Assyrian colonial system was hierarchical, with kārum Kanesh as its administrative centre and a kind of extension of the government of the City of Assur. ${ }^{777}$ It took care of the diplomatic relations with the Anatolian rulers, often in conjunction with the "Envoys of the City" (siprŭ šo alim), who seem to have been present on a fairly permanent basis. Körum Wahšusana, according to KTP 14 (CMK 40) tells the ruler of Wašhania that "kärum Kanesh is our master", and an Anatolion ruler may call the authorities of kārum Kanesh "our fathers" (see f/k 183 = CMK 53). As a number of official letters written by and to kärum Kanesh show, ${ }^{778}$ it could give orders and instructions to the other kārums, also for the implementation of decisions taken by the City Assembly in Assur and forwarded to kārum Kanesh, and in AnOr6, 12 (CMK 50) kārum Durhumit tells kārum Kanesh that it has carried out its instructions. A new illustration is the handling of the instructions of Assur about the levying of the tithe on iron traded in Anatolia, by kanum Kanesh. ${ }^{779}$ They were passed on to the other kārums and wabartums via circular letters delivered by Kuliya, the messenger of kārum Kanesh, discovered in his archive in 1992. ${ }^{780}$ Kärum Kanesh added to the decision of the city its own instructions, not only on the procedure for collecting this tax. If also demanded that henceforth every single trader, including the privileged "datu-payers", would pay the saddu'utu-tax on iron, owed to kärum Kanesh, at the local kärum or wabartum where he traded, without being able to postpone its payment until his arrival in Konesh. New letters bring additional evidence for the role of kārum Kanesh, e.g. kt k/k/ 118 (courtesy Hecker). where if orders the plenary kärum Wahšušana to revise a judicial decision, ${ }^{781}$ and $k t 94 / k$ 502 (courtesy Larsen), where kärum Kanesh reproaches kārum Timilkia for not having complied with the order to transfer an unwilling debtor to Kanesh: "Why do you disrespect us when we send you a written order to transfer (somebody)?"782

While kărum Kanesh may also be considered to be the highest Assyrian judicial authority in Anatolia, it is remarkable that there is not a single case where a party appeals from the decision of a local kārum or wabartum to kärum Kanesh, in the way one could appeal from a colonial decision to Assur by declaring: "Bring my case before the City and my lord!"783

777 See Orlin 1970, 65f. and Larsen 1976, 247f.

778 Most are now available in Iranslation in CMK chapter 1.

770 This instruction meant a change in the system, since thus for Assur (the god a the cily) had received a share in the proceds of that trade. I will treat this interesting topic in a special anticle on the trade in iron.

$780 \mathrm{Kl} 92 / \mathrm{k} \mathrm{200}, 203$ and 221, see Cecen 1997a and Dercksen 2004a, $113 \mathrm{ff}$.

781 Kórum Wahsusana had set a term for conflicting parties to appear and start negotiotions, but it is now told: "Kārum Wahšušana shall not sel a term!"

782 In both cases kārum Kanesh took action after having been appealed to (mahänum) by a trader with a legitimate claim \{a standard procedure, see the examples discussed in Larsen 1970, 255 f.\} and both had obtained on attorney (rabisum) to assist them, which implies that the City Assembly in Assur had already judged their complaint legilimote.

783 Ana ölim u belia awiti bito, examples in EL 253,3250, VS 20, 118:13', and BIN 0, 219:18'f. 
When a party declares "Bring my case before the (plenary) kärum!", it is an appeal to rurn a confrontation before witnesses or arbiters, frequently in the framework of a private summons, into a formal lawsuil before the (plenany) kărum, but not necessarily before that of Kanesh. This appeal formula does not mention the name of a kārum and it apparently means the local karum where the summons had taken place or the one nearest to the place where conflict had started. ${ }^{784}$ There are of course many examples of the judicial activity of karrum Kanesh, ranging from depositions asked by and made before it to final verdicls passed, and also the so-called "Statutes of the Kanesh Colony" (Larsen 1976, 283ff.) conrain rules on how to reach decisions (dinam diānum) and solve cases (awatam pas̄ärum). But these last lexts, as far as preserved, seem to deal in particular with the procedures of settling accounts, in which conlext "men of accounts" (awilu sa nikkassi), are repeatedly mentioned and there is question of "passing verdicts concerning silver and gold". ${ }^{785}$ Without minimizing the well-documented judiciary tasks of kärum Kanesh, its role in regulating and administrating the trade and in settling accounts of collective transactions seems to have been more important. This involved collecting datu-contributions from the main traders as a kind of share-holders, facilitating trade ventures by communal fund raising to provide enterprisse with capital, raising taxes based on assigning standard values to the main commodities shipped in both directions, and periodic settlements of accounts. These rather sophisticated procedures and tasks, with their technical vocabulary have quite recently been analyzed in delail by Dercksen 2004a, chapters 7-11, to whom the reader is referred.

Wabartums seem to have ranked under a nearby kärum, though the increase in the number of both types of settlements does not yet yield a clear pattern. Because the exact location of most lowns is unknown, it is difficult to use distances and good communications (roads) as a criterion. Letters of kärums and wabartums, most of which are translated in CMK chapter 1, offer clues, but have to be used with care. That the wabartum of Saladuwar writes a letter to kärum Wahšušana (KTP $10=C M K$ 57) could be explained from the fact that the latter probably was the nearest kărum (see for the contacts between these two cities IV.2.2 no. 20), but this very letter tells us that this wabartum had also written to (karum?) Burušhaddum. The reason seems to have been a serious crisis, since the end of the letter quotes an order or appeal by somebody, possibly the ruler of Burushaddum, to invade the country of Wahšušana, and the letter warns the Assyrions in that city of this threat. In such emergency situations different rules may have obiained. That the new ruler of Wašhania in KTP 14 (CMK 40) turns to kārum Wahšušana for renewal of the commercial treaty, could be understood as reflecting the Assyrian hierarchical lines and is not necessarily in conflict with the fact that the wabartum Wašhania itself also writes a letter KTK 6 (CMK 55) to kärum Kanesh. The

784 See EL 320:34f., 338:21ff., and ICK 1, 86:16F. The kōrums appealed to in these examples are those before which the restimonies recorded in these documents had been given, those of Kanesh, Burushaddum and Durhumit.

785 See now also kt 94/k 840:34ff. (courtesy Larsen), where a verdict of the City of Assur is quoted, which prescribes how to act when "the karum passes a verdict concerning silver or gold", and when the person involved has to or is allowed to come to Assur and when not. 
ruler of Wašhania may not have realized that diplomalic contacts by nature ranged under kärum Kanesh, ${ }^{786}$ whom kärum Wahšušana in this very letter acknowledges as its "lord" |bej/um\}. The just mentioned letter of wabartum Wašhania deals with a diplomatic incident, which involved the seizure of a trader's assets by the local rabi sikkitim, which was an issue to be handled by karum Kanesh, together with the "Envoys of the City", to whom this letter is indeed addressed. Similarly, a letter of the wabartum of Šamuha to kärum Kanesh (VS $26,195=$ CMK 56) deals with the seizure by the local palace of a large quantity of wool, again a diplomatic problem. This letter reports that it hos been solved and that the wool in question is now being brought to Kanesh by "your messengers". These last words reveal that in the first phase of the conflict the wabartum of Šmuha had turned to karum Kanesh, which had sent its messengers with instructions to the palace and the wabartum, messengers who can now return to report that the crisis is over. The wabartum of Kusssara also writes directly to kärum Kanesh when wo Assyrians were killed in the land of Luhusaddia (Kayseri 1830 = CMK 59). That wabartum Wašhania writes the (damaged) letter KTK 5 (CMK 54) to kärum Kanesh and not to kärum Wahšušana, can be explained from the fact that the issue reported concerns travelers (älikü, hence a caravan), who had arrived from Wahšušana and apparently were on their way to Kanesh. The system apparently had some flexibility and we have to take the subject matter of the letters, the past history of the relations between the various cities, and also practical matters into consideration before using them for a reconstruction of the administrative system and the diplomatic procedures.

Wabartums too enjoyed a measure of administrative competence, primarily that of solving problems and passing judgments in conflicts between its members, presumably in cases that arose locally (e.g. by private summons, distress, accusations, etc.). Some wabartums which acted in this way (those of Hanaknak, Ulama, and Zaipal are at times even qualitied as "plenary" (șaher rabi), which implies a certain size and the existence of an executive body of "big members", ${ }^{787}$ and also of certain facilities, as is shown by the mention in $\mathrm{kl} 00 / \mathrm{k}$ 7:3f. (Donbaz 2004, 184) of "Zua, the scribe of the wabartum of Wašhania". What further facilities a wabartum had, e.g. for storage and meeting, is not known and a "wabartum office" (bet wabantim) is not attested. According to kt $89 / \mathrm{k} 230$ (courtesy Kawasaki) two traders who entered Hanaknak were seized in the bet kārim, obviously in this town, and this leaves us with the question whether this expression was a scribal mistake or was used as a substitute for a never attested "bet wabartim.

780 A principle which was known to the ruler of Tawinia, who according to $\mathrm{kt} / / \mathrm{k}$ 183 (CMK 53) does not wish to deal with the messengers of kórum Durhumit and asks for those of körm Kanesh, "my fathers. Let them come here and it is from them that I will take the oath".

787 See Hecker 2003. 


\section{COMMERCIAL TREATIES}

The existence of trealies between the Assyrians and the rulers of the various cities in Anatolia has been known for a long time, especially from references in official letters about the swearing of the relevant caths. ${ }^{788}$. The contents of these treaties are being gradually recovered and the recent publication of two new ones (in Günbatt 2004, see below, § 2) is an important step in a development that this chapter wants to trace. It can be divided into four phases.

A. A first reconstruction of the substance of the treaties was based on what letters tell us about the procedures followed when a caravan arrived al and was cleared in an Anatolian palace and about what was said during confrontations between Assyrians and local rulers when problems had arisen. This exhibits a fairly regular pattern, which can be transiated into a set of stipulations.

B. Next we have the rather poor remains of a treaty concluded ca. 1740 BC. between Assur and the ruler of the cily of Apum (Tell Leilan), ${ }^{789}$ a stop for Assyrian caravans, and already during the level II period the seat of an Assyrian kärum (see above, chapter IV, 2.1, comments on no. 2), located roughly $300 \mathrm{kms}$. to the northwest of Assur, in the northeastern part of the Khabur Triangle, on the Wadi Jarrah.

C. In 1994 Bilgic published kt $n / k$ 794, from kärum Kanesh level II, the text of and the report on the conclusion of a rrealy with the ruler of a lown whose name is not mentioned, presumably somewhere in Southern Anatolia. ${ }^{790}$

$D$ and E. Finally, two large, but damaged new treaties, concluded with Kanesh (D) and Hahhum $\{E)$, discovered in 2000 in a house belonging to kärum Kanesh level lb and edired in Günbattı 2004.

788 See the analysis of the texts then available in Garelli 1963, 329ff., Larsen 1976, 249ff., and for many letters $C M K$, chapters 1 and 2.

789 Edited in Eidem 1991

790 New editions by Ceccen-Hecker 1995 and quite recently in Günbattl 2004, 250, editor's nole. 


\section{Earler data on treaties}

A. The contents of the treaties as reconstructed from data in the archival records were summarized by Larsen 1976, 245f., as follows:

The rulers or palaces are entitied to:

a) Five percent of the textiles and of $2 / 65$ th of the tin (which equals four minas per donkey load), designated as nishatu-tax. ${ }^{791}$

b) Buying another ten percent (called "tithe", išräum, or "those to be bought", sa simim) of the imported textiles.

d) A monopoly on the trade in iron and lapis lazuli.

The Assyrians were granted:

d) Residence rights, presumably with protection, in their körums and wabartums.

e) Extraterritorial rights, so that the colonies were in a political and juridical sense extensions of the government of Assur.

f) Protection of the roads and guarantees against losses due to attacks and robbery in the territory controlled by the king.

This reconstruction in the main still stands, but $c$ ) should be omitted, because it has become clear that there was no monopoly, although the palaces were eager to ocquire these products (see below Db), in particular iron. Still, there may have been certain rules or restrictions concerning their sale, ${ }^{792}$ just like their sale in Assur was concentrated in the City Office, which could thus regulate their circulation (see chapter II. 2.3).

B. The unfortunately very damaged lext of the treaty between Assur and Apum, which is called a nis ilim, an oath by the gods (IIl:14), starts with the invitalion to swear (tama) by a great many gods, "great gods" and local deities, among which those of both parties, 793 those of the mountains, the land and the rivers, those of heaven and earth, and those of Amurrum and Subarûm. The Assyrians are the ones who address the ruler of Apum in the second person, while they themselves figure as "we/us".

791 The odd last figure was derived from the standard load of tin carried by a donkey, 05 kilos, stored in two "halt-packs". See for details, AOATTch. II.

792 The idea of a monopoly of the palaces, which would iurn Assyrian trade in these items, or at least their sale to others, into a form of contraband, still upheld by Michel 20010 and CMK ch. 4, "Lo frauder, cannol be maintained, see Veenhol 2003d, $99 f$.

793 Among which the Assyrian Samaš, Nergal of Hubsalum, Eštar Aššritum, Bēlat-Apím, and Bēlat Ninuwa. 
Of the actual stipulations the following is preserved:

a) Col. II mentions "one donkey", copper and a nishatu-lax, which must be understood as a kind of transit tax "per donkey", perhaps comparable to the one stipulated in $\mathrm{Ce}_{\text {, }}{ }^{794}$ while the remarkable mention of copper (tin is absent!) could indicate the use of copper for payments and perhaps even imply that some donkeys carried loads of copper.

b) The end of col. II stipulates that [Assyrian traders] who travel in the countryside and [have been seized for illegal actions] by the ruler, should be released by him after he has received their ransom (iptirü). ${ }^{795}$

c) Col. III stresses the obligation to always speak "the truth in complete sincerity with us" and "to observe from this day onwards the text $(\breve{s a}$ pi $)$ of this tablet which you have sworn to the city of Assur, the Assyrians (in the next lines specified as belonging to caravans "traveling up or down"|796 and the kärum.

d) A very broken passage in col. III seems to deal with losses and, presumably, their compensation.

e) Column IV first demands a fair and equal treatment of Assyrians and citizens of Apum ("of your [city] and your land") and perhaps forbids the ruler to punish or assail (šagãsum) Assyrians in the same way as (kima is restored) he can do his own citizens. The next clause deals with how to handle when the donkeys of "travelers in the countryside" (álik eqlim) [and of] Assyrians have been seized [by] citizens of Apum. ${ }^{797}$

f) A final, broken section deals with the situation in which the ruler of Apum is approached by another ruler(?), who wants to harm the Assyrians. He has to tell him that he is bound by the oath to Assur and the local karum [and therefore refuses to join him] by saying "Go away. ...".798

794 Dercksen 2004a, 158 with note 447, where he proposes to read, "per donkey (could we read / ANŠE.T[A]?] ... in/from ...... you will take and ... " [ta]-tá-qé-m[ $[a \ldots]$.

795 This interpretation is suggested because it is the ruler who receives the ransom. OIP 27, 5:17 mentions that a local palace asks iptiru for the release of hapiru who are in jail, but we do not know why. The situation is different in CMK 58:33f., where Assyrian traders seem to have been kidnapped by natives who iry to earn money from their ransom.

790 e-li-tim is a-ri-tim (in 1:28 possibly spelled árittim), female adjectives which refer to ellurum, "carovan".

797 The interpretation is difficult due to the breaks. I would prefer to read in IV:Ilf.: [/u sa a $\bar{a}$ ]lik eqlim

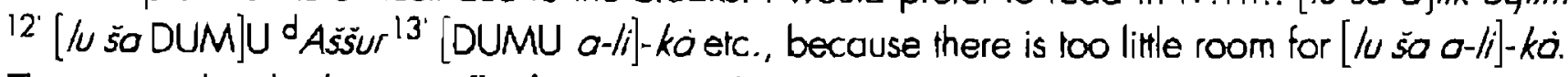
This means that the former suffer from actions by the latter.

798 Interpretation suggested by Eidem on the basis of similar passages in other treaties from Tell Leitan, where a ruler says: "Go off, and like an ignoramus kill Till-Abnû!" The "ignoramus", presumably tā müdûm, is somebody who is willing to commit the crime, because he does not know or understand the curses implied by the invocations of the gods. Such people were also used to destroy written monuments (royal inscriptions and kudurrus) protected by curses (references in CADM/11 167f.) 
C. The treaty with an unknown ruler, recorded on the well preserved tablet $k t n / k 794$, that contains the stipulations of the treaty (lines 1-28) and also relates (lines 29-42) how it was sworn to by a ruler who apparently had succeeded his father on the throne / see below, stipulation d) and was accepted by the members of his court. The abrupt beginning, "In your land no losses whatsoever shall occur", matches a similar stipulation on losses in the new trealy with Hahhum (below Ed.), where, however, it appears in a slightly expanded version and in the body of the treaty text. ${ }^{799}$ This allows the possibility that $k i n / k 794$ was the second of a sel of two tabets, presumably because the treaty text was very long, in which case the missing first tablet might have contained the invocation of the gods, with which $B$ and $D$ start. But the alypical nature of $C$, with at the end a unique report on the swearing of the oath, should make us cautious, and it would not be surprising if the text started with the for the Assyrians vital stipulation which aimed at preventing all losses.

Our tablet does not mention the ruler's cily, but it has to be localed somewhere in the area where the Euphrates was crossed, because the Assyrians promise to send him tin from Hahhum, if due to hostilities (nukurtum) no caravans visit his town and he is temporarily deprived of income. ${ }^{800}$ The stipulations are in the form of an injunction, in the second person singular, to the ruler (in the subjunctive since they are made under cath), while the Assyrians figure in the first person plural and those in Hahhum, who will send him some tin, as "they". The tablet ends with a description of how the ruler swore the oath, while performing certain symbolic actions, and how it was also accepted by members of the court or local officials.

\section{The obligations of the ruler are:}

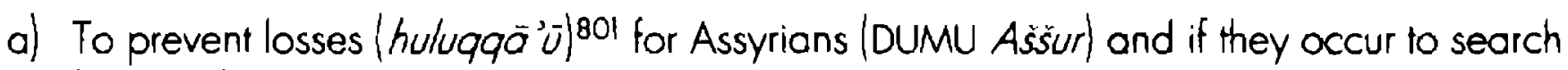
(se's'um) for the lost goods and return them to their owners.

b) To prevent bloodshed (damü) of Assyrians and if it occurs to extradite the culprits to be killed by the Assyrians.

c) Not to attempt to attract ${ }^{802}$ Akkadian traders to his land and 10 extradite those who might cross his borders to the Assyrians to be killed.

d) Not to demand anything which exceeds what is agreed upon in this treaty, which is also what his father thus far had received.

790 "Whatsoever" is expressed by "neither rope, nor peg, nor anything whatsoever", and see for the version in III [11]: Iof. of the Hahhum treaty, below chapter 2.2.j) and note 849; see also Dercksen 2004a, 270.

800 One might think of Hohhum's neighbours to the south and north, Batno and Timilkia, mentioned as such in the new treoty $(E d, I[111]: 20 f$.$) , but Timilkia seems to be too important for assigning its ruler$ the small amounts on tin and sitver mentioned in $\mathrm{kt} n / \mathrm{k} 794$.

801 The rext uses the plural in the general statement, but the singular for a particular toss that might occur inabsümi.

802 In line 12, tâ husellà admits a more passive translation, "to allow to come up", and o more active one, "to make come up", almost by invitotion. 
e) 12 shekels of tir and 11/4 shekel of silver for every donkey that passes on the way to Anatolia or to Assur.

f) 5 minas of tin will be sent him from Hahhum, if there are hostilities (nukurtum) and consequently $(m \bar{a})$ no caravans visit his town.

The text is interesting in describing how the ruler accepted the slipulations ${ }^{803}$ by raising his hand and swearing by Ašsur, the weather-god, the netherworld, and the spirit of his father, ${ }^{804}$ and by pouring out the contents of a cup. At the end we read: "They said: "If we reject the oath sworn to you our blood shall be shed like (the conlents of) this cup!", where the "we" shows that alongside the ruler also his court and officials accepted the stipulafions under oath. The plural in "your oath" indicates that it was administered by an Assyrian deputation, probably sent by karum Kanesh. While the text states what the Assyrians will do in certain situations, it is basically a kind of loyalty oath sworn by the ruler and his court, in which it is stated what "you will/must (not) do". The treaty is also special because the ruler's town apparently is not one where traders cleared their merchandise for selling it in its territory. Therefore there are no references to the taxes (nishatum and tithe) accorded to local palaces by stipulations a) and b) of $A$ and only a very small payment as a kind of transit tax. Points d) and e) of A also do not apply, since the town does not seem to have harboured an Assyrian commercial settlement. To understand the amount the ruler receives per donkey, we have start from the "declared value" (awitum) of the caravan goods, expressed in tin, ${ }^{805}$ for which one textile was considered the equivalent of 2 minas of tin and about the same amount was reckoned for the donkey. Since one donkey usually carried ca. 130 minas of tin plus 4 textiles, or ca. 25 to 30 textiles plus a few minas of tin, the 12 shekels of tin (of which the $11 / 4$ shekel of silver apparently was considered the equivalent) amount to between 0,04 and 0,08 percent of the value of one donkey load. Small as the percentage was, if the ruler's town was on the caravan road he could have expected many times these amounts. It must have amounted to much more than the mere five minas (or 300 shekels) of tin, the equivalent of what twenty-five passing donkeys would yield him, which were promised him if there was no caravan traffic (though this situation need not have lasted a full season). For the Assyrians these small payments did add up, since records of caravan expenses (met from the "loose tin" made available to the caravan leader) show they had to be made in many towns passed en route, and not only to the ruler or mayor, but frequently also to other local officials. ${ }^{800}$

803 Part of the oath and the symbolic actions, which mention the overturning of a table and a throne accompanied by an additional statement of the ruler, are nor clear.

804 etammi abisu, not abbā'ésu, hence singular.

${ }^{805}$ See Dercksen 2004a, 151, whose tigures are now contirmed by kr g/ 199 (Günbatt 2002).

806 See the edition and discussion of such records by Nashef 1987, especially nos. 24 and 25, which concern the passage through Northern Mesoporamia. 
The two new treaties, $D$ and $E$, with Kanesh and with Hahhum, are extremely welcome and we are grateful to Günbattı for having made them available so soon. Both tablets, especially the second, have suffered damage and the reading and interpretation are at limes difficult, also because of their unique character. What follows is based on the editio princeps and in the absence of a copy of the cuneiform text and with only photos available, it is difficult to make progress with the damaged lines, but occasionally I will make a proposal, usually based on the photos, the context or my understanding of OA terminology. My summary of the contents, below, from time to time mentions key words of the Assyrian texts, and footnotes occasionally quote a few lines, but the transtiteration of the recent editio princeps is not repeated.

The treaties are important because both cities were not simple road stations on the way to Anatolia, as were those of $B$ and $C$, but important trading centres with Assyrian kōrums, where imported goods were cleared in the palaces for local or regional sale, though the role of Hahhum and Konesh in the trade must have been different. There is a complicafion, because both treaties are from the level lb period, when changes in the system had taken shape. Dercksen 200la, 63ff., has recently described the situation, which due to the limited number of sources leaves several questions open, but it is the only picture we have and against the background of which the new treaties have to be appreciated. It shows that there still was trade in tin, textiles and wool, that karum Kanesh still functioned as administrative centre and highest judicial authority of a fair number (at least fifteen) of commercial settlements, that the important "dótu-payers" were still around, and that contacts with Assur were maintained. But we do not have the typical "caravan records" (as defined in Larsen 1967), which report on the selection, quantities and prices of the merchandise bought in Assur and on their arrival and sale in Anatolia. We also have no evidence for joint-stock companies (naruqqum) and for the role of the kārum in "communal transactions", and conlacts with Assur land perhaps also between kärum Kanesh and other settlements) were occasionally apparently difficult or interrupted, as is clear from the fact that in the kārum of Hattus the name of the new eponym appointed in Assur once remained unknown for nearly two years. But there were portnerships (rappo üum), also between Assyrians and Anatolians, such as the one documented in kl n/k 32, ${ }^{807}$ presumably from the early years of level $i b$, in which the partners wanted to trade in silver, gold. cups of iron, tin, rextiles, slaves and lapis lazuli, both in Kanesh and in Mamma. We also hove evidence of commercial loans and service contracts (from the archive of Eddin-Ašsur in Kanesh\}, which imply the use of transporters and agents, and data from Mori show that large caravans were still leaving Assur for Anatolia (see above chapter III.2.3). Bul the quantities of tin mentioned are modest, the assortment of textiles shows changes, with fewer kutanu-textiles (predominant during the level II period) and more products called 
kušsotum and saqqum, and also the Anatolian pa/ ira/ ikannu-textiles. "Except for the remaining wealthy traders a general impoverishment is discernable, expressing itself not only in the volume of merchandise, but also in the number of cases where Assyrians had been detained by a native creditor for insolvency" 808

The limited number of sources asks for caution and it seems possible that some of the facts just mentioned were the outcome of a development within the Late Old Assyrian Period, e.g. after the death of Šamši-Adad I and the end of Hammurabi's reign. The situation may then have become more difficult for caravans, as the dramatic lelter $\mathrm{kt} 98 / \mathrm{k} 118$, addressed by "the merchants in distress" to "the gods and the city of Assur" shows, when they complain about risky journeys, revolt and threats by the habbatu, which means financial losses and poverty. ${ }^{809}$ Dangerous situations are also implied by the newly discovered letter addressed to king Hurmeli of Harsamna, which informs us about his war with Zalpa and his request of Assyrian aid (see above chapter III.2.3, with note 649). It is possible that the situation in Kanesh, the "colonial capital", (at first?) was (still) better then in outlying areas and that the archive of Eddin-Aššr, which evokes the picture of successful trade, reflects this situation, although the value of the merchandise and claims registered in its texts are modest, never more than a few minas of silver and there are no letters on caravan traffic with Assur. ${ }^{810}$ The question whether the new trealies with Kanesh and Hahhum reflect these changes will be considered after I have presented their substance. But it is clear that the relations with both obviously do not cover the large areas east, west and north of Kanesh, but only Kanesh and the region where the Euphrates was crossed. The treaty with Hahhum considers the possibility of military conflicts with it southern and northern neighbour, Batna and Timilkia, but its date remains uncertain. While admitting that style, writing and language of the fablets do not exhibit typically late features, we can only guess when and why the treaties were concluded. If not at the very beginning of the level Ib period, when the commercial relations were resumed, then probably later, in connection with a change of rule, because the loyally oath only bound the ruler who had sworn it. This could be on the occasion of regular succession, as when the ruler of Wašhania was succeeded by his son and the latter asked the Assyrians "make me swear the oath"; see KTP $14=C M K$ 4O). But it could also be due to a conquest by a new ruler, which must have happened at Kanesh later during the lb period, when Pithana (who conquered Kanesh), his son Anitta or Zuzu of Alahzina occupied the throne of Kanesh (see above III.2.3 and 4). The very end of the Kanesh treaty mentions the ruler whom it concerned, whose name is missing due to damage, but he bears the title "the great king

\section{Dercksen 200la, 66.}

809 Edited in Dercksen - Donbaz 2001; habbäh probably were a kind of mercenaries.

${ }^{810}$ See for this archive, which consists of tablets with low $\mathrm{kt} n / \mathrm{k}$ numbers, Veenhof 1998a, 44l; for $\mathrm{kt} \mathrm{n} / \mathrm{k} 27$, Donbaz 2004a, 180; and for kt $n / k$ 32, Dercksen 2004b, 166. $\mathrm{K} \mathrm{n} / \mathrm{k} 5$ is a verdict by the wabarium of Mamma about the settlement of a debl owed to an Anatolian, $k t n / k 10$ one by kârum Kanesh about a piece of lapis lazuli shipped from Zalpa to Mamma and then to Hattuš, which had been sold eight years ago and still had not been paid. $\mathrm{K} \mathrm{n} / \mathrm{k} 33$ is a quiltance about the poyment for 90 parakannu-textiles, deposited in Eddin-Aššur's house. 
of Kanesh". This leaves us, as far as we know, with two candidates, Anitta and Zuzu, who occur as such in some 'notarizations' (see above IV.2.5.1). It is difficult to date them, but Anitta may belong in the period after ca. $1770 \mathrm{BC}$, and Zuzu most probably is a still later conqueror.

\subsection{THE TREATY WITH KANESH}

This treaty, $D$, is preserved on a large, damaged one-column tablet with ninery lines of text. A year after Günbatt 2004 it was also published, independently, by Donbaz 2005, with photos, a cuneiform copy and short comments. The differences between both editions, especially in their rendering of the remains of the first 15 lines (line 14 of Donbaz is line 16 in Günbalti's edition!) show how serious the damage of the obverse is. The present writer, having been unable to study the tablet itself and working from the photos (those in Günbatti are larger and sharper) and Donbaz's copy, faced a difficult job. In general, also on the basis of my analysis of the contents of the text, I am much more in agreement with Günbatfi's readings. The comparison between both editions could result in a number of detailed observations on the possible reading and restoration of the lext, but this volume is not the place to do so, certainly not without having studied the tablet. Therefore, in what follows I follow Günbatti's edition princeps, while adding occasional remarks on my preferences for certain readings or restorations.

The trealy starts with a very damaged invocation of the gods, ${ }^{811}$ first those of the land of Kanesh and the mountain $A^{2}$ aškašipa, probably mount Erciyes (Günbatti), ${ }^{812}$ then, after a small gap, the moongad and the sungod and after again a gap Kubaba. Her mention may indicate that the whole (first?) sequence consisted of gods of the land of Kanesh, reason for me to write "moongod and sungod", without identifying them as the Assyrian gods Suen and Śamaš. It is not clear whether in what follows (in lines 4ff.) also Assyrian gods were invoked, since no names of them have been recognized in what remains of the text. In trealy $B$, with Apum, they do occur in a mixture of "great gods", Assyrian gods (see note 793) and local deities, but the cultural environment of this city, in the orbit of Mesopotamia, was different from that of Kanesh. Moreover, the beginning of the Kanesh treaty (with its unintelligible first line) also seems to be different from that of $\mathrm{B}$, where each line starts with "Swear by ..." "(ramo).

When the lext again becomes readable \{line 12\} we find a series of stipulations in which the ruler of Konesh is addressed in the second person singular, ${ }^{813}$ some of which are difficult to understand because the tablet is damaged. The text ends, in lines 89-90 (Donbaz 87-88) with the warning: "These gods, the lords of your (sing.) oath, will watch you!", fol-

Bll But we do not know whether the gods were the object of an imperative tama (os in $B$ ).

812 Donbaz's rentative reading $[K] a-n i-i[\tilde{s}]$ at the beginning of line 3 does not agree with the troces visible on the photo.

813 This applies also to verbal forms with a double subjunctive ending - $u$-ni, which by themselves could be plural, because they alternate with indicative forms in the singular (e.g. $08-70$, to roddununi ... rologael. 
lowed by the statement: "The oath of [........], greal [king] of Kanesh", where unfortunately the name of the king is missing.

\section{The stipulations concern:}

a) imported textiles (at least 12-23), with mention of kutānum, raqqutum and kusitum. First are mentioned those which the ruler seems to be entitled to "take" (laqä'um, lines 12f., specifications broken off), presumably as nishatu-lax, ${ }^{814}$ and (also?) for his personal wear (ša litabsika), but he is forbidden to appropriate (etärum) them by force or below the price (ana simim batqim). Next it is stated that, apart from the nishatu-tax, he can buy a few makühu-815 and two kutänutextiles at [x shekels] of silver apiece.

The syntax of lines 19ff. is difficult. Günbatt takes ana ši mim ša] in 21 as "as preemption of (the makuhu-textiles)". Pre-emption (during the level II period) indeed regularly follows the levy of the nishatu-tax, but for pre-emption I would expect ana si[ [mim hù ralaqge 'uni], followed by the price (cl. AOAT369f.). Ana simim šo occurs as "as payment for/price for", but then we need a relalive s̆a, to arrive at: "As price of ... the textiles, which you take, you will pay $x$ shekels of silver per ... ", but there is no sa. The end of line 21 has ku-ia-ni/im (IM on the right edge above NI).

Due to damage of the tablet it is not clear where the next parograph starts, it could already be at the end of 1.23 , "When ... "(inumi), but the figure 10(line 26) better fits a stipulation on textiles than one on lapis lazuli or iron.

b) Lapis lazuli and iron (28ff. or earlier until 39a). If an Assyrian offers such an item for sale "he sells to you if he likes it" (šmma rabsum, apparenlly the price offered), if not, "you must give (it) back and he can bring it where he wishes". ${ }^{816}$ The verb "to give back" implies that the items were presented to the ruler for inspection 'because there were differences in quality and probably shape; see below $\S 3.4 .2$ ) and to make a price offer. It is followed by unclear clauses, which seem to mean that the ruler in the latter case nowhere in his land will inierfere? 817 with what the "owner of the iron" does.

Line 28 , where lapis lazuli appears, remains unclear, especially the final $[x \times]-\mathrm{Bl}_{4}-$ iš-tim, which does not fit the masc. noun husārum. The link between lapis lazuli and

Likely (in line 12 -ha- is still readable), because lines 19f. state what he can buy "after you have taken the nishatum you are entitled to", and since otherwise the basic right to and rate of this tax would not have been slated.

815 Specifications unknown, but regularly bought by local palaces, see $A O A \Pi 169,14$.

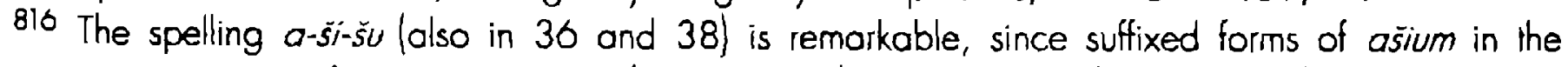
accusative are of the type a-š-a-ka(ATHE 62:38) and a-š-ós-nu (ATHE 64:30).

$817 \hat{i j-s a-r}[i-\dot{u}]$-ni in 34 is unclear, it cannot be derived from wašsurum, "to let free", nor from sarru 'um, "to take the initiative, to begin doing something", used in lines 52 and 55 in the hendiadys ušarrama ... ilagqe, "he will take first" itwice followed by urkatom, it occurs also in the testament kt $\circ / \mathrm{k}$ 196c:16, Albayrak 2000, and in occounting noles dealing with the proceeds of a caravon), see Dercksen 2004a, 178 nole 478, EL 287:17ff., and CAD Ś/III, 359, 2'. "Interference" in our rext is suggested by the words "before him or after him" of 35 . 
iron (lines 28-30) is unclear, because the text only speaks of returning "his iron", and what follows also deals only with iron. "Nowhere in your land" summarizes a remarkable sequence of locations, which presents problems, because it is strange to read wice "in your land and in your city" and the plural rabiütim after matika is impossible. Moreover, the convincing, restoration $[\dot{v} a-/ i]-k a$ in line 34 means that line 33 had an additional sign ( $L$ lends where in $34 \mathrm{GA}$ ends). Whatever the exact reading of these lines (one would like to find something like "on the squares and in the streets"), they suggest that the Assyrian traders, like peddlers, would try to seil these items in many locations.

c) Murder (damum inneppaś) and losses (huluaqa'um; 39-45). They are mentioned together as the result of an attack or a robbery, but losses are treated again, more in detail, in e). Bloodshed (damü) has to be compensated by paying the fixed (standard) amount (simtum] of silver as compensation and the culprit shall be handed over to the Assyrians in order to kill him, without the possibility of substitution (püham tadanum). The missing goods (found with the perpetrator) shall be returned.

d) Administration of justice (46-57). This stipulation was presumably triggered by the previous one on killing and robbery, since these actions must have led to a lowsuit and verdict. It demands a fair judgment in a trial which involves both a native Kaneshite and an Assyrian, without [ favouring? "] "your own citizen". It is applied in particular to conflicts about debt liabilities, where the creditor, irrespective of whether he is Kaneshite or an Assyrian, has priority in realizing his claims (see nole 817 ).

e) lost textiles (57-61). The ruler will search and return the textiles that got lost "in his city and land" and compensate their owner if they are not found on the basis of a decloration under oath (presumably on their number and value) by the latter.

f) Protection of Assyrion households against privote high-handed actions by the citizens of and other people living in Kanesh (61-63).

Since the trealy wants to protect the interests of the Assyrian trading community, "the house of a tamkañum, (of) a widow" must refer to them. The mention of the widow acknowledges the fact that some continued to live in Kanesh (in the house their husband had assigned to them in his testamenti and they may have been singled out as more vulnerable to high-handed actions. The protection consists of not allowing citizens of Kanesh and hapin to go to the houses of the Assyrians and uses the verb wašsurum. Used with a personal accusative object it normally means "to let go, set tree, release", used in particular of persons who are in somebody's power or custody las pledge, slave, or child; see ATHE 47:9; BIN 4, 2:21; 6, 19:6, and cf. El II p. 53). or, with ana + personal dative object, "to relinquish, to hand over" a person to somebody, into somebody's power (CCT 2, 36a:24, a boy ana mamman; 5, 16b:5, a slave for a certain period ana PN). The treaty uses the latter construction, but it can hardly mean that a Kaneshite and hapirum shall not be delivered to the household (into the power) of an Assyrian, since this would have been in the latter's interest, as plaintiff (if the person was handed over as penally for a crime). The meaning here has to be (although I cannot adduce a parallel for this use of wašsurum ana) that the ruler must not allow, not leave a free hand to his citizens and other people who had taken refuge and stoyed as foreign- 
ers in his city, 818 to go to, to get at the household of an Assyrian to oblain satisfaction for a claim (comparable to $\mathrm{OB}$ ana bir PN sasä um, "to dun somebody's household"), or to solve a conflict by forceful private action. Positively: the ruler must interfere and prevent such private attacks on Assyrian households; this makes a good transition to paragraph g), where the ruler's own interests are at stake.

g) Prolection of Assyrian property (64-68). The ruler of Kanesh shall not covel and appropriale by force any Assyrian property (houses, slaves, fields, and gardens) and (or: in order to) give it to a servant of his.

h) Anatolian textiles (lines 69-72). The ruler can take ten percent of the parakannu-textiles (brought into his city) as nishatu-tax, but those taken at the city gate will fetch their full price.

i) Fugitive debtors (72-77). If an Assyrian indebted to a Kaneshite flees to another land, no other trader (=Assyrian) $)^{819}$ shall be seized in his place, only the debtor in question (habbulannum) will be sued for the capital owed.

i) Administrative and legal measures (78-85). Assyrians shall not be affected when the ruler registers his subjects for performing service duties (unušsum). ${ }^{820}$ And when he [effectuates] the manumission (addurārum) of (debt)-slaves and slave-girls [it shall not apply to those of the Assyrians]. ${ }^{821}$

k) Trade during war (87). Presumably stating that the ruler must let the Assyrian caravans depart (harrañam waššrum), also when he is in hostility [with (?) ...] [ inümi] nakrätini]).

1) Oath procedures (88f.). When - in a conflict or during a trial before the local ruler - Assyrians have to swear an oath they will do so only by the emblems of Aššur. ${ }^{822}$

m) The last two lines state that "these gods" - those invoked at the beginning of the text, - "lords of the oath", will watch (dagälum) the ruler (to see whether he lives up to it), and they identify him as "the great [king] of Konesh".

818 There is even a year-eponym in Assur (no. 49) who was a hapirum. The reading sa [halpirim in the Hahhum trealy (see below $E_{j}$ ) is not convincing, but hopiru are attested in level lb texts, see Dercksen 200la, 43. OA also knows the verb hab/pärum, "to take refuge, flee" (BIN 6 , 2268:16, a debt-slave ippān hubulišsu ih-Bl-ar, Kienast 1984, no. 29), also known at Mari (see ARMT 14, p. 228 on $50: 14$ \}.

819 There are several examples of lamkärum used for "Assyrian", especially when conirasted with

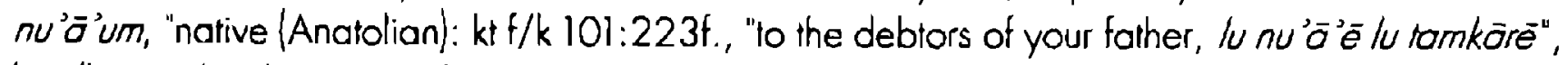
$\mathrm{kf} \mathrm{n} / \mathrm{k} 141$, the divorced wife can go where she wishes, either to a nu'ä'um or to a romkarum".

820 See for this term now Dercksen 2004b, 140 ff.

821 The passage is badly damaged, but one expects lasokkununi at the beginning of line 84 . The purpose of the stipulation must be to protect the Assyrian interests ("you shall not seize them - sloves owned by Assyrians - by force"). See for another occurrence of addurärum, apparently a cancellation of debts, III.1.3, with note 578 .

822 When the Assyrians, in the case of trader caught for treason (reported in kt n/k 504, see Günbatt 2001,152 ), offer that the accused can either "swear by Ašsur's dagger or go to the river (ordeal) as one of your cilizens", the seriousness of the case prabably induces them to make a concession. 


\subsection{The treaty With HahHum}

$E$ is the damaged upper half of a large tablet, which originally moy have contained ca. 250 lines, of which less than half are preserved and many of which, especially on the reverse, are damaged. I hove to start my remarks by proposing a reconstruction of the rext which differs substantially from that presented by Günbattı. What is col. III in his reconstruction of this two-column tablet (unique at karrum Kanesh), should be col. IV. Reading the text in this way one discovers that the subject matter of the end of what is now col. III, the proper administration of justice, continues on what is Günbatti's col. II, which then suggests to exchange the obverse en reverse of the editio princeps. This is possible since nothing of the leff edge remains and Günbattı offers no arguments for his choice. In this reconstruction the first half of col. I [III] is missing, and its first part offers sufficient room for the invocation of the gods, which is present in treaty $D$. Where col. I becomes readable we have three clauses in which the magnates of Hahhum are enjoined "to exert themselves" (sutamrusum) to do something (object missing), which may well be the end of the introductory section, which asks them "to do their utmost" to implement the substance of the treaty. After that, quite naturally, the first concrete subject is related to the arrival of Assyrian caravans and the question what the magnates of Hahhum may acquire trom it, by purchase or as levy. After a stipulation on the continuation of the trade in times of war (I [II]: 26'ff.) there follows a long gap and when the text resumes it still or again deals with the prerogatives of the magnales (II [iV]:1'- 14'], followed by stipulations on losses and bloodshed suffered by the Assyrians (II [ IV]:15'-22'). Then we have stipulations on the administration of justice (if there is a "case", awōtum, 1. 24), demanding fair and public treatment, without secrecy but with a public announcement $\left\langle\|[N]: 23^{\prime}-32^{\prime}\right\rangle$. This subject continues on the rev. without a gap, in col III [11]:1-10, which mentions a "decision" (nikistum, 1. 1), a "contractual judgment? ?)" (din ri<k>sātim, I. 5), and a fair procedure (ina kinätim diānum, I. 10). To help the reader references to the text of the treaty always give my column numbering followed by that of Günbattı between square brackets (e.g. I [ill]:10'\}.

As is obvious from the photographs we have only ca. half of the tablet and this contains mony damaged lines, so that many stipulations remain unknown or are poorly understood. What is preserved shows that the trealy covered more issues and was at times more detailed than D. Some of it may have been due to the specific noture and role of Hahhum, at the crossing of the Euphrates (the stipulations on "the ferryman" in III [II]:11f.), where one entered Anatolia, and the particular political structure of the city, withour a king and with a few magnates as treaty portners. The text may also have taken into account past experiences with the city, and perhaps also difference in date played a role. The general scarcity of dala from the level lb period makes it difficulf to give an answer, but one would hove expected the long troditions of such treaties with Anotolian rulers to have resulted in a more or less fixed formulary covering the main issues, of which there are certainly traces (main subjects, the lormulation that "no losses whatsoever" are accepted, see note 799), but the variation is substontial.

An important difference is that the Hahhum trealy addresses the Anatolian partners always in the plural, apparently because it was concluded with the court or the palace organization. That the ruler, attested for level II (where he is designated both as LUGAL and as 
$\left.r u b \bar{a}^{3} u m\right)^{823}$ is never mentioned in the text of a treaty normally concluded with the ruler, suggesls that there was none; even if the "son-in-law" (hatunum, I [III]:10', II [IV]:4]) was (to be?) married to his daughter, he himself remains absent. This situation reminds me of that described in the letter CCT 4,30a (cf. CCT 6, 15b, see CMK 98-99), from level II, which mentions that the "king" (LUGAL) has committed bloodshed and that his throne is not secure, and that (consequently) the ruba' 'u (plural), "are watching each other", and they are the ones who negotiate with an Assyrian delegation about the oath, an occasion where one would expect the king himself. ${ }^{824}$ Perhaps the situation described in these two letters led to the expulsion of the king and the establishment of an oligarchy consisting of $r b \bar{a} \bar{u}^{2}$. a situation which then might have continued into the time to which this treaty dates, at least three to four generations later.

Hahhum was an important city, well attested during the level II period (see chapter IV.2.I no. 8), ${ }^{825}$ seat of an Assyrian kărum and the texts mention several traders who lived there. It was a commercial centre and prominent road station for Assyrian caravans on the way to Anatolia, strategically located in the area where the Euphrates was crossed las is clear from the stipulations in this treaty, see below under j). ${ }^{820}$ Several letters mention traders who passed through or visited Hahhum on their way to Anatolia or Assur, and there are references to wool and textiles of this city. There is also some evidence that merchandise imported from Assur was kept in store there or changed hands, presumably because the city was located at the southern border of Anatolia, from where caravans might leave in various directions. KUG 13:20 speaks of "textiles of (in) Hahhum", presumably belonging to Suejia, who, according to BIN 6, 35:6f. had "entrusted merchandise in Hahhum". According to $\mathrm{kt} \mathrm{m} / \mathrm{k} 8: 5 \mathrm{ff}$. five donkeys loaded with merchandise were entrusted to a transporter for shipment to Kanesh, and in BIN 4, 7:11ff. a trader, who plans to travel with a caravan of seventeen donkeys to Kanesh, writes that he wants to "select hundred textiles of good quality in Hahhum" and to spend all the silver he still has. ${ }^{827}$ KTS $36 \mathrm{c}$ shows that one could sell imported textiles there in order to buy Anotolian soptinnu's, which were to be shipped on. According to TC 3, 208 three donkeys loaded with rextiles and tin, which had arrived from Assur, were "given" there to a transporter to bring them to Mamma, and Garelli 1964, 59 no. 4 mentions copper in deposit in Hahhum.

823 See above chapler N.2, comments on 8.

824 The first letter in lines 8ff. speoks of "the copies of the oath which they offer us, addressed to/written down for the kärum (Kanesh?)" (mehrät mamitim sa ukallüniătini ana kārim lapputānim); see also Larsen 1976, 27lf. The second mentions that "the ruba''u refused to listen to the written message sent them by the kärum".

825 See Garelli 1998b, bur 1 do not believe that its ruler figures in KKS 2.

820 See for Hahhum as road station, Nashef 1987, 61k., and we now have several additional references to confirm it. Note KUG 22:0ff., "in all 16 minas and 16 shekels of silver, expenses from Hahhum until Assur as calculaled and established".

827 There are a few more references to "selecting (be 'arum) textiles, AKT 2, 34:5, 3, 47:18 and Cole 6:4 (Michel 1991d no. 242), and wice this happens in connection with losses, which have to be compensated, perhaps also in order to restore a carovan's full load. 
These references indicate that the city served in particular as a transit centre and entrepot, with good facilities, where many traders and caravans would meet, goods could change hands on their way to Anatolia, and where also native textile products and wool could be bought. To what extent the area around the cily also functioned as o market for selling what the Assyrians imported is not clear. We have almost no data on the city during the level ib period, but OIP 27, 7+46b: Iff. mentions wool of Hahhum shipped to Amkuwa, ${ }^{828}$ and the very damaged letter $\mathrm{KBO}$ 9, 7 refers to persons or goods arriving from Hohhum. We can do no better than assume that the city during this period, when it harbored an Assyrion kärum, played a similar role and try to understand the new trealy against this background.

The "magnates" mentioned in the treaty are three dignitaries, who are entitled to buy goods (at favorable prices), levy a tax and receive gifts. They are the müsium (I [III]:8', 20', 23', II

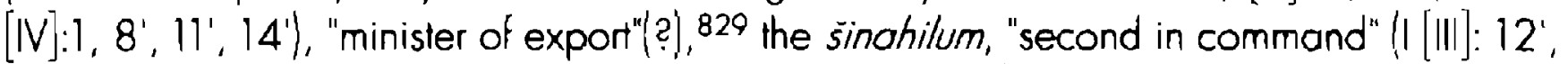
II [IV]:[4]], 830 and the hotunum, "son-in-law" (of the king?). Of these the mussium is clearly the most important one, who is allowed to buy most textiles at the best prices, he receives or buys tin $\left([1]\right.$ III:23') and acquires other goods as nishatu-tax (II [IV]: $8^{\prime}$ ), in short he appears in stipulations comparable to those in which in D the king appears. Another difference is that this treaty repeatedly mentions kärum Hahtum and the inhabitants/members of the kärum (DUMU kärim), who are distinguished from DUMU Hahhim, ${ }^{831}$ while the Konesh treary does

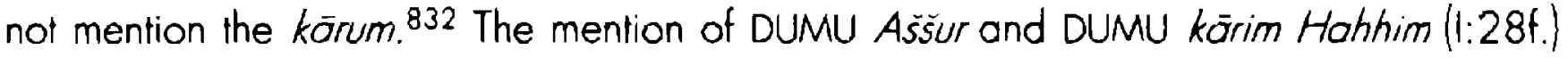
probably dislinguishes visiting Assyrion traders (of "caravans going up and down", as in Bc) from Assyrians settled in the local körum. Compare B III: Of., which mentions "the city of Assur, any Assyrian and the kōrum" (of Apum).

The stipulations as far as preserved and understandable, probably preceded by an invocation of the gods, concern. ${ }^{833}$

a) I [III]:I'-4'. The end of a number of general clauses which stress the obligation of the authorities of Hahhum "to do their utmost (suramrusum) for/in order to [......]".

The repeated sutamrusum presumably refers to the spirit that should govern the leaders of Hahhum in whatever they do to live up to the treaty and the oaths sworn, an interpretation also suggested by the way this verb is use in $O A$ lefters. ${ }^{834}$

828 See Dercksen 200la, 47, note 44. KBo 9, 28 rev., occording to his note 118 , does not mention Hahhum.

829 The translation tries to express the meaning of the underlying verb wasa' um, "lo go out". See for this official, also attested in the city of Assur, where he was involved in the levy of the export tax, Dercksen 2004, 72 with nole 236

830 See for him Veenhof 1993, 524.

831 I do not consider Günbatti's emendation of kárim Hahhim in III [II]:2, 21 and II [IV]:25' into <DUMU> kärim Hahhim, necessary.

832 Günbatt finds it in the Hahhum trealy, III $[11]: 19, k\left[\sigma^{1}-r^{\prime}-i\right] m^{\prime}$ Kanis ${ }^{-k}$, but this reading is uncertain and the broken context unclear.

833 Uncertain translations and proposals to restore the damaged text are in italics.

834 See some examples quoted in CAOM/I, 270, 8, with the comporitive kima so, "just as if ..... 
b) Acquisition of textiles from a caravan which arrives from Assur $\left(\left[[111]: 5^{i}-17^{\prime}\right.\right.$ ? $)$ by the three magnates of the city:

müșium, "minister of export"?

hotunum, "son-in-law" (of the ruler?) sinahilum, "second in command"

-5 rextiles at $62 / 3$ shekels of silver apiece,

-2 rextiles at $91 / 3$ shekels of silver apiece,

-1 textile for $\left[12^{2}\right]$ shekels of silver.

The first, who may have managed the flow of goods, was by far the most important and his status earns him more textiles at a lower price. Read in 6'ff. perhaps: "After you have [ cleared" $\left.{ }^{2}\right] 50,100$ or more loaded donkeys", ${ }^{835}$ to indicate the norm for the pre-emption, but then the prerogatives of these officials were very modest compared to the right of the palaces during the period of level II and more like that of the ruler of $C$, who gets a little tin for every donkey load. Lines 13'f. could restrict or extend (the verb is missing) this right (essubartē < el-subärēe, "apart from/beyond the textiles"), mentioning the more expensive ones (abarnium, kusitum, in conneclion with the nishoh-tax.

c) Acquisition of imported tin by the local dignitaries, very broken (I [II]:22 $f$. or earlier). Probably the right of some dignitaries to buy a certain amount for a fixed (favorable) price, or the mention of the fact that they were entitled to (modest) amounts of tin (per donkey load?) as a gift or transit fee, just like in C:18ff.

The paragraph on tin could have started in 18 'b by mentioning the arrival of a caravan [with lin] $\{[$ summ] a ellutum [... $]$ and what the mussium was entitled to acquire. But the fact that the mussium is also the subject of lines 23 'f. is disturbing and why mention the purchase of tin for silver, which was always possible, while the level II treaties seem to have regulated only the nishatutax on tin? The alternative is to start the paragraph on tin in line $22^{\prime}$ and to assume that the amounts (since no price is stated) were gifts. The "sealer" (kānikum, line 25'), who also received some tin, presumably was an official who sealed the containers after they had been opened for inspection and to produce the tin, before departure from Hahhum. 830

d) Consequences of war $\{1[111]: 26$ '-end between Hahhum and the neighboring cities of Timilkia and Batna. It shall not induce Hahhum to forbid the Assyrian traders to trave//in

835 I would read išı 50: I me-af I ANŠE.HI.A I sé-er-DIM I ú elis [...... is the conjunction, "after you have ......". A reading $51 /$ me at, "5100 (donkeys)", yields an add and impossibly big number. See for serdum the combination emäre serdam in $\mathrm{kt} 92 / \mathrm{k}$ 203:29f.//200:26f., also with a plural noun (instead of normal emā̄ū sardütum, of. TC 3 , 28:6); the word looks more like a noun in apposition than an adjective. The verbal form which ends in ]-a-nimust be a second person plural, with the magnates of Hahhum as subject, perhaps a Š-stem of the verb eläum, "to bring up (to the palace)" (rušeliāni), or perhaps from zakku um, "to clear" (tuzakkiāni). The former verb, in the G-stem, may occur in the comparable II [IV] o'f., where Günbatt reads [ANŠE.H]\}.A sé-er $[$ dim] ... ša ana [/]i-bi a-linti : e-li-ü[ni], where the donkeys would be the subject, which is excluded in our stipulation. See for the problems raised by his reading the remarks on this passage below under $f$.

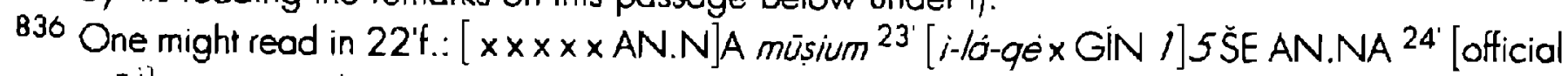
$\times$ Gi]N AN.NA kōnikum. 
both directions). ${ }^{837}$ The words "Any Assyrian, wherever [...]" could be the remainder of a positive statement of the rights of the traders.

\section{lacuna of a least 30 lines.}

e) The right to buy gold from caravans on the way to Assur (II [IV]:1'-5"), an interpretation demanded by the (damaged word) "gold" in line 4". The "second in command", who in b) paid the highest price, still gets it at a favorable rate of exchange of $6: 1$, which is less than the normal rate of $8: 1$, current in Assur.

f) Further prerogatives to acquire goods from caravans traveling to Anatolia (II [IV]:6'-14'), damaged, but obvious from the mention of tin in II [N]:13', but the prices one has to poy have disappeared.

Günbattl assumes that this part, just like e) concerns carovans going to Assur and reads in 7' [and] libbi alimk elá 'um, "to go up to the Centre-of-the City", ${ }^{338}$ and lets the mussium acquire silver (as the ruler could in C) from caravans returning to Assur, which carried silver and gold. But the use of Libb'älim for Assur would be unique in $O A$, "silver" is completely restored, and for the trip to Assur warädum, "to go down", is common, not elā'um. ${ }^{839}$ Since the goal of the caravan decides on its load and on what the officials in Hahhum can acquire from it, the mention of "in" (if certain) in line 13' suggests a caravan on the way from Assur to Anatolia. ${ }^{840}$

The subject of lines 9'-14' is not clear, but they must add something new, since the müsium appears again. They may concern a fee, paid in tin, perhaps for the passage of the donkeys and this would be confirmed if we could read [ $\check{s}$ o ne] birim in the beginning of 14', but this is not centain. Which rate is meant in $11^{\prime}$ ( 5 grains of ... each) is not clear, but line 9 ' seems to speak of gulgullu, a rare term, presumably bolts of cloth, which could be stored in leather bags, ${ }^{841}$ and this also suggests caravans en route for Anatolia.

g) Losses and blood-shed in Hahhum's territory (II [IV]:15'-22'). The second, which returns in i) as caused by a provoked shipwreck, is here treated more in general, together with murder, as in Dc. The culprits have to be caught and handed over for execution by the Assyrians, with the obligation to refurn the lost goods.

h) No secrecy in the handling of conflicts between Hahhum and the inhabitants of the

837 The reading $k 6$ to-ló $[q \dot{e}]$ in $30^{\circ}$ ' is doublful, also because it is in the singular. I preter 'You shall not go to ..... (la ta-f(a-ko]). In $20^{\prime}$ the conjunction probably was [inumi], since the verb is in the subjunctive.

838 Presumably also because ano libbi as compound preposition is not used tor "towards"; alum, if certain, could also refer to Hahhum.

$839 \mathrm{CF}$. the use in B 1:27t. and 11t:16 of elitum and wöritum for carovans going to Anatolia and returning to Assur.

${ }^{840} \ln 7^{\prime}$ " [x shekels silver as] (nishotutax)" is completely restored and the line does not seem to have enough space for this restoration, and of the verbal form only e-liseems unambiguous. The end of line 9' may have contained the word gulgullum, used for cylindrical containers or boles with textiles carried by donkeys on the way to Analolia, but not attested for the transport of silver to Assur.

841 See AOAT39f. Prag 1 718:23 torbids to place packels of tin in the g., presumably wrapped in a boll of cloth. AKT 2, 35:6f. and 13t. speak of hursionnu-containers so gulgulte entrusted for mansport. 
kărum and Assyrian traders passing with caravans (II [IV] 23'-32').842 The cases/complaints must be presented? ( $k a^{23} u / u m$ ) publicly, no ${ }^{843}$ secret dealings $s^{844}$ within the confines of the palace, ${ }^{845}$ but a public announcement in the city and its territory.

i) A fair administration of justice (III [11]:1-10). No administrative decisions (nikišlum) 846 against Assyrians and the karrum due to the fact that the authorities of Hahhum intercede for/side with $\mid[a-b] u-f i$ PN sabātum? $) \|$ of the city's soldiers, slaves and citizens, but fair verdicts for Assyrians according to normal judicial practice in Hahhum (kima din Hahhim ... radinnänil and not according to specific contractual stipulations(?). ${ }^{847}$

i) No mean instructions to a ferryman ${ }^{848}$ to let his boat sink and cause the loss (also by subsequent robbery?) of Assyrians goods (III [II]:11-18?). Compensation of anything whatsoever ${ }^{849}$ should a boat sink ${ }^{850}$ and losses occur "on the river, in the mountains and in your land".

This stipulation is understandable since Hahhum was a city at or near the crossing of the Euphrates, which is confirmed by $\mathrm{kr} 94 / \mathrm{k} 928$, which lists expenses of a trip to Hahhum that comprise payment for lodging and one shekel of silver "crossing fee" (nëbartum). while line 14" lists a payment "[ ] of the river".

k) Unclear (III [II]:18-28). Very damaged, mentions contacts with $\left[k a \bar{r} u m^{2}\right]$ Kanesh and "any Assyrian" and kärum Hahhum, and may deal with theft of silver and gold by a man's personnel (suhär awilim) and items belonging to "his boss".

Lacuna of ca. 35 lines.

I) Confiscation and seizure (IV [I] until ca. 20/22'). After an isolated "you shall not administer an oath" (I. 5') and a clause which perhaps includes the word "border" (see N. 2.6, the remarks on $p \bar{a}(u m)$, there follow stipulations that seem to forbid the seizure of somebody else instead of a defaulting debtor (restore in line 10 ho [bu-lá-nim], cf. D:7), or the con-

842 I assume that the words of $23^{\prime}$, "from this day onwards and as long as you live", introduce this stipulation, but they might also conclude the previous one, which is also of great importance.

843 Line $30^{\prime}$ should start with $/ \bar{a}$.

844 Verb broken, perhaps wašäbum $\overline{\mathrm{S}}$-slem, used for convening a court.

845 Lines 28'b-32', ina puzrim [ina e]kallikunu ina parišrim [/ā tušešs̆a]bäni nägiram ina älikunu Hahhim u mälikunu [/ü h]šassō $[n i]$.

846 See for this word below, note 857.

$847 \|: 5$, din ri-<ik>-so-tim, according to Günbatti's convincing emendation, which probably means verdicts based on (imposed?) contractual stipulations.

848 The reading ša $[\text { ho-p }]_{i-r i-i m}$ is grammatically difficult and makes no sense, better $\breve{s a}{ }^{\star}[n e-b] i-r i-i m$, which fits clauses about sinking boats and a city on the river. The normal OA term nébartum (VS $26,150: 22, \mathrm{kt} 91 / \mathrm{k} 437: 33$ ) is used (in expense accounts) for "the costs of crossing", the crossing or ferry itself apparently is nēberum, which is used in $O A$ as euphemism for somebody's death (CADN/II, 146, 1,c; also kt 94/k 796:25 and 815:26), but is well known in OB and so nébirim occurs in OB lú A $302 f$. as "ferryman".

849 "Neither rope, nor peg, nor stick, nor anything whatsoever"; see also nole 799.

850 Nole the use of the precative (litbima) to describe a possibility, as it is in some paragraphs of the laws of Eshnunna. 
fiscation (as compensation or penally) of houses and other possessions of an inhabitant of the kārum, who brings (smuggles?) goods into the city. ${ }^{851}$ Soldiers (rädium) of Hahhum shall not be instructed to [seize] slaves, oxen, donkeys, sheep and goals (restoring [sé-n],-im) belonging to kārum members [because of .......].

m) Unclear (IV [I]:22-30'), perhaps the continuation of I). Something should not happen "in your city Hahhum and in your land" with "any Assyrian", which seems to involve his house, and with Assyrians and inhabitants of the kanum.

Remainder of the column, lower and leff edges (in all ca. 35 lines/ missing.

851 "To bring into the city" can be neutral, but is also used in letters dealing with smuggling (BIN 4 , $48: 20,24,26,37$; CCT $6,22 c: 7,10)$. 


\section{Comparison and interpretation}

When comparing the available data we should not forget our sources are damaged and incomplete. $C$ might be the second page of the treaty text, parts of $D$ are unreadable, and of $E$ we have less than half of the text, including many broken passages. Moreover, $A$ and $C$ concern the period of level II, while $B, D$ and $E$ are from the level $l b$, while $B$ is special because of the location and commercial role of Apum. As is clear from $B$ and $D$, and may be assumed for $E$ (beginning missing) the text of the treaty included the invocation of the gods by whom the oaths were sworn. C does not include it, unless $\mathrm{kt} \mathrm{m} / \mathrm{k} 794$ was the second of a set of two tablets, and it is unique in describing in its last part how it was sworn, what was said by the Anatolian partners and which symbolic actions were performed.

\subsection{Status and judiciary treatment of the Assyrian traders}

If we start from $A$, we note that the basic conditions of residence rights for the Assyrian traders (Ad) and the possibility to be commercially active in the city and its territory are nowhere explicitly stated. This may be understandable in $C$, which seems to concern a town passed by Assyrian caravans, without Assyrian settlement, but is remarkable for $D$ and $E$. I assume that these were basic and accepted rights or facilities, implied by the existence of a kārum, which were taken for granted. The absence of relevant stipulations means that we do not know the statule of foreigners living in a kārum (called wāšib kārim in ht $92 / \mathrm{k}$ 203:32) nor whether they needed permission of the local authorities to settle down there and buy houses. It is clear that inhabitants of a kärum were not considered local citizens, and Df distinguishes them also from hapiru, people who had found refuge in a city (see note 818). Bc and $f$ mention the kârum (of Apum), which is different from the town as such and also not identical to the Assyrians (Iraders) who visit the city when traveling with their caravans up or down (I:27f., III:16). This suggests that the karum was an institutionally separate city quarter in which Assyrian and presumably also other traders had settled and whose members could do business in the cily and its countryside (they may have belonged to the alik eqlim mentioned in II: $3^{\prime}$ and IV:11). The same distinctions apply in E. Alongside the citizens proper of Hahhum (DUMU Hahhim, III [II]:4) there are DUMU kárim Hahhim, "inhabitants/members of kārum Hahhum" (III [II]:9, IV [I]:8f. and 29; in II [IV]:25', III [II]:2 and 21 abbreviated to "kārum Hahhum"), and DUMU Ǎšsur, "Assyrions/citizens of Assur" [II $[\mathrm{IV}]: 25$, IIII $[\mathrm{II}]: 1,8,20 ; \mathrm{IV}[\mathrm{I}]: 25,28)$. The latter appear together as the ones to enjoy the protection of the treaty, clearly in II [IV]:24'ff., where the repeated bariti, "between", distinguishes the two groups which have a conflict (awatum): on the one hand "you" (plur., the magnates of Hahhum), and on the other kärum Hahhum and "any citizen of Assur" (šsumsu). The oddition of "any, whosoever" (sumsü) emphasizes that all kind of Assyrian traders were included, notably also those (belonging to a caravan) "going up (to) or coming down (from Anatolio)" (II [IV]:26', elitum u[wōritum]). This added sumsu is also used in B III:10 ("any Assyrian and the kärum"l, also in order to distinguish between all kind of Assyrian traders 
visiting Apum as members of a caravan and the Assyrian traders more permanently settled in its kärum. It is interesting to note that this distinction between Assyrians settled in körums and those traveling with caravans is used in the treaties with Apum and Hahhum. We can explain it from the fact that both towns where important road-stations on the way to Anatolia proper, where a distinction between visiting traders and caravons and traders settled in their kärums was sensible, since the treaties (ultimately) concluded by and with the city of Assur wished to protect both categories. Due to the different role and location of Kanesh such a distinction there must have been less obvious.

The statute of people living in and belonging to a kärum is important for understanding $\mathrm{Di}$, where the ruler of Kanesh is forbidden to conscript Assyrians for service duties [unušsum), otherwise only attested as incumbent on native Anatolians. ${ }^{852}$ In Mari the "people of the kãrum" (DUMU.MEŚ KAR.TA or DUMU kárim) were distinguished from the common citizens and from the specialized craftsmen. ${ }^{853}$ This was also the case in ARM 23, 430:4, when an army of 1600 people was recruited to depart for Babylon, but it did include a few hundred "people of the kärum", whether this was an emergency measure or a normal procedure. ARM 14, 64:6'ff. shows that Iddiyyatum, Mari's "overseer of the "raders", had been charged by the king to register "people of the karum" and they must have been foreigners, who had somehow settled down there for various reasons. I doubt whether foreign traders (ramkärum), settled in the kārum, could be conscripted as soldiers, unless in case of extreme danger. If so, $D_{j}$ would be in line with the situalion at Mari. We may compare the fact that in Babylonia the owner of a "residence" (bet naptärim) in a foreign city, possibly a trader, is indignant over the fact that his "house" has been dunned for service duties. ${ }^{854}$

Extraterritorial rights $(\mathrm{Ae})$, though not explicitly stated, seem to be a fact, to judge from the abundant evidence for the administrative and judicial roles of kärums and wabartums in all kind of cases which concern only Assyrians (fixing the interest, regulations for the trade, specific decisions, lawsuits and verdicts, etc.). It is confirmed by the role of attorneys \{rabissum\} acquired in Assur, by the decisions of the City of Assur transmitted to the kărum, and by the institution of the "Envoys of the Ciry". A different issue are cases where interests of Assyrians and Anatolians clashed and in particular where the Assyrians had to confront the local rulers and palaces. Most of the stipulations on the administration of justice found in the treaties B and D-E apparently deal with such issues. The damaged $B e$ probably concerns conflicts between citizens of Apum and Assyrion traders which end up before the ruler, who has to promise a lair (ina kinatim) handling of the affair, without

852 See now Dercksen 2004b, 140 .

B53 ARM 6, 43:19, as reod in MAR/5 (1987) 604. They occasionally appear as a separate group in texls that register people who join "the king's table", see B. Latont, in: Melanges offerts a Mourice Birot (1985), 101ff. nos. 12:2 and 19:5. Nole olso J.-M. Durand, MAR/6 (1990) 79, nale 202 line 10, on people of the körum who bought wine.

854 See Veenhof 1991, 295. He speaks of "being confronled with a summons" (sisam kullumum) by the recruiting officer. 
bullying $\{\text { ? ; sagaāsum }\}^{855}$ the Assyrian party. These last words can be understood as "treat them just like you would your own subjects", or "do not treat them the way you can treat your own subjects". The second inlerpretation, which seems grammatically more likely and supplements the positive injunction of line 6, means that the ruler has to treat the traders differently, with more consideration and perhaps without physical force.

In Dd too a verdict ina kinatim is required ${ }^{850}$ and something similar is meant in $\mathrm{Ei}$, where twice a procedure and verdict ina kinatim, in accordance with the judicial practice of Hahhum is demanded. This is not in order to bring Assyrians under local law, but to prevent in conflicts between Assyrians and locals, which must have been tried by the local ruler, arbitrary measures, designated as "taking an (ad hoc) administrative decision" (nikišum), ${ }^{857}$ and passing a "contractual verdict" (din riksätim), which probably means a deviation from common law, which could be dangerous. The magnates of Hahhum are explicitly forbidden to take sides and favour (abbütam sabätum) their own people in lawsuits. A more general stipulation in this spirit is Eh, which in a conflict "between you and kärum Hahhum and/or the Assyrian citizens", demands openness and publicity /including a public announcement of the trial), to prevent secret judicial dealings inside the walls of the palace. A different situation is envisaged in Em, where the ruler is forbidden to administer an oath, which perhaps means that he should not use this heavy instrument without prior careful investigation by a court.

Other stipulations fit this pattern and many concern the protection of Assyrians against AnaIolians, both the local authorities and their Anatolian clients, who could be their creditors. Such rules are understandable in view of the rights which common ancient Near Eastern law grants to creditors and their possibility to resort to one-sided actions such as seizure of pledges and distress, which may have been particularly feared by people living in a foreign country with only legal means and an appeal to fairness to prevent worse. Their mention in $D$ and $E$ can be explained from what Dercksen 200la, 66, concluded on the basis of an analysis of the level lb texts, where he observed "a general impoverishment..., expressing itself ... also in the number of cases where Assyrians have been detained by a

855 In $O A$ it can also mean "to ruin somebody", see CAD $\breve{S} / 1$, 68f.; we con read tašaggi pronominol object suffix. The verb is also used in the Apum Trealy (B), IV:9, where Eidem translates "you must nol pressure(?) ....".

850 The following "[........ to a citizen of yours", could be positive ("equaling him to ...") or negative |"not delivering him to ...").

857 See for this term Veenhof 1995c, 330f. An additional occurrence in kt 91/k 100, a severely damaged letter of the ruler (waklum) of Assur, addressed to the Envoys of the City and kärum Kanesh, dealing with smuggling: rev. 4' From this da $[y \text { onwards }]^{5}$ ni-ki-iš-tám $[x \times x]^{\circ}$ DUMU $A$ -

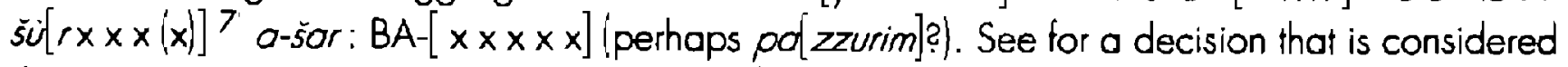
detrimental to the Assyrians, kt 87/k 387:33f. (courtesy Hecker), "If there is a nikišmm concerning kutōnu-textiles, appeal to the kōrum, soying: He must go to the rabi sikkitim (of Wahšušana) ... for his affair, that they may release to you 5 kufänu-textiles". It is not clear wherher this was an Assyrian decision (e.g. to boycott the Anatolion official, because he did not pay his debts), or one by the Anatolian palace, for whatever reason. 
native creditor for insolvency". Seizure of (loaded) caravan donkeys by the ruler's subjects, which should be [repaired ${ }^{2}$ ] according to $\mathrm{Be}_{1}^{858}$ is an example. In cases of defaulting and perhaps bankrupt or dead debtors, according to Dd, Anatolian debtors should not be favored and the main creditor, irrespective of whether he is Anatolian or Assyrian, is indemnified first. ${ }^{859} \mathrm{~A}$ fugitive Assyrian debtor, according to $\mathrm{Di}$, can be seized and forced to pay, but if he cannot be traced the creditor cannot seize a fellow Assyrian instead.

Some stipulations want to protect the Assyrians and their households against illegal, highhanded actions aiming at members of their household or their possessions. The difficult paragraph Df must envisage private actions by local inhabitants, citizens of Kanesh and persons who had found refuge and settled down there (see note 818). If demands from the ruler of Kanesh not to allow such actions and the explicit mention of (Assyrian) widows as potential victims shows the concern for protecting those who are most vulnerable. The damaged and unclear paragraph Em also mentions what could happen to the house (hold) of an Assyrian and might have had a similar purpose. Dg reminds the ruler himself of the fact that he shall not covet and seize possessions of the Assyrians (houses, slaves, fields, and gardens\}, presumably not as an act of simple greediness, but rather as a way of obtaining what he likes by punishing them or demanding compensation if they misbehave or default. These paragraphs show clearly how important the houses in the karum, where they lived, kept their merchandise and archives, and felt safe, were for the Assyrians.

Something different may be at stake in El, where a likely reference to illegal import ("to bring into the city") may indicate that the seizure was a highhanded response (carried out by soldiers of Hahhum, acting on instructions of the ruler). This stipulation, by mentioning the seizure of property and houses "instead of [...]", suggests that such seizures could be rather brutal, one sided solutions to problems, which bypassed careful judicial procedures. The Assyrians knew that their misbehaviour, especially infringement on what had been agreed by treaty, could be punished by the rulers by putting the culprits in jail, as happened to Püšu-kēn, when he accepted smuggled merchandise (ATHE 62:30ff.). When $\mathrm{Bb}$ mentions that an Assyrian trader, who had been apprehended, could become free when a ransom was paid, and it is indeed the local ruler who gets this money, he must have had him arrested for an illegal action, such as smuggling. Ransom occurred often, but in the conflict reported in kt n/k 504 (see next paragraph), in a case of espionage, the ruler asks the almost impossible sum of one pound of iron or ten pounds of gold for the release of the suspect.

Consideration with the Assyrians is also clear when DI stipulates that an Assyrian (occused or called upon as witness?) will only swear by the symbols of his own god. Since religious sensitivities are hardly involved, this rule must have offered the reassuring advantage of being able to swear in the cella in his own karum, with an oath by his own

858 Line IV:19 could deal with compensation of expenses (gamnm) incurred by the seizure.

859 This interpretation is required because in both cases, ofter the one who "rakes first", there is somebody else who takes after him. This implies debtors with both Anatolian and Assyrian creditors. 
god, administered by his own people. He did not hove to go to the river ordeal, where Anatolians were sent to discover the truth, probably a rather daunting experience that was better avoided. 800 Whether something similar may be at stake in the beginning of $\mathrm{El}$, when the oath is mentioned, is not clear.

\subsection{Free trade and the protection of caravans}

Assyrians feared interruptions of the trade and lack of safety for their caravans. The writer of KTS 2,40:27ff. is happy to report that "there is peace ( sulmum) in Burushaddum, Ulama has just accepled the oath (peace Ireary) from Burušhaddum" and asks to send donkeys for the transport of copper. The one of VS 26, 83:39ff. promises: "When peace has been established and my goods have come down from the palace in Kanesh, rake action concerning my tin and textiles, so that you yourself and my merchandise are safe and convert them into silver". ${ }^{801}$ Interruptions meant that traders were "held up" (kaläum) and they or their wares were "ried down" (kassudum Dt). At times the behavior of the Assyrians themselves may have been responsible for such delays, in particular when smugglers were caught. This must have been the situation in which the ruler of Assur (wak/um) wrole the letter kt 91/k 100 to the Envoys of the City and kärum Kanesh, about a caravan which had been stuck in Zalpa for no less than eight months. ${ }^{802}$ Most of the letter is broken, but the mention, on the left edge, of the "sukinnu-route", suggests that it had to do with smuggling. In VS 26, 29:15ff. a trader complains that one has delayed him for eight months in Saladuwar, so that "merchandise for a value of 20 minas of silver got stuck together with me", but the reason for this incident is unknown.

A vital issue was what would happen in times of war or hostilities, which apparently were not too rare. A first concern of the Assyrians, devoid of any military power, must have been not to get involved and stay as neutral as possible. The case of the Assyrian trader arrested and accused of treason, because he would have rendered services to the local ruler's enemy ( $k t n / k$ 504, see above II.2.6) must have been a warning example. Living in a town's kărum the Assyrians at times may have felt the pressure to take sides, which was perhaps the case in the incident reported in KTP 10 /see note 746), a letter of the wabartum of Šala<du>war to kārum Wahšušana. It reports that somebody, presumably the ruler of a neighbouring rown (Burušhaddum?\}, had said in a letter (rev., lines 9-13): "Invade? (plur.) the country of Wahšušana, if not, I am your

${ }^{800}$ Reported in kt n/k 504, see Günbatr 2001, 152:21f. kima mer'a alika ana i-id lillik. In this extremely serious case (an Assyrian accused of treason and liable to be killed) the Assyrian authorities make the exceptional offer of letting him be lested "in the Anatolian way".

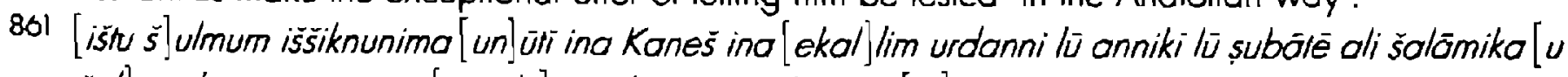
salläm luqütia épušma [armiki] u șubätia ana kaspim [to] 'er.

802 illat Puzur-Äšur is̆[U] ITU 8 KAM ina Zalpa kal'at, see for this text also note 857. 
enemy!". The second concern, once hostilities (nukurätum) or a revolt (sihitum) 803 had erupled, apparently was to be able to decide for thernselves, using information received from elsewhere and calculating the risks, whether it was possible to travel or not or whether

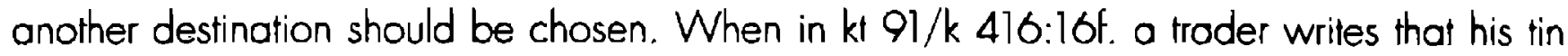
"should not be shipped on beyond (ebor) Šalahšuwa, but beyond Timilkia to Durhumit, so that it stays safe", 864 the last words could refer to such dangers. At times commercial traffic was impossible due to a sukurtum, "blockade", 865 probably when the local outhorities, who were responsible for the roads and the safety of those who rraveled in their territory las mentioned in Af), refused "to let the caravan leave" (ellatam waššurum) or "to give the road free" (harränam wašsurum) ${ }^{800}$ CCT 5, 15b:3-10 (CMK 89) reports: "The ruler of Wašhania has arrived here and has prevented me (kaläum) from going to Burušhaddum or Haltum. I have now wailed fifty days and if he does nol give the road to Hattum free ... I will leave for Kanesh". ${ }^{807}$ A prohibition to travel could also have other causes, due to legal problems, as seems to have been the case in TC 3, 75 (CMK96), where Dadōya writes: "As long as I am stuck here I am staying in Naduhtum. No less than ten times we went up to the ruler and the second-in-command, and I said: "Allow me to travel!" (harrannam dinam). But they refused to grant his request, since he had to stay as a guarantor, until an instruction from (känm?) Kanesh would arrive. In many cases, however, the reasons were of a political nature, including danger on the roads. By means of a stipulation like Dk the Assyrians wanted to make sure that they could travel, even in times of hostilities, and this is also the purpose of $\mathrm{Ed}$, in case Hahtum would be at wor with one of its neighbors, Timilkia or Batna. Both were towns with an Assyrian settlement and on the caravan road trom Assur to Kanesh and their mention shows that caravans traveling both ways were meant. The possibility of traveling under certain conditions during periods of hostilities or war is mentioned in a text from Mari, whose writer compares Bedouins, who penetrate everywhere, with "a trader who travels between (regions at) war and (regions at) peace", 808

$803 \mathrm{~K}, 94 / \mathrm{k}$ 1323:9ff., "There is a cevolt in Burushaddum, it is impossible to enter by road either Ulama, Šaladuwar, or Šabâ"; a revolt in this city is also reported in $\mathrm{kt} \mathrm{m} / \mathrm{k} 13: 24 \mathrm{f}$. (Countesy Hecker), which means that "no individual (wedum) can enter (the ciry)." Note also Prog | 704:31., "the country is in revolt and the road is closed" (harranum pahi< ar >).

864 kima solām anniki.

$865 \mathrm{Il}$ could cause serious problems, as is shown by $\mathrm{kt} \mathrm{m} / \mathrm{k} 69: 68 \mathrm{ff}$. (courtesy Hecker), where a man writes that he look out a loan of $11 / 2$ mina of silver with an Anatolian "to keep my people alive during the blockade"

886 The same expression also in Babylonion, in the letter IM 49307:1Off. (W.F. Leemons, Foreign Trade in the Old Babylonian Period, 1960, 106f.), where the karum of Sippar writes that the king said: "Until we have captured the cities $\mathrm{K}$. and $\mathrm{H}$. we will not give the road free".

$867 \mathrm{~K}+92 / \mathrm{k}$ 326:3-15 (courtesy Alboyrak) reports: "Previously I wrote to you: The palace tries 10 cheat (sala' 'um) the kornum and the carovan must fend tor itself (? qässa isabbar), but us, they do not let us go (wassiurum). Speak to the karum that they should not bring the carovan in as long as they do not let us go!".

${ }^{888}$ A 350+: 5H, see Charpin-Durand 1997, 378, with nate 81, kima tamkörim sa birit nukurtim u salimim illake. 
and the Assyrian traders certainly were of that kind. The background of the stipulations in Dk and Ed seems to be that the local authorities by their oaths had guaranteed the safely of the Assyrians and their caravans inside their land/territory and promised compensation for losses not recovered and blood money for people killed, without limitations or exceptions. In periods of war and unsafety the rulers quile nalurally must have been rempled to stop commercial traffic coming to or leaving their cities, in order to prevent such risks. But the Assyrians wished to decide for themselves what to do, stay inside the walls or travel with their caravans, perhaps trusting their immunity or profiling from information on the safety of certain roads, as is shown by $\mathrm{kt} 91 / \mathrm{k} 416$ (quoted above) and the important letter TC 1, 18:32ff. (Larsen 2002 no. 18). In the latter fear of entering Hahhum suggested using another crossing of the Euphrates, by traveling by way of Uršu to Mamma. The letter then mentions an instruction (te 'ertum) of the City Assembly in Assur (which shows how in such situations information was communicated between Anatolia and Assur) to divide the carovan into three parts and to let the second part leave Uršu only after it has become clear that the first parl, slarting out from Mamma (where there are also problems), has safely reached "the land of Kanesh".

Donkey caravans loaded with valuable merchandise implied risks and this could lead to losses, both commercial ones, due to delays, bad prices etc. $\left\langle i b i s s \bar{a}^{3} \bar{u}\right\}$, and to the loss of donkeys and their loads (hulugqa' $\bar{u}$ ). Some were due to accidents in bad weather, in the mountains and even in Assur, ${ }^{809}$ and several caravan reports mention expenses caused by the death of donkeys. ${ }^{870}$ Other losses could be the consequence of "smuggling", as was the case in Sadberk 12:5ff., where of a load of $41 / 3$ talents of tin and 140 kutonnu-textiles no less than 1 talent of tin and 12(!) textiles were lost during smuggling (ippazzuntim halqü). Such losses had to be accepted, but certain risks could be reduced by spreading them over the members of a caravan (ellutum) according to a rule laid down by a decision of the City of Assur:

"As for the losses of $\mathrm{PN}_{1-5}$, the caravan of $K$. shall compensate their losses to them in accordance with [the words] of the stele, (whether they) be tin, silver or rexiles". 871

Losses due to theft or high-handed actions of Anatolians were a different matter. I assume that theff from houses in a kārum, wabartum or a lodging (bët ubrim), used en route, which

$869 \mathrm{~K}+94 / \mathrm{k} 963$ mentions lapis lazuli that got lost in the City".

870 See $A O A T 251,5$.

$87 \mathrm{Kt} \mathrm{n} / \mathrm{K}$ 1570, see Veenhof 1995a, 1730, and now also Dercksen 2004a, 172. Compensation (mally'um) of such losses is also mentioned in CCT 2, 11:15ff. (loss of lextiles in the mountains of Mamma) and $\mathrm{kr}$ 91/k 451:1-5, "for the 17 kutanu-textiles which got lost in Batna the caravan has paid us a compensation of 1 1/3 mina of tin apiece". CCT 3, 33a:3ff. may deal with a similar case, because the kārum decides to detain the caravan for five doys. In BIN 6, 180:4't, the writers gave "1 kuronu-textile for the losses in Zalpa", which must be their share in the losses incurred by a caravan, and such losses belonged to the expenses of a trip which had to be balanced (BIN 6 , 212:18ff.J. 
could have been prevented by guarding one's premises and belongings, were the owner's risk. ${ }^{872}$ Larsen under Ad added to residence rights "presumably some kind of protection", but this may have concerned a kärum or wabartum as a whole, hardly that of individual houses against thieves and burglars, although the Assyrians in such cases probably could ask the local "police" to find and punish the culprits. Ek may have dealt with theft, but is too damaged to be sure. Dramatic cases of theft are reported in SUP 7, which relates how thieves stole valuable items from the shrine of Ašsur in Uršu (see Larsen 1976, 26if.), and in $k t k / k 108,{ }^{873}$ According to this letter thieves entered the house of the writer's father in Burushoddum, cut the throats of three men and disappeared with silver and much copper, fin, and textiles, which the writer had been searching in vain. The text does not mention an appeal to the local ruler to find the criminals and compensale the losses, but we cannot be sure that this has not happened, because the purpose of the text is different. It is a deposition made before wabartum Zimishuna, which states that the victim accused his partner, whose goods were in the same house but, miraculously, had suffered no losses, but he was unwilling take part of the losses for his account. ${ }^{874}$ The background of losses due to "seizure" (sabätum) of merchandise usually is not clear. CCT 4, 19c:15ff. reports obout the seizure of 25 kutonu-textiles in Luhusaddia, where the queen told the owners: "The one who seized the textiles and? the tin will come. If the kutanu-textiles are available, take them, and if they are damaged take silver (as compensation)". The queen's promise, "he will come", could be taken to mean that she was sure to find the thief, but may also imply that she knew more about the action of one of her subjects, perhaps an official who had overstepped his competence, in which case "seizure" could mean "contiscation". ${ }^{875}$ "This case may be compared with those where textiles "got lost" in the palace and where we do not know whether this was theft, illegal confiscation or something else. In $k t 94 / k 848$ textiles were brought into the palace, a few were taken as nishatu-tax and bought, but also "three textiles went lost in the palace". And when kt 88/k 963 asks a trader to overcome his fears and bring merchandise to Kanesh for clearance in the polace, the addressee is reassured by the words "The paloce will take the nishan-tax and absolutely no losses will occur in the palace". ${ }^{776}$ This last remarks suggests that centain losses were due to the fact that the palace officials tried to toke more textiles than they were entitled to. This is indeed considered in treaties Cd (line 24, "you shall not take anything extra") and Da (line 17 mentions "to take away by force", ina emüqe etarum) and $\mathrm{Eb}$ ("beyond the(se) textiles") implies it by fixing the number of textiles which can be bought at favourable prices.

872 Note kt 88/k 507b:00f. (courtesy Albayrak), where a trader's rablets were stolen (sorqü), and the fomous letter CMK 51, which reports on the thett of sacred objects from the lemple of Ašsur in Urs̀u.

873 Hecker 1990a, text no. 4

874 His opponent states that thanks 10 the aid of the gads he escaped unharmed, with his merchondise. but the victim is suspicious becouse his opponent, when listing his merchandise (tin, textiles and copper) "concealed a lot of merchandise" (kqütom mathom takium, line 19f.).

875 The meaning of larsen who edited the letter as Larsen 2002,89.

870 mimmo ina ekallim huluqgã iu lä ibašsi, see Albayrak 2003:12f. 
Loss of donkeys and merchandise traveling on the roads in Anatolia due to raids and robbery were a serious matter. The fact that the local rulers were held responsible for repairing such losses implies that traders could count on protection by the local palaces, which could guard the roads and make armed escorts (rädium) available. Such losses were not accepted and all treaties stipulate that the palaces had to look for and return ${ }^{877}$ the lost goods or pay the owner a compensation (mallu'um), as we read in $\mathrm{Bd},{ }^{878} \mathrm{Ca}, \mathrm{Dc}$ and $\mathrm{e}$, and $\mathrm{Eg}$ and $\mathrm{j}$. Compensation will have been based on the value or price of the goods lost, and $\mathrm{De}$ adds that the size of the loss will be established on the basis of an oath by the owner. Assyrian complaints and demands for compensation are mentioned in several letters, some of which report verbatim the conversation with the ruler. In the letter $k+b / k 471$, which reports on the loss of twenty-five textiles, we read in lines 8ff., "We went up to the palace and they gave us back twenty rextiles. ... The palace gave us the thieves to kill them and the palace said: "Kill the [culprits?] and then your textiles will not get lost". ${ }^{879}$ Here the palace seems to acknowledge that killing the thieves will work as a deterrent to prevent future losses. In AAA I, no. 6 (CMK 36) the ruler of Kapitra is reminded of what his "fathers" (kärum Kanesh and the Envoys of the City, to whom this letter is addressed) have written him: "Return the goods lost, then we will pray for you before Aššur!", and he now promises to do so in the near future. In TC 3, 85,880 the ruler of Zalpa, after receiving a present of gold to solve the problem of lost goods, says: "Let the owner of the lost goods come here and I will pay to him personally my compensation". ${ }^{881}$ But this does not satisty the Assyrians and when he is told that the silver lost is property of a god (ikribü sa ilim), he finally promises: "I myself will return to you the lost goods".

Stipulation $\mathrm{E}$ is an interesting specification of possible losses, in my reading caused by the ferryman (or perhaps the man who instructs the caravans how to cross the local ford), who acts on instructions from above. It indicates that the Assyrians, who may have learned from experience, did not exclude tricks played by the local palaces and several letters indeed reveal what the rulers and their dignitaries could do, using their power. ${ }^{882}$ The stipulation fits the cily of Hahhum, where the Euphrates had to be crossed, but there were several other towns on rivers and near crossings - Durhumit, Habnuk, Nenaššă, Wahšušana, Zalpa - where such things might happen. The related texts $k t / / k l$ and 25 (Sever 1996) mention expenses paid in Wahšušana, after leaving Šaladiwar, because of the transport of a mule, "On the bank of the river" and to the boatman (malahum, $\mathrm{kt} \mathrm{t} / \mathrm{k} \mathrm{1:16f.,} \mathrm{29-35),} \mathrm{or} \mathrm{"at} \mathrm{the}$ bridge" in Salodiwar ( $k t+/ / k$ 25:10f.).

877 še'äum u to" urum, C:6-7, D:59; E I [IV]:22.

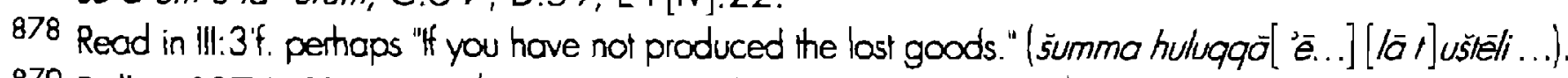

879 Balkan 1974, 31 note 16 (šăriqē ano duäkim ekallum iddinniäri).

880 See already Garelli 1963, 344t, and see now CMK 90.

881 The word translated "compensation" is arnum, "fine", apparently a financial indemnification, which, as the continuation shows, is different from a return of the lost goods. As Garelli's analysis shows, this was a complicaled case, in which the Assyrian victims presumably had seized a slave of the ruler to put pressure on him.

882 See for an example Hecker 1996a, text $4=$ CMK94. 


\subsection{HOMICIDE, BLOOD MONEY AND COMPETITION}

The stipulations in the reaties indicate that such losses due to athacks and robbery could cost human lives and they therefore mention "losses" and "bloodshed" together, a realistic combination as shown by various letters. $\mathrm{K}+87 / \mathrm{k} 145$ reports that "one killed a young man in Ulama and my silver and your textiles ore lost". ${ }^{883}$ When Assyrians were killed one demanded the payment of "blood money" (damü) and the attempts to obtain it and ensuing complications are the subject of several letters. Collection of the money could entail expenses, which somehow had to be paid for, 884 and some records show that its collection (and division?) were the subject of judicial decisions. $\mathrm{K}+\mathrm{b} / \mathrm{k} 162$ and $180^{885}$ deal with the blood money for a certain Ennamayya. In the first the City allows his father to send an artorney to Kanesh in connection with this money and the second states that a certain $\mathrm{S}$. has now collecled the money in the name of the father. According to Kayseri 1830 (CMK 59) representatives of the wabartum of Kušs̆ara tell the palace in Luhusaddia: "Two Assyrians have been killed in your country" and demand satisfaction, but the ruler proved unable to identify and catch the offenders. $K \uparrow 94 / k$ 937 (courtesy Larsen) is a report of a man who "accompanied your (the kärum's?) messengers in order to search for the blood money of my brother", which results in an (unsatistactory?) meeting with the ruler of Tawinia, who was told to get the money. ${ }^{880}$ The decision of the kärum, k! 94/k 1454, that nobody shall set a foot "beyond Tawinia" until the blood money for the man had been obtained, must deal with the same affair.

The trealy stipulations $C b, D c$ and El demand extradition of the murderers (plural in $C: 9$ and $E$ $\mathrm{N}: 19^{\prime}$, singular in $D: 44$, ) and the right of the Assyrians to kill them, but only $D$ and $E$ mention Financial compensation. E. II [IV]:18' uses the terminology allested in letters (damé kasōódum). but D:43 speaks of "giving us simtum for the bloodshed". Simtum means "fixed amount", especially the capital (borrowed) as distinguished from the interest on it (see also D:71), and this suggests that there moy have been a fixed financial compensation when a man was killed, but we do not know how much it was. Comparison ${ }^{887}$ is difficult, because the money paid in $D$ and $E$ is not a substitution for life, a ransom, but a fine in addition to the death sentence.

883 Hecker 1996a, 143, note 13. See olso CMK 37:26ff.

884 According to KTH 16 the wabartum of Soladuwar seized some textiles and tin of a trader, apparenily as compensation for its efforts to oblain the blood money (dame kosadum) paid for the writer's brother, but he contests it and wants to oppeal to the korrum to get his merchondise back. $\mathrm{Ki} \mathrm{b} / \mathrm{k} 258$ is a debt-nole for an amount of $11 / 3$ mina of silver owed to a kärum. described as "expenses for (collecting) the bloood money which Z. (Anatolian name) paid for Ennum-Assuur".

885 Cecen 1998. The end of $k t b / k 180$ is difficult, because da-me so PN i-si-qi-ils does not make sense.

880 Line 8, [dam] $e^{-2}$ sa awilim se-e (se 'ä' um has the double meaning of "to search" and "to sue for") There were complications, because the man was killed for the silver earned by trading iron that belonged to another trader, and the kärum told the latter to search for the money "since a man has been killed because of your iron".

887 Compare the stipulation in $\S 48$ of the Laws of Eshnumna, that cases involving a tine ranging belween 20 and 60 of silver will be deall with by the judges, but that "copital coses are for the king", which suggests that the fine for killing somebody - if silver could substitute for life - was more than one mina of silver. 
Since these cases ploy in Anatolia, one might look at Anatolian legal custom, the penalties for breach of contract stipulated in Anatolian records, especially those notarized by the rulers. Those compared in Balkan 1955, 45f., all three stipulate a fine of five minas of silver and/or $\langle u\}$ capital punishment. If these penalties are not meant as deterrents and if the copula $v$ is taken as "or", we may see them as alternatives, which would imply that the price paid for one's life was five pounds of silver. Compare also ARM 8, 1, where the penally for who contests a hereditary adoption is $31 / 3$ pounds of silver, called "silver of a case involving life/a capital crime" (kasap din napistim).

Killing the murderers, irrespective of the financial compensation obtained, was an act of blood-revenge, in the texts of the treaties with a plural subject, "we". This fits the style of the treaties - "we" versus "you" - and does not exclude that the culprits were executed by the victim's nearest kin, but we have not textual evidence to prove it and we cannot even exclude that the loss of life could be compensated by paying a sum of silver.

A surprising stipulation is $\mathrm{Cc}$, which forbids the unknown ruler to attract Akkadian traders, rivals of the Assyrians, and makes him promise to extradite them, so that the Assyrians can kill ihem. This is a ruthless way to exercise a monopoly, enforced with the help of "clients", which we had not expected from the commercially minded Assyrians. One wonders which "Akkadians" the text had in mind during the level II period, traders from Eshnunna or perhaps Babylonian ones, who tried to penetrate into Anatolia along the Euphrates, by way of Karkemish? Perhaps this stipulation was conditioned by the location of the town, in the border area ${ }^{888}$ where one entered Anatolia, because the treaty as such is focused on the transit of caravans. From level II texts we know nothing about such measures and nothing similar seems to be stipulated in the later treaties, when the influence of Assur was anyhow smaller.

\subsection{TaXation and purchase by the Anatolian authorties}

\subsubsection{Textiles}

The basic rules formulated under Aa-b, which took care of the interests of the local rulers and rewarded them for what they granted under Ad-f, in general seem to have worked well, although the palace did not always buy the ten percent to which it was entitled and occasionally "seized" additional textiles ${ }^{889}$ or tried to gain other advantages. ${ }^{890}$ The

888 See above, chapter IV.6 on Talhat and the Euphrates as a border.

889 Note kt $\mathrm{g} / \mathrm{k}$ 190:13F., "20 rextiles have been seized in the palace".

890 There is an interesting, damaged account of an altempt by the king of Hurama to extend his prerogatives, in $k \mathrm{~m} / \mathrm{k} 134$ (courtesy Hecker;, a letter of kärum Hurama to kāum Kanesh. The king is said to have "given" an cath, perhaps a proposal for a treaty offered to the local kārum, and kārum Hurama exptains that "the king will take 10 iextiles from your textiles and one will search the bags (with textiles)", apporenty in order to check the numbers or to select the best pieces. Kãnum Hurama refuses to act accordingly and writes to kärum Kanesh, "you are our fathers and lords, it is up to you over there!". 
rules fixed in Ce-f are of a different nature in stipulating a modest transit fee and not the substantial taxes levied for clearance in the cily-stale where the goods would be sold. The question to what extent these rules were still in force during level $\mathrm{lb}$ is difficult to answer, because $D$ and $E$ are damaged and we lack from this period the typical "caravan records" which describe how merchandise entered the palace and it took what it was entitled to. It is important to note that laqo um. "to take, collect", is used for what the ruler is entitled to by agreement [see E I [II]: '9'ff.], while sabätum, "to seize", means a one-sided action, which may amount to confiscation. ${ }^{891}$ The contents of $\mathrm{Bb}$ are too damaged to yield much, 892 but they show that the ruler of Apum "receives" something (perhaps as a giff; maharum). The next lines mention what he will take (laqa' um in line $\left.6^{\text {? }}\right)$ "per donkey [...]", but the mention of copper is unexpected. The nishatum (13) is levied from [merchandise?] in the kärum, perhaps [when it is sold] "in your city and in your land", and the next line may slale that its rate was the same as that for his father, an interpretation in line with C:17.

The clearest statement is in Dh, where the ruler "takes" ten percent of the imported parakannulextiles as nishatu-tax, while for additional textiles "seized" outside the palace, at the city gate, ${ }^{893}$ the full price will be paid. Ten percent is more than the rate during level II (when the tax on textiles was five percent), but the ten percent ("ithe", israfum) that the palace could buy during that period is not mentioned here, though lines $21 f$. speak of the few textiles which he can buy $\left(21\right.$, ana $\overline{s i}[\mathrm{mim}]$ loqa $\left.{ }^{3} u \mathrm{~m}^{2}\right)$ for silver (price not presenved) "after you have taken the nishatum you are entitled to". What the ruler could take as nishatum must have been mentioned in the part ending with line 13, to which lines 14-18 add that specific textiles, which the ruler desires for his own wardrobe, hove to bought at the normal price ${ }^{894} \mathrm{~Eb}$ lists how many textiles (no specifications) the main dignitaries of Hahhum can "take" and at what price, and since the prices listed were lower than normal (with the greatest reduction for the "minister of exporn"), this must be a survival of the just mentioned "tithe" of level II. The damaged continuation of this passage $\left(E[I] \mathrm{III}: 13^{\prime} \mathrm{ff}\right.$. seerns to stipulate that addifional textiles ${ }^{895}$ can or cannot be taken as nishatum and the end states how many shekels of silver apiece the "minister of expor" has to pay for them.

\subsubsection{Metals and lapis lazuli}

Db does not mention tin, unless it occurred in lines $9 f f .$, logether with the basic rules for the tox on textiles, which is unlikely, also for reasons of space. Tin occurs in EF, which must deal with caravans traveling to Anotolia, but as mentioned above, the passage is very damaged

891 Even stronger is ina emügé elárum, "to take owoy by force", in D:17, 671 ., compore ina emüqé sabātum in D:85.

892 Eidem's reading to $/[a-5 a-q] \dot{o}-a /(11: 9)$ is dubious land GA uncertain), since one expects the opposite of line 4 (nomahhar, e.g. that the ruler of Apum shall not toke/get something (perhaps talabbal? .

893 The passive form, issabbat, indicales that this was done by other people than the palace.

894 And not ana simim bataim.

895 The beginning of '4' might hove read [i e-TUG] abomeim. 
and it is not clear where the paragraph on tin begins and whether it had to be bought by the Anatolians or was an (obligatory) gift to them.

During level II there are no rules on how much tin a palace could buy and al what price, since the basic rule was that it would receive ca. 3 percent of the loads as nishatu-tax. This makes it likely that line 21 ' still deals with textiles, in which case the tin of 22 'ff. would be a giff. The disappearance during level lb of a nishatu-tax on tin - it was still imported, but presumably in smaller quantilies, see Dercksen 200la, 65 - could have been compensared by a gift or transit-fee (as in C:18ff.), or by the right to purchase it at a favorable price, as was stipulated for textiles in Eb. The choice is difficult, but I prefer the idea of a gift, because in cose of purchase the amount bought should have been a round figure and not "[ $x$ shekels and 1$] 5$ grains of tin" (III:24'), while also the lack of a distributive TA excludes a price (in silver).

The damaged paragraph Db mentions the trade in lapis lazuli and iron Lašium, also called amütum), 896 both of which were obtained in Assur from the Ciry Hall, while Assyrian traders also managed to acquire and sell iron inside Anatolia, where this expensive metal was much in demand. ${ }^{897}$ The stipulations on lapis lazuli (which may have been comparable to those on iron) have not been preserved, but for iron they are that when Assyrian traders offer it for sale, they only have to sell it if they consider the price offered satisfactory. If not, they should be free to take it elsewhere, without interference by the palace. The protection thus assured was not superfluous, since a variety of lexts show how eager palaces and local dignitaries were to acquire it and how they could exert pressure to sell it. It could fetch a very high price, but with considerable variation due to the shape and especially the quality (purety) of this meteoric iron (see above 11.2.3.4). Itlustrative is BIN 4, 45:7ff., "Here the generals (rabi sikkitim) of Ušša and Hudurut keep pressuring me, saying: "Send us a message if there is somewhere iron available, so that $\mathrm{I}$. and $\breve{S}$. can collect it ..., but I have not given them my word for the iron. If you have in mind to send iron, the kärum here must not get knowledge of it!" 898 And in kr 94/k 1461:16ff. (courtesy Larsen) a trader writes that he is afraid to enter Burušhaddum "because of the iron, which you promised to the "minister of export" (mussium), but did not send, while you did nothing to appease him". ${ }^{999}$ We may assume that the situation during the level lb period was not essentially different, which made this stipulation necessary, and it may have been part of the treaty with Hahhum too.

896 See for lapis lazuli, Michel 200la, and for both Veenhof 2003d, $99 \mathrm{f}$; the trade in iron deserves a special investigation, which I hope to present in a forthcoming article.

897 Note the references in chapter VI.1.2.3, under rabi sikkitim, several of which mention that he still had to poy for the iron he bought. $k+89 / k 231$ (courtesy Kawasaki) reports that an amount of no less than 123 shekels of iron, belonging to a group of traders, was sold for silver.

898 Apparently because the generals are ready to pay silver and gold, and perhaps also because the rade in iron was taxed by the Assyrian authorities. See Veenhof 2003d, 102.

899 Fear is also expressed in ICK 1, 46:57f., "When you informed the palace about the iron, our father became afraid for himself", a letter which belongs to a small dossier on the fortunes of a parnership, with a capital of no less than twenty minas of silver, founded in order to acquire iron inside Anatolia. It was analyzed by Londsberger 1950, 33iff. 
Ej stipulates what the dignitaries of Hahhum may acquire from caravans on the way to Assur that carny silver and gold. Gold was valued everywhere, we meet it regularly as a gift to rulers and the dignitaries here are granted the right to buy it from the Assyrians at favorable prices, below those current in Assur. The fact that gold could be bought was already a prerogative, since Assur was very concerned about acquiring and keeping it, presumably for commercial reasons. This is clear from a remarkable verdict of the City Assembly, which became a law and forbade Assyrian traders to sell it to Akkadians, Amorites and Subaraeans, on penalty of death. 900 We do not know whether this Assyrian policy continued during the level lb period, but Hahhum, as a South-Anatolian city probably was not affected by this interdiction, which would have harmed commercial activity there.

\subsection{The obilgations of the Assyrians}

The redaction of the rreaties is one-sided, spelling out only the obligations and rights of the Anatolian rulers, while what the Assyrians had to do is only implied. They had to bring the imported merchandise into the palaces for clearance, so that thee latter could levy the tax and decide what they wanted to buy. Assyrian traders might try to dodge these obligations, perhaps by using special routes, the so-called "sukinnu-route", certainly by smuggling (pazzurum) their wares into the cities, a subject I Ireated long ago. 901

It is doubfful whether "sukinnu-route" refers to a specific road, between two cities, identifiable on a map, but it seems clear that it refers to routes which evaded towns with their tolls (see BIN 4, 48:16ff. = CMK 176), but probably did not provide the protection to which caravans were entitled on the "official" roads. They were no "narrow tracks" suited only for individual merchants with a few donkeys, for two letters show that caravans of no less than thirty donkeys used them. ${ }^{902}$ Their use was by no means rare and there are several cases where they were an aliernative to "smuggling", 903 but they were not always considered "appropriate, feasible" (natum), which probably means they were at limes forbidden or too risky. The attitude of the Assyrian authorities concerning the use of this route is not clear. A letter of kärum Wahšušana to kärum Kanesh ${ }^{904}$ apparently takes its use for granted and only states that traders using it are thereby not exempl from paying the saddu'utu-tax due to kärum Kanesh. But a letter of Assur's ruler, kt

900 See Veenhof 1995a, 1733, and Dercksen 2004a, 81, on the importance of gold.

901 AOAT ch. XIV-XVI. Note also kt 94/k 503:14f., "Smuggle Akkadian textiles, if it is not feasible, let them enter the palace with the carovan".

$902 \mathrm{~K}+92 / \mathrm{k} 200: 2$ ff. (CMK 22) and ki 94/k 705:30f.

903 And note kt 94/k 1164:35f., "Why is it that A. let my smuggled goods (pazzumi) behind in Hahhum? Let one bring my smuggled goods in via the sukinnuroure". Tronsporting merchandise in this way, according to kt 94/k 441, was an alternative "if you hove not caught up with PN's carovan".

904 Günbottl 1998 no. 3 = CMK 43, cf. CMK 22, which translates "le chemin détourne", 
$91 / \mathrm{k} 100$ (quoted in notes 857 and 862 ) and the letter Chantre $11^{905}$ probably advised to be careful or to stop its use. The letter $k t 94 / k 786$ states, in reaction to repeated requests to use this route, that the orders of the palace are strict (awatum dannō) and that "one has seized the son of $A$. on the sukinnu-route and that he is in detention until the very day". To this the related letter $\mathrm{kt}$ 94/k 1004:17ff. adds: "Over there the orders of the karrum and of the palace a strict, therefore we will not import the merchandise there". 900 . This shows that its use was checked and could be forbidden, and that in this particular case the local karum and the paloce were united in their efforts to prevent its use.

Smuggling and the use of the sukinnu-route were private actions, which entailed risks foffenders could end up in jail and have to be ransomed) and were not appreciated by the Assyrian authorities, since they infringed upon what had been promised. As far as I can see the Anatolian palaces did not blame the kärum arganization as such for these actions and were content to punish the offenders. While the Assyrian authorities wished to prevent the use of the sukinnu-route in cerlain situations, the stance of the karrum Kanesh on smuggling is clear: "Nobody shall smuggle tin or textiles, the caravan which does smuggle, the order of the kārum will catch it!" (kt a/k 1055).907 This was also known to the traders, as CTMMA 1, 72:28ff. stoles:

"The ruling of the kārum is firm, your plan to smuggle, about which you wrote to us, is not feasible, so we will not write ladvise/ you about your smuggling. It is entirely up to you, do not go by your colleagues. Beware!"

This appeal wished to prevent negative reactions of the local rulers, such as the sharpening of the controls (massāoratum donnā), described in the letter ATHE 62:28ff. (CMK 207), which must have made commercial traffic more difficult. How serious the rulers took such practices becomes clear from the letter $\mathrm{kl} 94 / \mathrm{k}$ 1692:4ff., which mentions an ukase of a king and queen about "the smuggle roads" (or: trips, harrānätum s̆a pazzuntim): "Seize those who carry textiles, copper and tin in the land ... and detain the tin and the textiles". They also wrote on "those involved with the sukinnu-route", which makes the writer of this letter ask "Please, do not smuggle tin and textiles and put nothing on the sukinnu-route. Please, the orders are strict!"

\subsection{DeVELOPMENTS AND DIFFERENCES}

In trying to understand the stipulations and their background I have consistently drawn on textual sources from level II, which in various cases provide good illustrations for what the new treaties state or imply. Nevertheless, there are differences between the periods of level

905 See Larsen 1976, 248f., with note 3. Kärum Zalpa tells that it has received a letter from the Ciry "That the sukinnu-route [........], anybody [who ......]", which looks like an order not to use it.

900 This links up with kt 94/k 808:10f. and 33f., "As for the sukinnu-roule, as I hear the orders are strict .... if you see that the sukinnu-route is not given free ... ." (wašsurat)

907 Quoted in Bolkan 1974, 29 note 2. 
It and $\mathrm{lb}$, and the two cities involved, Kanesh and Hahhum, were also different, not only becouse the latter seems to have lost its king and was ruled by an oligarchy, but also due to their location and strategic importance. The purely geographical aspect is clear from what the Hahhum treaty stipulates in Ed in connection with the crossing of the Euphrates, and it may also explain why the Kanesh treaty does not speak about the acquisition of gold by its ruler and about transit fees, since the carcvans returning to Assur starled out from there. Apum (B) presumably played a different role as road station and was much closer to Assur. The mention of a possible war with Hahhum's main neighbours, Batna and Timilkia, is matched by Dk, where there is hardly room for the names of possible enemies and the statement "you are at war" may have sufficed. Cf provides a good parallel by simply mentioning "hostilities". Why the Hahhum treaty is much longer and more detailed (even though we have only half of its text) than $D$ is unknown. Since treaties existed during the level II period, we may assume that there was a continuity, which may also explain the difference in the sequence of the items treated in $D$ and $E$. Since the treaty texts take the characteristics of each town into consideration (also in C, which was only a road station), the history of their relations with the Assyrians may also have played a role, but we have too few data to prove this.

As for the differences between level II and $\mathrm{lb}$, it seems clear that the role of tin has diminished and this may explain why (unless the missing parts of $E$ were to prove me wrong) the basic rules of the nishatu-tax of two kilograms per donkey-load are not mentioned. As concerns the lextiles, the rulers can still acquire them as nishatu-tax (Da), but there are additional stipulations about the possibility to buy selected textiles at favorable prices, which seem to be a continuation of the right of pre-emption that was standard during the level II period. While these stipulations mention the well-known types of imported textiles (kutanum, abarnium, kusitum, raqgatum and makühum). Dh in a short passage mention the ruler's right to obtain parakannu-textiles as nishatu-tax and the rate of ten percent is twice that current during level II. Parakannu' were Anatolian woolen products, cheaper than those which the Assyrians imported, but not without quality. ${ }^{908}$ At some moment during level H the City Assembly issued a verdict and formulated a rule that forbade Assyrians to deal in saptinnu- and pirikannu-textiles and penalized "many people", 909 probably a measure to protect the import trade and/or the local Assyrian textile production, but it did not prevent Assyrians from continuing to trade them. The more surprising it is to find that trade in these

908 See for pol iro/ ikannu-textiles, $A O A \Pi 124 \mathrm{ff}$. There are now many additional references, $\mathrm{K}, 94 / \mathrm{k}$ 1675:21, speaks of the purchose of "sot and tine" (norbum, wosmum) specimens, kt $94 / \mathrm{k} \mathrm{364:17}$ mentions "extro fine" $p ., \mathrm{kt} / \mathrm{k}$ 518:94f. $p$. of the land Hahhum, TC 1, 43:3f. p. of Mammo, and $\mathrm{kt} 89 / \mathrm{k} 421: 4$ records a number of no less than $209 p$. Purchase of and trade in $p$. is mentioned o. o. in kl 94/k 443: 12 (29 p.), 403 (2) p.). 1124:10f. (03 p. at 7 minas of copper apiece), 1302 (105 shekels of silver for 90 soft $p$., or a litlle less than 2 shekels apiece), 1457:12 (44 p.), $1674: 10(114 \mathrm{p}$.). See for trade in these textiles also the damoged leter CCT 0. 38b.

909 VS 26, 9:30ff., latest treatment in Veenhol 2003d, 891., a clear example of protecting the local rextile industry and trade, of which another example was analyzed ibiderm 9lff. 
products according to Dh is an accepted fact and is integraled into the text of the lreaty with Kanesh. But its strange place, between a stipulation about the protection of the possessions of the Assyrians and that about fugitive debtors (Dg and i) may suggest that it was a later addition. The mention of these textiles implies that the Assyrians traded in them during the level Ib period, but thus far the evidence for this, alongside new types of textiles (kušsatum and saqqum) that turn up now, is rather poor. 910

Another feature which gets remarkably much attention is the protection of indebted Assyrians, who have to salisfy their creditors with pledges, whose possesions can be seized and whose dependents can come into the power of Anatolian creditors. During level II there are also cases where Assyrians were indebted to Anatolians and occasionally Assyrians may take out a loan with Anatolians, ${ }^{911}$ but they were exceptions and it is only during the level lb period that we read (in KBo 9, 5:11f.) "I paid I mina and 1/2 shekel of silver in Kanesh to the native Anatolian and so got you oul of his housen. This shows, as pointed out by Dercksen 200la, 66, that during level lb Assyrians were economically weaker and more often indebted and the treaty stipulations reflect this new situation, which requires protective measures.

The stipulations which have to protect the Assyrians from summonses to perform services for the local ruler and from decrees which demand the manumission of slaves (Di) are also new features and I believe that it is extremely unlikely that during the level II period the possibility of conscripting Assyrians for service was even considered. The Assyrians in that same period owned Anarolian slaves, bought as chattel slaves or acquired when Anatolian debtors defaulted and persons entered into debt-servitude. But, while we have evidence that the local ruler of Kanesh could "wash the debts away" (Balkan 1974) and there even is an unpublished debt-note, which in this connection uses the term addurarum, there is no indication that this might affect Assyrians. I consider the many, often detailed new stipulations meant to protect the Assyrians, which may well have been inspired by painful experiences, indications that the position of the Assyrion traders had become weaker. They were still traders who imported goods and administratively ranged under their own kārum and City, but they were present in smaller numbers, with less economic power and more involved in inner-Anatolian commercial activities. This made them more vulnerable for demands and measures of the al times powerful local rulers, such as the "grear king" of Kanesh mentioned in $D: 90$.

The treaties show that the Assyrians successfully tried to conclude agreements with the Anatolian rulers, which offered them economic and legal protection, because their trading activities, both as importers and as traders active inside Anatolia and between the various

See Dercksen 200la, 64

911 AKT 2, 53:20ff., "Make S. pay the silver and if he refuses tell him: 'I will borrow it at interest in the house of an Anatolian!'". In kt k/k 78:7ff. an Assyrian, summoned to make silver available, answers "(IFI do it) the Anatolian might take away my house!", whereupon his opponent reproaches him for not hoving mentioned earlier that he was indebled to that man. In kt m/k 69:42f. an Assyrian has to confess that "he entered the house of an Anatolian and borrowed there two pounds of silver for the burial of his father". 
ciry-states, made them valuable for the local rulers and economy. The oaths sworn by their own gods, who would watch (dagalum, D:89) (and punish) their Anatolian partners if they did not keep what they had promised, must have convinced the Assyrians that the agreements would work. 


\title{
VI. ANATOLIAN TITLES, OFFICIALS AND PAYMENT TERMS
}

\author{
1. ANatOLIAN TITLES AND OFFICLALS 912
}

\section{1. TITLES OF THE TYPE RABI + NOUN IN THE GENITIVE}

The texts acquaint us which a great variely of titles and professional designations, which show that Anatolian towns and palaces, in particular those of the capitals, were well organized under an administrative hierarchy. In many cases, in particular for the more important officials, we have little more than titles (like "second in command", sinahilum, "head of the stairway", rabi simmitfim, "head of the market", rabi mahiriml, which tell us little about their status and competence, and for most professional designations we lack a meaningful context to give us concrete information about their tasks and affiliation. The reason is that most of them occur as witnesses in Anatolion legal documents, in particular from the level lb period, or as persons who were involved in or supervised transactions in the sphere of debts, sale and family law, and it is often difficult to make out wherher they figure as private persons or ex officio. During the level II period many are mentioned in letters, when Assyrians report on their trips, transactions and commercial contacts, others occur in lists, usually as clients and debtors of the Assyrians or as members of the palace administration. More information is supplied by letters which report on problems and confrontations with a number of high officials (especially the rabi simmilitim and rabi sikkitim), but in many cases it remains unclear to which towns they belong, unless the find-spots of the texts are known, as is e. $\mathrm{g}$. the case with $\mathrm{kt} s / 192$, found on the cily-mound of Kanesh. ${ }^{913}$ As examples of lists, which register many Anatolians as clients, presumably debtors, I mention BIN 6, 193; CCT 5, 34b; CCT 6, 34a; KTS 1, 58a; TC 3, 191.914

In what follows I present the titles of dignitaries and other officials in list form, and the first list contains titles of the rype rabi + noun in the genitive. The second list gives a number of lifles without robi, whose bearers seem to have had administrative functions, and it includes occurrences where a title holder is said to "belong to" ( 50$)$ an other, higher official or to be from a particular town. ${ }^{915}$

912 See for earlier literature Garelli 1963, 216ff., Veenhof 1982, 160 note 42, Donbaz 1996b, $236 \mathrm{ff}$, and Hecker 2003, 184 note 4.

913 See for this rext Özgüc 1986, pl. 62.1, and Donbaz 1993a, 131f. note 9.

914 See for these texts Ulshöfer 1995 nos 310,320,328,350, and 370, and for CCT 6,34 a also above chapter II.2.3.5.

915 Several additional titles of this type, found in text editions and listings, connot be accepted:

* rabi dajjäle, kt n/k 1429:9 (so Ceçen 1995, no. 8), read iši Galdāya IGI Hada[......];

"robi eriqqătim, "chief of the wagons", BIN 6, 258:8, wrong, see Dercksen 1996 note 207;

"rabi siparrim, "chief of bronze", KUG 25:11, read GAL ZABAR, "bronze cup";

"rabi betim, KUG 25: 13, "majordomus", read: sa! 12 11/3 mana kaspim ša-wi-ru, "bracelets". 
In many cases, especially when applied to a witness in an Anatolian record, 910 the tifle alone was considered sufficient to identify its bearer, who remains anonymous. Others add names, but only a limited number of references sheds some light on their office and activities, in particular those of the rabi huršatim, mahirim, sikkitim, and simmiltim. The litles composed with rabi are usually of wo kinds, depending on the meaning of the added noun. If it refers to an impersonal item, the title identifies the official is "the head of, in charge of ..." certain goods, facilities or places, In such cases the noun can be both in the singular \{rabi mahirim) and in the plural (rabi esset). When the following noun refers to persons we consider the title bearer their chief ("upper ..."), the head of a group of professionals (rabi

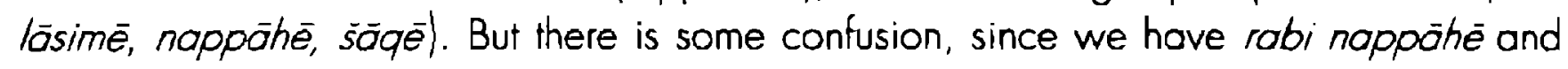

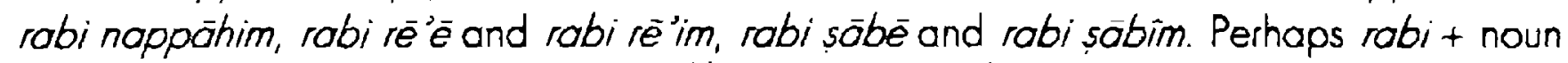
was conceived as a compound noun ("rabnappāhum?), which as such (especially aher $\mathrm{Gl} /$ mahar, "in the presence of", when the title bearer figures as witness) received a genitive ending. But we may also think of scribal mistakes, in particular if the title occurs in purely Anatolian records.

\begin{tabular}{|c|c|c|}
\hline rabi & meaning & references and literature \\
\hline abullätim & chief of gates & $k+g / 142+z / \uparrow 11: 8 ; k+d / k 9 a: 1$ \\
\hline adrim & $\begin{array}{l}\text { chief of the } \\
\text { threshing floor }\end{array}$ & $\begin{array}{l}\text { RA } 58 \text { (1964) 130:3; CCT 6, 34a rev:7, owes copper; } \\
\text { kt k/k 31:3, Śariša rabi säbim ša r. a. }\end{array}$ \\
\hline \multirow[t]{4}{*}{ allahhinnim } & chief steward & El 188:7, r. a. sa robi sikkitim, \\
\hline & & TC 3, 181:2, allahhinnum GAl (owes wheat); \\
\hline & & BIN $0,00: 33$ (has to give silver). \\
\hline & & See below on simple allahhinnum. \\
\hline olpōtim & chief of oxen & EL 219:21, Kulakula (hardly [ $k$ albätim). \\
\hline ar - [ ] & chief of ... & kt $89 /$ k 376:5, Hasui rabi ar-x-[...]. \\
\hline aślakē & chief of the fullers & $\begin{array}{l}\text { kt } 93 / \mathrm{k} 50 \mathrm{l}: 2 \mathrm{ff} \text {. (courtesy Michel), PN śăpirum robi aslakē } \\
\text { so rubótim. }\end{array}$ \\
\hline awilè & chief of men & k+ 87/k 39:27f., Tam(u)ria, witness. \\
\hline \multirow[t]{4}{*}{$B A-t e-e^{?}$} & chief of ...? & $\mathrm{kt} \mathrm{s} / \mathrm{l}$ rev. $: 5 ?$ \\
\hline & & Donbaz 1993, 132 notes 9 and 11, reads DUMU rabi po- \\
\hline & & $r e^{\prime}-e$, but DUMU and E are doubtful (see photo in T. Özgüc \\
\hline & & $\begin{array}{l}\text { 1986, pl. 61, la-cl; read probably rabi kalbatim, see be- } \\
\text { low s.v. }\end{array}$ \\
\hline betim & majordomus & kt $n / k$ 1888, Aše'ed. \\
\hline$b i_{4}-l a-t i$ & chief of ...? & kt 73/k 12:3 (Özgüc 1986, pl. 01,2) \\
\hline esssē & chief of the wood & $\begin{array}{l}\text { EL 219:18, Haršo r. essēe, reading based on MAH 19616:8 } \\
\text { (RA 59 [1965] 47, nr. 22), Halgias̀u [x] šo GIŚ.HI.A. }\end{array}$ \\
\hline
\end{tabular}

910 Dercksen 2004b, 151 note 36, has suggested that in some coses, where a professional is identified as being (in the service) of the queen, rabi, "chief", has been omitted, see below under robi re'im, on ICK 1, 13:6f. 


\begin{tabular}{|c|c|c|}
\hline \multirow{3}{*}{$\begin{array}{l}\text { Gl-sú-um } \\
\text { hathim }\end{array}$} & chief of ... & kt n/k 31:3, Galia r. G. \\
\hline & chief scepter & KTH 36:26, debi of house of GAL ho-fim, \\
\hline & bearer917 & $\mid C K 1,46$ seal A $\mid=$ Teissier 1994, no. 221$\}+2.76-77+$ \\
\hline & & KKS 45, seal of Zatibro GAL ho-fi-im, of. Özgüc 1953a, \\
\hline & & 2400, no. 721 \\
\hline & & Cf. kt s/\$ 92 obv.: 2', PN ... [ [sa h]a-fim. Title in Mari, of. \\
\hline & & B. Lafont, NABU1988/29:3. \\
\hline
\end{tabular}

huršătim

chief of storehouses $\mathrm{kt} \mathrm{g} / \mathrm{t} 42: 25^{\prime} / / \mathrm{kt} \mathrm{g} / \mathrm{t} 36: 5 \mathrm{~F}$, persons in the service of Halgiašu r. h.;

CCT 3, 28b:12; tablet De Munck :16;

$\mathrm{k} \mathrm{m} / \mathrm{k}$ 135:17, is promised textiles;

$\mathrm{kt} 91 / \mathrm{k}$ 108:1-3, rextiles given to the $r . h$;

VS 26, 146:7, receives textiles in the remple of the weathergod; kt $89 / k$ 371:5, Kulor:Halnuwan r. $h$.

See Dercksen 1996, 69f. for storerooms of the palace mentioned in $\mathrm{kt} \mathrm{n} / \mathrm{k} 1318: 9-12$.

kakkē

chief of weopons

DTCFD 6, 50785; TC 3, 158:8, r. kó-ke;

BIN 4, 163:4, r. ka-ke-e.

Eponym 65 is identified as sa kakkē, see Veenhof 2003, 26.

kalbätim

chief of the bitches

AKT 3, 41:17f., Šipunahšuš;

Chantre 2:21k., Kulakua r. [kó]-al-ba-fim;

k† c/k 1641:17, Nawašu r. k. bēlsu ša Kuliya

Here also PN's š GAL BA-lim, kt g/ 36:8-13, M. ina ölim

Parwā, R. ina álim Zapala, P. ina ālim Wars̄ama?

See under BA-té-e.

kirānim chief of the wine $\mathrm{kt} 93 / \mathrm{k} 946$, Šmnuman (cournesy Michel).

kiriäfim

kišarānim

kittōtim

lōsimè

luksēe

mahirim chief of the gardens kt 87/k 253:1, Hištahšu, Hecker 1998a no. 8.

chief of ...?

Müller-Marzahn 2000, no. 4:21, Kapialšunuwa (see for the PN TuM 1, 17d:6) (kišarānum = kišal eršum, "jail"ê).

chief of the linens? BIN 4, 160:8, copper isti r. ki-ta-a-fim.

Cf. $A O A \pi T 152$.

chief of the runners $k 187 / \mathrm{k} 39: 20 f$., Peruwa, lord of Kikaršan.

chief of ...?

chiet of the market
ATHE 67:7, $l u-u k-\bar{s}[\hat{e}]$, see $A H w 562 a$ s.v.

CCT 2,18:35; DTCFD 6, 508 nole 94;

Aše'ed, $k+n / k$ 32:8, 34 (witness);

Duduli, kt 92/k 185:1 (witness);

Dušara, kt r/k 15:15f., 25 (his unušs̆um and arhalum, see

Dercksen 2004b, 142;

Halgiašu, wimess al slave sole, k 93/k 215b:22;

Hašu'uman, kt 89/k 383:3;

Kalua, $k+k / k 35: 1$ and $k+87 / k$ 39:22;

917 A reading Hattim, yielding "Chief of Hattum" is excluded, since Hattum is not a stake. 
massantim or massarätim

müṣe

noppōhē

niqe

nuk(i)ribbe

pašsūure

perdim

qaqqidē chief of the guards

chief of ...

chief of heralds?

chief of offerings

chief gardener

chief of tables,

chief of the mule(s)

chief of ...
Panwaliuman, $k t k / k$ 10:15f. (receives some silver at the sole of a house):

Wašhubo, TC 3, 253:1; BIN 6, 2268:15; CCT 5, 260:2 (witness to sale of pigs). See AOAT 394f., with nole 519.

Anonymous: BIN 6, 235:3*; kt m/k 132:2;

$\mathrm{kl} \mathrm{c} / \mathrm{k} 99: 6$, took textiles in obsence of ruler;

$k t 87 / k 447: 5,23$, alllahhinnum and $r . m$. in Ušša approached for debt at palace gate;

C 5:9f., Nakile'ed; EL 223:6', [PN];

BIN 4, 160:5, Sulia.

Cf. Atana ša mossarälim, kt k/k 91 :19; Zuba ša mossaräfim. kı 87/k 274:2; anonymous, KUG 24:13.

CCT l, 38c:0, grain bet r. m.;

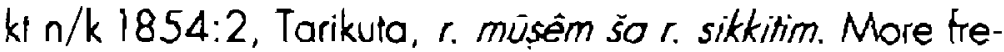
quent is müsium alone, see CADM/II 249f., mùsû́ $B$, "official", see note 829 .

TC 3, 214B:2f., Elali;

$\mathrm{kt} \mathrm{n/k} 31: 5$ and $k+99 \mathrm{k} / 128 \mathrm{~A}: 2$, Peruwa:

kt n/k 32:1, 33, Happuala;

kt 89/k 379:1f., Wališra [GAL n]a-ki-re.

chief of blacksmiths TC 3, 254:1 and kt 94/k 158:18, Kurō;

$\mathrm{kt} 89 / \mathrm{k}$ 193:0, anonymous r. noppähim;

Cf. $\mathrm{kt} \mathrm{g} / \mathrm{t}$ 36:27, 2 nappōhü ina Kanis,

kt 94/k 208:26ff., silver for nappōhum "who forged amütum in the polace".

kt 99/k 138A:4, Kammalia.

ICK 1, 111:10, debt of 4 minas of silver;

$k t \mathrm{p} / \mathrm{k} 5+6: 11$, r. nu-uk-ri-bi

Prog I 610:10, anonymous;

89/k 367:24f., Hadiani. 918

EL 219:191., Šulia;

TPAK 1, 205:7, Tarikuda so r. p., but in $\mathrm{kt} \mathrm{m} / \mathrm{k} 35: 40$ he is called sol.GIS;

$\mathrm{kt} \mathrm{m} / \mathrm{k} S \mathrm{rev} .2$, Kario r. p. sa rubāim,

$\mathrm{kt} \mathrm{n} / \mathrm{k}$ 533:0, Zuba, delivers copper;

See below $\S 1.2 .4$, for persons so pašsure.

kt 87/k 320:14, owes a debr;

kt 94/k 1226:5, textiles sold to him.

kt i/k 025:4t., Pithana [r.] q. (Donbaz 1989a, 84).

$918 \mathrm{Cf}$. nukiribbum in OIP 27, 10:25, inümi Bu $\times \times$ nu-ki-ri- $/$ ba- $\sigma m]$ nissiv; kt 73/k 14 rev.:12, 2 nukiribbe:; Prag I 625:4. 


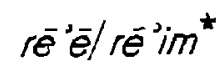

sikka/ itim

simmiltim

$\operatorname{sise}$

șābē/șābim * chief of herdsmen $\quad k \mathrm{~g} / \uparrow 42+: 10$, men sa $r .[r e-i]$-e-ern in Kanesh;

$\mathrm{kt} \mathrm{g} / \mathrm{h} 42+: 26 f$., sa r. r. ina alim Kasena;

CCT I, 4lb:5; kt 88/k 990, and kt 88/k 1063:4, all Peruwa; kt 94/k 1527:14, Hašui;

BIN 6, 193:5', anonymous.

kf 93/k. 501:5, allahhinnum sa r. r. *

Dercksen (2004b, 151 nore 36) rakes Happuala re-i-um sa rubätim in ICK 1, 13: of. as short for rabi rēè.

chief of the ... See below, \& 1.2.3.

chief of the stainway

Passim in notarizations, see chapter IV, 2.5.1.

$k t b / k$ 95:17, should receive a gift to save the lives of some (Assyrian) men;

$\mathrm{kt} \mathrm{g} / \mathrm{t} 36: 28 \mathrm{f}$., Turupani, personnel of him;

kt $89 / \mathrm{k} 317: 4$, look price of house ișer PNs;

kt 89/k 353, Kura, sells family to Assyrian;

kt 94/k 208:7, buys expensive textile;

$\mathrm{kt} 91 / \mathrm{k} 282: 8$, tuzinnum šo r. 5.;

Müller-Marzahn 2000, no. 4, house bought iqqärēe r. s. (see chapter N.2.5.1, no. 20);

$\mathrm{kt} 94 / \mathrm{k}$ 1495, payment of silver to a r. s.;

TPAK 45:6f., $70 \mathrm{~m}$. of copper so betr. s;

KTK 106:23, witness of a debt arrangement;

EL 273, boycol of r. s. who does not pay;

$k+b / k$ 95:17, to be approached with a gift;

TC 3, 254:2; kt a/k 805:2, brothers of r. s.;

OIP 27, 5:12, rubātum + r. s. of Šalahšuwa approached because of hapiru-prisoners.

chief of horses $\mathrm{KTH} 35: 2$, betr. s.;

wife of r. 5., BIN 4, 2:24; 38: 27; CCT 2, 30:14;

TC 3, 15:21; A 22181 (Siudies Veenhof 139): 10.

ATHE 12:1,8,10, Tarmano, buys slave;

TC 3, 16:14, anomymous, debtor.

CCT 2, 30:10*, Happuašu (debtor);

kl 89/k 342:4,101., Wašhaniuman, belongs to the iuzinnum sa qaštim sa rabi sikkitim (14ff.);

$\mathrm{kt} \mathrm{n/k} \mathrm{32:12,} \mathrm{Bulino} \mathrm{r.} \mathrm{șābēsu} \mathrm{of} \mathrm{priest} \mathrm{Inar;}$

KKS 2la:4f., b:6, Hišlahšu" , r. șābēsū, scil. of the allahhinnum of $\mathrm{GN}$;

kt 94/k 1501, Aše'ed";

$\mathrm{kt} \mathrm{m/k} \mathrm{7:10,} \mathrm{"both} \mathrm{r.} \mathrm{s.'s"} \mathrm{will} \mathrm{give} \mathrm{silver;}$

$\mathrm{m} / \mathrm{k} 127: 3$, r. mosșarâtim and rabi sābēsu,

kt k/k 31:3, Śariša r. s.. " ša rabi adrim, witness;

$k$ t $a / k$ 852:5. Tatašmis ${ }^{*}$, owes silver for gold ( $k$ t $a / k$ 


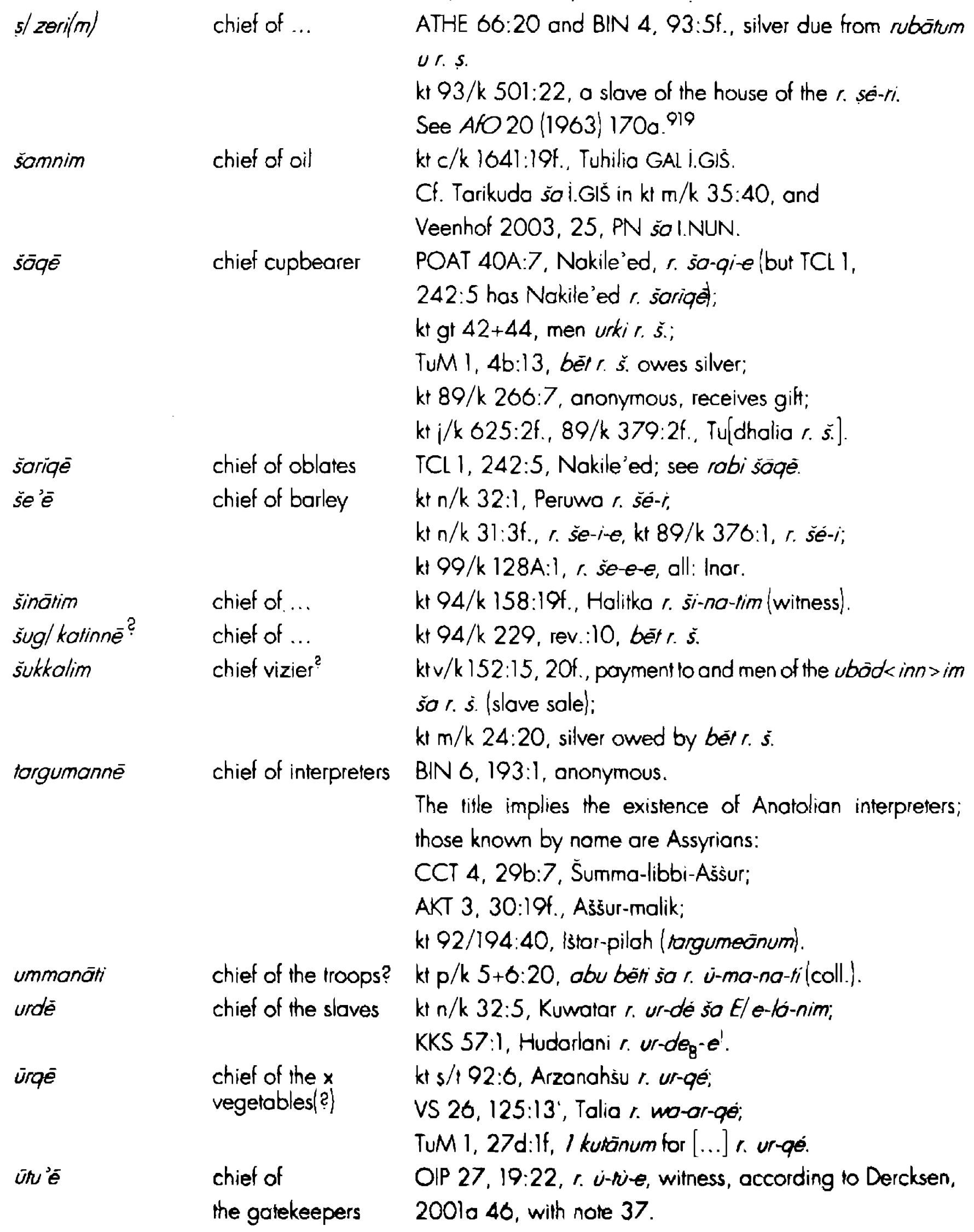

843:3f., same man = obu räbisim $\left.{ }^{2}\right)$;

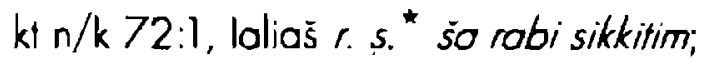

kt a/k 1263: 6, Hanu r. s. ${ }^{*}$, member of the ubädinnum of the rabi sikkitim;

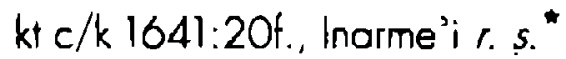

$\mathrm{kt} 93 / \mathrm{k} 501: 22$, a slave of the house of the r. se-ri.

Cf. Tarikuda sa i.GIS in $\mathrm{kt} \mathrm{m} / \mathrm{k} 35: 40$, and Veenhof 2003, 25, PN sal.NUN.

242:5 has Nakile'ed r. sariget:

kt gt $42+44$, men urki r. 5 ; ;

TuM 1, 4b:13, bëtr. s. owes silver;

k† 89/k 206:7, anonymous, receives gift;

kt i/k 625:2f., 89/k 379:2f., Tu[dhalia r. s.].

sarigè

chief of oblates

TCL1, 242:5, Nakile'ed, see robi sage.

$\mathrm{kt} \mathrm{n/k} \mathrm{31:3f.,} \mathrm{r.} \mathrm{se-i-e,} \mathrm{kt} \mathrm{89/k} \mathrm{370:1,} \mathrm{r.} \mathrm{še-i;}$

kt 99/k 128A:l, r. see-e, all: Inar.

919 The parallel ATHE 06 refutes the doubts expressed in CADS, 148 s.V. seiru A. 


\subsection{VARIOUS TITLS AND OFFICIALS}

There are many desingations of craftsmen, professionals and local officials, the latter in particular in lists of travel expenses of caravans, edited in Nashef 1987, nos. 25f., which include many small payments to local dignitaries, designated as bëlälim, bël ha-Di-tim, kăšum, massu'um, räbișum, and šappir älim. The following lists does not include those of the craftsmen etc., and I also limit myself to those in Anarolia and those which seem to have belonged to $(\dot{s} a)$ a town, an institution or an estate, or were in the service of ( $\bar{s} a$, occasionally sa urki, "follower of") a high official or even the ruler. Note that we have almost no references to officials belonging to a temple, apart from the priests (kumrum, see below chapter 1.2.4l. as we also lack information on possessions or economic activity of the temples. Some of these "offices" (designated as parsum) were granted by the ruler, at times in exchange for a present (erbum), see Veenhof 1989, 523. In the letter published there an Anatolian has paid to acquire the offices of sinahilum and allahhinnum, which also shows that cumulation of offices was possible.

\subsection{1. allahhinnum, "steward, manager"}

The allahhinnum was important official in the local economy, possibly a kind of manager or steward in the service of various magnates and instifutions, and especially of the local palaces; his role in the economy and trade has been described in Dercksen 1996, $166 f f$. The references suggest that there was presumably in most cases only one per town, apparently the reason for referring to him by his title and not mentioning his name. A rabi allahhinnim occurs in capitals, where he may have been the head of a branch of the palace economy. Rare cases where his name is given are TC 1, 87:26, Haršumnuman $a$, and $\mathrm{kt} 94 / \mathrm{k} 1512$, Sariša $a$. He is occasionally identified by mentioning the name of the town where he functioned, in Ušša (nisbe, CCT 5, 28b:5; perhaps also CCT 5, 35c:2f. ša U $<<d^{i}>>-5 a^{2}$ ), Nenašš (nisbe, kt a/k 488b:1f. ${ }^{920)}$ ), Tahadizina (kt 91/437:21), Tiwadi (kt 94/k 1504:3f.), a. saplium of Tumlia (kt 94/k 1502:3f.). Kt b/k 682b:6ff. mentions the/an allahininnum of Talhat, a city located in the western part of the Khabur Triangle.

An $a$. can be associated with a rabi sikkitim (EL 188:17), a ruler ( $\mathrm{kt} \mathrm{m} / \mathrm{k} 5: 12$, indebted for the price of a mule), a queen $(\mathrm{kt} \mathrm{m} / \mathrm{k} 35: 13$, Happuala, sa rubatim), and KKS 21: $\mathrm{a}:$ 가 $/ / \mathrm{b}: 5$ mentions persons acting for the ubadinnum of $A \bar{s}^{3} \mathrm{ed}$, the $a$. of Data'iš, followed by Hištahšu his rabi sābim. CCT 1, 33b:20 mentions silver due by the $a$. of the "Lord of the town" (sa bëlalim), and kt m/k 78:22 the "a. of the temple of Bēl Qablim". Some texts mention his "house(hold)" (bëtum\}, which fits the reference to "the gate of the a." (CCT 5, 6b:31). A group of letters of Buzāzu (CCT 2, 30; TC 3, 14 and 15) describes transactions with "the household of the $a$." and complains about the delay in the delivery of barley (CCT $2,30: 34$., cf. TC 3, 14: $20 \mathrm{ff}$. and 15:23ff.). CCT 2, 30:8ff. show that the a.'s house-

920 Letter to him by an Assyrian trader, who reminds him that he has to pay for two textiles $\breve{s a}$ lubur̆ rubä'im and lapis lazuli shipped to him by the a.'s own rädium. 
hold also comprised his brother and a chief of the personnel (rabi säbim), who also owed silver. As buyer of Assyrian goods (ex officio or for his own commercial purposes) an $a$. in CCT 2, 15:77. promises to produce one talent of silver within one month for the goods he requests. Several texts mention sale of textiles "to the household of an $a$." "Iwo textiles in Garelli-Kennedy 1960a, no. 4:27f.; Prag 1 575:11ff.; payment for textiles in barley in CCT $2,30: 3-5$ ). In BIN 4, 45:25ff. an a. buys iron (amütum), and BIN 4, 63:3 speaks of copper of "the house of the $a$. .", the payment of which is "hanging" or "suspended" (isqallalma ana sagälimma, cf. line 15, "they have not given any copper").

Since the $a$. was an important, powerful and at times also difficult customer, probably linked with the palace economy, one had to keep him a friend by gifts and invitations (BIN 4, 157: 29ff., see CAD B s.v. bušalu). Since he could be slow in poying, CCT 2, 30:31 advises to give barley only to "reliable $a$.'s." And a verdict of kärum Kanesh (kt a/k 606) orders to boycott a defoulting $a$.: "Whoever has given merchandise (for sale) to the house of the allahhinnum shall not do so (anymore) until their silver becomes secure/established" (ku'ãnum), which could mean until the house of the $a$. (to which "their silver" refers) has issued valid debt-notes acknowledging the claims, or until he has regained solvency. ${ }^{921}$

\subsection{2. kašs̆um, "official"}

Very frequent are persons designated as kaššum (conventional transcription for lack of a convincing elymology). 922 They occur as recipients of small payments or gifts in many towns passed by caravans, ${ }^{923}$ and also as week-epanyms (hamusium), always in the formula hamuštum ša kaššim saa qäté PN (ilqe). "week eponymy of the kašsum, who took over from PN", quile recently discussed in Kryszat 2004a, 162ff. The kassium is nearly always anonymous," 924 and whatever the chronological position of the "kašsum hamuštum", it seems clear that the word is a general term for "dignitary" - those receving gifts in the towns passed by caravans may have been local chiefs or mukhtars - used because the scribes did not think it necessary to give or did not really know his name or title, some of which may not have had a suitable Assyrian equivalent. This was, in my opinion, also the case with the kašsum as eponym, becouse he always is the successor of the previous one, and the scribe probably did not (yet) know his name. This interpretation explains the widespread occurrence of this designation and is confirmed by a set of closely related let-

921 See tor the verb kuänum, typical for $O A$ in the G-stem (not recorded in the $C A D K$ ) Veenhot 1995a, 1729, with examples where it refers to "be confirmed/established" by witnesses or tablets (additional exmple in kt 94/k $1133: 144$., ina ruppésu u sibèsu ikuanma ... ilaqge). If this is meant here one might think of a written acknowledgment of debt, repealedly called isurtum, when issued by local palaces and officials, see Veenhof 1995c, 321ff.

922 See larsen 1976, 3591.

923 See AOAT 253, the list in Nashef 19B7, 23-26, and Kryszat 2004a, 162 note 523.

924 The exceptions are mentioned in Balkan 1965b, 173, note 34: D/Tumana in El 14:1lf., and $\mathrm{D} /$ Tuli in $\mathrm{kt} \mathrm{a} / \mathrm{k} 825: 17$. $\mathrm{Kt} \mathrm{i} / \mathrm{k} \mathrm{5:7f}$. mentions the kašsum of (the town) Kupita. 
ters already mentioned by Larsen. ${ }^{925}$ In CCT 2, 30 Buzāzu writes about silver due from "the house of the allahhinnum" as payment for textiles and asks his correspondent: "Collect the silver) from the kašsum and from his brother Ašsur-bejli and from the chief of the personnel, Happuašu, and so extract 10 pounds of silver from that house". In TC 3, 14 Buzāzu is much shorter and writes: "Be concerned about the silver, that of the allahhinnum and his brother and that of Happuašu and my ...". The allahhinnum in the first letter is referred to as kă̌sum, because the scribe, having identified the debtor as "(the house of) the allahhinnum", continues by writing simply "the official (mentioned)". $\mathrm{Kr} 94 / \mathrm{k} 432: 19 \mathrm{f}$. registers a small payment to "the kašsum of lšhara", presumably a cultic official. There are also a few references to transactions that took place in the "house of the kaššm". According to kt 94/k 727:9f. two Assyrians settled accounts there (this is probably is olso meant in AKT 2, 34:14f.) 926 and according to $\mathrm{kt} \mathrm{b} / \mathrm{k} 144 \mathrm{~b}: 3 \mathrm{f}$. (Balkan 1965b, 173 note 39) arbiters reached a verdict there. Since kašsum seems to be a general designation that substitutes for a specific title or function, it is not included in the list of chapter 1.2.4.927

\subsection{3. rabi sikka/itim}

Men with this title (henceforth $r$. s.) were important and powerful officials who belonged to the palace organization of Anatolian towns (see BIN 6, 23:6-9; in KTK 20:24 one "goes up", eläum, to him) and could have personnel at their disposal. ${ }^{928}$ The meaning of the title and the substance of his function are still unclear and recently also Kryszal 2004c, 25ff., who assumes that the function was similar in nature in the various towns, can only point out certain aspects of his activity, mentioning "Handelskoordinierung mit den Assurern" and "eine hervorragende Position im altanatolischen Staatswesen". There apparently was only one r. s. per town, the reason why the pitle, "r. s. of town GN", was sufficient to identify him. Proper names therefore are rarely mentioned, but in some texts he is explicitly linked with a particular town. In BIN 4, 45:18f. we meet those of Ušša and Hudurut, who want to buy amütum, in TC 3, 271:24-27 the one of Ulama is to be asked for a "commissioner" (räbișum) to bring Assyrians safely into Wahšušana; kt 87/k 387:26,37, kt 92/k 564:14f.,42 and kt 93/k 936:4f. mention the one of Wahšušana; KTK 6: 5 the one of

925 Larsen 1976, 359, note 19. His argument probably was not followed up, because the numbers of both texts were misprinted, they should read CCT 2,30 and TC 3, 14.

926 The text lists 91 textiles belonging to different persons, followed by ina Mamma bët Abäya kà-si-im ni-si, but where sasa $\bar{\sigma}^{\prime}$ um without nikkassi could also mean "to call for, to claim".

927 A different kašsum presumably in $\mathrm{kt} n / \mathrm{k} 306$ : $5 \mathrm{ff}$., who asks payment of a debt "when the ruler enters the kašsum" (to which kt $j / k$ 9:11 adds: "in the lemple of Anna"), where kašsum seems to be a facility as part of a temple (see also Dercksen 200la, 45 note 35).

928 Soldiers (radium, kt m/k 127:15f., 133:14, and kt 87/k 479:5f.), a rabi säbim (kt n/k 72:1f/), a rabi müsêm ( $\mathrm{kJ} \mathrm{n} / \mathrm{k}$ 1854:2), and a rabi allahhinnim (KTK 106:7f.). In addition there is mention of the tuzinnum and an ubädinnum of the r. s. (kt a/k 12630:4f.,11f.; $\mathrm{kt} 89 / \mathrm{k}$ 342:16f., tuzinnum so qastim sa r. s.), and of a threshing floor (adrum) of a r. s. (I//ustr. London News of 14-1-1950, p. 70. fig. |6); see for most texts Kryszar 2004c, 39ff. 
Wašhania, and in TC 3,70: rev.4 the r. s. of Ha[...] occurs. To which towns the r. s.'s with the names Ganuša ( $\mathrm{kt} \cdot \mathrm{n} / \mathrm{k}$ 533:4) and Ahumila (VS 26, 51:25f.) belonged is nol known. Many occurrences are in texts where r. s.'s figure as (often difficult) customers of the Assyrians, who buy or supply merchandise (textiles, copper, iron) or are indebted to them (ct. CCT 2, 37b:25; 5, 1b:14,28; 13a:19; KTH 14:4, 20). The acknowledgment of such a debt can be recorded in a document called isurtum $(k t 92 / k$ 564:4lf., kt 93/k 942:4). See for a case which shows his power in connection with the seizure of textiles, $k+87 / k$ 387 , presented in note 857 . A different picture, again, is offered by $\mathrm{kt} \mathrm{m} / \mathrm{k} 14$ (Hecker 19960, text 1, with commentary), where a r. s. (of which town is not mentioned) adjures an Assyrian trader (whom he addresses as "my son") not to report a sensitive piece of information to "the elders" (presumably the kärum authorities\}, while drinking to his health and invoking the favour of Ašsur and Šamaš. Above (chapter V.3.4.2) I mentioned their interest in acquiring iron, for which they were ready to pay silver and gold.

Kryszat 2004c has recently studied the lerm sikkätum, always in the plural and apporently the name for a large scale, perhaps ceremonial outdoor event, and the tifle $r . s$, presenting and discussing most of the ca. 30 references for the latter (p. $25 \mathrm{ff}$. and $38 \mathrm{ff}$.), to which I refer the reader. He tries to establish a link between the wo, because the title is four times not spelled rabi sikkitim but rabi si-ko-tim, and both terms occur logether in kt 87/k 387:26ff., where we read that "the r. s. of Wahšušana is staying at/with/in (ina) the sikkartim", where an the Assyrian trader has to visit him (ano sikkātim ... illak). Kryszat assumes (p. 27) that sikkatum (singular, in OA sikkutum, with vowel harmony) is the name of the object (in Akkadian a peg or nail, used a.o. as boundary marker, as part of o lock and as peg driven into the wall) which, in the plural, gave its name to the event sikkätum, which he calls "der Festzug der sikkōtum". He constructs the following link between the title and the event. Since the r. 5. was "Oberste über den/einen sikkatum" (singular) of one particular lown, the existence many towns, each with its $r$. s., meant that "mehrere sikkätum existiert haben", and the presence of all of them in one cultic centre would have given the event the name sikkotum. The r. s. present at such a ceremony would "nur in diesem Fall" have become (been called) rabi sikkätim, "Oberste uber die sikkähum". This ingenious explanation fails to convince me, because in none of the four cases where the title is written rabi si-ko-fim (Kryszot p. 2b) and the noun coutd be plural, the required relation ("nur in diesem Fall") to the sikkötum ceremony is evident. Moreover, in TC 3 , 271 the titte of the $r$. s. of Ulamo is written both rabi si-ka-tim (line 24) and rabi si-ki-tim (line 27). which suggests that the former is one of the cases where the Assyrian vowel harmony is not expressed (as in uttatim alongside uttitim). Kryszat's reconstruction also implies a fair measure of cooperation between the various towns, meeting in one cultic centre where their rulers, officials and people would have come together, which for an Anatolia divided into often rivaling city-states requires much more proof. ${ }^{929}$ Until more evidence turns up the relation between sikkätum as a ceremony and the title remains problematic.

929 See for the meaning of the sikkätum also note 940 . In nole 747 I mentioned the important tex $\mathrm{kl} 92 / \mathrm{k} 526$ (complete text now in ArAn 5 [2002], 67f.), which suggests the presence of a violent element the sikkantum event (which may have been the reason for the worries of Assyians. when it took place). Note that, contrary to what Hecker (KUG p. 105, 5) suggested, there is no 
The title, as Kryszat also observes, is identical to that attested in the Old Babylonain period loccurrences CADS 253,b), where its bearer played a role in the administration of the city, notably in Kutalla (Tell Sifr). Here a certain Qišri-|rra appears several limes as a presumably official witness in house sales, both with the title rabianum, "mayor", and with that of $r$. s., which could reflect a development in his career; in one contract (Tell Sifr 45) the tablet designates him as NU.BANDA, PA and the envelope as r. s. ${ }_{3}^{930}$ The r. s. was prominent enough to feature in $O B$ omina as a man who could open the cily-gate (in order to let an enemy in), start a revolt, seize the throne, and his death was also important enough to be mentioned (see CADS 254, d). M. Stol in OBO 160/4 (2004) 666f., suggests to explain his title from sikkotum,"peg", as part of the lock of a gate ${ }^{931}$, which would make the $r$. $s$. the official authorized to open and close the cily-gate, which meant that he was responsible for the security of a town. If we assume that the Anatolian title (even if it was a translation of an Anatolian designation) was somehow inspired by its Mesopotamian analogue, already attested during the Ur III period (we have no examples from Assur), his duties may have been similar, covering perhaps both civic administration and security. His involvement in the trade might be part of his official duties, but could also be explained from the fact that he was rich enough to engage in commercial activities, facilitated by his association with the palace, in particular if it included admitting Assyrian caravans into a town or palace in order to have them cleared. But note that in Hahhum, where according to the new reaty a king seems to be missing, the $r . s$. is not among the "magnates" who are the treaty partners of the Assyrians and are entitled to levy raxes and buy merchandise (chapler V.2.2).

Two occurrences deserve separate mention. Prag | 651 records the settlement of claims in connection with the divorce of the Assyrian couple Püšu-kën and Lamassi, sealed by an oath sworn by (the gods) Ašsur and Anna, the ruler (rubä'um\}, and the rabi sikkatim. Since the last two appear alongside the main gods of Ašsur and Kanesh, they should be the main Assyrian and Anatolian civic authorities, and their role is perhaps explainable from the fact that the husband lived in Kanesh and his wife in Assur. One might have expected the local ruler to figure here, but perhaps the r. s. played a role in taking oaths. This might also be the case in the still unpublished letter kt a/k 1165 (Kryszat 2004c,39, d) where the/a r. s. has to make the rulers of Burušhaddum and Wahšušana and a certain Ušunālum (probably identical to Uši/unālum, well attested in the kt 94/k archive as a powerful man involved in the wool rrade) swear an oath, which would allow the Assyrian addressee to travel safely to Wahšušana. We do not know to which town the r. $s$. in question belonged, but mediating belween and taking an oath from the rulers of different cily-states to solve a conflict which hampered the trade was an important task, only entrusted to an important official.

evidence for its taking place in Assur too. The cily mentioned in TC 2,37:4 $\left[a-<l i m>>^{k i} \mid\right.$ refers to an Anatolian one, where due to the sikkătum silver and gold to be paid for wool and copper could not be collecied. The letter must have been sent to Imdilum in Kanesh by his agent/ransporter Ahsalim, who was on business elsewhere in Anatolia (ch. his role in ICK 1, 135 and TC 1, 53).

930 See for the Tell Sifr texts D. Charpin, Archives familiales et proprièté privée en Babylonie anciennne. Etude des documents de "Tell Sifr", Genève 1980, and for the references p. 346, s.v. rabi sikkafim.

931 See CADS 249, 2, and for the construction of such a lock now A. Fuchs, SAAS 8 (1998) 97ff. 


\subsection{4. kumrum, "priest"932}

Priests usually occur as witnesses of legal transactions and occasionally also as creditors, in particular the priest of Higiša, who is attested in some records excovaled in 1988 and 1992. His debtors are always Anatolians who owe him silver, barley and beer bread (bappirum). In kr $88 \mathrm{k} / 1087$ four persons owe him 200 beer breads and 21 bags of barley; in kt $88 / \mathrm{k} 1087$ three minas of silver and two bags of barley are owed by five persons, and in kt $89 / \mathrm{k} 314$ and 358 a large group of people owe him considerable amounts of barley and beer breads. ${ }^{933}$ The loans usvally are secured by high interest, joint liability or pledges. One wonders whether the priest acted for his own account or used remple properly for this purpose and whether he (or the temple) was somehow involved in the production of beer.

\begin{tabular}{|c|c|c|}
\hline god & priest & references \\
\hline$\overline{A n n a}$ & Aluwa & kt 89/k 376:4; Azu, TC 3, 181:8. \\
\hline \multirow[t]{2}{*}{ Bēl qablim } & Inar & $k \neq n / k 32: 10$ \\
\hline & & $\begin{array}{l}\text { An allahthinnum of the temple (bēium) of Bël gablim in } \mathrm{kl} \\
\mathrm{m} / \mathrm{k} 78: 22 \mathrm{f} \text {. }\end{array}$ \\
\hline \multirow[t]{9}{*}{ Higišalmj } & {$[\ldots]$} & El 188:24 (witness of sole into debt-servitude); \\
\hline & fitle only & $\mathrm{kt}$ 92/k 1038: 3f. $\left(\tilde{s o} \mathrm{Hi}-g i_{5}-\bar{s} d\right)$ \\
\hline & & kt 92/k 1047: 4f. (š Hi-gis-si-im): \\
\hline & & kt 92/k 1048:4 (so Hi-gi-so-am); \\
\hline & owilum. & k1 88/k 1082:15f. \{awilum k. so H. \}; \\
\hline & Asuan & $\mathrm{kt} 88 / \mathrm{k} 383: 1$ \\
\hline & Haršula & Müller-Marzohn 2000, no $4: 18 \mathrm{~F}$.; \\
\hline & Kikarša(n) & OIP $27,53: 3 ; \mathrm{km} n / \mathrm{k} 32: 24$ \\
\hline & Šiwašme'i & kt $88 / \mathrm{k} 1087: 14 f . ; \mathrm{kt} 89 / \mathrm{k} 358: 13 \mathrm{f}$ \\
\hline Ilalionta & Torhuše'ed & $k+k / k 1: 5$ \\
\hline llat alim & Nakile'ed & $\mathrm{kl} \mathrm{c} / \mathrm{k} \mathrm{1340:13t}$ \\
\hline \multirow[t]{8}{*}{ dIŠKKUR } & llaliuman & $k+89 / k$ 371:2; \\
\hline & & $\mathrm{kt} \mathrm{i} / \mathrm{k}$ 625: 6f. (Donbaz 1993a, 139f.); kt 89/k 371:2; \\
\hline & Ká-zi & $\mathrm{kI} / \mathrm{k} B \mathrm{BO}: 1 \mathrm{k}$ \\
\hline & Peruwa & Prag 1 837:2?; \\
\hline & Suhurpia & TC 3, 214B:4, k1 89/k 370:2, kf n/k 31:64;; \\
\hline & Šupunahšu & $\mathrm{k} 1 \mathrm{n} / \mathrm{k} 31: 8 \mathrm{.}$ \\
\hline & Wališra & $k+n / k 31: 6 v$; \\
\hline & Workali & TC $3,191: 111 ?$ \\
\hline
\end{tabular}

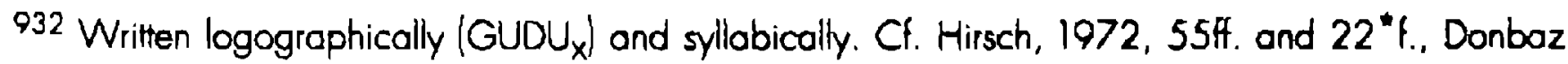
19960 and Schwemer 200I, $242 f f$.

933 In $\mathrm{kt} 89 / \mathrm{k} 314$ seven people owe him 305 bags of barley and 270 bear breads (bapoinum), in $\mathrm{kt} 89 / \mathrm{k} 358$ nine people 160 bags of barley and 400 bear breads, in both case to be delivered ana harpe. 
Anatolian Titels / Tirels and Officials

\begin{tabular}{|c|c|}
\hline dIŚKUR ša qaqqidim & Peruwa \\
\hline & Gadudu \\
\hline Kubabat & {$[\ldots]$} \\
\hline & Peruwaš ... \\
\hline & Nokile'ed \\
\hline Nōrum $\left({ }^{d} D_{2}\right)$ & Appuna \\
\hline & Labarša \\
\hline Nipas & Šulili \\
\hline Nisabo & Wa-ša-tap-ra \\
\hline & Kommalio \\
\hline Peruwa & Happuala \\
\hline dUTU & Haršu<m>numan \\
\hline & Kuzia \\
\hline$?$ & Ušhueni \\
\hline$?$ & Hašui \\
\hline$?$ & Tarikuta \\
\hline$[\ldots]$ & anonymous \\
\hline
\end{tabular}

TC 3, 214B:1;

$\mathrm{kt} n / \mathrm{k} 32: 3$, level $\mathrm{lb}$.

BIN 6, 193:5; KTH 36:24;

$k+k / k 1: 2$;

$\mathrm{kt} n / \mathrm{k}$ 1787:1f.

$k+f / k 80: 2 t$;

$\mathrm{kt} f / \mathrm{k} 80: 4 \mathrm{f}$.

kt $88 / \mathrm{k} 1090: 5 \mathrm{f}$.

kt k/k 10 :7; kt 89/k 383:1 (Donbaz 1993a, 134);

kt $89 / \mathrm{k} 379: 36.934$

kt 87/k 320:21.

ATHE 2:A,4=B,5;

kt $89 / \mathrm{k}$ 371:1;

Müller-Marzahn 2000, no. 4:20;

kt 87/k 266:1;

kt 87/k 266:2;

CCT o, 34a:12 (owes copper).

1.2.5. Other titles and functions

asilakum

fuller

bèl àlim

lown prefect

bel betim

majordomus

bel ha-Di-lim

bel mátim

bel mulim lord of the land lord of ... kt $94 / k$ 833:31, Subrum the fuller of the ruler; ${ }^{935}$

TC 1, 87:9, the fuller of Salinuman;

see above under rabi ašlakē.

kt 94/k 195:If., Peruwa bël bétim sa b. a:;

TuM 1, lb:4f., meeting with $b$. $a$. in palace;

TC 3, 165:15 (of Nenaššâ); KTK 7:7';

CCT 6, 34a:15', copper owed by him;

kt 91/k 548:4, one nahloplum for him;

kt 94/k 672:8, gift to PN $\check{s a}$ b. a.

kt 94/k 195:1f., Perva 6. b. so bëlälim.

kr 94/k 208:12, Šezur bel belišs of rabi simmillim;

$\mathrm{kt} \mathrm{m/k} \mathrm{247f.,} \mathrm{PN} \mathrm{bël} \mathrm{bêtisu} \mathrm{ša} \mathrm{Babola;}$

Note: belal belim in kt a/k 851:8f.;

$\mathrm{kt} \mathrm{a/k} \mathrm{907:3,} \mathrm{claim} \mathrm{on} \mathrm{bëlat} \mathrm{bëlim} \mathrm{sa} \mathrm{mahirim.}$

TC 3, 165:17, a gift to him.

CCT 6, 34a:4, owes copper.

kt s/t $92: 11 ': 4, \mathrm{PN}_{1-4}, 4$ bël mutim.

934 In all cases spelled Ni-sä-ba, cf. also kt 87/k 139:6, poyment $i-w a-s a ~ N i-s \dot{-}-b a$, "when the grain cornes up.

935 See for fullers and their task, Dercksen 2001a, 62 with note 130. 
bo/urullum (rabium) (great) "chief"

mūsium

nāșir ālim

nōsir Kanis̆

rōdium

so hattim

sakkanakkum

so pašsurēe

so patrim $\{\mathrm{GiR}\}$

säpirum

so gos̆i

sinahilum
OIP 27, 498:91., Happualo 6. r. of Amkuwa; kt r/k l, Aniskibal b. r. sa Tiburzia; ${ }^{936}$

CCT 1, 29:8, barullum sa Bahadima;

Prag | 491:31., kt 87/k 386:40k. lli-bāni burallum.

See above under rabi müsê/müsim and for his role in the Hahhum treay, note 829.

TC 3, 161:5, invitation to the bet mussim;

$\mathrm{kt} b / \mathrm{k} 198: 18$, textiles sold to "the house of the $m$. .;

$\mathrm{kt}$ 89/k 243:8, $8 \mathrm{tal}$. of wool so bet müsim;

$\mathrm{kt} 94 / \mathrm{k} 1461$ 12f., 17f., a müsum is feared since he had nol receved the iron promised.

protector of the city $\mathrm{kt} 89 / \mathrm{k} 370: 33$ \% (his arha/um);

$\mathrm{kt} \mathrm{m} / \mathrm{k} 24: 24 f$. PN so $\mathrm{n}$. 0 .

prolector of Konesh $\mathrm{kt} \mathrm{n/k} \mathrm{31:1,} \mathrm{Niwašu} \mathrm{(witness} \mathrm{al} \mathrm{house} \mathrm{sale);}$

kt 89/365:4t., Peruwa (his arholum).

soldier, ormed escort passim, but note r. so rubā' im, KKS 2lb:4;

1. so rubätim, TC 3, 211:45.

scepter bearer'?] ～kt s/192:2', Asupola (ct. k! 89/371:7) 10';

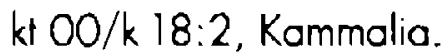

governor $\quad k t n / k 1374: 25$, sent to Amkuwa.

butler $\quad k t s / 192$ iev. 6 ', several men;

kt 89/k 371:8, Nikile'ed;

cf. rabi passiùre.

dagger bearer \{\}$^{937} \mathrm{kt} 89 / \mathrm{k} 371,4$, Happuaśu sa GIR2:

$\mathrm{kt} 89 / \mathrm{k} 370: 11 ., \mathrm{Wa}[.$.$] sa \mathrm{GlR}$;

TC 3, 214B:16, Śaduwan sa $\mathrm{GIR}_{2}$ (collated).

manager, $\quad \mathrm{kt} \mathrm{m} / \mathrm{k} 5: 3 \mathrm{f}$, Inarme'i s. sa bèt $M$.

administrator $\quad \mathrm{kt} \mathrm{g} / \uparrow 36: 16$, Kulanala;

Garelli 1905, 20 no. 2:4, U'ushhata;

CCT 4, 44b:26, s. Mammöium;

$\mathrm{m} / \mathrm{k}$ 24:27f.. PN s. so besMarila;

TC 3, 165:가., anonymous šäpir älim.

bow-man $\quad k t o / k 18: 11$, Huknuan s. 9 .

second in command TC 3, 75:7, ruba'um and $s$. of Naduthtum;

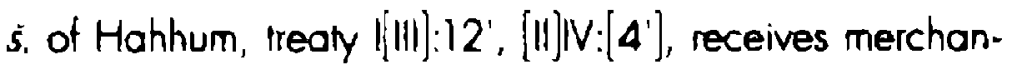

936 See for burullum, CAOB 344. in ATHE 31:4lf., kima K. i-Bu-r[u-lim $[x \times x(x)]^{43}$ ró $\left(u 5^{2}\right)-b u-m o$, the preposition $i(n a)$ rules out a title and suggests the place-name Bura/ullum (see Nashef 1991, 27, with now several additional occurrences; see for Mari, Charpin-Ziegler 2003, 100 note 206 , and 273).

937 See Donbaz 200la, 92. He connects patrum with the dagger (of Ašsul) by which the oath was sworn, but this is unlikely as a title of Anatolians. 
watar?

2938

dise \{see above chapier V.2.2\}.

In Nesr C 1 (Veenhof 1989, 518):17, the abstract sinahilutum.

kt 88/k 1070:1, Šezur wa-to-ar,

kt 86/k 9-10, Harša'an/il wo-to-ar,

kt 99/k 138A:3, seal of Du-ba wa-tar.

938 See Donbaz 200la, 94. Not to be derived From Akkadian watrum, "extra, additional", since an absolute state is ruled out as profession or tifle. He also quotes $\mathrm{kt} 87 / \mathrm{k} 39: 24 \mathrm{ff}$., "before $\mathrm{K}$. ina $\dot{\mathrm{E}}$ A-no pa-at-ru-um", where palrum in the nominative in apposition to mahor $\mathrm{PN}$ is unlikely. 


\section{Terms of payment in Anatollan debt-Notes}

Many debt-notes in which Anatolians figure as creditors and debtors, quite a number where they are debtors of Assyrians, but also some between Assyrians, ${ }^{939}$ do not (in a few cases not only) indicate lerms of poyment by mentioning a week, month or year, but by seasonal events, such as the phases of and activities during the agricultural year and by the festivals of a number of gods. 940 The festivals in many coses were probably also linked with the agricultural calendar, when important moments of the season were celebrated by religious ceremonies. Their use suggests that ancient Anatolia by that time had not yet developed a calendar with month-names, as it was also not customary to date events and contracts by the number or name of a ruler's regnal year. A few debt-notes are dated after important events, such as the death or accession of a ruler, "when Asu, king of Luhusaddia had died" $(k \mathrm{n} / \mathrm{k} 716: 12 \mathrm{f}$ ), and "when Labarša become king" ( $\mathrm{CKK}$, 178:2ff.), but they are not helpful for us and in the second case we do not even know which city the king had ruled.

What follows is a lists of the festivals and of the moments of the agricultural year which figure as due dates for payments. Which times of the year are meant can be deduced from the annual cycle of seasonal work and from references that show which fruits etc. became available. Several debt-notes record loans consisting of barley and silver, which have to be paid back at different moments, or stipulate payment in instalments. This results in the mention of more than one event or festival, which gives us a clue about their sequence, and there are are even a few which mention the week or month when the loan was contracted. The nature of the goods borrowed may also help, since payment of barley loans is usually after the harvest, when the grain has been threshed. Together they offer clues for the sequence and daling of the events mentioned, but in the case of the festivals questions remain. I am not the first to deal with these issues and references have been collected and analyzed in the past by Landsberger, Matouš, Donbaz, and Bayram. ${ }^{941}$ The increase of data is helptul, but there are also some new problems, because the neat distribution of four festivals over four seasons by Landsberger 1949, 293, is now complicated by references to additional festivals. ${ }^{942}$ Since all references are in economic records (debt-notes) we con almost exclude that the transactions recorded took place during the Anatolian winter, and there are indeed no occurrences of ana küssim, "not later than the winter", which presumably was also too vague for a due date, unless there was a particular festival to mark the end of the outumn, the beginning of the winter, or the winter solstice.

939 Some of these record significant amounts of silver, e.g. ICK I, 191:31ff., a commercial debt of 12 minas of silver to be paid at "the coming testival of Pirka".

940 There are a tew exceptions, such as kt f/k 100:5f., payment due ana tuwär sikkötim, which hence must have been a datable and predictable event.

941 Landsberger 1949, 287ff, Matous 1965, 1980, Bayrom 1990, and Donbaz 1988a, 54ff.

$\$ 42$ Landsberger already had to admit that he could not fit the festival of Tuhruhanu(m) into his scheme. 
Payment at the time of the festival of an Anatolian deity is designated simply by ina/ana sa + the name of the god, without the use of the word "festival". Because their place in the calendar is uncertain, I present them in alphabetical order. Many of the gods, whose priests or festivals are mentioned, are just names for us and we have to assume that logograms (ISKUUR, UTU) and Akkadian names (Bëlum, Bël qablim, Nisaba, etc.) may hide native Anatolian deities, some of which might be identified with the help of their names in Hittite rexts (e.g. Nisaba equal to Halki\}. But one should also consider the distinction between the various local panthea and the different ethnic strata (Proto-Hattian, Neshite, Luwian\} of ancient Anatolia. Some of the names in our list might perhaps be identilied with gods of the land of Kanesh mentioned in the "Anitta Text" (e.g. Siun as sungod, Tarhunna as weathergod), and invoked in the beginning of the treaty with Kanesh (see above chopter V.2.1), which probably also mentions the (deified) mount Erciyes (see above nole 812). These are questions the Hittitologists have to answer on the basis of their data on cults and festivals. At any rate, our list does not include a festival of Perwa (also written Parwa, Peruwa, a priest of whom is attested, see abovel, a god associated with horses, who belonged to the pantheon of Kanesh and appears in many personal names. ${ }^{943}$ Of the festivals ( $s a$ DN) mentioned in our texts only that of Parka (Pirka) is still attested in later Hittite texts, where he is known as a god who had a cult in the temple of the grain goddess at Hattuša. But it is by no means certain, as assumed by Haas, that the god Anna, after whom a month was named in one of the ritual calendars of Emar, can be identified with the god Anna of Kanesh. 944 That some gods, such as Higiša, whose priests occur several times, are not represented by their festivals mighi be due to the cullic calendar, if their festival did not match a suitable payment term correlated with the agricultural season. There is in general a lack of data on the temples of the Anatolian deities, two of which were found on the city-mound of Kanesh ${ }^{945}$ and many of whose priests figure as (at times prominent) witnesses in Anatolian contracls (see above chapter 1.2.4.). Temples apparently were not involved in the commercial transactions and therefore do not occur in the lexts, with rare exceptions, such as the statement that a payment was accepted in the temple of the weathergod (VS 26, 146:7).

Part of the references listed below are taken from listings by Balkan and in Bayram 1990, where further details and especially information on the nature of the debt (silver or barley, etc.) are usually missing.

943 The statement of Haas 1994, 614, 'Die Gruppe der kanisischen Gottheiren sind altkleinasiatischkappodokischen Ursprungs, deren Kult die indoeuropäischen Ankömmlinge in Kaniš übernommen hoben", claims that the gods of Kanesh are pre-Hitite/Neshite native Anatolian gods.

944 See D.E. Fleming, Time at Emar. The Cultic Calendar and the Rituals of the Diviner's House (Winona Lake 2000) 162f. with note 97, on Anna and the various identificalions of this god, who moy appear as Ana at Eblo.

945 See Özǘc 1993a. 
1. Anna, written A-na (passim), A-na-a (1 453, tablet), An-na (a/k 899a, 1164a), and dA-na $(a / k 1351)$.

Anna seems to have been the main god of Kanesh, whose temple there is mentioned in

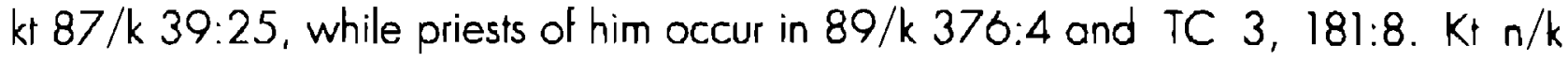
306:5ff. stipulates payment of a debt "when the ruler enters the kašsum", to which kt j/k 9:11 adds: "in the temple of Anna". Anna was invoked in the oath alongside Ašsur (ICK 1, 32:11; Prog 1 651: 12'ff.) $)^{946}$ and must be meant by i/ Kanis, "the god of Kanesh", invoked as witness in kt m/k 7:18f. (courtesy Hecker), Ašsur Amurrum u il Kanis lü ide 'ä. His consort could be ilat alim, "the goddess of the cily", mentioned in kt c/k 1340:13f. (where her priest acts as witness), but her identily is unknown.

Lit. Malous 1965, 175f.; Bayram 1990, 457 f.

EL67:8f. (silver, and); ICK 1, 115:11 (silver, from month IV, and; ICK 2,4:5'silver, ina, among Assyrians) and 50:3 (silver, ana); KKS 6:5 (silver, ana); Prag I 552:6 (silver, ana); TC 3, 254:11 (redemption of slaves ana s. A.); kt a/k 672:6, 811b:6f., 899b:6 (ana); 1164b:6f. (silver), 1351:5 (ina); AKT 1, 60: of. (silver, ana); $\mathrm{kt} f / \mathrm{k} 64 \mathrm{~b}: 6 f f$. and $72 \mathrm{~b}: 5 f f$., silver in instalments išsattim sattim ina sa Anna isaqquiū.

Note: $\mathrm{kt} \mathrm{m} / \mathrm{k} 104: 10 f . \quad$ payment of silver ina sa Anna, of barley ino harpe; $\mathrm{kt} \mathrm{a} / \mathrm{k} 899 \mathrm{~b}: 6 \mathrm{f}$., half of debt ana harpe, the other half ana sa Anna, kt 93/k 946:23f. silver ina sa Anna, grain ina adrim; ICK 2, 4:5ff. ICK 2, 5:5f.

2. Bêlum, "the Lord" silver debt, 1/6 ina ša Anna, 5/6 ina ša Nipas; silver debt, half ana sa Anna, halt ana sa Parka.

Lit. Boyram 1990, $458 \mathrm{f}$.

$\mathrm{Kta}$ a/k 335:4//931:10, a/ina sa Bëlim, silver owed by Atali to Ištar-bašti.

3. Bel gablim, "Lord of baltle", whose priest Inar occurs in $\mathrm{kt} \mathrm{n/k} \mathrm{32:10.}$

kt 92/k 1048:5t., silver + sheep owed to priest of Higiša, payment ina ša b. q.; kt 92/k 1045:18f.; kt f/k 114:4f; 157b: 9; ana sa b. q. in kt 86/k 179:9.

4. Harihari

Lit. Matouš 1965, 180.

ICK 1, 24b:7, silver loan among Anatolians, ana sa Ha-ri-ha-ri tosagagl.

5. Nipas, his temple is attested in $\mathrm{kt} \mathrm{n} / \mathrm{k}$ 1716b:9, see below; in $\mathrm{kt} a / \mathrm{k} 852: 9$ (Balkan 1992, 23, no. 3), gold "which the rabi sabim donated to the son of his lord in the remple of Nipas" (ana mera belisu in E Nipas iqisu); a priest of Nipas, Sulili, in kt 88/k 1090:5f. Construed with ina and ana.

Lit. Matouš 1965, 179f., Bayram 1990, 456, note 31.

E1 12:4f., silver (ēzib Nipas sa illakanni ana sanim sa Nipas); 45 + CCT 6, 47a:7, silver, Assyrians, ana s. N.; 69:12, silver, Assyrians, part ina s. N.; EL 217; 16ff., silver, in three annual instalments ana $\check{s}$. N.; ICK 1, 10:5, 16, silver and copper, ina s. $N$; ICK 2, 4:5ff.; o/k 1048:4; 1199:6; b/k 260b:11f., silver, ina s. $N_{\text {; }} \mathrm{n} / \mathrm{k}$ 75:13, silver, remainder of purchase price, ina sa $N_{i} ; \mathrm{kin} / \mathrm{k}$ 1506:6.

946 niš Ašsur niš Anna niš rubo'é u niš rabi sikkatim, where the Assyrian and Kanishite god are paired by the ruler of Assur and the "commander" of Kanesh. 
Nole: $\mathrm{kt} 86 / \mathrm{k} 190: 9 f f$.

ICK 2, 4: 5f., $\mathrm{kln} / \mathrm{k}$ 1716b: 9 . ištu sá Ni-pátS ana ettišunu ina ša Ni-pátS išaqquis,

silver debt, $1 / 6$ ina ša Anna, 5/6 ina ša Nipas;

silver debt, from the week of $A .+\breve{S}_{\text {., }}$ month IV, payment in one year, "when the ruler leaves the temple of Nipas" (ina bet Nipas ussianni; Bayram 1990, 461).

6. Parka: written Pá-ar-ká (passim), Pár-ká (ICK 2, 132:33), Pi-ir-ká (v/k 165:12); construed with ana and ina.

Lit. Matous 1965, 177ff.

ATHE 2: 9 (ana ša P. ša illakanni); ICK 1, 16b:5 (silver\}; 30:13 (gold), 40b:18 (silver\}; Adana 237E: 4; ICK 1, 191:36f:=2, 130:24' (12 minas of silver), ICK 2, 132:33 (all three ina Pirka sa illakanni); $\mathrm{kt} \mathrm{f} / \mathrm{k}$ 54:0 (silver), 168:8 (ana); kt n/k 168:6 (silver, ana); $\mathrm{kt} v / \mathrm{k}$ 105:12 (silver, i-so Pi-ir-kä); kt 87/k 65:14 (silver).

Nole: ATHE 2,

ICK 1, 40b,

$\mathrm{kt} \mathrm{a/k} \mathrm{1110:4-8:}$ silver loan, month III, payment. within 13 weeks ana ša Parka,

poyment from the week of kašsum within 15 weeks, and at the end: ina ša Parka is̆aqqu/ü;

payment from the week of $\mathrm{E}$. ana sa Parka.

7. Tuhtuhānum: written ana/ina $(\check{s a})$ Tuhruhāni $(m)$

Lit. Matouš 1965, 179f.

k/4 v/k 166:6f., ana s̆a Tuhruhäni, $\mathrm{F} / \mathrm{k}$ 94b:5f. ina sanim Tuhruhänim;

$\mathrm{f} / \mathrm{k}$ 65b, ina sa T. kaspam ilqe ina sa T. kaspam utarrū, month VIl;

kl 94/k 1095:6f., silver debt, payment ana ša Tuhtuhänim.

Note: TC 3, 227

ICK I, 129: 8f.

$\mathrm{kt} 86 / \mathrm{k} 153:$ ㄱf. $k+f / k 65 b: 8 f f$. from week of $\mathrm{PN}_{1-2}$ half ana Tuhituhāni, half in 15 weeks;

payment ana Tuhruhänim, 13f., additional gifts ana ša T:

silver, month I, week of Kurub-|štar, ana Tuhtuhäni; silver debt, payment of barley and one sheep las interest or "Zugabe") ina sibit niggalli, of silver ina sa $T$, month VII.

8. Usumù: ina ša ú-sü-me-e

lit. Bayram 1990, $459 f$.

b/k 134a/b:6/10, $21 / 2$ mina of silver; kt 94/k 1512:5, silver, debt of an allahhinnum).

9. dUTU: ina s̆a dUTU

Lit. Balkan 1965b, 168 note 16.

$\mathrm{kt} \mathrm{c/k} 201: 5-8$, from the week of Enna-Suen they will pay ina saduTu, some creditor and debtors in $\mathrm{kt} \mathrm{c} / \mathrm{k} \mathrm{181:6ff.,} \mathrm{payment} \mathrm{ana} \mathrm{harpe.} \mathrm{kt} 87 / \mathrm{k} 432: 11-13$, the capital to be given back ina so dUTU.

Note: kt 89/k 285:16, payment of $3 / 8$ shekel of silver when "he brought you safely (sallumum) to the temple of "UTU". 


\subsection{Agricultural SEASONS}

Landsberger 1949, 294, olready pointed out that the traditional Turkish designations for the main phases of the agricultural years agree well with those found in our texts. They are: orak zamani, "time of the sickle" = sibit niggallim, July/August; harman zamani, "time of the threshing floor" = adrum, Aug./Sept.; bag bozumu, "time of the picking of the grapes" = qitip kerānim, Sept./Oct.; and cift zamanı, "time of the harnessed plough" = itti eräsim, $\mathrm{Oct}$./Nov. For the sequence and dates of the various events mentioned in the due dates one may consult Holfner 1974, chapter II. The designations of the payment terms use four prepositions, the most frequent ones of which, ana, "not later than", and ina, "on", seem to be used indiscriminately, especially when referring to a festival, which would have taken place on a particular day or days. Urkil warki, "after", is rare, and išu, "since", is only used to indicate when a liability had stanted. In addition they use a temporal phrase with inumi (see below 2.2, nos. 3 and 4 ) and a prepositional infinitive (imwasa Nisaba). Other variations are between the construct states of verbal nouns (sibit and qitip) and rare infinitives (sabät and qatäp) connected with niggallum and keränum, niggallum alone, and miqit niggallim, "the falling of the sickle".

I offer the payment terms in chronological order, beginning in autumn, with the ploughing of the fields, also because the Old Assyrian calendar must have started in that time of the year, between the time of the autumnal equinox (Sept. 23) and the time of the winter solstice (Dec. 21). 947 Some of the terms refer to what we would call seasons, daš"u, "spring", and harpü, "summer", which therefore may cover several months, and this explains the occasional use of more precise designations, like rēs das' 'é," "the beginning of spring". Others mention specific features, like the picking of the grapes, the harvesting the olives, or the time when the seedlings break the ground, which provide more precise dates and refer to work that took much less time. Only ana buqlatim is difficult and we might connect it with buq/um, "malt", lo make it refer to the time the malt was made, obviously after the harvest, in the summer. But the feminine plural is strange and therefore I follow a suggestion by Stol to start from the basic meaning of bualulum, "green sprouting plants" 948 This could make our expression an equivalent of dos"u, "spring", which refers to its abundant vegetation, but l assume that while the latter refers to vegetation in general and to spring grass, buglätum could mean in particulor the green sprouts of the barley which break the ground, which would make it an equivalent of the (rare) expressions listed under no. 4. This is an example of a certain overlap in meaning of the various words, which is also the case with harpu, "summer". It comprises the months July-September, which includes the time of the harvest - also designated by

947 The issue of the beginning of the Old Assyrian calendar is difficult, see the observations in Veentiof 2000,141 . Larsen 1970, 193, considered the winter solstice a more likely moment for the beginning of the calendar.

948 See RIA 7 (1987-90) 323a, where he proposes the meaning "Gemüse". 
the words ebūrum, lit. "harvest", and esādum, "to reap, to harvest"949 - and runs from the "seizing the sickle" until the "gathering (of the stalks or sheaves) on the threshing floor" (sibit niggallim, eräb adrim). The verb erōsum and the noun merašium in Akkadian refer to the final "seed ploughing", after deep ploughing (majäri mahassum) and harrowing have been completed. But when used in Anatolia these words probably comprise both the ploughing and the seeding, two activities that together could cover quite some time. "Seeding" is not mentioned, but the occurrence, alongside general erāsum, of ana erāšim wașā um, "to slart ploughing", and gamār erāsim, "the termination of the ploughing", show that one was aware of the time difference and that some writers may have preferred more precise due dales.

1. qitip kerānim, "the picking of the grapes", ca. Sept-Oct., with ana, ina and urki. ana qitip kerānim. Ank. 2800:4f.; b/k 54b:5f.; KKS 31b:16 (case); f/k 52:5; ina qitip kerānim, KKS 31a:13; kt k/k 59:10r. (silver); kt z/t 14; kt 83/k 282: 5f.; kt 87/k 272:15f.; kı 92/ 1041 (grain);

ina qaf $[\overline{a p}]$ kerānim, kt 92/k 1037 (silver debt); i-qitap kerānim, kt 93/k 148:13f. (silver, part of mixed debt); urki (qitip) kerānim, kt m/k 101:6 (silver debt), 87/k 104:9.

Nore: $\quad \mathrm{kt} k / \mathrm{k}$ 34:16f., kt 87/k 272:141., barley ina ebürim, silver ina q. k.; kt 93/k 148:8ff., mixed debt, grain ina ebürim, silver iqqitap kerānim.

2. eräs̆um, "ploughing land seeding)", ca. Oct.- Nov., various constructions.

ina gamãr eršim, AKT 1, 45:4f., when the cultivation is ready; ina itti erōsim TC 3, 240; EL 99, "at the time of cultivation"; inümi ana erāšim usșiüni, $\mathrm{n} / \mathrm{k} 73: 11 \mathrm{f}$, silver, "when they go out to cultivale". Note: $\mathrm{ktf} / \mathrm{k}$ 58:13f., summa a-di a-ra-ši-im nüșiuni isaqgal; ina meraštim, ATHE 75, "at the time of cultivation".

3. serdum, "(the time of the olives", ca. Oct. - Dec., with ana. ana serdim, $\mathrm{kt} \mathrm{a} / \mathrm{k} 604 \mathrm{~b}: 5 \mathrm{f}$., ana sé-er-dim panêmma išaqqal.

4. "the coming up of the sown", late autumn. inümi eršum ușșiu, kt v/k 160:가., "when the sown comes up"; i-wa-so Ni-sò-ba, kt 87/k 139:6, "when the barley appears",

5. buglatum, the sprouting (of the barley seeds), late autumn (?), with ana and ina. ana buqlätim, a/k 568:5f.; Prag | 500:6, silver; ina ̌̌a buqlátim isaqgal, kt 86/k 198:5, gold debt.

Note: kt 86/k 200:9f., ana ettisu ina buq/ätim, undaled silver debt.

949 Landsberger 1949,287, staled that ebürum in the meaning "summer" is the Babylonian equivalent of harpü, and that ebürum in OA should not mean "summer" but "harvestingl, crop". The latter indeed fits all occurrences listed below (note poryment in two instalments, ina ebürim and ina qitip kerānim). the expression mala ebürisunu, "as long as they are havesting" (BIN 4, 44:1Of.), and especially the combination ebüram sèrubum (see CADE $17,1, a, 1$ ', and kl a/k 1060:3, ebürni nušerrab). It must also apply in kt 89/k 355:2f., ina ebürim ana șer PN allik ... ${ }^{27}$ awérma iš̆ ${ }^{28}$ ebürim sazzuztum azziz, "at havest time I went to PN ... I took action and since harvest lime I have acted as representative". 
6. daš'ü, "spring", April - June, ana/ ina dašs"ē, rare.

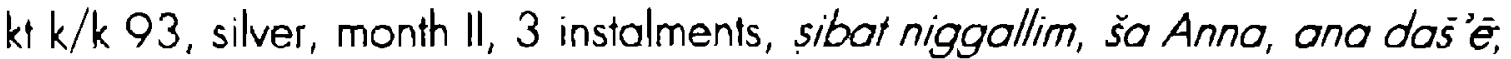

$\mathrm{kt} 87 / \mathrm{k} 336$, silver, half [ina da] $\breve{s}^{\prime} e^{-}$, half ina qitip keränim;

TPAK 98:Ilf., silver received ištu dašé, month VIl; end: from the week of A.

Note: (cf. Landsberger 1949, 287, nole 124):

ana daš ${ }^{\prime} \mathrm{kt} n / \mathrm{k} 1654:$ 가., a. d. liddiššm;

ana rēśs dašë CCT 3, 7a:5, a. r. d. ašapparakkim; TTC 14:20, r. d.;

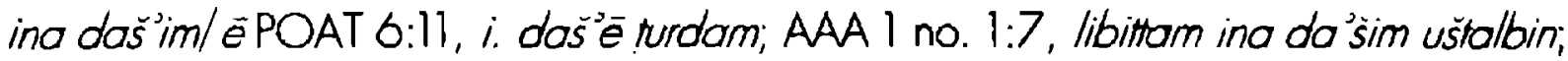

ina daš ésü950 BIN 6, 204:40; kt 87/k 453:22, kima i. d. sikkätunni;

išt dašê JSOR 11 no. 1:11, i. d. adi harpē POAT 8:26, i. d. ušébilakkum.

7. kubur uttitim, "when the grain is ripe", end of June, beginning of July, with ana/ina.

ana kubur uttitim, kt a/k 1116b:5f.; 1585:5f.; kt v/k 178:8f.; POAT 36:10f.;

ina kubur uttalim, Sadberk 29:7f. (silver debt); kt 91/k 390:12 (copper debt).

8. harpü, "summer", July-Sept., with ana and ina, harpü, herpü (once) and harpum.

Note: ina harpia in $\mathrm{kt} \mathrm{o} / \mathrm{k} 64: 16$.

ana harpe, kt a/k 801:9f.; 899b:5; 1214:9f.; 1453b:가.; ktf/k 45:5, 62:8f, 103:7,

111:6; 184b:13 'silver); kl k/k 9:8 'groin); kl s/k 51:51., 54:94.; kt 86/k 35;

$\mathrm{kt} 88 / \mathrm{k} 1082$ (barley and malt); ana he-er-pe, kt 88/k 1087:17;

ana harpim, $k+f / k$ 175b:10 (silver); $k t \circ / k 46$ (silver and grain); $k t n / k 77: 11 f f$. (silver,

two instalments, ana harpim, ana sanim harpim; $\mathrm{k} 92 / \mathrm{k} 1047: 6$;

ina harpim, $\mathrm{kl} \mathrm{o} / \mathrm{k} 81$; ina harpe: $\mathrm{kt}$ a/k 931b:4ff; $\mathrm{kt} \mathrm{b/k} \mathrm{45b:5f.;} \mathrm{kt} \mathrm{d} / \mathrm{k} 8 \mathrm{a}$ :

18, 24a:10, 48b:10; kt g/k 12:10; k/k 32:16 grain; 33:14' grain;

TPAK 113:13, Anatolian debtors, silver and grain, $\left[\right.$ ina $\left.^{2}\right]$ harpé;

$\mathrm{kt} \mathrm{m} / \mathrm{k} 103 \mathrm{16}$, annual instalments ihharpe ittonaddin.

Note: $k t c / k 181: 6 f f$., from the week of $E$. ana harpei;

$\mathrm{kt} \mathrm{o/k} 39$, mixed, month II, barley ana sibir niggallim, silver ana harpe,

$\mathrm{kt} \mathrm{m} / \mathrm{k} 104$, mixed loan, silver ina ša Anna, barley ina harpe:

$\mathrm{kt} \mathrm{o} / \mathrm{k} 44$, silver debt, payment from the week of $\mathrm{A}$. ana harpim,

$\mathrm{kt} f / k 73$, silver, barley as interest ina harpē, silver ina sa Anna,

$\mathrm{kt} 89 / \mathrm{k} 310: 9 f f$, silver, month II, three annual instalments ina harpim.

9. sibit niggallim, "seizing the sickle", July, with ana and ina, with sibit, sabart or sabit niggalli(m), also niggallim alone, warki sibit n., once ana miqit $n$.

ana sibit $n$., kt a/k 810:b:9f.; kt e/k 162:4, 164:7 (silver loan); kt n/k 1727:9; 1858; kt

o/k 40:16; AKT I, 39: ilf.; BIN 4, 208:9; Garelli 1965, no. 22:6; KTH 20:8;

ana sabät ni-ga-li, kt 86/k 162: cose 4f., silver ona sabät niggallit.

i(na) sibit ni-ga-li, kt m/k 105, annually one third ina s. n.; t/k 65a:5 (silver);

950 See for this "situalionsdelerminierendes" suffix, Landisberger 1949, 288, and now M. Stol, in: Studies Hirsch, 413-24, who states "Der Standort des Sprechers bestimmt die Übersetzung" and suggests that "his" may approach "over there", "that one", but is apt to become frozen. See for a rare OA occurrence of the first person suffix under harpu, where it relates to the creditor who receives the payment. Note payment ina harpini, $k t t / k 22 a: 16 f$. 
i-sa-bi-it ni-gá-li, f/k 162b:4f. (silver);

ilna) niggalli/m), a/k 1177:6; kt 86/k 163:5f., ana ettišnu ina n., silver; El 90:7, silver, among Assyrians, i-ni-ga-lim;

warki șibit niggallim, kt a/k 1430b:7-11;

ana migit niggallim, Prag | $491+$ ICK 2, 52 \{case\}, 5 1/2 minas of silver.

Nole: $0 / k 40$,

mixed loan, "from the week of the kašsum, month II, they will give the barley ana șibit niggallim and pay the silver ana harpe";

$k \nmid k / k 93$ silver debt, month 11 , first instaiment ana [șaba] t nig-

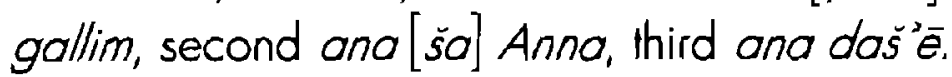

10. eșädum, "havesting", July-Aug., with ina.

ina esāodim, $f / k$ 129:4, silver loan.

Note: TC 3, $322 \mathrm{f}$., lamo mätam esädum isbutu $/ \mathrm{m} /$ " "before the land is fully occupied by the harvest".

11. ebürum, "harvest, crop", july-Aug. ", with ina.

ino ebürim, AKT 1, 79; Garelli-Kennedy 1960a, no.12; kt d/k 19a; kt y/ 4:11, mostly grain loans.

Nore: $\quad k t k / k 34: 12-18, k t 87 / k 272: 14-16$, loans of silver and barley, barley to be given ina ebürim, silver to be paid ina qitip keränim.

$\mathrm{kt} 93 / \mathrm{k} 148$, loan of silver and grain, grain to be given ina ebürim, silver to be paid iqqitap kerānim.

12. adrum, "threshing floor", ca. Aug.-Sept., with ina, ina eräb / pahār / sapat adrim.

ina adrim, ICK 1, 93; kt a/k 842:5f.; kt n/k 1933; kt 86/k 160:7f., [il ana] adrim grain ubbuls, $\mathrm{kr} 87 / \mathrm{k} 304: 11$;

ina erāb adrim, $\mathrm{kt} \mathrm{z} / \mathrm{t} 14: 7-12$, barley "when it arrives at the threshing floor", silver ina qitip kerānim;

ana pahär adrim, "not later than it (the barley) is brought together on the threshing floor", kt a/k 1259:8f., kf 94/k 1040:8f. (silver, Assyrians);

ina sapat adrim, kt 87/k 292:17, "at the edge of (for "as soon as it has reached"?) the threshing floor".

Note: kt 93/k 946:23, mixed loan, silver ina ša Anna, grain ina adrim.

13. buqunum, "the plucking (of the wool)", in late spring, exceptional as the only due date related to husbandry, better known from $O B$ texts, see $C A D B, 325,2$, but there usually restricted to wool debis.

ana bu-qü-nim išaqal, kl 94/k 1149:8 (courtesy Larsen), small silver debt.

\subsection{InTERPRETATION}

Clues for dating the various events and festivals are provided by contracts in which the debts consists of two different commodities with separate payment terms (a), by contracts which stipulate payment in several instalments (b) and by some contracts which mention months (and weeks) as the date when the liability started (c). 
a) different commodities

\begin{tabular}{|c|c|c|c|c|}
\hline & text & month & barley/grain & silver \\
\hline 1. & $k+87 / k 272$ & - & ebürum & qitip kerânim \\
\hline 2. & $k+k / k 34$ & - & ebürum & gitio kerōnim \\
\hline 3. & $k t 93 / k 148$ & - & ebürum & qirap kerānim \\
\hline 4. & $\mathrm{kt} \mathrm{m} / \mathrm{k} 104$ & - & harpu & $\breve{s a} A n n a$ \\
\hline 5. & $\mathrm{kt} 93 / \mathrm{k} 946$ & | & ino adrim & so Anno \\
\hline 6. & ATHE 75 & - & harpū & mēraštum \\
\hline 7. & $\mathrm{kto} / \mathrm{k} 40$ & $\|$ & șibit niggallim & harpū \\
\hline 8 & $\mathrm{ktf} / \mathrm{k} 65$ & VII & șibit niggallim & ša Tuhtuhānim \\
\hline 9. & $\mathrm{kt} \mathrm{z} / \mathrm{t} / 4$ & - & erāb odrim & qiitip kerōnim \\
\hline
\end{tabular}

In 4 and 5 the order of payment stipulaled in the conlract is so Anno - harpu / ina adrim. In kl $91 / k 518$ a debt of 15 shekels of silver is equated with 5 bags of groin and payment in grain has to take place ino harpim, but if poyment is in silver, they will pay at the festival of Anno.

b) one commodity to be paid in instalments

\begin{tabular}{|c|c|c|c|c|c|}
\hline text & month & commodity & instalment 1 & instalment 2 & instalment 3 \\
\hline 10. kt k/k 93 & $\|$ & silver & șabāt nigallim & ša Anno & $\operatorname{das} \bar{u}$ \\
\hline 11. $\mathrm{kl} 87 / \mathrm{k} 258$ & - & silver & horpü & so Anno & \\
\hline 12. kt $87 / \mathrm{k} 336$ & - & silver & $\operatorname{dos}^{3} \bar{U}$ & qitip kerânim & \\
\hline 13. kt a/k 899 & - & silver $^{2}$ & horpü & ša Anno & \\
\hline 14. ICK 2,4 & - & silver & ša Anna & sa Nipos & \\
\hline 15. ICK 2, 50 & - & silver & so Anno & so Parko & \\
\hline
\end{tabular}

c) month-names in combination with payment terms

16. ATHE 2

17. TPAK 98

18. ICK 1, 40

19. TC 3, 227

20. kt n/k 17l6b

21. $k 180 / k 153$

5. $\mathrm{kt} 93 / \mathrm{k} 940$

7. $\mathrm{kro} / \mathrm{k} 40$ silver debt, in month III, payment in 13 weeks ( 3 months) at Parka's festival. silver debl, from das'iz, monih VII, from the week of Ennam-Aššur, year 113. silver debt, from the week of kassium, payment in 15 weeks, on Parka's festival. silver debl, from week $x$, month VII, year 107, half on Tuhtuhōnum's festival, half in 15 weeks (after first instalment or from start of transaction?).

silver debt, from week $x$, month IV, payment in one year, "when the ruler leaves the temple of Nipas".

silver debt contracted in month 1, to be paid ana Tuhishanni.

mixed debt, month I, silver ino sa Anno, grain ina adrim.

mixed debt, month II, barley ina șibit niggallim, silver ana harpé.

Matouš 1965, 180, tentatively concluded that the order of the festivals, according to the Babylonain spring calendar (months in Roman numerals) would have been:
Anna ca. $1 / 11$
Tuhithānum ca. III/N
Nipas ca. VIINIII
Parko ca. XI/XII. In the Assyrian calendar (month 1 = Bēlet-ekallim, ca. Oct.-Nov.) this would mean: 


\section{Annaca. VI/VII Tuhiuhänum ca. YIII/IX Nipasca. XII/I. Parkaca. INN.}

Some festivals are related to the calendar by the mention of the month in which the debt was contracted:

5:

16:

20:

18: month I, silver at Anna's festival, grain at the end of the havest; month III (+ week), ${ }^{951}$ in 3 months at Parka's festival, hence Parka $=\mathrm{ca}$. VI; month IV, payment after a year al Nipas' festival, hence Nipas = ca. IV; month VII, half of debt at Tuhtuhōnum's testival, the other half 15 weeks later.

The texts under a) betray a pattern of delivering barley in the summer, at the time of the (completion of the) harvest, which falls in the beginning of harpu, and paying silver in autumn, at the time of the harvest of the grapes, Sept./Oct. $(1-3,9)$, but there could of course be exceptions, conditioned by the wishes of creditor and/or debtor. Correlating agricultural dales and features with festivals is to some extent possible, since the latter most probably were also linked with the main events of the agricultural year. This means that they could figure as alternative datings, perhaps used because they offered the advantage of being more precise, thanks to the cultic calendar, ${ }^{952}$ since festivals would be held on particular days and generally would last only a short period.

Sibit niggallim, the (start of the) harvest, must be the (beginning of the) summer (harpu), July, ca. month $X$, and erāb adrim, "when (the barley) comes on the threshing floor", its end, several weeks later, ca. month $X \mid$; the two due dates in 7 accordingly should mean the beginning and the end of the harvest. When there are different due dates (but to all appearances still within one year) for silver and grain, sibit niggallim is followed by harpü and sa Tuhiuhānim (7-8), and erāb adrim (9) and ebürum (1-3) by qitip keranim (Sept./Oct.). The fact that in 4 and 5 payment of silver ina sa Anna precedes payment of grain ina adrim/ harpe must be explained from the date of the debt in 5 ( 4 does not mention a date), month I; the order of payment suggests that the festival of Anna preceded the havest, but how long is unknown. Of the texts that demand payment of one commodily in two instalments, only two mention phases of the agricultural year, in 10 the first instalment is at the beginning of the harvest, the third in spring $\left(d a \bar{s}^{\prime} \vec{u}\right)$; in 12 the first instalment is in spring, the second in autumn (aitip keranim!. Text 17 shows that the Assyrian month VIl fell in "spring" ica. April-June!, which suggests that month I may be equated with Oct./Nov.

These data imply that the main dates for the payment of such loans were the summer, the time of the grain harvest, and the outumn, the time when the grapes were picked. Since at leasi part of these loans were presumably consumptive ones, payment normally would take place as scon as the debtor had acquired the means to do so from what his harvest had yielded, grain or fruits. The main harvest and therefore due date was that of barley and whear and this suggests that harpü, ebürum, kubur untitim, sibit niggallim, eșädum, and adrum were alternative ways of stipulating that date; the variation may be due 10 the fact

951 The week-eponym is attested five times, four times during month $\mid \mathrm{l}$ and once during month $1 \mathrm{ll}$ of eponymy year 93.

952 With festivalt the preposition ina is more frequent than ana. 
that no fixed terminology (the Assyrian terms could be translations of Anatolian ones) had yet evolved (the sequence șibit niggallim - "spring" occurs only in 10). These terms/dates accordingly all refer to July/August. Therefore they are never contrasted or mentioned as alternatives, with the exception of text 7 , where the rather vague harpu must have meant the end of the summer, after the harvest had been completed, but before the autumn. The second main due date apparently was the autumn, in which two events took place, the picking of the grapes (qitip kerannim) and the ploughing and sowing of the fields (erösum, meraštum). They did not coincide, the former happened in Sept./Oct., the latter in Oct./ Nov. Dozens of loans (also those mentioning only one due date) mention qitip kêränim, but references to the cultivation of the fields are much rarer (in all five occurrences) and méraštum (in the sequence harpü-méraštum) occurs only in 6 .

Since the main agricultural activities could take many weeks, there apparently occasionally was the wish to be more specific. This was rare with sibir niggallim, though the harvest may have taken several weeks, and we have only once "after the handling of the sickle". We also have "alter the picking of the grapes", hardly a chronological distinction, since the picking of the grapes presumably did not require much time. The unique "at (the time of) the olives" could be a further chronological specification, but it is too rare to draw conclusions. The various expressions using adrum do not imply chronological differences, but in connection with the cultivation of the field (êrösum, see above chapter 2.2.2) one may differentiate between its beginning ("when one goes out to plough") and its end ("when the ploughing is finished"), which could be alternative dates, depending on how much time this work required. However, since ploughing did not yield something that could be used to pay one's debts, the chronological distinction may have been of minor importance. The date ana/ ino buqlatim is too rare and too ill-defined to draw chronological conlusions, but "the plucking of the wool" (ana buqünim) and "when the sown/the grain comes up/appears", datable to late spring and late outumn, may refer to specific, but anyhow not very common times of payment.

The next question is how these agricultural dates relate to those named after religious festivals, and how the former can help us to fix or approach the dates of the latter, many of which, to all appearances, must also have been related to the phases and main events of the agricultural year. The data of table a) and b/ provide a few clues: a comparison of various columns suggests that the festival of Anna took place alter the summer, somewhere in autumn, and this fits text 10, which places it between the summer and the spring. "Autumn" implies two possibilities, the time of the plucking of the grapes (Sept./Oct.) and that of ploughing (Oct./Nov.), and the choice is difficult. One of the two presumably should be reserved for the festival of Tuhtuhānum, which according to rext 8 also fell after the summer. Its position in (late?) autumn would fit the information of 18 (several months after month VII) and, in a general way, of 21 (dated to month I), if the credit term was at least ten months. Table b) also indicates that the festivals of Nipas and Parko were later than that of Anna and the autumn, presumably somewhere between early spring and summer, which is confirmed by 16 of table c). This table is helptul in mentioning in which month and week $a$ debt started, but unfortunately we cannot narrow down these dates, since we do not know which part of the month the week-eponyms mentioned in 18-20 covered. Moreover, there 
is still uncertainty when the Assyrian calendar started, at the time of the autumnal equinox or at that of the winter solstice (Larsen prefers the latter). Anyhow, 16 makes it clear that Parka's festival fell in month $\mathrm{Vl}$, which fits the sequence of text 15. If we assume that the visit of the suler to the temple of Nipas, mentioned in 20, took place during this (annual) festival, the credit term of one year would fix it in month IV, before the festival of Parka. Texts 18 and 19 are less helpful, because we do nol know whether in case of payment in several instalments their length was the same or nol (both are attested in Assyrian debt-notes that give these perods in weeks). Differences in the length of the instalments could be due to the time when the liability started, the wish to have the money back at a particular time, or personal circumstances. If in 19 (month Vili) the first term was also 15 weeks, Tuhtuhānum's festival should be placed in month $X I / X$, and the loan of 21 (of month I) would have run for at least eight to nine months. If not, this festival could have been earlier or later, and later is preferable considering the likely dates of the festivals of Nipas and Parka and because of the sequence "harvest" - Tuhtuhānum in 8 , which suggests a festival after the summer. Most references are to the festival of Anna, for which texts 4-5, 10-11 and 13 suggest the (late) autumn. The only problem, as mentioned above, might be 5 , where this festival precedes the harvest, but we may assume (also because the order of the payments is unusual) that it deals with a debr contracted at the end of the previous calendar year with a credit lerm of perhaps nine to ten months.

On the basis of these data, considerations and uncertainties, taking into account that festivals during the Anatolian winter (months $\| I-V$ ) are less likely as payment dates, I suggest the following sequence and dates for the main festivals:

$\begin{array}{lll}\text { festival of } & \text { manth } & \text { agricultural season } \\ \text { Anna } & \text { ca. Oct./Nov. } & \text { late autumn } \\ \text { Nipas' } & \text { ca. March/April } & \text { beginning of spring } \\ \text { Parka } & \text { ca. May/June } & \text { summer and grain harvest } \\ \text { Tuhtuhānum } & \text { ca. Sept./Ocl. } & \text { harvest of fruits. }\end{array}$

This concerns only the most frequently mentioned and therefore presumably most important and os payment terms most suitable festivals. Several others ( $\$ 2.1$ nos. 2-4 and 8-9), though rarely mentioned, also occur as due dates and have to be fitted into the calendar, which makes my reconstruction hypothetical. We need more data to discover whether the (rare) occurrences of the latter are explainable from their seasonal dates, or were due to regional variation or to the specific wishes or affiliations of creditors and debtors. The publication of more Anatolion debt-notes with due dates of the type analyzed here, especially those from the archives of Anatolian moneylenders and business-men (Peruwa, Suppiahšu, Sarapunuwa, etc.) will certainly allow us to reach more certainty.

My concern, here and in other tables and lists, has been to register and arrange the data now available in order to present and discuss a framework into which the new data we may expect from the publication of thousands of still unpublished "Kültepe texts" can be fitted. 


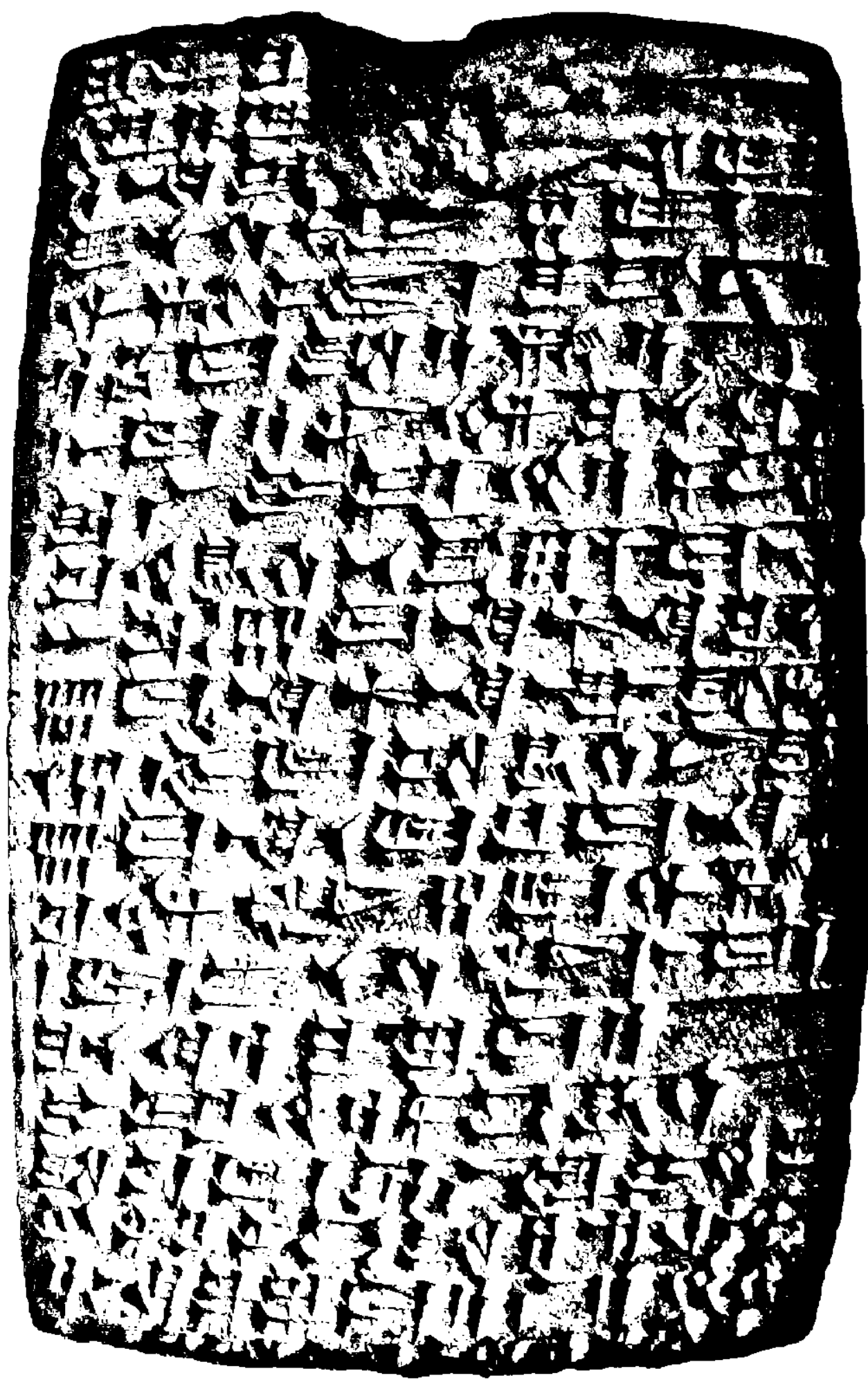

Fig.l Obverse of BM 113258, cuneiform copy published as CCT 2,2, a letter of Šalim-ahum to Püsukēn, written in Assur in a protessional hand that exhibits the classical Old Assyrian paleography. 


\section{ABBREVIATIONS AND BIBLIOGRAPHY}

\section{AbBreviations}

Abbreviations for editions of cuneiform texts, series and journals are those used in the Chicago Assyrian Diclionary, vol 17/III (Chicago 1992), v-xii, but note:

AKL

AKT 1-3

AMMY

AOAT

ArAn

$C M K$

CRRA/34

CRRA/38

CRRA/39

CRRA/40

CTMMA

DTCFD

El

GKT

Prag $1+$ number

$\mathrm{ICH}$
The Assyrian King List, as edited in Grayson 1981.

Ankara Kültrepe Tabletleri = Ankaraner Kültepe Texte, I, Ankara,1990; II, Ankara, 1995; III, Stuttgart 1995.

Anadolu Medeniyetleri Müzesi Yilliğı (Ankara 1986ff.).

K.R. Veenhof, Aspecls of Old Assyrian Trade and its Terminology, SD 10, Leiden 1972.

Archivum Anatolicum, Ankara Üniversilesi Basımevi.

Texts translared in Michel 2001, quoted by number.

XXX/Vime Rencontre Assyriologique Internationale, 6-10/VII//987, Istanbul. Kongreye Sunulan Bildiriler, TKY XXVI/3, Ankara 1998.

D. Charpin-F. Joannes (eds.), La circulation des biens, des personnes et des idees dans le Proche-Orient ancien, CRRA/ 38, Paris 1992.

H. Waetzoldt-H. Hauptmann, Assyrien im Wandel der Zeiten. XXXIXe Rencontre Assyriologique Internationale, Heidelberg 6.-10. Juli 1992, Heidelberger Studien zum Alten Orient 6 , Heidelberg 1997.

K.R. Veenhof (ed.), Houses and Household's in Ancient Mesopotamia, CRRAI 40, istanbul 1997.

1. Starr (ed.), Cuneiform Texis in the Metropolitan Museum of Ant, Vol. 1. Tablets, Cones and Bricks of the Third and Second Millennia, New York 1988, 92-142, nos. 71-98, Old Assyrian Texts, by M. Trolle Larsen.

Dil ve Tarih-Cografya Faküliesi Dergisi (Ankara).

G. Eisser - J. Lewy, Alrassyrische Rechtsurkunden vom Kültepe, I-II, MVAeG 30, 35/3, Leipzig 1930, 1935.

Grammatik der Kültepe-Texte, see under Hecker 1968.

Siglum by with the texts edited in Hecker e.a. 1998 are quoted.

International Congress for Hittitology.

1. Uluslarasi 1. Hititoloji Kongresi Bildirileri, 19-21 Temmuz, Corum, 1990, Corum (without dare).

11. Atti del /l Congresso Internazionale di Hittitologia, Pavia 1993, Pavio 1995.

III. Uluslararı 3. Hilitoloii Kongresi Bildirileri, Corum 1996, Ankara 1998.

IV. G: Wilhelm (ed.), Akien des IV. Internationalen Kongresses für Hethiolologie, Würzburg 1999, SBBOT 45, Wiesbaden 2001. 


\section{KKS}

ki a (etc.)/k

kt 73(etc) / $/ k$

$\mathrm{kt} . . / \mathrm{t}$

MEC

POAT

RIMA 1

RIME 4

$O A$

$O A A$

OAAS

Sadberk

Studies Alp

Studies Bilgic

Studies Garelli

Situdies Gülerbock 1

Sindies Gürerbock 2

Studies Hirsch

Studies Kienas!

Siudies larsen

Studies londsberger

Siudies Marous

Studies Oelsner

Studies N. Özgǘ

Sindies T. Özgüs
L. Malouš - M. Maloušovó-Rajmová, Kappadokische Keilschrifttafeln mit Siegeln ous den Sammlungen der Karlsuniversität in Prag. Prag 1984.

Sigla of texts from Küliepe $(k)$ found in kārum Kanish (/k) from 1948 (=a) until $1972(=z)$.

Külsepe toblets found since 1973 in Kārum Kanish.

Kültepe tablets found on the ciry-mound (tepe).

Mari Eponym Chronicle, edited by Birot 1985.

W.C. Gwaltney Jr., The Pennsylvania Old Assyrian texts, HUCA Sup-plement 3, Cincinnoli 1983.

Royal Inscriptions of Mesopotamia. Assyrian Periods, vol. 1. A. K. Groyson, Assyrian Rulers of the Third and Second Millennia BC /to IIIS BC). Toronto 1987. Royal Inscriptions of Mesopotamia. Early Periods, vol. 4. D. R. Frayne, Old Babylonian Periad (2003-1595 BC). Toronto 1990.

Old Assyrian.

Old Assyrian Archives. Leiden $2002 \mathrm{f}$.

Old Assyrian Archives. Studies. Leiden $2003 \mathrm{f}$.

V. Danbaz, Sadberk Hanım Müzesinde Bulunan Civizazll Belgeler, Istanbul 1999. H. Otten e.a. (eds.), Hittite and Other Anatolian and Near Eastern Studies in Honour of Sedar Alp, Türk Tarih Kurumu, Ankara 1992.

H. Ertem e.o. (eds.), Emin Bilgic anı Kitabi, Archivum Anatolicum 3 (1997). Ankara 1998.

D. Charpin F. Joannès (eds.), Marchands, diplomates et empereurs. Érudes sur la civilisation mesoporamienne offertes ò Paul Garelli, Paris 1991.

K. Bittel e.o. (eds.), Analolian Studies Presented to Hans Guslov Gürerbock on the Occasion of his 65th Bitthdoy, PIHANS 35, Istanbul 1974.

H.A. Hoffner-G.A. Beckman (eds.), Kanišsumar: A Tribure to Hans G. Gürerbock on his Seventy-Fith Bitthdoy, AS 22, Chicago 1980.

Fessschritf für Hans Hirsch zum 65. Geburtslog gewidmet $=$ WZKM 80 (1996).

G.J. Selz (ed.), Fesschritf fir Burkhan Kienost zu seinem 70. Geburtsigge, AOAT 274, Münster 2003.

J.G. Dercksen (ed.). Assyria and Beyond. Siudies Presented to Mogens Trolle lorsen, PIHANS 100, leiden 2004.

H.G. Güterbock-Th. Jacobsen (eds.), Studies in Honor of Benno Londsberger on his Seventy-Fith Bitthday, April 21, 1965, AS 16, Chicago 1965.

B. Hrouska-G. Komorôczy leds.), Fesschrift lubor Marous, I-II, Budapes! 1978.

J. Marzahn-H. Neumann (eds.), Assyriologica el Semitica. Festschrift für joachim Oelsner, AOAT 252, Münsler 2000.

M.J. Mellink e.a. (eds.), Aspects of Art and kanography. Anaralia and is Neighbours. Studies in Honor of Nimet OZzǚc. Ankara 1993.

K. Emre e.o. (eds.), Anardia and the Ancient Neasr East. Sudies in Honor of Tahsin Ozgüc, Ankara 1989. 
Siudies Slol

Studies Veenhof

TPAK

TTKY
Festschriff for M. Stol (forthcoming, CDL-Press), Bethesda 2007). W.H. van Soldt e.a. (eds.), Veenhof Anniversary Volume. Studies Presented to Klaas R. Veenhof on the Occasion of his Sixty-fitth Birthday, PIHANS 89, Leiden 2001.

C. Michel-P. Garelli, Tablettes paléo-assyriennes de Kültepe, 1 (K, $90 / K)$, Poris 1997.

Türk Tarih Kurumu Yayınlarından (Publications of the Turkish Historical Sociery), Ankara. 


\section{BIBLIOGRAPHY}

NB. Several publications by the same author in the same year are distinguished by adding the letters $a, b$. etc., in which I have followed the system of C. Michel's bibliography (below. Michel 2003c, with a first supplement 10 be published in A O 51, 2007). also when I do not list them all, so that certain letters are missing in my list. In her lists of lablets these abbreviations are used to indicate where texts are published, studied or quoted and by consulting them readers of this volume can easily find information on texts quoted in this volume only by excovation or publication number. Note that the edition of the eponym list, Veenthof 2002 in Michel 2003c, due to the time of its publication is listed below as Veenhof 2003.

AlBaYRAK, I.

1998 Koloni Cağanda Yerli Bir Bayan "Madawada", $\mathrm{KCH} 3,1-14$.

2000 Ein neues allossyrisches Testament aus Küliepe, $\operatorname{Ar} A \cap 4,1-27$.

2001 Kültepe Metinlerinde Gecen mä'ü, "Su" Kelimesi, AMMY 2000, 300-11.

2002 Kültepe'den Degisik Bir Masraf Listesi, ArAn 5, 1-10.

2003 Kaniš-Kärum'unun Bir Mekiubu, ArAn 6, 1-9.

2004 "She will live, eat and be anointed together with them", in: Studies larsen, 9.20 (Turkish version in $\operatorname{Ar} A n 7,2004,1-21$ ).

2006 Fünf Urkunden aus dem Archive von Peruwa, Sohn von Šuppibra, JEOL 39 (2005) 95-106 (edits $\mathrm{kl} \mathrm{c} / \mathrm{k}$ 1634-35, 1637, 1639b and 1041).

Bär, J.

2003 Die älieren Ischior-Tempel in Assur, WWOG 105, Saarbrücken.

2005 Die Beziehungen zwischen Mari und Assur während der sokkonokkuPeriode, in: W.H. van Soldi (ed.). Ethnicity in Ancient Mesopotamia (CRRAl 48, Leiden 2002), Leiden, 11-30.

BAIKAN, K.

1955 Obsenations on the Chronological Problems of the Kärum Kanis, TKKY VIV/28, Ankara.

1957 Lether of King Anum-Hirbi of Mama to King Warshamo of Kanish, MKY VII/3la, Ankara.

1965a The Old Assyrian Week, in: Studies Landsberger, 159-73.

1905b Review of L. Matous, ICK 2, in OLZ60 \{1905\$146-62.

1967 Contributions to the Understanding of the Idiom of the Old Assyrian Merchants of Kanish, ONS 36, 393-415.

1973 Eine Schenkungsurkunde aus der althethitischen Zeit, getunden in Inandik 1960. Ankaro

1974 Cancellation of Debts in Cappadocian Tablets from Küliepe, in: Studies Gürerbock 129-41.

1979 Makris and asis, Components-parts of wagons and ploughs respectively in a Cappadocian tablet from Kültepe, in: Florilegium Anarolicum. Mélanges offerts a Emmanue/ Laroche, Paris, 49-58.

1986 Betrothal of Girls During Childhood in Ancient Assyrio and Anotolia, in: Shudies Gürestock 2. $1-12$.

1992 The Conception of Trinity in the Tablets of Külrepe, in: Studies Alp, 15-34.

BAYRAM, 5.

1990 Kültepe tabletlerinde gecen yeni bir vaóde ifódesi ve cıkan neticeler, Türk Tanih Kongresi 10, Ankara, 453-62. 
1998 New and Some Rare Geographical Names in the Kültepe Texts, in: ArAn $3=$ Studies Bilgic 41-66.

2001 The nadium of the Stele, in: Studies Veenhof, 1-8.

Bayram, S. - Ceccen, S.

19956 Neve Urkunden über Heiat und Scheidung aus Kaniš, $A r A n$ 1, 1-12.

1996 The institution of Slavery in Ancient Analolia in the light of New Documents, Belleten 60, 606-45. BAYraM, S. - VeENHOF, K.R.

1992 Unpublished Küllepe Texts on Real Estate, JEOI 32, 87-100.

BIGGS, R.

1996 A Woman's Plight in an Old Assyrian Lether, in: Studies Hirsch, 47-52.

BuGIC, E.

195la Die Ortsnamen der "kappadokischen" Urkunden' im Rahmen der alten Sprachen Anatolies, A $1015,1-37$.

1954 Die einheimischen Appellativa der Kappadokischen Texte und ihre Bedeutung für die Anaıolischen Sprachen, Ankara Üniversitesi Dil ve Tarih-Coğratya Fakültesi Yayınları no. 96.

1964 Three Tablets from the Ciry Mound of Kültepe, Anatolia 8, 145-63.

BIROT, $M$.

1985 Les chroniques "assyriennes" de Mori, MAR/4, 219-42.

BRYCE, T.R.

1998 The Kingdom of the Hittites, Oxford, 21-43, "Anatolia in the Assyrian Colony Period". CameYer, $P$.

1977 Das Grab eines altassyrischen Kaufmans, Iraq 39, 87-98.

Canby, J.V.

2003 A Figurine from Urkesh: a "Darling" from Troy to Mesopolamia, Iraq 45, 171-73.

Carruga, $O$.

2001 Anitta res gestae: paralipomena I, in: /CHIV, 51-72.

CAnR, $M$.

2004 Kültepe'den yerli bir tüccara ait bes tablet, ArAn 7, 45-57 (edits kt e/k 154-158).

CECEN, S.

1990a Kültepe Metinlerinde Bulunan Yeni 'waklum' Mektupları, DTCFD 34, 35-51.

1990b Yeni Kültepe Metinlerine Göre Yerli-Asurlu Münâsebetleri, in: $/ C H I, 140-53$.

1995 mutānü in den Kültepe-Texten, ArAn 1, 43-72.

1997a Kaniš kōrum'unun Diğer Kōrumve Wabartumlar'o "KÙ.AN" (amưum) île ilgili Önemli Talimatlan, Belleeren 61, 219-33.

1997c idinnum Kelimesinin Anlamı Hakkında Yeni Bir Teklif, ArAn 2، 19-24.

19980 Yerli Krallarin Mabedleri Ziyareli ve Cikan Neticeler, in: $/ C H \mid l l, 119-24$.

1998b Yeni Delillere Göre Kültepe'de "kan parasi", in: CRRA/34, 291-291, pl. 71-73.

CECEN, S. - HECKER, K.

1995 ina mälika eblum. Zu einem neven Text zum Wegerecht, in: M. Dietrich - O. Loretz (eds.), Fesischritt für Wolfram Freiherrn von Soden zum 85. Geburtsiag am 19. Juli 1993. AOAT 240, Münster, 31-41.

Charpin, D. - Durand, J.-M.

1997 Aššur avant l'Assyrie, MAR/8, 367:-92. 
Charpin, D. - Ziegler, N.

2003 Mari el le Proche-Orient ò l'époque omorrite. Essai d'histoire politique. Florilegium marianum 6. Paris.

DAllEY, $\mathrm{S}$.

1979 A Calologue of the Akkadian Cuneiform Texts in the Collections of the Royal Scottish Museum, Edinburgh, Edinburgh, nos. 6-14 (Old Assyrian texts).

DERCKSEN, J.G.

1996 The Old Assyrion Copper Trade in Anatolia, PIHANS 75, Istanbul.

1998a The Silver of the Gods. On Old Assyrian ikribü, ArAn 3, 75-100.

1998b Review of Michel-Garelli 1997 (TPAK) in AKO 44/45, 333-39.

1999 On the Financing of Old Assyrian Merchants, in: J.G. Dercksen (ed.), Trade and Finance in Ancient Mesoporamia, MOS Studies I, Leiden, 85-99.

2000 Institutional and Private in the Old Assytian Period, in: A.C. Bongenaar (ed.), Interdependency of Institulions and Privale Entrepreneurs, MOS Studies 2, Leiden, 135-52.

2001 "When we met in Halluš". Trade According ro Old Assyrian Texts from Alishar and Bogazköy. in: Studies Veenhor, 39-66.

2002a Kulfureller und wirtschattlicher Austausch zwischen Assyrern und Anatoliern (Anfang des zweiten Jahnausends v. Chr.), in: H. Blum e.a. (eds.), Brückenland Anarolien? Ursachen, Exrensitäl und Modi des Kulturaustausches zwischen Analolien und seinen Nochbarn, Tübingen, $35-44$.

2002b Review of Hecker, K. e. a. 1998 (Prag I) in AKO 48/49, 183-96.

2003 Twee Oudassyrische koningen: Ilusjuma en Erisjum, in: R.J. Demaree-K.R. Veenhof (eds.), Zij schreven geschiedenis. Historische documenten vit het Oude Nabije Oosten, leiden, 93102.

2004a Otd Assyrian Institutions, MOS Studies 4, Leiden.

2004b Some Elements of Old Anatolian Society in Kaniš, in: Studies Larsen, 137-177.

2005 Metals According to Documents from Kültepe-Kanish Dating to the Old Assyrian Colony Period, in: Ünsal Yalšin (ed.), Anarolian Meral, III, Der Anschnitt(Bochum), Beiheft 18, 17-34.

2006 Adad is King! The Sorgon Text from Kültepe, JEOL 39 (2005) 107-130 (new edition and analysis of the text published in Günbatt1 19980).

DerCKSEN, J.G. -DONBAZ, V.

2001 Merchants in Distress: an Old Assyrian Text mentioning habbät,. JEOL 35-36, 103-10.

DONBAZ, $V$.

1984a A Kültepe Text from the Museum at Adana (237B), AKO 31, 15-24.

1985 More Old Assyrian pablets from Aššur, Akkadica 42, 1-23.

19880 The business of Ašéd, an Anatolian merchant, AKO 35, 48-63.

19890 Some remarkable contracts of 1-B Period Kültepe tablets (I), in: Studies T. Özgüc. 75-98.

$1989 \mathrm{~b}$ Old Assyrian terms for bread, in: H. Behrens e.o. (eds.), OUMU.E. OUB.BA.A. Studies in Honor of Ake W. Sjöberg. Philadelphia, 91-97.

19900 Külrepe 1-B Kati Tabletlerine Genel Bakis, ITK 10 1986, 433-51.

1993a Some remarkable contracts of 1-B Period Külrepe tablets (II), in: Studies N. Özgǘ, 131-54.

$1996 \mathrm{~b}$ Old Assyrian Influence on the Hittite Onomasticon and Toponyms, Anadolu Arastrmator 15 , 229-41. 


\section{Bibliography}

1998c Tablets from the Palace of Waršuma, CRRA/34, 413-19.

200la Mahor patrim Sa Ašsur. A new interpretation, in: Studies Veenhof, 83-101.

$2001 \mathrm{~b}$ Some Recently Discovered kăruml.b Tablets and Related Obsenvations, in: KCHIV, 106-114.

$2001 c$ The Eponymy of Urad-Šerūa son of Ašsur-bäni. Inventory No. 1439, NABU2001/55-56.

2004a Some Old Assyrian Texts with Rare Terminology, in: Studies Larsen, 179-89.

2004b Some remarkable contracts of 1-B Period Kültepe tablets (III), in: D. Groddek-S. Rössle (eds.), Sarnikzel. Hethirologische Studien zum Gedenken an E.O. Forrer, Dresden, 271-84.

2005 An Old Assyrian Treary from Küliepe, JCS 57, 63-68.

Doneaz, V. - Horansanic̆E.

1976 Burso Arkeoloji Müzesinde Bulunan Kültepe Tabletleri, Belleten 40, 175-83.

DONBAZ, V. - VEENHOF, K.R.

1985 New Evidence for some Old Assyrian Terms, Anádolica 12, 131-55.

DreEL, G. VAN

1969 The Cult of Ašsur, Studia Semilica Neerlandica 13, Assen.

DURANO, J.-M.

1997 Les documents épistolaires du palais de Mari, I, LAPO 16, Paris.

1998 Les documenis épistolaires du palais de Mari, II, LAPO 17, Paris.

2000 Les documents épistolaires du pakais de Mari, III, LAPO 18, Paris lesp. 45-60, "Les marchands et les caravanes").

2001 Une alliance matrimoniale entre un marchand assyrien de Kanesh et un marchand mariote, in: Siudies Veenhof, 119-132.

EDER, CHr.

2004 Assyrische Distanzangaben und die absolute Chronologie Vorderasiens, Aof 31, 191-236.

EOZARD, D.O.

1989 Alrossyrische nuwö'um, in: Siudies T. Özǘ, 107-10.

2001 Silbenschliessendes ['] im Altassyrischen?, in: Siudies Veenhof, 133-35.

EIDEM, J.

1991 An Old Assyrian Treaty from Tell Leilan, in: Sivdies Garelli, 185-207.

2004 In the names of Aššr!, in: Siudies Larsen, 191-203.

EIDEM, J - LAESSEE, J.

2001 The Shemshara Archives 1. The letters. Historisk-filosofiske Skrfiter 23, Det Kongelige Danske Videnskabernes Selskab, Kabenhavn.

EISSER, G.

1939 Beiträge zur Urkundenlehre der altassyrischen Rechrsurkunden, in: Festschritt Paul Koschaker zum sechzigsten Gebursiag überreicht von seinen Fachgenossen, III, Weimar, 94-126.

ESEN, I.

19941953 Ylı Kültepe Kazılarında Bulunmus Olan Bir Grup Vesika, 1, AMMY1993, 34-53.

20001953 Yilı Kültepe Kazilarndo Bulunmus Olan Bir Grup Vesika, 2, AMMY2000, 194-214.

20011953 Yilı Kültepe Kazılarında Bulunmus Olan Bir Grup Vesika, 3, AMMY 2001, 257-64.

FARBER, W.

1990 Honum kauft Gadagada. Eine aliassyrische Selbstverkaufs-Urkunde, AuOr 8, 197-203.

2001 "... But she refuses to take the silver!" The Strange Case of the ašs̆at rabi sisi'ē, in: Sindies Veenhof, 137-143. 
FORLANINI, $M$

1985 Quelques remarques sur les rextes cappadociennes, Hethitica 6, 45-67.

1992 Am mittleren Kızilırmak, in: Studies Alp, 171-79.

1995 The Kings of Kaniš, in: KCHII, 123-132.

2001 The Geography of Hittile Anatolia in the Light of the Recent Epigrophic Discoveries, in: $\mathrm{KCH}$ IV, 217-27.

2002 Tapikka: una marca di frontiera. Note sulla struttura territoriale ed economica, in: S. de Martino - F.P. Daddi (eds.), Anatolica Antique. Studi in Memoria di Fiorelle Imparati, I, Firenze. 255-77.

2004 Dall'Alto Hobur alle montagne dell'Anatolio nel II millennio A.C. Note sulla Geografica storica di una regione poco conosciuta, Amurn 3 (Paris), 405-28.

2006 Étapes et itineraries entre Ašsur el l'Anatolie des marchands paleo-assyriens: nouveaux documents et nouveau problemes, KASKAL 3, 147-170.

GALTER, H.D.

1996 Gott, König, Vaterland. Othographisches zu Aššur in altassyrischer Zeit, WZKM 86, 127-41.

1997 Assyrische Königsinschritten des 2. Jahtausends v. Chr. Die Entwicklung einer Texłgattung, in: CRRA/39. 53-59.

1998 Textanalyse assyrischer Königsinschriften: die Puzur-Aššur-Dynastie, SAAB 12, 1-38.

2004 Geschichte als Bauwerk: Der Aššurtempel und das assyrische Geschichisbewustsein, in: $G$ Frame \{ed.\}. From the Upper Seo to the Lower Sea. Studies on the History of Assyria and Babylonia in Honour of A.K. Grayson, PIHANS 101, Leiden, 117-35.

Garelu, P.

1963 Les Assyriens en Cappadoce, Paris.

1964-66 Tablettes cappdociennes de collections diverses, RA 58 (1964) 53-68, 111-136; RA 59 (1965) 19-48, 149-176; RA 60 (1966) 95-152 (145-152: index).

1977 Marchands el ramkarü assyriens en Cappadoce, Iraq 39, 99-107.

1979 a Femmes d'affaires en Assyrie, ArOr 47, 42-48.

1982 Serments et procès dans l'ancienne Assyrie, in: Shdies Kraus, 56-60.

1989 Le marchè de Burushattum, in: Studies TÖzgüc, 149-152.

19980 Le problème du ramkārum à l'èpoque paleo-assyrienne, in: Studies Bilgic, 125-30.

1998b Hahhum, un relais assyrien sur la route commerciale de la Cappadoce, in: CRRA/34, 451450.

Garelu, P. - Homes-FredericQ, D.

1987 Une tablette de la couche lb de Kaniš, in: F. Rochberg-Halion (ed.), Language, Literature and History: Philological and Historical Studies Presented to Erica Reiner, AOS 07. New Haven, 107-123.

Gareli, P. - Kennedy, D.

1960 Seize lablettes coppadociennes de l'Ashmolean Museum d'Oxford, KCS14, 1-22.

GASCHE, $\mathrm{H}$.

2003 La fin de la première dynastie de Babylone: une chule difficile, Akkadica 124, 205-20.

GASCHE, H., E.A.

1998 Dating the Fall of Babyton. A Reoppraisal of Second Miltennium Chrondogy. Mesopatamion Hislory and Environment, Series II, Memoir IV, Ghent. 
GelB, I.J.

1974 An Old Assyrian Votive Vessel, in: Studies Gülerbock 1, 95-104 with pl. XX.

GelB, I.J. - SOLIBerGer, E.

1957 The First Legal Document from the Later Old Assyrian Period, JNES 16, 163-75.

GÖKCEK, L.G.

2003 Kültepe Merinlerinde Geçen Kaplar, ArAn 6, 73-87 (on ealing and drinking pors).

2004 Asur Ticaret Kolonileri Caği'nda (M.Ö 1975-1723) Anadolu'da Haywancilik ve Hayvan

Ticareti, $\operatorname{Ar} A n$ 7, 59-78 [on onimal husbandry and animal trade).

GOODNICK WeSTENHOLZ, J.

1997 Legends of the Kings of Akkade, Mesopotamion Civilizations 7, Winona Lake.

1998 Relations between Mesopotamia and Anatolia during the Age of the Sargonic Kings, in: CRRA/ 34, 5-22.

GRAYSON, A.K.

1981 Königstisten und Chroniken. B. Akkadisch, § 3.9-11, King Lisls 9-11, Assyrian King Lisl, in: RIA 7. Berlin 1980-1983, 101-16.

GÜNBATĞC.

1989 Ev Satiși lle llgili Besültepe Tableti ve Bunlardan Cikan Bazı Sonuclar, Belleien 53, 51-59.

1995 More Examples of Correspondences between kärumis, ArAn 1, 107-15.

1997 Two New Tablets Throwing Light on the Relations between Anatolian Kings and Assyrian Merchants, ArAn 2, 25-37.

19980 Kültepe'den Akadlı Sargon'a âit bir Tablet, ArAn 3 = Sivdies Bilgic, 131-55.

1998c Kārum'lar Arasındaki Metuplașmalardan Yeno Örnekler, in: CRRA/34, 479-85 with plates 139-41.

2001 Kültepe'den Kervan Güzergāhlarma Ișik Tutan Iki Yeni Metin, ArAn 5, 79-91.

2004 Two treaty texts found at Kültepe, in: Siudies Larsen, 249-68.

HAAS, $V$.

1994 Geschichte der hethitischen Religion, HdO Abt. I, Band 15, Leiden.

HARPER P.O, E.A.

1995 P.O. Harper, E. Klengel-Brandi, J. Aruz, and K. Benzel (eds.), Discoveries at Ashur on the Tigris. Assyrion Origins, New York 1995.

HECKER, $K$.

1968 Grammatik der Külrepe-Texte, AnOr 44, Rome (abrreviation: GKT).

1978b lib 'immo arolkim. Assyrerinnen im kärumzeitlichen Anatolien, OrNS47, 404-18.

1980a Der Weg nach Kaniš, ZA70, 185-97.

$1980 \mathrm{~b}$ Zur Beurkundung von Kauf und Verkauf im Altassyrischen, WO11, 64-75.

1986 Zur Rolle der einheimisch-anatolischen Bevölkerung im altassyrischen Fernhandel mit Kleinasien, Türk Tarihi Kongresi 9 (1985), Ankora, 145-52.

1990a Zur Herkunft der hethitischen Keilschrift, in: $\mathrm{CHI}, 53-63$.

1993 Schultexle von Kültepe, in: Studies N. Özgüc, 281-91.

19960 Rechtlos in der Fremde?, in Anadolu Medeniyetleri Müzesi Konteronsları, 1995 Yill (Ankara), 145-59.

1998a Über den Euphrat. Ortsbezogene Restriktionen in aA Kaufurkunden, in: Studies Bilgic, 157-172. 
1998b Zur Daver des Intervalles zwischen den Schichlen kärum Il und lb am Kültepe, in: KCHIII 297 308.

2003 Kunuk kārim saher rabi, in: Studies Kienast, 183-96.

2004a Beim Tode unseres Vaters. Der leidige Streit ums Erbe, in: Studies Larsen, 281-97.

2004b Kaspum mädum sa tuppē mädütim, in: H. Woetzold (ed.), Von Sumer nach Ebla und zunück. Festschriff Giovanni Pettinato, HSAO 9, Heidelberg, 63-72.

HECKER, K., E. A.

1998 Kappadokische Keilschriftrateln aus den Sammlungen der Karlsuniversität Prag. Praha (rexts from this volume quoted as Prag I+numberl.

HIRSCH, $\mathrm{H}$.

1972 Untersuchungen zur alkassyrischen Religion (2. durch Nachträge und Verbesserungen erweiterte Auflagel. AKO Beiheft 13/14, Osnabrück.

ICHISAR, $M$.

1981 Les archives cappadociennes du marchand Imdilum, Paris.

JOANNES, $F$.

1991 L'élain, de l'Élam à Mari, in: CRRA/36, 67-76.

KIENAST, B.

1984 Das aliassyrische Kaufvertragsrecht, FAOS Beihefte 1, Stultgart.

1989 The Old Assyrian be 'ülätum, JCS 41, 87-95.

KIENGEL, $\mathrm{H}$.

1999 Geschichte des Hethilischen Reiches, HdO Abt. 1, Bd. 34, Leiden.

KOGAN, L.

2007 Old Assyrian vs. Old Babylonian: the lexical dimension, in: G. Deutscher-N.J.C. Kouwenberg (eds.), The Akkadian language in its Semitic Context, PIHANS 100, Leiden, 77-114.

KOUWENBERG, N.J.C.

2003 Evidence for (Post)-Glottalized Consonants in Assyrion, KCS 55, 75-86.

2004a Initial Plene Writing and the Conjugation of the First Weak Verbs in Akkadian. JEOL 38, 83104.

$2004 b$ Assyrian Light on the History of the N-stem, in: Studies Larsen, 333-52.

2006 The Proto-Semitic Gutturals in Old Assyrian, in G. Deutscher - N.J.C. Kouwenberg (eds.). The Akkadian lanugage in its Semitic Context, PIHANS 106, Leiden, 150-76.

KraUS, F.R.

1970 Sumerer und Akkader. Ein Problem der allmesoporamischen Geschichre, Medelingen der Koninklijke Nederlandse Akademie van Welenschappen, Afd. Letterkunde, Nieuwe Reeks 33/8, Amsterdam-London.

KRYSZAT, G

2001 Beobochtungen zum Archiv des Iddi(n)-lštar, in: Studies Veenthof, 203-74.

2003 Ein altassyrischer Brief an die Göltin Tošmtum, in: Sudies Kienast, 251.58.

2004a Zur Chronologie der Kautmansarchive aus der Schicht 2 des Kärum Kanes, OAAS 2, Leiden.

2004b Wer schrieb die Waklum-Briefe? in: Shudies Larsen, 353-58.

$2004 \mathrm{c}$ Herrscher, Herrschaft und Kultradition in Anatolien nach den Quellen aus den altassyrischen Handelskolonien. Teil 1: Die sikkähum und der rabi sikkitim, Aof 31, 14-45. 
LAMBert, W.G.

1983 The God Aššur, Iraq 45, 82-86.

LANosberger, B.

1925 Assyrische Handelskalonien in Kleinasien aus dem driten Jahnausend, Der Alte Orient 24/4, Leipzig.

1949 Jahreszeiten im Sumerisch-Akkadischen, JNES 8, 248-97.

1950a Kommt Hattum, "Hettiterland" und Hatti" um, "Hettiter", in den Kültepe-Tafeln vor?, ArOr 18/12. 329-50.

1950b "Hettiterland" und "Hettiter" in den Kültepe-Tafein, ArOr 18/3, 321-29.

1954 Assyrische Königsliste und 'Dunkles Zeitalter', KCS 8, 31-73, 106-33.

1965 Tin and Lead: The adventures of wo vocables, JNES 24, 285-96.

LANDSBERGER, B. - BAIKAN, K.

1950 Die Inschriff des assyrischen Könings lrišum gefunden in Kültepe 1948, Bellelen 14, 219-268.

LAROCHE, E.

1966 Les noms des Hittites, Études linguistiques 4, Paris.

1981 Les noms des Hittites: supplement, Hethifica 4, 3-58.

LARSEN, M.T.

1967 Old Assyrian Caravan Procedures, PIHANS 22, Istanbul.

1972 A revolt against Hattuša, JCS 24, 100-01.

1974 The Old Assyrion Colonies in Anatolia (review of Orlin 1970), JAOS94, 468-75.

1976 The Old Assyrian Cily-State and its Colonies, Mesopotamia 4, Copenhagen.

1977a Seal Use in the Old Assyrian Period, in: M. Gibson - R.D. Biggs (eds.), Seals and Sealing in the Ancient Near East, Bibliotheca Mesopotamica 6, Malibu, 89-106.

19776 Parnerships in Old Assyrian Trade, Irag 39, 119-49.

$1982 a$ Your Money or your Life! A Portrait of an Assyrian Businessman, in: J.N. Postgate (ed.), Sociefies and languages of the Ancient Near East. Studies in Honour of I.M. Diakonoff, Warminster, 214-45.

1987 Commercial Networks in the Ancient Near East in: M. Rowlands e.a. (eds.), Centre and Periphery in the Ancient World, Cambridge, 47-56.

1999 Naruqqu-Veträge, RIA 9, 181-84.

2000 The Old Assyrian City-State, in: M.H. Hansen (ed.), A Comparative Study of Thitty City-State Cultures, Copenhagen, 77-87.

2001 Affect and Emotion, in: Siudies Veenhof, 275-86.

2002 The Ašsur-nādō Archive, PIHANS 96, Leiden != OAAI).

LARSEN, M.T. - Mouler, E.

1991 Five Old Assyrian Texts, in: Studies Garelli, 227-52.

LEINWAND, N.W.

1992 Regional Characteristics in the Styles and Iconography of the Seal Impressions of Level II at Kültepe, JANESCU 21, 141-72.

Lewr, $H$.

1956 On Some Old Assyrian Cereal Names, JAOS 76, 201-04.

1963 Neša, JCS17, 103-04.

$1964 \mathrm{~b}$ The Assioad, the Sack, and other Measures of Capacily, RSO 39, 181-97. 
1971 Anotolio in the Old Assyrion Period: Assyria c. 2600-1816 B.C., in: Cambridge Ancient Historyl/2, Cambridge, 707-70.

LEWr, 」.

1934 Les textes paléo-assyriens el l'Ancient Testament, RHR 110, 29-65.

1938a Old Assyrian Deuments from Asia Minor, II, AHDO 2, 113-42.

1938b Noles on the Pre-Hurrian Texls from Nuzi, JAOS 58, 450-61.

1939 The Assyrian Calendar, ArOr 11, 35-46.

1950 Hatta, Hattu, Hatti, Hattuša and "Old Assyrian" Hattum, ArOr 18/3, 360-440.

1952 Studies in the Historic Geography of the Ancient Near Eost, OrNS 21, 265-92,393-425.

1956 On Some Institutions of the Old Assyrion Empire, HUCA 27, 1-80.

1957 A propos of a Recent Study in Old Assyrian Chronology, OrNS 26, 12-30.

1958 Some Aspects of Commercial Life in Assyrio and Asia Minor in the Nineteenth Pre-Christian Century, JAOS 78, 89-101.

1961 Amurritica, HUCA 32, 31-74.

1962 Old Assyrian Evidence concerning Kuššaro and its Location, HUCA 33, 45-57.

LIVERAN, $M$.

1988b The Fire of Hahhum, OrAnt 25, 100-172.

MAEDA, T.

1992 The Defense Zone during the Rule of the Ur III Dynasty, AS/14,135-72.

1969 Der Streil um den Nachlass des Puzur-Aššur, ArOr 37, 156-80.

MANNING, S.W., E. A.

2001 Anatolian Tree Rings and a New Chronology for the East Mediterronean Bronze-lron Ages, Science 294, 2531-35.

MaRZAHN, J. - SAUJ, B. (EDS.)

2003 Wiedererstehendes Assur. 100 Jahre deutsche Ausgrabungen in Assyrien, Mainz. Matous, $L$.

1965 Anatolische Feste nach "kappdokischen Tafeln", in: Studies landsberger, 175-82.

1969 Der Streit um den Nachlass des Puzur-Ašs̆ur, ArOr 37, 156-80.

1974b Der Ǎšur-Tempel nach Altossyrischen Urkunden aus Kültepe, in: M. Heerma van Voss e.o. (eds.). Trovels in the World of the Old Testament. Studies Presented to Professor M. A. Beek. Assen, 1974, 181-89.

1980 Zur Bestimmung der einheimischen Fälligkeitstermine in "kappodokischen" Tafeln, Rocznik Orientalistyczny 41,73-76.

MAYER, W. - WILHEIM, $G$.

1975 Altassyrische Texte aus Privatsammlungen, UF7, 315-28.

Maxwell-HysLOP, R.

1972 The Metals amütu and assi'u in the Kültepe Texts, AnSt 22, 159-02. MiCHEl, $C$.

1986 Reédition des trente tablettes "cappodociennes" de G. Contenau, RA 80, 105-40.

1991a Durhumid, son commerce et ses marchands, in: Studies Garelli, 253-73.

1991d Innãya dans les rablemes paléo-assyriennes, I-II, Paris.

1992b Transporteurs, responsables el proprietaires de convois dans les tabiettes paleo-assyriennes.

Reflexions sur les expressions sisp NP el ellat NP, in: CRRA/38, 137-50. 
1992c Le décès d'un coniractant, RA 86, 113-19.

1994 Réglement des comples du défunt Hurașānum, RA 88, 121-28.

1995 Validire el durée de vie des contrats et reconnaissances de dette paléo-assyriens, RA 89, 15 27.

1997a A table avec les marchands paleo-assyriens, in: CRRA/39, 95-113.

$1997 \mathrm{~b}$ Propriétés immobilières dans les tablettes paleo-assyriennes, in: CRRA/40, 285-300.

1997c Hommes et femmes prètent serment à l'époque paléo-assyrienne, in: S. Démare-Lafont (ed.), Jurer et maudire. Praliques politiques et usages juridiques du serment dans le Proche-Orient ancien, Mediterranees 10-11, 105-23.

1997d Les enfants des marchands paléo-assyriens, in: B. Lion e.a. (eds.), Enfance ef éducation av Proche-Orient ancien, Kiema 22, $91-108$.

1997 e Une incantation paléo-assyrien contre Lamašlum, OrNS66, 58-64.

1998 a Les marchands et les nombres: l'exemple des Assyriens à Kaniš, in: J. Prosecky (ed.). Intellectual Life in the Ancient Near East, CRRAl 43, Prague, 249-67.

1998c Quelques reflexions sur les archives récentes de Kültepe, in: $1 \mathrm{CH}$ III, 419-33.

1998d Les malheurs de Kunnaniya, fernme du marchand, in: Studies Bilgic, 239-53.

1998 e Le suites de la mort d'un ramkäruen Anatolie, in: CRRA/34, 457-65.

2000a Les litiges commerciaux paléo-assyriens, in: F. Joannès (ed.), Rendre justice en Mésopolamie: Archives judiciaires du Proche-Orient ancien (IIfe.fe millienaires avant J.-C., Paris, 113-40.

$2000 b$ A propos d'un restament paleo-assyrien, RA 94, 1-10.

200la La lopis-lazuli des Assyriens au début du lle millénaire av. J.-C., in: Studies Veenthof, 341-59.

$2001 \mathrm{~b}$ Correspondance des marchands de Kanish, LAPO 19. Paris (quoted as CMK + no.).

2002a Le commerce des Assyriens en Anatolie centrale au dèbut du IIe millénaire av. J.-C., Médirerranées 30-31, 145-66.

2003a les femmes et les defles: problèmes de responsibilité dans la Mésopolamie du lle millenaire, Méditerronées 34-35, 11-34.

$2003 \mathrm{c}$ Old Assyrian Bibliography of Cuneiform Texts, Bulloe, Seals and the Results of the Excavations at Aššur, Kültepe/Kaniš, Acemhöyük, Alisar and Boğazköy, OAAS I, leiden.

2004a Deux incantations paléo-assyriens. Une nouvelle incantation pour accompagner la naissance, in: Siudies Larsen, 395-420.

2006 Bigamie chez les Assyriens au débur du lle millenaire avant J.-C., Revue de I'histoire de droit $84,155-76$.

MKCHEL, C. - FOSTER, B.R.

1989 Trois lextes palèo-assyriens de New York et les affaires confuses d'lddin-lštar, JCS 41, 34 56.

Mchel, C. - Garew, P.

1996 Heurts avec une principauté anatolienne, WZKM 86, 277-90.

1996b New Old Assyrian Marriage Contracts, AMMY1995, 295-302

1997 Tablettes paléo-assyriennes de Kültepe, volume $($ (kt $90 / \mathrm{k})$, Paris (= TPAK)

MUCHEL, C. - ROCHER, P.

2000 Lo chronologie du lie millénaire revue à l'ombre d'un éclipse de soleil, JEOL 35-36, 111-20. MGIUS, P.A.

1989 Untersuchungen zum Alien Palast in Assur, MDOG 121, 93-133. 
1990 Aul der Suche noch dem 'Ekur' in Assur, BaMi 21، 303-20.

2001 Der Aššur-Tempel des Königs Šamšī-Adad I. und die mesopotamische Sakrolarchitektur seiner Zeif, in: Studies Orthmann, 322-31.

MILER, J.L.

2001 Anum-Hirbi and his Kingdom, Aof 28, 65-101.

Moren, S.M.

1980 Four Old Assyrian Tablets in a Private Collection, OrNS 50, 98-105.

MUHLY, J.D.

1973 Copper and Tin. The Distribulion of Mineral Resources and the Nature of the Metals Trade in the Bronze Age. Transactions of the Connecticut Academy of Arts and Sciences 43, New Hoven, 155-535.

Müller, M. - Marzahn, J.

2000 Fünt altassyrische Texte aus dem Vorderasiatischem Museum zu Bedin, in: Studies Odkner, 295-309.

NASHEF, $\mathrm{KH}$.

1987 Rekonstruktionen der Reiserouten zur Zeit der altassyrischen Handelsniedertassungen, TAVO Beiheft Reihe B 83, Wiesbaden.

1991 Die Onts- und Gewössernamen der allassyrischen Zeit, RGTC 4, TAVO Reihe B Nr. 7/4, Wiesboden.

Neu, E.

1974 Der Anitro-Text, StBoT 18, Wiesbaden.

OPPENHEIM, A.L.

1939 Lexikolische Untersuchungen zu den "koppdokischen" Briefen, AFO12, 342-62.

1974 Old Assyrian magāru or makäru, in: Studies Gürerbock 1, 229-37.

ORIN, L.L.

1970 Assyrian Colonies in Cappadocia, The Hague-Paris.

OWEN, D.I.

1995 An Old Assyrian Letter from Nuzi, SCCNH7, 65-67.

ÖzGüc, $N$.

1965 The Anatolian Group of Cylinder Seal Impressions from Küliepe, TKY V/22, Ankara.

1968 Seals and Seal Impressions of level Ib from Korum Kanish. TKY V/25, Ankara.

1980 Seal Impressions from the Palaces at Acemhöyük, in: E. Porado (ed.), Ancient Ant in Seals, Princeton, 61-100.

1988 Anatolion Cylinder Seals and Impressions from Kültrepe and Acemhöyük in the Second Millen. nium B.C., Bulletin of the Middle Eastem Culture Center in Japan 3, Wiesbaden, 22-34.

1989 Bullae from Kültepe, in: Studies T. Özgüc, 377-406.

1996 Seal Impressions on Küllepe Documenls Notarized by Native Rulers، in: H. Gasche - B. Hrouda (eds.), Collectanea Orientalia. Histaire, ats de lespace et industrie de ta rerre. Eludes offertes en hommage à Agnes Spycker, Neuchírel, 267-78.

2006 Kullepe-Kanis / Nesa. Seal Impressions on the Cloy Envelopes from the Arctive of the Naive Peruwa and the Assyrian Trader Usur-sa-/star son of Ašsur-imitti V/ 50, Ankara (the seal imprerssions from the $k t d / k$ and $k t n / k$ archives).

ÖzGüc, N. - TunCA, Ö.

2001 Küliepe-Kanis. Sealed and Inscribed Clay Bultae, TKY V/48, Ankara. 
ÖzGưc, T.

1950 a Türk Tarih Kurumu Tarafindan Yapilan Küllepe Kazısı Raporu 1948, TTKN/10, Ankara.

1953a Küliepe Kazısı Raporu 1949, TKY V/12, Ankara.

1959 Kültepe-Konis. New Researches of the Center of the Assyrion Trade Colonies, TKY V/19, Ankara.

1964 The Art and Architecture of Ancient Kanish, Anatolia 8, 27-48.

1986 Kütiepe-Kanis II. New Researches at the Trading Center of the Ancient Near East, TKY V/41, Ankara.

1993a Temples of Kanish, Istanbuler Mitteilungen 43, 167-74.

1999 Kültepe-Kanis/Nesa. The Palaces and Temples of Kültepe-Kanis/Neša, TKY V/46, Ankara. 2003 Kültepe. Kanis / Nesa. The Earliest International Trading Center and the Oldest capital of the Hittires, The Middle Eastern Culture Center in Japan, Tokyo.

2004 Archives of the Karum at Kaniš, Level lb, in: Studies larsen, 445-50.

ÖZKAN, S.

1993 The Seal Impressions of Two Old Assyrian Kings, in: Studies N. Ozgüc, 500-01, pl. 90.

PEDDE, F.

2003 Der Palast der Väter. Die Ausgrabung des Alten Palastes, in: Marzahn-Salje 2003, 119-28.

PEOERSEN, $O$.

1985 Archives and Libraries in the Ciny of Assur. A Sunvey of the Material from the German Excavations, I, Uppsala.

1989 Remains of a Possible Old Assyrian Archive, MDOG 121, 135-38.

1997 Use of Writing Among the Assyrions, in: CRRA/39, $139-52$

PORADA, E.

1980 Kaniš, kārum. C. Die Glyptik, R/A 5, 383-89.

PRUSZINSKY, R.

20060 Šamši-Adads I. 'neve' Regierungsdaten und Assyrische Distanzangaben, in: E. Czerny e.a. (eds.). Timelines. Studies in Honour of Manfred Bietak. OLA 149/3, 73-79.

$2006 \mathrm{~b}$ Die 'verkürzte mittlere Chronologie' unter Berücksichtigung der Distonzongabe des TukulfiNinurta I, NABU2006/13.

READE, J.

2005 The Ishtar Temple at Nineveh, Iraq 57/1, 347-90.

REINER, E.

2001 Who is Afraid of Old Assyrian? in: Studies Veenhor, 389-94.

RENS, R.

1996 Eine Kleinigkeit zum aliassyrischen Eherecht, in: Studies Hirsch, 355-67. ROSEN, B.L.

1977 Siudies in Old Assyian Loan Contracts, unpubl, dissertation Brandeis Universily, UM 77-22 827. SALABERGER W.

1999 Ur III-Zeit, in: W. Sallaberger- A. Westenholz, Mesopolamien. Akkade-Zeit und Ur III-Zeit, P. Attinger - M. Wöfler (eds.), Annäherungen 3, OBO 160/3, Freiburg-Göttingen, 121-390. SCHWEMER, D.

2001 Die Wethergottgesialten Mesoporamiens und Nordsyriens im Zeitaller der Keilschrifturkunden, Wiesbaden. 
SEVER, $\mathrm{H}$.

1990a Yeni Külepe Tabletlerinde Geçen "kima awāł naruā'im" Tabiri ve Deg̀erlendirilmesi, OTCFO 34, 251-65.

1991 Kültepe Tabletlerinin Anadolu Tarihi ve Kültür Tarihi Bakımından Önemi, DTCFO 35, 247. 256.

1992a Eine neue Ehescheidungsurkunde, in: Studies Alp, 483-486.

1992b Anadulu'da Nisanın Bozulması Hakkında Verilmis Kanis Kanumu Kararı, Belleren 56, 067 675.

1996 Die Ufformen der Börse und Inftation in Anatolien und ein Gestein, dessen Austuhr in der Zeit der Kolonie ous Anatolien verboten is1, Bellelen 60, 237-242.

1998a Köleșłı Hakkında Yeni Kültepe Metinleri, in: CRRA/34, 485-94.

STURM, TH.

1995a kaspum ammurum, ein Begriff der Silbermetallurgie in den Kültepe-Texten, UF 27, 487-503.

2000 Zwei Kültepe-Texte aus der Hilprecht-Sammiung zu Jena, in: Studies Oelsner, 479-512.

2001 Puzur-Annō. Ein Schmied des Kōrum Kaniš, in: Studies Veenhof, 475-501.

TEISSIER, B.

1994 Sealing and Seals on Texts from Küliepe karum level 2, PIHANS 70, Istanbul.

TuNCA, Ö.

1989 Cylinder Seal Impressions of Samši-Adad I and his Officials from Acemhöyük, in: Studies N. Özgür, 481-84.

1993 Des inscriptions de sceaux-cylindres diverses provenant d'Acemhöyük, in: Studies T. Ozgǘ, 629-33.

UISHÖFER, A.M.

1995 Die altossyrische Privaturkunden, FAOS Beiheff 4, Stuttgant.

VEENHOF, K.R.

1978 An Ancient Anatolian Money-Lender. His Loans, Securities and Debt-Slaves, in: Studies Malous II, 279-311.

1982 A Deed of Manumission and Adoption from the Later Old Assyrion Period, in: G. van Driel e.a. (eds.), Zikir sumim. Assyriological Studies Presented to F.R. Kraus on the Occasion of his Seventieth Birthday, Leiden, 359-85.

1985 Observations on Old Assyrian Memorandums, JEOL 28 (publ. 1985), 10-23.

19870 'Dying iablets' and 'hungry silver', in: M. Midlin e.o. (eds.), Figurative longuage in the Ancient Near East, London, 41-75.

1987c Review of KKS, OLZ82, 350-56.

1991a Privale Summons and Arbitration among the Old Assyrian Traders, Bulletin of the Middle Eashern Culture Center in Japan 5. Wiesbaden, 437-59.

$1991 b$ Assyrian Commercial Activities in Old Babyloninan Sippar. Some New Evidence, in: Shudies Garelli, 287-304.

1993 On the identification and implications of some bulloe from Acemhüyök and Külrepe, in: Sndies N. Özüc. 045-57, pl. 124.

1994b Miete.C. Altassyrisch, in: R/A 8 (1994) 181-184.

1995a 'In accordance with the words on the stele': Evidence for Old Assyrion legisiation, ChicagoKent low Review 70/4, 1717.44. 
1995b Old Assyrian ișurum, Akkadian esërum and Hittite GIŠ.HUR, in: T.P.J. van den Hout - 1. de Roos (eds.), Studio Historiae Ardens. Studies Presented to Philo H. J. Houwink ren Care, PIHANS 74, Istanbul, 311-31.

1996a The Old Assyrian Hamuštum Period: A Seven Day Week, JEOL 34, 5-26.

1997a 'Modern Features' in Old Assyrian Trade, JESHO 40, 333-66.

1997b Review of Ulshöfer 1995, JESHO 40, 301-4.

1998a The Chronology of kārum Kanish. Some New Observations, in: CRRA/34, 421-50.

1998b Review of Uishöfer 1995, JAOS 118, 582-85.

1999a Silver and Credit in Old Assyrian Trade, in: J.G. Dercksen (ed.), Trade and Finance in Ancient Mesoporamia, MOS Studies 1, Leiden, 55-83.

$1999 \mathrm{~b}$ Redemption of Houses in Assur and Sippor, in: B. Bock e.a. (eds.), Munuscula Mesopotomica. Fesischriff für Johannes Renger, AOAT 267, Münster, 599-616.

2000 Old Assyrian Chronology, Akkadica 119-120, 137-50.

2001 The Old Assyrian Period, in: R. Westbrook - R. Jasnow (eds.), Security for Debt in Ancient Near Eastern Law, Culture and History of the Ancient Near East 9. Leiden, 93-159.

2003 The Old Assyrian List of Year Eponyms from Kärum Kanish and its Chronological implications, Publ. of the Turkish Historical Society VI/64, Ankara.

2003a Archives of Old Assyrian Traders from kārum Kanish, in: M. Brosius (ed.), Ancient Archives and Archival Traditions. Concepts of Record-Keeping in the Ancient World, Oxford Studies in Ancient Documents, Oxford, 78-123.

2003b Three unusual Old Assyrian Contracts, in: Studies Kienast, 693-705.

2003c Old Assyrian Period, in: R. Westbrook (ed.). A History of Ancient Near Eastern Law, Handbook of Oriental Studies, Section One, vol.72 /I, Leiden, 431-83.

2003d Trade and Politics in Ancient Ašsur. Balancing of Public, Colonial and Entrepreneurial Interests, in: C. Zaccagnini e.a. (eds.), Trade and Politics in the Ancient World, Saggi di Storia Antica 21, Rome, 69-118.

2004a Trade with the Blessing of Samaš in Old Babylonian Sippar, in: Studies Larsen, $551-82$.

2006b Traveling in Ancient Anatolia: Two New Sources from Karum Kanesh, in: Betül Avunç e.a. (eds.). Hayar Erkanal'a Armağan; Kültürlerin Yansıması / Studies in Honor of Hayat Erkanal; Cultural Reflections, Istanbul, Homer Kitabevi, 778-83.

2007a The Death and Burial of Ishtar-lamassi in Kōrum Kanesh, in: Studies Sto/(forthcoming).

2007b Sisterly Advice on an Endangered Marriage in an Old Assyrion Letter, in: M.T. Roth - W. Farber-M.W. Stolper (eds.), Studies Presented to Robert D. Biggs, June 4, 2004, Chicago, (forthcoming).

2008 The Archive of Kuliya, son of Aläbum (kt 92/k 188-263), Ankara (forthcoming).

VEENHOF, K.R. - KIENGEL-BRANDT, E.

1992 Allossyrische Tontafeln aus Kültepe. Texte und Siegelabrollungen, Vorderasiatische Schriftdenkmäler der Staalliche Museen zu Berlin, Heft 26, Berlin.

VON SODEN, $W$.

1963 Die Assyrer und der Krieg, Iraq 25, 131-44.

WILCKE, C.

1976 Assyrische Testamente, $Z A 66,196-233$.

1982 Drei altasssyrische Kültepe-Texte aus München, OrNS 52, 194-200. 
WILHELM, G.

1996 Zu den hurritischen Namen der Kültepe-Tafel kt k/k 4, SCCNH8, 335-43.

YAMADA, S.

1994 The Editorial History of the Assyrian King List، Z4 84, 11-37.

ZiEGLE, N.

1996 Ein Bittbrief eines Händlers, WZKM 86, 479-88.

2002 Le royaume d'Exallälum el son horizon geopolitique, in: D. Charpin - J.-M. Durand (eds.), Recueil d'études ò lo mémoire d'André Parrot, Florilegium marianum 6, Paris, $211-74$. 
TELL 2

JESPER EIDEM

Apum: A Kingdom on the Old Assyrian Route 

Making their way from Assur on the Tigris to their far-flung network of commercial settlements in Anatolia, the Old Assyrian traders and their caravans crossed the Habur headwaters region in present-day northern Syria. During the earlier phase of the Old Assyrian trade (=Kültepe Level II, ca. 1950-1835 BC) the traders passed a town named Apum. Although as yet unidentified this town was located in the vicinity of Tell Leilan, ancient Šehnā/Subat-Enlit, which during the later phase of the Old Assyrian trade $\{=$ Kültepe Level $l b$, ca. 1800-1700) functioned as capital of "the land of Apum". In this latter period Leilan seems to have inherited the earlier role of Apum as relay station for the traders, probably as a result of intervention by Šamši-Adad, who made Leilan his own residential capital. Subsequently, in the mid-1 $8^{\text {th }}$ century BC, we find an Assyrian commercial establishment (kärum) at Leilan. The official nature of this institution is underlined by the conclusion of a formal treaty between the king of Leilan and the city of Assur, while contemporary administrative texts show that its functions included banking activity in the local region.

This information and much more is provided by the archives found at Tell Leilan in 1985 and 1987 in the so-called "Lower Town Palace East" 'Operation 3), excavaled by an expedition from Yale University directed by $\mathrm{H}$. Weiss.' The tablets formed parts of archives belonging to the kings Mutija, Till-Abnû, and Jakūn-Ašar, who reigned at Leilan ca. 1755-28 B.C. (middle chronology). The archives include more than 200 letters from the royol correspondence, more than 500 administrative documents, and remains of 5 tablets with the texts of political treaties concluded by Leilan rulers. The documentation is important on several levels. Although dwarfed by the Old Assyrian archives from Kültepe and the archives from ancient Mari, the Leilan archives are the largest as yet found in northern Mesopotamia, and more comprehensive than the groups of tablets found at sites like Rimah, Chagar Bazar, and ancient Tuttul. In this latter sense they provide an opportunity for a sketch portrait of an important city-state in what was later to become "Assyria". In addition they stem from a period a generation or two after the documentation from Mari comes to an end, and thus offers a logical sequel to evidence from there pertaining to the North.

In the spirit of the present series I have attempled in the pages that follow to present some "approaches" to this evidence, and an ovenview of the most important information it offers. General parameters and some specifics of the leilan archives have been presented in various preliminary reports and studies," and major selections of the administrative documents are available in provisional editions. A final edition of the lefters and treaties has been completed, but "in press" since 1998, while a final and complete edition of the administrative texts is not yet ready. This means that a more comprehensive overview should be

\section{See Akkermans and Weiss 1991.}

"Thus Eidem 1988, 1990, 199la, 1991b, 1991c, 1991d, 1996a, 1996b, 2000, 2002. Cf. also the fine summory in Charpin 2004, 348-351. 
welcome, "I" while it must inevitably suffer slightly from a lack of completeness. IV Portions of Leilan letters and treaties are here quoted in translation with a minimum of technical commentary, which will be found in the official edition, due to appear shortly.

This presentation includes or overlaps with issues dealt with recently in volume 4 of the $A n$ näherungen series (D. Charpin, "Histoire Politique du Proche-Orient Amorrite (2002-1595)", $O B O 160 / 4$ (2004) pp. 25-480), and again with specific reference to the evidence from Mari in a book by D. Chapin and N. Ziegler (Mari et le Proche-Orient a l'époque amorrite. Essai d'histoire politique. Florilegium marianum V (Memoires de N.A.B.U. 6. Paris 2003). Readers are referred to these two works for much general background material not treated here, and for further bibliographical references, here kept to a sensible minimum.

It should be noted that tablets from the 1987 Leilan archives are referred to here with the numbers used in the editions: YTLR = J. Eidem, The Royal Archives from Tell Leilan. Old Bobylonian Letters and Treaties from the Lower Town polace. YTLR, Yale University Press; FI = F. Ismail, Altbabylonische Wirtschaftsurkunden aus Tall leilän/Syrien/, Unpubl. Ph. D. Diss., Eberhard-Karls-Universitäl, Tübingen 1991; $\mathrm{CV}=\mathrm{C}$. Vincente, The 1987 Tell leilan Tablets Dated by the Limmu of Habil-kinu. Unpubl. Ph. D. Diss., Yale University 1991, while tablets and sealings not included in these editions are referred to with their L.87-field numbers."

I would like to express my gratitude to Markus Wäfler for his kind invitation to lecture in Berne in early 1999, and for accepting this contribution for publication in Annäherungen. To $\mathrm{H}$. Weiss I owe thanks for entrusting me with publication of the letters and treaties from the 1987 season at leilan, and for subsequent advice and information. Professor $F$. Ismail (University of Aleppo) and Dr. C. Vincente, who prepored editions of Leilan administrative texts for their Ph. D. theses, provided pleasant company during long stays in Deir ez-Zor to study leilan rablets, and shared with me notes on some still unedited rexts. My own work on Leilan material was generously funded by the University of Copenhagen, The Carlsberg Foundation, The Martin Levy Memorial Grant, and The Danish Research Council for the Humanities.

III The presentation here incorporates introductory matter in the official edition Eidem, YTLR, but is an updated and more comprehensive version. It involves more evidence from the administrative texts and provides numerous quotalions from the letters and ireaties.

N A number of tablets and fragments from the archive, undaled administrative lexts, remain basically unedited.

$\checkmark$ The numbering used in the editions of the administrative texts will probably be changed in the final, formal publication of the complete administrative corpus from 1987. Texts in these editions will also require further collation and study, and some readings presented below ore al varionce with those of the editions. 


\title{
1. General Introduction
}

\section{1. Šehnā, Apum, Šubat-Enul}

It has long been established that the imposing 90 ha site of Tell Leilan should be identified with ancient Šehnā/Subat-Enlil. Tablets found on the high mound "Acropolis" of Leilan in 1985 made the identification with Subat-Enlil virtually certain,' and almost simultaneously it was demonstrated from Mari evidence that the original name of the city was Šehna, ${ }^{2}$ and as such the site is mentioned several times in Old Akkadian texts found at Tell Brak. ${ }^{3}$ Presumbaly renamed Šubat-Enlil by Šamši-Adad (ca. 1835-1778 B.C.), whose imperial ambitions included emulation of the enormously successful Old Akkadian kings, the city was again referred to with its old name following the dernise of his kingdom. In Mari texts contemporary with the reign of Zimri-Lim both names are used, and in the still slighty later documentation from Leilan itself, the original name prevails. ${ }^{4}$ Šehnā is also encountered in the year-formula for the 23rd regnal year $(=1728 \mathrm{BC})$ of the Babylonian king Samsu-iluna, which records the destruction of Šahnā (= Šehnā): "The Year: Samsu-iluna, the king, by the fierce power which Enlil gave him, destroyed Šahnā, the capital city of the land of Apum, Zarhanum, Putra, Šusā, ...-lazia $(2)$ <and > ... Jakūn-Ašar .... Jakūn- ...". 5 This is the latest extant reference to leilan, where major occupation also seems to have come to an end about this time.

The Babylonian year-formula, as well as sources from Mari and Leilan itself, show clearly that Šehnā/Subar-Enlil was the capiral for an area called "the land of Apum", which presumably covered a large eastern portion of the Habur Basin. Apum, however, must also have been the name of a town. Old Assyrian texts from Kültepe Level II (ca. 1950-1835 BC) show that Assyrian caravans passed a place called Apum, located in the Habur Basin. In parallel with other localities along the Old Assyrian routes Apum should be a lown and not a land. Further the documentation for a paramount local goddess, Bēlet-Apim, points in the same direction, since such compounds usually involve a town. ${ }^{6}$

\author{
Whiting 1990a and 1990b. \\ Charpin 1987a. \\ 3 Eidem, Finkel, and Bonechi 2001, nos. 14, 31, 59.
}

4 Thus many administrative texts have the note "in Šehnō", while only one refers to Šubat-Enlil in a note "when the enemy approached the gate of Subat-Enlil" (FI 98). In letters Šehna is mentioned 4 times (YTLR 16, 136, 141, and 157), and Subat-Enlil 6 times (YTLR 42, 75, 76, 89, 111, 176). In no case does context suggest a location different than the place of receipt of the letter. Horsnell 1999, Vol. 2, 211-213.

- Charpin (1987a) succinctly set out these arguments, and pondered the possible existence of a lown Apum distinct from the site of Tell Leilan, but for lack of specific evidence concluded that Apum was only the name of a land. 
Although a town or city Apum is not in clear evidence outside the Kültepe material, it thus seems likely to have existed. It seems unlikely moreover to be identical with Leilan itself, where the excavator has repeatedly stressed a "hiatus" in settlement for the period co. 2200-1900 BC (Leilan period IIc). Where then is oncient Apum? Tell Mhm. Diyab, located only a few kms southeast of Leilan, and obviously of some considerable importance, seems a possible candidate, and one notes the find of an Old Assyrian cylinder seal at Mhrn. Diyab, which prompted the following comment from one of the excavators: "on peut affirmer désormais que Mohammed Diyab se trouvait sur la route commerciale qui relait l'Assyrie à l'Anatolie centrale, en plein cáur du "pays d'Apum".7 Also Mhm. Diyab, however, seems to have been abandoned during leilan period $\mathrm{llc}^{8}$, and must therefore, at least formally, be discounted. According to recent and very detailed survey work in a $30 \mathrm{~km}$ strip of the Syrian Habur Basin the Leilan Project team found only a lew, mostly very small sites, which show occupation in period llc. Although even the best survey has obvious limitations, especially with regard to identification of such a narrow time range, it seems prudent to limit search to the sites presently identified. Since Apum should be a relatively large and important place this allows virtually only a single candidale, namely Tell Aid, ca. $15 \mathrm{~km}$ due west of Leilan, and ca. $15 \mathrm{~km}$ southeast of Qamishli. ${ }^{9} \mathrm{~s}$ this possible? One observation which could point in the same direction is the rather curious fact that among the senders of letters to the kings of leilan only the king of Šnna, a vassal, reports on the well-being of the "land of Apum" (YTLR 101\}, as if Šnō was particularly associated with Apum. Was Šunō,

7 Castel 1990, 53. The idea to identify Mhm. Diyab with ancient Apum would of course run counter to the identificalion of the site with ancient Azamhul proposed by Charpin in 1990 (1990b) and subsequently often repeated, but built on fairly slim evidence. Charpin, for instance, stated that ARMT XXVI/2, 357 and A.2496 (= ARMT XXVIII, 132) show the proximily of Subat-Enlil and Azamhul, but the mention of Azamhul in the former text moy relate to its importance as residence of Hāja-abum's brother Züzu (ct. below), while the latter lext in fact mentions Jumros-El, king of Daragum and Azamhul, and therefore rather shows the proximity of these two towns, both probably located some distance east of leilan. Daragum at least is known as an intermediate point belween Razamō and Apum in the Old Assyrian documentation (ct. Nashef 1987). Nicolle 2005, 181.

9 Ristvet and Weiss 2005, p. I and Fig. 5 (sire 90). In the Leilan Ilc period occupation is estimated at 10-20 ha. The same site is no. 106 in Meijer 1980: 19-20, where it is reported to be co. $500 \mathrm{~m}$ in dm., and that: "Ancient remains consist of four summits, the western one ca. $35 \mathrm{~m}$ high, the eastern (covered by the modern village) co. $22 \mathrm{~m}$., the southern and northern ones lowish". Occupation was estimated to cover EB IV through LB.

The correlation of archaeological and historical dato is of course precorious. The end of the Leilan llc periad would formally include the inceptive phose of the Old Assyrian trade, and it is of course logical to think that there is a general connection here: the revival of settlement in the North would have provided the stability and prosperity which allowed the trade to proceed, further supporting the revival. In archaeological terms the margin is slim, but one would still prefer clear evidence for "pre-Šamši-Adad" occupation at any particular site betore claiming that it was occupied when the Old Assyrian trade began. 
a town which must clearly be sought west/northwest of Leilan, somewhere in the vicinity of Qamishli, 10 thus perhaps closer to the core of Apum than Leilan itself?

Whalever the correct location of ancient Apum, however, the much larger Šehnä/Leilan would have been the capital of a fair-sized Habur state prior to its abandonment around $2200 \mathrm{BC}$. In the following centuries Apum would have become a political and religious center for this part of the Habur Basin, and as such a natural relay point for the Old Assyrian traders. When in the late $19^{\text {th }}$ cent. Samši-Adad conquered the Habur Basin he chose the possibly still deserted mound of Leilan as his residence, instead of the local capital, a strategy also seen elsewhere in this period. Qabrā, for instance, replaced Erbil as capital, Ekallātum replaced Assur, and Nurrugum replaced Niniveh/Ninet." Šamši-Adad is known to have deposed and persecuted some local rulers in the areas he conquered, while allowing others to remain as vassals. Whal happened to the ruler of Apum is uncertain. The cult of Bēlet-Apim was probably transferred from Apum to Subat-Enlil, which now also became mansit point for the renewed Assyrian trade on Anatolia. Possibly Apum was destroyed or at least severely reduced, to the extent that only a few references to it may be detected. ${ }^{12}$ Instead Apum remained as a designation for the region.

This state of affairs helps to clarify the turbulent history of Leilan after the dissolution of the Šamši-Adad kingdom. After the death of the mighty king himself and the loss of Mari, lšmeDagan could only hold on to a small area around his capital Ekallătum, but in the Habur Basin the fortified cities of Kahat and Šubat-Enlil held out for some time. ${ }^{13}$ In Šubat-Enlil the old official Samija stayed in control some 4 years into the reign of Zimri-Lim, but was in conflicr with a certain Turum-natki apparently supported by inhabitants of Šubat-Enlil itself. 14 Together they sought help from Zimri-Lim of Mari to get rid of Samija, and promised him the "rreasures of Šamši-Adad", apparently still somewhat intact, in return. ${ }^{15}$ Likewise Samija received a letter from Simah-ilanem of Kurdā, who offered to kill Turum-natki and join the country of Apum to Subat-Enlil. This uneasy situation ended in the year ZL 4, when lbal-pi-El II of Ešnunna invaded the Habur supported by Qarni-Lim of Andarig. ${ }^{16}$ Samija disappears from view, while Turum-natki somehow came to grief since we hear:

10

11

14 A group of letters from Samija were intercepted and ended up in Mari. As if the poor Samija did not have enough professional troubles, he also seems to have suffered domestic worries! (see Durand, DEPM III, pp. 501-504).

Eidem 1994.

16 See Charpin and Ziegler 2003, 198: Ešnunna troops occupy Subat-Enlil where there is struggle between Samija who supports them and inhabitants who support Turum-narki of Apum, and it is said: "Let us kill Samija and the notables, and let us either make "the son of Assur" (dumu "Aššur) king or give the city to Turum-natki, but we shall not join Ešnunna"(A.1421 cited ibid. n. 245). The rather mysterious Mār-Aššur may perhaps be understood as "director" of the Assyrian merchant office, later referred to as "the House of the servant of Aššur" (ct. below Ch. 4.2). 
"and Qarni-Lim buried Turum-natki in Apum. He assembled the kings around ŠubarEnlil, and they mourned him. Qorni-Lim bowed, and they installed a son of Turumnatki as king of Šubat-Enlil". 17

As such Turum-natki is the first documented figure who may have had legitimate, i. e. "pre-Šamši-Adad", claims on Apum. In several cases descendants of the princes ousted by Samši-Adad came back to claim the ancestral throne, and Turum-natki was quite likely one such figure. ${ }^{18}$ The rather opaque statement that he was buried "in Apum" presumably refers to a precise locality, probably the site of the town of Apum. Thus Turum-natki did manage to return to his presumed ancestral base, and it may be from there that jars sealed by one of his officials were sent to Subat-Enlil, where two such sealings have been found. 19

His son and successor who became king of Subat-Enlil, was apparently a certain Züzu, who does not seem to have been much favoured either by Zimri-Lim or his own people, since less than a year later it is reported that the "commoners" of Apum have evicted him and instead chosen Hāja-abum as king. ${ }^{20} \mathrm{~A}$ new piece of information provided by one of the Leilan reaties (L.T.-1) is the fact that Haja-abum was a son of Turum-natki, and it would seem that he and Züzu for a short time shared kingship of Apum. The aftermath of Züzu's "eviction" is described in a letter from Mari, which concerns reports of Züzu's death, attributed consecutively to an illness, a serious accident, and finally to "natural causes". ${ }^{21}$ Following this event officials of Bunu-lštar of Kurdā arrived to seal the residence of Züzu and retain a caravan of his assembled to transport grain from Azamhul to Saphum, while QarniLim of Andarig, presumably residing at this stage in Subat-Enlil, proceeded to install Hājoabum as king. This may reflect a situation where the Sinjar cily-states of Andarig and Kurda shared control of Apum, and Züzu may have ended his career as a Kurdā-sponsored king in Azamhul. If so we have interesting evidence for two sons of Turum-natki, who may, for a time, have shared kingship of Apum, residing in respectively Subat-Enlil and Azamhul.

In any event Hāja-abum was left as sole king of Apum, although under control from Andorig, over the next years until mid-ZL 10,22 when Elamite troops and their allies invaded the Habur. Events during this year are exceptionally well documented in the published sources from Mari. Hāja-abum was killed and an Elamite general, Kunnam, ${ }^{23}$ resided for a time at Subat-Enlil and controlled a large sector of the Habur Basin, but later the same year the Elamites and their allies were defeated. Qarni-lim came to a sad end, and his place was

18

19

20

21

22

23

Charpin 1987a, 136.

Cf. Charpin and Ziegler 2003, 183. For the example of Kurdō see Chorpin and Durand 2004 See Weiss 1985, 283.

Charpin and Ziegler 2003, 204, reported in a letter from Sammêtrar (A.4406, dated 1/viii ZL 5).

A. 350t, published in Charpin 1990b = DEPMI, no. 333. Cl. also Sasson 2001.

Charpin and Ziegler 2003, 204f. As noted there L.T.-1 was concluded jointly by Hāja-abum and Qarni-lim (with a king of/near Ašnakkum), and the archive found at leilan in 1991 shows that Qarni-Lim had a permanent residence in Šehnã.

Charpin and Ziegler 2003, 217f. 
taken by a certain Atamrum, ruler of the Sinjar town Allahad, who now controlled both Andarig and also Subat-Enlil, where a centain Subram was installed as governor. During the following years Alamrum, and simultaneously and subsequently from ZL 12 his successor, Himdija, were in control of Leilan. ${ }^{24}$

After 1761 B.C., when Hammurabi of Babylon conquered Mari, documentation for the history of northern Mesopotamia basically comes to an end for a very long time. Texts found at Tell al-Rimah in the Sinjar Plain provide some information on a few years within the decennium 1760-50 B.C., and show that Hammurabi of Babylon now was in control of northeastern Mesopotamia.

This was the situation in 1985, when the first rooms of the Lower Town Palace at Leilan were excavaled, and a handful of tablets and sealings appeared bearing names of new kings, and evidently dating to a period later than that documented at Mari. The more extensive excavations in 1987 produced major archives, and it became clear that the tablets contained references to three kings of Apum, who reigned after 1761 BC., viz. Mutu-Abih, Till-Abnû, and Jakūn-Ašor. The sequence of these kings presents no immediate problem. The basis for a reconstruction is provided by two synchronisms with material from Babylonia. The first is the Samsu-iluna year formula already referred to, and which shows that Jakunn-Ašar was king in 1728 B.C., and that his reign probably ended that year. The second synchronism is provided by the limmu Habil-kēnu, used to date many administrative tablets associated with the reign of Mutu-Abih, and which is also found in tablets from Sippar in Southern Mesoporamia. From the Sippar texts the limmu can be dated to a year either very late in the reign of Hammurabi or very early in the reign of his successor Samsu-iluna, i.e. approximately 1750 B.C. ${ }^{25}$ Finally the Leilan material itself provides ample evidence that Till-Abnû directly succeeded Mutija, who is referred to retrospectively in several letters sent to Till-Abnú.

Mutu-Abih'20 is the full form, but usually this king is referred to with the hypocoristicon Mutija. Numerous tablets are sealed with his seal, which bears the legend: "Mutu-Abih, son

The excovations af leilan have produced some evidence from this period. On the Acropolis sealings pertaining to Turum-naki and Hāja-abum have been found (see Weiss 1985), and in the Lower Town Palace a few sealings have the legend of a centain Bêli-emūqi, servant of Hājaabum. Himdija, Atamrum's successor, is represented by a few sealing frogments, and two tablets. Among the sealings are envelope fragments from Room 2 (1.87-86) and L.87-865) which carry the full legend of Himdija's seal ("Himdija, prefect of Sinn, the lord of Jamutbalum, king of Andarig"). The two tablets are a legal document secled by a servant of Himdija and dated with the limmu ha-ab-d[u(?)-...] found in Room 22, and a single letter [L.87-887] addressed to Himdija, from Room 5 . The latter text, which contains important new information, will be published separately by F. Ismail.

25 See Veenhol 1989; of. Charpin 1990d.

26 For this name meaning "Man of Ebih (Jebel Hamrin) see Durand 1991, 85. It could be speculated that this name has $a$ bearing on the history of the lamily to which Mutija belonged, and one notes that his father carried the same name as a man briefly king of Ahäzum, on the Lower Zāb /see Charpin and Ziegler 2003, 100 and 107). 
of Halun-pî-liujmu27, beloved of Adad and Bëlet-Apimn". ${ }^{28}$ In the treaty L.T.-2, concluded between Mutija and Hazip-Teššup of Razamā, he is repeatedly referred to as lugal māt Apim - "king of the land Apum".

Till-Abnú ${ }^{29}$ is the current form of the name, while the hypocoristicon Tilläj is found once or twice. ${ }^{30}$ A number of administrative tablets are sealed with his seals, on which the two first lines in the legend invariably read: "Till-Abnû, son of Dari-Epuh", while the third line either appears as: ir sa d|M - "servant of Adad". or as: lugal ma-a-at [a-pi-im|ki|] - "king of the land Apum", and this is the title found also in the treaties L.T.-3 and L.T.-5.

Jakūn-Ašar is the current form, but a hypocoristicon, Jaküja (ia-ku-ia) is found in several seal legends belonging to servants of the king. The legend of his own seal is found on numerous tablets and reads: "Jakün-Ašar, son of Dari-Epuh, king of the land Apum". ${ }^{31}$

It is clear that Till-Abnû and Jakūn-Ašar, both sons of Dari-Epuh, were brothers, and possibly other members of the family are attested. ${ }^{32}$ Since Mutija, and Till-Abnû and Jakūn-Ašar had different fathers it might seem that two different dynasties were involved, but apporently the situation is not that simple. Various references show that men named Till-Abnu and Jakūn-Ašar were actively supporting Mutija during his reign, and the evidence suggests a geo-political construction where Mutija, as king of Apum and based in Šehnā, was supported by two sub- or junior kings on the borders of Apum.

This of course raises the question of the exact relationship between the three men. Himdija's reign and control of Leilan beyond the last year of the Mari archives, 1701 B.C., is unknown, but presumably of short duration, and the year of the limmu Habil-kênu which may be the last regnal year of Mutija, can be dated to ca. 1750 B.C. Consequently there is a gap of ca. 10 year in the history of Apum. Neither Dari-Epuh, Mutija, nor his father Halun-pî-\{ju\}mu are known from other sources, and our texts reveal nothing about their

This follows writings like ha-lu-(un/m-/piPI-mu in texts from Mari (ARMT XVI/L, 97), and in L.T.-2 iii 5 ' ha-kv-pi-u-mu

29 For this name and its possible etymologies of. Durand 1987b. For a Habur region town Till-Abna see Charpin and Ziegler 2003, 235 w. n. 604

30 In the address of YTLR 23, sent from Hammurabi of Halab; and possibly in the oddress of YTLR 27, sent from Bin-Dammu, the Halab general.

31 ia-ku-un-a-sar, dumu da-ri-e-pu-uh, lugal ma-a-al a-pi-im/see Parayre in Weiss el al. 1991, 504 fig. 34).

32 Two seoling tragments are relevant in this context. The first is $[L .87-151]$ where the fragmentary 3 line

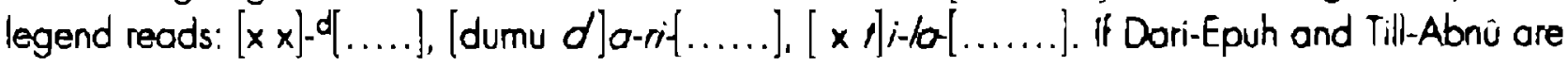
involved here we must have o figure related to, but presumably subordinated Till-Abnu.

The second is [L.87-152], again with only part of the legend preserved: $[x \times]^{5} x^{7} \cdot d y[\ldots . .$.$] , [dumu$ ia-k]u-un-a-[sar], [ir? $r-l a-a] b-n u-\dot{u}$. In this case it could be speculated that a nephew of Till-Abnu is involved, and hence that Till-Abnu was taity aged - or considerably younger than his brather Jakün-Ašr. 
origins. The same names occur in rexts from Mari, but in contexts which render it unlikely or mere speculation that the same individuals are involved. It seems possible that Dari-Epuh, the father of Till-Abnû and Jakūn-Ašar, could be related to earlier kings of Apum. Some evidence to this effect can be found in YTLR 28, where Ea-malik states that Till-Abnû has ascended his "father's" throne, and in YTLR 115, where Take writes to his lord: "This is the advice which your father gave me: if you write to Till-Abnû, he shall come to you(r aid) like one man, and if he calls on you(r help), go to him at once!" Assuming that the "father" in question really was Dari-Epuh, and that he once ruled Leilan, it might be thought that Mutija was an outsider who had usurped the throne after the death of Dari-Epuh. However that may be the best theory which can be offered at present is perhaps that Till-Abnũ and Jakūn-Ašar were nephews of Mutija.

This summary has clearly shown how limited and often uncertain the evidence for the history of Apum is at present, reflecting also very complex historical scenarios. If the main outline should prove correct it may be asked why a town Apum is not or barely in evidence in the extensive evidence from Mari and Leilan. The answer must be that Apum was sufficiently devoid of political and other importance to have accidentally crept into the available documentation. The basic scenario, however, is highly inleresting. Sehnâ/Leilan was no doubt the capital of a large kingdom during its mid-third millennium floruit, while Apum may have been one of the relatively few settlements which persisted throughout the period ca. 2200-1900 BC, or was perhaps a first choice for the earliest resettlement. After ŠamšiAdad revived leilan, and here in effect created an imperial capital, Apum was eclipsed, and not revived when locals rulers returned. Instead Šehnā became the capital for a land Apum, whose rulers strove to emulate the power attached to possession of Subat-Enlil. The efforts seem to have had little success until after the fall of Mari when external interference became weaker. In the case of the last Apum rulers it seems Šehna had regained its political importance as one of the main powers in the Habur Basin.

\subsection{The Archives from leilan Operation 3}

The Lower Town Palace East at Tell Leilan has so far only been explored during two field seasons, in 1985 and 1987. This work exposed c. 1000 square meters of the building, which is estimated by the excavators to have comprised perhaps 12.500 square meters. ${ }^{33}$ The epigraphic evidence excavated in 1985 has been summarised in some delail by $R$. Whiting. ${ }^{34}$ It was mainly found in the two partially excavated rooms numbered 2 and 5 , and it included 16 administrative texts dated with the limmu eponyms: Adad-bani (1 lext), Aššur-taklāku (1), Išme-El (7), warki lšme-El (1\}, and Niwer-Kubi (6). All of these texts came from Room 2 except the one daled to Adad-bani, which was found in Room 5. In addition 
to this was found half a dozen undated or frogmentory administrative texts and a single letter addressed to Samija. The sealings found had inscriptions relating to the kings ŠamšiAdad, Himdija, Till-Abnû, Mutija, and Jakūn-Ašar. The seal of Jakūn-Ašar himself was also found impressed on all the odministrative tablets dated with the limmu lšme-El (including one dated warkil.-E.).

During the 1987 season the rooms 2 and 5 were completely excavated, and finds here matched those of the first season. The tablets are administrative texts, many dated to the limmu year Išme-El, firmly associated with the ruler Jakün-Ašar. The texls virtually all concern wine, and were part of a smaller, specialized archive, and the latest texts so far found in the palace.

In addition o large new area of the palace was excavated, and a much larger second group of tablets was found, scaltered in three different adjacent rooms. This material consists of both administrative texts, letters, and fragments from political treaties. With very few exceptions it belongs to the latest phase of Leilan history, i.e. the period ca. 1755-28 B.C. The bulk of the group was found in Room 22, in brick collopse above the level II floor, while much smaller portions were found in Room 17 north of Room 22, and in Room 23 just west of 22 . Several joins among the three groups make it centain that they originally formed a single group, stored high above the floor or on a second storey, and dispersed as excavated when the building collapsed. ${ }^{35}$

\section{The Sumerian King List}

Several fragments could be joined to form the lower part of a large tablet inscribed with a version of the the famous Sumerian King List. The text has been fully edited by $C$. Vincente. ${ }^{30}$ It is the only literary type text so far discovered at leilan, and it is tempting to see its presence there as a trace of Šamši-Adad's period of residence. Why it was kept and inserted in much later tablet groups is more difficult to explain, but it seems likely that scribes and others were aware of the special nature of this lext, and therefore wanted to preserve it.

\section{The Trealies}

A total of 76 field nos. represents fragments from at least 5 different rablets with political treaties. They can be classified as follows:

\section{L.T.-l: Trealy between Hāja-abum-Qarni-Lim and ruler of Sümûm(/Ašnakkum) \\ L.T.-2: Treaty between Mutija and Hazip-Tešsup of Razamā \\ L.T.-3: Treaty between Till-Abnû and Jamși-Hatnû of Kahar}

35 In the years following this find 4 tablets, which thematically belong with it, have turned up on the at market. An administrative tablet has been published in Waetzoldt 2003, while 2 letters from Brussels are published in $Y T L R$, Appendix 3. For one of these letters see Ch. 3.3. 


\section{L.T.-4: Trealy between Till-Abnû and unidentified king ${ }^{37}$ \\ L.T.-5: Trealy between Till-Abnû and Assur ${ }^{38}$ \\ L.T.-6: Miscellaneous trealy fragments \\ L.T.-7: Trealy Bullael?}

L.T.-I is clearly older than the rest of the material. It is possible that the trealy still had some contemporary relevance, but more likely that the tablet was kept to have a kind of "model" at hand for such compositions. L.T.- 6 fragments cannot with certainty be assigned to any of the tablets L.T.-1-L.T.-5 and are therefore kept separate. For the possible treaty bullae L.T. -7 see below Ch. 3.2 .

\section{The Letters}

A lotal of 22T letters or letter fragments have been found in the LTP. Two of these, both found in Room 5, are older than the bulk of the material. One is addressed to the Šamši-Adad official Samija, the other to the Andarig king Himdija. The remaining all seem to date to the reigns of the last three Apum kings. ${ }^{39}$ They can be classified according to the reconstructed sequence of these rulers, Groups I-III), and again subdivided according to the status-marker used in the address formula: abum "father" = superior status, no status marker = neutral", ahum "brother" = equal status", marum "son" = inferior status, wardum = "servant". Group IV consists of letters addressed to an unnamed "Lord". 40

The status markers provide important information. ${ }^{41}$ In the case of individuals who wrote to the Leilan kings as father, brother, or son it can be deduced that these individuals themselves enjoyed status as kings. From the Mari archives it is clear that the style of address between the same kings or kingdoms could change due to political circumstances, and we see, for instance, that while Jarim-Lim of Jamhad was the "father" of Zimri-Lim, his son and successor Hanmurabi was first "son", later "brother" of Zimri-Lim, a sign of courtesy from a young and unproven ruler. In the list below it can be noted that Jakün-Ašar, Mašum, and Niqmi-Adad all call Mutija their "farher", but refer to Till-Abnû as "brother". Since Jakün-Ašar was actually a brother of Till-Abnû his case is easy to explain, while for the others the date and political context of the letters may be the reason. The absence of any status marker (neutral) found in a number of letters must probably be viewed as a deliberate avoidance of the status issue. People like Bin-Dammu (Halab general) and Ea-malik (Kahat "prince") probably used this style because they did not belong to any of the distinct status slots indicaled by "brother" and "son". In other cases it seems that writers may have avoided the issue pending establishment of regular relations with Till-Abnû. Halu-rabi, Niqmi-Adad, and Sukrum-Teššup all write both as "neutral" and as "brother", and it could be thought that the

37 Fairly little remains of this tablet, but it is possible that Jamși-Hatnû of Kahat is mentioned.

38 Published in Eidem 1991b.

39 These letters vitually all come from Room 22.

40 See the complete classification in Appendix 2.

41 For a detailed discussion of these matters see Lofont 2001, 232-243. 
"neutral" letters are the earliest. Also among the individuals writing as "servants", however, could be "kings", although vassals with status lower than "sons". A special case is presented by the correspondents who address their letters to belum, but add the nomes of Mutija or Till-Abnû. It has plausibly been suggested that this mode of address was used when writing to a "foreign" lord. 42

This brings us to o fundamental problem. All the letters sent to Mutija as named addressee must of course belong to a period before his death and the accession of Till-Abnû, which can be placed sometime in late Habil-kēnu or early Amer-lštar. For the letters addressed to an anonymous belum "lord", however, only internal evidence can show whether Mutija or Till-Abnû, or some other figure was the addressee. A similar difficulty applies to the letters sent to Till-Abnû, a few of which seem to date to a time when Mutija was still king, while most belong after Till-Abnü's accession. Evidently these two difficulties cannot be entirely eliminated. but apart from explicit internal evidence in some letters the address formulae can provide some indications. The seven correspondents who used the address "to my lord PN" to Till-Abnû were not his own officials or vassals, but considered either Mutija or some third king their proper "lord". Two of these, Sangara and Takē, also employ the simpler form in letters almost certainly sent to Till-Abnû, and we may here have a criterion for separating some letters sent to Till-Abnü before and after his accession.

The tables below provide an overview of the letters sent to Mutija and Till-Abnû by figures whose status markers indicate that they were kings. Names of their bases/capitals are supplied when identifiable on present evidence. For a complete formal classification of the epistolary evidence with the relevant YTLR nos. see Appendix 2. 
Letters to Mutija

\begin{tabular}{|c|c|c|c|}
\hline Status & Base & Name & No of texts \\
\hline Father & Halab & Hammurabi & 4 \\
\hline Brother & Kurdā & Aštomar-Adad & 4 \\
\hline - & Tabāłum(?) & Halu-rabi & 1 \\
\hline - & Karanā(?) & Šepallu & 2 \\
\hline Son & $?$ & Asdi-.. & 1 \\
\hline - & |lān-sūrā & Jakūn-Ašar & 1 \\
\hline - & ? & Jasmah-Addu & 1 \\
\hline - & Habur & Kanisānu & 2 \\
\hline - & Šurnat & Kuzzuri & 1 \\
\hline- & Sinjar & Mašum & 1 \\
\hline- & Habur & Niqmi-Adad & 1 \\
\hline Other letters & & & 3 \\
\hline
\end{tabular}

Letters to Till-Abnû

\begin{tabular}{|c|c|c|c|}
\hline Status & Base & Name & No of texts \\
\hline Father & Halab & Hammurabi & 2 \\
\hline Brother & $?$ & Aplahanda & 1 \\
\hline- & Kurdā & Aštamar-Adad & 5 \\
\hline- & Andarig & Burija & 10 \\
\hline Neutral/brother & Tabātum(?) & Halu-rabi & 6 \\
\hline Brother & Razamā & Hozip-Teššup & 1 \\
\hline- & Sinjor & Ila-Hatnû & 1 \\
\hline- & |lān-șurā & Jakūn-Ašar & 3 \\
\hline- & Kahat & Jamși-Hainû & 15 \\
\hline- & Sinjar & Mašum & 5 \\
\hline- & $?$ & Muti-Addu & 1 \\
\hline Neulral/brother & Habur & Niqmi-Adad & 4 \\
\hline Brother & Karanā(2) & Šepallu & 2 \\
\hline Neulral/brother & Eluhut & Šukrum-Teššup & 3 \\
\hline Brother & $?$ & Ta-... & 1 \\
\hline Son & Šunō & Aja-abu & 10 \\
\hline- & Alilānum & Masum-atal & 2 \\
\hline- & Japtur & Mehilum & 2 \\
\hline- & Amaz & Zigè & 1 \\
\hline Other letters & & & 23 \\
\hline
\end{tabular}


The Administrative Texts

The nearly 600 remaining tablets from the LTP are administrative notes, but many mere fragments. A total of 344 pieces have part of a limmu eponym preserved, and the table provides an overview of these. 43

Disiribution of limmu dated texts.

\begin{tabular}{|c|c|c|c|c|c|c|c|c|c|c|c|c|c|}
\hline limmu/month & $\mathrm{i}$ & ii & iii & iv & $v$ & vi & vii & iix & iix & ix & $x$ & $x i$ & $x_{i i}$ \\
\hline Habd[uś-...] l & & & & & & & & & & & 1 & & \\
\hline Habil-kēnu $178^{44}$ & & & & & 17 & 24 & 24 & 31 & 17 & 19 & 14 & 14 & 1 \\
\hline Amer-|štar $61^{45}$ & 2 & 11 & 9 & 7 & 8 & 4 & 3 & & & 4 & 6 & 2 & 1 \\
\hline |piq-|štar 17 & & 1 & 3 & 2 & & & 3 & 54 & & 1 & & 1 & 1 \\
\hline |šme-El 58 & 1 & & 2 & & 1 & 1 & 12 & 9 & & 5 & 9 & 8 & 3 \\
\hline warkilšme-El 2 & 2 & & & & & & & & & & & & \\
\hline Adad-bani 3 & & & 1 & & & 2 & & & & & & & \\
\hline Aššur-kašid 1 & & & & & & & & & & & & & 1 \\
\hline Aššur-taklāku 3 & & & 1 & & & & 2 & & & & & & \\
\hline Azzubija 1 & & & & & & 1 & & & & & & & \\
\hline Nimer-Kubi 17 & & 1 & & 1 & 1 & 2 & 4 & 7 & & & & & \\
\hline Pilah-Sin 1 & & & & & & & & & & 1 & & & \\
\hline Śu-bêli 1 & & 1 & & & & & & & & & & & \\
\hline
\end{tabular}

The name of each limmu is followed by rotal number of texts, including tablets where the evidence for month is lost. Figures in bold face include sealed tablet(s) with evidence for royal name. ${ }^{47}$ Such evidence is only available from 6 different years.

43 For the names and the sequence of months (so-called "Šamši-Adad colender") see Charpin 1985, Cohen 1993, 255ff, and for the correct reading of month viii see lacombre 2002.

44 To this number may be added the text (month vii) published in Woetzold 2003.

45 To this number may be added a single lext (month iii) from the Brussels tablets (d. above n. 35).

46 One of these, $\mathrm{Fl} \mathrm{138}$, is dated to the intercalary niggallum by the editor, but the sign min moy be remains of a sign from the broken obv. If the reading should prove correct, however, it would seem unlikely that this limmu year is only 2 years removed from Habil-kennu.

47 Month iix, which is only attested for Habil-kennu, is the intercalary niggalum. All texts dated with Aššrur-takläku, lšme-El/ warki ls̀me-El come from Room 2, where also 10 of the tablets dated with $\mathrm{Nim} /$ wer-Kubi were found. With the exception of a few rexts from isolated contexts, all the other dated rexts were found in Rooms 17, 22, and 23. The table includes the 10 daled administrative texts found in 1985. 
Habd $[u(?)-\ldots .$.$] is associated with the seal of a servant of Himdija.$

Habil-kēnu is firmly associated with seals of Mutija or his servants. A single such seal is found in Amer-lšlar (FI 116, dated 6.iv).

In Amer-lštar the earliest sealing associated with Till-Abnû is in month iii $\langle F| 112$, dated 18.iii). A single tablet dated in Ipiq-|štar is sealed by a servant of Till-Abnú $\langle F|$ 106, dated 15.vii).

Jakūn-Ašar seal legends are found exclusively in lšme-El tablets and a single tablet dared to warki lšme-El.

This means that Habil-kēnu, Amer-lštar, and Ipiq-tštar form a perhaps directly consecutive series beginning ca. 1750 B.C., followed by a gap of unknown duration before the years lšme-EL/warkil.-E, which must belong before 1728 B.C. Nimer-Kubi is also attested in a tablet found at Qal'at al-Hãdi southeast of Leilan, and dated to warki Nimar-Kubi (see below $C h$. 2.3). Since this limmu is best represented in the texts from Room 2, it may belong close to lšme-El, and perhaps equals the preceeding year. The single text dated to Aššurkašid mentions "Jakūn-Ašar of llăn-șurā", and if this is the same individual as the later king of Leilan, the text should date before his accession to the throne in Apum. ${ }^{48}$

The 9 rablets dated by 5 other limmu cannot be placed very firmly at present. The large beer archive found at Leilan in 1991 (in the Lower Town Palace North) provided 4 limmus belonging to the time when Qarni-Lim of Andarig controlled Leilan, that is the period $c$. Zl 5-10. Three of these limmus, Ašsur-taklāku, Zabzabu, and Ahu-waqar, can be shown to have followed each other directly, while the fourth, Adad-bani, cannot be placed. ${ }^{49}$ Aššur-taklāku and Adad-bani from the East palace tablets are most reasonably identified with their namesakes in this series, and can therefore be dated to the reign of Haja-abum. Finally Azzubija is probably identical with the limmu of this name attested in the llrani archive from Rimah, and can be dated to the years ca. 1760-50, i.e. late in the reign of Hammurabi of Babylon. The last limmus, Pilah-Sin and Šu-Bēlī, are attested elsewhere, but cannot be placed very accurately. ${ }^{50}$

48 This eponym may be identical with the eponym attested in Kültepe, son of Zl-ta-mu (see Veenhof 1998 , no. 8).

49 See Mieroop 1994.

50 The single lext daled Su-Bēli provides no conclusive internal evidence, but its occurrence elsewhere supports a "lale" date. Veenhof (1998) suggests a dale ca. 1770 B.C., but this seems too early (the limmu is no. 34 in his list'.

A limmu Su-Bēli is known from the MEC (B7) for the year before Šamši-Adod's accession, but this definitely seems too early for our limmu. The relevant text mentions the official Bajiann, who can be firmly associaled with the reign of Till-Abnu, and although his activity may cover a long period, it can hardly be strelched back that far. 
It seems likely in the end that all of these limmus belong within the time ca.1760-1728 B.C.. If correct we may, adding some eponyms from the lltani archive at Rimah, have vitually all the limmus fram the reign of Mutija and his predecessoris\}). Himdija (and possibly DariEpuh) affer the fall of Mari. Then after Ipiq-lštar (which may be the last regnal year of TillAbnû) we have perhaps a considerable gap since, dating lpiq-Ištar to ca. 1748-45 B.C., we seem 10 have only the limmus from Room 2 representing a total of 4 years to cover the period down to 1728 B.C. Although it is a likely theory that the texts from Room 2 belong towards the end of this period, and that warki Isme-El may actually equal 1728 B.C., this cannot be proved.

Veenhof has been able to isolate approximately 40 eponyms which must belong after the death of Šamši-Adad, and to the last part of the period related to level lb at Kültepe/Kaniš (ca. 1800-1700 B. C.). A number of these late eponyms is certainly still missing in extant sources, and it is not yet possible to establish a continuous sequence. The fact that only two of the eponyms related to sizeable partions of texts from the Lower Town Palace, viz., Habil-kēnu, Išme-El, Amer-lštar, Nimer (or Niwer)-Kubi, and Ipiq-lštar, are yet attested elsewhere is hardly surprising, since the Leilan material probably is later than any other text group so far discovered. ${ }^{51}$

The dated texts are mostly small cushion-shaped notes concerning particular receipts or issues. The table below provides a general overview of the main subjects in tablets from the best documented years. It is immediately clear that the tablets from Rooms 2 and 5 basically relate to the administration of wine, while also the tablets from the second group basically concern manipulation of fairly costly items, metals, equipment, garments, oil, wine, and for food mostly delicacies like honey, shrimps etc.

\begin{tabular}{|l|c|c|c|c|c|}
\hline Type/Year & Habil-kēnu & Amer-lštar & Ipiq-Ištar & Nimer-Kubi & $\mid$ Isme-El \\
\hline silver & 43 & 14 & & 2 & \\
\hline equipment & 32 & 17 & 8 & & \\
\hline animals & 3 & 3 & 1 & & \\
\hline food & 25 & 3 & & 1 & \\
\hline wine & 13 & 15 & 2 & 14 & 55 \\
\hline oil & 14 & 2 & 1 & & \\
\hline ransom & 14 & & & & \\
\hline included & 144 & 54 & 12 & 17 & 55 \\
\hline Total & 177 & 61 & 17 & 17 & 58 \\
\hline
\end{tabular}


The mixture of letters and administrative texts of this kind is similar to that found in other smaller palace archives like the litani archive at Rimah and the Kuwari archive at Shemshāra. This can be fairly easily explained by the kind of administrative texts involved at all three sites, in the main documents pertaining lo expensive items like metals, garments, expensive food products, and presumably demanding closer control by the archive "owner", or the top level administrators. Other administrative documents concerning typically agriculture and circulation of agricultural products were kept separately elsewhere, and one example of this is found at Shemshara. ${ }^{52}$ Also accounts for the circulation of wine and beer could be kept completely separate, perhaps close to the actual cellars. Apart from the archive from Room 2 in the leilan palace, a clear example is the wine archive excavated in the Rimah palace.

\subsection{COMPOSITION OF THE EVIOENCE}

The large archive from Rooms $17 / 22 / 23$ is clearly a composite group of tablets. In diachronic terms it covers the reigns of two different kings of Apum, Mutija and Till-Abnū, and with a formal division as follows:

Texts relating to Mutija:

22 letters addressed to Mutija ( $\mathrm{X}$ letters sent to him as belum)

178 administrative documents dated with limmu Habil-kēnu

1 political treaty

Texts relating to Till-Abnû:

98 letters addressed to Till-Abnû (+ X letters sent to him as bëlum)

ol administrative documents dated with limmu Amer-lštar

17 administrative documents dated with limmu lpiq-lštor

3 political treaties

Evidence from the letters as well as from the sealed tablets show that the archive straddles the death of Mutija and the accession of Till-Abnû, while Jakūn-Ašar is not in evidence as king of Apum. This leads to the logical conclusion that the main archive(s) from jakūn-Ašar's reign must have been stored elsewhere in the palace, and may be retrieved one day when more of the building is excavated. Thus the archive at hand must have been regarded as "inactive" during a period prior to the abandonment of the palace, and originally stored as such. Several fealures reveal that the archive cannot represent anything like complete archives from the reigns of Mutija and Till-Abnũ. The number of letters sent to Mutija is very small, the large group of administrative texts dated with the limmu Habi-kennu covers only the last 8 months of the year, and the series of administrative lexts related to the reign of 
Till-Abnu are clearly too small to represent total outputs. This means that the archive must represent the result of one or several selections of original archival groups, and it is therefore important to attempt a reconstruction of this process in order to evalute the nature of the available evidence.

As shown in the previous section the evidence from the sealed tablets suggests that the limmu years Habil-kēnu, Amer-lštar, and Ipiq-lštar followed each other, and it might therefore be expected that the number of administrative texts would show an increase in relation to this diachronic scheme, but in fact the opposite is the case. The best way to explain this feature is too assume that the extant archive is the result of two consecutive selections, one which took place at Till-Abnû's accession, and a second which took place at Jakūn-Ašar's accession. When Mutija died Till-Abnû and his officials selected a number of Mutija's letters and administrative notes to be kept for reference. logically these would predominantly have been the latest documents, hence only Habil-kēnu-dated records from the last months of the year. This selection would then have been kept, perhaps together with new letters and administrative records, while the older texts where either discarded or stored elsewhere. Subsequently when Till-Abnû disappeared Jakün-Ašar and his officials would have made a similar selection of the latest and most relevant tablets to be stored with the "active" archive of the new reign, and which has not yet been found. What remained from this second selection is then quite likely the archive found in Rooms 17/22/23, which consequently is a kind of "torso" of records from two different reigns, and centered on the period of transition between them.

This state of affairs obviously imposes heavy restrictions on historical reconstructions from the evidence. The Mutija "archive", although small, resembles a fairly normal case, that of a restricted group of records from a presumably "final" archaeological context, prior to a destruction or an abandonment. In this sense the group parallels Old Babylonian archives found elsewhere, like the archive of Kuwari at Tell Shemshara, and the archive of lliani at Tell al Rimah. The parallel, late Till-Abnú "archive", on the other hand, is missing, and perhaps to be found elsewhere in the palace together with records from the reign of JakunAšar. In addition to this it remains possible that other tablet groups, especially administrative records, discarded or stowed away by either of the three kings, may be retrieved somewhere within or near the palace. This is the general situation, but of course many details cannot be explained with certainty. A number of isolated texts no doubt become mingled with our archive, for any number of reasons. If, for instance, Mutija, and subsequently TillAbnu wanted to keep a copy of the Sumerian King List, or the no longer relevant treaty concluded by Hāja-abum, then why did Jakunn-Ašar decide to put them aside? This question is obviously not easy to answer, but probably Jakunn-Ašar selected other prominent texts, which are therefore, at least temporarily, lost to us, while it must be remembered that the archive would still have been available for consultation if desired.

Another question which deserves consideration is whether the spatial distribution of the tablets in Rooms 17/22/23 con help us understand the original archival order, and perhaps suggest an early or late date for individual segments of the archive. Unfortunately this does not seem possible. The tablets were carefully excavared as part of a number of excavation units ("lots"), and each item given a sequential object number, but the exact placement of 
each tablet cannot be reconstructed, and many were found lumped closely together in the debris. The particularly rich lot 18, for instance, produced no less than 226 tablets and fragments. The letters addressed to Mutija (by name), and which should belong to an early segment were found in 5 different lots, and in no apparent cluster. Similarly no clusters of dated administrative tablets can be observed. What may have remained of an original archival ordering of the tablets would therefore seem to have been severely disrupted by the sorting of materials by ancient officials, and not least by the final confusion caused by the collapse of the building.

\subsection{Historical SumMarY}

\section{General Parameters}

Untortunately dated administrative texts provide very few links to events mentioned in the lefters, an important exception being the evidence for diplomatic activity and trealy-making found in texts from the limmu-year Habil-kēnu (see Ch. 3.2). In this situation attempls to place the evidence in diachronic perspective must rely mainly on other observations, both external and internal.

An important premise for a diachronic scheme is provided by the theories about the archival composition of the texts presented above. If these are correct it can be assumed that the letters are basically contemporary with the administrative lexts, and mostly date within the three consecutive limmu years Habil-kènu, Amer-lštar, and lpiq-lštar. It can further be assumed that the number of administrative texts from each of these years within the archive should be roughly indicative for the number of letters from each year within the archive. This means that most of the letiers should belong to the period from late Habil-kēnu to midAmer-lštar. Evidently it is impossible to prove such a scheme for all individual texts, but it does seem to have some basic validity, and there are so many obvious links between events and individuals mentioned that a limited time frame in any case seems a necessary conclusion.

Within the letters it is possible to distinguish major groups of texts which concern four different situations. The first is a war between two coalitions of city-states: Mutija of Apum, Aštamar-Adad of Kurdā, and Šepallu of Karanā (a) were allied against Burija of Andarig and Hazip-Teššup of Razamā (Ch. 3.1). This situation clearly belongs to the end of Mutija's reign, but involves also letters sent to Till-Abnu. The war apparently was brought to an end by intervention from Halab, and treaties of peace concluded under the supervision of Halab envoys (Ch. 3.2). The second situation is the ransition between the two reigns of Mutija and Till-Abnû, reflected in a number of letters which explicitly refer to the change of rule. A third group consists of the many texts which concern troubles on the marches of Apum caused by the king Halu-rabi or his allies. Halu-rabi, whose kingdom perhaps was located around modern Hassake, marched into the central part of the Habur Basin and here caused alarm in places like Sunō and llān-șura (Ch. 3.3). The purpose and outcome 
of this affair are not clear, but it seems that the situation ended without major confrontations, and we next find Halu-rabi writing friendly letters to Till-Abnú. It must have been during the campaign of Halu-rabi that Mutija died and was replaced by Till-Abnú. Subsequently we have series of letters sent from various kings to Till-Abnû, and which reflect a fairly peaceful situation. The longest series are those sent from Jamși-Hatnû of Kahat and Burija of Andarig. The general impression of these series is that they probably do not cover very long periods of time, and this reinforces the idea that the bulk of the letters to Till-Abnu belong either to a short period before his accession, or to the first year or so of his reign.

While the letters contain the best historical evidence it is of course the dated administrative texts which provide the firmest chronological anchor. In spite of the limited nature of the evidence it may therefore be of interest to briefly review what can be gleaned from this material, which is summarized below in Appendix 1.

For the year Habil-kennu we note that in the first month documented, $v$, there is evidence for celebration of the elunnum festival, and shipments of wine for this by various Apum vossals. In month vii a major event is the conclusion of a treaty between Apum and Razamā, supported by the Halab "field marshal" Bin-Dammu. In month viiib (the intercalary niggallum) Bin-Dammu seems instrumental in a second treaty between Apum and Burija of Andarig, and the king of Apum sends presents to the court in Halab. The end of the year is marked by a prolonged stay of Bin-Dammu and of up to several hundred representatives of "auxiliaries" and "countrymen". The purpose of this event is not clear. Tablets sealed by Mutija or his officials are still in evidence until the $24^{\text {th }}$ in month $x i,{ }^{53}$ but it could still be speculated that the large gathering was occasioned by the death of Mutija and the official mourning over him, leading up to the accession of Till-Abnú. This must remain speculation, however, and Till-Abnû only makes his first official appearence as king of Apum in L.T.-3 which is dated to 1/iii Amer-lštar.

The beginning of Amer-lštar sees Bin-Dammu in Leilan and a series of shipments of wine from Apum vassals in month ii, prior to the elunnum festival in month iii. In early month iv the king of Apum meets the king of Kahat and some of his vassals, a meeting which could tentatively be connected with the conclusion of L.T.-3 - since the date on the tablet itself may be the day of dratting. After the meeting the king goes to Nawali, probably for religious ceremonies. Subsequently, in late month ix, the king visits Kahat, and only a week later we hear that an enemy has reached the gate of Subat-Enlil. This, however, seems not to hove been a major disturbance, and the event is perhaps referred to in a letter sent to Till-Abnû from Burija of Andarig, who writes:

Say to Till-Abnû: Thus (says) Burija, your brother:

I have heard the letter you sent me. You wrole to me that Hazip-Feššp came, and that you went out and met him, and that you talked to him obout your towns which he holds, and 
that he said: On my return I will release them. He is in Mari, ${ }^{54}$ your town - Force was applied! He went to the fisherman and demanded fish (and) the fisherman said: "You worry (roo) much; send your retainer to me, and I shall supply you" - "Why would you not give to $[. . . . . . . . . .$.$] who asked you, but you will give to my retoiner?" This [word] Hazip-Teššup$ $[\ldots . . .$.$] your [\ldots . . .$.$] and his towns [\ldots$. break .... $]$

(rev.) and $[\ldots \ldots \ldots$ your rowns $(?)]$ he did not release $[\ldots \ldots .$.$] from his own land he has$ seized $[\ldots . . . . . .$.$] they carry presents to him. He will release [the towns]? The man is just$ pretending! (YTLR 43; for the last portion of the letter see Ch. 4.3).

Hazip-Teššp of Razamā, in spite of his treaty with the late Mutija ( $=$ L.T.-2) seems indeed not to have had very good relations with Till-Abnû. The phrasing of the letter suggests that Hazip-Teššup did not arrive as a friend being allowed into the town, wined and dined, since Till-Abnú leaves Leilan and meets him outside. It seems that Hazip-Teššup had not fulfilled the obligations attached to his treaty with Mutija, and still held towns in Apum occupied, which he had originally promised Mutija to evacuate. ${ }^{55}$

The few texts from the year Ipiq-lštar record only some journeys made by the king to Kahat and Kudimmar (month iii), and to Nahur (month iv), and Zabalum (month xii).

Subsequent events are obscured for us, presumably because of the archival reorganisations discussed above. What remain are some notes in the wine archive from the years NimerKubi and Išme-El, presumably shortly before Jakūn-Ašar's faral end, and we shall return briefly to this below (Ch. 5).

\section{The Three Kings}

The relationship between the three last Apum kings is clearly an important question for a correct understanding of the evidence. Unfortunately the question connot be fully and securely answered at present, and we are left with what may be described as a working hypothesis. This has already been briefly alluded to: The brothers Till-Abnû and Jakūn-Ašar supported Mutija, possibly their uncle, during his reign, and subsequently and consecutively succeeded him as kings of Apum. In order to clarify the basis for this hypothesis, and its uncertainties, it is necessary to take a closer look at the available information.

The LTP archive does not include any letter from Till-Abnû to Mutija, but a prominent figure named Till-Abnû is mentioned in two letters from the official Kuzuzzu to "my lord", almost certainly sent to Mutija (YTLR 137 and 139; see Ch. 3.1). The implication here is that this Till-Abnú supported Mutija, and must have been an ally, vassal, or governor of Apum. Also

54 A local Habur town, apparently located on the border of Apum, and also mentioned in e.g. FI 130.

55 Two letters (YTLR 156 and YTLR 157), which both concern unfriendly activity by Hazip-Teššup, may well belong to the reign of Till-Abnu. Only a single letter is preserved which Hazip-Tešsup may hove sent to Till-Abnu. This is YTLR 57, sent by the "brother" ha-zi-i[p-....] who refers to a legal case, but also inviles his "brother" to a festival for Adad. Since the sender must be a king of equal stalus to Till-Abnú, he can be fairly safely identified as Hazip-Teššup of Razamā. 
administrative texts from the year Habil-kēnu mention a Till-Abnû: in CV 112 (dated 19/v) a Till-Abnû, "man" of Šurnat, delivers wine, and in month ix two texts (CV 55 and 106) probably mention other deliveries by a Till-Abnū, in these instances without information on his background. On the basis of this evidence it seems reasonable to assume that Till-Abnú, before his accession, was based in Surnat as a kind of viceroy. The relative uncertainty of this assumption, however, is underlined by the fact that we have evidence for another prominent "man" of Surnat, a centain Kuzzuri, who appears 25/vii, Habil-kēnu, where he brings wine and has a meeting with the king (CV 111). A single letter from Kuzzuri to his "father" Mutija (YTLR 17) may have issued from the same figure, but unfortunately the text is too broken to provide firm clues. It could be thought that Kuzzuri replaced Till-Abnû in Surnat, but since he does not appear in doted texts from other years, such a theory connot be substantiated. In sum we are left with the assumption that Kuzzuri may have been the local "king" of Surnat, while Till-Abnû was the later king of Apum, who used Śurnat as base. ${ }^{50}$ Turning next to Jakūn-Ašar we face similar problems, but the evidence is more extensive. First an administrative text dated 18/xii in the isolated limmu Ašsur-kašid mentions an issue to a certain "Kazikuk, retainer of Jakūn-Ašar of llän-surā" (FI 104). Granted the possibility of homonymy - like equally in the case of Till-Abnû of Surnat - we may then assume that Jakūn-As̆ar was based in llōn-șura before replacing his brother on the throne of Apum. The important town of llän-suura cannot be located very accurately, but must be sought west of Leilan. ${ }^{57}$ The letters sent from Jakūn-Ašar to Mutija (YTLR 13), and Till-Abnû (YTLR 59-61) are unfortunately not very helpful, except to show that a local king named Jakunn-Ašar was active in the Habur Basin, and probably west of Leilan. In YTLR 60 jakün-Ašar writes on behalf of a man from BEšannim, a lown located near(?) Chagar Bazar. ${ }^{58}$ Jakūn-Ašar is further mentioned in two letters from Sangara in connection with military operations touching Urkiš and Ašnakkum (see below Ch. 3.3). This evidence at least places Jakūn-Ašar in the right direction, and may be said to support the idea that he was based in llān-șura before his accession. Both Surnat and llän-șurā could fit roles as important border points for Apum, and be logical bases for viceroys.

Another question is what happened when Mutija died. The event is referred to in several letters, but in general terms:

so For more information on Surnat see Ch. 2.3 .

57 J.-M. Durand hos suggested that the town should be sought in the central part of the Basin (Durand 1990, 9). A more recent proposal by Guichard (1994, 244) to place llan-suro of Tell Sharisi southwest of leilan seems effectively ruled out by the archaeological evidence adduced by Wafler (1995), who instead suggested Tell Farfora, localed some $20 \mathrm{kms}$ southwest of leilan. The Leilan texts provide no decisive evidence for this problem, but lend to support the general ideo of Durand.

58 Letter quoted Ch. 4.3. For a discussion of the ancient name of Chagar Bazar see Charpin and Ziegler 2003, $128 \mathrm{~F} n$. 432, where it is concluded that the site belonged to the orea of Qirdahot and should be identified either with that town or with Habba'um. According to Talon 1997.

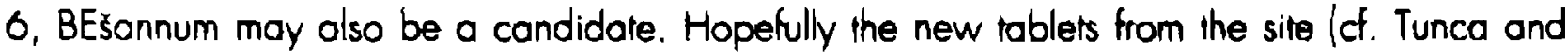
Lacambre 2002) may help solve the riddle. 
Say to my lord: Thus (says) Bahdi-Lim, your servant:

May Šamaš and Bēlet-Apim for my sake give my lord a long life!

The enemy of my lord, Mutija, who did nol accept my reports, is dead. Now my lord (is)

Till-Abnû. Šamaš and Belet-Apim have for my sake put him on the golden throne.

My lord Mehilum stayed 5 days in Qirdahat, but he did not come to your messengers.

Also, may my lord not enter Kahat! The word I heard I have written to you; may your God stand between us! (YTLR 128).

Unfortunately the crucial word enemy is a very uncertain reading of the text, ${ }^{59}$ but another letter provides a lantalising hint of trouble between Mutija and Till-Abnû:

Say to my lord: Thus (says) Abbuttānu, your servant:

Let Takē, Bajiānu, and Tišwen-atal stand before my lord and hear this letter of mine. They must not say anything against me who is a servant of my lord Till-Abnû. (It was) I (who) made all the kings bend to my lord's feet. When the elders of Apum went to Kahat to my lord, $[\ldots . . .$.$] , and I held [\ldots$ break .... $]$ (YTLR 127, 1-11).

Did Till-Abnû perhaps seek refuge in Kahat, where he was approached by the elders of Apum after Mutija's death? A slight support for such a theory is supplied by YTLR 28 (see Ch. 4.1) where Bëlet-Nagar, the famous goddess at Nagar, which formed part of the territory of Kahat, claims credit for Till-Abnû's accession, but in any case the delailed circumstances of these events are unknown at present. 


\section{Geo-Pouncal Overview}

\subsection{The International Horizon}

The kingdom of Jamhad centered on Halab (modern Aleppo) in northwestern Syria ${ }^{60}$, appears as the decisive political power in the northern Jezira at the time of the leilan archives. Given the brevity of the period documented the establishment of Halab's position so far east cannot be reconstructed in detail, but in general easily explained as a consequence of the power vacuum left in the region after the collopse of the Mari kingdom, and subsequently the diminished influence of Babylon at the end of Hammurabi's reign.

Hammurabi of Halab ascended the throne in ZL 10, and was followed by his son Abbon sometime into the reign of Samsu-iluna of Babylon. He sent letters to both Mutija and TillAbnû, but most of these are unfortunately very short or broken. In YTLR 24 the writer, who is almost certainly Hammurabi, tells Till-Abnû :

"[......... I heard that $]$ you had entered your father's [house] (i.e. ascended the throne), but I was busy [(and) therefore have not written] to you until now ............... this town is your town and this country is your country!" (YTLR 24, $\left.7^{\prime}-4^{\prime}+7^{\prime}-8^{\prime \prime}\right)$.

This affirmation reflects Halab's supremocy, and it is noteworthy that in a number of texts the king of Halab is simply referred to as "the king" (lugal), another clear indication of Halab's political importance.

An administrative text (CV 53; dated $6 /$ viiib, Habil-kènu) is a list of presents "carried" to Halab, and intended for Jahdun-Lim, Abbā "son of the king", Nür-ahhišu, and Kilimani, "his vizier" ( sukkallum). Abba is surely the later king Abban of Halab, while Kilimani is attested as vizier in a tablet from Alalah Level VII, ol where he is a witness together with Abban. Who the two other figures are, especially Jahdun-Lim, who heads the list, and receives a larger amount of silver than the rest, is uncertain, but one theory could identily him with the homonym king of Karkemish who ascended the throne very late in the reign of Zimri-Lim. ${ }^{62}$ Possibly he was to be given a present en route to Halab. Nür-ahhišu was, judging from his name, a younger brother, possibly of Abban.

The Halab agent Bin-Dammu occurs repeatedly in the administrative texts (ct. Appendix 1) which charter his long stays there, and CV 15 provides his actual title "field marshal" (sag-galmar-tu-mešl. He is mentioned also in administrative rexts dating to the years Amer-lštar and Ipiq-Ištar and in letters, including those he himself sent to Till-Abnû, both unfortunately short and

60 For a survey of the evidence outside Leilan see Klengel 1992, 44ff. For an archoeological view see Nigro 1997-99.

ol Wiseman 1953, no. 56.

02 For the Karkemish kings see Charpin and Ziegler 2003, 264. 
badly preserved. Especially the tablets from the year Habil-kènu are replete with references to his extensive staff of retainers, and quite likely he was accompanied by a substantial military command. A letter from an unidentified writer mentions one of his departures from Halab, and also provides a possible hint at Aleppine control with areas in modern Lebanon:

Say to Till-Abni: Thus (soys).

[That] Bin-Dammu left [for] the country of Apum, Abban told me in the market of Zibat (2), ${ }_{1}^{63}$ in the house of [PN? .........] (rest too broken for translation). (YTLR 122).

Two letters provide important, but fairly enigmatic information relating to international events involving Halab, Karkemish and Babylon:

[Say 10] “il[l-Abnü] ${ }^{\circ 4}$ : [Thus] (says\} Burija, your brother:

We mustered $[x]$ of our retainers and sent [them to] Halab; they were turned back from Kubšum. Two of my retainers, couriers (however)[......... (they) went direct via Tuttul to Halab and reached Hammurabi, and he brightened like a sunrise. (These are) all the favourable words he said: "I will not cut (support to) Burija; since Burija [has .......... the king of Babylon [has ........], and before the Babylonians [reach?] Karkemish, [they will pass] through there, and [attack?] my son Burija. 10.000 soldiers with Ahi-Dabih shall depart, and stay two years with him in Andarig, and perform all his wishes. Since they will look after his interests, let him come here together with Ahi-Dabih and meet with me." These soldiers have arrived via the steppe route to Andarig (and) are staying with me. [The day I sent $]$ you this letter of mine $[\ldots$ break .... $(Y T L R$ 41).

The actual arrival of the Halab army, now scaled down to 6.000 men, is reported in another letter:

Say to my lord: Thus (says) Takē, your servant:

A retainer of Ahi-Dabah, bringer of good news (mubassirum), came to Halu-rabi, and said as follows: "I hove crossed through to Andarig with 6000 soldiers; I shall cross between the Haneans and among the sheep, [the .........], and the camps of the Haneans [...2 2 lines broken .... there will be no [violation(?) - be plleased!" This he sent words about to Halurabi, and the retainer of Ahi-Dabah [....... went to Kahat, and Ea-malik gave him a l-shekel piece of silver. Now hereby I have sent him to my lord. Lel him dine and wine before my lord, and moy my lord give him a 2-shekel piece; also let a retainer from my lord who carries with him his greetings go with him to [assist him?] with his mission [(........)]. (YTLR 150).

63 The signs are damaged and the reading not entirely certain. For the town Zibat, located in the Beq'a Valley, see Charpin 1998.

o4 Materially the oddressee could also be Mutija, but on historical grounds this seems less likely. The implication of the first passage is that Burija and addressee have tried to send messengers to Halab jointly - something which would only fit the very end of Mutija's reign. 
The deployment of a Halab army for wo years in Andorig shows more clearly than any other evidence the power and influence of Hammurabi in this region. The hint of a Babylonian campaign northwards in the direction of Karkemish and a consequent danger for Andarig seems to be the background for this, but the poor preservation of this portion of YTLR 41 renders a precise evaluation difficult. Since the letter mentions envoys from Andarig en route to Halab being turned awoy at Kubšum, 65 it seems possible to assume that the Upper Euphrates country, including the imporiant kingdom of Karkemish, ${ }^{60}$ was frying to assert its independence from Halab. Such a theory could provide a logical explonation for a Babylonian campaign taking advantage of the situation. The deployment of Halab troops in Andarig, if meant to anticipate the Babylonian troops, indicates that these were expected to follow a route up the Tigris and across the Upper Jezira, and this was in fact the roule later taken by Samsu-iluno when he roided into the Habur. ${ }^{67}$ While the Babylonian push towards Karkemish seems not to have materialised, the mere expectation should indicale a situation of relative strenght, not easily correlated with the meagre information on Babylonian politics in the years around $1750 \mathrm{BC} .08$

The local ruler Halu-rabi, whose capital perhaps was Tabātum on the Lower Habur, tried to persuade Till-Abnû to join him on a journey to Halab to conclude a treaty with the king, but instead seems to have acted on Till-Abnû's behalf in Halab. We hear no more of this, and it must remain undecided what prompted this trip and accasioned the projected treaty.

Say to Till-Abnû: Thus (says) Halu-rabi, your brother:

I have heard the letter you sent me. Concerning your decision not to go to Halab, that you wrote to me about: since you will not go to Halab, and you will not meet with the king, let (one of) your trusted servants take charge of your guard and go with me to Halab; and in Halab let the king "touch" his throat for you, and let your servant observe him, and convey to you (about) what the king has "touched [his throot"] for you, and you will be reassured; and when I have returned from Halab, you must come and have a meeting with me, and I will explain to you the king's intention(s). (YTLR 54).

Say to Till-Abnû: Thus (says) Halu-rabi, your brother:

I am well. I met with the king; the opinion of the king is my opinion (as well). Let you heart be happy! I handled your affairs before the king as you would hove yourself. Do not be negligent about the herders (nawim). May your [greetings] and news to me be regular. (YTLR 55).

During the reign of Jakūn-Ašar Bin-Dammu is no longer in evidence, but several texts dated Nimer-Kubi and lšme-El mention the presence of a "governor" (sápinum) (cf. Appendix I), quite likely the local representative of Halab.

Kubsium is attested in the Old Babylonian itinerany texts, where it is a station on the inbound rood atter Tuttul (Tell Bi'a) and Zalpah on the Balih, and before towns in the Habur Basin (Hallo 1964). The lown is also mentioned in $\mathrm{Fl} 89$.

bo For a survey of the history of Karkemish see Kupper 1992.

67 For this route see Charpin 2004, 348 .

$68 \mathrm{Ct}$. the summary in Charpin 2004, 331-330. 
While Halab then was the main international referent for the north Jezira kingdoms, other conlacts are attested. The region formed part of international trade networks, discussed below in Ch. 4.2, and also had contacts with northeastern Mesopotamia. Auxiliaries were drafted from Kakmum and Šimurrum, ${ }^{\circ 9}$ and during the reign of Jakūn-Ašar administrative texts record envoys coming from Arrapha (FI 42 and 79). Finally it seems that the notorious habbatum mercenaries (cf. Ch. 4.3) also principally came from the East.

\subsection{THE JeZIRA KINGDOMS}

Apum was clearly one of the mosi powerful city-states in northeastern Syria. A fairly confidenf list of the other main powers in the region is provided by the letter writers who address the Apum kings as "brother", but unfortunately the evidence is often less specific than could be desired, and the capitals of even quite important rulers like Šepallu and Halu-rabi cannot be identified at present. The administrative texts, moreover, are not particularly helpful here. Many of the rulers attested in the letters are not mentioned in the administrative texts at all, and possible new rulers are difficult to identify because of the frequent use of the opaque lu GN "man of GN", which may refer lo rulers as well as other citizens. With these reservations in mind, however, we can identify a number of kingdoms as important. In the region south and east of the Habur Basin Andarig, Kurdā, Alilānum, and Razamā, and several unidentified kingdoms ruled by Šepallu (Karanā/Qattarāe), Mašum, lla-Hainû, and Halu-rabi (Tabātum?). Within the Habur Basin the most prominent kingdoms besides Apum seem to have been Kahat, Ašnakkum, and Talhājum. Urkišs, Tillā, and Qirdahat are also mentioned. 70

\section{Region South and East of the Habur Basin}

Alitānum

Mari texts show that this town was located in the region northeast of the Jebel Sinjar, and mention a certain Masum-atal as its king. ${ }^{71}$ It seems very likely that this figure is identical with the king Masum-atal who sent two short letters to Till-Abnû (YTLR 103-104). These letters provide little information, but Alilānum is mentioned in YTLR 138, where it is stated that habbātum troops have entered Alilānum and continued lowards Razamā.

69 For the location of these places $\mathrm{cf}$. Eidem and Laessee 2001, $23 \mathrm{f}$.

70 For information on kings of individual cities attested in the Mari archives, and for general geographical locations see the appendices I ("les rois du Proche-Orient dans les archives de Mari") and It (Notes de geographie historique") in Charpin and Ziegler 2003, 263-276. Cf. also the useful indices and discussions of historical geography in Wöfler 2001. See Birot, ARMT XXVII, pp. 23f. 


\section{Andarig}

Burija is attested as sender of 10 letters to his "brother" Till-Abnū, and the evidence, in e.g. YTLR 41, shows that he was king of the imporlant and powerful kingdom of Andarig, located in the region south of the Jebel Sinjar. On present evidence we cannot relare Burijo to any earlier kings, and the name of Burija's father is unknown. If not belonging to an entirely new family Burija could be associated either with Qarni-Lim, who was the son of a certain Muti-Addu (L.T.-1\}, with Atamrum, son of Warad-Sin (the regional governor during the reign of Šamši-Adad, and possibly an original king of Andarigl, or finally with Himdija, whose relationship with Atamrum is not clear. ${ }^{72}$

\section{Kurdā}

A king Aštamar-Adad is attested as sender of letters to Mutija and to Till-Abnû, both addressed as "brothers", and he is also frequently mentioned by other correspondents. Although he is not explicitly referred to as king of Kurda, this identification emerges clearly from his association with both the town itself, with Kasapā, onother important town in this kingdom, and with its iribal designation Numhum/Numahum. Aštamar-Adad appears as a firm ally of Apum throughout the correspondence. He was allied with Mutija and Šepallu against Andarig and Razamã, and his letters to Till-Abnû discuss the arrangements for a political trealy.

The central area of Kurda must clearly be sought south of the Jebel Sinjar and for a location of the capital itself Balad Sinjar has been suggested. The evidence trom Mari about Kurdā and its earlier kings has recently been discussed by Charpin and Durand, ${ }^{73}$ but it should be noted that there is evidence for a pre-Šamši-Adad ruler Aštamar-Adad, which reveals a conscious and perhaps factual link between that dynasty and the king of our period.

\section{Razamā}

A fragment belonging to L.T.-2 provides the explicit information that a king of Razama contemporary with Mutija was named Hazip-Teššup. In spite of this treaty and the parallel evidence from administrative texts dated to Habil-kènu (cl. Ch. 3.2) Hazip-Teššup mostly appear as an enemy of Apum in these letters, which also explains why we hove no letters sent from him - with one possible exception. In YTLR 8 Mutija and his allies are waging war on the lands of Jassonn and Jamutbolum, often ossociated with respectively (the northern' Razama and Andarig, and indeed the text makes it clear that Mutija's opponents were precisely Hazip-Teššup and Burija. Again in YTLR 157 Hazip-Tešsup is connecled with the land of Jassān and with Razamā.

Razama of Jassān was located in the plain east of the Habur Basin, and has tentatively been identilied with Tell al-Hawa. ${ }^{74}$

72 See Joonnès, ARMT XXV1/2, pp. 244-249; also Joannès 1991, 170.

73 See Charpin and Durand 2004.

74 See Charpin and Ziegler 2003, 22. 


\section{Halu-rabi}

This man, no doubt an importank king, is a central figure in the archive. He sent letters to his "brothers" Mutija, and Till-Abnû, and as "neutral" to Jakūn-Ašar, and is mentioned in numerous other letters. Unfortunarely his geo-political background is never stared explicitly, and must be reconstructed from various bits of evidence. A letter (YTLR 112) reports that Halu-rabi will march against Ida-Maraș, which suggests that he belonged outside the Habur Basin. Another letter (YTLR 150) shows that an army from Halab marching to Andarig via the straight "steppe" route, where the Haneans graze their sheep, sends envoys to successively Halu-rabi, Kahat, and Apum. This suggests that Halu-rabi's capital should be sought west or south of Kahal. Finally in YTLR 51 Halu-rabi asks Till-Abnû to send envoys for a meeting in Tabālum, a lown presumably identical with Tell Tābān on the Habur river below modern Hassake. $^{75}$ The best theory which can be offered at present is that this was Halu-rabi's own seat of kingship. The Mari evidence for Tabātum provides some suggestive parallels for Halu-rabi's situation: a diviner is sent to Tabatum to rake omens about the Haneans and the border (ARMT XXVI/1, 141), and a route from Tabatum across steppe to Andarig via Rapšum is given in ARMT XXVII, 65. A further implication of the Mari evidence is that Tobatum was controlled by the Mari kings, and therefore played no independent political role in this earlier period.

\section{lla-Hatnû}

This king is only attested as sender of a single letter (YTLR 58) to his "brother" Till-Abnû. The letter discusses the case of some Apum citizens captured by lla-Hainû's troops, while these were operating with troops of his "brother" Burija, the king of Andarig. This may be a reference to the war between Apum and Andarig and Razama (see Ch, 3.1), where lla-Hatnú then was an ally of Andarig. Since lla-Hatnû styles himself "brother" of both Till-Abnû and Burija, he must have been a fairly powertul king. As for the name and location of his kingdom present evidence allows no specific suggestions, but his assistance to Andarig points in a direction south of the Jebel Sinjar, and the presence of just a single reference to him, perhaps to a fairly distant location.

\section{Mašum}

This king is attested as sender of 1 letter to his "father" Mutija, and 5 letters to his "brother" Till-Abnû. Unfortunately his place of residence is not named, but a general location is provided by the letter to Mutija (YTLR 18), where Mašum states that his town is "your" (sing.) lown and that he is guarding the frontier of "your" (plural), land - "from the crest of mount Saggar hither to the land of Jassānn". This places Mašum Firmly east-southeast of Apum in the land of Jassān(um\}, where a number of towns are known. ${ }^{76}$ Among these Razamā and Alilannum are excluded, and the same must apply to Azuhinnum from the way it is referred to in YTLR 18.

70 See F. Joannès in ARMT XXVI/2, 235f. for discussion of some towns in this area. 
The letters sent from Mašum to Till-Abnû mostly concern routine affairs and are not easy to date. The only text with clear historical implications is YTLR 81 where Mašum, who himself has made peace with Burija, advises Till-Abnû to evacuale grain from the villages. This information seems to fit a context towards the end of the war against Andarig, i.e. late in the reign of Mutija.

Say to Till-Abnū: Thus (says) Mašum, your brother:

All is well here, may all be well there

Concerning Burija you said to me: "Why did you not write to me." I have made peace with him, and he released my towns. How could I possibly break the peace? Now you must give firm orders about the grain, so that they take the grain immediately from the villages to a (fortified) center. Not even 1 liter of grain must be left in the villoges! (YTLR 81).

Šepallu

Sepallu must have been an important king as shown clearly by the aftairs reloted to the war against Andarig and Razamā late in the reign of Mutija, where he was an ally of Apum and Kurda. Unfortunarely the evidence for his seat of kingship is not clear, but points to a location south of the Habur Basin. This evolves first of all from the texts relating to the war against Andarig and Razamā, and where towns like Zannōnum and Sabum (YTLR II) seem to belong to his land, which was invaded by the enemy. Since Zannānum ${ }^{77}$ and Sabum may be identical with towns located not too far from the Rimah area, one could lentatively think that Šepallu was king of Karanā/Qattarā. ${ }^{78}$

\section{The Habur Region}

Ašnakkum

See Chapter 2.3. subUrkiš.

\section{Ašlakkă}

This town is only referred to once, in an administrative text ( Fl 135) which mentions a prominent Asdi-lštar of Ašlakkā, but it is nol clear whether this man was the ruler of Ašlakkā. The question of possible identity with Asdi-[....], who sent YTLR 12 to Mutija must remoin open.

\section{Eluhut}

Three letters from Sukrum-Teššup to Till-Abnû (YTLR 89-91) show that this man was king of Eluhut. From the Mari archives we know two different kings of Eluhut, the earlier Śarrāja and the later Ṡukrum-Teššup \{from ZL 11), who must be identical with our king, and thus one

77 For this lown see Eidem 19900.

78 This important kingdom is not mentioned in the texts from 1987, but a single reference is found in 1.85-490 dated in the limmu Adad-bani, which lists a certain Warad-Samas iu Karono (Whiling 19906, 509: a man with this name is also mentioned as recipient of a garment in CV 100), but he may well have been an envoy or similar. 
of the very few surviving figures from the time covered by the Mari archives. ${ }^{79}$ In the most informative of the letters sent from Suukrum-Teššup it is indicated that relations between Apum and Eluhut have been strained, but a meeting and the conclusion of a treaty is anticipated. The writer further suggests an exchange of "houses" between their capitals.

Say to Till-Abnũ: Thus (says) Šukrum-Teššup:

You wrote to me as follows: "Why is the path broken? Why does your messenger not come to me, and my messenger not to you?" This you wrote to me. Since long ago the house of Eluhut - if it had granted favour to a prince, did they not return its favour? - [but] you did not write to me! I slaughtered [a donkey?] on its "back", (and) I (said to myself): "Seemingly he does not want [peace] with me, and this is why he did not send his messenger to me." $[\ldots . . .$.$] | have written to you (again) [. . . . . .$.$] I. soid: "Let there be [. . . .$.$] between us$ $[\ldots . .$.$] sincerely [......... let us confer. [The house of Eluhut] is your house, [and the house$ of Subat-Enlit] is my house!" [And concerning] the men you wrote to me about, I have [not (yet)] released them, but they said: "Till-Abnû 'says): I shall come up to Eluhut"! - and until you come up, and you and I meet (and) swear an oath to each other and blood bonds are established between us, I shall not release the men! And the house I request in Subat-Enlil you must not give to someone (else), and I shall give you a house inside Eluhut, and I shall give you the town you wish. You [ask] me for a house in Eluhut, and I [ask you for] a house [in Subat-Enlil ..... rest of rext on left edge too broken for translation ....]. (YTLR 89). ${ }^{80}$

Eluhul cannot be located with much precision, but must be sought in the mountains across the Turkish frontier, possibly near modern Mardin.

\section{Kahat}

Jamși-Hatnũ can be securely identified as king of Kahat since he is so described in L.T.-3, which also provides the name of his father, a certain Asdi-Nehim. The same treaty places Ea-malik, withoul title or filiation, as party to the proceedings together with the king. From the period of the Mari archives we know of three kings of Kahal, Kabija, Alraja, and AsdiLim, none of whom can be related to Jamși-Hatnû or Asdi-Nehim on present evidence. ${ }^{81}$ Jamși-Hatnû was sender of no less than 15 letters to Till-Abnû. All these letters concern routine affairs, and Jamși-Hatnû is never mentioned by other correspondents. Ea-malik, on the other hand, himself sender of 4 lefters to Till-Abnû, is mentioned by several other correspondents, and appears more "executive" than the king. Possible explanations could be that Ea-malik was a sukkallum "vizier" of the king, or aliernatively the heir apparent of an aged king. Yet another possibility is that Kahat, with its own important cult of Adad/Teššup, and apparently in nominal control of two other important cults, had a special status and perhaps a peculiar system of government.

\footnotetext{
79 See Charpin and Ziegler 2003, 237 w. n. 634

80 Quoted in Eidem 2000, 258.

81 One notes that an earlier king of Talhājum carried the name Asdi-Nehim (cf. immediately below). and it cannot be excluded that it was one of his sons who became king of Kahat.
} 
The trealy L.T. - 3 provides other interesting information about Kahat. In several passages towns and citizens of Kahat are categorised with the strange designations si-al-Pl-ri and nu-ha-sit. Since both towns and citizens are involved the two terms must have served to describe a main ethnic, geographical or social division in the land of Kahat other than settled-nomad. The wo rerms seem respectively Hurrian and Semitic, which hints al an ethnic division. A more precise understanding does not seem possible at present, but the example underlines the heterogenous traditions which seem to have existed in differents areas of the North.

Another problem is the definition of the territory of the kingdom as "from Nawar to Nawar" (istu Nowar adi Nowark) in several passages of the treary. Kahat itself is presumably to be located at Tell Barri on the wadi Jaghiagh, and one of the two points referred to as Nawar can be identified with Nagar (in the Mitanni period spelled Nawar) to the south, surely identical with Tell Brak, ${ }^{82}$ while the second Nawar mentioned in the reaty could be another, northern Nawar, tentatively identified with Nawali/Nabula, perhaps the mound of Girnavaz $5 \mathrm{kms}$ north of modern Qamishli. If correct there seems to be a clear logic in defining the kingdom by these two outer points of the wadi, both important religious centers (see below Ch. 4.1).${ }^{83}$ Recently, however, it has been suggested that the phrase in the Leilan treaty refers, not to two different localities, but to a "round-Irip" Nagar-Nagar made by the goddess, ${ }^{84}$ and while this interesting idea cannol be dismissed, it should be noted that the trealy text consistently places the geographical determinative only after the second Nawar, and possibly this was to differentiate the compounded divine and geographical entily Nawar $\{=$ Nagar $\}$ and a mere locality Nawar.

\section{Talhājum}

This town was associated with the region known as Japtur, in the northwestern part of the Habur Basin, and close to important towns like Nahur, Qirdahat and Ašnakkum. From the Mari texts we know four different kings of Talhäjum (Rakabium, Hammi-Epuh, Jawi-lla, and Asdi-Nehim). Talhājum itself is not mentioned in the Leilan texts, but the region of Japtur was ruled by a certain Mehilum:

Say to my lord: Thus (says) Take, your servant:

A retainer of Mehilum of Japtur, who is bringing a letter to my lord, and a man of Qirdahat, an important man of Qirdahat - he was sent with instructions together with Mehilum's retainer to my lord - hereby I have sent them (on) to my lord. Please will my lord pay close altention to their message! ........ (YTLR 149, 1-11).

Mehilum of Japtur is also attested in an administrative text ( $C V 79 ; 18 /$ viiib HK), and we have 2 letters from Mehilum to Till-Abnü, his "friend" (YTLR 105), and his "father" (YTLR 106).

While this identification now seems generally accepted, Wäller $(2001,23)$ deems the arguments "unzureichend", and instead prefers to locate Nagar at Tell Arbid (ca. $10 \mathrm{~km}$ eost ol Chagar Bazar). 
a change of style which perhaps was occasioned by Till-Abnu's accession to the throne. The association of Mehilum with Qirdahat is also found in YTLR 128 (quoted above Ch. 1.4) which reports that Mehilum stayed 5 days in Qirdahat without meeting envoys of Till-Abnû. Thus Mehilum was lord of the land Japtur, and perhaps also controlled Qirdahat.

\section{AŠKe-Addu 85}

This man was a prominent figure of unknown origin, and not necessarily a king. He is mentioned in a number of letters, but is not attested as sender, and was clearly an enemy of Apum. For the troubles caused by his activities see below Ch. 3.3 .

\section{Muti-Addu}

This figure is attested only as sender of a letter to Till-Abnû (YTLR 82), where he asks TillAbnû for troops and states: "... and since your route is near, I shall come up to a town, so that you and I can meet, and establish brotherhood between us". This information would place Muti-Addu's base somewhere south in relation to a route of march or trovel planned by Till-Abnû, but a more exact location cannot be suggested.

\section{Niqmi-Adad}

This king wrote as "son" to Mutija, and as "neutral", and subsequently as "small brother" to Till-Abnû, in the two latter texts addressed "big brother". This fairly rare style of address would indicate that he considered himself almost equal to the new king of Apum, although formerly a vassal, and it can not be excluded that he really was a younger brother of Till-Abnû. His capital can not be identified, but the geographical information in the rexts, which mention towns like Kuzzaja, Ahanda, Putrum, and Nilibšinnum, points generally to a location somewhere in the central part of the Habur Basin.

\subsection{The Kingdom of Apum and its Vassals}

The core of the land of Apum would have been relatively close to leilan, but it is more difficult to ascertain the borders of the area which effectively was under the control of its kings, and which would have varied over time. A fairly good indication of Mutija's realm may be provided by a letter which lists 4 lowns denoting points possibly close to its borders:

Say to Mutija: Thus (says) Šepallu, your brother:

All is well here; may all be well for my brother there!

Previously my brother wrote to me as follows: "Send me 4000 sheep, and I will divide them to the four towns Sunā, Nawali, Azamhul, and Urpan". I sent these sheep to my brother; will my brother please write to [the towns], that they must not drive away these sheep from

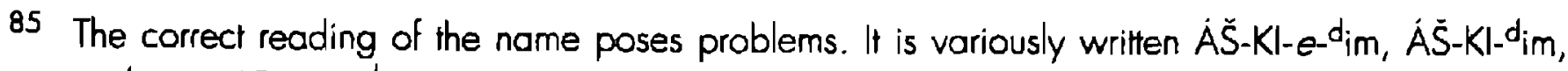
and once $\mathrm{AB}-\mathrm{Kl}-e^{\mathrm{d}} \mathrm{im}$. 
grazing, and not trouble the shepherds. Just like the sheep of your own country let them move around together, (Let) him who wishes (story) in Urpan, and let him who wishes drive (his sheep) through beyond. (YILR 10).

Šuna must be sought well west of Leilan, ${ }^{80}$ and Nawali to the north. It is also established that Azomhul should be sought south/southeast of Leilan. Urpan finally is not attested elsewhere at the moment, but could be thought to belong in the area south/southwest of Leilan, which would complete a "circle" around the area of Apum. At least the latter lown should be placed south of Leilan, since the meaning of Sepallu's reservation probably is that those of the shepherds who do not want to proceed beyond this point - and further into the Habur Basin, should be allowed to stoy there, in relative proximity to their home land.

Sunā is well attested in the Leilan archive as a vassal kingdom. Severol administrative texts lists shipments of wine from Šuna, and from similar texts it is possible to provide a tentative list of Apum vassals, since the exant material never mentions such shipments from the major kings:

\begin{tabular}{|c|c|}
\hline Amoz & by Zigẽ of $\mathrm{A} .(F \mid \mathrm{II}\}$ \\
\hline Amursakkum & by elders of $A .(F \mid 3)$, Šamaš-nașir merchant of A. ( $C V \| 6)$ \\
\hline Azamhul & by Samsu-malik of A. (CV 119$)$ \\
\hline Hālabā & by Bunu-|štar of $H .(F \mid 5)$ \\
\hline Hurāșā & by Kabizza of $\mathrm{H}$. (FI 24) \\
\hline Nadbum & by Qarrōdu of N. $(F \mid 6)$ \\
\hline Nowali & $\begin{array}{l}\text { by Hawurni-atal of N. (CV 113), Ukku of N. (F| 12); Tariš-mätum, priestess of } \\
N \text {. }(F \mid \text { \&); Ustap-Ulme and Jaddin-Addu, priests of Adad, king of N. }(F \mid 1)\}\end{array}$ \\
\hline Šunā & by Aja-abu king of Š. (CV 108); Šibilānu of Š. (CV 107) \\
\hline Šmal & by Till-Abnû of Ś. (CV 112); Kuzzuri of Ś. (CV HII) \\
\hline Tehhi & by Zozial(2) of T. (FII3); elders of T. (CV 110) \\
\hline Urkiš & by elders of $U .(F \mid 3)$ \\
\hline
\end{tabular}

This list is certainly incomplete, but helps to delineate the geo-political sphere of control exercised by the leilan kings. Only Aja-abu of Suna is explicitly referred to as "king", and since several shipments are clearly from non-royals it is necessary to review the evidence in more delail to evaluate the significance of the list.

\section{Amaz}

The town of Amaz appears in Old Assyrian texts as an intermediate station between Apum (Leilan) and Nahur, and can therefore be placed west of leilan. ARMT XXVI/2,313, which describes the route of an army from Subat-Enlil to Šnna to Amaz allows us to place the town more specifically west of wadi Jaghiagh. Texts from Mari show that Amaz was a typical walled town with ciradel and lower town, and that it was contested by neighbouring kingdoms like Susā, Eluhut, Šunā, and Šubat-Enlil (which was controlled by Atamrum of Andarig). Although Amaz had its own kings, the earlier Sambuganni, and the later 
Hișrija, it clearly did not belong to the more powerful Habur states. In the Leilan archive is a single letter sent from Zige to his "father" Till-Abnû (YTLR 107), and although the rext gives no details about the sender's background, it seems likely that this person was the king of Amaz. Indeed CV 164 (29/ix HK) records an ox brought by Zige "when he was made madārum". ${ }^{87}$ Other Leilan letters mention Amaz in relative proximity to Sabbãnum (YTLR 116) and Japtur (YTLR 130). An administrative text mentions a shipment of 127 sheep from a prominent Hammi-Epuh of Amaz $(\mathrm{CV} 165 ; x, H K)$, and this figure is probably identical with a namesake who sent 2 letters to his "Lord" Till-Abnu (YTLR 129-130), and in another letter is commanding troops stationed in Amaz (YTLR 116). This man seems tikely to have been an Apum(?) governor or general posted in Amaz.

\section{Amursakkum}

No kings of this town are attested. It is best known for the role it played during the Turukkean rebellion late in the reign of Šamši-Adad, and the relevant texts show that it was a fortified town of some importance. It is tentatively located close to modern Qamishli. ${ }^{88}$

\section{Azamhul}

This was an important town in Apum, and as discussed above $\{C h .1 .1$ it seems that it should perhaps rather be placed on its eastern borders than at Tell Mhm. Diyab. Samsumalik who sent wine to Leilan may have been "king" of the town, but at the same lime letters connect a certain Inganum with Azamhul. Most explicitly he reports to "his Lord" that he has gathered the district in Azamhul (YTLR 135). Since Inganum seems to have been an Apum official it is possible that he functioned as governor of Azamhul or at least in this sector of Apum. His letters also show that the otherwise poorly attested towns of Nihru and Sathura must have been located in this area.

\section{Hālabō}

This town is probably mentioned in texts from Mari, and Durand places it near the Wadi Radd south of Leilan. ${ }^{89}$ Bunu-lštar is nol mentioned elsewhere, and all that can be said is that he was a prominent figure associated with Hälabā.

\section{Hurāsā}

According to an unpublished Mari text this town was located not too far from Leilan, 90 and the events discussed below (Ch. 3.1) show that it should be sought near the southern border of Apum. Mari texts refer to a king Awikiriš, and the Kabizza of Hurāṣā in Leilan rexts may be a later king. Al the same time CV 32 mentions a governor (šäpifum) Hazip-Teššup of Hurāsāa, and this could be an Apum official. Hurāsōo seems, however, to have belonged to the territory of Šepallu (cf. Ch. 3.1).

\footnotetext{
87 For this term, denoting a person of princely status, see Charpin and Durand 2004, 113.

88 See Charpin and Ziegler 2003, 115 f.

89 Durand, ARMT XXV1/2, p. 135 ad $358 \mathrm{~b}$.

90 Charpin and Ziegler 2003,116 w. n. 345
} 
Nadbum

A town Nadbum (or Natbum) is apparently nol attested in other sources. Qarrädum was possibly its ruler, and a man with the same name is attested as sender of a single letter to "his Lord" (YTLR 142), but unfortunately it reveals nothing about his background.

\section{Nawali}

A certain Howur-atal is attested as sender of a letter (YTLR 119) to Till-Abnû. The letter is not well preserved, but connects the writer with activity near Sunâ and Kiduhhum. This fits the second attestation of Hawur-atal (in YTLR 97), where Aja-abu of Suna complains to Till-Abnû that Hawur-atal recruits troops from Eluhut and frighiens the citizens of Sunā, while in a following letter (YTLR 102) he reports that Eluhut troops have entered Nowali. It is therefore possible to identify Howur-atal securely with Hawurni-atal of Nawali who sent wine to Leilan. It seems most likely that he was the ruler of Nawali, and that Ukku of Nawali was an official. The real king of Nawali, however, was Adad/Teššup /cf. below Ch. 4.1).

\section{Šunō}

Aja-Abu was explicitly the king of Šnnā, a town located west of Leilan. A prominent visitor to Leilan named Aja-abu is attested in an administrative text which dates to the reign of Jakūn-Ašar (FI 72), and although no title or GN is given, it seems likely that Aja-abu of Sunā is involved, and that his reign continued until the end of our documentation. From Mari there is evidence for a king of Sunā by the name of lli-lštar, who married a daughter of Zimri-Lim, but in general the kingdom seems to have had little political impontance.

A similar situation is reflected in the Leilan archive, where Aja-abu appears as a vassal of the king of Leilan, referring back to him a so on apparently minor mathers, and stating blankly that the town of Sunā is "your town" (YTLR 93). In one instance Aja-abu sends a letter together with a certain Sibila (YTLR 10I), no doubt identical with the Sibitäni lú Sunā who sent wine to Leilan, and presumably a high official \{ šukkallum? $\}$ of Sunā. Another letter was sent jointly by Aja-abu and the "elders" (YTLR 102).

\section{Šrnat}

We have already discussed the relationship between Till-Abnû and Kuzzuri of Surnat, and suggested that the latter figure may have been a local ruler (above Ch. 1.4). Surnat is mentioned in a number of Mari texts, which show that it was located southeast of leilan, and Charpin has suggested that the town belonged to Apum. ${ }^{91}$ ARMT XXVI/2, 422 shows that Šrnat must have been a fairly large walled town: (Hammurabi of Kurda) "sent 2000 soldiers and they attacked the town Surnat which belongs to Zü-Hatni, and captured as much of its salhum, its cows and sheep, and people, as they could get hold of, but the townspeople mounted to the citadel, and saved themselves in the citadel" (II. 25-31). An interesting possibility for a more precise identification of ancient Surnat is provided by the 
Old Babylonian tablet accidentally found on the surface of Tell Qal'at al-Hādi on the wadi Rumeilan southeast of Leilan. The tablet is an administrative note of silver divided as payment for habbätum mercenaries and overseen by a certain Ewri. ${ }^{92}$ This figure could weil be identical with a man who wrote two of the Leilan letters, one to Také $\{Y\lceil L R$ I7I\}, and one to "his Lord" Till-Abnû (YTLR 110).

Say to my lord Till-Abnû: Thus (says) Ewri, your servant:

Burija with habbatum troops has made a raid right into the land of Numha, and gives us trouble. May my lord know this - and your brother(s) is/are not available for a relief force. Please will my lord instruct me about gathering the country in its forts, and I shall act according to my lord's instruction (YTRL 110).

This letter (also quoted below Ch. 3.1) belongs in the context of the war against Andarig and Razamā, and shows that Ewri was placed near the southeastern border of Apum. From there he writes to the prince Till-Abnu for instructions about local affairs, which suggests that Till-Abnû had a special role in that area. Consequently it is realistic to think that Tell Qal'at al-Hādi could be ancient Šurnat, and that Ewri was an Apum official placed there. ${ }^{93}$

Tehhi

This town or its possible ruler Zazija(?) is apparently not attested outside the Leilan texts. In Fl 135, which accounts for a journey from Leilan to Nahur it is the first town mentioned, and it was probably located not far west of Leilan.

\section{Urkiš}

Recent excavations have made it certain that Ulkiš is identical with Tell Mozān near modern Amouda. ${ }^{94}$ The Mari texts document a king Terru, and that the town in this period was under some order of control from As̆nakkum. For the period of the Leilan texts it seems likely that the king of Urkiš was a certain Jașịib-Hanû. He is mentioned in two letters sent from Sangara, who quotes a message from Jașsib-Hatnû: "I have evacuated (my territory) to Urgina" (YTLR 143). In another letter it is reported that a messenger has gone to Jașșib-Hainû and the king of AšKAkum to get help against Halu-rabi YYTLR 144; for the historical context see Ch. 3.3). In spite of the forms the two towns are probably identical with Urkišss and Ašnakkum. A letter to Till-Abnû from Janși[b-....] (YTLR 33), but with no real clues to the writer's identity, may have issued from the king of Urkiš.

Surnat is not attested outside the Old Babylonion sources referred to here. If identical with Qal'at al-Hãdi, the town may have changed its name since there is evidence for later occupation on the site (see Meijer 1986, 19\}.

95 A town ur-gi-na (NA certain!) is olso attested in CV 27, and probably this is the Hurrian name of Urkiš \{ct. the spellings $u-u r-k i-n i-i n, u-u r-k i-n i$ listed in del Monte and Tischler 1978, 463). 
Without further evidence a precise evaluation is precarious, and we cannol assign firm roles to many of the prominent figures associated with these towns. Significantly shipments are made by "elders" from Amursakkum, Tehhi, and Urkiš, and the traditionally strong position of the local assembly in the latter town is well attested from the Mari evidence. ${ }^{90}$ The heterogenous local traditions are also evident in the case of Nawali, where the prestige of the Adad/Teššup cult gave its clerics special prominence.

In geographical terms it seems likely that these towns represent the circumference of the territory of Apum. The relevant towns were located on or near its borders and obliged to cultivale contacts with the kings of Leilan. From clauses in the L-Treaties we get glimpses of how relationships between the major and minor polities were organised. An example is found in L.T.-3, concluded between Apum and Kahat:

L.T. -3 col. iii

When a town, a king, my equal, or a local official

who makes his heat big, and

with Jamși-Hanû

and Kahat becomes hostile, and

5 assumes independent powers, and (says:)

"With Jamși-Hatnû

and Kahat [I will break truce, and]

to Till-[Abnû I will go!"]

10

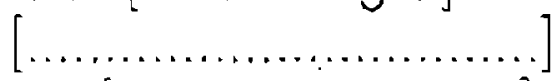

and $[\ldots \ldots \ldots \ldots \ldots \ldots \ldots . . . . . . . . .$.

and $[\ldots \ldots \ldots \ldots \ldots \ldots$ on $]$ his $[\ldots \ldots]$, near

and lar, on his land,

his fruit, his "anomaly", his toil,

15 his well-being I shall not cast my eyes.

A previous governor I shall not remove, and

I shall not appoint my own governor or commander.

Besides the guord (as) military assistance

further help I shall not demand of him.

20 I shall not give oxen the rod!

Let [him give me(?)] grain, sibsum-tax, and silver, [and]

no cultivators (or) harvesters

I shall demand of him. Cloth for equipment

I shall not deliver. I shall demand no (part in) loot.

25 Besides military assistance nothing (further)

I shall demand of him. 
In spite of some unexpected or unclear delails 97 the idea here seems to be that Till-Abnû must promise only to take partial advantage of a situation where a vassal of Kahat decides to change allegiance.

Finally as an example of lowns which were probably more directly under control by Apum, we may quote o letter from Niqmi-Adad:

Say to my elder brother Till-Abnû: Thus (says) Niqmi-Adad, your small brother:

Previously I wrote to you about my sheep, and you said: "Place your sheep in Ahanda, let (them) go there!" This my elder brother told me. The sheep (were ready) to be led to Ahanda, but the god struck my sheep, and until I appeased the god, I kept (them) back, but (then) the sheep of Nilibšinnum were placed in Ahanda. Afterwards when I had appeased the god, Jaqbija the chief shepherd indicated the town Kuzāja for the sheep; the sheep were placed in Kuzāja, but the sugăgum of Kuzāja chased my sheep away. Now will my elder brother please send his retainer with my retainer, so they will not chase away my sheep in Kuzōja. (YTLR 85).

Ahanda and Kuzāja are not altested outside the Leilan texts, and would have been minor settlements closer to the core of Apum. Texts from Mari and Leilan provide a number of other candidates for this calegory: Izhizzi, Hidar, Hurranum, Kudimmar, Kumulhum, Lazapatum, Nawardi, Saphum, Šebišă, Zahiki, Zalumri. ${ }^{98}$ The Leilan survey recorded 157 period I (1900-1728 BC), sites within the $30 \mathrm{~km}$ strip investigated, and although all of these were hardly occupied simultaneously, it is clear that the Apum countryside would have been dotted with smaller settlements during our period. ${ }^{99}$

97 The "anomaly" (Akk. izbum) is probably included to underline that not even the humblest thing will be coveled; neither will oxen be "given the rod", i.e. removed for work elsewhere. The sibsum-tax on private land can be collected, however, and the regular troops levied.

99 Ristver and Weiss 2005. 


\subsection{Apum against Andarig and Razamá}

The letters addressed to Mutija by name focus on dramatic events involving Apum and its allies a war with Andarig and Razamā, and these events are also described in other letters (addressed to belum or Till-Abnü). A good point of departure for analysis of the situation is a letter sent to Mutija from Aštamar-Adad of Kurdā:

Say to Mutija: Thus (says) Astamar-Adad, your brother:

The day I sent you this letter of mine, two of your retainers arrived here from Halab, and conveyed to me Hammurabi's opinion. Hammurabi said this: "Why have Aštamar-Adad, Mutija, and Šepallu taken command of Kakmum troops and destroy land Jassān and land Jamutbalum, and bring the land out of my grip?" This is what they told me. After my own retainers (lett? ) he has sent this (message? ) hither to the interior of the land. Now the day you hear this letter of mine - Takē his governor- make (him) tear up a coat, and take apart a composite bow - turn (these things) over to him, and send him to me!

[Further] here HaZip-... [and] Hazip-Teššup [arrived]. Šepallu is with them; I shall muster them, and they shall take 1000 Kakmians and march off these auxiliaries. I have written 10 you [and accordingly] you must send (them?) quickly to me!

Further Burija is massing with his troops in Hubšil, and awaits Hazip-Teššup. Until I have investigated their intentions, I will not go there! (YTLR 8).

Hammurabi of Halab complains that Mutija, Aštomar-Adad, and Šepallu are "destroying" the lands of Jassān and Jamutbalum, namely the city-states Andarig and Razama with their respective kings Burija and Hazip-Teššup. It seems expected that Hazip-Teššup will join forces with Burija in Hubšil (=Hubšālum), situated south of Andarig. Meanwhile Šepallu has arrived logether with wo named individuals, a certain HaZip-...., who cannot be securely identified, and Hazip-Teššup, who cannot be the king of Razamō, but probably is identical with a homonym "man of Hurāsā" (cf. Ch. 2.3). Asstamar-Adad will arrange reinforcement from the Kakmum troops, presumably mercenaries supplied by the kingdom of Kakmum.

Three letters sent from the Apum general Kuzuzzu help to clarify the situation:

Say to my lord: Thus (says) Kuzuzzu, your servant:

My lord wrote this to me: "Are none of your retainers that I know well staying with you, since you send wwo of your retainers that I don't know?" This my lord wrote to me. Tirukkanu, my retainer that I sent before my lord, this man I took out of the palace workshops in Šehnä; he is indeed a faithful servant of my lord. His wife and son are living in my own house. (It is only because) I have never before sent him before my lord, that my lord does not know him, but previously there were no retainer('s) who (used to gol before my lord at hand among my retoiners, and I sent this man after careful selection. 
Another matter: the troops of the enemy are confronting Till-Abni, [and the doy I sent] this letter of mine to my lord, Ašstamar-Adad will come to Hurāsāa. (YTLR 137). ${ }^{100}$

Kuzuzzu then is slaying in Hurāșā where Aštamar-Adad is expected to arrive, and Till-Abnû is confronted by the enemy. Subsequently Kuzuzzu and his party leoves Hurāṣā:

Say to my lord: Thus (says', Kuzuzzu, your servant:

Yesterday we left Hurāsāa and went to Agā. A messenger came from Kurdā with this message: "Burija raided the land towards Kurdā, and the habbātum troops [entered(? ?)] Ali|ānum, and loday continued(?) lowards Razamā; and Ašlamar-Adad went away to Kasapā, and it is said: Burija went to Razama, left his heavy forces, and will raid the interior of the land. My lord should not let out the herds (hallatum) or anything else! (YTLR 138).

Thus Kurdā is under attack and Aštamar-Adad therefore hastily leaves to protect his country.

Say to my lord: Thus (says) Kuzuzzu, your servant:

Sepallu called me and Hazipna-El (in audience) and said this to us: "Why will my brothers not come? Aštamar-Adad came, but left again. Now what is this? Since $x$ days the enemy is settled in the midst of the country. He carries away grain, and destroys my towns, but they do not come (to help me). Is it this we agreed on? Now send words that they must come here. In truth when they arrive here, will this enemy not take fright!" And he also said this: "Let them come and I shall march out, and Till-Abni shall know who is coming. If they do not come, then (the pair of) you thad better) push off!" (YTLR 139).

From these texts it can be established that Šepallu's land is invaded by the enemy; that Till-Abnû is with troops in the same area, and that also Asstamar-Adad is present, but hastily leaves for his own country when it is reported that Burija has attacked Kurda. The initial situation may be echoed in a letter where Sepallu writes to Mutija that he has attacked enemy troops laying siege to his own town Zannōnum near the Jebel Sinjar and asks for help.

Say to Mutija: Thus (says) ${ }_{5}$ epallu, your brother:

Since three days ago the enemy is staying in Zannānum. Yesterday he released the town herds (salhum $)^{101}$ in open country, and I mounted a horse, and with 60 men I went to the town Sabum to his sathum. I slew 60 men and took 50 prisoners; I chased him (right) to the gate of his fieldcamp, and carried away one (of the) leader(s). My brother should rejoice! Muster the troops and march off to me. Do not hesitate! (YTLR 11). ${ }^{102}$

100 Published in Eidem 1991c, 121.

I0) For this term see Eidem 1991c, $133 \mathrm{f}$.

102 Published in Eidem 1991c, 131-34. 
It may have been somewhat later that the YTLR 8 was written: Mutija perhaps sent Till-Abnû to assist Šepallu, and also Aštamar-Addu arrived. Together they survey the situation staying in Hurāsā and await the next move by the enemy.

Subsequently the habbatum arrived on the scene and were presumably recruiled by the enemy. This event seems to be reported by Mošum in a letter where he states that the habbatum "have returned from across the river", and that they are raiding in Numha. He asks for troops from Mutijo, Aštamar-Adad, and Šepallu, and gives advice about guarding of the sheep.

[Say to my father Mut]jia: Thus (soys) Mašum, your son:

All is well here; may all be well there!

In the land behind the mountains they have begun to seize the townspeople, Numheans or anyone living there. A man from Allahad fled from there and said this to me: "The habbartum have refurned from across the river and in the land of Ja[ssän(2)] joined $[A z]$ uhinnum". I shall ascertain further news of these troops and write to my father.

What about the 100 soldiers for deployment here that l asked of my father? If you, AstomarAdad or Šepallu had sent [the troops] that should be sent, they would have stayed here on the border of your land - in the district. I here am constantly concerned with guarding the land - thus from the crest of mount Saggar all the way hither to land Jassan. Is this town not your town? Is it it not a border town - a district which protects the front of your own land? Now will my father please send me 100 soldiers, and they shall indeed stoy here in the district!

You must sound alert about the sheep, and the sheep must not be left in one place, but should be left in the fortified towns individually, and I here how can I be successful? let your troops gather in one place, and I will come, and depart with these troops, and I shall organize the route of the troops. (YTLR 18). ${ }^{103}$

From the Kuzuzzu letters we learnt that the habbäum moved into Alilōnum /southeast of the Habur Basin), and that Burijo intended to march in the same direction and attack the interior of the land from Razamā.

The ensuing panic in Apum is mirrored in two letters from Ewri: In the first he reports to his lord Till-Abnû thal Burija with habbötum rroops is raiding in the country of Numhum, a virtud echo of the information transmitted by Kuzuzzu in YTLR 138. He states also that TillAbnu can expect no help from his brother(s?) and asks whether, in view of this situation, the countryside should be evacuated.

Say to my lord Till-Abnû: Thus (says) Ewri, your servant:

Burija with habbätum troops has made a raid right into the land of Numha, and gives us rrouble. Moy my lord know this - and your brother(s) is/are nol ovailable for a relief force. Please will my lord insiruct me about gathering the country in its forts, and I shall act according to my lord's instruction. (YTLR 110). 
At the same time Ewri also wrote to Takē giving the same basic information, but with more details. The number of habbatum is given as 6.000 , and they are staying in the otherwise unattested town Suprum in Numhum. He adds also that Asstamar-Adad has gone back to Kurda (cF. YTLR 138), and discusses the evacuation of the countryside.

Say to Take: Thus (says) your friend Ewri:

I heard rumours of the habbortum roops and wrote to Ahi-maraș, and he sent me a complete report: 6.000 habbatum troops are staying in the town Suprum and hove eaten the land of Numhum clean. (Even) the nail has been torn out of the wall! Aštamar-Adad has gone off to Kurdã. I have wrilten the news I have heard to you. Know this, and you must write the news you have heard to me.

Also in view of this news the sheep of the country were moved towards (you). I fear the shepherds will harass them. Give orders to the chief shepherd that they must not harass them. Otherwise you must say (so), and they shall remain as they are. (YILR 17I).

Thus the action, with the arrival of the habbätum, shifts from the land of Šepallu to the land of Aštamar-Adad which was now under attack, while another enemy push into the southeast of Apum is expected. In YTLR 8 we hear that Burija was waiting in Hubšalum for Hazip-Tešsup, who moy have been the enemy raiding the land of Šepallu, but next we see Burija, having received support from an arriving army of 0.000 habbätum, make a raid into Kurda thereby splitting the enemy forces.

Subsequently, however, the action shifts once again. The next move was directed not at the southeast, but the southwest corners of Apum. This seems clear from two letters sent from this region.

Say to my father Mutija: Thus (says) Asdi-[....], your son:

The same day I sent you this letter, Hazip-Teššup with 10.000 habbātum troops has made halt for the night in the town Šur'um. My father should devise a course of action [i.......)] (YTLR 12). 104

Say to Mutija: Thus (says) Kanisānu, your son:

Concerning news of the [habbätum] troops: Hazi[p-Teššup] has taken command of them. The day I sent you [this] letter of mine they stayed the night in Anamas. I will not meet with any of his retainers(?). Now hereby I have sent my retainer to you - pay close attention to his message! (YTLR 15).

Since the geograhical information in both letters can be associaled with the central sector of the Habur Basin، ${ }^{105}$ it may be concluded that Hazip-Teššup of Razamã, with a large force of habbätum is attacking into the (south) central part of the Basin. Particularly interesting in this connection is a letter sent from Supram to belum:

105 For the lown Sur'urn see Guichard 2005; for Anamaš see Durand, DEPM II, p. 469 F. 
Say to my lord: Thus (says) Supram, your servant:

News of the habbätum arrived and Kirija spoke to us like this: "Send words to your lord"; we (said): "This is your decision; and you yourself must tell us (what to write)!". He (said): "You should not give battle! Let them advance to your city gate, but do not give battle!"- And in my previous letter I wrote to my lord (about) 6.000 troops, (but) now (it is) 10.000 troops; my lord should not worry (YTLR 147).

Our imperfect understanding of the historical geography obviously makes it difficult to ascertain the details of these events which apparently mostly took place in the intermediate zone between the Habur Basin and the Jebel Sinjar, and area which would allow quick moves and countermoves with quite large forces and rapid shifts in strategy with the military emphasis tocused on the land of Šepallu, then Aštamar-Adad's Kurdā, and finally the borders of Apum. This less populous, but certainly not deserted region, ${ }^{100}$ no doubt functioned as a buffer-zone between the Habur and Sinjar kingdoms, and both the new Leilan texts as well as the Mari texts indicate that it was far more important than hitherto suspected.

What happened next is somewhat harder to establish, but quite possibly a letter sent from Ahi-maras to belum (said to be brother of Jakūn-Ašar, hence probably Till-Abnü) provides a sequel. The writer reports that Jakunn-Ašar has defeated an enemy, and that the habbärum subsequently gathered and sent him a message of submission.

Say to my lord: Thus (says) Ahi-maras, your servant:

Since Jakün-Ašar [won] a victory I sent words to my lord with mubassiru-messengers. Now we are staying there; the interior of the [town is calm(?)]. The habbatum troops who were [defeated] afterwards(?) [.......] gathered and sent words to my lord, your brother, as follows: "Either let (us) go free, or take command of us and lead us where you please!". This (message) they sent to your brother. (YTLR 126). ${ }^{107}$

Thus the threat against the inlerior of Apum seems to have been averted, and it seems that the scenario envisaged in YTLR 147, namely the habbatum reaching the gates of SubotEnlil, never materialized. Instead the hostilities ended and gave way to a succession of diplomatic initiatives.

106 The leilan survey recorded several large Period I sites south of the Wadi Roodd /Ristvet and Weiss 2005 .

107 LI. 10-19 quoted in Eidem 1996b, 84 ก. 7. 
Peace with Razamã and Andarig

Administrative texts dated in the limmu year Habil-kēnu record a diplomatic exchange between Apum and Razamā:

CV 2 ( $w$. duplicate CV 9), dated 10/vii, lists issues of clothing to retainers of the Halab general Bin-Dammu and to retoiners of Hazjp-Tešsup "when they made the king swear an oath by the gods". 108

CV 7, also dated 10/vii, lists issues of silver rings to retainers of Bin-Dammu "when the king swore an oath by the gods".

This evidence shows a situation where envoys of Razamā received a treaty oath from the king of Apum, at this time cerlainly still Mutija, in the presence of Halab envoys. 10 days later a document records silver issued from Šehnā to certain individuals "when they stayed in Razamā" (CV 52, 20/vii HK), presents issued by Apum envoys sent to Razamã, probably to receive the parallel oath from Hazip-Teššup.

In any case it seems highly likely that the treaty rablet L.T.-2 relates to these events. The tablet contains the text of an oath to be sworn by Hazip-Teššup of Razamā to Mutija of Apum, and although severely damaged large portions of the text have survived (quoted below in 3.2).

Another diplomatic exchange occurred some weeks later. CV 131, dated to $3 /$ viiib HK, records a meeting attended by the king, Bin-Dammu, and Burija, the king of Andarig, and Vincente suggested that this meeting was the occasion of prepatory negotiations leading up to the second instance during this year when it is recorded that the king swore an oath, namely in CV 10, daled to 20+/ix, incidentally also the latest text in the archive which is sealed with the seal of Mutija. If this evidence, as seems likely, pertains to a treaty between Mutija and Andarig, it has apparently left no trace of a written document.

\section{Old Babylonian Treaty Procedures}

These two diplomatic events apparently fit current understanding of Old Babylonian treaty procedures as established by $D$. Charpin in a fundamental study. While the basic component in conclusion of a political treaty was the solemn oath, the nis ilim/ilani, sworn by both parties before divine statues or symbols, the nature and the distribution of other important components mentioned in the evidence have been less easy to explain or account for. These components include the frequently mentioned ritual slaughter of a "donkey" 
(hajäram qatalum\} or the ritual of "louching the throat" (lipit napistim/ napištam lapaitum). and the infrequent mention of written tablets in connection with treaties. Charpin showed that the two lypes of ritual belonged with two different procedures. The ritual slaughter of a donkey was performed when the treaty was concluded at a face to face meeting between the kings and their representatives, while in cases where the treaty was concluded without such a meeting the kings "touched the throat". Only in these latter cases did the problem of distance necessitate written documents. ${ }^{109}$ Thus in the case of the first of the leilan treaties mentioned above the two kings apparently did not meet, but performed an oath ritual in front of representatives of the other party, and a tablet with the full text of the agreement was used. In the second case the king of Apum and Burija actually met, and apparently no tablet was used. Although this is not recorded one would expect that the first ireoty involved the ritual of "louching the throat", and the second the "slaughter of a donkey".

This operational understanding of the different procedures has since been confirmed by a recent very detailed study by B. Lafont, 110 but some important questions remain unresolved. A major problem is that we do not know what the two rituals concretely involved. Having examined carefully all extant evidence Lafont concluded that the "slaughter of a donkey" ... "est manifestement l'expression d'une alliance conclue par le sang [ina dämim], taisant des protagonistes des parents par alliance .... L'origine bedouine de ce rituel ne fait pas de doute ..."." He noted further that the ritual is followed by a drinking ceremony where the kings both drink out of the same cup and considered the possibilities that the liquid could be blood of the sacrificed donkey, blood of the kings themselves - or simply wine symbolizing blood."12

For the ritual of the "touching of the throat" the most detailed description is found in a letter from Mari"13. Zimri-Lim's envoy places two kinds of flour before Hammurabi (of Babylon), who raises his hand to Šamaš and "touches" his throat, and then swears the oath dictoted by the envoy. Other examples show how two types of tablets could be used in conjunction with the procedings. First the partners exchanged a "small" tablet, and it was on this that the "touching of the throat" was performed. Subsequently "large" tablets would be exchanged and the final oath sworn. Ideally then each treaty concluded this way would create wo sets of parallel tablets, first the drafts and then the final texts exchanged, and additionally one could expect each party also to keep a copy of the set he had sent to the other party. As for the ritual of "touching the throat" traditional understanding is that, in the words of B. Lofont, "... les parties contractantes, en mimant le geste utilise pour sacrifier un animal, mettent ainsi leur vie en jeu, la gorge etant le lieu même ou coule le sang et par où passe le souffle de la vie." 114 Lafont further noted that a new lext from leilan may show that the ritual was not purely symbolical. Someone, probably Halu-rabi, convenes representatives from his land and says:

110 Lafont 2001, 262-293

III Ibid., p. 271

112 lbid. , p. 267 n. 211.

113 A.4626 (Charpin 1990c, IIIf.; = DEPMI, no. 286).

114 Lafont 2001, 275. 
"I undertook a journey//campaign), and Till-Abnû sent me blood. Before we slart on the campaign let us touch his blood, and let us swear an oath. [When] we touch his blood and have sworn the oath, (then) let Jahil-pî-.., Bẽlšunu, and Jasrah-Dagan go there the same evening, and the next day [Till-Abn]û, his sons, and the local officials $\{?)[(\ldots)]$ of his district who follow him, will touch (my?) blood and swear an oath, so they can return the (same) evening, and the following day ... [....], and [I can] march [.......... $]^{\prime \prime}$ (YTLR 185). 115 Unfortunately not all delails in this lext are clear, but it seems that Halu-rabi(?) has received blood from Till-Abnu which he and his people should now "touch", and then swear the oath. Immediately afterwards three men will transport blood of Halu-rabi to Till-Abnû, so that he and his representatives can "touch" it and swear an oath. Thus blood is exchanged over a distance, and it seems possible that this is blood of the kings themselves and not of animals. This leads to a suspicion that the ritual of the lipit napistim actually involved a small incision and blod-letting by the kings, as cautiously suggesled by Lafont. ${ }^{116}$ In sum both of the wo ritual procedures connected with treaty-making may in fact have involved concrete mixing of blood between the main protagonists, the kings. In fact one notes how treaties are often referred to in letters of this period with just one key component, and it seems to me likely that the "touching of the throat" may also have been performed when the kings met and the procedure involved the collective ritual of the "slaughter of a donkey", which then took preference as the main referent. Possibly new evidence may confirm this theory, and meanwhile we may take a look at how the tablets entered the procedure, since also for this question the texts from Leilan seem to provide important new evidence.

The leilan letter just quoted reveals that blood could be exchanged as part of a collective treaty procedure. Blood would hardly have been transported in liquid state, but mixed with some dry substance. If so a candidale is suggesled by the flour which the Mari envoy must place before Hammurabi in the lipit napištim ritual described above, and which would then be formed into a small "loaf".117 It further seems likely that this "loaf" would have been wrapped up in something for the transport, and that this wrapping could have been clay inscribed with a short version of the trealy - namely the "small" tablel. In ARMT XXV|/2, 469 Zimri-Lim wants Hammurabi of Babylon to surrender certain towns, and they are listed in the "small" tablet which he has sent. Hammurabi makes objections and attempts to evade or postpone the "touching" of the throat: "If Sin is not compacted on the tuppi lipit napistim, I shall touch my throat on the 25th. Now Sin has become compacted; on the 25th I cannot do the touching". How is it decided whether "Sîn is compacted on the tablet", and what does this mean? The phrasing suggests that the phenomenon is not initially visible, but somehow becomes so, and it seem possible that it was a sign or feature visible on the "loaf" inside the "small" tablet. ${ }^{118}$ This rather bold theory is suggested by a group of curious trealy

110 Lafont 2001, 275.

117 The same kinds of flour were used in the "Ritual of Ištar", where they were placed on a table before the goddess and mixed with a liquid (see Durand and Guichard 1997, 49).

118 The verb translated "compacted" (kupputum) is particularly used about ominal features on the liver [CAD K, 552f.), and one could think of an accidental feature on the wrapped substance. 
fragments from Leilan (L.T.-7). These fragments are markedly different from the rest of the material, and seem to come from thick, possibly hollow "tablets", which could be remnants of the real "small" tablets. In fact this would explain why the extant corpus of "small" tablets is so limited, since - if most of these "tablets" were routinely broken - we would be left only with some dratts for their texts, like the two examples of supposed "small" tablets from Mari, found at the same site where they were written. 119

However that may be the Leilan evidence also serves to revise theories aboul the "big" tablets and their use. It will be recalled that Charpin has suggested that these were used only when the treaties were concluded over a distance, and not during an actual meeting. The treary between Till-Abnû and the king of Kahar, L.T.-3, seems likely, however, to have been concluded at an actual meeting. In contrast to other treaty tablets this text employs both singular and plural pledges, showing that alternately only the king or all Apum representatives swore, and it may be assumed that the large number of representatives from both Apum and Kahat listed in the text were present. Also the meeting is probably referred to retrospectively in a letter from the king of Kahat to Till-Abnû:

Say to Till-Abnû: Thus (says) Jamsii-Hatnû, your brother:

Two men from Šimaški - at the time of the raid - men from Kirānum caught them, and Abi-Samas and Napsija bought the Šimaškians for silver from the Kirānians. They have run away and are staying in Subat-Enlil. I keep sending you the masters of the slaves, but you do not give them satisfaction. What about the oath we swore between us? When I had you swear I told you this: "When a fun-away slave from my land turns up, let him be seen in your land, and let me send the master of the slave to you. You shall indeed return the slave to his master!" This we said in the oath between us. Now a slave in my land has run away, and he enters your town and you do not release him. What about our treaty and the straight talk between us? Now hereby I have sent Abi-Samas and Napsija to you. Release their slaves; they should not be chealed. Another matter: Neither the first nor the fourth time I sent a letter to you did you ever send an answer to my letter. Since you never send me an answer to my letter $(s)$, how indeed can there be straight talk between us? You just have to soy so, and I shall not write to you again!" (YTLR 75).

Jamși-Hatnû here quotes one of the clauses of the trealy: "When a run-away slave from my land turns up, let him be seen in your land, and let me send the moster of the slave to you. You shall indeed return the slave to his master!" Unfortunately this clause is not preserved in L.T.-3, but would have been parallel to a clause in L.T.-I, col. v:

[A] slave or slave girl from the country of Qarni-Lim and Hāja-abum

$15^{\prime \prime}$ [who] fled here in my palace, my [chancell]ery [shall] be seized, I shall not sell him for silver.

I shall nol dispose of [him] as palace property; [from] their master 
I shall not hide him. One shekel silver as due to the palace I shall receive, and I shall release (him).

The conclusion of the treaty between Apum and Kahat is perhaps also documented by administrative texts. In Fl 115, dated 2/iv Amer-lštar, thus almost exactly one month later than the date of L.T.-3, we find issues of luxury items to a number of prominent figures, headed by Ea-malik and including noblemen from smaller localities near Kahat, like Kirān (cf. YTLR 75) and Kallahubri, ${ }^{20}$ and a subscript reads: "when the king met with the "man" of Kahat".

In the final analysis it does not seem possible to offer a clear explanation for the role played by the actual treaty tablets, especially for L.T.-3, which in fact reproduces a kind of script for a collective treaty meeting between two kings and their subjects. It is possible that the tablet was used only during the planning stage and sent to the other party to make sure that he would accept in advance what would lake place of the meeting. Another possibility is that the tablet was actually used during the meeting, and read aloud as this proceeded. We simply need more evidence to solve both this and other problems, like the supposed "sets" of parallel tablets. Only one, fairly uncertain example is known, namely L.T-3, coupled with L.T.-4, which could be the tablet produced in Apum for the treaty with Kahat. A provisional conclusion must be that the "large" tablets, like the Leilan examples, basically were applied "as convenient", as a practical rool when a number of different circumstances, like complicated negotiations over a distance, prompled their use. The Leilan examples also show that such tablets probably were much more common than the few extant specimens would indicate, and that fairly fixed, traditional models for them had been developed.

\section{Format and Contents of Treaty Tablets}

The Leilan treaties all follow the same general pattern, and can be divided into four main sections: introductory adjuration - clauses - curse section - subscript/date. The fragmentary state of the texts unfortunately does not allow us to reconstruct any one complete text or to make very precise comparisons between the different compositions. Instead comparison of the preserved portions of text can be used to reconstruct in oulline the basic contents of this type of document.

The language of the texts is very similar to that of the Mari treaties and loyally oaths, and the quotations of such material found in epistolary evidence. The texts make use of what may be regarded as stock phrases, which, with numerous minor variations, would have been in common use for such purposes throughout Northern Mesopolamia and Syria. In spite of this international "standard", however, it may be observed that distinct local traditions seem to have existed as is shown by clear differences between L.T.-1, 2, and 4, all composed in Apum, and L.T.-3 composed in Kahat. ${ }^{121}$

$120 \mathrm{Cl}$. Charpin 1990a, $76 f$.

121 To mention but one feature: the curse section in L.T.-3 is much longer than in the other treaties, and tokes up nearly half the tablet. 
From what remains of clauses in the tablets it is clear that the texts to a considerable extent ran parallel, but since often the same portions of the tablets are lost, and the texts are not outright duplicates, it is not possible to reconstruct any complete sel of clauses in any of the compositions. It should be noled that the tablets themselves are divided into a number of sections marked by double rulings. This system provides a number of "paragraphs" in each lext, but unfortunately the fragmentary nature of the material renders full exploitation of this feature impossible. The preserved clauses or parts of clauses mainly concern six themes:

1) Purpose of the treaty
2) Non-annulment clauses
3) Auxiliaries and military
4) Political loyalty
5) Vossals
6) Trealment of citizens

These main themes are distributed as follows in L.T.-1 to 4:

$\begin{array}{lllll}\text { Theme } & \text { L.T.-1 } & \text { L.T.-2 } & \text { L.T. }-3 & \text { L.T. }-4 \\ 1 & \text { col. } v & \text { col. iv } & \text { col. iv } & - \\ 2 & \text { col. iv } & \text { col. v } & \text { col. iv } & - \\ 3 & \text { col. i-ii } & \text { col. iii } & \text { col. ii } & \text { col. ii-iii } \\ 4 & \text { col. iv } & \text { col. iv } & \text { col. ii } & - \\ 5 & \text { col. } v & - & \text { col. iii } & - \\ 6 & \text { col. } v & \text { col. iv-iii } & \text { col. iii } & \text { col. iv }\end{array}$

To exemplify the nature of these compositions we present a complete translation of L.T.-2.22

col. i

\author{
Swear by Enlil! \\ Swear by Sin of Heoven! \\ Swear by [Šmaš] of Heaven! \\ Swear by [Adad] of Heaven! \\ 5 Swear by Aššr! \\ Swear by Adad of Arraphum! \\ Swear by Adad of Nawali! \\ Swear by Sin, the lord of Jamut-balum! \\ Swear by Nergal, the king of Hubšalum!
}

122 A few fragments from this tablet cannot be ploced. One of them (L.T-2d) provides the name and title of the trealy parner: Hazip-Tešsup, king of Razamā. 
10 Swear by Nergal, the king of Zirrami!

Swear by lštar of Ninet!

Swear by Bëler-Apim!

Swear by ...-rāja!

Swear by [Ninkar]rak!

(The remainder of this col. and all of col. ii are too broken for translation)

col. iii

When Mutija, son of Halun-pi-(ju)mu,

king of the country of Apum,

has sent for auxiliaries,

on thal very day my elite troops

5 and a trusted commonder for my troops

I shall send!

I shall have no objection;

I shall not say: "My Iroops are not available!"

To my troops and the commander of my troops

10 I shall not say as follows:

"When the rroops of Murija

[son] of Halun-pi-(ju)mu, king of the country of Apum,

to the front of his enemy

has approached to do battle,

15 [in words] of disobedience

decamp, and Mutija

and his troops will be killed!"

(Thus) I will not order, I will not have ordered,

I will not instruct, I will not [send words],

20 and (by) letter I will not send words!

Thus I will [instruct] them

as follows: ["Like] your own lives

[you must protect Mutija, ......]

(Remainder of column missing or too broken for translation)

col. iv (rev. of tablert)

[From the very day]

[that] this [oath by the gods]

[to Mutija, son of Hal]un-pî-(ja)mu

[king of Apum, / swore]

BREAK 
I shall not....

From this very day [for as long as I live]

an evil-doer and en[emy ..........]

$5^{\prime}$ an adversary [of Mutija],

son of Halun-pi-(ju)mu, [king of the country of Apum]

and for gold [

lines $8^{\prime}-12^{\prime}$ too broken for translation

with Mutija, son of Halun-pi-(ju)mu,

king of the country of Apum [...

as long as a live I shall not $[\ldots \ldots \ldots \ldots$.

lines $16^{\prime}-17^{\prime}$ too broken for translation

[...... befo]re(?) [Mutija]

[son of Halu]n-pi-(ju\}mu, ki[ng of the country of Apum,]

$20^{\prime}$ I shall not [..... him, I shall not bring him to account,

....... I shall not ....] him.

From this very doy for as long as I live

any confidential or secret matter,

which Mutija, son of Halun-pî-(ju)mu,

$25^{\prime}$ the king of the couniry of Apum,

lells me, sends words to me about,

or sends me a letter about,

this matter for as long as I live,

I shall keep secret.

Its master I shall not

30' From this very day for as long as I live,

with Mutija, son of Halun-pi-(ju)mu,

king of the country of Apum.

brotherhood, military aid, peace [...],

discourse in complete sincerity

35. for as long as I live I shall perform.

A haijötum, men ${ }^{123}$

[from the country of Ap]um

$[\ldots \ldots \ldots \ldots$ in my country $]$

123 The term haijöhm occurs in several letters from Mari and Leilon, usually in contexts which discuss their ransom, but it is not easy to decide what particular status people thus designated had. 
$40^{\prime}$

$[\ldots \ldots \ldots \ldots$ anyone $]$ there are

either a "lord" [...... or a worker

to whatever extent

I shall reinstate in their rights;

I shall release them;

45' I shall not delain (them);

I shall not hide (them) , I shall nol sell (them) for silver;

I shall not lead (them) secretly away to another country;

I shall not declare (them as belonging) to my commoners, and

I shall not lead (them secretly) away.

\section{END OF COL.}

col. v

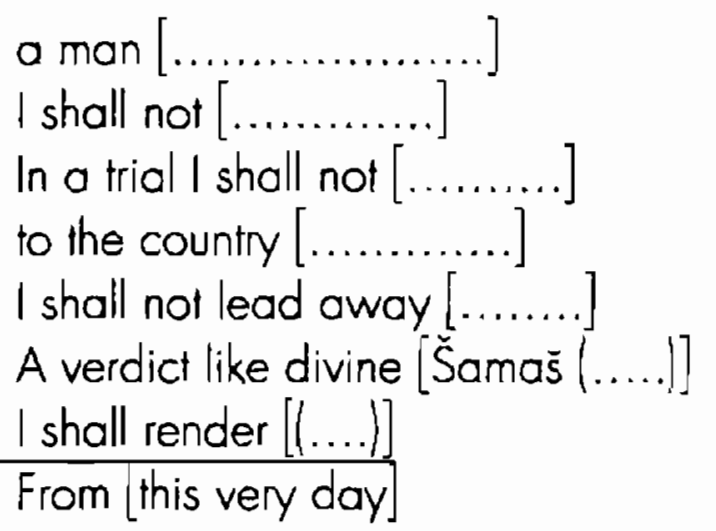

\section{BREAK}

(Lines 1"-3" too broken for translation)

[...] I shall not have "separated".

5" Who leads women, a male or female captive

from the country of Apum,

either a merchant or foreign troops

through the interior of my country,

(whether) they cry for help

$10^{4}$ or have not cried for help, they shall not lead them through!

I shall detain his captor;

with his coptor [for jugdment]

before Mutija,

son of Halun-pî-(ju)mu, [king of the co]untry of [Apum],

15" I shall have [him] sent;

I shall not detain (him)!

A verdict for cilizens [of the country of Apum] 
like the verdict of a man [from my own country] I shall secure [for him]

$20 "$ In the verdict I shall not $[\ldots \ldots \ldots .$.

to the hand of [his] opponent I shall not

A just verdict [like divine Šamaš] I shall render!

From this very day

$25^{\prime \prime}$ that this oath of mine by the gods

to Mutija, son of Halun-pi-(ju)mu,

king of the country of Apum, his sons,

his servants, his troops, his seasonal comp,

and his kingdom, I swore,

$30 "$ for as long as I live I shall not say thus:

"My oath by the gods

has become old and the treaty has become void!

Enough! To Mutija, son of Halun-pi-(ju)mu,

king of the country of Apum, his sons,

35" his servants, his troops, his seasonal camp. and his kingdom I shall do evil!"

For as long as I live I shall not say thus, and with any magic of mankind

I shall not be active, and to make void

$40^{\prime \prime}$ this oath by the gods

which to Mutija, son of Halun-pi-(ju)mu,

the king of the country of Apum, his sons,

his servants, his troops, his seosonal camp,

and his kingdom I have sworn,

$45 "$ I shall do nothing, and this ooth of mine by the gods

I shall not make void.

in word(s) of complete sincerity

$[\ldots \ldots \ldots \ldots \ldots . . .$.$] for him I shall keep.$

[o Mutija, son of Halun-bim]u,

50" [king of the country of Apum], his [sons, ]

[his servants, his troops, ] his [seasonal camp]

(tines 52"-56" too broken for translation)

col. vi

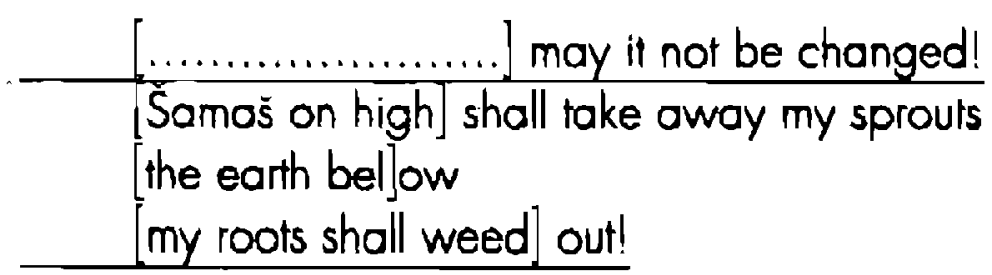


(Four lines too broken for translation)

May Sin [on evil punishment]

which for [ever cannot be changed]

on me and [my country impose; ]

forever [let it not be changed!]

5" Like Adad against his enemy [is brought into ragel]

let him against me and against my descendants [.......

be brought into rage and [blow me away!]

[and no off-]spring of descendants [...... there shail be!

[Like a cough] does not return to its base

10" $[1$ to my $]$ home shall not return!

[Istar, the Lady of] Weapons and Battles

[my weapons] and the weapons of my country

[shall break! In] front of my opponent

[weapons / shall not car]ry!

(Lines 15"- 22" too broken for translation)

(Subscript at battom of col. vi $)^{124}$

[To] Mutija, son of Halun-pi-liu)mu

[king of] the country of Apum you swore

None of the treaties from either Leilan or Mari show any trace of having been sealed. It seems possible, however, that trealy tablets exchanged between rulers could have been encased in sealed envelopes. ${ }^{125}$

\subsection{New Troubles}

If we are correct in assuming that the diplomatic activity documented for months vii-ix Habit-kènu marked the end of the hostilities, a next question is what happened subsequently in the months(?) preceeding Mutija's demise? The latest text sealed with the seal of Mutija himself is dated 20/ix Habil-kēnu, while the treaty tablet L.T.-3, where Till-Abnû is king of Apum, is dated $1 /$ iii Amer-lštar. It is within the intervening 5 months that we must place the

124 The subscript was clearly written when the toblet was drier, and possibly only at a time when the oath had actually been performed.

125 In ARM XXVIII 94, Subram of Susā asks Zimri-Lim to send līi-Sümu (contender for the throne of Ašnakkum) a seal, stating that (otherwise?) the name of his father will be on the tuppi nis ilani. This seems to show that seals were somehow used in this context. 
death of Mutija and the accession of Till-Abnû. The assumption that the years Habil-kēnu and Amer-lstar followed each other directly is supported by a text dated O/iv Amer-Istar, sealed with the seal of a Mutija "servant". Since this specimen is isolated by numerous texts with Till-Abnù related sealings it must reflect use of a seal not yet brought au fait with the dynastic change. Even before the death of Mutija, however, new troubles clouded the political landscape:

Say to [my father, Mu]tija: Thus (says) Niqmi-Adad, your son:

To get news of Halu-rabi I sent retainers to the district of Japtur, and they picked up the [following] news about Halu-rabi: "He sent words to the kings [of the region] of Japtur [as follows]: "Do not ..... all your troops ....... come quickly to the town [Šnä(?)]. In the town

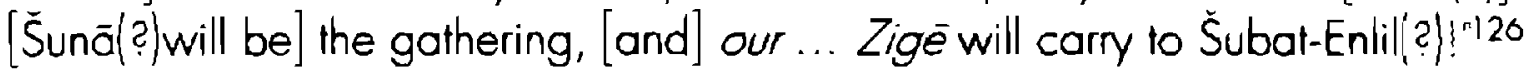

These things the retainers picked up. Whether he will (just) visit Sunā or he [will be] hostile or peaceful [there.......] does not know. Who indeed knows?

Also I have heard the following unofficial news: "He sent words to Hawilija and AŠKeAddu, and has made them enter Kahal". My tather should be aware of this! (Brussels ), YTLR appendix 3).

The centre of apprehension is evidently Halu-rabi's intentions, but also Howilija and AŠKeAdad seem involved. From Songara in Tillō came another report:

Say to Till-Abnû: Thus (says) Sang[ara, your servant]:

Your servants and the army $[\ldots . . . . .$.$] Now outlaws who [. . . .$.$] with Qilti-[.....] come to$ "take my head" - he has defended them - pardon these men! Previously he always sent me good news, but since he heard the plan of Holu-rabi he has sent bad news. [The campaign/journey of] Halu-rabi [to?] lda-Maraș [and] llän-șur is announced for the end of this month. Mary my lord be aware of this report. A messenger from the habbatum [............ habbätum into llān-sur [... rest too broken for tronslation ....] (YTLR 112).

Somewhat later Sangara again reported on the activities of Halu-rabi, this time probably to Mutija:

Say to my lord: Thus (says' Sangara, your servant:

All is well with the town and district of my lord!

As for my retainers which I send to my lord - it is servants of my lord I send; I shall send no one else, and I shall not reveal the confidential plans of my lord. Halu-rabi has reached irbinazu and Jașsib-Hamû wrote to me: "It is because of you and your district that Jakunn-Ašar pulls us together there - and I have retreated into Urgina". I fear that these men will march against us, so please will my lord be attentive to my fire signals and my need for relief. (YTLR 143).

120 Reading and interpretotion of this passage is unfortunately not clear. It seems that the "gathering" will result in somelhing being "carried" to Šubal-Enlil(?) by Zige(?) (king of Amaz, d. Ch. 2.3). 
Say to my lord: Thus (says) Sangara, your servant:

All is well with the town and district of my lord!

Yesterday Züni went to Jașșib-Hatnu and the king of AšKAkum. "Come, and I will march out with you; alone I cannor march ouf". This message Jakun-Ašar wrote to thern; may my lord know this. (YTLR 144).

The march of Halu-rabi was clearly a matter of great concern for the rowns placed in the central sector of the Habur Basin, ${ }^{127}$ and not least Aja-abu, the king of Sunā, was worried, and wrote several letters about the affair, all addressed to "his father" Till-Abnû.

Say to my father Till-Abnû: Thus (says) Aja-abu, your son:

Previously you wrote to me as follows: "Send a rrusted servant of yours to me and I shall give you a full briefing". Now will my father please grant me full confidence! Also Halu-rabi has set himself on Šunā. Please will my father give instruction (and) write to me whether I should go out (to do battle) or not. (YTLR 95).

Say to Till-Abnū: Thus (say) Aja-abum and Šibila, your sons:

May Adad and Aškur grant our father long life!

2000 supplementary of lord Halu-rabi became dissatisfied(2) and detached themselves together with lord AS̆Ke-Addu. AS̆Ke-Addu has taken command of these troops and reached the town Gurdabahhum. Among these troops were two men from Šunā, who marched with these troops, (and) told me this. Also AŠKe-Addu sent off 1000 Eluhut troops, and they have reached Sabbānum. Now send me 150 soldiers, and let a commander come, and I have done what (is necessary for defense of) Šuna and the district of Apum. Let these troops come without provisions as reinforcements.

The town Sunā is well, and the land of Apum is well. (YTLR 101).

As slated above we can only guess at the original purpose or purposes of Halu-rabi, but it seems that his strategy somehow collapsed and that regiments of auxiliaries from his army, dissatisfied with the whole affair, went off in different directions to start their own little wars. Some attached themselves to AŠKe-Addu, who also had troops from Eluhut under his command, and altacked towns in the northern part of the Habur. The result was a rather chaotic situation which caused a number of Apum governors, officials and allied kings to write more or less agitated letters to Mutija or Till-Abnû, who seem not to have taken much action. Quite likely it was at about this time that Mutija died and was replaced by Till-Abnù. A certain Ahušina writes about AŠKKe-Addu:

Say to Till-Abnû: Thus 〈says\} Ahušina, your [.......]:

AŠKe-Addu, the evi[l-doer], whom you previously told me to apprehend - until now I have repeated: "If I apprehend him, I shall turn the country against me, and the [.....] and the kings - his master who $[\ldots$ break .... $]$ (YTLR 118). 
Subsequently someone reports to Till-Abnû that AŠKe-Addu has been dealt with:

[... break ....] You wrote to me both once and twice about AŠKe-Adad. This man is in my hands, and I will not depart from your instruction. Just like Mutija and I had good relations, you and I - let us have good relations. Concerning this man your heart should rejoice! Hereby [I have sent you $]$ a complete report $[\ldots$ break ....] $(Y T L R$ 121).

Judging from a long, but unfortunately very fragmentary letter it would seem that Till-Abnû and Halu-rabi concluded an alliance, and subsequently kept the peace:

Say to Till-Abnû: Thus (says) Halu-rabi, your brother:

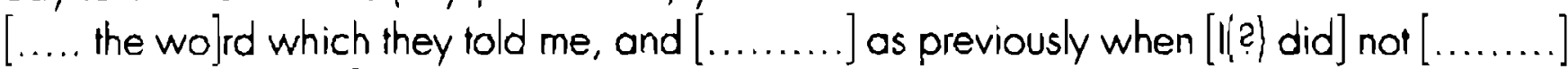
with you, did [they?] nor answer [me(?), and ........... to you. (6) Since I swore an oath to $[$ you $]$ and slaughtered the donkey, Burija slanders me to Hammurabi as follows: "Halurabi has [made peace] with an enemy town; he has sworn an oath and slaughtered the donkey." This [... 12ff. too broken for translation ....] (YILR 56).

Most letters to Till-Abnû which may belong to a time after the period of transition are concerned with routine affairs, and do not reveal much about his activities. Since also many of the later or more interesting letters sent to him may have ended in another archival group (ct. above Ch. 1.3) we cannot really judge his record or say much more than his reign probably was quite short, possibly little more than a year. If this is correct it seems more than likely that his brother Jakün-Ašar may have contributed to his demise, but pending the emergence of new evidence, this must remain speculation. 


\section{GIMPSES OF SOCIEN}

\subsection{Gods and Festnals}

Evidence for religious affairs is somewhat sparse in the Leilan archive. The political treaties, however, provide lists of dieties in their introductory adjuration sections, which are substanlially preserved in four of the compositions.

\begin{tabular}{|c|c|c|c|}
\hline L.-Treaty 1 & L.-Treaty 2 & L.-Trealy 3 & L.-Treaty 5 \\
\hline & & Anum & Anum \\
\hline Enlil & Enlil & Enlil & Enlil \\
\hline & & & Šarra-mātin \\
\hline & & & Dagan \\
\hline Sin of heaven & Sinn of heaven & Sin of heaven & Adad of heaven \\
\hline Šamaš of heaven & Šamaš of heaven & Šamaš of heaven & Sîn of heaven \\
\hline Adad of heaven & Adad of heaven & Adad of heaven & Šamaš of heaven \\
\hline & & & Assyrian Šamaš \\
\hline
\end{tabular}

Aššur

Adad of Arraphum Adad of Arraphum Adad of Holab

Adad of Nawali Adad of Nawali

Adad of Kahat

Sin of Jamutbalum

Nergal of Hubšalum Nergal of Hubšalum Nergal

Nergal of Hubšil

Nergal of Zirrami Nergal of Zirrami

Bēlet-Nagar

Eo

Ištar of Ninet

Ištar of Ninet

Ištar of Ninet

Assyrion lštar

Bēlet-Apim

Bēlet-Apim

Bēlet-Apim

.- ra-a-ia

…-ra-a-ia

Ninkarrak

$[\ldots \ldots \ldots . .$.

BREAK

Lady of Nineveh

Ninkarrak

Ištor of Nineveh

Lady of Battle

Lady of Battle

Išhara

$[\ldots \ldots \ldots . .$.

divine Mt. Zara 
$[\ldots \ldots \ldots . .$.

BREAK gods of heaven

gods of land/water

NO MOORE gods of land/water

gods of heaven/

earth

gods of Saggar/

Zara

gads of Amurrum

and Subartum

NO MOORE

These lists clearly include several calegories of deities. ${ }^{128}$ First the gods of the international pantheon: Anum, Enlil, and the other greal gods "of heaven". Sinn, Samaš, and Adad. Next important regional hypostases of the great gods located in the major cult-centres of the North like Halab, Arraphum, Nawali, Hubšalum, and Zirramum. Thirdly some deities which can be considered as "local" in the sense that their inclusion is due to the specific treaty partners involved. To this category belongs Bêlet-Apim, whose name is preserved in three of the lists. in L.T.-3 presumably Adad/Teššup of Kahat, Bēlet-Nagar, and Ea owe their inclusion to the fact that the treaty oath was formulated by the king of Kahat, while Šarra-mätin $\{=A \dot{s} s ̌ u r ?\}$ and the "Assyrian" Šamaš and "Assyrian" Ištar are specific for L.T.-5 concluded with Assur. The inclusion of Aššr and Adad of Arraphum in L.T. 2 may be explained by the fact that the kingdom of Razamā lay on the fringe of the Habur region and had close links to the east and south, but the inclusion of Adad of Arraphum in L.T.-3, concluded between the two Habur kingdoms of Kahat and Apum, is less obvious. As a final category the completely preserved lists in L.T.-3 and L.T.-5 end with a round-up of gods of general categories from "heaven, earth, water", from the mountain ranges of the Sinjar, and from Amurrum and Subartum (i. e. non-Assyrian gods). Similar passages can be assumed to have existed also in the other texts.

The traditional and formal character of these lists is of considerable interest. Even modest city-states on the fringes of the Mesopotamian arena conducted their affairs according to what must have been common international standards, while simultaneously also keeping to some local, possibly ancient and heterogenous traditions.

\section{Bēlet-Apim}

In Šehnā itself the most prominent deity appears to be Bēlet-Apim "The Lady of Apum", a local hypostasis of lštar. The central part of her temple in Subat-Enlit is described in a text from Mari, which gives measurements for the cello (the kummum, $9 \times 3 \mathrm{~m}=27 \mathrm{~m} 2$ ), the ante-cella (the papahum, $15 \times 5,25 \mathrm{~m}=\mathrm{ca} .79 \mathrm{~m} 2$ ), and the forecourt ithe kisallum, width $14,5 \mathrm{~m}) .129$ The impressive temple partially excavated on the leilan Acropolis does not correspond well to this description, ${ }^{130}$ and also seems more tikely to have been

128 Little comparative evidence is ovailable from the Mari trealy fragments (cf. Durand, DEPM I, nos. 290-293).

130 See Weiss 1985. 
dedicated to Enlil. The temple of Bēlet-Apim may therefore have been located elsewhere on the high mound.

The principal festival for Bëlet-Apim was the elunnum, celebrated in early winter, and corresponding to the festival for lštar at Mari, where a detailed description of the ritual performance has been found, showing that a central component of the festival was the king's participation in o banquet inside the temple of the goddess. ${ }^{131}$ For the year AmerIštar there is evidence that the elunnum was celebrated during month iii (FI 127, 11/iii), and the same is the case in the year lšme-II $\{\mathrm{FI} 30,2 / \mathrm{iii}\}$. Ar Rimah the elunnum was in one instance celebrated 15/iv, while during Habil-kēnu, a year where an intercalary niggallum was inserted, it was celebrated in month v. A series of texts from lšme-ll provides interesting information on the proceedings. $\mathrm{Fl} 30(2 / \mathrm{iii})$ is an account of wine dispensed during the elunnum-festival, and shows that the king offered wine in the "temple of the gods", and was served wine in the hamrum in the "temple of the goddess", and at night when he left the "temple of the goddess". The hamrum must have been a special area used for religious ceremonies, probably inside the temple, and other leilan texts show that the king would spend time there on a number of occasions. ${ }^{132}$ After the festival of Bēlet-Apim the king could send sacred portions from the banquet to other kings:

Say to Mutija: Thus (says) Aštamar-Adad, your brother:

Since you celebrated the elunnum festival of Bēlti-Apim who protects your life, and sent me my portion, I have eaten of my portion that you sent me, and it pleased my heart much. (YTLR 5).

A number of parallels for this procedure is known from Mari. Qarni-Lim of Andarig celebrated the elunnum of lštar of Andarig, and sent a meat protion to Zimri-Lim (ARMT XXVIII 169), and Asqur-Addu of Qattarā sent Zimri-Lim a portion from the elunnum of Ištar of Qattarā (ARMT XXVIII 174). The Leilan kings were also invited to participate in festivals by other kings:

Say to Till-Abnû: Thus (says) Aštamar-Adad, your brother:

Tomorrow I shall perform the entering of the lady. Come and let us spend the day together; and let them bring the fruit which is in your garden. (YTLR 39).

Say to Till-Abnû: Thus (says) Mašum, your brother:

I shall celebrate the elunnum of Ištar, "Lady of the Citadel", who protects your life; come here and we shall discuss one day; do not tarry! (YTLR 79).

Other scattered evidence indicates that there was a temple of Adad/Teššup in Šehnā (CV 123). In Fl 107 (6/viii, Ipiq-lštar) gold and silver is used to produce ornaments for Šamaš and Sîn, and we see the king offering sacrifices to Bēlet-Apim and Nergal/Amum (Fl 65).

131 See the detailed study and analysis by Durand and Guichard 1997, especially pp. 38-40.

$132 \mathrm{Cf}$. FI $32(4+/ \mathrm{v})$ : wine before king in the hamrum morning and evening; FI 34 (3/vii): wine in the hamrum when ... of the gods; FI 37 (11/vi) and FI 38 (12/vii); Fl $46(9 / \mathrm{viii})$, when king swore in the hamrum. For a detailed discussion of the hamrum see Schwemer 2001. 


\section{Bēlet-Nagar}

Nagar with its cult of the goddess Bëlet-Nagar has been the subject of a series of studies by Guichard, who has published several interesting lexts from the Mari archives, among them a letter which shows how the statue or emblem of this deity was taken on ceremonial tours in the region. The ruler of Hazzikannum, Huziri, writes to Zimri-lim: "Here Bēlet-Nagar, who protects the life of my lord and grants my lord long life is passing through the lands. I will receive her in Huna-ahi, and Hāja-Sümu will receive her in Miškillum, and I will receive her (again) from Hāja-abum and perform her sacrifices in Hazzakannum". ${ }^{33}$ A similar tour of the goddess is attested in one of the most interesting letters from leilan:

Say to Till-Abnû: Thus (says) Ea-malik:

Previously Mutija, before he ascended his throne, several times made the following vow: "If I were allowed to ascend my throne I would donale silver, gold, cups of silver, cups of gold, and clever maids to Bēlet-Nagar, my Lady!" This vow he made several times, (but) when this man ascended his throne, he did not send greetings to the goddess, and he never ever saw the face of the Goddess. Now it is you the Goddess has touched with a finger, and you have ascended the throne of your father's house. From this day - 14 days hence - the gaddess will leave her house and the boundary markers will be (re)arranged. And the foce of the gaddess will be set towards the town Alä. You must grant the goddess her wish - do not withhold (it). And don't make objections like: "People are pulting much pressure on us and we are ruined". Do not say this! Make the goddess happy with whatever there is, and this Goddess will keep you alive. Hereby I send to you the sangú-priest of Bêlet-Nagar, your Lady. Put your detailed plan whether this or that to him, and send him to me. (YTLR 28).134

Bēlet-Nagar, however, wos only one of several important regional deities. To this group belonged also prominently Adad/Teššup of Nawali, a lown poorly attested outside the leilan material. The special status of this cult centre is underlined by the shipments of wine from both priests and a priestess of the god (ct. Ch. 2.3), and the king of Apum visits Nawali in early Amer-lštar (Fl 128 and 139). Belonging also to the categon of regional deities were Nergal of Hubšalum and Nergal of Zirramum. Hubšalum can be locared near Andarig. while Zirramum is hardly in evidence outside the Leilan treaties. ${ }^{135}$

Although more evidence is needed to reach firmer conclusions, an as yet dim image emerges of a small number of probably very ancient and highly prestigious cults spread out over Upper Mesopotomia. Together with deified topographic features, like the hills of Sinjar (Saggar and Zara) they formed the core of a religious landscape, replete also with minor, local hypostases and city-gods. In the case of Bëlet-Nagar we can correlate the cult with the enormously important ancient site of Tell Brak, and it seems possible that other mojor deities could have belonged in once paromount cities.

133 A. 221, 5-14; Guichard 1994, 237f.

134 Cited in extenso in Eidern 2000, 259F.; also Eidem 1991c, 125, and Matthews and Eidem 1993, 204. Discussed in detail in Sasson 1997.

135 Cf. Eidem 19960. 


\subsection{Trade and ECONOMY}

Unfortunately the few Old Assyrian texts which mention Apum provide little information on the character of relations between the traders and the town. The colonial network connected with Kanesh began only in the upper Balih valley, and the available documentation does not allow any firm conclusions regarding Assyrian commercial activity within the north Syrian area. It can hardly be doubted, however, that the Assyrians participated on various levels in commercial activity in this region. In the later documentation from the period contemporary with the archives from Mari and Leilan we have firmer evidence for Assyrian activity in the Habur Basin. Texts from Mari describe how the Assyrian traders were temporarily evicted from their "houses" in Šehna by Kunnam and the Elamites in ZL 10, and it has even been suggested that the Elamite invasion of the Habur was inspired by desire to control part of the Assyrian trade network. 130

The most important evidence for Assyrian presence from Leilan itself is the tablet with the text of a treaty between Till-Abnû of Apum and Assur (L.T.-5). No doubr it dates to the beginning of Till-Abnû's reign, and would have been necessitated by the change of rule. The details of the treaty are unfortunately obscured by the broken condition of the tablet, but basically the preserved rext consists of two main parts. The godlist/adjuration closes with a direct appeal to Till-Abnû, the king of Apum, to swear to the Assyrians, i.e. representatives of the "city of (divine) Assur, the son(s) of (divine) Assur in transit (litt. "going up or going down"), and the karrum in your city". Then follows the clauses of the treaty in the form of oral statements put by the Assyrian representatives to the king, who is addressed in the 2nd person sing. Few of the stipulations are preserved or can be reconstructed fully, but the following subjects are mentioned: goods like copper, probably in the context of regulating the nishatum import tax (col. II), ransom and release of people (col. II), properly of the traders'? ? \{end of col. II-III), promise to deal justly with the Assyrians, and keep the treary (col. III), lost property (col. III), legal claims (?) and stolen propery (col. IV), promise not to induce others to commit actions prohibited by the treaty (col. IV). The large four-column rablet would have had a longer tex: than any of the Old Assyrian treaties known from Kanesh, but otherwise seems very similar, especially with the rreaty concluded between Assur and Hahhum.137

Although extant evidence points to substantial differences in the organisation of the Assyrian trade from the period of level II to that of level $\mathrm{l} b$, these differences cannot yet be outlined with any precision, but must await publication of more evidence from level lb. It seems, however, that the late phase to which our text belongs witnessed a partial reestablishment of patterns prevailing before the interventions by Šamši-Adad, Zimni-Lim etc. Such a process has long been suspected from the famous inscription of Puzur-Sin, who claimed to have ended the rule of the foreign Šamši-Adad dynasty in Assur. This king moy in fact have ruled Assur at the time of the L.T.-5, and a significant trait is that the treaty was concluded not with the king, but with the cily of Assur, a clear echo of the political structure in Assur in classical Old Assyrian times.

$137 \mathrm{~K}$ 00/k 10. For all three OA reaties see Günbatt 2004. 
The leilan letters do not furnish any information on the Assyrian "colony", but administrative texts provide interesting evidence. First CV 153 (6/vii Habil-kēnu) mentions a present of oil from a merchant Innāja arriving from Mammā. The typical Assyrian name in connection with Mammā effectively shows that focus for Assyrian activities still was the Anatolian area. Another merchant with a ypical Assyrian name, Ali-waqrum, presents a jar of wine to the palace (FI 15, 11/v Amer-lštar). The most important information, however, is found in a series of tablets dated to Habil-kēnu:

CV $168(15 / \ldots H K)$ lists 22 slaves, among them boys, girls, "old" women, from "the House of the servant of Ašsur", entrusted to the palace official Mannum-balti-El.

CV $64(24 / \mathrm{vi} \mathrm{HK})$ is a note of 1 mina of silver received from "the House of the servant of Aššur".

CV $31(27 / \mathrm{vi} \mathrm{HK})$ is a note of $1 / 3$ mina silver as ransom for a man from "the House of the servant of Aššr", and released to a man from Hizhizzi (=Izhizzi).

CV $35(27 / v i H K)$ is a nole of $1 / 3$ mina silver as ransom for a woman from "the House of the servant of Aššu" to a man from lazapat.

It seems likely that CV 168, where the month is broken, also belongs in month vi, and that the four texts form a series concerning the same matter. The "servant of Ašsur" could also be understood as a simple personal name, Warad-Aššr, but almost certainly qualifies the "house" as an Assyrian institution. The name Warad-Aššur is rare in Old Assyrian sources, and an Old Assyrian text mentions 1/2 mina of copper "in Apum for lodging, paid to the servant of Aššr" (ir $a-$ sün. 138 It therefore seems that the Assyrian merchant establishment in Leilan, although also referred to as "colony" in L.T.-5, normally was called the house of the Ašsur-servant, presumably a conventional term for the resident Assyrian official. At the moment this evidence is unique, and since the vast Old Assyrian evidence so for only connects Apum with this type of establisment, it could be that the Apum "office" had a special history or function, not precisely paralleled elsewhere.

In the above series it would seem that the Assur office had received the listed people, possibly picked up by a caravan en route, and that they were lodged in the palace owaiting ransom by their local relatives, since both lzhizzi and lazapatum were towns in Apum. The 1 mina of silver paid by the Assur office was perhaps payment for the trouble, while the silver received by the palace in ransom probably reverted to the office at some given point.

In any case the Assur office was not the only "colony" in Leilan, where we also find the official "overseer of the merchant offices" ( wakil kär), a certain Iși-ahu, mentioned with his title in CV 05 (10/ix HK), where he is issued silver from the royal coffer to purchase jewelry, 
and without title in CV $114(26 / v H K)$ where he brings a jar of wine "when he .... with the king". 139 This figure is best compared to the wakil tamkari known from Mari. 140

At the moment the evidence is probably insufficient to present a complete list of the merchant offices in Leilan, but those documented include prominently an office from Sippar in Babylonia (CV 176), and offices of local Habur towns, Kahat, Sunā, and Amursakkum. Some insight into the affoirs of the latter is provided by the important, but difficult text $\mathrm{Fl} 103$.

The rablet is an interim account for silver set aside for purchase of wool and barley for the palace cultivators ("the farmers of the villages"). It totals $145 / 6$ minas of silver, listing expenses and incoming amounts of silver. The text is unique, and not all details are clear, but some interesting features emerge. First that wool is procured from $\}, 438$ sheep $(=\mathrm{ca}$. no. of $\mathrm{kgl}$, probably belonging to the palace, and shorn by Haneans, i.e. The semi-nomadic population of Apum, for a fee of 1 shekel silver for each 7 or 8 sheep. Next wool \{ca. 600 $\mathrm{kg}$ ) is purchased from the "merchant offices" of "the man of Sunā" and "the man of Amursakkum". Although this phrasing is unusual it presumabaly means offices of these towns, rather than specifically their kings, both vassals of Apum. The explanation for these purchases is possibly that sheep belonging to Sunā and Amursakkum had been shorn close to Leilan, and the wool therefore was most easily sold through the merchant offices there. Why the palace larms needed two tons of wool is not stated, but presumably the staffs were supposed to spin and weave in their spare time.

The rext is dated to month vi (in the poorly attested year Adad-bani), and also lists purchase of seed, 132 homers = ca. 13.200 liters, and purchase of fodder for 30 oxen for 5 months, from iv-viii, i.e. through the winter, when additional fodder was required. Similar farms are attested in the Mari evidence, where we learn that they were called "plows". They consisted of both animals and male and female staff. One example of such a farm had 8 oxen, 17 men and 2 women for the work on the land, and 1 man and 5 women for the house work. ${ }^{141}$ An example of such a farm is also found ar Leilan, in CV 162, where rations are issued to members of a "house", divided basically into female (17) and male (11) groups, and including equids. Fl 103 states that it concerns the farm teams of the "villages", and presumably this means plots of palace land in a number of the many small settlemenst around Leilan, but it is unlikely that the text comprises anything like the total of palace agriculture. Without more evidence statistics are uncertain, but the amounts mentioned are too small. Judging from the Mari example 30 oxen would only suffice for $3-4$ teams, and since the seed needed to cultivate 1 ha of barley would have been ca. $150 \mathrm{I}$. our 13.200 I. would only correspond to ca. 100 ha.

These are tantalising glimpses of the local economy, and evidently the nature of the extant Leilan archives is not well suited to provide comprehensive overviews of the situation. What is clear, however, is that Šehna was the focus for both international and regional networks

Michel 1996, 420-422

4) See Joannès, ARMT XXIII, 83ff, and Van Koppen 2001. 
of trade, and must have housed a bustling merchant quarter. The 1991 excovations at Leilan tested the possibility of a karum type quarter in the southern part of the lower Town, but found only a Mitanni period cemetery imposed on $3^{\text {rd }}$ millennium BC remains. ${ }^{142}$ The Leilan kärum district therefore must be sought elsewhere, but quite likely within the safely of the walls. Although the large Lower Town may not have been densely inhabited in the Old Babylonian period, we are gradually gaining some insight into the lopography of the site. Apart from temples on the Acropolis, the Lower Town Palace East and the administrative building belonging to the king of Andarig (LTP North, Operation 7), residences of other foreign kings, ${ }^{143}$ the merchant offices, residences for many officials, service personnel etc. etc. must after all have filled much of the intramural space.

\subsection{PEOPLE}

While gods, kings, envoys, and traders criss-crossed the Habur Basin and Upper Mesopotamia, also many commoners were on the move, and not always voluntarily. The extensive hostilities documented in the royal letters brought danger and hardships to many ordinary citizens. Even the soldiers occasionally complained:

Say to my lord: Thus (says) Kuzuzzu, your servant:

The auxiliaries under Šanigi gathered and said this to Šanigi: "For four months one fieldcamp has taken us (only) to (another) fieldcamp. We do not receive grain-rations, nor are we given wool-rations, and winter has set on!" This they said. Now hereby Sanigi will come to my lord. Please will my lord listen to his word. (YTLR 140).

More unlucky, however, were the numerous people caught by rooming soldiers, the nolorious habbäum mercenaries, or simply common outlaws. The habbätum seem to constitute a new phenomenon. From the slightly older texts found at Mari we have many examples of kings using foreign troops, but such troops were usually sent as auxiliaries by foreign allies. The habbätum, on the other hand, were apparently independent groups of professional soldiers who seem basically detached from fixed political control. On two separate occasions they are said to return, in one case apparently from the country east of the river Tigris. This indicates that the arrival of the habbäum in the Habur and Sinjar areas may have been seasonal and related to the conventional periods for conducting war, and the habbatum are found in virtually all of the Near East at this time. An Old Assyrian text from Konesh (Level lb), refers to habbortum in Anatolia. ${ }^{144}$ From Alalah we hear of a certain Muzun-Addu and his hobbötum assisting rebels against Abban of Halab, and a seal inscription refers to Muzun-Addu's general TaheAddu, who is also called a habbäum. 145 Finally we hove also from southern Mesopotamia

1991

143 Like the one requested by the king of Eluhut in YTLR 89; see Ch. 2.2.

144 Dercksen and Donbaz 2001.

145 Dietrich and Lorelz 1969 


\section{Glimpses of Society}

evidence for habbaitum soldiers in organised groups during the reign of Samsu-iluna. 146 The few personal names belonging to habbätum which occur in all these texts show the same mixture of Akkadian, Amorite, and Hurrian which was current across northern Mesopotamia, and it seems certain that the habbätum did nol constitute a new or different ethno-linguistic group, but basically must have been made up of local Mesopotamians or Syrians.

The new appearance of large groups of redundant soldiers roaming the countryside is hardly surprising in view of the foregoing events. With the elimination of Larsa, Ešnunna, and Mari, Babylon appeared preeminent in the south, and in the north Jamhad could reach out for the northern Jezirah left by now edipsed city-states. Neither Babylon nor Jamhad, however, had the ability to integrate firmly all this space, and this left room for the habbätum, a dangerously uncertain element which could be turned from side to side in the inter-state struggles, and on a long term basis their existence must clearly have constituted a destabilizing factor.

The noun habbätum stems from a semantically complex root which can mean "move crosscouniry", "hire/hire out", and "rob/steal", 147 and it is easy to see how these different meanings all convey information about the habbatum. highly mobile, employed as paid hands - and of course an unstable and unreliable social element.. Interestingly the verb habātum in the meaning "rob" is used frequently in the Leilan texts, not about the habbortum, but about common outlaws. When habbäum are said to have plundered the verbs sabātum or lequim are used, whereas the individual "robbers" connected with the verb habartum are described as sarrärum "outlaws" or with a special noun häbitanum to avoid confusion with the distinct calegory habbätum.

A series of letters sent from Burija of Andarig to Till-Abnû illustrates the danger posed by such outlaws.

Say ro Till-Abnū: Thus (says) Burija, your brother:

Aja-abu, the Jamutbalum, lived as emigrant (häbirum) in the lown Zurra. After peace was established in the country, he took command of outlaws and began to steal men from the country of Jamutbalum. He was not, however, allowed to enter Zurra, but they led them through to Kaspātum in the country of Ida-Maraș. From the town Kaspātum two of the men fled. These men they have led either to the country lda-Maras, or to the country of SubatEnlil, or the town of Kahat. I have written to Šepallu, and to the town of Kahat. Sons of Jamutbalum your servants must not ransome with silver in your country. Hereby ! have sent to you people who know these men. If these men are seen there, seize them; restrain them, and have them lead to me by the carrier of this letter. In the whole country - outlaws who steal - whom does that benefit - except he who wants to create enmity in the land? Put these men on the spot, and they must not escape [......... others will [..........] and why will you never send [your greetings(?)] to me? (YTLR 42).148

$140 \mathrm{Cf}$. Krous AbB 7, p. 95 ad $116 a$.

147 Krous 1975.

148 U. 3.8 quoted in Eidem 1996b, p. 85 n. 17. 
Say to Till-Abnû: Thus (says) Burija, your brother:

.... I wrote to you about the Jamutbalum people who were stolen in the mountains, and you stood up before my retainer (soying): "So help me Sin, the lord of Jamutbalum, and Nergal, the king of Hubšalum, I shall return (them)!" Since you hove not seized these men and their stealers, let the crime agoinst these people rest with their stealers; since they have long disappeared - what can we do to them? (YTLR 43). ${ }^{149}$

Say to Till-Abnû: Thus (says) Burija, your brother:

I have written to you both once and wice about searching for the people who are stealers, but you do not seize these people. Now (still) there are people who steal cilizens of Jamutbalum and sell them there for silver. Now lit-Ešuh, the bearer of this letter of mine, logether with his brothers, they caught and sold for silver $[\ldots \ldots \ldots$.$] . Hereby you [?]$ must $[\ldots \ldots \ldots . .$. the buyer $[\ldots \ldots \ldots .$.$] the buyer [\ldots \ldots \ldots .$.$] his captor [\ldots \ldots \ldots . . .$.$] have them led to me, and$ a brother (of) his, who was stolen with him, is in the house of Take. Release his brother! If, on the other hand, these outlaws are roaming on your own instruction, then write to me that I may know this! (YILR 44).

The series, sent probably in this order, cannot cover a very long period, and the statement in YTLR 42 places the beginning of this period shortly after peace between Burija and Apum was established. The lown Zurra is well-known from the Mari texts, and can be located fairly accurately near the eastern ranges of the Sinjar. ${ }^{150}$ It was thus on the border between Apum and Andarig territory, and Burija's letters show that the town functioned as a base for raids into his realm, a problem echoed also in letters sent from Jamși-Hoinû of Kahat.

Say to Till-Abnû: Thus (says) Jamși-Hatnû, your brother:

When you stayed in Kahat, you said this to me concerning the men from Nilibšinnum, whom the men from Zurra had taken: "[... II.10-15 too broken for translation ....] (16) I will hand them over to [........], and they will lead them to you." This you said to me. Now hereby I send my retainer and Milkija to you. Hand over the men you apprehended and the captors together with their people to Milkija and my retainer, and let them lead them to me, and in exchange for their brothers I will release them. (YTLR 64).

Say to Till-Abnû: Thus 'says) Jamși-Hatnû, your brother:

With what justification have you assumed authority to put sons of my country in tetters? Previously your semants captured shepherds from Nilibsinnum, and in Zurra sold them for silver or had them ransomed against silver. Now indeed why have they also detained a shepherd of Zimri-lštar within the town. Let them release his shepherd; they must not detain him! (YTLR 67).

Apparently life in this environment was precarious and dangerous, but the numerous references to events like the above should not creale a wrong impression. The political treaties 
were much concerned with these problems, and the very fact that many letters exchanged between the major kings deal with them, shows that mechanisms 10 minimize lawlessness existed, and were used to some effect. Captives could usually be ransomed, and would return to their families:

Say to Till-Abnû: Thus (says) Jakūn-Ašar, your brother:

Hubizzam, a weaver from BEšannim ${ }^{151}$ (and) the bearer of this letter of mine, ransomed Tarinnam of Alama from the habbötum for 13 shekels of silver, and he dressed him in garments and a nahloplum-coat, and then released him. And he pledged him before the elders thus: "You will refund my outlay in full, and return my 13 shekels of silver, and you can go (free). This he pledged 'him', and he released him. Now this man has absenled himself!" Hereby I have sent Hubizzam to you. Let his claim be justly satistied. (YTLR 60).

Among the Leilan letters are a few examples of private messages sent to palace officials, and they provide rare glimpses of more mundane concerns:

Say to Warad-[......]: Thus (says) Jakün-a[r-...], your brother:

May Šamaš and Saggar grant you life forever!

Why do you never send me your greetings. I have written about your greetings - send me your greetings! Indeed you know that ( $\mathrm{am}$ ) nearby (in) a house in Kasapã; the house is wretched , and there are no furnishings. I have now sent my servant to you. A single chair so that I can (at least) sit down my brother will (surely) not deny me, and if a door for sale [..... , buy a door and I here will send you the price for the door. Jarim-Šamaš returned [...... to me]. Jašub-Halû [came (back) to me] and he (still) has my silver, he has not spent (it). (YTLR 173).

The door- and chair-less writer of this letter, leaving in Kasapā in the kingdom of Kurdā, may have been affected by the pillaging in Kurda reported in e.g. YTLR 171 (see 3.1). He may well have lived in a house not unlike those recently excavated in crowded residential neighbourhoods at sites like Mhm. Diyab and Chagar Bazar. ${ }^{152}$

The addressee may be identical with an Apum official, Warad-lštar, who on one occasion was in charge of delicale negotiations over a ransom with another king:

Say to my lord: [Thus] (says) Warad-lštar, your servant:

[When he heard] the instruclions our lord [gave] us, he agreed; in the early morning he heard the message, and did not make any objection. And the message which my lord added, he then received (and) agreed to; and we told him about the 11 shekel in ransom and he answered thus: "I will send words that the elders must gather and I shall give an answer". The day I had this letter of mine sent to my lord, this evening, we shall pay out the 11 shekel and tomorrow we shall swear; he has sent words to his elders and his local officials. [Please will my lord] write to [Us?]! (YTLR 153).

152 See, e.g. MacMahon et at. 2005. 
Given the high-level activity over this affair it seems unlikely that just one person is to be ransomed for the very moderate sum of 11 shekel, but rather that this is the agreed price for each member of a larger group, presumably prisoners of war. 


\section{Eplogue: The End of an Era}

Regarding Old Babylonian upper Mesopotamia many perspectives present themselves. The modern landscape has changed, but not to a degree that precludes inspiration, and at a distance in dim light a site like Leilan itself, with modern buildings on the high mound and enclosed by ruined city-walls, may convey a sense of the sight that once met the caravans, armies, and casual visitors approaching its gates. One such visit made a lasting impression on the ciry. The army of Samsu-iluna conquered it, and king Jakün-Ašar was either captured or killed. Subsequently the Babylonians withdrew, but Leilan seems not to have revived to any considerable degree. 153 The administralive texts from what may have been the last years before the end in $1728 \mathrm{BC}$, show hectic diplomatic activity with envoys moving between Šehna and Babylon, but we can only guess at the background for the raid. Quite likely further excavations in the Lower Town Palace (East) may produce pertinent evidence.

Outside the ramparts of Leilan the perspective moves to the Turkish hills, and the routes that ance led to Kanesh, Eluhut, and Nowali - or south, west, and east towards other horizons and scores of ancient lells, of which only a few have been investigated and lewer identified. The archives from Mari and Leilan provide a bewildering image of settlements once strewn across upper Mesopotamia, and we are just at the beginning of rediscovery. Between the fixed points of ancient Šehná \{Leilan\}, Nagar \{Tell Brak\}, Urkiš (Mozān\}, Kahat (Tell Barri), and Tādum (Tell Hamidi) countless other sites await identification, and as this process continues, with excovation, survey, and other methods, ${ }^{154}$ the spatial dimensions of life in the Old Babylonian period will become much clearer.

The ancient lexts offer their own perspectives. The Old Assyrian archives provide just casual notes on upper Mesopotamia, the Mari archives provide overviews and often confusing details about the political landscape, while the small local archive from Leilan provides more spare and circumscribed information. Few of the letters in the archive discussed here contain developed stories or long and detailed reports like those often found in letters from Mari. The scale of things was different, and oral communication predominated in this environment. Still we see how the different cities and towns maintained their own scribal traditions, allowing us to identify a number of different fablet "styles" among the letters. ${ }^{155}$ In general the Leilan archives seem to portray a region where not much had changed over the generation or so following the end of Mari. Indeed one senses a revival of local patterns prevailing before the hectic years covered by the Mari archives: Šehnō seems again to have become an important cily-state, and Assyrian caravans moved through the region as of old. Countering this image are the new international situation, with the city-states of upper Mesopotamia now contested between the super-powers of Jamhad and Babylon,

Mitanni period burials in the lower Town, however, could indicate some occupation of mid- $2^{\text {nd }}$

154 millennium date (cf. Akkermans and Schwarz 2003, 347f.).

155

Eidem 2002. 
and disturbed by the roaming habbätum. After 1728 BC this Old Babylonian world would survive for yet some generations, before being swept aside by new forces that led to the forging of the Mitanni kingdom. How much of it persisted through these developments will only become clearer as new research produces enough archaeological and epigraphic evidence, but the evident resilience of local society, deeply rooted in the $3^{\text {rd }}$ millennium BC and earlier, no doubt left its marks long into the Late Bronze Age and beyond. 


\section{YEAR HABIL-KËNU}

$\checkmark$

6: Wine shipments for elunnum-festival (CV 115)

9: Silver for diviner Bina-Addu (CV 50); silver tax from Šupram (CV 66)

10: Silver from ... when Lawila-Addu of Šupā became king (CV 63)

14: Silver objects sent for elunnum-festival (CV 57, with duplicale 62)

15: Summary of items sent for elunnum-festival (CV 70 )

16: Food issues for elunnum-festival \{CV 133\}

17: Wine shipments for elunnum-festival (CV 109)

19: Wine from Till-Abnû of Surnat (CV 112)

25: Ransom of woman by man from Urgina $(=U r k i s ̌ s)(C V 27)$

VI

7: Ransom of people sold in Kurdā (CV 33); ransom of man from Tappišu (CV 39)

11: Wine from Samsu-malik of Azamhul (CV 119)

14: Wine from Šamaš-nașir, merchant of Amursakkum (CV 116)

15: Wine from Aja-abu, king of Śunã (CV 108), honey for Bēlet-Apim (CV 127)

22: Shoes for general Šupram (CV 86)

24: I mina of silver from House of the sevvant of Aššr (CV 64)

27: Ransom of man from House of servant of Aššur by man of Hizhizzi (CV 31); ransom of woman from same place by man from Lazaparum (CV 35)

VII

5: Wine from Šibilani of Šunā (CV 107)

10: Issues to "retainers" of Bin-Dammu and Hazip-Teššup "when they made the king swear" (CV 9, with duplicate 2); issues to same "envoys" of Bin-Dammu "when the king swore" (CV 7 )

11: Issue to man arriving from Babylon (CV 93)

20: Issue to messenger from Kakmum (CV 83); silver for men when they stayed in Razamā (CV 52)

21: Wine from elders of Tehhi (CV 110)

VIII

(day lost): Silver to retainers of Bin-Dammu and to Bin-Dammu "field marshal" 'sag-gal-martu-meš) when he swore (CV 15)

5: Silver to envoys from Zirānum, Nihrija, Anzowawa(?) (CV 18)

7: Issues to envoy of Halab (CV 91 with duplicate 94)

18: Shoes to Ea-malik, messenger from Karkemish (CV 85)

25: Garment to Kuzzuri of Surnat, and garment to Sumu-Addu retainer of Bin-Dammu who 
went to Halu-rabi (CV 84); wine from Howurni-atal of Nawali (CV 113); wine from Kuzzuri of Surnat when he came to meet the king (CV III)

\section{VIIIb}

1: Issue to retainer of Bin-Dammu (CV 80 with duplicate 89)

3: Foodstuff when Burija and Bin-Dammu met with the king (CV 131 and 132)

4: Set of clothing to Bin-Dammu (CV 99)

6: llems to Bin-Dammu and his retainers when he met the king ( $C V$ 72); presents for the Halab court (CV 53)

7: List of wine shipments from Nawali, Kuzzuri of Surnat, Aja-abu of Šnnā (CV 117$\}$

18: ltems sent to Mehhili of Japtur (CV 79)

20: Silver to retainers of Kahat king (CV 14)

IX

(dory lost): item to Zigẽ of Amaz when he met the king (CV 95)

4: Silver to Idin-Kubi, retainer of Halu-rabi (CV 11);

10: Silver for purchase of jewely, to lși-ahu the "overseer of the merchant offices" (wakil kōri) (CV 65)

11: Silver from Abdila-ila "when with Till-Abnûl? ) he gave" (CV 55)

20 + $+x$ ': Silver to 5 named envoys when king swore(?); latest text sealed with royal seal of Mutija (CV 10)

25: Sheep brought by jaqbija "when with Till-Abnũ he gave" (CV 106)

29: Ox delivered by Zigē of Amaz "when he was made madārum" (CV 164)

$X$

(day lost): 127 sheep from Hammu-Epuh of Amaz (CV 105)

18/x-19/xi: Numerous texts altest the presence of Bin-Dammu. Most record issues of oil for the "delegates of the auxiliaries and the countrymen"

24/xi: latest text sealed by servant of Mutija

$X \|$

12: Latest text from this year (and only one from this month) (CV 76)

YEAR AMER-ISTAR

I

(days lost): earliest texts from this year (F/ 89 and 140)

II

6: Wine from Bunu-lštar of Hālabã (F| S)

9: A coal to Bin-Dammu when he went from .... to Hušlo (FI 90); o gorment to the cook 
of Bin-Dammu $\{F \mid 141\}$

13: Wine from Qarrōdu of Nadbum $(F \mid$ 6)

15: Wine from Tatturru, the general $(\mathrm{Fl} 7)$

25: Issues when Bin-Dammu stayed (FI 109)

27: Wine from the priestess Tariš-mātum of Nawali $(F \mid 8)$

28: Wine from llija of ... (FI 9); wine from priests of Adad of Nawali (FI 10)

30: Wine and honey from Zigè of Amaz (FI II)

III

1: Date on rreary between Till-Abnû and Jamși-Hahnû of Kahal $\{$ L.T.-3\}

1: Wine from Ukku of Nawali (FI 12)

11: Issues for the "meat-house" "during the elunnum-festival" (FI 127)

15: Silver ring to retainer of Qarrädu of Nadbum when he came to Takūn-mātum (FI 111)

18: Silver ring to (same) retainer when he brought ... to Takün-mătum; earliest text sealed with seal of Till-Abnû (FI 112)

20: Garment to Ahuni, envoy from Halab, when he was sent off from Zurra (FI 91)

28: Issue in Nowali (Fl 139)

29: Silver rings issued in Šnō $|F| 114\}$

IV

2: Garments and silver issued to Ea-malik, Niqmija-El, Aki-Erah, Šupir-nanu, ... of Kiran, Tahe of Kallahubri, lli-malik, Šadu-... of ..., and Hindu of Buzahi, when king met the lú Kahat (FI 115)

3: Issues of oil for sacrifice by king during hamandunu-festival, for Qutū in Tehhi, and for Tariš-mātum, the priestess, when the king went to Nawali 'Fl 128,'

6: Isolated example of text sealed with seal of Mutija "servant", note of axes received (FI 116)

7: Wine from Zazijal? ? of Tehhi $(F \mid 13)$

30: Wine for the king when envoys of Numha $\{?$ ? and Supir-nanu stayed $(\mathrm{Fl} \mathrm{14})$

$\checkmark$

11: Wine from Ali-waqrum, the merchant $(F \mid 15)$

13: Garments for Takūn-mātum, Aja-Hammu, and Tatur-mātum, the "maid" of the king (FI 94)

$20(+x)$ : Wine for the king when Kabi-Larim of Andarig and Supir-nanu of Kahat stayed (FI 16)

VI

(day lost): List of spears from Azamhul and Tille (F| 124)

VII

4: Shoes etc. for llurānu when he went to Halab (FI 96)

12: Issue in Kahat (F| 97) 
$\mid X$

28: Donations of sheep from Hilabukonum, Kallahubri, and $\check{S}_{u r i}$, when the king went to Kahat (FI 129)

$x$

6: List of garments when enemy reached gate of Subat-Enlil (FI 98)

18: Garments to Sillabi and Hubidam when they came for meeting (F| 100); garment present of Akuki the envoy, from Nihrija (FI 101)

22: Donations of animals from i.a. Samsu-malik of Azamhul (FI 131)

$X \mid$

(day lost): Silver rings to "maids" of the governor (šāpitum), latest text from this year sealed with seal of Till-Abnû (FI 121)

$X \mid I$

(no day): Latest text from this year, list of silver rings to many named individuals (FI 122)

YEAR IPIQ-IŚTAR

$\|$

16: Earliest text from this year; water bags to Jaridi-Addu envoy of Halab and Irim-munu when they went to Halab (FI 82)

III

14: Silver issued to Mašum to buy garments from habbätum (FI 105)

15: Remaining equipment from journey to Kahat added to journey to Kudimmar, and issue to envoy llurānu $(\mathrm{Fl}$ 83)

26: Wine from elders of Urkiš and Amursakkum (FI 3)

IV

(no day): Account for contributions received during journey to Nahur (in Ašnakkum and Suduhum) $(F|135\rangle$

18: Issues of oil to Ahum-marșum the habbatum and Dadu-maras, general of Andarig, in Nahur, and issues in Hešsum (FI 126)

VII

15: Only sealed text from this year: seal of Till-Abnû "servant" (Fl 106)

24: Shoes to Jaddin-Addu, envoy of Hawurni-atal of Nawali [F| B4]

VIII

3: Garments for Halu-rabi and his two companions $(\mathrm{Fl} \mathrm{85})$

8: [Wine] when habbätum stayed (FI 4) 
ix

26: Weapon to Nuhumi-Addu of Qirdahat (FI 108)

XII

23: Latest rext from this year; garments brought to the king in Zabalum (FI 88)

YEAR Nimer-Kubi

$\checkmark$

6: Wine when ... came with Abdu-|star $\{\mathrm{Fl} 20\}$

VII

2: Wine when šäpitum stayed (Fl 21)

VIII

12: Wine from Kabizza of Hurașā when šăpitum and Tišwen-atal slayed, wine when Ajaabu and others stayed (F) 24)

15: Wine in temple of Bēlet-Apim when the king [look?] Šunhum (FI 25)

20: Wine when Tišwen-atal stayed (FI 26)

23: Wine for king and envoys at night $\{F \mid 27\}$

YEAR IŚME-EL

2: Wine for offering when Abdu-... stayed $(F \mid 29)$

III

2: Wine during elunnum-festival when the king stayed in the "temple of the goddess" $|\mathrm{F}|$ 30)

26: Wine for the king, ar night $(F \mid 31)$

$\checkmark$

$4(+)$ : Wine in the hamrum morning and night when Akkujo died (FI 32)

VII

1: Wine for king when Abdi-lštar stayed (FI 33)

$1(+x)$ : Wine for envoy of Arrapha, and wine when king went to - and refurned from Zalumri (FI 42)

$2(+x)$ : Wine at night when envoys of Babylon stayed $\langle\mathrm{F} \mid 43\rangle$

3: Wine in hamrum and when envoys of Babylon stayed (FI 34)

4: Wine when šapitum and wedürum stoyed $(\mathrm{FI} 35)$ 
11-12: Wine for hamrum in the morning (F| 37-38)

28: Wine when šäpitum stayed

VIII

8: Wine for the general Tišwen-atal $\langle F \mid 45\rangle$

9: Wine when the king swore, and wine at night when the sapitum stoyed $(\mathrm{Fl} \mathrm{46)}$

21: Wine for the general Tiswwen-atal when he went to the fieldcamp of the habbätum (FI 49)

22: Wine for envoys from Babylon, for Kabi-larim and Těšena when they returned from Babylon (FI 50)

IX

20: Wine when Tišwen-atal stayed ( $F$ | 52)

21: Wine when men from Kahat stayed (FI 53)

24: Wine for habbätum (FI 54)

$x$

2(+x): Wine when envoys of Babylon stayed (Fl 61)

$5(+x)$ : Wine when envoys of Arrapha, Bizune, and Shehuwa stayed (F|79)

$X$

15: Wine when $\|$ i-Epuh came $(F \mid 64)$, wine when sons slayed, when Tišwen-atal and "maids of the king stayed, and when Hazikakku stayed $\langle\mathrm{Fl} 65\}$

17: Wine when sons stayed in the (palace?) gate $(F \mid O 9)$

20: Wine $(\mathrm{Fl} 68)$

XII

23: Latest text from this month (FI 7I)

YEAR WARKI IŚME-EL

।

2: Wine for journey to Zatumri (FI 77) 


\section{APPENDIX 2. COMPIETE CLASSIFICATION OF L.87 IETTERS}

(in parantheses YTLR publication nos.)

I. LeTERS tO MutUA

A. Sender abum

1. Hammurabi (1-4)

C. Sender ahum

1. Aštamar-Adad $(5-8)$ - 2. Halu-rabi $(9)-3$. Šepallu $(10-11)$

D. Sender marum

1. Asdi-[...] (12) - 2. Jakūn-Ašar (13) - 3. Jasmah-Addu (14) - 4. Kanisānu (15-16)

- 5. Kuzzuri(?) (17) - 6. Mašum (18) - 7. Niqmi-Adad (19)

E. Sender wardum

1. Ea-malik $\langle 20\rangle-2$. [... $-\operatorname{tim}(21)$

F. Unclassified

1. Šinurhi (22)

II. LetTers to TILL-ABNÛ

A. Sender abum

1. Hammurabi $(23-24\}$

B. Sender "neutral"

1. Attabnãja $(25)$ - 2. Bin-Dammu (26-27) - 3. Ea-malik (28-32) - 4. Janși-[...]

(33) - 5. Sumu-Hadû (34)

C. Sender ahum

1. Aplahanda $(35)-2$. Aštamar-Adad $(36-40)-3$. Burija $(41-50)-4$. Halu-rabi A. as "neutral" $(51-53)$ B. as ahum $(54-56)-5$. Hazip-[Teššup?] $\{57\}-6$. lla-Hatnû (58) - 7. Jakūn-Ašar (59-61, - 8. Jamși-Hahú (62-76) - 9. Mašum (77-81) - 10. Muti-Addu (82) - 11. Niqmi-Adad $A$. as "neutra)"(83-84) B. as ahum sihrum (8586) - 12. Šepallu (87-88) - 13. Šukrum-Teššup A. as "neutral"(89-90) B. as ahum $(91)-14 . \mathrm{Ta}-[\ldots](92)$

D. Sender marum

la. Aja-Abu (93-100) - 1b. with Šbila (101) - lc. with sibütum (102) - 2. MasumAtal (103-4)-3. Mehilum A. as rá imum (105) B. as marum (106) - 4. Zigē (107) -5 . [....] $](108-109)$. 


\section{E. Sender wardum}

1. Ewri $(110)-2$. Hawilija $(111)$ - 3. Sangara $(112)$ - 4. Sümu-ditana $(113)-5$. Takè

$(114-115)-6$. Zimri-[...] $(116)-7 .\left[\ldots \mathrm{di}_{\mathrm{d}}\right] \mathrm{m}(117)$

F. Unclassified

1. Ahušina $(118)-2$. Hawur-atal (119) - 3. Šinurhi (120)

G. Name of Sender lost',121-124\}

III. Letter to Jakūn-Ašar

B. Sender "neutral"

1. Halu-rabi $\{125\}$

N. Letters to belum

1. Ahi-maraș (126) - 2. Abbuttōnu (127) - 3. Bahdi-Lim (128) - 4. Hammi-Epuh (129-130)

- 5. lli-Epuh (131) - 6. Inganum (132-135) - 7. Jašub-[...] (136) - 8. Kuzuzzu (137-141)

-9. Qarrādu (142) - 10. Sangara (143-146) - 11. Šupram (147-148) - 12. Takē (149-151)

- 13. Tišwen-atal $(152)-14$. Warad-lštar $(153-154)-15$. Warad-[...] $(155)-16$. [.....

$(156-157)-17$. [.....] (158) - Fragments from letters to belum (159-163)

V. Miscellaneous letters

1. Aham-arši from Warad-lštar (164) - 2. Ahatani from Sîn-tukulti (165) - 3. Asstamar-Adad from Šepallu (166) - 4. Inganum from Ahi-maras (167) - 5. Tābija from Warad-lštar (168) -6. Šupram from Inganum (169) from Samum (170) - 7. Takē from Ewri (171) - 8. WaradIštor from $[\ldots$.$] -zali (172)$ from Jakūn-c[r-..] (173) from [...] (174)

VI. Letters where name of addresssee lost

C. Sender ahum

1. Šepallu $(175-176)-2$. Šinurhi $(177)$

F. Unclassified

1. Kanisōnu (178)

VII. Letters/frogments where both names in address lost

Tablets/fragments with substantial information preserved (179-187)

Tablets/fragments with little information preserved (188-219) 
$A b B$

ARM $(T)$

CAD

CV

DEPM

FI

YTLR

Allbabylonische Briefe in Umschriff und Übersetzung, Leiden 1964 -

Archives Royales de Mari (Textes). Paris 1950-

The Assyrian Dictionary of the University of Chicago, Chicago/Glückstadt 1956 -

C. Vincente, The 1987 Tell Leilan Tablets Daled by the Limmu of Habil-kinu. Unpubl. Ph. D. Diss., Yale University 1991.

J.-M. Durand, Documents épistolaires du palais de Mari I-III. Paris: Les èditions du cerf 1997-2000.

F. Ismail, Altbabylonische Wirtschatisurkunden aus Tall Leilän (Syrien), Unpubl. Ph. D. Diss., Eberhard-Karls-Universität, Tübin+gen 1991.

J. Eidem, The Royal Archives from Tell Leilan. Old Babylonian Letters and Treaties from the Lower Town palace. YTLR, Yale University Press.

AKKERMANS, P. AND G. SCHWARTZ

2003 The Archaeology of Syria. Cambridge Universily Press.

AKKermans, P. AND H. WeISS

1991 "Tell Leilan 1987: Operation 3 .A Preliminary Report on the Lower Town Palace", AAAS $37 / 38$ (1987/88), 91-109.

BucCELLAT, G. AND M. Kelly-BUCCELLAT

1996 "The Seals of the King of Urkesh. Evidence from the Western Wing of the Royal Storehouse AK", WZKM 86, 65-98.

CASTEL, C.

1990 "Découverte d'un sceau cylindre poló-assyrien: Mohammed Diyab, une étape pour les marchands assyriens en route vers la Cappodoce", in Tell Mohammed Diyab, Campagnes 1987 ef 1988. Cahiers de NABU I. Paris, 51-58.

CHARPIN, D.

1983 "Temples à découvrir en Syrie du Nord d'après des documents inedits de Mari", Iraq 45, 56-63.

1985 "Les Archives d'époque "Assyriennes" dans le Palais de Mari", MAR/4, 243-268.

1987o "Šubat-Enlil et le poys d'Apum", MAR/ 5, 129-140.

$1987 b$ "L'Épée offerte au dieu Nergal de Hubšalum", NABU 87/76.

1988 "Tell Leilan et la fin du kārum lb de Kültepè", NABU88/20.

1990a "A Contribution to the Geography and History of the Kingdom of Kahat", in S. Eichler, M. Wäler, and D. Warburton (Eds), 1990, 67-85.

$1990 \mathrm{~b}$ "Conclusions ef Perspectives Tell Mohammed Diyab, une ville du pays d'Apum", in Tell Mohammed Diyab, Campagnes 1987 et 1988. Cahiers de NABU1. Paris, 117-122.

$1990 \mathrm{c}$ "Une alliance contre l'Elam et le Rituel du lipit napištim"، in F. Vallat (Ed.), Contribution à I'Histoire de I'ran (Mélanges Perrat). Paris: ERC, 109-18.

$1990 d$ "Notices prosopographiques 3. Les "prévöts des marchands" de Sippar-Amnōnum", NABU $90 / 9$.

1998 "Toponymie amorrite et toponymie biblique: la ville de Sibat et Șobāh", RA 92, 1998, 79-92.

2004 "Histoire Politique du Proche-Orient Amorrite (2002-1595)", OBO160/4, 25-480. 
Charpin, D. AND J.-M. Durand

2004 "Prélendants au thrône dans le Proche-Orient Amorrite", in J. G. Dercksen (Ed.), Assyria and Beyond. Studies presented ro Mogens Trolle Larsen. NINO, 99-115.

Charpin, D. AND N. Ziegler

2003 Mari et le Proche-Orient a l'époque amorrite. Essai d'histoire politique. Florilegium marianum $\checkmark$ (Mémoires de N.A.B.U. 6.) Paris.

COHEN, $M$.

1993 The Culfic Colendars of the Ancisnt Near East. Maryland: CDL Press.

DERCKSEN, J. G. AND V. DONBAZ

2001 "Merchants in Dislress. An Old Assyrion Texł mentioning habbätum", JEOl 35-36 (19972000), $103-110$.

DIETRICH, M. AND O. LORETZ

1969 "Siegel des Tahe-Addu (ca. 1750 v. Chr.)", UFI, 213-15.

DURAND, J.-M.

1987a "Tell Qal'at al-Hādí", NABU87/37.

$1987 b$ "le dieu Abnu à Mari", NABU $87 / 78$.

1990 "Mille et une capilales à redécouvrir", Les Dossiers d'Archéologie 155, 4-13.

1991 "L'emploi des toponymes dans l'onomastique de l'époque Amorrite (1)", SEl 8, 81-97.

Durand, J.-M. and M. Guichard

1997 "Les Rituels de Mari", in D. Charpin and J.-M. Durand (Eds). Florilegium marianum III. Recueil d'éludes à lo mémoire de M. -T. Barrelet. Mémoires de NABU 4. Paris, 19-78.

Eichler, S., M. Wäfler, and D. Warburton (Eds)

1990 Tall al-Hamidiya 2. Freiburg/Göttingen.

EIDEM, J.

1988 "Tell Qal'al al-Hâdi again", NABU88/9.

1990 "Les Archives poléo-babyloniennes de Tell Leilan", Les Dassiers d'Archeólogie 155, 50-53.

1991a "Tell keilan Tablets 1987. A Preliminory Report", AAAS 37/38 (1987/88), 110-127.

199ib "An Old Assyrion Treaty from Tell Leilon", in D. Charpin and F. Joannes (Eds), Marchands, Diplomates el Empereurs. Eludes sur la civilazation mesopotamienne offertes a Poul Garelli. Paris: ERC. . 185-207.

1991c "The Tell Leilan Archives 1987", RA 85, 109-135.

1991d "Jakūn-Ašar?? at Tell Brak", NABU91/108.

1992 The Shemshāra Archives 2. The Administralive Texts. Kgl. Dan. Vid. Selsk, Hisl. Fil. Skr. 15, Copenhagen.

1994 "Raiders of the Lost Treasure of Shamshi-Adad", in D. Charpin and J.-M. Durand (Eds), Florilegium marionum II. Receuil d'études a la mémoire de Maurice Birot. Mèmoires de NABU 3. Paris, 201-208.

1990a "Some Upper Mesopotamian Toponyms", and "Hitl-panom", NABU1990, 5-6.

$1996 b$ "North Syrian Social Structure in the MB Period. New Evidence from Tell Leilan", in F. Ismail (Ed.), Proceedings of the Invernational Symposium an Syrio and the Ancient Near East 3000 300 B.C., University of Aleppo Publications, 77-85.

1999 Review of J.-M. Durand, Documents Épistolaires du Balais de Mari Tome 1. Litteratures anciennes du Proche-Orient 10. Les Éditions du Cerf, Paris 1997. Syria 70, 290-297. 
2000 "Northern Jezira in the 18th Century BC. Aspects of Geo-political Patterns", in O. Rouault and M. Wäfler \{Eds\}, La Diezziré et L'Euphrate Syriens. Subartu VII. Brepols, 255-264.

2002 "The Clay they wrote on: Old Babylonian letters as anelacts", in L. Al-Gailani Werr et al. (Eds), Of Pots and Plans: Papers on the Archaeology and History of Mesopotamia and Syria presented to David Oates in Honour of his 75th Bitthday. London: NABU Publ., 74-81.

EIDEM, J, I. FINKEL, AND M. BONECHI

2001 "The Third-millennium Inscriptions", in D. Oales, J. Oales and H. McDonald, Excovations at Tell Brak 1l: Nagar in the third millennium BC. British School of Archaeology in Iraq, 99-120.

EIDEM, J. AND J. LESSEE

2001 The Shemshäro Archives /. The letters. Kgl. Dan. Vid. Selsk, Hist.-Fil. Skr. 23, Copenhagen. FIENWING, D.

2004 Democracy's ancient ancestors: Mari and earty collective governance. Cambridge Universily Press. GUICHARD, M.

1994 "Au pays de la Dame de Nagar", in Charpin and Durand \{Eds\}. Florilegium marianum II. Receuil d'études à la mémoire de Maurice Birot. Mémoires de NABU3. Paris, 235-272.

1997 "Zimri-Lim à Nagar", MAR/8, 329-337.

2005 "Remarques sur ARM XXVIII 62 el la prise d'une place-forte", NABU 05/99.

GÜNBATI, C.

2004 "Two Trealy Texts Found at Kültepe", in J. G. Dercksen (Ed.), Assyria and Beyond. Siudies presented to Mogens Trolle larsen. NINO, 249-268.

HaLO, W. W.

1964 "The Road to Emar", JCS 18, 57-88.

HORSNEL, M. J. A.

1999 The Year-Names of the First Dynasty of Babylon. McMaster University Press.

ISMAl, F.

1991 Altbabylonische Witschaftsurkunden ous Tall Leilän (Syrien), Unpubl. Ph. D. Diss., EberhardKarls-Universitäl, Tübingen.

JOANNES, F.

1988 "La ville de Hablblanum", NABU 88/19.

1990 "Une expédition dans la région de Shoubat-Enlil", les Dossiers de l'Archéologie 155, 42-49.

1991 "Le traité de vassolité d'Atomrum d'Andarig", in D. Charpin and F, Joannes (Eds), Marchands, Diplomates et Empereurs. Ehudes sur la civilazation mésopolamienne offertes a Paul Garelli. Paris: ERC, 167-177.

KIENGE, $\mathrm{H}$.

1992 Syria 3000-300 BC. Berlin: Akademie Verlag.

KRAUS, F. R.

1975 "Akkadische Wönter und Ausdrücke, IX", RA 69, 31-40.

KUPPER, J. R.

1992 "Karkémish aux llième et llème millénaires avant notre ère", Akkadica 79/80, 16-23. LACAMBRE, D.

2002 "Niggalum, lecture akkadienne du mois ŠE.KIN.KU5 dans le calendrier dit "de Samsi-Addu", in D. Charpin and J.-M. Durand (Eds). Florilegium marianum VI. Recueil d'éhudes a la mémoire d'Andre Parrot. Paris: SEPOA, 505-511. 
LAFONT, B.

2001 "Relations internationales, alliances et diplomatie au temps des royaumes amortites", in J.- $M$. Durand and D. Charpin (Eds), Amurru 2. Paris: ERC, 213-328.

Macmahon, A., C. Colantoni, and M. Stemple

2005 "British Excovations al Chagar Bazar 2001-2", Iraq 67. 1-16.

MATHEWS, D. AND J. EIDEM

1993 "Tell Brak and Nagar" Iraq 55, 201-207.

MEIJER, D. J.W.

1986 A Survey in Northeostern Syria. Istanbul.

MICHEL, $C$.

1996 "Le Commerce dans les textes de Mari", in J.-M. Durand (Ed.), Amum /, Paris: ERC, 385-426.

MIEROOP, M. VAN DEN

1994 "The Tell Leilan Tablets 1991. A Preliminary Report", Or 63, 305-344.

MONTE, G. F. del AND J. TiSCHLER

1978 Die Onts- und Gewässernamen der hethilischen Texte. Beihefte zum Tübinger Arlas des vorderen Orients, B $7 / 6$. Wiesbaden.

NASHEF, KH.

1987 Rekonstruktion der Reiserouten zur Zeit der altassyrischen Handelsniedertassungen. Beihefte zum Tübinger Atlos des vorderen Orients, B 83. Wiesbaden.

Nicolle, $C$.

2005 "L'identification des vestiges archéologiques de l'aniconisme a l'époque amorrite", in J.-M. Durand, Florilegium Marionum VIII, 177-189.

NIGRO, L.

1997-1999 "Yamkhad/Aleppo: Investigating the Second Millennium B.C. Copital of Northern Syria through Islamic, Byzantine and Classical Towns", in M. Calia ef al. (Eds), Trails to the East: Essoys in Memory of Paolo Cuneo, vol. 1/2.

OHNOMU, K. ano H. Numoto

2001 "Excavations of Tell Taban, Hassake, Syria (3): Report of the 1999 seoson of Work", al-Röfidãn 22, 1-64.

Parayre, D. ano H. Weiss

1991 "Cinq Campagnes de fouilles à Tell Leilan dans la Haute-Jezireh (1979-1987): bilan et perspectives, Journal des Savants, 3-26.

RISTEt, L. AND H. WeISS

2005 "The Hābur Region in the Late Third and Early Second Millennium B.C.", in W. Onthmann SASSON, J. M.

(Ed.). The History and Archaeology of Syrio, Vol. I. Saarbrücken.

1997 "The Vow of Mutiya, King of Shehna", in G. Young et al. (Eds), Crassing Boundaries and linking Harizons (Fs. Astour). Maryland: CDL Press, 475-490.

2001 "On reading the Diplomatic Letters in the Mari Archives", in J.-M. Durand and D. Charpin (Eds), Amurru 2. Paris: ERC, 329-338.

SCHWEMER, D.

2001 Die Weltergottgestalten Mesopotamiens und Nordsyriens im Zeitalter der Keilschriltkulturen. Wiesbaden: Harrossowitz Verlag. 
TALON, P.

1997 Old Babytonian Texis from Chagar Bazar. Akkodico Suppl. X. Brussels.

TUNCA, Ö. AND D. LACAMBRE

2002 "Notes préliminaire sur les nouvelles decouvertes épigraphiques de Chagar Bazar", in D. Charpin and J.-M. Durand (Eds), Florilegium marionum VI. Recueil d'études à la mémoire d'André Parrol. Paris: SEPOA, 545-546.

VAN KOPPEN, F.

2001 "The Organisation of institutional Agriculiure in Mari", JESHO 44/4, 451-504.

VEENHOF, K. R.

1989 "The Date of the Eponymy of Habil-kēnu", JEO/ 30, 30-37.

1998 "The Chronology of kãrum Kaniš. Some New Observations", in XXXIV. Uluslararasi Assiriyoloji Kongresi, 1987-Islanbul. Ankara, 421-450.

2003 The Old Assyrian List of Year Eponyms from kärum Kanish and its Chronological Implications. Publications of the Turkish Historical Society, Ser. VI/04. Ankara.

VINCENTE, C.

1991 The 1987 Tell Leilan Tablets Dated by the Limmu of Habil-kinu. Unpubl. Ph. D. Diss., Yale University.

1995 "The Tall Leilon Recension of the Sumerian King List", $Z A$ 85, 234-270.

H. WAETzOLT

2003 "Zahlung von lösegeld in Šehnā", in G. Selz (Ed.), Festschrift fü B. Kienast، AOAT274, 707-716. WeISS, $\mathrm{H}$.

1985 "Tell Leilan and Šubat-Enlil", MARI 4, 269-292.

1991 "Tell Leilan (Syria)", Orientexpress 1991/2, 3-5.

WeISS, H. ET AL.

1990 "1985 Excavations at Tell Leilon, Syria", AJA 94, 529-581.

WHITNG, R. M.

1990a "Tell Leilan/Subat-Enlil Chronological Problems and Perspectives", in Eichler, Wäfler, and Warburton \{Eds\}, 1990, 167-218.

$1990 \mathrm{~b}$ "The Tell Leilan Tablets A Preliminary Report", in Weiss el al. 1990, 568-579.

WISEMAN, D.

1953 The Alalakh Tablets. Occasional Publications of the British Institute of Archaeology at Ankara No. 2, London.

WäFLER, $M$.

1995 "Kahat, Tâdum und llanșurā", NABU1995/31.

2001 Tall al-Hamidiya III. Zur hislorischen Geographie von Idamaras zur Zeil der Archive von Mari/2) und Subat-Enlil/Sehnō. OBO 21. Freiburg/Göttingen. 
TEIL 3

INDICES 
Indices

The Indices cover both parts of the book.

Nole to the indices according to "Teil 2"

The indices are selective. They provide references only to YTLR letters and treaties extensively quoted or discussed, and for PNs, GNs, and DNs only references to places with (main) discussion of these. Thus names mentioned in quoted texts are generally not referred to. Cf., however, also the lists in Appendices 1-2. 
1. SUBJECTS donkeys

(see also the assyrian words, below under 7)

\begin{tabular}{|c|c|}
\hline agriculture & $\begin{array}{lllll}147 & & & & \\
20 f f & 96 & 98 & 1266 & \end{array}$ \\
\hline Akkodians & $\begin{array}{l}2 \text { off., } 96,98,126 f . n . \\
582\end{array}$ \\
\hline Amorites & $\begin{array}{l}19 \text { ก. } 2,22,63 \text { п. } 258, \\
89,971 ., 134,214\end{array}$ \\
\hline Anatolians & 93 \\
\hline $\begin{array}{l}\text { Anatolian law } \\
\text { nomes }\end{array}$ & $\begin{array}{l}96 \\
101 f\end{array}$ \\
\hline rulers & $\begin{array}{l}\text { 10lf., 136-140, 160-164, } \\
183-187\end{array}$ \\
\hline antimony & $85 f$. \\
\hline appeal & $181 \mathrm{n.} 784$ \\
\hline archives & $\begin{array}{l}43-51,44 \text { n. } 139,46 \text { n. } \\
154.157-160,68 f f ., 129, \\
133,135 f ., 147 \text { n. } 681 \text {, } \\
148 \text { n. } 683,151,181,185, \\
189 \text { n. } 810,205,229, \\
245,\end{array}$ \\
\hline "big men" & 43 \\
\hline $\begin{array}{l}\text { blood money } \\
\text { bloodshed } \\
\text { bronze }\end{array}$ & $\begin{array}{l}101 \text { n. 439, 16l, 207, } 210 \\
101,186,192 . c, 194 f ., 211 \\
85 f .86 \text { n. 361 }\end{array}$ \\
\hline bullae & $\begin{array}{l}33,55,15,114,116,140, \\
167\end{array}$ \\
\hline burial & 108 \\
\hline calendar & 21 n. 13,30 n. 63 \\
\hline carovans & $\begin{array}{l}32,33,50,60,74,77 f ., \\
97 f ., 148 f ., 185 f f . ~ n .796, \\
193 f ., 205 f f ., 212,214, \\
216,225 t .\end{array}$ \\
\hline $\begin{array}{l}\text { children } \\
\text { chronology }\end{array}$ & $\begin{array}{l}106 \\
28-34\end{array}$ \\
\hline city assembly & 21, see olum \\
\hline ciry hall & $\begin{array}{l}21,23 \text { n. } 24,36,40 \mathrm{n} . \\
114,57 \mathrm{n} .219,88,373, \\
111 \text { n. } 490,129,133,140, \\
213 \text { see bêt älim }\end{array}$ \\
\hline copper & $\begin{array}{l}85 f f ., 126,151 f . \text { п. 696- } \\
703,185\end{array}$ \\
\hline coppersmith & 152 ก. 705 \\
\hline credit & 92 \\
\hline "dōtu-poyers" & $\begin{array}{l}47,76,78 f \text {. п. } 332,134, \\
180,188\end{array}$ \\
\hline debls & $\begin{array}{l}54,73,93,96,105 \mathrm{ff}, \\
126 \mathrm{f.}, 192 \mathrm{f} ., 199,204, \\
217,219\end{array}$ \\
\hline dendrochr & 30 n. 64 \\
\hline "Distanzangaben" & $30 \cap .65$ \\
\hline
\end{tabular}

$53,78,794 ., 82,87,90$, $105,108,132,149,151 \mathrm{k}$, $156 f f, 178,184 f ., 187$. 195, 200, 204f., 207, $209,212,214$

eating and drinking 148 n.686

"Envoys of the city" 43,78 n. 333, 141, 180, $182,202,205,209$

eponym list

eponym(ie)s

2 If., 28 n. 54 f., 33

2 Iff $27 f$., 32 n. $72,33 \mathrm{n}$. 75,37 ก. 97, 120, 131, 133 n. 603 ., 135 ก. 617 , 137,139 ก. 640, 145 ก. 677,172

fields $\quad 147 f ., 147$ n. 680,148 n. 687

figurines of gods $56 f, 103,108$,

fugitives 193.i, 204, 217

fuller

garning board

gate of kārum

gates of Assur

girls

gods

$220,230 f ., 231$ n. 935

57

103

103,116

107

82,103 . $125,148,184$ n. $793,186,1894 ., 193$, 230 f., $236 \mathrm{ff}$.

gold 51, 53F., 56, 58, 86f., 9lf., $96,98,103 \mathrm{~F} .108,116$. 122, 128f., 133, 135, 147. $149,151,153,160,181$, $188,198 f ., 205,209,214$, $216,223,228,236 f$., 239

grain 87 .

grarnmar $\quad 112$

groves $\quad 40,56$

"great king" 123, 140, 144f., 171, 178, 189,217

hapirum $\quad 23,118,192,193$ n. 818

Hattions $\quad 120$

Hititites $\quad 120$

homicide 210f.

houses 93,107

Hurrians 23 n. 20. 23, 59, 97, 12 Off. ก. 546

72 n. 306

106

84 f., 101, 136, 147, 150 .

$161,177,180,184,188$, 190 off., 213, 226, 228, 232

irrigation

jewely

96 ก. 417

93, 108

"joint-stock company" 51, 89, 91f. п. 385, 131, 188 , see noruqqum 


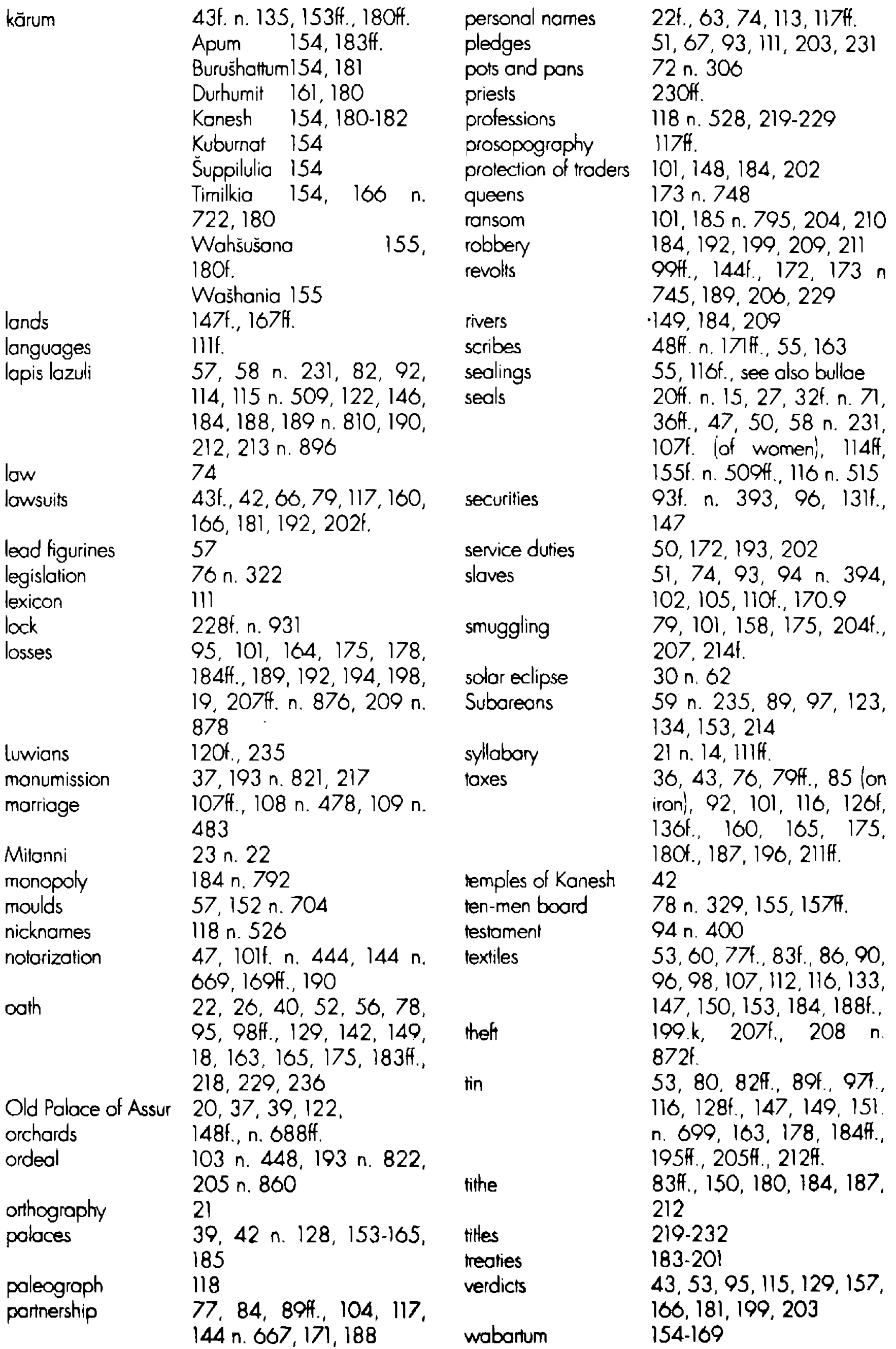




\begin{tabular}{|c|c|}
\hline Eluhut & 154 \\
\hline Kuburnat & 154,160 \\
\hline Kuššara & 164,175 \\
\hline Mamma & 189 n. 810 \\
\hline Somuha & 154,166 \\
\hline S̄uppilulia & 154,166 \\
\hline Ullamo & 155,166 n. 724 \\
\hline Upê & 155 \\
\hline Wašhania & 155,166 \\
\hline wagons & 152 ก. 706 \\
\hline wall of Assur & 124 \\
\hline wall of kānum & 56 \\
\hline war & $\begin{array}{l}33,60,62 f_{1}, 143,189 \\
193 \mathrm{f} ., 197,205 \mathrm{ff}, 216,\end{array}$ \\
\hline week eponyms & $68 n .280$ \\
\hline weights & $\begin{array}{l}44,57 f . \text { п. 224-228, 61, } \\
82,84,86 f, 162.30\end{array}$ \\
\hline wives & 107ff. \\
\hline women & $93,107-110$, their seals \\
\hline wool & 87,148 n. $682 f$. \\
\hline
\end{tabular}

\begin{tabular}{|c|c|}
\hline & 12 16 lant 162 \\
\hline "Anittideyt" & \\
\hline "Anilta Text" & $33,136,143 t, 16 /, 235$ \\
\hline Assyrian Kinglist & $\begin{array}{l}19 \text { n. } 2,24 \text { n. } 27-29,26 \text { n. } \\
44,29-35,28 \text { n. } 55,61 \text {. } \\
65 f ., 36\end{array}$ \\
\hline "caravan accounts" & 74 \\
\hline coniracts & 51 \\
\hline of service & 90,94 ก. 392, 126 \\
\hline of brotherhood & 51,90 \\
\hline of divorce & 108 \\
\hline of inheritance & 94 ก. 396 \\
\hline of marriage & 94 ก. 35, 107ff. \\
\hline of naruqqum & $\begin{array}{l}88 f f ., 88 \text { n. } 372,92 \text { n. } \\
385\end{array}$ \\
\hline of sale & $90 f ., 94$ ก. 394 \\
\hline of separation & 51,90 \\
\hline copies of Iablets & 67 \\
\hline debt-notes & $\begin{array}{l}42,51,54,71,74,87,91, \\
131\end{array}$ \\
\hline depositions & 52 \\
\hline exercise rablets & 44 \\
\hline from Amkuwa & $32,49,75$ \\
\hline city-mound Kanesh & $41,42 n \cdot 126-132$ \\
\hline Hattuša & $32,49,75$ \\
\hline kārum level lb & $\begin{array}{llll}46 f f . & 46 & \text { n. } & 158-168 . \\
162 f . & \end{array}$ \\
\hline small collections & 45,66 п. 271 \\
\hline incantalions & 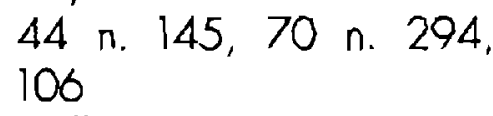 \\
\hline inscribed bullae & $55 f f$. \\
\hline "ifineraries" & 74,80 \\
\hline judicial records & $52 f$ \\
\hline eponym lists & $\begin{array}{l}28-33,28 \text { ก. } 54-57,43 f f . \\
63,68,73,118\end{array}$ \\
\hline letters & 50,72 n. 305, 74f. \\
\hline of kārum & $\begin{array}{l}50 f, 43 \text { п. } 135,72 \text { n. } 305 \\
75 \text { п. } 319\end{array}$ \\
\hline of woklum & $72 n .305$ \\
\hline memorandums & 53 \\
\hline non-privale document: & is 44 f. \\
\hline "notifying messages" & 74,88 \\
\hline "private records" & 74 \\
\hline privale summonses & 75 \\
\hline quiltances & 51 \\
\hline royal inscriptions, & next $\S$ under RIMA 1 \\
\hline $\begin{array}{l}\text { sale documents } \\
\text { of houses }\end{array}$ & $\begin{array}{l}74,91 \mathrm{f} \\
74\end{array}$ \\
\hline of slaves & 74 \\
\hline of fields & 96 n. 414 \\
\hline
\end{tabular}


Indices

"Sargon Tale"

44 n. 146, 174 n. 753

Slatutes kārum Kanesh 44, 181

$\begin{array}{ll}\text { testament } & 105 \\ \text { testimonies } & 52 \\ \text { "tronsport records" } & 53 \mathrm{t}, 74 \mathrm{n} .316,80 \mathrm{ff} . \\ \text { treaties } & 183-201 \\ \text { verdicts } & 52 \mathrm{t} .\end{array}$

2.2. After text editions and collections

\begin{tabular}{|c|c|c|}
\hline AAAl & 1 & 240 \\
\hline & 6 & 209 \\
\hline & 10 & 22 n. 17 \\
\hline AKT & 1 & $72,114,160,162,239$. \\
\hline & $1,1-18$ & $\infty$ \\
\hline & $1,1-33$ & 70 \\
\hline & $1,19-29$ & 65 n. 265 \\
\hline & 1,39 & 240.9 \\
\hline & 1,45 & 240.2 \\
\hline & 1,60 & 236 \\
\hline & 1,77 & $160.18,175$ n. 757,178 \\
\hline & 1,78 & $100,162.35$ \\
\hline & 1,79 & $42 \mathrm{n} .130$ \\
\hline & 1,81 & 42 n. 130 \\
\hline & $1,79-82$ & 69 n. 283 \\
\hline & 2 & $70,71,72,114,156,162.27$ \\
\hline & 2,19 & 97 ก. $422,154.2$ \\
\hline & 2,24 & 168 ก. 728 \\
\hline & 2,34 & 195 n. 827,227 \\
\hline & 2,35 & 198 n. 841 \\
\hline & 2,53 & 217 n. 911 \\
\hline & 3 & $69,114,133$ \\
\hline & 3,30 & 224 \\
\hline & 3,41 & 221 \\
\hline & 3,47 & 195 n. 827 \\
\hline & 3,48 & 162.32 \\
\hline & 3,49 & 82 \\
\hline & $3,55-57$ & 162.32 \\
\hline & 3,73 & $82 \mathrm{~F}$. \\
\hline & 3,74 & 82 \\
\hline & 3,70 & 156.5 \\
\hline AnOt 6 & 12 & 180 \\
\hline & 15 & 78 n.329, 159.18 \\
\hline & 18 & 173 ก. 746 \\
\hline ATHE & & $45 \mathrm{n} .151,62,114$ \\
\hline & 2 & $231,237.6,242.16$ \\
\hline & 12 & 223 \\
\hline & 32 & 9 n. 233,152 n. 703 \\
\hline & 46 & 156 п.71 \\
\hline & 47 & $192 . f$ \\
\hline & 62 & $\begin{array}{l}158.12,160.21,173 \text { n. } 748, \\
175,191 \text { n. } 816,204,215\end{array}$ \\
\hline & 63 & $\begin{array}{l}137 \text { n. } 628,153 \text { n. } 707 \\
158.12\end{array}$ \\
\hline & 64 & 191 n. 816 \\
\hline & 66 & $158.12,224$ n. 919 \\
\hline & 67 & 221 \\
\hline & 75 & $239.2,242.2$ \\
\hline PIN & 2 & 139 n. 638, 223 \\
\hline & 7 & 152 \\
\hline
\end{tabular}


2. Texts; 2.2. Text Editions

\begin{tabular}{|c|c|c|c|c|}
\hline & 39 & 147 ก. 679 & 180 & 153 \\
\hline & 44 & 239 n. 949 & $19 c$ & $159.16,169 n .735,208$ \\
\hline & 45 & 176 n. $764,213,226 f$ & 24a & 57 ก. 219 \\
\hline & 48 & 200 ก. 851,214 & $27 a$ & 165 ก. 717 \\
\hline & 63 & 226 & 296 & 224 \\
\hline & 73 & 139 n. 038 & 300 & 78 п. $329,100,157.8,168$ \\
\hline & 93 & 224 & & ก. 730,195 n. 824 \\
\hline & 157 & 226 & $42 a$ & 100,173 \\
\hline & 160 & $22 \mathrm{lf}$. & $44 b$ & 232 \\
\hline & 163 & 221 & CCT 5 & 62 \\
\hline & 181 & 87 n. 365 & $3 a$ & 117 ก. 522 \\
\hline & 199 & 151 ก.701 & ob & 225 \\
\hline BIN 6 & 7 & 58 n. 231 & $9 a$ & 115 \\
\hline & 23 & 150 n. 695,227 & $9 b$ & 58 ก. 231 \\
\hline & 6 & 220 & 100 & 132 \\
\hline & $\infty$ & 103 ก. 451 & 12 & 154 \\
\hline & 179 & 57 ก. 219 & 150 & 92 ก. 388 \\
\hline & 180 & 207 n. 87 & $15 b$ & 206 \\
\hline & 188 & 66 n. 272 & 180 & 162.31 \\
\hline & 193 & 59 ก. $233,219,223 \mathrm{~F}$. & 260 & 222 \\
\hline & 205 & 58 ก. 228 & $28 b$ & $162.34,225$ \\
\hline & 212 & 207 n. 87 & $30 a$ & 161.27 \\
\hline & 219 & 180 n. 783 & $34 b$ & 219 \\
\hline & 226 & 193 n. 818,222 & $35 c$ & $162.34,225$ \\
\hline & 235 & 222 & CCT 6 & 65,114 \\
\hline & 258 & 219 ก. 915 & 120 & 162.29 \\
\hline Brussels & 1 & 323 & 14 & 83 n 348, 162.33, 164.38 \\
\hline & 5 & 169 n. 738, 171, 222 & $15 b$ & 78 n. 329,195 n. 824 \\
\hline & 26 & $60 n \cdot 2 \pi$ & 16 & 132 \\
\hline & 34 & $\infty 6 n .27$ & $20 \mathrm{~b}$ & 104 \\
\hline CCT 2 & 2 & 246 (pholo) & $22 a$ & 80 n. 337,156 n. 711 \\
\hline CCT 2 & 3 & 97 n. 426 & $22 c$ & 200 n. 851 \\
\hline & $4 a$ & 120 ก. 541 & $23 c$ & 51 n. $187,112,132$ \\
\hline & $5 a$ & 97 ก. 426 & $27 b$ & 54 n. 206,104 n. 462 \\
\hline & 0 & 66 ก. 274 & 340 & $86,160.19,219$ ก. 914,220 , \\
\hline & 11 & 207 ก. 87 & & 231 \\
\hline & 13 & 151 n. $698+701$ & $38 b$ & 216 ก. 908 \\
\hline & 15 & 226 & $46 b$ & 118 ก. $530,162.34$ \\
\hline & 18 & 221 & $47 a$ & 236.5 \\
\hline & 25 & 48 ก. 173 & 52 & 132 \\
\hline & 30 & $223,225 \mathrm{~F}$ & Chantre 11 & $155.37,215$ n. 905 \\
\hline & 360 & 192 & 16 & 42 n. 131 \\
\hline & 37 & 228 & CIMMA 1,72 & 215 \\
\hline & 48 & $159.16,174$ n. 749 & "De Munck" & 221 \\
\hline & $49 a$ & 97 ก. 426 & EL & $62,73,95,119$ n. 537 \\
\hline $\operatorname{CCT} 3$ & $7 a$ & 240.6 & 1 & 60 ก. $2 \pi$ \\
\hline & $27 b$ & 110 n. 487 & 2 & 109 ก. 483 \\
\hline & 280 & 100,173 & 6 & $106 \cap .474$ \\
\hline & $28 b$ & 221 & 8 & 106 ก. 469 \\
\hline & 330 & 207 n. 871 & 11 & 60 ก. 271, 110 \\
\hline & 360 & 78 п. 329, 155.4, 156 ก. 71 , & 14 & 226 ก. 924 \\
\hline & & 160.23 & 17 & $42 \mathrm{n.} 131$ \\
\hline CCT 4 & be & 106 & 36 & 60 n. 27 \\
\hline
\end{tabular}


Indices

\begin{tabular}{|c|c|}
\hline 97 & 51 n. 187 \\
\hline $110-137$ & 74 ก. 316 \\
\hline $138-144$ & 74 n. 316 \\
\hline 150 & 150 ก. 695 \\
\hline 157 & 42 n. 131 \\
\hline 167-169 & 92 ก. 388 \\
\hline 173 & 92 n. 388 \\
\hline 188 & 110 n. 486 \\
\hline 228 & 57 n. 225 \\
\hline 244 & 40 n. 119,52 п. 192 \\
\hline 246 & $66 \mathrm{n} .27$ \\
\hline 253 & 180 n. 783 \\
\hline $260-261$ & 92 п. 388 \\
\hline 263 & $66 \mathrm{n} .27$ \\
\hline 269.270 & 92 n. 388 \\
\hline 273 & 170 ก. 739 \\
\hline 276 & 106 n. 474 \\
\hline 278 & $60 \mathrm{n} .27$ \\
\hline 287 & 191 n. 817 \\
\hline 303 & 66 n. 27 \\
\hline $303 B$ & $66 \mathrm{n} \cdot 27$ \\
\hline 320 & 181 ก. 784 \\
\hline 325 & $66 n .27$ \\
\hline $325 a$ & 180 n. 783 \\
\hline 338 & 181 n. 784 \\
\hline
\end{tabular}

\begin{tabular}{|c|c|c|}
\hline & & \multirow[b]{2}{*}{242.15} \\
\hline & 50 & \\
\hline & 52 & 241.9 \\
\hline & 132 & 237.6 \\
\hline & 139 & $\begin{array}{l}47 \mathrm{n.} 163,163.35,166 \mathrm{n} . \\
723\end{array}$ \\
\hline & 156 & 164.38 \\
\hline & 293 & $162.31,167 n .724$ \\
\hline & 301 & 47 n. 163 \\
\hline & 345 & 63 п. 259 \\
\hline Koyseri & 1830 & $159.16,175,182,210$ \\
\hline & 5064 & 159.18 \\
\hline KBo 9 & 4 & $33 n .75$ \\
\hline & 5 & 217 \\
\hline & 0 & $166 n .724$ \\
\hline & 7 & 196 \\
\hline & 10 & 118 п. 528 \\
\hline & 28 & $\begin{array}{l}49 \text { n. } 177,138 \text { n. 632, 157.8, } \\
196 \text { п. } 828\end{array}$ \\
\hline & 36 & $49 \mathrm{n} .177$ \\
\hline $\mathrm{KBO} 28$ & 181 & 79 ก. 334.138 ก. 632 \\
\hline $\mathrm{KB} \circ 36$ & 113 & 49 ก. 175,137 ก. 625 \\
\hline KKS & & 114 \\
\hline & 2 & 157.8 \\
\hline & 6 & 236.1 \\
\hline & 7 & 77 \\
\hline & 15 & 109 \\
\hline & 21 & $223,225,232$ \\
\hline & 31 & 239.1 \\
\hline & 45 & 221 \\
\hline & 57 & $170.23,224$ \\
\hline & seal 130 & 109 \\
\hline KTB & 14 & $139 n .640$ \\
\hline KTH & 3 & 168 ก. 728 \\
\hline & 16 & $210 \cap .884$ \\
\hline KTK & & 65 \\
\hline & 2 & 160.20 \\
\hline & 5 & $163.35,182$ \\
\hline & 6 & 181,227 \\
\hline & 7 & $172 n .741,231$ \\
\hline & 10 & 99,145 n. $070,157.10$ \\
\hline & 20 & $170 n .739,227$ \\
\hline & 33 & 50 n. 181 \\
\hline & $\$ 4$ & 154.20 \\
\hline & 106 & $223,227 n .928$ \\
\hline & 107 & $138 n .634,155.30,162.30$ \\
\hline KTP & 4 & 154 \\
\hline & 0 & 140 ก. 776,142 \\
\hline & 10 & $155.34,173,181,205$ \\
\hline & 14 & $\begin{array}{l}155.36,163.36,165,1801 . \\
189\end{array}$ \\
\hline & 43 & 170.9 \\
\hline KTS I & $\begin{array}{l}3 b \\
8 a\end{array}$ & $\begin{array}{l}152 \text { n. } 706,161.26 \\
158 \text { n. } 72\end{array}$ \\
\hline
\end{tabular}




\begin{tabular}{|c|c|c|c|c|c|}
\hline & $19 \mathrm{~b}$ & $86 n .358$ & & 40 & 224 \\
\hline & $34 a$ & 148 ก. 689 & Prog 1 & 445 & 78 ก. 332 \\
\hline & $36 c$ & 154,195 & & 447 & $103 n .451$ \\
\hline & $50 c$ & $99,163.34,169$ ก. 736 & & 47 & 151 п. 701 \\
\hline & $55 b$ & 39 ก. 113,110 n. 485 & & 478 & 78 n. 332,79 n. 334,138 n. \\
\hline & $58 s$ & 219 & & & $631,162.30$ \\
\hline KTS 2 & & 65 & & 490 & 106,176 \\
\hline & $1-11$ & 65 & & 491 & $232,241.9$ \\
\hline & 29 & 153 ก. 707 & & 500 & 239.5 \\
\hline & 31 & 153 & & 537 & 174 \\
\hline & 40 & 205 & & 550 & 156 ก. 71 \\
\hline & 43 & ות.756 & & 552 & 236.1 \\
\hline & 45 & 115 n. 551 & & 575 & 226 \\
\hline Kulina's & archive & see $\mathrm{kt} 92 / \mathrm{k} 188 \mathrm{ff}$. & & 610 & 222 \\
\hline KUG & 22 & 195 n. 826 & & 625 & 222 n. 918 \\
\hline & 25 & 219 ก. 915 & & 633 & $60 n .272$ \\
\hline LB & 1201 & 158 ก. フ72 & & 651 & $22,229,236.1$ ก. 946 \\
\hline & 1202 & 86 ก. 358 & & 705 & 110 ก. 487 \\
\hline & 1209 & 175 n.758 & & 78 & 198 ก. 841 \\
\hline & 1220 & 86 ก. 361 & & 764 & 206 ก. 863 \\
\hline L.T.-1 & & $314 f$. & & 784 & 103 ก. 451 \\
\hline L.T.-2 & & $310-321$ & & 804 & 155.2 \\
\hline LT.-3 & & $304 f$. & & 837 & 230 \\
\hline L.T. -5 & & 329 & RIMA & 1 & $19 \mathrm{n}, 3 \mathrm{f}, 20 \mathrm{n}, 7,21 \mathrm{n}$ \\
\hline L.T.-7 & & 314 & & & 10, 23f, n. $21+25 f, 25$ n. \\
\hline Neșr. B & ว.̆. 2 & $49 \mathrm{n} .175,159.15$ & & & $30+32+47,26$ n. $44,31 \mathrm{n}$ \\
\hline 0 & 3684 & $154.25,161.25$ & & & $69 ., 35 f . n \cdot 79+80,36 n$. \\
\hline OIP 27 & & 49 ก. $170,170.19$ & & & $82 f .+87,38 f f$. п. 102f., 39 n. \\
\hline & 1 & $144,154.1$ & & & $106+109 f, 40$ n. $116+118,44$ \\
\hline & 3 & $49 n \cdot 175$ & & & ก. 144,84 п. 352,95 ก. 410 , \\
\hline & 5 & $\begin{array}{l}155.1,160.21,164.38,185 \mathrm{n} . \\
795,223\end{array}$ & & & $\begin{array}{l}96 \text { n. } 418,122 \text { n. } 549,125 \text { n. } \\
566,129 \text { n. } 57,128 \text { n. } 585\end{array}$ \\
\hline & 7 & 196 & & & 142 ก. $652+657$ \\
\hline & 8 & 49 n. 175,137 & Sodbe & & 207 \\
\hline & 10 & $222 n .918$ & & 16 & 58 ก. 226 \\
\hline & 13 & 176 n. 764 & & 29 & 240.7 \\
\hline & 17 & 49 & TC 1 & 1 & 43 ก. 135 \\
\hline & 18 & 49,79 ก. 336 & & 5 & 134 \\
\hline & 19 & 224 & & 11 & 97 n. 419 \\
\hline & 41 & 57 n. 219 & & 18 & $158.12,174,207$ \\
\hline & 46 & 196 & & 30 & 117 ก. 523 \\
\hline & 49 & 144,145 n. $670,170.21$, & & 32 & 160.20 \\
\hline & & 231 & & 39 & $150,162.30$ \\
\hline & 53 & 114 n. $667,170.3,230$ & & 43 & $154,216 \cap .908$ \\
\hline & $54-62$ & 65 & & 53 & 229 ก. 929 \\
\hline & 56 & 134 & & 62 & 170.6 \\
\hline POAT & 6 & 240.6 & & 70 & 88 \\
\hline & 8 & 240.6 & & 81 & 153 п. 710 \\
\hline & 9 & 67 n 278, 161 & & 87 & 225,231 \\
\hline & 16 & 175 n. 756 & & 118 & 162.31 \\
\hline & 18 & $56 \div 216$ & & 122 & 170.8 \\
\hline & 21 & 158.12 & TC 2 & 18 & 152 n. 706 \\
\hline & 36 & 240.7 & & 22 & 84 \\
\hline
\end{tabular}


Indices

\begin{tabular}{|c|c|c|c|c|c|}
\hline & 37 & 229 п. 929 & & 182 & $154.22,166$ \\
\hline & 57 & 150.7 & & 198 & 161.27 \\
\hline TC 3 & 3 & 147 n. 679, 241.10 & & 205 & 222 \\
\hline & 14 & $225,227 n .925$ & VAT & 4536 & $169,170.22$ \\
\hline & 15 & 223 & VS 20 & & 65,67 n. 276,114 \\
\hline & 16 & 223 & & 7 & $56 \cap 216$ \\
\hline & 20 & 97 ก. 426 & & 9 & 83,216 ก. 909 \\
\hline & 28 & 197 n. 835 & & 10 & 118 n. 528 \\
\hline & 43 & 88 & & 12 & 84 \\
\hline & 60 & 111 ก. 490 & & 17 & 97 ก. 419,127 ก. 582 \\
\hline & 65 & 87 & & 29 & 205 \\
\hline & 68 & $116 n .516$ & & 51 & 228 \\
\hline & 70 & 228 & & 54 & 11.4 ก. 504 \\
\hline & 75 & 206,232 & & ol & 84 \\
\hline & 85 & $164.37-38,209$ & & 7 & 88 \\
\hline & 106 & 103 ก. 451 & & 83 & 205 n. 861 \\
\hline & 112 & 100,173 & & 118 & 180 n. 783 \\
\hline & 129 & 104 & & 125 & 224 \\
\hline & 158 & 221 & & 132 & 110 ก. 487 \\
\hline & 161 & 158 n. 712,232 & & 138 & 159.18 \\
\hline & 162 & 161.28 & & 146 & 221,235 \\
\hline & 163 & 97 n. 422 & & 148 & 160.23 \\
\hline & 165 & $154.19,160.19,231 \mathrm{f}$. & & 150 & 199 ก. 848 \\
\hline & 17 & 57 n. 225 & & 195 & $154.21,160.22,182$ \\
\hline & 181 & $22,220,230,236.1$ & YTR & 5 & 327 \\
\hline & 183 & 110 п. 488 & YTRR & 8 & 306 \\
\hline & 191 & 161 n. $714,219,230$ & YTR & 10 & 300 \\
\hline & 192 & 53 ก. 200 & YTR & 11 & 307 \\
\hline & 203 & $104 n .461^{\circ}$ & YTRR & 12 & 309 \\
\hline & 208 & 195 & YTRR & 15 & 309 \\
\hline & 211 & 232 & YTR & 18 & 308 \\
\hline & 214 & $144,170.17,222,230$ ff. & YTRR & 24 & 290 \\
\hline & 219 & 118 n. 528 & YTR & 28 & 328 \\
\hline & 227 & $237.7,242.19$ & YMR & 39 & 327 \\
\hline & 240 & 239.2 & YTLR & 41 & 291 \\
\hline & 250 & $139 \cap .640$ & YMR & 42 & 334 \\
\hline & 252 & 177 & YTLR & 43 & 287 \\
\hline & 253 & 222 & YTR & 43 & 334 \\
\hline & 254 & $222 f ., 236.1$ & YTRR & 44 & 334 \\
\hline & $2 \pi$ & $227 \pi$ & YTRR & 54 & 292 \\
\hline TPAK & 1 & 133 & YTRR & 55 & 292 \\
\hline & 4 & 104.39 & YTRR & 56 & 325 \\
\hline & 7 & 117 n. 523 & YTR & 57 & 287 N. 55 \\
\hline & 11 & 161.27 & $Y T R$ & $\infty$ & 335 \\
\hline & 45 & 223 & YTRR & 64 & 335 \\
\hline & 50 & 161.27 & YTR & 67 & 335 \\
\hline & 98 & 240.0 .242 .17 & YTR & 75 & 314 \\
\hline & 109 & 59 п. 233,115 п. 513 & YTR & 79 & 327 \\
\hline & 113 & 240.8 & $Y T R$ & 81 & 296 \\
\hline & 116 & 118 ก. 528 & YTRR & 85 & 305 \\
\hline & 120 & 91 ก. 382,115 ก. 513 & $Y T R$ & 89 & 297 \\
\hline & 161 & $175 f$. & YTR & 95 & 323 \\
\hline & 170 & 162.29 & YTR & 101 & 323 \\
\hline
\end{tabular}


2. Texts; 2.3. Excovations Numbers

\begin{tabular}{|c|c|c|}
\hline YTR & 110 & 308 \\
\hline YTLR & 112 & 322 \\
\hline YTLR & 115 & 275 \\
\hline YTRR & 118 & 323 \\
\hline YTLR & 121 & 325 \\
\hline YTLR & 122 & 291 \\
\hline YILR & 126 & 310 \\
\hline YTLR & 127 & 289 \\
\hline YTR & 128 & 289 \\
\hline YTR & 137 & 307 \\
\hline YTLR & 138 & 307 \\
\hline$Y M R$ & 139 & 307 \\
\hline YTR & 140 & 332 \\
\hline YTLR & 143 & 322 \\
\hline YIRR & 144 & 323 \\
\hline YMR & 147 & 310 \\
\hline YTLR & 149 & 299 \\
\hline$Y M R$ & 150 & 291 \\
\hline YTRR & 153 & 337 \\
\hline YTLR & 156 & 287 ก. 55 \\
\hline YTRR & 157 & 287 п. 55,294 \\
\hline YMR & 17 & 309 \\
\hline YMR & 173 & 335 \\
\hline YTR & 185 & 313 \\
\hline
\end{tabular}

2.3. After excavation numbers (Kt/ etC.)

\begin{tabular}{|c|c|}
\hline$a / k$ & 46 \\
\hline 165 & 174 \\
\hline 244 & $103 n .488$ \\
\hline 264 & 117 \\
\hline 335 & 236 \\
\hline 339 & $103 \cap .451$ \\
\hline 403 & 154.14 \\
\hline $465 a$ & 159.14 \\
\hline 488 & $159.19,225$ ก. 920 \\
\hline 503 & 154.23 \\
\hline 568 & 239.5 \\
\hline 583 & 148 ก. 690 \\
\hline $604 b$ & 239.3 \\
\hline 606 & 223,226 \\
\hline 672 & 236 \\
\hline 801 & 240.8 \\
\hline 805 & 223 \\
\hline 810 & 240.9 \\
\hline $811 b$ & 236.1 \\
\hline 825 & 226 ก. 924 \\
\hline 842 & 241.12 \\
\hline 843 & 223 \\
\hline 851 & 231 \\
\hline 852 & $223,236.5$ \\
\hline 899 & $236.1,240.8,242.13$ \\
\hline 906 & 78 \\
\hline 907 & 231 \\
\hline 931 & 240 \\
\hline 1048 & 236 \\
\hline 1055 & 205,215 \\
\hline 1060 & 239 ก. 949 \\
\hline 1070 & 49 ก. 179, 137 п. 627, 154.1 \\
\hline 1110 & 237 \\
\hline $1116 b$ & 240.7 \\
\hline $1164 a$ & 236.1 \\
\hline 1165 & 229 \\
\hline 1177 & 241.9 \\
\hline 1199 & 236 \\
\hline 1214 & 240.8 \\
\hline 1258 & 157.9 \\
\hline 1259 & 241.12 \\
\hline 1263 & 224,227 ก. 928 \\
\hline 1315 & 236 \\
\hline 1412 & 164.39 \\
\hline 1429 & 154.29 \\
\hline 1430 & 241.9 \\
\hline 1453 & 240.8 \\
\hline$b / k$ & 47 \\
\hline 21 & 160.22 \\
\hline $45 b$ & 240.8 \\
\hline
\end{tabular}


Indices

\begin{tabular}{|c|c|c|c|c|}
\hline $54 a$ & 158.10 & & 166 & 234 ก. 940 \\
\hline $54 b$ & 239.1 & & $175 b$ & 240.8 \\
\hline 95 & 223 & & $177 t$ & 161.26 \\
\hline 98 & 182 & & 181 & 161.26 \\
\hline 134 & 237 & & 183 & $154.6 .26,161.26,180,182$ \\
\hline 144 & 227 & & & ก. 786 \\
\hline 162 & 210 ก. 885 & & $184 b$ & 240.8 \\
\hline 176 & 154.17 & $g / k$ & 12 & 240.8 \\
\hline 180 & 210 n. 885 & & 36 & 172 n. 742 \\
\hline 198 & 232 & & 51 & 159.17 \\
\hline 258 & 101 n. 439,210 n. 884 & & 190 & 211 ก. 889 \\
\hline $260 b$ & 236 & & 199 & 160.23 \\
\hline 47 & 209 ก. 879 & & 220 & 155.2 \\
\hline 612 & $154.7,157.8,168 n .730$ & $g / 1$ & 35 & $48,143 n .663,154.12$ \\
\hline $682 b$ & 225 & & 36 & 170 n. $739,221-223,232$ \\
\hline$c / k$ & $72 n .301$ & & 42 & $56 n \cdot 215,220-223$ \\
\hline$\infty$ & 222 & & 44 & 42 ก. 132 \\
\hline 181 & $237.9,240.8$ & & 199 & 187 ก. 805 \\
\hline 201 & 237.9 & $h / k$ & & 72 ก. 301 \\
\hline 339 & $74 n .451$ & & 38 & 86 ก. 357 \\
\hline 441 & 115 n. 509 & & 331 & 42 п. 129 \\
\hline 839 & 54 ก. 204 & $i / k$ & 5 & 226 ก. 924 \\
\hline 841 & 154.17 & & 120 & 161.27 \\
\hline 1340 & 230,236 & & 124 & フ ก. 297 \\
\hline $\begin{array}{l}1634 f f \\
1641\end{array}$ & $\begin{array}{l}72 \text { ก. } 303,250 \\
221.224\end{array}$ & ik & 9 & $\begin{array}{l}236.1,19 \text { n. 737, } 227 \text { n. } \\
927181\end{array}$ \\
\hline$d / k$ & 147 n. 681 & & 80 & $162.30,177$ \\
\hline$\infty$ & $177.19-21$ & & 97 & 168 n. 728 \\
\hline$e / k$ & 251 ก. 30 아 & & 025 & 145. $170.26,222,224$. \\
\hline 162 & 240.9 & & & 230 \\
\hline 104 & 240.9 & & 059 & 103.35 \\
\hline$f / k$ & 26,147 ก. 081 & & 605 & 57 ก. 225 \\
\hline 45 & 240.8 & $k / k$ & 1 & $170.24,230 t$ \\
\hline 52 & 239.1 & & 4 & 59 \\
\hline 54 & 237.0 & & 9 & $170.18,240.8$ \\
\hline 58 & 239.2 & & 10 & $170.7,222,230$ \\
\hline 62 & 240.8 & & 14 & 170.14 \\
\hline 65 & 242.8 & & 31 & 147 ก. 680,148 ก. 684,220 \\
\hline$a 4 b$ & 236.1 & & & 223 \\
\hline 650 & 240.9 & & 32 & 240.8 \\
\hline $05 b$ & 237.7 & & 33 & 99 ก. 431, 169 n. 734 \\
\hline $72 b$ & 236.1 & & 34 & $239.1,241.11,242.2$ \\
\hline 73 & 240.8 & & 35 & 221 \\
\hline 80 & 230 & & 46 & 91 ก. 380 \\
\hline 84 & 147 n. 680 & & $5 t$ & 154.16 \\
\hline $94 b$ & 237.7 & & 57 & 154.27 \\
\hline 101 & 193 ก. 819 & & 59 & 239 \\
\hline 103 & 240.8 & & 03 & 154.24 \\
\hline 111 & 240.8 & & 70 & $154.9,1579$ \\
\hline 114 & 236.3 & & 78 & 163.36 . 217 ח.911 \\
\hline 115 & $17.8-13$ & & 79 & 86 ก. 357 \\
\hline 129 & 241.10 & & 87 & 159.14 \\
\hline $157 \mathrm{~b}$ & 236.3 & & 89 & 161.26 \\
\hline
\end{tabular}




\begin{tabular}{|c|c|c|c|}
\hline 91 & $154.9,222$ & 27 & 46 n. 158,189 ก. 810 \\
\hline 93 & $240.6,241.9,242.10$ & 270 & 155.36 \\
\hline 94 & $174,127.37-38$ & 31 & 42 n. $129,170.10,171.1,221-$ \\
\hline 98 & $164.37-38$ & & $224,230,232$ \\
\hline 101 & 137 n. 627 & 32 & 79 ก. 334,144 n. $605+667$, \\
\hline 108 & 208 n. 873 & & 146 n. 678, 170.1.5, 188 \\
\hline 118 & $180 \cap .781$ & & $221-224,189$ n. $810,230 f$. \\
\hline 122 & 160.20 & & 236.3 \\
\hline 126 & 160.21 & 33 & 189 ก. 810 \\
\hline 212 & 73 & 39 & 170.28 \\
\hline $\mathrm{m} / \mathrm{k}$ & 73 ก. 312 & 47 & 116 \\
\hline 1 & 86 ก. 357 & 63 & 162.34 \\
\hline 2 & 174 & 66 & 85 ก. 354 \\
\hline 3 & 156 & 67 & $84,85 \cap .354,136$ \\
\hline 5 & $222,225,232$ & 72 & 224 \\
\hline 7 & $103 \cap .450,223,236$ & 73 & 239.2 \\
\hline 8 & 195 & 75 & 236.5 \\
\hline 11 & $164.37-38,174$ & 76 & $99,154.16,169$ \\
\hline 13 & $100,173,206 n .863$ & 7 & 240.8 \\
\hline 14 & 228 & 141 & 193 ก. 819 \\
\hline 16 & 161.28 & 168 & 237 \\
\hline 24 & 224,232 & 211 & $157.10,161.25$ \\
\hline 35 & $222,224 \mathrm{~F}$ & 306 & 169 п. 737, 227 п. 927, \\
\hline$\infty 6$ & $161.28,166 n .722$ & & 236.1 \\
\hline 69 & $\begin{array}{l}119 \text { n. } 536,206 \text { ก. } 865,217 \\
n 911\end{array}$ & $\begin{array}{l}388 \\
473\end{array}$ & $\begin{array}{l}154.26,158.13,161.26,176 \\
161.26\end{array}$ \\
\hline 75 & 81 & 482 & 145 n. $670,154.29,155.1$ \\
\hline 78 & 225,230 & 490 & $145 n .670$ \\
\hline 93 & 84 & 504 & 44 n. 139,100 n. 434,168 \\
\hline 101 & 239.1 & & n. 732,173 n. 748,193 n. \\
\hline 103 & 240.8 & & $822,204 f ., 205$ n. 860 \\
\hline 104 & $242.4,236.1,240.8,242.4$ & 518 & $154,216 \pi .908$ \\
\hline 105 & 240.9 & 522 & 97 n. 426 \\
\hline 110 & 152 n. 705 & 524 & 97 n. 426 , \\
\hline 127 & 223,227 п. 928 & 533 & 222,228 \\
\hline 130 & 161.26 & 661 & 156 \\
\hline 132 & 222 & 681 & 119.6 \\
\hline 133 & 227 n. 928 & 695 & 57 ก. 219 \\
\hline 134 & $154.11,158.11,211$ ก. 890 & 76 & 234 \\
\hline 135 & 221 & 794 & 44 ก. 142,98 n. 428,150 n. \\
\hline 137 & 155.31 & & 692,172 п. 744, 178, 183, \\
\hline 144 & 159.16 & & 186,100 n. 436 \\
\hline 148 & $154.14,159.14$ & 931 & 97 ก. 425 \\
\hline 247 & 231 & 1007 & 164.39 \\
\hline 794 & 201 & 1024 & $158.11,168$ n. 731 \\
\hline$n / k$ & 46 п. 158, 47, 69, 133, 72 ก. & 1318 & 221 \\
\hline & 300,147 n. 681,189 n. 810 & 1339 & 101 п. 743 \\
\hline 1 & $102 n \cdot 445$ & 1371 & 169 \\
\hline 5 & 79 ก. 334,189 ก. 810 & 1374 & 145 n. $670,155.1,232$ \\
\hline 10 & $164.37-38,189$ ก. 810 & 1406 & 154.2 \\
\hline 11 & 144 n. $669,170.16$ & 1408 & 154.6 \\
\hline 21 & $157.10,161.25$ & 1414 & 91 п. 380 \\
\hline 22 & 49 & 1429 & $100,139,172,219$ n. 915 \\
\hline
\end{tabular}


Indices

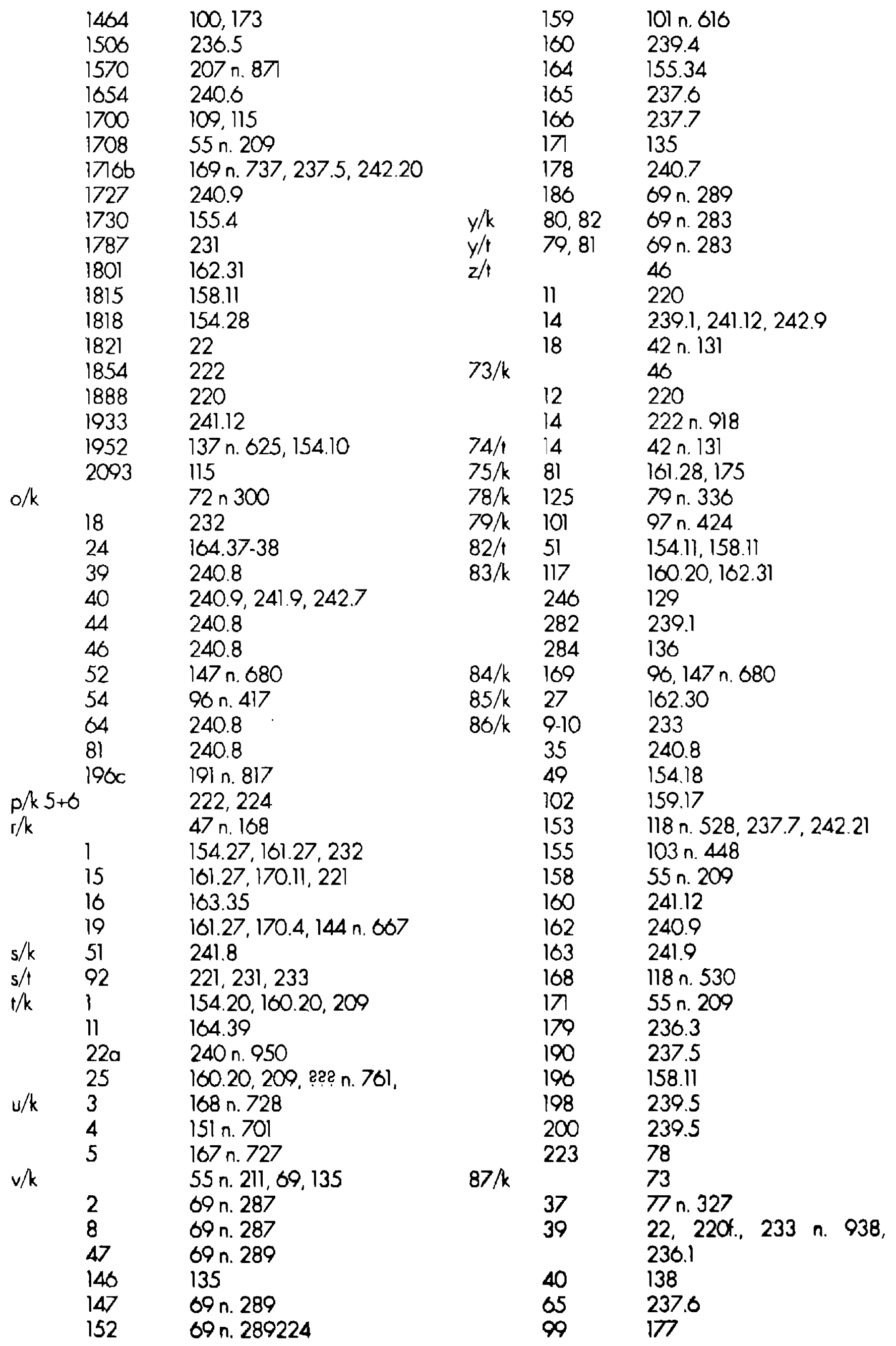


2. Texts; 2.3. Excovalions Numbers

\begin{tabular}{|c|c|c|c|c|c|}
\hline & 104 & 239.1 & & 266 & 224 \\
\hline & 120 & $164.37-38,174$ & & 267 & 124.21 \\
\hline & 139 & 231 ก. $934,239.4$ & & 270 & n. 730 \\
\hline & 145 & 210 & & 279 & 116 \\
\hline & 179 & $162.33,164.37-38$ & & 285 & 237.9 \\
\hline & 249 & 100 n. 434,168 n. 732 & & 310 & 240.8 \\
\hline & 253 & 221 & & 314 & 230 ก. 933 \\
\hline & 256 & 131 ก. 596 & & 317 & 223 \\
\hline & 257 & $160 \div .722$ & & 342 & 223,227 n. 928 \\
\hline & 258 & 242.11 & & 353 & 169,223 \\
\hline & 260 & 78 & & 355 & 239 ก. 949 \\
\hline & 206 & 231 & & 358 & 230,230 n. 933 \\
\hline & 272 & $239.1,231.11,242.1$ & & 365 & 170.29 \\
\hline & 274 & 222 & & 367 & 222 \\
\hline & 275 & $158.12,176 f$ & & 369 & 145 ก. 673,168 ก. 730 \\
\hline & 292 & 241.12 & & & $170.27,171.23-27$ \\
\hline & 304 & 241.12 & & 370 & 168 ก. $730,170.25,232$ \\
\hline & 320 & 222,231 & & 37 & 101,145 n. 670,145 ก. 670 , \\
\hline & 336 & $240.6,242.12$ & & & $170.20,221 f ., 230$ ff. \\
\hline & 384 & 18.12 & & 376 & $22,220,224,230,236$ \\
\hline & 386 & 232 & & 379 & 144 ก. $669,170.15,224$, \\
\hline & 387 & $163.35,227$ f., 203 n. 857 & & & 231 n. 934 \\
\hline & 432 & 237.9 & & 383 & $170.12,221,231$ \\
\hline & 447 & $162.34,222$ & & 387 & $154.24,157.10,161.24$ \\
\hline & 453 & 240.6 & & 421 & 83 ก. 348,216 ก. 908 \\
\hline & 460 & 103 n. 450 & $90 / k$ & & 70 ก. 292 \\
\hline & 464 & 87 ก. 365,165 ก. 719 & & וו1 & 70 \\
\hline & 479 & 227 n. 928 & & 112 & 70 \\
\hline & 522 & 138 ก. 631 & & 178 & 70 ก. 294 \\
\hline & 547 & $164.37-38,125.15$ & & $206-07$ & 70 \\
\hline & 551 & $127.37-38,159.16,164.37-$ & & $209-10$ & 70 \\
\hline & & 38 & & 212 & 70 ก. 296 \\
\hline & 552 & 78,134 n. 610,138 ก. 631 , & & $358-60$ & 59 ก. 235.70 ก. 294 \\
\hline & & 162.30 & & $429 f f$. & 70 ก. 292 \\
\hline & 559 & $176 \sqcap .765$ & $91 / k$ & & 70 п. 296,133 \\
\hline $88 / k$ & 383 & 230 & & 100 & 203 n. 857,215 \\
\hline & 507 & 208 n. 872 & & 107 & 70 п. 296 \\
\hline & 963 & 208 ก. 876 & & 108 & 161 ก. 714,221 \\
\hline & 990 & 223 & & 119 & 70 ก. 296 \\
\hline & 1063 & 223 & & 122 & 70 ก. 296 \\
\hline & 1070 & 233 & & 123 & 177 ก. 769 \\
\hline & 1082 & $230,240.8$ & & $123-246$ & 70 \\
\hline & 1087 & $230,240.8$ & & 141 & 48 n. 173 \\
\hline & 1090 & $231,236.5$ & & 145 & 154.15 \\
\hline $89 / k$ & & 70 & & 146 & 107 \\
\hline & 37 & 144 & & 148 & 154.20 \\
\hline & 193 & 222 & & 149 & 155.38 \\
\hline & 207 & $150,163.35$ & & 157 & 70 ก. 296 \\
\hline & 222 & 160.21 & & 165 & 70 n. 296 \\
\hline & 228 & 163.36 & & 17 & $154.4,155.4$ \\
\hline & 230 & $157.9,182$ & & 176 & 159.14 \\
\hline & 231 & 213 ก. 897 & & 181 & 156.6 \\
\hline & 243 & 232 & & 195 & 91 ก. 382 \\
\hline
\end{tabular}


Indices

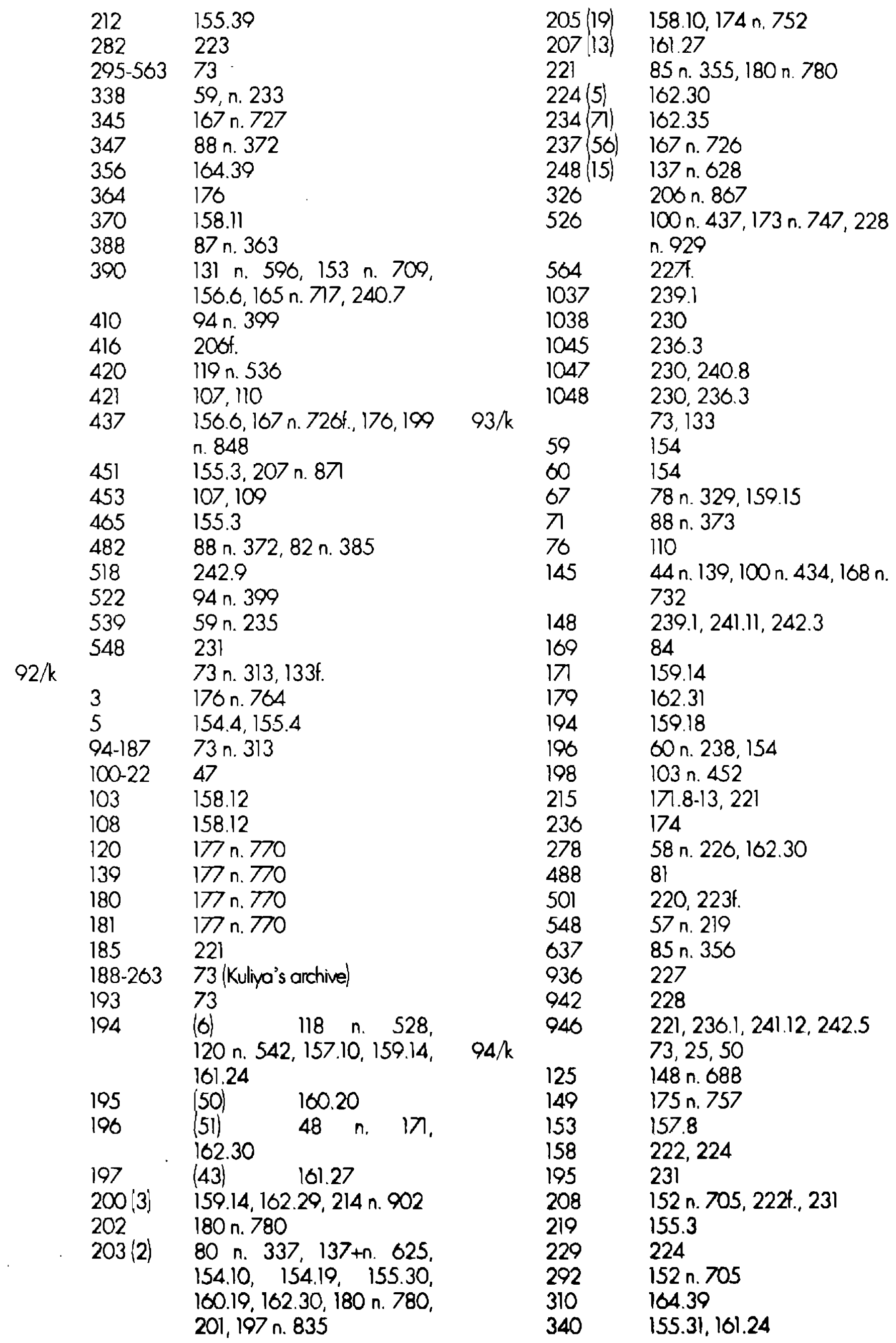


2. Texts; 2.3. Excavations Numbers

\begin{tabular}{|c|c|c|c|c|}
\hline 345 & 160.19 & & 1461 & 213,232 \\
\hline 350 & 40 ก. 119 & & 1472 & 174 \\
\hline 354 & $138 n .633$ & & 1482 & 151 n. 682 \\
\hline 364 & 216 n. 908 & & 1495 & 223 \\
\hline 378 & 164.39 & & 1501 & 223 \\
\hline 421 & 59 ก. 233 & & 1502 & 225 \\
\hline 432 & 227 & & 1504 & 225 \\
\hline 438 & 152 ก. 705 & & 1512 & 225,237 \\
\hline 441 & $159.14,214$ n. 903 & & 1527 & 223 \\
\hline 442 & 163.36 & & 1534 & $160.19,163.36$ \\
\hline 480 & 40 n. 119 & & 1610 & 157.10 \\
\hline 486 & $154.25,166$ & & 1629 & 157.10 \\
\hline 502 & $154.28,166$ n. $722,180 \mathrm{n}$. & & 1675 & 216 ก. 908 \\
\hline & 782 & & 1679 & 82 \\
\hline 636 & 159.14 & & 1686 & 90 ก. 376 \\
\hline 644 & 159.14, & & 1692 & 215 \\
\hline 672 & 231 & $98 / k$ & 11 & 146 n. 677 \\
\hline 705 & 214 n. 902 & & 118 & 189 \\
\hline 726 & 157.10 & & 125 & $78,159.14$ \\
\hline 727 & 227 & $99 / \mathrm{k}$ & 13 & 78 ก. 328 \\
\hline 757 & 84 ก. 351 & & $128 \mathrm{~A}$ & 224 \\
\hline 760 & 158.10 & & $138 \mathrm{~A}$ & $170.13,222,233$ \\
\hline 786 & 215 & & 139 & 144 n. $667,170.2$ \\
\hline 802 & 78 ก. 333 & $\infty \mathrm{k}$ & 6 & $149-151$ \\
\hline 808 & 215 n. 906 & & 7 & 182 \\
\hline 815 & 199 ก. 848 & & 10 & $154 f .3,157.8$ \\
\hline 826 & 85, ก. 356 & & 12 & n. 145 \\
\hline 833 & 231 & & 14 & 163.35 \\
\hline 840 & 181 n. 785 & & 18 & 232 \\
\hline 848 & 208 & & 73 & 163.36 \\
\hline 886 & 160.22 & $\mathrm{Ol} / \mathrm{k}$ & 217 & 141 n. 649 \\
\hline 917 & 151 n. 701 & & 287 & 143 \\
\hline 928 & 199.1 & & 325 & 47 n. 160,94 n. 400 \\
\hline 937 & $121.26,210$ & & & \\
\hline 963 & 207 n. 869 & & & \\
\hline 1002 & 147 ก. 679 & & & \\
\hline 1004 & 215 & & & \\
\hline 1023 & 58 ก. 226 & & & \\
\hline 1047 & 157.8 & & & \\
\hline 1095 & 237.7 & & & \\
\hline 1124 & 156.6 & & & \\
\hline 1128 & $150,157.9$ & & & \\
\hline 1133 & 131, n. 590,235 n. 921 & & & \\
\hline 1136 & 57 ก. 225 & & & \\
\hline 1164 & 214 ก. 903 & & & \\
\hline 1197 & 160.20 & & & \\
\hline 1226 & 167 п. 72,222 & & & \\
\hline 1247 & 86 ก. 361 & & & \\
\hline 1263 & 32, ก. 72 & & & \\
\hline 1323 & 210 ก. 863 & & & \\
\hline 1352 & 82 ก. 345 & & & \\
\hline 1374 & 163,35 . & & & \\
\hline 1454 & 210 & & & \\
\hline
\end{tabular}


3. Geographical names

3.1. Geographical names, ancient

\begin{tabular}{|c|c|}
\hline Abrum & $80,150.7$ \\
\hline Ahanda (Apum) & 305 \\
\hline Alilānum & 293 \\
\hline $\bar{a} l u m \mid=$ Assur $\}$ & 24 ก. 29,60 ก. 240 \\
\hline al buṭnâtim & 167 ก. 726 \\
\hline àl ișșurātim & 167 ก. 726 \\
\hline āl Kaniši'ēe & 158.12 \\
\hline âl Kupilšon & 167 n. 726 \\
\hline Akkad(ians) & $\begin{array}{l}59,89,97 f ., 123,126 f ., \\
134,153,186,211,214\end{array}$ \\
\hline Amaz & 301 \\
\hline Amkuwa & $\begin{array}{l}26,32,41,45,49,75, \\
79,81 \text { n. } 338,99,119, \\
137,144 \text { n. } 667,145 \text { n. } \\
670,146,154.1,155.1, \\
160.21,165 f, 171.19-21 \text {, } \\
174,196,231 f .\end{array}$ \\
\hline Amurrum & $\begin{array}{l}97 \text { ก. } 426,174 \text { ก. } 753 \text {, } \\
184\end{array}$ \\
\hline Amursakkum & 301 \\
\hline Anamas̆ & 309 n. 105 \\
\hline Andarig & 294 \\
\hline Apia & 155.2 \\
\hline Apoum & $\begin{array}{l}26,31,33,60 \text { n. } 238,61, \\
80 f, 97 \text { n. } 422,140 f f ., \\
141 f ., 146,154.2,155.2, \\
183,184 . B, 185 . e-f, 190, \\
196,201 f ., 203 \text { п. } 855 \text {, } \\
212,216,270\end{array}$ \\
\hline Arropha & 293 \\
\hline Assur & 19.27, passim \\
\hline Ašlakkā & 296 \\
\hline AšKAkum & \\
\hline$\{=$ Ašnakkum? $\}$ & 304 \\
\hline Ašnakkum & 296 \\
\hline Azamhul & 301 \\
\hline Babylon & 291 \\
\hline Bagarime & 167 n. 727 \\
\hline Baniharsum & 157.10 \\
\hline Baraddum & $156 n>11$ \\
\hline Batna & $\begin{array}{l}98,99 \text { n. } 430,154.3 \\
155.3,186 \text { n. } 800,189 \\
197 . d, 206,207 \text { n. } 87, \\
216\end{array}$ \\
\hline $\begin{array}{l}\text { Bitu'um } \\
\text { Burallum }\end{array}$ & $\begin{array}{l}158.12 \\
97 \text { п. } 452,158.12,232 \text { n. } \\
936\end{array}$ \\
\hline Buruddum & $\begin{array}{l}78,154.4,155.4,156 \mathrm{n} . \\
711\end{array}$ \\
\hline
\end{tabular}

Burušhaddum

Daragum

Dèr

Dibosnāium (nisbe)\}

D/Tumelia

Durhumit

D/Tuwania

Ebla

Ekalläum

Elmelme

Eluthut/Eluhut

Eshnunno

Gasur

Hoburata

Hahhum

Hālabōa

Hamisōnum

Hanaknak

Hanigga

Horobis

Harsamna

Haššum

Hottum
$26,46,81$ ก. 338,89 , $99 f_{.}, 101$ n. 438, 135t., 136 ก. 623, 144, 150, 151 ก. 697, 152 ก. 706 , 153 ก. 708, 154.5, 155.4, 162.31, 165f., 167 n. 724 , $17.19-21,172$ n. 743, 173 n. $745,175 \mathrm{f}, 178,180$. 205f., 208, 213, 229 270 n. 7 82,87 ก. $367,98,126 f$. 108 ก. 728 167 ก. 727 81 ก. 338, 86, 89, 117 . 135f., 151, 152 n. 706 , $153,154.6,156.6,159.14$, $160.19,161.24+26,165$, 175f., 178, 180, 206. 209,

167 ก. 727 59 ก. 233,98 n. 427

24 n. 29,25 n. $36,30,59$ n. 237,141 f

174

60 ก. 238, 80, 154.7, $156.4+7,165 f,, 297$

21 n. 10, 22, 25, 29, 59, 82, 97f. $n 41,125,127$, $142,156,211$

19 n. 4,38 n. 100

151,153

$27,45,49,73,78 \mathrm{n}$. $329,80 f . n$. 338,90 , 98ff. n. 430, 100 n. 4351 . 122, 140f. n. 643, 150, 153f., 155.3, 156 n. 711, $157.8,161.28,165,168$ n. 730,172 n. 744, 173, 175f., 183.D, 186.C, 187. $188 \mathrm{ff}, 193 \mathrm{n} .181$. 194f. n. 826, 201f., 213f. n. 903 . 216, 229, 232

301

$158.12,100.23$

136, 153, 154.9, 157.9, $159.14,176,182$

167 ก. 727

174

$45,47,60,141,143,144$ ก. 666, 189,

59,81 n. 338,143 ,

63 ก. $257,85,89$ $157 f .10,161.24,164.37$ 


\begin{tabular}{|c|c|c|c|}
\hline & $38,167,174$ n. $752+754$ & Luhusaddia & $\begin{array}{l}86 \text { п. } 357,87 \text { п. } 365,99, \\
136,153,15416 \quad 15812\end{array}$ \\
\hline Hattušla) & $\begin{array}{l}26,33 \text { ก. } 73,41,45,49 \\
\text { n. } 175,60,63 \text { п. } 257 \\
75,79 \text { п. } 334,81 \text { n. } 338, \\
99,119,136 f ., 138 \text { n. } 632\end{array}$ & & $\begin{array}{l}159.16,160.21,165 \mathrm{n} . \\
719,169 \text { n. } 735,173 \mathrm{n} . \\
748,175 f . n .755,182 \\
208,210,234\end{array}$ \\
\hline & $\begin{array}{l}144 f, 154.10,157.10 \\
160.19,161.25,165 f . \\
724,174 \text { n. } 754,188 \mathrm{f} . \\
810,235\end{array}$ & Mamma & $\begin{array}{l}33,42,48 f, \text { n. } 175,59 \text { n. } \\
235,62,79 \text { ก. } 334,80 \text {, } \\
81 \text { ก. } 338,87,89,102 \\
\text { n. } 446,143,144 \text { ก. } 667,\end{array}$ \\
\hline Hathušãium (nisbe) & $99,157.10$ & & $146 \mathrm{n}, 678,153,154.17$ \\
\hline Hawilium (nisbe) & 118 n. 530 & & $157.10,158.12,159.15+17$ \\
\hline Hidar (in Apum) & 305 & & 164.37-38, 167, 170.1, \\
\hline Hubšolum & 328 & . & $171.1,1771 ., 188,189 \mathrm{n}$. \\
\hline Hudurut & & & $810,195,207$ n. 871,216 \\
\hline & $\begin{array}{l}158.11-12,160.21,164.37- \\
38,168 \text { n. } 731,175 f ., 211 \\
\text { n. } 890\end{array}$ & Mari & $\begin{array}{l}\text { n, } 20 \text { n. } 7,26 \text { n. } 44,271 . \\
30 f f ., 38 f . \text { n. } 107,59 f . \\
80 f f ., 87,89,98 \text { n. } 429\end{array}$ \\
\hline Hurāșā & 302 & & 123 ก. 556,127 ก. 576 \\
\hline Hurronum (in Apum) & 305 & & $128, \quad 137, \quad$ l40ff., 15 \\
\hline Ikiztepe & 136 & & $153,150.4+7,157.8+10$ \\
\hline |lān-șūrā & 288 & & $160.20,162.37-38,168$ \\
\hline |štanuwa & 151,153 & & 178 ก. $772,188,193$ n. \\
\hline Izhizzi (in Apum) & 305 & & $818,202,206,221,232$ \\
\hline Jamhad & 290 & Mari (Habur town $\}$ & 287 \\
\hline Japtur & 298,301 & Nadbum & 302 \\
\hline Jassãn & 294 & Nagar (= Nawar) & 298 \\
\hline Kahat & 297 & Nawali & 302,328 \\
\hline Kakmum & 293 & Nowar & 298 \\
\hline Kallahubri (in Kahat) & 315 & Nawardi (in Apum) & 305 \\
\hline Konesh & passim & Nehrio (Nahria) & 60 ก. 238,78 ก. 329,80 \\
\hline Kammalia & $\begin{array}{l}101,169, \quad 170.20+22 \\
171.19-21,172,222,231 \mathrm{f}\end{array}$ & & $\begin{array}{l}97 \text { п. } 426,159.18,165, \\
175 \text { ก. } 757,178\end{array}$ \\
\hline Kapitra & 99,209 & Nenaššā & $151,153,154.19,160.19$, \\
\hline Karahna & $154.13, \quad 157.10,158.13$ & & $209,225,231$ \\
\hline & $159.14,161.25$ & Nèro & 23,97 n. 421 \\
\hline $\begin{array}{l}\text { Karanō/ā } \\
\text { Karkemish }\end{array}$ & $\begin{array}{l}81 \text { п. } 340,141 \text { n. } 640,290 \\
60.16020211290\end{array}$ & Niniveh/Ninua & $\begin{array}{l}37,75 \text { n. } 79,97 \text { ก. } 425, \\
122\end{array}$ \\
\hline Kilārium (nisbe) & 168 ก. 728,174 ก. 753 & Pahus & $60 n .238$ \\
\hline Kirōn (in Kahat) & 315 & Palurušna (nisbe) & 168 ก. 728 \\
\hline Kubšum & 292 & Qaltarā & 27, off. ก. $238,80,158$ \\
\hline Kudimmar (in Apum) & 305 & & 296 \\
\hline Kumulhum (in Apum) & 305 & Qirdahat & 298 \\
\hline Kunanamit & $\begin{array}{l}100,151,153,173,175 \text { n. } \\
758 \text { (mä K.) }\end{array}$ & $\begin{array}{l}\text { Razamā } \\
\text { Sabbänum }\end{array}$ & $\begin{array}{l}60 \text { n. } 238,176,294 \\
301\end{array}$ \\
\hline Kurdā & 294 & Sabum & 296 \\
\hline Kuššara & $\begin{array}{l}49 \text { n. } 175,78 \text { n. } 329, \\
81,137,154.15,159.15 f ., \\
164.37-38,175,210\end{array}$ & $\begin{array}{l}\text { Sophum (in Apum) } \\
\text { S/Sowit } \\
\text { Sippor }\end{array}$ & $\begin{array}{l}305 \\
153,162.32,174 \\
26,61,122,142,331\end{array}$ \\
\hline Kuzōjo (in Apum) & 305 & S/Zittunium (nisbe) & 168 ก. 728 \\
\hline Lazapatum (in Apum) & 305 & Susa & 8289 g7f $\cap 429$ \\
\hline Luhöya & 156.7 & Sabó & 206 n. 863 \\
\hline
\end{tabular}


Saladi/uwar

Šalahšıwa

Šarla

Śamuha

Šebiš̄o (in Apum)

Sehna

Simala

Šimaški

Simurrum

Sinahutum

Sirmuin

Subarilium

Šubat-Enlil

Suñ̄ā

Suppilulia

Šurnat

Surșum

Sušarrō

Tadmur(ium)

Tahodizina

Tahruwa

Taišima/Tēšima

Talhat/Talhōyum

Tapogaš

Topašatta

Tapigga

Taritor

Tawinia/Tomnio

Tegarama

Tehhi

Tiburzio

Til-Tumman

Timilkia
79, 85, 154.20, 159.15, Tišmurna

$160.20,162.31,166,182$,

205, 206 n. 863, 209, Tuhpia

210 n. 884

$154.21, \quad 155.1, \quad 158.12$,

$160.21,206,223$

174 (māt)

79 n. 334, 154.22,

$160.22,162.28,160,182$

305

27, 269 see Apum

78 ก. 329, 118 ก. 530

$154.23,156 \mathrm{n} .711,160.23$

314

293

$99,136,154.24,157.10$

$161.24,174$

168,178

25,97 ก. $425,142,156.4$

$184 . \mathrm{B}$

209

271,302

$79,154.25,157.10,161.25$

$166 f ., 174$

288,302

309 n. 105

27

23 n. 20,118 n. 530

167 n. 727,225

174 (māt T.)

178 ก. 773

60 ก. $238,80,122,153 \%$.,

177 ก. $770,225,298$

81 ก. 338

$151,153,168$ n. 728

81 n. 338

153. 168 ก. 728

$100,136,137$ n. 028,148

n. $688,154.26,158.13$,

160.19, 161.26, 108 n.

$732,173 \mathrm{f}, 176,182 \mathrm{n}$.

786,210

$81,136,154.27,161.27$, 177

303

$161,27,232$

178

79 ค. 334, 81, 98, 99

ก. 430,131 ก. 96, 153 ,

$154.28,155.2,150 \mathrm{n} .711$.

$158.12,100.22,162.28$,

$106,175,177,181,186 \mathrm{n}$.

B00, 189, 197, 206f., 216

Urāmē

Uršu

Uššo

Zibat

Zirromum

Zurra
136, 151, 153, 154.29.

$159.14,176$

58 ก. 226, 78f., 136, 138,

$150,153,155.30,159.14$

$160.19,162.30,166,174$

174 ก. 753

59

$27,60,154$

295

$81, \quad 155.31, \quad 160.20$.

$162.31,166$ n. 724,182 ,

205, 206 n. 863, 211. 227 .

$162.32,160$,

36 ก. 87

Urgina $(=$ Urkiš

Urkiš $\quad 303$

Urpan $\quad 300$

60 ก. 238, 80, 103,

$135.33,162.33$, 164f.,

177,2071 . 208 n. 872

$155.34,102.34,213$

79, 81, 99f., 109, 135ff., $150, \quad 155.35, \quad 158.12$, $160.20,162 \%$., 166f., 169 n.736, 173, 175f., 180ff., 205, 209, 214, 227f

Wašhania

Zahiki (in Apum)

$136,151,153,155.36$. $163,165 \mathrm{ff}$.

305

Zalpa (southern)

60 n. 238,81 ก. 338,

141 n. 049, 153 ก. 707,

$155.37,103.37-38,104$.

$174,177,182,189$ ก. 810 . 205, 207 n. 871, 209. 215 n. 905

Zalpo (northem)

136, 143f. 154, 155.38. 164,209

see Zalpa (nonthern)

296

Zannōnum

305

291

$155.39,208$

Zimishuna

328 


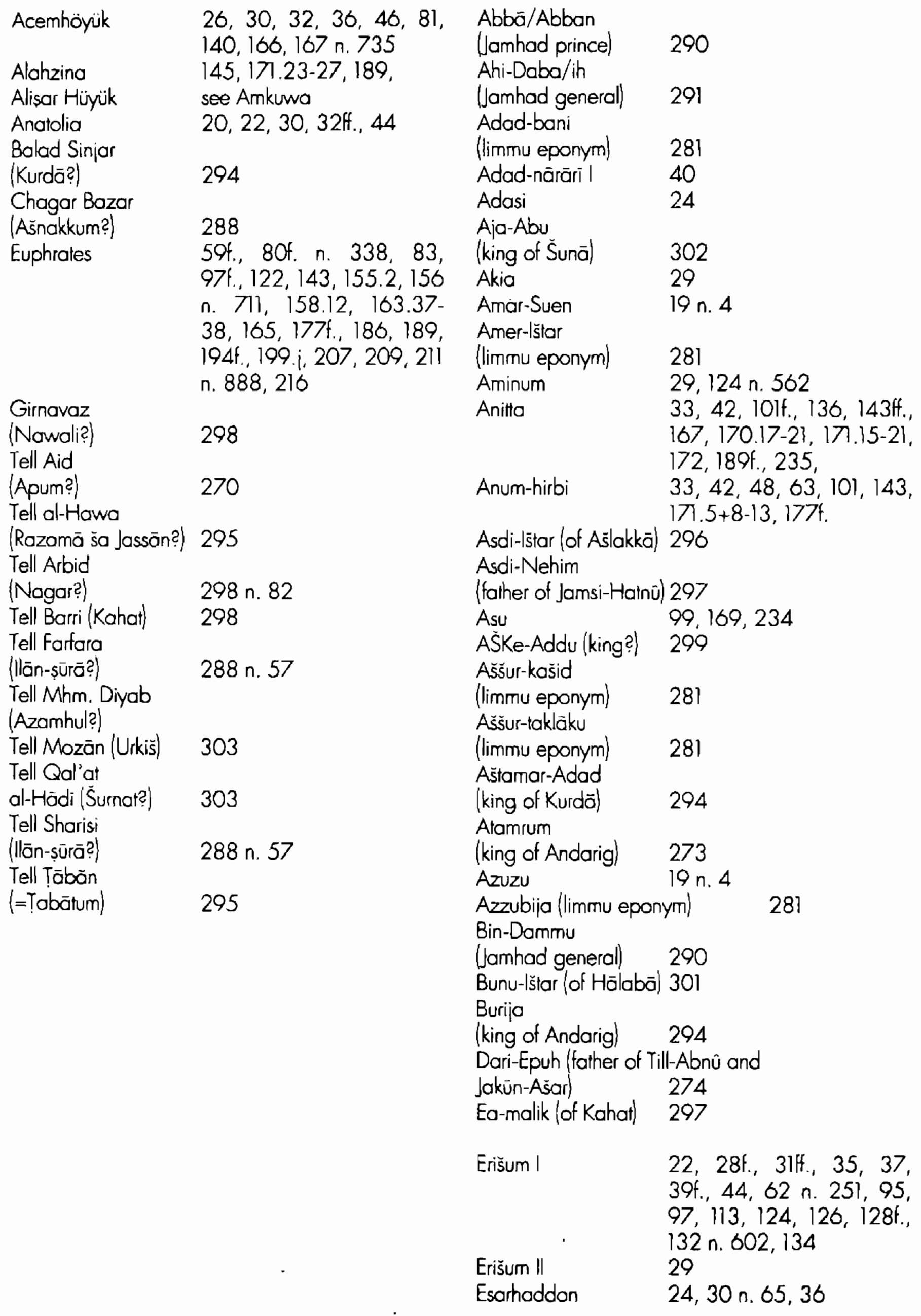




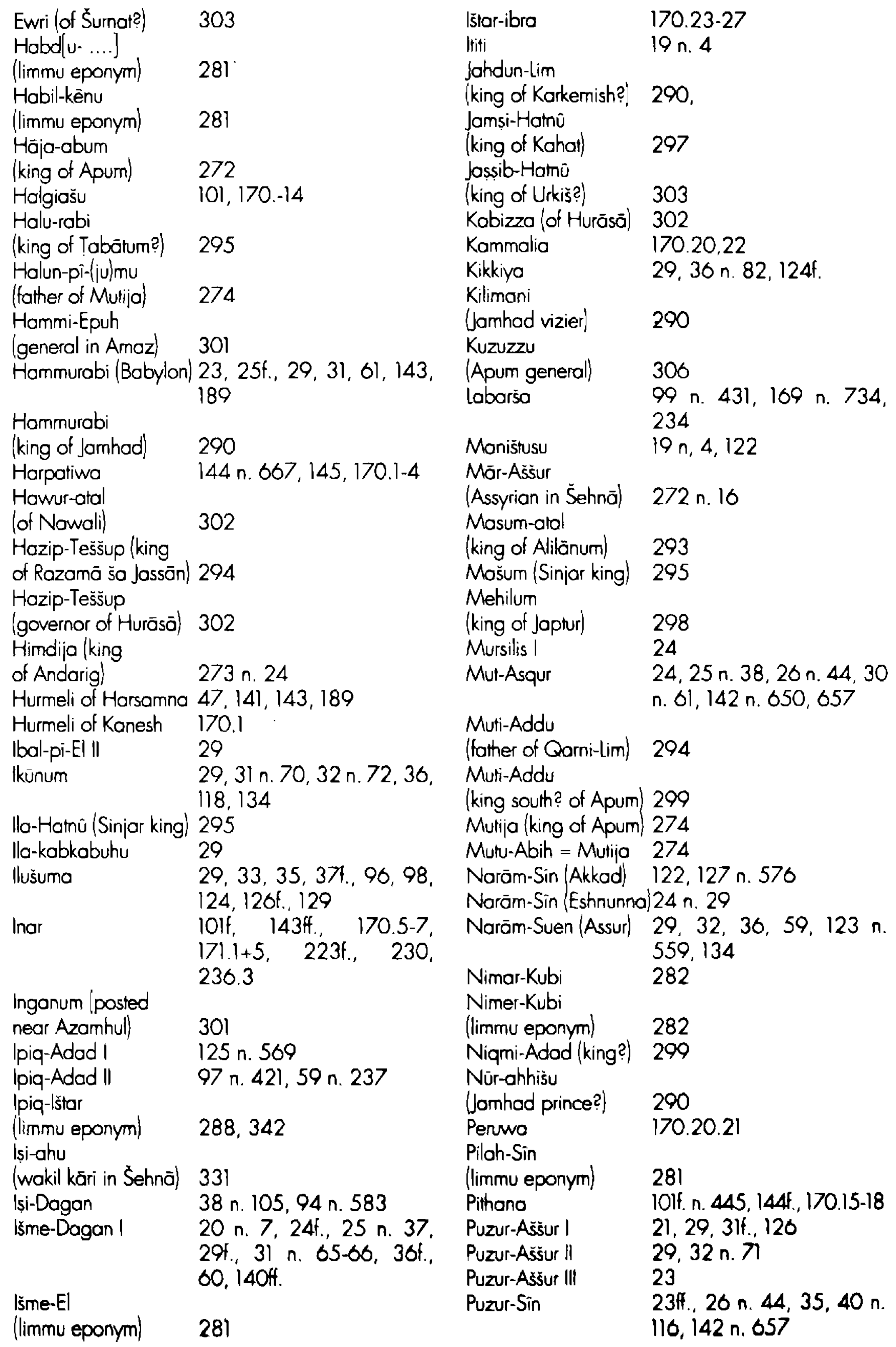


4. Kings and Rulers

Qarni-Lim

(king of Andarig) 272

Qurrōdum

(of Nadbum)

Rimuš

Samsu-iluna

Samsu-malik

(of Azomhul)

Sauštatar

Shalmaneser 1

Su-a-bu

Sulili

Silulu

Šlim-ahum

Samnuman

Šamši-Adad I

Śms̄-Adad III

Šarru-kīn I (Assur)

Šamši-Adad (king of

302

26 n. $44,122,142$ n. 657

26f., 31, 33, 6l, 142f.,

146, 269

301

23

19 n. 3,31 n. 65

31 ก. 67

31f., 124f., п. 564

$21,32,114$ n. 502,125

29,69 n. 288

170.5-6

23ff., n. 29-34, 29ff., $36 f f ., 58 f ., 60,124,128$.

140f., 142 n. 652, 143.

189

23f. ก. $30+37,36$ ก. 84 ,

142 n. 652

$29,32,36,38,123,131$, $133 f ., 174.753$

Upper Mesopotamia) 271

Sarru-kin

(Sargon, Akkad) 123 n. 558

Sepallu (Sinjar king) 296

Sibila (of Sunā) $\quad 302$

Su-Bēit

(limmu eponym) 281

Su-ilia

125 ก. 569

Šubram

(govemor of Apum)

Sukrum-Teššup

(king of Eluhut)

Sulgi

Tiglath-Pileser I

Tillāja != Till-Abnū!

Till-Abnû

(king of Apum)

Tukulti-Ninunta I

Turum-natki

('king' of Apum) 277

Tušpiya 124

Uhna 136

Ukku (of Nawali) $\quad 302$

Ušpia

Warad-Šamaš

(of Karanō)

Waršama

273

297

20 n. 7,30

274

$26,142,185$ n. 798,274

38,124

19

296 n. 78

42,63, 10lf., 143, 145,
Yahdun-Lim

Zarriqum

Zazija (of Tehhi)

33,39 n. 107, 60, 140 n.

641

19 ก. 4,21 ก. 9

Zige- (king of Amazl 301

Zige (king of Amaz) 301

Zimrilim

Zuzu

Zūzu (king of Apum) 272
30,60

$102,145,170.23-27,18$ of

$17,178,221$, 
5. GODS AND TEMPLES

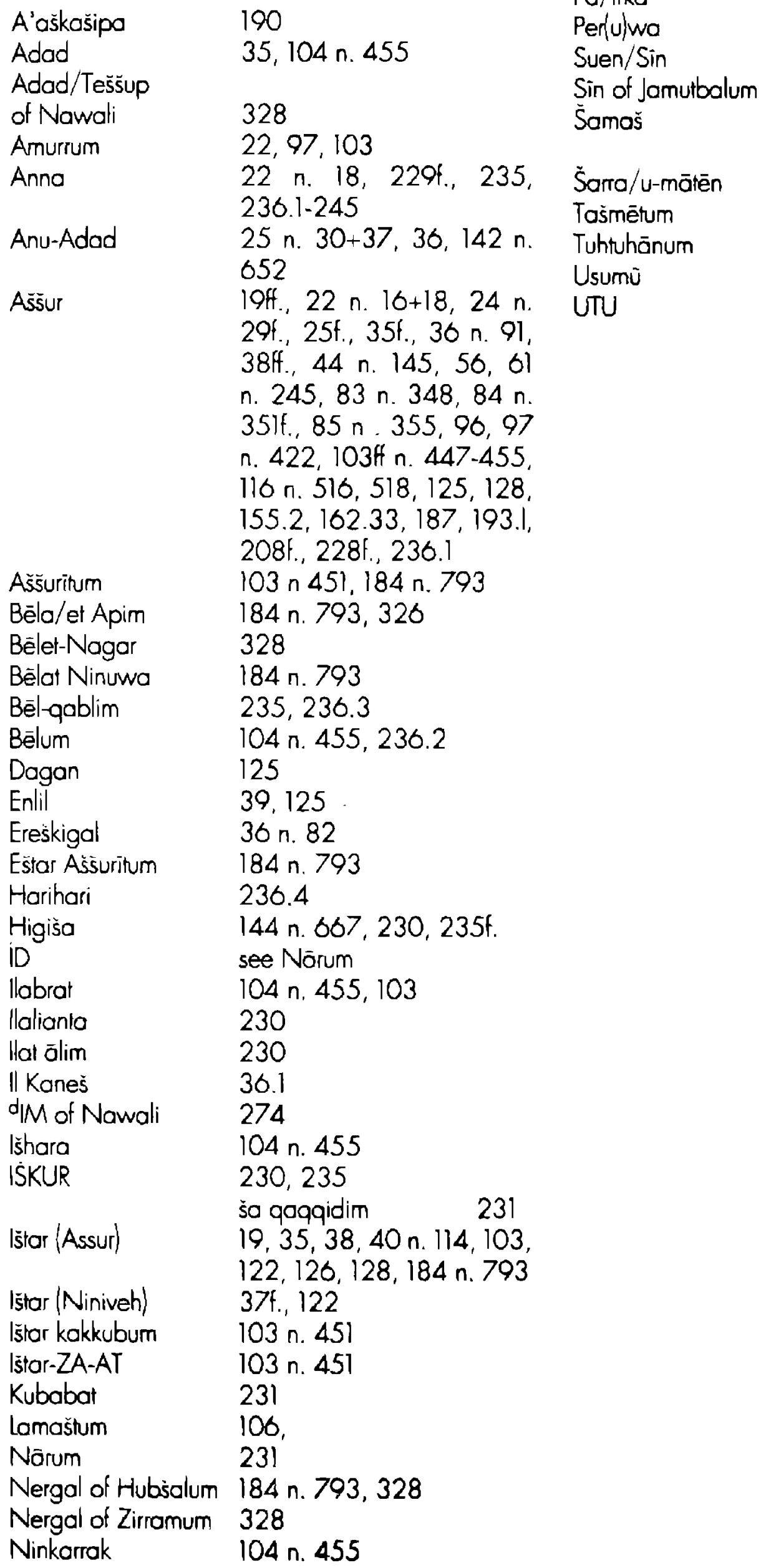

231, 236f., 242ff.

$103,231,235,238$

$235,236.1,237.6,242 f f$. 235

104 n. 455,105 n. 463

273 ก. 24

104 n. 455,184 ก. 793

(see UTU)

103 n. $545 f$.

104 ก. 455

237.7. 242ff.

237.8

$235,237.9$ 


\section{Persons}

\begin{tabular}{|c|c|}
\hline Abluhul & 77 \\
\hline Adada & $48 \mathrm{n} .173$ \\
\hline Adad-șululī & $\begin{array}{l}46,69,118 \text { n. } 526,119 n . \\
538,133\end{array}$ \\
\hline Adad-ella & 113 n. 501 \\
\hline Ahaha & 110 \\
\hline Alähum & $\begin{array}{l}44 \text { n. } 139,46,73,118 \\
\text { ก. } 530,119 \text { ก. } 538,133, \\
162.34\end{array}$ \\
\hline Asqūdum & 39 n. 113 \\
\hline Ase'ed & $\begin{array}{l}72 \text { n. } 303 f ., 93 \text { n. } 391 \text {, } \\
22 \text { of., } 223\end{array}$ \\
\hline Aissurur-bōni & 49 n. 175 \\
\hline Aŭšur-idí & 106 ก. 470 \\
\hline Aššur-imithi & 36 \\
\hline Aššur-mulappil & 49,7 Of., 119 \\
\hline Aššur-rādā & $\begin{array}{l}46 \text { n. } 154,68,106 \text { n. } 470 \text {, } \\
117 f .\end{array}$ \\
\hline Aššur-taklāku & $46,72,118,133$ \\
\hline Aššur-țäb & $118 \cap .530,167 n .725$ \\
\hline Awarnahuš & 78 \\
\hline Azu & 230 \\
\hline Būsija & 120 n. 540 \\
\hline Buzōzu & $49,120,225,227$ \\
\hline Dān-Aššur & 69 ก. 288 \\
\hline Dāya & 49,119 \\
\hline Eddin-Ǎšsur & $47 \mathrm{f} ., 146$ n. $678,188 \mathrm{f}$. \\
\hline Ehli-Addu & 59 \\
\hline Elālī & 46 n. $456,48,78,104$ \\
\hline Elamma & $\begin{array}{l}46 \text { n. } 157,54,73,87,88 \\
\text { n. } 372,92 \text { ก. } 385,107, \\
110,117 \text { n. } 522,133 \mathrm{ff} .\end{array}$ \\
\hline Enišla)ru & 93 ก. 391 \\
\hline Ennänum & $152 n .705$ \\
\hline Ennum-Aššur & $\begin{array}{l}69,101 \text { n. } 439,135,210 \text { n. } \\
884\end{array}$ \\
\hline Habdu-mālik & 60 \\
\hline Hannanārum & 48 \\
\hline Hupitum & 114 п. 502 \\
\hline Huraș̣̄num & 120 ก. 540 \\
\hline Iddin-abum & 42 ก. 129 \\
\hline Iddin-|šlor & 120 ก. 540 \\
\hline Iddin-Kübum & $49,78,119,161.27$ \\
\hline Iddin-Numušda & 60 \\
\hline Idnoya & $120 \cap .540$ \\
\hline Ikuppi-Aššur & 70 n. 292 \\
\hline Nliš-tikal & 42 n. 131 \\
\hline Iltrani & 61.245 \\
\hline Indilum & $66 f ., 116\} ., 119,134$ \\
\hline Innāyo & $67,118 f ., 159.17$ \\
\hline
\end{tabular}

Istar-bašiti
Ištar-lamassi
Kulinya

Kunnaniya

Kunnunu

Logani

Lamassani

Lamassatum

Lamassi-Ǎšsur

Mannuba

Madowada

Nabi-Enlil

Peruwa

Puzur-Anno

Puzur-lšlar

Rubātum

Samija

(Šamši-Adad official) 277

Suejia

Șilulu

Šalii)m-ahum

Śalim-bêli

Šalim-Aššur

Šep-älim

Šumi-abiya

Šumi-Ašsur

Š-Suen

Taāb-pi-Aššur

Tuhniš

Turupani

Unaps̄e

Urdum

Ușur-ša-Ištar

Ušinglum

Zua

143 109

77
109.236 .2

$106 f f .115$

$43,48,73,85,1354$. . $140,162.30,180,221$

120 ก. 540

70 ก. 296

42 ก 129

61 n. 245

57 n. $225,107,110,134$

118 ก. 528

93 ก. 391

$49,119,160.21$

$46,72,15,145$ n. 670 , 672,147 n. 681, 170.21, 171.19-21, 221ff., 230ff., 235,245

100,145 n. 670, 170.20, $171.19 .21,172$

23 ก. 20

46,48 ., 56 n. 216, 66 , 69 n. $288,78,87$ ก. 367 , 104, 106, 110, 117, 119, 120 ก. 541, 121, 133 n. $605,134,155.4,175$ n. $759,204,229$

120 ก. 540,152 ก. 705

71 n. 299, 140,

48 ก. 172,59 ก. 233,120 n. 541,195

21, 32, 117 n. 502, 125 n. 568

69 ก. 288,113 ก. 501

152 ก. 705

6. 47 n. $160,73,133,134$

ก. 010,135

113 ก. 501

70f. n. 296, $7 \ln 299,119$

167 ก. 725

120 ก. 541

113 ก. 501

223,42 ก. 127,170 n. 739,172 ก. 742

59 ก. 235

70 ก. 296

44 ก. 139, 69 n. 286, 115, 119 ก. 538,133

148 ก. 683

$163.36,182$ 


\section{ASSYRIAN WORDS}

(see also note 499 and the tables in chapter V|.1.1. and 1.2 .5 .)

\begin{tabular}{|c|c|}
\hline ahhitom cahōtum & \\
\hline abbūtam șabātum & 203 \\
\hline abnum & 57 n. $225 \mathrm{ff}$. \\
\hline abullum & 56 n. $215,163.35,220$ \\
\hline addurōrum & $\begin{array}{l}126 f f . \text { n. } 578,193 \text { ก. } 821 \text {, } \\
217\end{array}$ \\
\hline adrum & $238,241.12$ \\
\hline allahhinnum & $\begin{array}{l}159.19,162.30 .34,220, \\
223,225 f .\end{array}$ \\
\hline alōnum & 153 \\
\hline ālikū ša harrān ālim & $\begin{array}{l}67 \text { n. } 167,78 \text { n. } 332,79 \\
\text { n. } 334,161.25 \\
162.30\end{array}$ \\
\hline & $\begin{array}{l}n .334,101.20,102.30, \\
163.35\end{array}$ \\
\hline älum & $\begin{array}{l}21 \text { n. } 10,60 \text { n. } 240,175 \text { n. } \\
756\end{array}$ \\
\hline ammurum & 97 n. 426 \\
\hline amlum & 108 \\
\hline amūtum & $\begin{array}{l}72 \text { ก. } 307,84 f ., 85 \text { n. } \\
356,213 \text { n. } 896,222, \\
226 f .\end{array}$ \\
\hline arhalum & 50,96 ก. 416,221 \\
\hline arnum & 209 n. 881 \\
\hline ašium & $\begin{array}{l}84,191 \text { n. } 816,213 \text { n. } \\
896\end{array}$ \\
\hline ašlakum & 220,231 \\
\hline cššutum & 108 \\
\hline aštapirum & 42 ก. 127,170 n. 739 \\
\hline awilum & $162 f .35,230$ \\
\hline awilū ša nikkassi & 92,181 \\
\hline owitum & $76,90,187$ \\
\hline babbordillum & 56f. n. 216, 219 \\
\hline bābum & 56 ก. 215 \\
\hline bolātum & 132 \\
\hline ba/urullum & $\begin{array}{l}155.3,161.27,226 \quad n . \\
922,231 f .\end{array}$ \\
\hline$b / p a t / t u ̛(?)$ & 170 \\
\hline be'ōrum & 195 n. 827 \\
\hline be'ūlātum & $\begin{array}{l}51,94 \text { ก. } 392,107,111, \\
132\end{array}$ \\
\hline bêlum & \\
\hline bēl älim & 225,231 \\
\hline bēl bētim & 231 \\
\hline bell ha-Di-tim & 231 \\
\hline bēl mātim & 231 \\
\hline bêl mutim & 231 \\
\hline bikitum & 108 \\
\hline berultum & $79,159.15$ \\
\hline bētum & $39,103,225,230$ \\
\hline
\end{tabular}

bèt ālim

bēt kārim

bề ubrim

bikitum

$\mathrm{BI}_{\mathrm{a}}-\mathrm{la}-\mathrm{i}$

biriqqum

birum

bülātum

buqlullum

burullum

doijānum

buqlātum

buqünum

butnätum

dammuq(t)um

dāmù

dannunum

daš'ū

dātum

dinum

eblum

ebürum

ebuttum

ella/utum

epattum

eqlum

enōnum

erāb adrim

erōbum Ś-stem

erōsum

erbum

eršum

eșādum

essum

ešartum

etammum

etārum

etamdum

ézibtum

gāmir awātim

gigamlum

Gl-su-um

gulgullum

habbōum

hamišsum

hãmum

hamrum
$21,36,40,76,114$ ก. 505 .

116 ก. 518

$76,157.9,182$

$32,149,207$

108

220

103 n. 452

76,88 ก. 373

92

238 n. 948

232 ก. 936

95

$236,239.5$

241.13

153

152 ก. 702

101 n. 439,210 n. 884

67 n. 278

$238,240,242 \mathrm{f}$.

80

52

185 ก. 797

147 n. 679, 239 n. 949. 241.11

92

77, 79, 87, 90, 197.c, $206 t$.

153

175 ก. 756

96 n. 411

$239,242.12,243$

196 ก. 834

148, 239, 244

$150,162.30,225$

$221,239.4$

147 n. 679, 241.10, 243

220

58 ก. $228,77,78$ n. 329 ,

100 ก. 435, 155.4, 159.18,

160.23

103,187 ก. 804

212 ก. 891

53 ก. 201

106 ก. 474

95

132

221

198 ก. 840

73 n. $311,82,146$ n. 677 ,

189 ก. 809

52 ก. 192

94 n. 399,113 n. 499

56, 103 


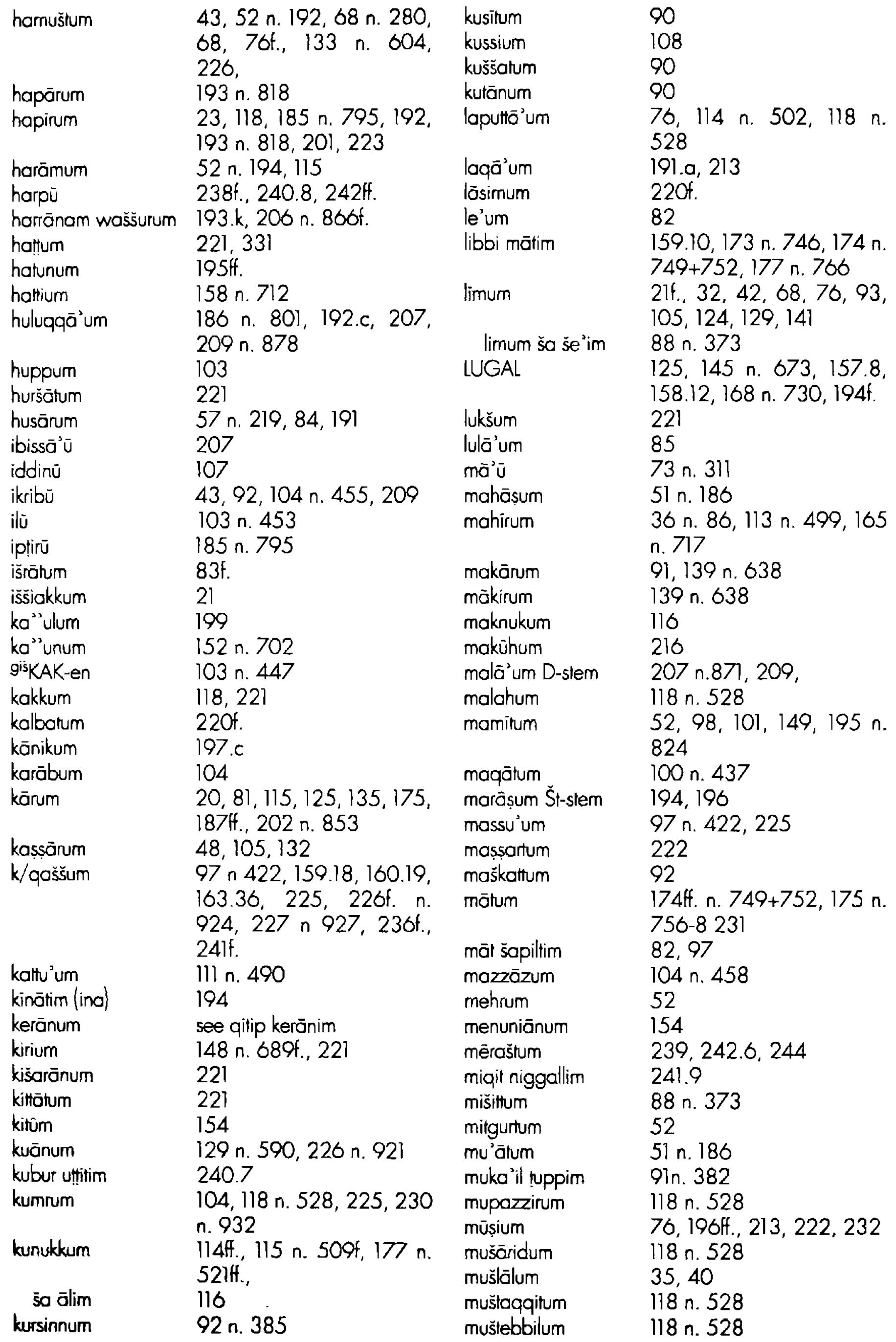


Indices

\begin{tabular}{|c|c|c|c|}
\hline mutōnū & $172 n .743$ & pazzurit\}um & 214 ก. $901 f f$. \\
\hline muttatum & 82 & perdum & 222 \\
\hline no’ālum & 52 n. 193, 115 n. 513 & pirikkum & 103 ก. 452 \\
\hline nabšûm & 67,186 ก. 801 & pitrātum & 117 n. 523 \\
\hline naditum & $73 n .311$ & pưhum & 192 \\
\hline nāg/kirum & 222 & qaqqidum & 222 \\
\hline nāgirum & 200 ก. 851 & qaqqad kārim & 141 ก. 645 \\
\hline nohlahum & 90 & qātum (iqqāıē) & $47 n .164,101,169,232$ \\
\hline nokārum & $\begin{array}{l}99 \text { п. } 430,100 \text { п. } 436 \text {, } \\
172 \text { п. } 744,73 \text { п. } 746\end{array}$ & $\begin{array}{l}\text { qātam sabātum } \\
\text { qiphum }\end{array}$ & $\begin{array}{l}206 \text { n. } 867 \\
92\end{array}$ \\
\hline nōpoltum & 52 & qitip kerānim & $148,238,239.1 \mathrm{ff}$ \\
\hline nappōhum & 118 n. 526, 220, 222 & rabium in tilles & 219-229, see also rubā'um \\
\hline naruqqum & 51 n. 189,88 п. 372,89 , & rabi huršōtim & 149,220 \\
\hline & 9lf., 131 ก. 593,188 & rabi nappāhē & 152 n. 705,220 \\
\hline nașbutum & 52 ก. 191 & rabi sikkō/itim & 22 n. 18, 99f., 149, 150 \\
\hline nāșirum & 232 & & n. $695,162.34 f, 170 \mathrm{n}$. \\
\hline našāum & 150 & & $739,183,213$ ก. 897 . \\
\hline nošpertum & 55 & & $219 ., 223 \mathrm{ff} ., 227 \mathrm{H} ., 228$ \\
\hline nolälum & 103 & & n. $929-931$ \\
\hline nèbantum & $149,156,198$ n. 837, 199.j & rabi simmiltim & 101,144 n. $605+607,145$ \\
\hline $\begin{array}{l}\text { nēberum } \\
\text { nēmulum }\end{array}$ & $\begin{array}{l}198 \cap .837 \\
91\end{array}$ & & $\begin{array}{l}\text { n. } 670+672,149,155.1 \text {, } \\
1694 ., 218,231\end{array}$ \\
\hline nēpešum & 53 & rābișum & $44,95 \cap .410,129,100.19$. \\
\hline nibrārum & 154 & & $163.36,180$ ก. 782,202 . \\
\hline nibum & $36 n .91,43 n .135,76$, & & 225,227 \\
\hline & 134 & rabiūtum & 43,92 \\
\hline niggallum & $238,240.9$ & rādium & $200.1,209,232$ \\
\hline nikištum & 203 ก. 857 & rōdi luqūtim & 74 ก. 316 \\
\hline nikkassū & $77,92,95,181,227$ n. 926 & rềm & 220,222 \\
\hline nimgir UruǍššr & 125 & rēš daš'ē & $238,240.6$ \\
\hline niqū & 222 & rikistum & 187 ก. 806,194 \\
\hline nishatum & $\begin{array}{l}36,83 f, 150,154.3, \\
157.6,163.36,184 f .0, \\
187,191 . a, 193 . h, 196 f ., \\
209,212 f .216\end{array}$ & rubōum & $\begin{array}{l}100 \text { n. } 437,144,145 n \text {. } \\
672 f ., 149,154 f ., 168 f \text {. } \\
n 730,179,195,229, \\
232\end{array}$ \\
\hline niš ilim & $184 . \mathrm{B}$ & rubā'um robium & 144,145 ก. 675, 156.5. \\
\hline nu'ónum & 168,193 ก. 819 & & 168 n. $730,171.19-21$ \\
\hline nuk(i)ribbum & 222 п. 918 & rubātum & 149, $157.10, \quad 158.12$ \\
\hline nukurtum & $\begin{array}{l}100 \text { ก. } 436,172 \text { п. 744, } \\
186 f .\end{array}$ & sābium & $\begin{array}{l}163.35,223\} \\
118 n .528\end{array}$ \\
\hline pahär odrim & 241.12 & sahā'um & 100,147 ก. 679,172 \\
\hline panã'um & 138 n. 036 & sakkukum & 118 ก. 526 \\
\hline paqōdum & 74 ก. 316 & sōmtum & 57 n. 219 \\
\hline $\mathrm{po} /$ iro/ikonnum & $\begin{array}{l}83 \text { n. } 348,84,154,193, \\
212,216 \text { n. } 908\end{array}$ & $\begin{array}{l}\text { sangûm } \\
\text { saptinnum }\end{array}$ & $\begin{array}{l}104 \text { n. } 456 \\
154\end{array}$ \\
\hline páširum & 86 & soqqum & 90 \\
\hline pãšir awātim & & sāridum & 105,132 \\
\hline patrum & $\begin{array}{l}56,72 \text { n. } 308,73 \text { n. } \\
311,103 \text { n. } 447,232 \text { n. } \\
\text { 937f. }\end{array}$ & $\begin{array}{l}\text { serdum } \\
\text { sihitum }\end{array}$ & $\begin{array}{l}197 \text { ก. } 835,239.3 \\
100,147 \text { ก. } 679,173, \\
207\end{array}$ \\
\hline $\begin{array}{l}\text { pāširum } \\
\text { pašsūurum } \\
\text { pāt/tum }\end{array}$ & $\begin{array}{l}139 \text { n. } 638,151 \text { n. } 700 \\
222 \\
176 \text { n. } 763 f .\end{array}$ & sikko/utum (sing.) & $\begin{array}{l}228,229 \text { п. } 930 \text { in rabi } \\
\text { sikka/itim, } 186 \text { n. } 799,225 \\
\text { n. } 920\end{array}$ \\
\hline
\end{tabular}




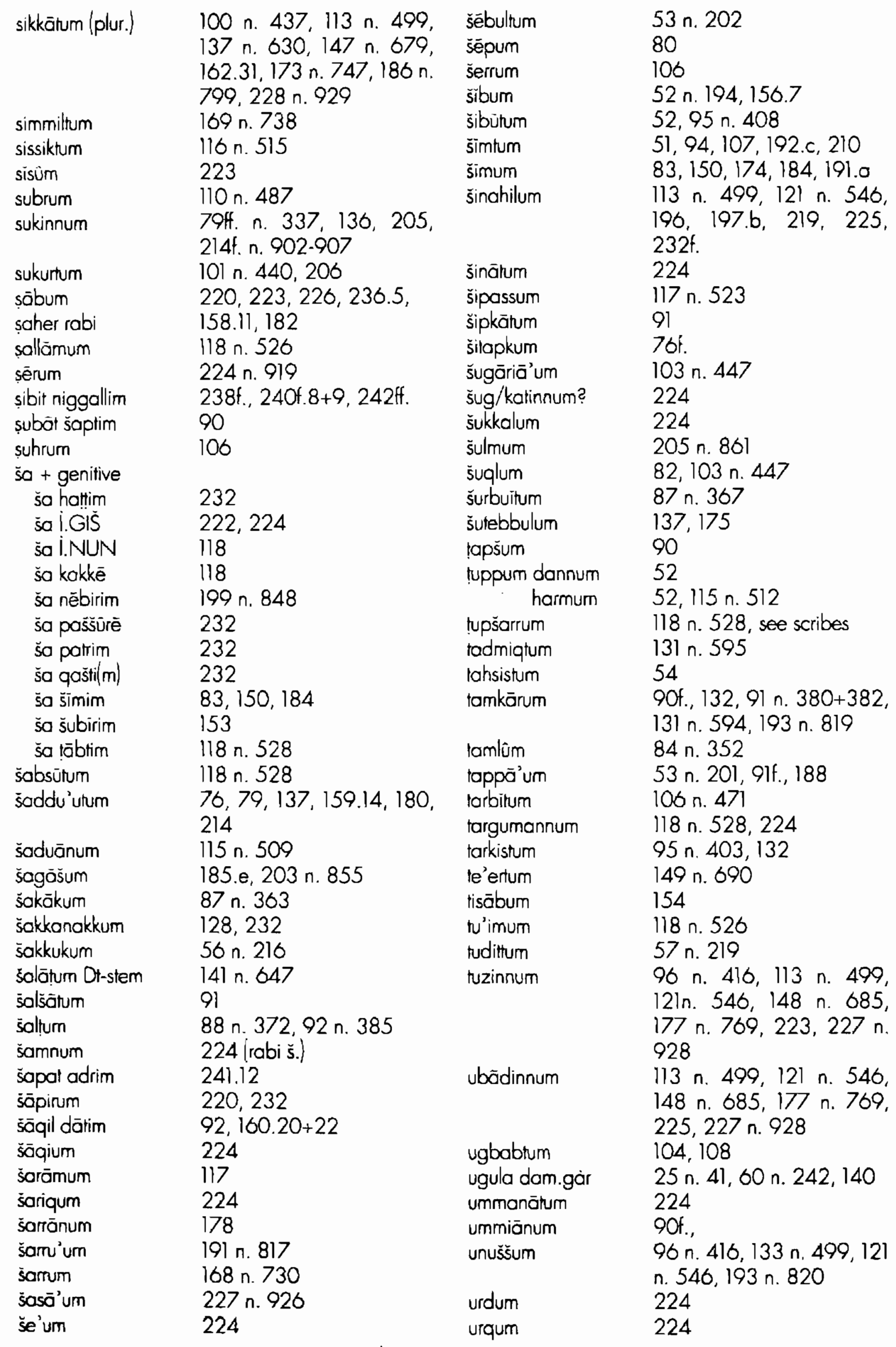


Indices

\begin{tabular}{|c|c|}
\hline urrubum & 109 n. 483 \\
\hline ūh'um & 224 \\
\hline wabartum & $49,52,78 f, 95,137 f$ \\
\hline wābil țuppim & 91 n. 382,132 \\
\hline waddu'um & 91 n. $382,116 f$ \\
\hline waklum & $\begin{array}{l}19 \text { n. } 4,28,39 \text { n. } 113,72 \\
\text { n. } 305,120,108 \text { n. } 733, \\
203 \text { n. } 857,205\end{array}$ \\
\hline wardum & 39 n. 113,110 n. 485 \\
\hline wašbūtum & $\begin{array}{l}\text { 78f. n. } 334,137 f . \text { n. } 631, \\
162 f .30+35\end{array}$ \\
\hline waššurum & $\begin{array}{l}127 \text { n. } 578,147 \text { n. } 679 \text {, } \\
191 \text { n. } 817,192 f ., 206 \text { п. } \\
867\end{array}$ \\
\hline watar & 233 \\
\hline watru & 333 ก. 938 \\
\hline zapp & 90 \\
\hline
\end{tabular}




\section{SUMMARY}

"The Old Assyrian Period" by Veenhof offers a critical overview of our knowledge of and at the same time an introduction to the study of the Old Assyrian Period (first two centuries of the 2nd mill. B.C.), as we know it from discoveries in ancient Assur and in particular from the cuneiform archives of the $O A$ traders living in a commercial colony (called karum) in the lower town of ancient Kanesh (modern Kültepe) in Central Anatolia. The first chapters establish what "Old Assyrian" is and analyze the chronology and the available sources (material and written). There follows a critical sketch of the publications of and research on the OA sources, subdivided in a dozen thematic studies. After a sketch of OA history, there follows an overview of "the Old Anatolian scene", which deals with the cities, local rulers and the ca. 40 OA commercial settlements in Northern Mesopotamia and Anatolia. A special chapter analyzes the importont Old Assyrian commercial treaties. The book ends with a detailed presentatation of the Anatolian titles and officials and the religious festivals and agricultural seasons that figure as terms of payments in Anatolian debt-notes. It is provided with comprehensive indices and a detailed bibliography.

The section on "Apum: A Kingdom on the Old Assyrian Route" contributed by Eidem summarises recent evidence for the history of northern Syria during the period contemporary with the late phase of the Old Assyrian trade. 